\title{
Data, Infrastructures and Geographical Imaginations
}

by

\author{
Tracey P. Lauriault
}

A thesis submitted to the Faculty of Graduate and

Postdoctoral Affairs in partial fulfillment of the requirements

for the degree of

Doctor of Philosophy

in

Geography

Geography and Environmental Studies

Carleton University

Ottawa, Ontario

Carleton University

May 23, 2012

(C) (0)

Tracey P. Lauriault, 2012 
Library and Archives

Canada

Published Heritage

Branch

395 Wellington Street

Ottawa ON K1A ON4

Canada
Bibliothèque et

Archives Canada

Direction du

Patrimoine de l'édition

395 , rue Wellington

Ottawa ON K1A ON4

Canada
Your file Votre référence

ISBN: 978-0-494-93705-1

Our file Notre référence

ISBN: 978-0-494-93705-1
NOTICE:

The author has granted a nonexclusive license allowing Library and Archives Canada to reproduce, publish, archive, preserve, conserve, communicate to the public by telecommunication or on the Internet, loan, distrbute and sell theses worldwide, for commercial or noncommercial purposes, in microform, paper, electronic and/or any other formats.

The author retains copyright ownership and moral rights in this thesis. Neither the thesis nor substantial extracts from it may be printed or otherwise reproduced without the author's permission.
AVIS:

L'auteur a accordé une licence non exclusive permettant à la Bibliothèque et Archives Canada de reproduire, publier, archiver, sauvegarder, conserver, transmettre au public par télécommunication ou par l'Internet, prêter, distribuer et vendre des thèses partout dans le monde, à des fins commerciales ou autres, sur support microforme, papier, électronique et/ou autres formats.

L'auteur conserve la propriété du droit d'auteur et des droits moraux qui protege cette thèse. $\mathrm{Ni}$ la thèse ni des extraits substantiels de celle-ci ne doivent être imprimés ou autrement reproduits sans son autorisation.
In compliance with the Canadian Privacy Act some supporting forms may have been removed from this thesis.

While these forms may be included in the document page count, their removal does not represent any loss of content from the thesis.
Conformément à la loi canadienne sur la protection de la vie privée, quelques formulaires secondaires ont été enlevés de cette thèse.

Bien que ces formulaires aient inclus dans la pagination, il n'y aura aucun contenu manquant. 


\begin{abstract}
The central argument of this dissertation is that Canadian reality is conditioned by government data and their related infrastructures. Specifically, that Canadian geographical imaginations are strongly influenced by the Atlas of Canada and the Census of Canada. Both are long standing government institutions that inform government decision-making, and are normally considered to be objective and politically neutral. It is argued that they may also not be entirely politically neutral even though they may not be influenced by partisan politics, because social, technical and scientific institutions nuance objectivity. These institutions or infrastructures recede into the background of government operations, and although invisible, they shape how Canadian geography and society are imagined. Such geographical imaginations, it is argued, are important because they have real material and social effects. In particular, this dissertation empirically examines how the Atlas of Canada and the Census of Canada, as knowledge formation objects and as government representations, affect social and material reality and also normalize subjects. It is also demonstrated that the Ian Hacking dynamic Looping Effect framework of 'Making Up People' is not only useful to the human sciences, but is also an effective methodology that geographers can adapt and apply to the study of 'Making Up Spaces' and geographical imaginations. His framework was adapted to the study of the six editions of the Atlas of Canada and the Census of Canada between 1871 and 2011. Furthermore, it is shown that the framework also helps structure the critical examination of discourse, in this case, Foucauldian gouvernementalite and the biopower of socio-techno-political systems such as a national atlas and census, which are inextricably embedded in a social, technical and scientific milieu. As objects they both reflect the dominant value system of their society and through daily actions, support the dominance of this value system. While it is people who produce these objects, the infrastructures that operate in the background have technological momentum that also influence actions. Based on the work of Bruno Latour, the Atlas and the Canadian census are proven to be inscriptions that are immutable and mobile, and as such, become actors in other settings. Therefore, the Atlas of Canada and the Census of Canada shape and are shaped by geographical imaginations.
\end{abstract}




\section{Acknowledgements}

I would like to acknowledge the many individuals and organizations who have contributed to the completion of this research. First and foremost, I would like to thank Distinguished Research Professor of International Affairs and Geography and Environmental Studies (DGES), Director of the Geomatics and Catographic Research Centre (GCRC), and Royal Society of Canada Fellow, Professor D. R. F. Fraser Taylor of Carleton University, for his guidance, patience and endless support. I would also like to thank the members of my committee, Simon Dalby of Carleton University and David Moorman, Senior Programs Planning Officer with the Canada Foundation for Innovation, for their invaluable assistance and candid observations throughout this research process.

This research has required extensive assistance from librarians in order to access historical government documents, data and maps. The MacOdrum Library Government, Maps, Data and Government Information Centre (MADGIC) proved to be invaluable. I received tremendous research support from all of the staff, most notably Government Information Librarian Frances Montgomery, retired Map Librarian Beth Ray and Map Specialist Monica Ferguson. I would also like to thank all the floor staff of the Library, who made me feel like I was part of their family. The Statistics Canada Library, at the R.H. Coats Building in Ottawa, also holds an excellent collection, and special thanks are given to librarian Hans-Olivier Laroche, who assisted with finding specialized materials, and to Bernie Gloyn, Assistant Director Communications and Library Services. The Natural Resource Canada Library, on Booth Street in Ottawa, was an 
important source of information, and thanks go to George Duimovich and Martin Legault. I would also like to thank the members of the Data Liberation Initiative list who shared their expertise. Special thanks go to Donna Williams and Doug O'Brien at Natural Resources Canada, Gerald Fremlin, Chief Editor of the $4^{\text {th }}$ edition of the Atlas of Canada, and Iain Taylor, advisor to the $5^{\text {th }}$ edition, who all generously shared their knowledge.

I would also like to acknowledge the support of friends and colleagues at the GCRC, especially Barbara George and Amos Hayes for keeping the Centre's infrastructure intact, and to friends and colleagues Glenn Brauen, for continuously checking in and listening, Peter Pulsifer for his enduring support, and J.P. Fiset for keeping me smiling.

In the DGES, I would like to thank Fran Klodawski and Ken Torrance for ongoing encouragement, and Natalie Pressburger and the late Hazel Anderson for their administrative guidance.

Finally, much appreciation goes to a wonderful group of family and friends who have been tremendously supportive. For ensuring that my work is polished and for comic relief, thanks go to Cristina Usubiaga and Steffen Knippel. For keeping me sharp and providing ongoing encouragement, thanks go to Michael Lenczner. I also want to thank Meghan Maack for her empathy, my sister Renée for babysitting, and Lindsey McKay for being a great study buddy. Finally, thanks go to my two rascals, Jacques $\mathrm{X}$ Lauperr and Masayuki Y Lauriault, who grew up at a university library, lab and campus. 


\section{Table of Contents}

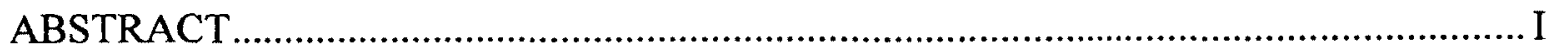

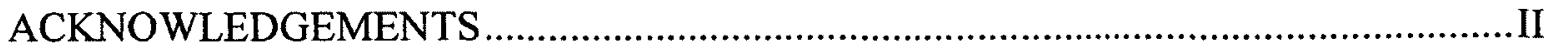

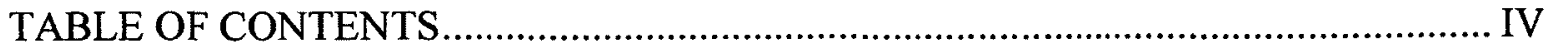

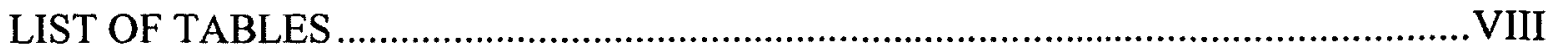

LIST OF FIGURES AND ILLUSTRATIONS........................................................... IX

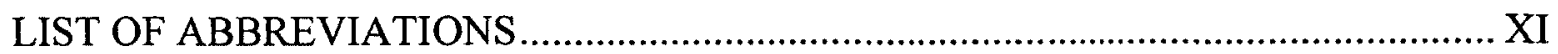

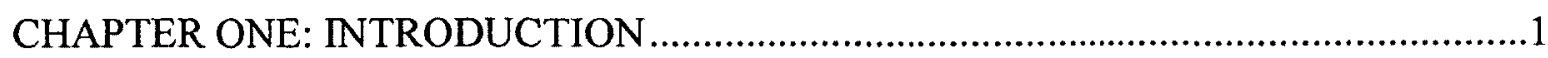

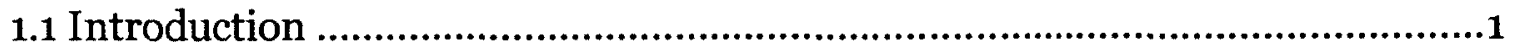

1.2 The Art of Government - Gouvernementalité ............................................... 6

1.3 Atlas, Census and Geographical Imaginations ............................................. 9

1.4 Data, Infrastructures and Geographical Imaginations .................................12

1.5 Structure of the Dissertation ........................................................................... 16

CHAPTER TWO: DATA, INFRASTRUCTURES AND GEOGRAPHICAL

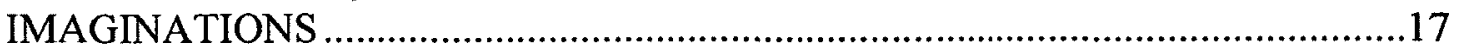

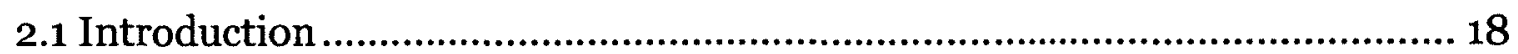

2.2 Data

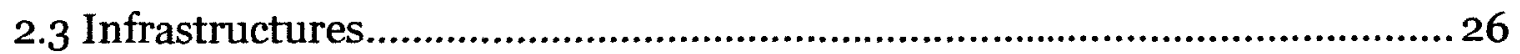

2.4 Data, Maps, Infrastructures and Discourse …..............................................43

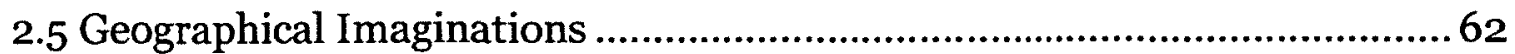

CHAPTER THREE: METHODOLOGY AND DATA COLLECTION ..........................82

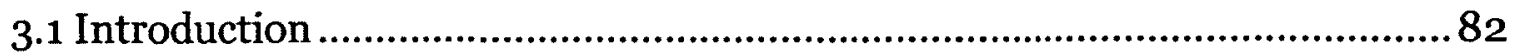

3.2 The Looping Effect and Making Up People: The Hacking Framework.......82

3.3 Making up Spaces: Adapting Hacking's Framework .................................. 105 


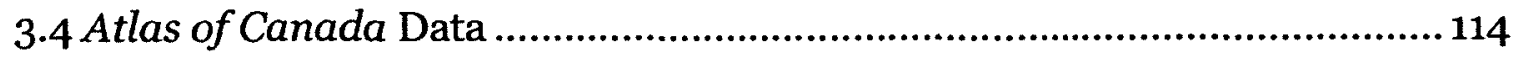

3.5 Census of Canada Data ................................................................................119

CHAPTER FOUR: THE ATLAS OF CANADA AND CANADIAN GEOGRAPHICAL IMAGINATIONS .............................................................123

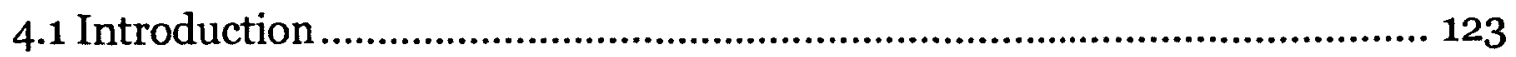

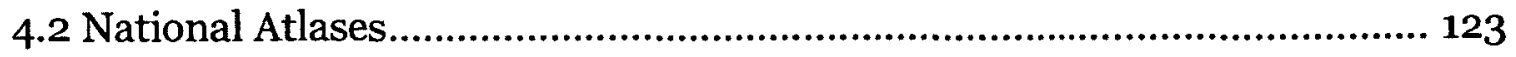

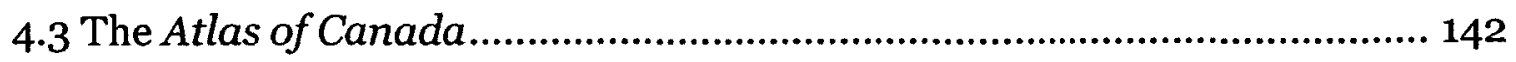

4.3.1 The Making of the Atlas of Canada........................................................ 146

4.3.2 Grouping Atlas Content.....................................................................147

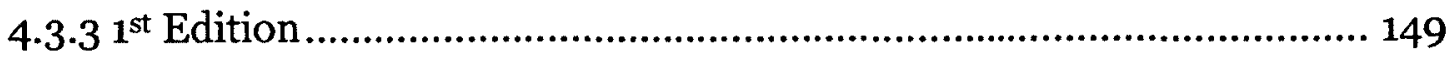

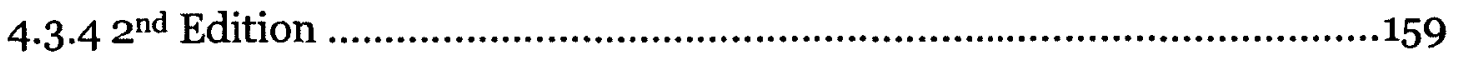

$4.3 .53^{\text {rd }}$ Edition ........................................................................................165

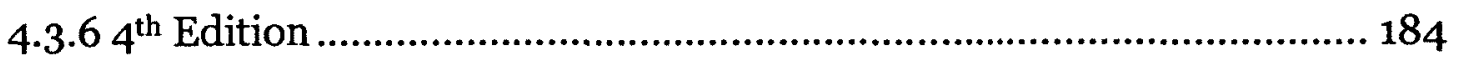

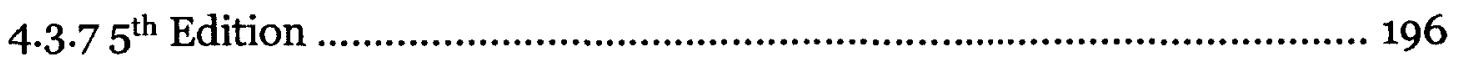

$4.3 .86^{\text {th }}$ Edition ............................................................................................. 219

4.4 Making Maps and Making Up Spaces and Places ..................................... 232

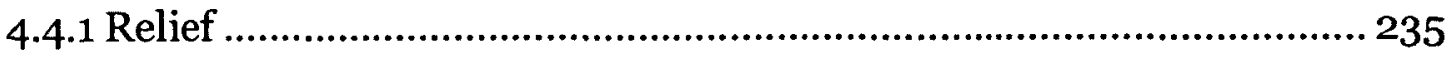

4.4.2 Forest Biogeography ..................................................................... 243

4.4.3 Communication Infrastructure ...........................................................260

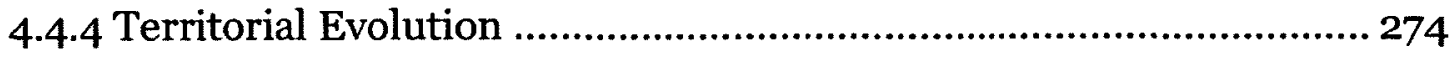

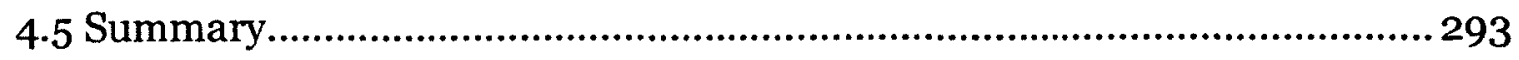

CHAPTER FIVE: THE CENSUS OF CANADA, MAKING UP SPACES AND CANADIAN GEOGRAPHICAL IMAGINATIONS............................................300

5.1 Introduction ............................................................................................300

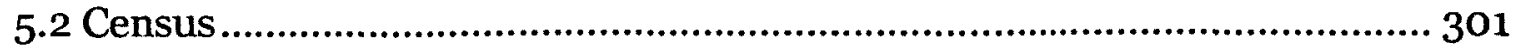

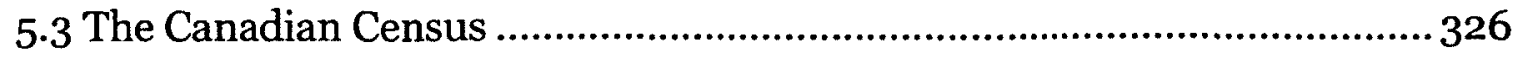




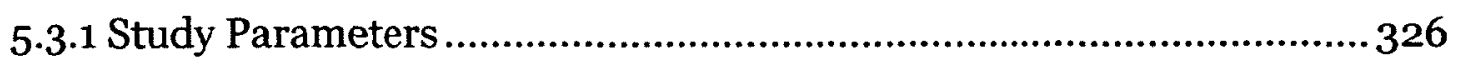

5.3.2 Census and Legislation ....................................................................331

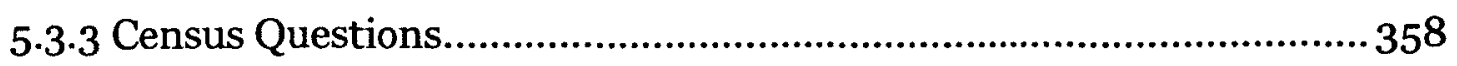

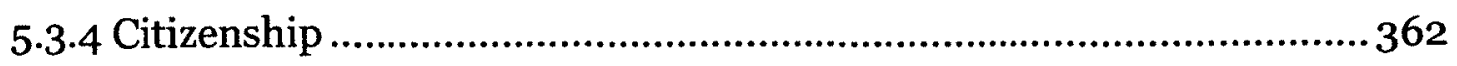

5.3.4.1 Reasons for Collecting Citizenship Data .................................362

5.3.4.2 Definitions and Historical Context for Citizenship Questions . 367

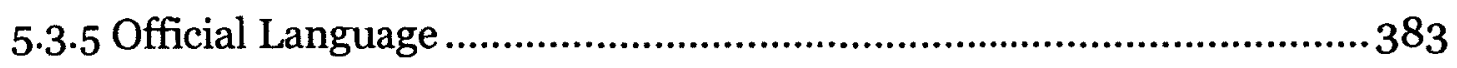

5.3.5.1 Reasons for Collecting Language Data .................................... 387

5.3.5.2 Definitions .................................................................................. 411

5.3.5.3 Mother Tongue ..................................................................... 412

5.3.5.4 Knowledge of French or English ............................................. 414

5.3.5.5 Language Used At Work............................................................415

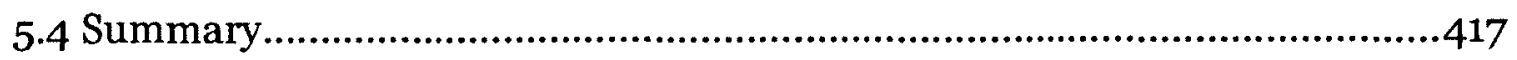

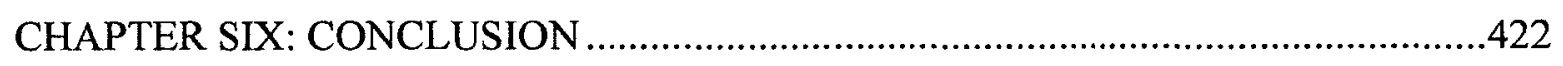

6.1 The Atlas of Canada: Making up Spaces and Geographical Imaginations423

6.2 The Census of Canada: Making up Spaces and Geographical

Imaginations ..........................................................................................432

6.3 Socio-Technopolitics, Gouvernementalité and Biopower ..........................443

6.4 Hacking's Framework and Geography ...................................................446

6.5 Contributions to Geography ................................................................450

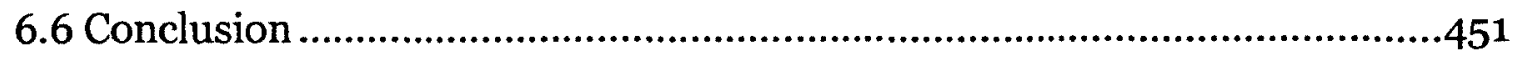

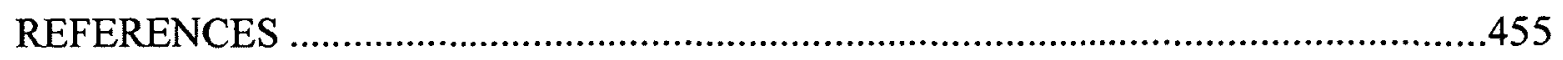

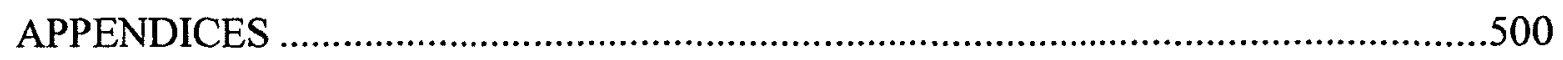

APPENDIX A: CENSUS OF CANADA QUESTIONNAIRES SOURCES ....................501

APPENDIX B: CONTENT 1ST EDITION ATLAS OF CANADA CONTENT............505

APPENDIX C: CONTENT 2ND EDITION ATLAS OF CANADA ……………..........521 
APPENDIX D: CONTENT 3RD EDITION ATLAS OF CANADA ........................529

APPENDIX E: CONTENT 4TH EDITION, ATLAS OF CANADA ..........................552

APPENDIX F: CONTENT 5TH EDITION ATLAS OF CANADA ........................571

APPENDIX G: CONTENT 6TH EDITION ATLAS OF CANADA ........................618

APPENDIX H: CONTENT COMPARISON OF ALL EDITIONS ATLAS OF

CANADA .653

APPENDIX I: CONTENT GROUPINGS DEFINED ...........................................681

APPENDIX J: LIST OF CANADIAN ATLASES BETWEEN 1825-1975 …............693

APPENDIX K: LIST OF BOUNDARY CHANGES IN THE ATLAS OF CANADA..695

APPENDIX L: LIST OF CENSUS SCHEDULES BETWEEN 1871 AND 2011 .......698

APPENDIX M: FEDERAL LEGISLATION REFERRING TO THE CENSUS ..........702 


\section{List of Tables}

Table 1. Atlas of Canada Editions Analyzed in this Study

(Compiled by the author)

Table 2. List of Censuses 1871-2011 (Compiled by the author)

Table 3. Atlas of Canada Print, Cost, Size and Form (Compiled by the Author)

Table 4. Atlas of Canada Content Groupings (Compiled by the Author).......149

Table 5. Value of Export of most important national products (1913), (Adams, 1915:10)

Table 6. Mapping the Coasts, $3^{\text {rd }}$ Edition list of maps ........................279

Table 7. Mapping the Interior, list of maps $3^{\text {rd }}$ Edition .......................2279

Table 8. List of Types Indian Treaties, $5^{\text {th }}$ Edition sheet $15.6 \ldots \ldots \ldots \ldots \ldots \ldots 282$

Table 9. Census of Canada and Institutional Information (Compiled by the Author) ............................................................ 334

Table 10. Major Federal Legislative Census Requirements (Email Correspondence Statistics Canada, 2010)

Table 11. Census Question Categories Between 1871 and 2011 (Compiled by the Author)

Table 12. Citizenship and Immigration Classifications between 1871 and 2011 (Compiled by the author)

Table 13. Place of Birth Classifications between 1871 and 2011 (Compiled by the author) 366

Table 14. Language Classifications, 1871 and 2011 (Compiled by the author) 386 


\section{List of Figures and Illustrations}

Figure 1. Canadian Geospatial Data Infrastructure (CGDI) Model (Adapted by the Author from GeoConnections 2003) ............................ 31

Figure 2. CGDI Conceptual Architecture (GeoConnections, 2005) ............. 39

Figure 3. The 1972 Blue Marble Image of the Earth seen from Apollo 17 (Wikipedia, 2005) ..................................................... 63

Figure 4. Hacking Five Interactive Elements of the Looping Effect ........... 92

Figure 5. Infirmities Category of Unsound Mind, Schedule 1 Nominal Return of the Living of the 1871 Census, Nova Scotia (CCRI, 2012). .............. 94

Figure 6. Detail of Halifax map extracted from Plate 39, 1st Edition, Atlas of Canada (1906) showing the location of the Insane and the Poor Asylums ............................................................... 96

Figure 7. Seven Engines of Discovery (Hacking, 2007).................... 97

Figure 8. Three Derived Engines (Hacking, 2007) ......................... 98

Figure 9. Elongated and Square Land Survey Grid Around Winnipeg Manitoba (Agri-Maps, 2011) .................................................. 103

Figure 10. The Hacking Looping Effect and Making Up People Framework ... 104

Figure 11. The World Map in the 2nd Edition of the Atlas of Canada Circa

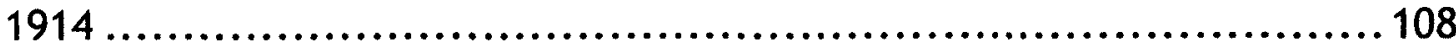

Figure 12. Modified Hacking Looping Effect - Making up Spaces............... 113

Figure 13. Atlas of Canada Timeline (Created by the Author) ...............143

Figure 14. Photo of Atlases of Canada ................................... 144

Figure 15. Atlas of Canada Content Comparison (Created by the Author) .... 148

Figure 16. Department of the Interior Ads in US journals, Bulletins and

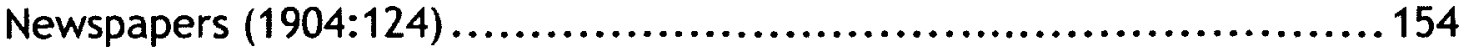

Figure 17. Telegraphs - Quebec and Maritime Provinces, $1^{\text {st }}$ Edition Atlas of Canada ................................................................ 163

Figure 18. Maps about Mapping, $3^{\text {rd }}$ Edition, Atlas of Canada................. 176

Figure 19. Extent of Topographical Mapping, $3^{\text {rd }}$ Edition, Atlas of Canada ... 178 
Figure 20. Relief Profile $4^{\text {th }}$ Edition, Atlas of Canada ........................ 188

Figure 21. Relief Profiles, 3rd Edition Atlas of Canada ....................... 188

Figure 22. Indian Treaties Map, $5^{\text {th }}$ Edition Atlas of Canada .................212

Figure 23. Forest Industry Maps, Atlas of Canada (Approximate scale) ......216

Figure 24. Former Iterations of Online National Atlas of Canada ............. 224

Figure 25. Atlas of Canada Map Page, $6^{\text {th }}$ Edition.......................... 228

Figure 26. Atlas of Canada Relief Maps................................... 238

Figure 27. Maps in the Atlas of Canada that Feature Forest ................245

Figure 28. Classifying, Mapping and Normalizing Ecological Land Classification (EC, 1981) .........................................259

Figure 29. Selection of Communication Infrastructure Maps .................261

Figure 30. Selection of Maps Representing Territorial Evolution .............277

Figure 31. Evolution of the Atlas of Canada (1905-2012) .....................299

Figure 32. Census of Canada Timeline (Created by the Author) .............. 333

Figure 33. Mother Tongues of the Population Map,

B \& B Commission, Book I 1967.......................................... 398

Figure 34. Official Language Minority is equal to or is more than $10 \%$ of the population by CD, B \& B Commission, Book I 1967 ....................... 399

Figure 35. Ontario District Recommendation's Map, $1^{\text {st }}$ Bilingual Districts Advisory Board, 1971 .............................................. 405

Figure 36. Ottawa Area Recommendations, $1^{\text {st }}$ Bilingual Districts Advisory

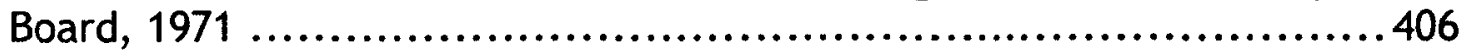




\section{List of Abbreviations}

AAAS American Association for the Advancement of Science

APEC Asia-Pacific Economic Cooperation

BC British Columbia

BMI Body Mass Index

BNA British North America

CBC Canadian Broadcasting Corporation

CCELC Canada Committee on Ecological Land Classification

CCRI Canadian Century Research Infrastructure

CCRS Canada Centre for Remote Sensing

CFS Canadian Forest Service

CGDI Canadian Geospatial Data Infrastructure

CGIS Canadian Geographic Information System

CLI Canada Land Inventory

CMA Census Metropolitan Area

CODATA Committee on Data for Science and Technology

CPCGN Canadian Permanent Committee on Geographic Names

CRA Canada Revenue Agency

CRTC Canadian Radio-Television Telecommunications Commission

DBS Dominion Bureau of Statistics

DIAND Department of Indian Affairs and Northern Development

DMS Diagnostic and Statistical Manual of Mental Disorders

EC Environment Canada

EMR Energy, Mines and Resources Canada 


\begin{tabular}{ll} 
ESWG & Ecological Stratification Working Group \\
FCM & Federation of Canadian Municipalities \\
GC & Government of Canada \\
GDI & Geospatial Data Infrastructure \\
GIS & Geographic Information Systems \\
GPS & Global Positioning System \\
GSC & Geological Survey of Canada \\
IBC & International Botanical Congress \\
ICA & International Cartographic Association \\
IGU & International Geographical Union \\
ISIUOP & Inuit Sea Ice Use and Occupancy Project \\
ISO & International Standards Organization \\
ITU & International Telecommunications Union \\
LAC & Library and Archives Canada \\
LICO & Low Income Cut Off \\
MPD & Multiple Personality Disorder \\
MTS & Mines and Technical Surveys \\
NAIS & National Atlas Information System \\
NANAC & National Advisory on the National Atlas of Canada Committee \\
NASA & National Aeronautics and Space Administration \\
NFB & National Film Board of Canada \\
NRCan & Natural Resources Canada \\
NSF & National Science Foundation \\
OED & Oxford English Dictionary \\
OS & Open Source \\
\hline
\end{tabular}




$\begin{array}{ll}\text { P\&T } & \text { Provinces and Territories } \\ \text { PBS } & \text { Public Broadcasting Service } \\ \text { SMB } & \text { Surveys and Mapping Branch } \\ \text { StatCan } & \text { Statistics Canada } \\ \text { TOC } & \text { Table of Contents } \\ \text { UCD } & \text { User Centrered Design } \\ \text { UN } & \text { United Nations } \\ \text { UNCLOS } & \text { United Nations Convention on the Law of the Sea } \\ \text { UNESCO } & \begin{array}{l}\text { United Nationals Educational, Scientific and Cultural } \\ \text { Organization }\end{array} \\ \text { USGS } & \text { United States Geological Survey }\end{array}$




\section{Chapter One: Introduction}

\subsection{Introduction}

The central argument of this dissertation is that Canadian reality is conditioned by government generated data and the related infrastructures that produce them. Specifically, the purpose is to demonstrate how Canadian geographical imaginations are strongly influenced by the Atlas of Canada and the Canadian census. Geographical imaginations, which will be explained in greater detail in this thesis, stem from a long line of images, models and descriptions of humans and their interaction with, and perceptions of, the physical world (Cosgrove, 2001; Tang, 2009; Debarbieux, 1992). Atlas and census are important in shaping and informing actions.

The Atlas and the census are well-established Government of Canada institutions that generate data that shape our geographical imaginations. The census, it will be seen, is explicitly embedded in Canadian governance structures, such as political representation and government transfer payments, and it informs the operations of numerous government programs and policies that affect people and spaces. Alternatively, the Atlas, it will be demonstrated, is a public display of 
national mapping interests and knowledge. It also informs decisions, but unlike the census, it is not structured into the government operations of spatial decision-making, but instead, represents them. The actors involved in the collection and management of geospatial data, who render these into maps such as those seen in the Atlas, are also part of the government bureaucracy that informs spatial decision-making.

National atlases and censuses are normally thought of as being objective and politically neutral, although respondents were aware that it was an instrument of power. It is argued here, that even though they may not be influenced by partisan politics, they may also not be entirely politically neutral, as social, technical, financial and scientific institutions nuance objectivity (Latour, 1987). Large data and mapping infrastructures are behind the production of these objects, which are also involved in shaping how Canadian geography and society are imagined. Infrastructures are considered here as being socio-technopolitical systems that have been strategically built to embody or enact politics and to serve government expert authority (Hecht, 2001; Hughes 2004). This view accepts that technologies are socially constructed.

The Ian Hacking dynamic Looping Effect and Engines of Innovation framework of 'Making Up People' was adapted and used empirically to study the Atlas and the census, in order to assess their space making qualities and how these influence and were influenced by geographical imaginations (Hacking, 1986, 1991, 2000, 2006, 2007). This framework was selected as it is enables the study of the genealogy of the classifications used in Atlas of Canada maps and derived 
from census questions. These classifications, as will be discussed, are involved with the production of spaces. This framework was particularly useful as a method to structure this analysis, as it helped unravel the governmental, technical and scientific discourses within which the Atlas and the census are embedded. The application of the framework also allowed for a critical examination of scientific classification, which is important to geographers who most often assess the technical and scientific merits of the data they use and collect, but rarely study how the facts they create, and assume to be true and objective, came to be so. The framework also proved useful as a methodology to reveal the gouvernementalité (Foucault, 1991; Garland, 1997; Hindness, 1997) and the biopolitical (Foucault, 1977-1978, Hacking, 1982; Hanson, 2008; Marks 2008) drive to govern and survey territory and people.

Biopower is a form of political power which revolves around populations rather than individuals. According to Foucault it is a form of thinking about power which emerged in the $17^{\text {th }}$ century, and was formulated by governors and administrators whose main concern was the power of the state. There was a shift where officials:

viewed the population of the state as a resource and developed knowledge about its people accordingly: on the one hand, it wanted to learn about humans as a species and come to know their biological secrets, and on the other hand, it wanted to develop the capacity of humans as machines by disciplining their bodies. Foucault termed this new kind of political rationality biopower because it concerned itself with every aspect of life, right down to its most minute parts, though only in the abstract. It was interested in the health of the people in statistical terms, not existential terms-it cared about how people live and die, but not who lives and dies (Buchanan, 2010). 
Biopower is a government tactic used to manage the subjects the state rationally creates. It is not possible for government to manage each individual and object within its territory, therefore, the state deploys techniques to survey the population and its resources in order to streamline the governing and administration of sub-populations and spaces. Biopower emerged along with the advent of human sciences and statistics which are discussed in chapters 2 and 5 . For Foucault and Hacking, population and territorial characteristics classifications, and not individuals, become kinds of people and spaces - are the subjects that government creates, and around which policies are made and actions are taken. Decisions and actions based on the techniques and outcomes of biopower are biopolitical. Health surveillance decisions, for example, are biopolitical and are often taken by chief medical officers of health ${ }^{1}$.

The census and the Atlas are other forms of surveillance used by government more broadly. Gouvernementalité can be characterized as government rationality, or a form of distributed power, employed by the government, via its institutions and bureaucratic operations, to create the people and spaces subjects to govern. Biopower is part of that rationality. For example, health promotion strategies in Canada now factor in the social determinants that influence health; because poverty is now understood negatively to affect people's

${ }^{1}$ The Public Health Agency of Canada (PHAC) (http://www.phac-aspc.gc.ca/ph$\mathrm{sp} /$ determinants/index-eng.php) has defined a variety of social determinants and the CommunityView Collaboration in Saskatoon (http://www.communityview.ca/) and the Espace Montréalais d'information sur la santé (EMIS) (http://emis.santemontreal.qc.ca/) are examples of social determinant of health data portals and mapping tools overseen by chief medical officers of health and created to keep citizens informed as well as providing evidence for biopolitical decision making. 
health outcomes, the government uses census data and maps to develop health promotion programs and to target limited health resources to poverty stricken areas. This is the art of government - gouvernementalite and biopower - in action.

Government geospatial data and their related infrastructure map Canada's territory, and resources, and the social, cultural, political, economic and environmental interactions of the people within its boundaries and, it is argued, they shape and are shaped by geographical imaginations. Geographical imaginations are considered important as they produce spaces (Lefebvre, 1991; Harvey, 2009). This thesis also undertakes a critical examination of the role played by data, maps and their infrastructures in making spaces, producing subjects, and effecting normalization (Foucault in Rabinow, 2010).

It is also argued that geospatial data and their related infrastructures are constitutive of and construct Canadian geographical imaginations, which, as will be demonstrated, are primarily governmental, because it is the government that controls what merits collection, the data representations created, and the kinds of people and spaces produced. The government is also responsible for building and maintaining the infrastructure to do so, and it determines the course of action to be taken upon the subjects it creates.

The following sections describe these concepts more fully. 


\subsection{The Art of Government - Gouvernementalité}

One way to gauge how government thinks is to examine critically the data it produces. Examining the data government collects, appraising what counts as worthy of being collected, following the reasoning why certain datasets are deliberately not released ${ }^{2}$, and inquiring into why some data are not being collected at all 3 reveals priorities, responsibilities, accountabilities, government concerns 4 and what government would rather keep to itself5. These data represent what the government: knows about its people and resources, what it surveys $^{6}$, and the facts about the country it is constructing. These facts are then used for evidence based decision-making, which increase the government's ability to administer, assess its performance, act and control. Data are therefore artifacts in a complex web of technology, people and social, political and

2 In April of 2009, Great Lakes United, Mining Watch Canada and Ecojustice won a lawsuit against Environment Canada to publicly report mining pollution data from 2006 onward to the National Pollutant Release Inventory (NPRI). The Federal Court of Canada decision forced the government to stop withholding data on one of Canada's largest sources of pollution - millions of tonnes of toxic mine tailings and waste rock from mining operations throughout the country (Ecojustice, 2009).

3 Mathew Coleman, in a lecture on immigration and border control in the US, stated that USMexico border crossing deaths are not counted, yet the number of people forcibly removed for immigration violations is known and reported. In the context of his lecture, it might be suggested that either Mexican deaths are unimportant to the US government, that if these data were counted and reported public outcry might not support current border control techniques, and alternatively, that reporting the statistics of the number of people expelled may be construed as an indicator to the public that the government is doing a good job (Coleman, 2009).

4 The Earth Science Sector (ESS) of Natural Resources Canada's Mapping Page offers as its concerns the following: topographic maps, the Atlas of Canada, aerial photography, geological maps, land surveying/GPS, forest maps, and mining maps.

5 The Homeless Individuals and Families Information System (HIFIS) is an intake software system used in shelters across Canada. It contains information about shelters, their capacity, the number of people served and demographics. Many researchers, city officials and community based organizations, have tried in vain to access aggregated data from HIFIS. To date, Human Resources Skills and Development Canada (HRSDC) has refused access and publish few HIFIS data variables in reports. In addition, HRSDC does not release the homelessness research reports they have commissioned, claiming that translation is too costly.

${ }^{6}$ As in surveillance. 
economic structures; these are not necessarily the oft-conceptualized neutral arrangements of facts they purport to be (Poovey, 1998; Latour, 1987; Hacking, 1982). Data collected by government officials are political in their creation, use, arrangement, dissemination, representations, technologies and purposes7. Data also provide a way for a government to manage, according to numbers, maps, trends and norms. The collection of data requires specialized knowledge, techniques, sophisticated technologies, and often, significant financial resources. Public data are therefore a form of state power/knowledge and represent government rationalities (Foucault, 1991). For Foucault, "government refers to a complex set of processes through which human behaviour is systematically controlled in ever wider areas of social and personal life...[it] permeates the whole of a society and operates through dispersed mechanisms of power" (Scott \& Marshall, 2009). Gouvernementalité includes experts and scientific disciplines which are involved in the disciplining of individuals (Scott \& Marshall, 2009). Biopower results from gouvernementalité, and the collection of government data and the creation and management of infrastructures are the means to rationally survey and control populations and territory.

7 Radarsat 2 is considered to be the world's most sophisticated radar technology. Its construction was primarily funded by the public although it was transferred to a private company. Once built shareholders decided to sell it to a US arms manufacturer until two scientists publicly resigned in protest. Eventually, the sale was halted by the Government, neither because the data it produces were inherently important, nor because significant public funds were used to build it, but because many organizations and a few journalists framed the technology as being necessary to the maintenance of Canada's sovereignty in the North. The proposed sale of Radarsat 2 was closely monitored by the author on the Serendipityoucity blog (Lauriault, 2008a). 
Geospatial datasets, for example, are put to work in innumerable government application areas (Lauriault \& Taylor, 2007, Lauriault, 2003): they help government meet its constitutional and regulative obligations (e.g., Petroleum Resources Act, Official Languages Act); departments and ministries have particular subject matter responsibilities that require data for their management (e.g., forestry, public health, employment insurance); and international treaties require data for oversight purposes (e.g., Convention on International Trade in Endangered Species of Wild Fauna and Flora). Governments and the private sector are the primary creators and maintainers of geospatial data, because these are very expensive to produce, manage and preserve. Citizens, non-profit organizations are generally users who provide value added services (e.g., geodemographic profiling), and they often combine their datasets with those of the government (e.g., FCM Quality of Life Reporting System, GPS navigation systems for cars). Geospatial data are produced and used in academic institutions, but at a much smaller scale. They are often created with the use of public funds (e.g., atlases at the Geomatics and Cartographic Research Centre). Geospatial data, in myriad forms, are also used for critical research (e.g., Counter Mapping), advocacy (e.g., Community Development Halton mapping), legal research (e.g., aboriginal treaty negotiations), storytelling (e.g., Living Cybercartographic Atlas of Indigenous Perspectives and Knowledge), and introducing other forms of knowledge (e.g., Inuit Sea Ice Use and Occupancy Project - ISIUOP). 
According to Benedict Anderson, the lineage of nationalist ideologies, the grammar or discourse of colonial nation building, is found in three institutions of power: the census, the map, and the museum, as these congeal and propagate the colonial imaginings of new dominions (Anderson, 1991:164). It is argued here that geospatial data and infrastructures, and census and atlas script, narrate and render the story of Canada's people, places and their relations in space and time, while also providing the stage and cues for those stories to be performed and enacted. They disclose how government thinks, as in gouvernementalité, and shape our geographical imaginations. This study therefore examines how government thinks with data, maps and related infrastructures.

\subsection{Atlas, Census and Geographical Imaginations}

This thesis sets out to demonstrate empirically the subject, knowledge and space producing features (Said, 1978, Lefebvre, 1991; Pickles, 2004; Harvey, 2009) of two large and important representative government datasets, institutions and infrastructures. This study reveals how these official institutions have been 'making us up' and creating humans as subjects (Foucault in Rabinow, 2010) by making explicit the 'real' material and social effects of counting, categorizing and map making. Further, it critically examines the Atlas and census as representations, specifically answering what they represent, what they say and what they do. Hacking's framework, as discussed, was used to structure the study of the six editions of the Atlas of Canada, first published in 1905, and to analyze Canadian census questions and their associated categories between 1871 and 2011. 
The study of the Atlas of Canada is less about cartographic techniques, as this is well-covered elsewhere (Thomson, 1966, 1967, 1969; Zaslow, 1975; and McGrath \& Sebert, 1999), and more about situating its content in discourse. This same approach is used for examining census questions.

The Atlas and the census are well-established Canadian representational and data collection practices, institutions and infrastructures. Mapping in Canada predates the Atlas ( $1^{\text {st }}$ edition 1905), and according to the 1956 Atlas of Canada (Sheets 1 \& 2), mapmakers and explorers were rendering Canadian shorelines as early as the 1500s, if not earlier. French surveyors were laying out seigniorial territories in the early 1600 s, and by the 1650 s, property lines were being demarcated on the banks of the St-Lawrence River. The Geological Survey of Canada (GSC), founded in 1842, was Canada's first official map-making institution and helped shape the Dominion; the maps it produced informed colonial powers, fueled their industrial revolutions, formed part of the cartographic imaginations (Pickles, 2004) of imperial expansion (Edney, 1997), and facilitated the Canadian resource extraction economy. These maps preceded the nation and therefore also constructed it. Borders were drawn and negotiated, cadastres parceled land into private holdings irrespective of previous dwellers, the scientific grid of surveyors presupposed an uninhabited landscape, and the maps erased the settlements of indigenous populations, as the absence of a grid presupposed vacant land. 
Atlases are often nation-building tools. For example, the $1^{\text {st }}$ and $2^{\text {nd }}$ editions of the Atlas of Canada were used to attract immigration and colonial investment. Atlases are also large collaborative government undertakings, which take years to produce. They require significant institutional support, financial resources, and political investment. Atlases are considered as objects designed to showcase the scientific knowledge of the state; as symbols of national pride; and as ambassadors, representing the nation internationally (Monmonier, 1994; Omerling Sr., 1979, Salichtchev, K. A., 1960, 1972, and Perkins, 2009a). A national atlas, as described by Canadian studies scholar Thomas H. B. Symons is:

a system of objective information whose compilation is justified by its direct contribution to utilitarian decision-making as, for example, in national and local planning. In the other opinion, the atlas is seen as refining and extending the reader's perception of the nation, in which case the atlas contributes to national self-awareness and cultural development (1979:4).

National atlases and the Atlas of Canada are discussed more fully in Chapter 4.

Census data collection does not predate the first recorded instances of mapmaking in the North American colonies. The New France census of population and agriculture, for example, was conducted in 1665-1666 and it was followed by many others, some conducted by religious orders, and others by linguistically distinct representatives of French and British colonial powers (Curtis, 2001). By 1841, the North American British Colony of the Province of Canada was formed, and official decennial censuses began in 1851-52. By 1871, the first Dominion of Canada census was taken in both official languages. The census, unbeknownst to 
most of the public until recently 8 , is a very powerful state institution that determines the size of electoral boundaries; the number of seats in parliament; and the amount, purpose and distribution of spending envelopes. The census counts people and directs how they are to be administered; it tells them who they are on census day, helps them see how they have changed, influences where they will be, and places them in social (e.g., low income groups) and geographic spaces (e.g., Census Metropolitan Areas). The census provides the evidence required for 'objective' and 'scientific' decision-making as it is the 'science of statists' or 'political arithmetic' (Petty, 1670 in Patriarca, 1996:13) used for putting things and people in their place.

The Atlas of Canada and the Canadian census are established Canadian institutions and infrastructures, which, it will be seen, have been instrumental in constructing Canadian geographical imaginations and producing spaces. It is for this reason that they have been selected for this study.

\subsection{Data, Infrastructures and Geographical Imaginations}

Underpinning any large state dataset, such as a census or an atlas, is an infrastructure that comprises institutions, people, knowledge, budgets, technology, standards, policies, laws, frameworks and practices (Groot \& McLaughlin Eds. 2000 and Coleman \& McLaughlin, 1997). These large social technological systems (Hughes, 2004 and Allen \& Hecht, 2001) are substrata or substructures that sink into the background, invisible but ever present (Dourish

\footnotetext{
${ }^{8}$ The media coverage and citizen outcry over the cancellation of the long-form census in the summer of 2010 made the census public and political.
} 
\& Bell, 2007; Dreiker et. al 2002, Graham \& Marvin, 2001 and Star \& Ruhleder, 1996). Infrastructures are labour intensive, and have economy wide effects (Gregory et. al, 2009), once built, they have a technological momentum 9 of their own, creating socio-technical norms that become hard to change as they become taken for granted practices (Hughes, 2004). They exhibit a kind of infrastructural determinism ${ }^{10}$. Infrastructures recede deeply into the background of daily life experiences, and are often forgotten (Graham \& Marvin, 2001:21). As invisible as infrastructures may be, they are path dependent technologies ${ }^{11}$, not neutral black boxes (Latour, 1987), and they have politics embedded within them, requiring large state expenditures, and they normalize subjects. The rationalities - gouvernemental thinking - inform data collection, data representations, and the infrastructures that are constructed to embody and perform those rationalities. These rationalities, it is argued, are shaped by and shape geographical imaginations, which in turn, form and transform social and material

9 Thomas Parkes Hughes developed the concept of technological momentum, and the following is a definition by Andrew Feenberg: "large scale technological systems acquire momentum as they grow. By this is meant that once the basic decisions have been made and implemented, the system tends to continue in the same direction indefinitely. The culture of the organization is shaped by its early technological choices and excludes the exploration of alternatives. Often the cost of changing direction is very high. The momentum of the system thus pulls it forward along what appears to be a predetermined pathway. So the electric power industry continues to be based on huge centralized generators although solar and other small scale generation is proving to be efficient and environmentally desirable" (2008).

${ }^{10}$ Infrastructural determinism is a term that emerged in conversation between Michael Lenczner and the author. The concept does not imply comprehensive determinism as that which is seen as being absolutist and reductionist, but it encompasses the idea that there is a sort of partial or local determinism, as infrastructure may possibly and/or probably determine how certain segments of its users will act and interact with it and continuously modify it.

"Path dependencies are those locked-in technologies, sometimes even inferior technologies, that are hard to move out of. They become so dominant that they cannot be unseated even if a better technology comes forward, as there are significant hardware, software and peopleware investments (Edwards, Jackson, Bowker \& Knobel, 2007). 
realities (Gregory, Harvey, 2009; Anderson, 1991; and Said, 1978, 1989). Geographical imaginations can be characterized as the normalized ways people come to know places and spaces, in other words, it is the social construction of geographical world views. Maps, data and their infrastructures help shape those world views, and those same artifacts and large technological systems are constructed by models of the world which are geographical ways of thinking. In the context of this study, how the Atlas of Canada and the Census of Canada construct ways to imagine Canada is examined.

Geospatial data and their infrastructures are considered essential for governing, because data and associated technologies, techniques and procedures, construct knowledge to inform decisions for managing Canada's population and territory; they are also socio-technological state formation activities which perform biopower. Data and infrastructures are the means for which governors do government, and because the Atlas and census are primarily gouvernemental objects, it means that the state sets the stage for how it will govern, and how its citizens will think of, and imagine, the Canadian territory and people. Although Aboriginal people, Québecois, Newfoundlanders and other 'kinds of Canadians' have countered government constructed imaginations, the government remains the final arbiter when it comes to the Atlas and the census.

A post-modern sensibility to the analysis of discourse is applied here to the study of data and infrastructures (i.e. Atlas and census) (Waitt, 2010; Sharp \& Richardson, 2001). This approach is useful as it allows for the study of normalized practices and processes, and reveals how knowledge about Canada is 
produced, reproduced and put to work. The study of geographical imaginations is a social constructionist view and discourse analysis, as a constructionist practice, helps unravel the way things come to be. In this case, data, maps and infrastructures, and how these construct geographical imaginations, are examined.

Further, Hacking's framework is also a social constructivist approach, which he applies to study how classifications dynamically create identities. It is applied here as a method to structure the analysis of the discourse associated with the creation of the Atlas and the census. It is particularly useful because his framework, also known as the 'looping effect', provides a method to examine how 'things' (i.e., kinds of people and spaces) get normalized, and by doing so, via a variety of engines and elements, these same 'kinds of things' dynamically change how people are viewed or view themselves, or how spaces are viewed, which changes how 'things' are imagined and in turn change spatial practices. The Atlas of Canada and the census are sets of carefully assembled maps in the former and spatially referenced data derived from questions in the latter, which are sets of socially constructed classifications that produce the spaces (i.e., subjects) government officials have deemed important. It is for this reason that classifications are understood in this study as ways to construct geographical imaginations. Throughout this study, data, maps and infrastructures are considered as objects, representations and technologies created in social worlds that, in turn, produce social realities and spaces, and studying their discourse helps reveal the knowledge/power that produces those realities and spaces. An 
analysis of the discourses of data and infrastructures helps reveal the situated knowledge that has formed around the policies, practices and technologies to construct these as objects, and how these objects have, in turn, constructed ways of seeing Canada and projecting it.

Natural Resources Canada (NRCan) and Statistics Canada (StatCan) have many divisions and branches producing many other surveys, maps, datasets and databases that are critical to the government and the public. It is, however, beyond the scope of this thesis to examine all their products. The Atlas was chosen for this study, as it is a carefully selected and bound collection of government maps and images that illustrate the type of mapping work the government does, while the census was selected as it is the legislated institution responsible for counting people, and it is argued, defining the Canadian population.

\subsection{Structure of the Dissertation}

Chapter 2 provides the theoretical background of the thesis, and includes concepts related to the critical examination of data and infrastructures as discourse and how these are engaged in the construction of geographical imaginations. Geographical imaginations, the power/knowledge of the Atlas of

Canada and Canadian census, as well as gouvernementalité, are also discussed in relation to the knowledge and space producing aspects of data and infrastructures. Chapter 3 describes the modified Hacking framework as the methodology used to study the Atlas and the census, while Chapters 4 and 5 apply it. Chapter 6 concludes by assessing the central arguments of this thesis. 


\section{Chapter Two: \\ Data, Infrastructures and Geographical Imaginations}

The new portrait of Canada is the product of more than 10 years intensive work by experts of the department's geographical branch, they collected a mountain of facts about the country and assembled them in 500 new maps telling Canada's story...What types of rock in the mountains? What region has most sun most snow? Where are the forests, farms, factories? The answers are all there, if you know where and how to look? Within each of the 500 maps the story of Canada unfolds across 3000 miles of geography from sea to sea. The habitat of wildlife, the structure of rock and soil regions, the results of years of scientific study in the field and in the laboratory are recorded in the Atlas reflecting the labours of naturalist, prospector, and soil scientist... Canada's latest portrait is the sum of knowledge that is accumulated since the first explorer; presented in a new way. Some of the men who were in at the inception are waiting like anxious parents for the birth of their book. The last page rolls off completing ten years intensive work, the geographers have written the story of their country in maps and captured between covers a new portrait of Canada.

NFB, 1959, All Canadian Atlas, Transcript from the short film about the 1957

National Atlas of Canada.

[The census is] nothing less than the periodical stock-taking of the peopletheir composition and condition - designed to show from the widest possible angle the stage that has been reached in the evolution of the national life...the data on these various points form a standard by which almost all other facts relating to the country must be measured if they are to have real significance; the well-being of the state, physical, moral and economic, including such important phases as the birth and death rates, criminality, production, trade, wealth, can be apprehended and interpreted only through the medium of population statistics

Dominion Bureau of Statistics (DBS), 1945, Eighth Census of Canada 1941:

Instructions to Commissioners and Enumerators (p.11-12). 


\subsection{Introduction}

This chapter argues that Canada's geographical imaginations are shaped by and shape the data and infrastructures used to produce geographical knowledge. Also, these data and infrastructures represent governmental rationalities to fulfill the need to govern; they are therefore gouvernementales, and the processes used to manage the population and the territory are the biopower of government. The financing and administering of government programs, services and electoral processes are evidence based and require data for their administration, and it is the infrastructures behind the data that provide government with the facts it requires to inform those decisions and guide actions which produce social and material spaces.

This chapter begins by describing how data are understood (Section 2.2), provides a definition of infrastructure (Section 2.3), with a particular focus on geospatial data infrastructures. Discourse is defined and examined in the context of geographical imaginations, which are socially constructed, and the data and infrastructures that help produce these imaginings, which are part of the technopolitical regimes of power/knowledge (Section 2.4). This chapter ends by describing geographical imaginations in the context of data and infrastructures (Section 2.5).

\subsection{Data}

Data are "thing[s] given or granted; something known or assumed as fact[s], and made the basis of reasoning or calculation" (OED, 1989). For scientists, they are "the primary building block of science" (CODATA, 2007). An earth scientist, 
urban planner, cartographer, electrical engineer or epidemiologist each represents a community of practice or epistemic group, each with their unique outlook on what constitutes data. Definitions, understandings, values and quality parameters also vary according to discipline (e.g., geography, physics, social work, archaeology), sector (e.g., communication, energy, housing, health), level of government and their departments (e.g., federal, provincial, municipal), private sector (e.g., Google, Environics, DMTI), non-governmental organization (e.g., Social Planning Councils of Ontario, Ducks Unlimited, Fraser Institute, CreativeCommons.ca) or to individual citizens. In addition, data resellers, lawyers, data value-added service providers, and researchers in academia or the private sector value data for different reasons. Finally, the roles people have in relation to data (e.g., data librarian, archivist, network specialist, database manager, GIS specialist, cryptographer, cataloguer, artist, project manager) frame how data are handled. Irrespective of these different outlooks, understandings, values, uses and roles, data share some common characteristics.

Data include "numerical quantities or other factual attributes generated by scientists and derived during the research process (through observations, experiments, calculations and analysis)" (CODATA, 2007). Data may contain facts which represent a one-of-a-kind event such as a volcanic explosion or a tsunami, population counts as in the case of a census taken on a particular date, or maybe the locations of points of interest arranged in a particular mapping format such as a Google mashup. Cumulative sets of data are useful to understand trends, frequencies and patterns, and can form a baseline upon which 
predictions can be made or assessed. Data may also be in the form of a data model, simulation or time series map such as those found in an atlas or in a visualization. Further, data may also be "numbers, images, video or audio streams, software and software versioning information, algorithms, equations, animations, or models/simulations" (NSF, 2005:18). Data may also be "facts, ideas, or discrete pieces of information, especially when in the form originally collected and unanalyzed" (Pearce-Moses, 2005). Data can be acquired directly from experimentation in laboratories (e.g., genetic testing) or from the physical world (e.g., a soil sample). Data can be derived from evaluated published data (e.g., textual analysis), or collected from multiple locations and sensors to serve a particular research agenda (e.g., air quality), or collected from an entire population within a given territory, as in the case of a census.

Data can also be distinguished by how they were collected: observational; computational; or experimental (NSF, 2005:19). Observational data, such as direct observations of ocean temperature on a specific date, the film footage of an Antarctic ice sheet breakup, pre-election polls, or the photographs of a meteorite cloud, are often historical recordings of particular events that cannot be replicated nor recollected. Computational data may be the results from a climate change model that includes comprehensive information about the model (e.g., descriptions of the hardware, software, original input data, metadata). Results from models may be reproducible but these may be considered less important than the models themselves. Experimental data "such as the measurements of patterns of gene expression, chemical reaction rates, or engine performance" 
(NSF, 2005:19) may be reproducible, but at a cost. Data are created, maintained and disseminated by any number of organizations, each with its own value structures, processes, mandates, and cultures (Lauriault, Craig, Pulsifer, \& Taylor, 2008).

Geospatial data can be all of the above with the addition of a georeference and are ideally, but not always, accompanied by metadata. Geospatial data often adhere to some sort of standard in terms of their quality, accuracy, reliability, and authenticity that guides how these are to be arranged, described, stored, rendered, and in what file formats. Geospatial data are usually stored with coordinates, and describe the location, shape, and spatial relationships of geographic features and attributes. These data are available in many forms, including: framework data, aerial photographs, satellite images, climate change models, census tract data, tabular demographic data in a spreadsheet, ice flow edge sketches by an Inuit elder, videos describing the story of a place, cinematic online atlases, a Google mash-ups created with user generated content, or audio recordings of political party speeches.

Geospatial datasets have innumerable government application areas (Lauriault \& Taylor, 2007): they help governments meet their constitutional and regulatory responsibilities; they assist departments and ministries that have particular subject matter responsibilities that require data for their management; and they guide international treaties that require data for oversight purposes. Census data, in particular, are used to determine electoral boundaries and provincial and territorial financial transfers, among many other uses. Governments, large public 
institutions such as hospitals, research universities and the private sector are the primary creators and maintainers of geospatial data because these are very expensive to produce; citizens, non-profit organizations and consulting firms are generally users and provide value-added services. Geospatial data are produced and used in academic institutions, but at a much smaller scale than government and are often created with the use of public funds. Geospatial data in myriad forms are also used for critical research. For instance, Derek Gregory's (2008) work on the cultural turn in US warfare tactics relied on the following types of datasets: computer games; battle simulations; transcribed interviews; instruction manuals; magazine covers; websites; air photos; maps; satellite images; photographs; blog posts; urban warfare settings on training bases; hand-held translator devices; and the information used and produced by military anthropologists.

Governments create, use and maintain massive datasets about the territories they govern, the resources they oversee, and the people they manage. These are publicly funded national assets or resources. Due to the division of powers in Canada, each level of government maintains its own data to inform decisions regarding its jurisdictional responsibilities. For example, the Federal government will maintain national scale framework data, coastal hydrological maps, federal election data, data related to security, national parks, sovereignty, and census data. Provincial governments are responsible for data related to health, transportation, lakes and waterways, parks, and cities, to name a few, 
while cities are responsible for infrastructure data, the location of public housing, and daycare services and facilities.

Although data are commonly understood in practical terms, understandings differ depending on the actors involved. Data are also part of and the result of large or complex socio-technological systems ${ }^{12}$, as in the case of satellite images. Data are artifacts in a complex web of technology, people, and social, political and economic structures. Furthermore, data are far from the often conceptualized, neutral arrangements of facts accompanied by descriptive metadata. They are political in their creation, use, arrangement, dissemination, representations, and in their ownership ${ }^{13}$. Their collection requires specialized knowledge, techniques, sophisticated technologies, and often, significant resources. Data are also owned, regulated, guarded, standardized, and created within a particular community of practice. They are collected according to a particular model of the world based on the author's worldview, and in turn, become an image or a representation of it. Data, cartographic or otherwise, are arrangements of "facts within a specific cultural perspective" (Harley, in Dodge 2011:276).

\footnotetext{
${ }^{12}$ Hetch and Allen discuss how "social choices shape technological development. But the resulting physical, financial, and institutional durability of systems means that, once developed, they-and the values they uphold-cannot be changed easily. As myriad manifestations of human choices, systems acquire momentum. In so doing, they embody, reinforce, and enact social and political power" (2001:3).

${ }^{13}$ Radarsat 2 is considered the world's most sophisticated radar technology. Its construction was primarily funded with Federal dollars and its ownership was transferred to the private company that designed and built it. Shareholders decided to sell it to a US arms manufacturer until two scientists publicly resigned in protest. Eventually, the sale was stopped by the Government, not because the scientific data were considered important, nor because significant public funds were used to build the technology, but because many organizations and a few journalists framed the technology and the data collected from it as being necessary for the maintenance of Canada's sovereignty in the North.
} 
Maps are also data, often representing census data; maps are created with data, sometimes spatially referenced census data, and maps and mapping are central to the geographical imagination. Maps, like other data, are also more than neutral and objective models of physical and social realities, as J.B. Harley's body of work on the deconstructing of maps has taught us. Normally, maps are evaluated by cartographers "on standards of 'objectivity', 'accuracy', and 'truthfulness"' (Harley, in Dodge 2011:278). However, like data, maps are also sophisticated artifacts, which should also be read "as much for what they reveal of the cultures that produce them as for the geographic information they represent" (Cosgrove, 2005:30). David N. Livingstone's (2010) work on Cultural Politics and The Racial Cartographies of Human Origins concluded: "racial cartographies are thus carefully staged productions that discipline and direct human imaginations through conveying the impression that they are simply mirror reflections of natural realities" (219). Livingstone's genealogical research on the representations of race demonstrated that these maps and visualizations are ideologically tinged with genesis myths.

Map-making grew between the $15^{\text {th }}$ and $17^{\text {th }}$ centuries because of advances in print capitalism, the growth of scientific practices with emphases on quantification and measurement, and their use in estate planning with the growth of private property regimes. Also:

projects of political unification, nation building and the consolidation of a notion of national space gave added importance to mapping projects, particularly in regard to the defense of territorial borders...and map-making then becomes a form of statecraft (Pickles, 2004:105-106). 
Maps also map nations, and by doing so, produce them. Such maps are proleptic as they create a geo-body, as Winichakul revealed in his study of the maps of Siam. These "anticipated a spatial reality and imagined community, rather than depicting one, they were a model for and not a model of' the nation (editor's note for Winichakul, in Dodge 2011:407). In Siam and elsewhere, the maps did not do this on their own. Force and a colonial imperative were used to define 'the Siam space' and as Winichakul underscores:

mapping vindicated it. Without military force, mapping alone was inadequate to claim a legitimate space. But the legitimation of the military presence was always substantiated by a map. Mapping and military became a single set of mutually reinforcing technology to exercise power over space in order to define and create the geo-body of Siam (Winichakul, in Dodge 2011:409).

Colonialists, scientists, statisticians, cartographers, survey engineers and others, with a nation building imperative, created the geo-body of Canada. Maps represent territory and produce and reproduce it, and as just mentioned, they have been known to:

precede territory, inscribe boundaries and construct objects which in turn become our realities, cadastres gave legal and material form to the new landscapes of private property, geomorphological mappings do not mirror the physical world but create textual abstractions (Pickles, 2004:145).

Government maps, in particular, "extend and reinforce the legal statutes, territorial imperatives and values stemming from the exercise of political power" (Harley, in Dodge 2011:286). As briefly illustrated, maps and data are technological and scientific products, and should be interrogated according to the norms of the scientific messages they convey as well as the social contexts of their 
emergence, dissemination and use (Pickles, 2004, Harley, in Dodge 2011). The socio-technological, cultural and political aspects of maps and data in relation to the Atlas of Canada and the Census of Canada will be discussed in greater detail in Chapters 4 and 5 as will their roles in the construction of Canadian geographical imaginations.

\subsection{Infrastructures}

Communication infrastructures are the means to facilitate the dissemination of ideas, texts, symbols, songs, etc. that a culture embraces as its own, and which provide its members with the means, media and cultural products to collectively identify and imagine themselves. Geospatial data infrastructures (GDIs) mediate culture and society by constructing stories, narrated with data and maps, to create geographical imaginings or representations that form notions of identity and community cohesion. People know the shape, form and territorial extent of the place they call Canada; it has a geometry, a projection, a datum and a unique identifier on a server, while data on myriad issues from demographics, environment, and health, to name a few, fill the polygons within which people are surveyed, managed and governed.

GDIs facilitate the dissemination of data, statistics and maps, which provide governments, scientists and geomaticians, and many others, with the tools they need to produce 'objective' stories or models about Canada. These information products inform actions which have both social and material effects. For example: indicators may be used as evidence to improve unemployment programs; maps can inform the building of a social housing project for the 
homeless; and air quality data may be used to predict respiratory health care costs. GDIs also constitute a kind of "storytelling organization or a collective storytelling system in which the performance of stories is a key part of members' sense making and a means to allow them to supplement individual memories with institutional memory" (Kim \& Ball-Rokeach, 2006:180). Users access geospatial databases via a portal, read the metadata to assess if the data are fit for their particular use, and then create maps or models, which will inform a decision that may change the way things are done and which may manifest in a change on the actual terrain. For example, an agricultural analysis may result in the need for irrigation subsidies for certain types of farmers in some parts of Canada. The infrastructure also becomes a kind of extrasomatic memory system that allows for the telling of stories about the nature of Canada's forests, or to explain the social determinants affecting the health of citizens. These stories are articulated with maps, graphs, models and statistics, which rely on sensors, data, interoperability and web mapping standards, portals, metadata and models, science, and open architectures, instead of words, text, song or cinema and their associated industries. This techno-scientific approach to the construction of geographical imaginations is examined in greater detail in Chapters 4 and 5 .

GDIs, like most infrastructures, are transparent to their users, and have networked geospatial database and data handling facilities. They encompass a complex network of institutional, organizational, technological, and human and economic resources, which interact with one another to underpin the design, implementation and maintenance of mechanisms that facilitate the sharing, 
access to, and responsible use of geospatial data for a specific application domain or enterprise (Groot \& McLaughlin, 2000). They are shaped by, shape ${ }^{14}$, and are integrated into the maintenance and creation of most other infrastructures while also being an integral part of the global information communication infrastructure. For example, the global positioning systems (GPSs) can be part of in car navigation systems, which use GDI framework data maps such as the National Street Network File, they also rely on wireless and cellular systems that are part of satellite space technology networks. Similarly, roads are maintained with the use of geographic information systems (GIS), which rely on satellite imagery. GDIs, like health, education, or census infrastructures, are viewed as a legitimate function for government support, because they provide a common, consistent infrastructure upon which a variety of government, private sector, economic, academic and community activities can take place.

GDIs are considered as objective and politically neutral. However, like all large socio-technological systems, GDIs are part of a long history of mapping, navigation, resource extraction, colonization, nation building and territorial, resource and population management. Their genealogies are complex and beyond the scope of this dissertation. Whether a GDI or census infrastructure, irrespective of where they reside or who manages and funds them, they are normatively understood as being essential for governing. The literature on GDIs

14 Hetch and Thad Allen discuss how "social choices shape technological development. But the resulting physical, financial, and institutional durability of systems means that, once developed, they-and the values they uphold-cannot be changed easily. As myriad manifestations of human choices, systems acquire momentum. In so doing, they embody, reinforce, and enact social and political power. Thus, human power rides upon the history of things." (2001:3). 
is almost exclusively pragmatic, practical and literal, normally written by public officials who are part of constructing and managing them, or it consists of committee reports, or it is the result of public administration and management research (Lauriault, 2003).

Even though infrastructures are inconspicuous in real terms, they are very real and are part of large technopolitical regimes 15 bien encadré by government. They are instrumental in shaping the enactment of government policies and how these are performed daily. For example, radar and satellite images that display receding ice shelves and opening sea passages in the Canadian Arctic also inform climate change models and rouse sovereignty debates (Pulsifer \& Taylor, 2007). Similarly, StatCan's provincial and territorial population counts determine the size of federal transfer payments related to legislative responsibilities, such as health or bilingualism.

Infrastructure is therefore an actor in technopolitical regimes, whereby it:

is simultaneously an actor whose activity is networking heterogeneous elements and a network that is able to redefine and transform what it is made of" [and it] "is reducible neither to an actor alone nor to a network. Like a network it is composed of a series of heterogeneous elements, animate and inanimate, that have been linked to one another for a certain period of time (Callon, 1987:93).

The Canadian Geospatial Data Infrastructure (CGDI), for instance, may have officially begun at the launch of the GeoConnections program in 1999, but one of

${ }^{15}$ Technopolitical regimes are "grounded in institutions, and they consist of linked sets of people, engineering and industrial practices, technological artifacts, political programs, and institutional ideologies which act together to govern technological development and pursue technopolitics" (Hetch, 2001:257). 
its first computerized manifestations was the National Atlas Information System (NAIS), which emerged in the late 1970s. NAIS was inspired by the invention of GIS, the production of the Canada Land Inventory (CLI) in the 1960s, and early computerization. The infrastructure of surveying and mapping, however, has been gridding and measuring Canada and its changing territorial divisions for centuries, and there were many occasions where centralizing and standardizing mapping processes were discussed and implemented. Furthermore, today's CGDI has dynamically changed from its 1999 version due to technological advances, new interoperability standards, organizational change and changing ideas about mapping. Its components (i.e. heterogeneous elements) are the same, while their composition, materiality and the techniques by which they are deployed and managed have dynamically evolved (Figure 1 below). The infrastructure to produce a census and disseminate its results has also changed since it was first taken in Canada by Jean Talon 1665--66. Aspects of mapping and census infrastructures as these pertain to the Atlas of Canada and the Canadian census, are examined more closely in Chapters 4 and 5 respectively. 


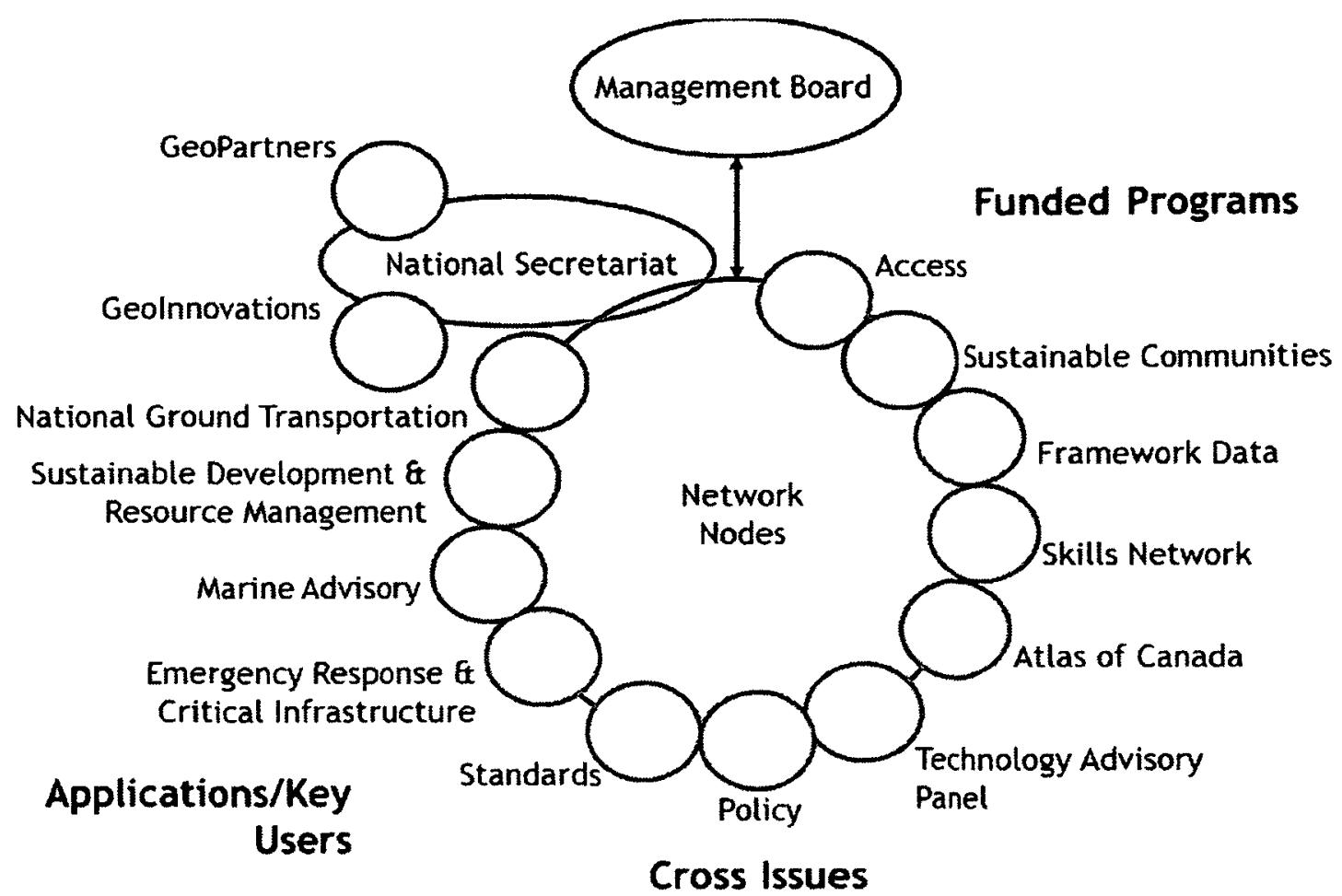

Figure 1. Canadian Geospatial Data Infrastructure (CGDI) Model (Adapted by the Author from GeoConnections 2003)

GDIs have distinct operational and implementation functions, including coordinative, administrative and managerial functions. Secretariats, advisory boards, steering committees, working groups and partnership programs are managerial components, while mapping, standards, framework data, interoperability, metadata and clearinghouses are technical. Some national GDIs have their managerial elements as formal extensions of their national mapping agencies, while others have separate institutions to carry out and guide these activities. In some cases MOUs, directives or legislation formally mandate their existence. Mechanisms such as terms of references, bylaws, accords, and directives are used to guide and define high level mandates and the activities of committees. The Canadian model, as seen above (Figure 1), includes non- 
geomatics experts (e.g., librarians, municipalities, information end users) along with experts. The CGDI includes application advisory nodes and formal programs to develop partnerships and mechanisms to award contracts to the private sector to help build components and services. The program advisory network is separate from operations, and is a consensus-making environment. The current CGDI organizational model has changed as many of its technological components have been built and standards have normalized, and today the focus is to "promote awareness of new applications of geospatial information and to educate stakeholders on the importance of interoperable solutions through the adoption of operational policies and standards (GeoConnections, 2011).

The CGDI is an example of the social construction of technology or social shaping approaches to technology, which:

reinforce the idea that technology is part of social life, and that technical objects are deeply embedded (or imbricated) into social and cultural relationships. These approaches thus challenge the idea that technology is neutral, or that social factors such as class, gender, or culture have no relationship to technological development at any stage (Powel, 2006:8).

In this view, infrastructures are "involved in sustaining what we might call 'sociotechnical geometries of power in very real - but often very complex - ways" (Graham \& Marvin, 2001:11), as they embody congealed social interests that represent "long-term accumulations of finance, technology, know-how, and organizational and geopolitical power" (Graham \& Marvin, 2001:12). For example, the CGDI was developed with an open architecture, using interoperability standards, based on distributed web mapping and the adoption of ISO19115 metadata standards, as well as a services model. These are techno- 
political choices, as the infrastructure allows for components to be built by external actors who can use and add to it, providing they adhere to these standards and specifications. Standards, like measurements or benchmarks, control processes and the will to standardize, which:

presumes the ability to constrain a phenomenon within a particular set of dimensions, as well as the ability to dictate behavior to achieve the narrowly defined dimensions that stipulate its outcome. A great deal of work is conducted to make the standard possible, and then this must be followed by agents committed to implementation and oversight. Again, standardization is a recursive practice, necessarily historical and embedded in a series of complex events and social structures (Star \& Lampland, 2009:14).

Standardization has normalizing effects. Government, in collaboration with external experts, has created a CGDI that allows for heterogeneous parts to be built, to fit together, and to be reused.

The spatial arrangements of the CGDI allow for the viewing of geospatial data that are distributed from multiple locations, but dynamically assembled for one view and accessible from anywhere. These arrangements also allow for many servers to make accessible layers, which are managed, owned and maintained locally but shared by simply adopting the same standards, specifications, technology, code and policy. The road network file, for example, was created by many jurisdictions, but was assembled centrally and then re-disseminated via GeoBase as a framework data layer. This layer was then reusable by anyone in Canada and elsewhere. Most importantly, all users were using the same data, which meant they could produce and integrate the results of their work within other processes. The collaboration between the provinces to co-build the National Road Network File was formally agreed to in an accord that stipulated 
how it was to be constructed, and how data were to be shared for mutual benefit, following CGDI standards.

The CGDI was imagined, then modeled and architected in a specific way, and it performs according to how it was imagined. The CGDI could have been imagined as a closed platform and as a software specific system with restrictive licences, and that would have created a very different set of socio-technological network relations and potentially much less uniformity in models as different frameworks could have been used as work-arounds to cost and platform specificities. The current CGDI evolved with the participation of heterogeneous actors from many government institutions, including scientists, engineers, developers and thematic and standards experts, all of whom shared the common interest to collaborate more effectively and to be application software agnostic (Lauriault, 2003, Lauriault \& Taylor, 2007).

Bonnie A. Nardi and Vicki O'Day characterize each infrastructure as being an information ecology, "a system of people, practices, values, and technologies in a particular local environment. In information ecologies, the spotlight is not on technology, but on human activities that are served by technology" (1999a). Their conceptualization of infrastructures includes systems ${ }^{16}$, with diverse ${ }^{17}$

\footnotetext{
${ }^{16}$ Systems: "like a biological ecology, an information ecology is marked by strong interrelationships and dependencies among its different parts. The parts of an information ecology may be as different from each other...but they are as closely bound together. Change in an ecology is systemic" (Nardi \& O’Day, 1999a).

17 Diversity "there are different kinds of people and different kinds of tools...that work together in a complementary way." In a library ecology "there are computers that provide electronic catalogs and Internet access, paper and pencils for writing down call numbers, and labels on the shelves so you know which section of books you are looking at" (Nardi \& O’Day, 1999a).
} 
actors that coevolve ${ }^{18}$ with keystone species ${ }^{19}$ and locality ${ }^{20}$. They also suggest

that values should be consciously embedded in these systems to ensure that the information ecology is not overwhelmed by technology alone, and to encourage the participation and engagement of actors in a given ecosystem, as it will evolve "with our own efforts to influence the shape and direction of the technologies we use and the settings in which we use them" (Nardi \& O'Day, 1999a).

For example, the CGDI - Architecture Overview (2005) is part of the information ecology or discursive community of geo-IT. This document was written to direct developers, and it includes the technologies, processes and standards of the CGDI; it is explicit that these are to be in open formats, to be interoperable and adhering to open standards and specifications. This architecture is also being shaped by broader societal approaches to software development that belong to the discursive communities of open source (OS). As

${ }^{18}$ Coevolution where "information ecologies evolve as new ideas, tools, activities, and forms of expertise arise in them. This means that people must be prepared to participate in the ongoing development of their information ecologies... Even when tools remain fixed for a time, the craft of using tools with expertise and creativity continues to evolve...This is part of the dynamic balance achieved in healthy ecologies - a balance found in motion, not stillness. Evolution implies a past, as well as a future. An information ecology as a persistent structure over time acquires its own history. It displays the stable participation of an interconnecting group of people and their tools and practices" (Nardi \& O’Day, 1999a).

19 Keystone species "whose presence is crucial to the survival of the ecology itself...Mediators people who build bridges across institutional boundaries and translate across disciplines - are a keystone species in information ecologies. Ironically, their contributions are often unofficial, unrecognized, and seemingly peripheral to the most obvious productive functions of the workplace" (Nardi \& O’Day, 1999a).

${ }^{20}$ Locality or habitation of a technology which "is its location within a network of relationships. To whom does it belong? To what and to whom is it connected? Through what relations? The habitation of a technology is its set of family ties in the local information ecology. An office computer is used by some person or group of people, maintained perhaps by others, and networked to other computers. It has a place... Only people who are immersed in a particular information ecology can provide a local habitation and a name to new technologies. Healthy information ecologies are sustained by the active, intelligent participation of the people involved in them" (Nardi \& O'Day, 1999a). 
seen in Figure 1 on page 31, many actors ${ }^{21}$ were involved in the creation of the CGDI and the choice toward a more open system over a closed proprietary system was made to ensure that the government did not have to rely solely on a closed proprietary national infrastructural technology over which they would have no control to change or modify should new requirements arise. Furthermore, the government decided that the infrastructure was to be co-created with actors outside of government and to do so parameters had to be set. This provided for a structured way to support and grow a Canadian geomatics sector. OS is considered a political, economic, technological, philosophical, and, some would suggest, ideological approach to software development. The document also provides insight into how ideology, discourse and technology development are interconnected. Further, the way this text is presented, disseminated and framed presupposes political neutrality, except of course to developers who will have to follow what the government has dictated if they wish to participate in the construction of the infrastructure and be awarded any contracts. Developers of the CGDI will not necessarily co-create discourse, but they will reproduce them, because it will be they who replicate the discourse - code and way to map established by the CGDI architecture. These discourses are the arrangements "of organizations of ideological materials in discursive form, and if these discourses exist in an already established repertoire of discourses in a social group, the individual speaker will not in fact be creating a discourse but will simply

${ }^{21}$ Actors were scientists, engineers, application users, cartographers, computer scientists, data administrators, interoperability associations, thematic specialists from government, the private sector, academia, professional associations, and administrators from multiple federal government and provincial departments. 
reproduce it" as the discourse is learned (Kress, 1985:30).

The socio-technopolitical aspects of infrastructures become more obvious when they are examined critically, as they begin to:

reveal the socially contingent effects of new technologies, the way they are enrolled into complex social and spatial power relations and struggles, and the ways in which some groups, areas and interests may benefit from the effects of new technologies, while others actually lose out. Thus, 'the increased liberation and freedom from place as a result of new mobility modes for some may lead to the disempowerment and relative exclusion for others' (Swyngedouw quoted in Graham, Stephen, 1998:176)

Wiebe E. Bijker, Thomas P. Hughes and Trevor Pinch point out that:

engineers, inventors, managers, and intellectuals in the twentieth century, especially in the early decades, created syntheses, or seamless webs. The great technological systems, utility networks, trusts, cartels, and holding companies are evidence of their integrating and controlling aspirations (Bijker, Hughes \& Pinch, 1987:9),

and these technopolitical regimes were constructed materially. Regarding the state of telecommunications infrastructures, Rob Kitchen reminds us that these may be considered as a seamless web that includes technocrats, telcos and engineers, and that:

technologies are not repressively foisted onto passive populations, any more than the power to realize their repressive potential is in the hands of a conspiring few. They are developed at any one time and place in accord with a complex set of existing rules or rational procedures, institutional histories, technical possibilities, and last, but not least, popular desires. All kinds of cultural negotiations are necessary to prepare the way for new technologies, many of which are not particularly useful or successful (Kitchin, 1998:58).

The CGDI was developed with distributed openness, and the technological regimes that lost out were those involved in the development of closed systems 
with closed applications that had to be reconfigured to interoperate with CGDI technologies if they wanted to participate in the rich procurement contracts of government sponsored infrastructure projects.

Susan Leigh Star and Karen Ruhleder (1996) have ethnographically examined infrastructures, and they have ascribed the following nine properties or dimensions to them: 1) embeddedness (they are "sunk into" other structures, social arrangements and technologies); 2) transparency in use; 3) reach or scope (going beyond a single event or site); 4) being learned as a part of membership in a community of practice; 5) linked to conventions of practice; 6) embodying standards; 7) dependency on an installed base; 8) visibility upon breakdown; and 9) being fixed incrementally rather than globally. Their dimensions resemble the information ecology view just discussed, and both views consider infrastructures to be dynamic social and technological systems.

The CGDI also technologically mediates Canada's geographical imaginations, and these are constructed via standards, specifications and the architecture itself. In this case, the geographical imaginations are also:

broadly the mechanisms by which people come to know the world and situate themselves in space and time. [They] consist, in essence, of a chain of practices and processes by which geographical information is gathered, geographical facts are ordered and imaginative geographies are constructed (Schawartz \& Ryan, 2003:6).

The Atlas of Canada is now a product of the CGDI, and together with the census of Canada infrastructure, they socially and materially changes the territory and the people on a daily basis. 
The CGDI Architecture just discussed is useful, as it makes explicit how social relations are produced and reproduced via terms of reference and specificities within requests for proposals, and the resulting technologies that reproduce technological ideologies. These are the tactics of biopower and they reflect gouvernementalité. The following image (see Figure 2) from the CGDI Architecture (GeoConnections, 2005) document illustrates the way maps and data narrate Canada, and more specifically, how Canada is reproduced in the infrastructure. In this model, users are developers, end users, suppliers and marketers and the architecture is made up of four key elements: data, services, applications and users. Together, these elements construct how Canadian geospatial data are viewed, shared and rendered into maps and atlases. When looking at maps or navigating the page of an online atlas, the infrastructure is invisible, as is the communication infrastructure that delivered it to your screen.

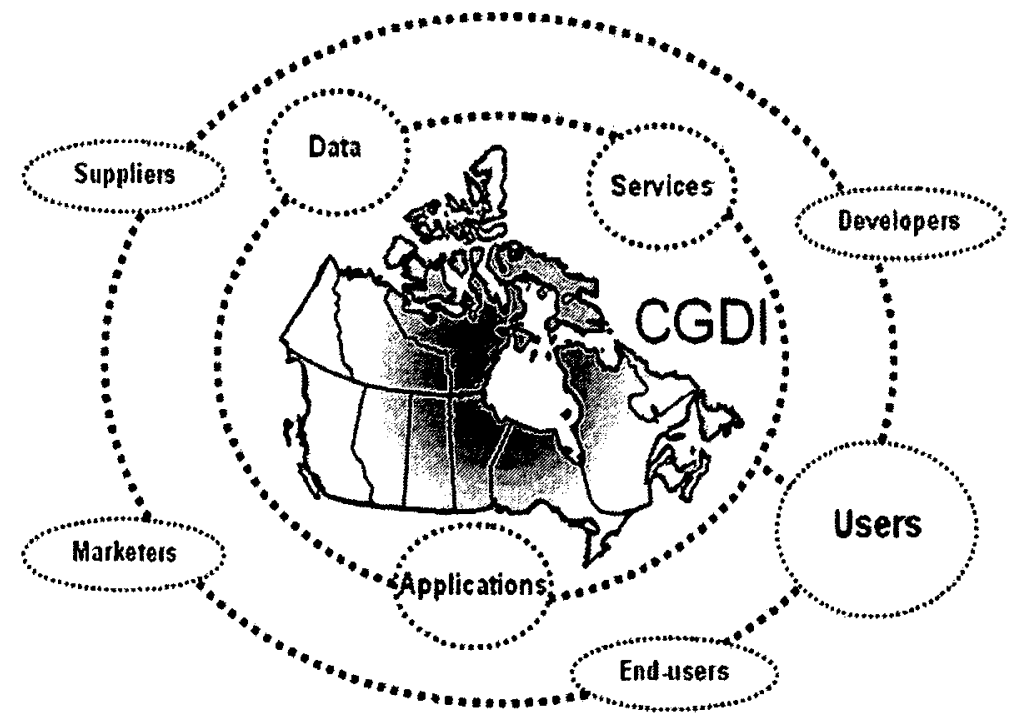

Figure 2. CGDI Conceptual Architecture (GeoConnections, 2005) 
Infrastructures are also defined as "technological networks that keep society connected and that define modern life" (ACSE, 2002). They are the cultural and technological achievements that facilitate most human activities and are the "background or invisible structurings that underpin mundane experience and everyday action" (Dourish \& Bell, 2007:423). "[A]s they become woven into the texture of everyday existence, the devices, techniques, and systems we adopt shed their tool like qualities to become part of our very humanity", the human built and constructed world (Winner, 1986:12). The normalizing effects and invisibility of infrastructures is a common theme. To the end user, infrastructures are what Bruno Latour refers to as black boxes of science, whereby:

scientific and technical work is made invisible by its own success. When a machine runs efficiently, when a matter of fact is settled, one need focus only on its inputs and outputs and not on its internal complexity. Thus, paradoxically, the more science and technology succeed, the more opaque and obscure they become (Latour, 1999:304).

It is this successful invisibility, opaqueness, or normalization that makes them incredibly powerful. Citizens allow others, namely scientists, engineers, technocrats, specialists and entrepreneurs, to design them, build them, maintain them, until one day they have a momentum of their own that is hard to change or redirect. Consequently, a type of infrastructural determinism emerges, directing consumption, production, the built form and social interaction. A kind of infrastructural amnesia (Lauriault, 2008) also sets in when "using a phone, driving a car, taking an airline or rail trip, turning on a tap, flushing a toilet or plugging in a power plug, which is so woven into the fabric of daily life and 
'normalized' to the point of banality that (whilst they function adequately) it scarcely seems important" (Graham \& Marvin, 2001:21). Yet they are very important. In many respects, infrastructures are "the technological fabric of society" or "the hardware that goes into making a civilization" (Hayes, 2005:2, 5). Infrastructures are path dependent technologies, and it is important "to take seriously the very real consequences that accompany technological devices, systems and practices" (Barney, 2007:7) as "artifacts do have politics, and conversely that politics have artifacts" (Carlson, 2001:28). Technological choices once made are difficult to change, and once in place lead outcomes that will affect the public for a long time to come, therefore, it is in the public interest to consider long term scenarios and potential societal outcomes.

Maps and data have their infrastructures and the CGDI has created a kind of open access culture as a result of how it was imagined and in how it continues to perform, which has opened more possibilities for the production of new geoinformation based products that are governmental in essence but not necessarily gouvernementale. For example, StatCan's recent policy change toward data accessibility may have been partially influenced by GeoConnections and the CGDI, which means that StatCan is reconfiguring many aspects of its infrastructure to adhere to this new policy. StatCan's resistance to this change since the mid-1980s speaks to the technological momentum of the data disseminating infrastructure and culture it had in place, and to the closed nature of the institution that evolved from the honourable practice of wanting to 
safeguard the privacy of the data and facts citizens contributed, but also to control access. Politics and policies can change infrastructures.

Inverting 22 the infrastructure, or some of its components, is a way to re-examine critically its normalizing effects and observe how it changes. In the end, society shapes its tools and in turn, the infrastructure shapes society, while the representations and the infrastructure also shape geographical imaginations. Alternatively, the infrastructure is implicated in the "cultural constructions of space, and in turn, infrastructure. Infrastructure is analytically useful both because it is embedded into social structures, and because it serves as a structuring mechanism in itself" (Dourish \& Bell, 2007:417). Star and Ruhleder suggest that infrastructures operate as another manifestation of cultural practice, and in parallel, "infrastructure is something that emerges for people in practice, connected to activities and structures" (1996:112) suggesting 'the infrastructure of experience'. Seeing infrastructures beyond their instrumentality ${ }^{23}$, and accepting that they are deeply cultural and steeped with social significance, opens the possibility for them to be un-black-boxed. This is key because infrastructures

\footnotetext{
${ }^{22}$ Infrastructural inversion means "foregrounding the truly backstage elements of work practice" (Bowker 1994 in Star, Susan Leigh, 1999:380). This inversion is a struggle against the tendency of infrastructure to disappear (except when breaking down). It means learning to look closely at technologies and arrangements which, by design and by habit, tend to fade into the woodwork (sometimes literally!). "Infrastructural inversion means recognizing the depths of interdependence of technical networks and standards, on the one hand, and the real work of politics and knowledge production on the other" (Bowker \& Starr, 1999).

${ }^{23}$ Instrumentalism, according to Darin Barney, is the insistence that technologies are neutral tools, empty of substance where outcomes depend entirely on how humans use them. Technology is merely an instrument, a means to an end, and are efficient or inefficient but are not imbued with values or politics which are only associated with ends and not means. Technologies are neutral as to ends and often but not always, the assumption is that technological progress and innovation are thought of as being good. The intentions may be good or bad but not the technology itself (Barney, 2004:37-38).
} 
"alter the structure of our interests: the things we think about. They alter the character of our symbols: the things we think with. And they alter the nature of community: the arena in which thoughts develop" (Postman quoted in Kitchin: 1998:74).

Government geospatial data, and their related infrastructures, map Canada's territory, resources and the social, cultural, political, economic and environmental interactions of the people within its boundaries - they shape and are shaped by geographical imaginations. In addition, geospatial data and infrastructures are considered essential for governing, because data and their associated technologies, techniques and procedures, construct knowledge to inform decisions for managing Canada's population, environment and territory, constituting socio-technological state formation activities, gouvernementale and biopower in action. Data and infrastructures are the means for governors to do government and the means for citizens to do citizenship, and these are shaped by and shape geographical imaginations.

\subsection{Data, Maps, Infrastructures and Discourse}

Geographical imaginations are cultural constructs, which can be examined in discourse. Derek Gregory (1994), for example, critically 'read' the many discourses of geography for his book, Geographical Imaginations. By doing so, he examined the social practices of geography and how geography is "implicated in myriad topographies of power and knowledge" (Gregory, 1994:11). His book is comprised of a series of essays examining the discourse of geography which involved analysing geographical thinking, the spatial practices resulting from 
geographical imaginations, the social construction of geographical imaginations, and their discursive history, namely, their "interventions in discourse" (3), and the geographical discursive formations observed in large bodies of geographical knowledge. He defines discourse as "all the ways in which we communicate with one another, to that vast network of signs, symbols and practices through which we make our worlds meaningful to ourselves and others" (1994:11).

Gordon Waitt (2010), in his work Doing Foucauldian Discourse Analysis, provides the following explanation of discourse: 1) all meaningful statements or texts that have effect on the world; 2) groups of statements that have a common theme and gives them a unified effect; and 3) that there are rules and structures behind these statements. Studying a discourse therefore involves unraveling what is understood to be the truth by critically examining the way things are done, in order to assess what is normative to a particular community and how that normality came to be. The examination of data and infrastructures, and the technosocial and scientific perspective employed to describe and analyze these, reflects a social constructivist view of technology and science, and a recognition that the material world is not independent from individuals or groups. The method employed to study and describe data and infrastructures, in this case, is grounded in the analysis of their discourse.

Examining discourse is useful as it reveals how language and knowledge are used to construct and reflect the world (Ogborn, 2003). Examining discourse means considering: 
the relationship between language and the social and cultural context in which it is used and looks at patterns of organization across texts. It considers what people mean by what they say, how they work out what people mean, and the way language presents different views of the world and different understandings (Paldridge, 2006:19-20).

The CGDI Architecture document, the 2003 organizational structure of the CGDI, and its components provide insight into how that infrastructure came to be constructed, how actors involved in its co-construction have structured where they fit into it, and how they will act, and these texts have normalized how the CGDI is performed. The CGDI has standardized and specified ways of doing what it does, it fits into pre-existing technologies and their processes, and it is the platform for many other geospatial acts.

Discourse is also socially and temporally situated, and texts are read to understand their positionality and to assess the variability of statements that are made (Waitt, 2010). Texts in this study are not restricted to the written word, and include data, maps, atlases, portals, and census forms. For example, a database, its "production, reproduction, storage, processing, management, distribution and consumption, can combine to create a ground for discursive practice" (Mitchel, 2003:283), as does a data portal or the compilation of code. Furthermore, the infrastructure, databases and maps are geographical representations, which "are more than depictions. They should be judged, not according to 'correctness' or 'fidelity to some great original', but in terms of their 'style, figures of speech, setting, narrative devices, historical and social circumstances' (Said, 1978:21 quoted in Phillips, 2009:542). J. B. Harley, in his 
now classic paper, Deconstructing the Map, revealed the discursive practice and performativity of maps:

all maps strive to frame their message in the context of an audience. All maps state an argument about the world and they are propositional in nature. All maps employ the common devices of rhetoric such as an invocation of authority (especially in 'scientific maps') and appeal to a potential readership through the use of colours, decoration, typography, dedication or written justifications of their method. Rhetoric may be concealed but it is always present, for there is no description without performance (in Dodge 2011:285).

A discursive practice is the historical and cultural set of rules for organizing and producing different forms of knowledge, and in the case of a data portal, for example, it is the metadata which comes from library and archival sciences that drives the 'discovery' component of the portal, and also the standards by which the data and databases are described and then catalogued, and the disciplinary context within which the data are disseminated. A geospatial data portal, for example, is quite different than a science portal in terms of what the portal contains, as is the community of practice producing and delivering those data 24 . Harley considers maps to be "a class of rhetorical images and are bound by rules which govern their codes and modes of social production, exchange, and use just as surely as any other discursive form" (1988:279). Rethinking maps in this way, he thought, would lead us to a better appreciation of the mechanisms by which maps, like books, are a social and political force. As previously discussed, maps are most often considered as objective and neutral facts. John Pickles also

24 There are many kinds of portals which are described in Lauriault, Pulsifer \& Taylor, 2008. 
eloquently explained in his work, Hermeneutics and Propaganda Maps that maps:

have the character of being textual in that they have words associated with them, that they employ as a system of symbols with their own syntax, that they function as a form of writing of symbols with their own syntax, that they function as a form of writing (inscription), and that they are discursively embedded within broader contexts of social action and power (1992:193).

In this case, Pickles' focus was propaganda maps, as these were extreme representations of a particular discourse. Examining such maps provided him with the evidence to demonstrate how traditional theories of maps as being objective depictions of reality were unstable ideas, and by so doing, he was able to show how 'regular maps' also socially construct a particular reality. Pickles' analysis of the positivist discourse of maps, and Brian Harley's work in Maps, Knowledge and Power (1988) and Deconstructing the Map (1989) changed the way maps were seen, as they "cease[d] to be understood primarily as inert records of morphological landscapes or passive reflections of the world of objects" and came to be "regarded as refracted images contributing to dialogue in a socially constructed world" (Harley, 1988:278).

Data, maps and infrastructures also perform in the world, in the sense that these are "part and parcel of [our] entanglement with the nonhuman world; with objects, equations, technologies and a range of other materials of life" (Penrose \& Smith, 2009:1011). Pickles also discussed the performativity of mapping: 
social statistics, public health, moral education and the institutions of urban planning and administration were from the beginning thoroughly spatialized practices of identity construction and social engineering. Mapping and statistics made citizens visible in particular ways, rendering them subjects to public administration, and it provided useful accounting tools for new practices, such as insurance (Pickles, 2004:131).

Geodemographic mapping, as just described, is the mapping of biopolitics. The biopower involved in mapping is revealed by critically examining these maps.

Biopolitical tactics are organized practices by which subjects are managed as a population and not as individuals. According to Michel Foucault, biopower emerged with the first demographers in the latter half of the 18th century, and it was not about epidemics but about endemics. Biopower emerged with urbanization and industrialization and was about:

the form, nature, extension, duration, and intensity of the illnesses prevalent in a population. These were illnesses that were difficult to eradicate and that were not regarded as epidemics that caused more frequent deaths, but as permanent factors which - and that is how they were dealt with - sapped the population's strength, shortened the working week, wasted energy, and cost money, both because they led to a fall in production and because treating them was expensive (Foucault 2003:243244).

Biopower included insurance, savings and the environment humans live in; the first numerical tabulations of data ever found were in actuarial notebooks.

Biopower regularizes biological processes - its object is life. Modern 'man' is an animal whose existence as a living being is challenged by politics and living beings, living in a particular environment, which becomes a political preoccupation (Marks, 2008:96). By the late 18th century, the emergence of “institutions to coordinate medical care, centralize information and normalize 
knowledge" (Foucault, 2003:244) is seen. For Foucault, biopower is also about the control over relations: of humans as a species; the population as a living entity; and as humans in their environment. This control over relations is not about individuals, and it includes climate, geography, hydrography, and how the environment, be it natural or human made, affects the population (e.g., urban planning, infrastructure). Maps and mapping were an "invention in the control of space [that] facilitated the geographical expansion of social systems" (Harley, 1988:280). This 'rise of statistical thinking' (Porter, 1986) and the biopower of mapping are discussed in greater detail in Chapters 4 and 5 .

Maps and statistics meet in the geometric plan that "represents a crucial step along the road leading to the development of Victorian social statistics, since the urban zones constituted by the zenithal point of view could then form the subject of procedures of census, measure and comparison" (Sederstrom in Pickles, 2004:129). Furthermore, institutions such as "the police, public health, architecture and urban planning were all rendered possible by the technologies of political statistics and mapping" (Rabinow in Pickles, 2004:131).

The study of the evolution of the Atlas of Canada found in Chapter 4, revealed a Canadian form of spatial biopolitics. Biopolitics deals not with individuals and property as in a social contract and not with society, but with the population and the territory as a political problem. Biopolitics is about making scientific and political decisions, based the population and the physical geography, and it is the government's responsibility to exert its power in an informed way (Foucault, 2003). In addition, power and control are exerted at a distance via a variety of 
inscription devices 25 that rationally and objectively inform decisions and how they are acted upon (Latour, 1987). Inscription can also be considered as a form of quantification, as it is:

the representation of some action, being, or model through numbers. Formal representations are those not tied to a particular situation or set of empirical data but, rather, are a synthesis of data and a presentation of rules for combining and acting. These are often conveyed in visual form, as graphs, tables, or formulae. They may also be conveyed in narrative form, such as conventional sayings or standard characterizations of phenomena (Star \& Lampland, 2000:9).

Latour finds inscriptions interesting in what they do, not in and of themselves, as many inscriptions have the power to mobilize action and muster new resources (Latour, in Dodge 2011).

Gouvernementalité allows for an understanding of government as a rational entity that relies on the tools of biopower to govern. This power is decentralized, diffused, and exercised in regulation (e.g., health insurance, old age pensions, hygiene rules to promote longevity, childcare, education). It is also manifested in standards, with the goal of maintaining a statistical norm. It is understood that the population "not only has a history, but also a biological reality; and, with the pervasive influence of evolutionary theories, biology itself acquires a historical dimension" (Marks, 2008:97). Biopower also "deploys statistical and regulatory mechanisms in order to predict and manage events, with the aim of establishing

25 Inscription devices are "an instrument (or inscription device) any set up, no matter what its size, nature and cost, that provides a visual display of any sort in a scientific text...A statistical institution that employs hundreds of pollsters, sociologists and computer scientists gathering all sorts of data...is an instrument if it yields inscriptions for papers written in... journals with for instance, a graph of the inflation rate by month and branch of industry" (Latour, 1987:68-69). 
homeostasis within the population" (Hanson, 2008:107). It is a move from individual sovereignty to regularization. It is no longer simply about laws to govern individuals but biopolitical decisions about populations and territory. Biopower and gouvernementalité are useful concepts to understand the invisible hand of data, maps and infrastructures, but also, these concepts help explain how the power mapping and census is diffused and invisible. Infrastructures are classic manifestations of gouvernementalite and the data they contain, and the evidence based decision-making processes they inform are also the processes of biopower.

Stephen Graham and Simon Marvin (2001), in their book Splintering Urbanism, demonstrated how infrastructures went from centralized megaprojects to pieces managed by multiple entities, where there is no one institutional entity overseeing these human built structures. It is as if infrastructures have an autonomous life of their own, shaped by society but never directly, deterministic but not explicitly removing agency. They exert control by counting individuals, managing populations and mapping territories, while humans who take these data to make decisions do so without having to actually decide, because the data do it for them, exerting power at a distance (Latour, 1987). It is only when infrastructures malfunction, as was the case of the Ice Storm or Hurricane Katrina, that we come to realize that there is splintering, decentralization and power diffusion without any authoritative centre.

Examining discourses also allows for the exploration of relationships between the discourses in selected texts and practices. For example, if data and infrastructure 
are the means for government to gather intelligence, survey ${ }^{26}$ and control territory and people, how does government go about doing this gathering of knowledge, how does it select, what is considered important to discuss, and why does it do this? Answering these and many other related questions foregrounds state formation practices and provides clues to how the state constructs geographical imaginations and then acts on them (Ogborn, 2003). Examining the discourses of atlases or census data may only be partial and fragmentary, yet these objects represent the enactments of larger social, political, scientific, technical and cultural aspects of Canada as envisioned by state officials, making the Atlas of Canada and the census of Canada inherently gouvernemental and excellent case studies.

Laws, acts, regulations, reports, committees, programs and projects, narratives and code are points from which to interpolate and depict the larger sociotechnological terrain of atlases and census data, which themselves are models of Canadian reality. These objects are representations of our reality, and reflect ways to imagine terrain and people and then manage them; they are neither the terrain nor the people. The Atlas and the Canadian census are reference points that play "a crucial role in their ideological formulation, in their communicative reproduction, and the social and political decision procedures, and in the institutional management and representations" (van Dijk, 1985:7). These are also depictions from the larger socio-technological terrain, including:

${ }^{26}$ As in surveillance. 
social institutions [that] produce specific ways or modes of talking about certain areas of social life, which are related to the place and the nature of that institution...it will produce a set of statements about that area that will define, describe, delimit, and circumscribe what is possible and impossible to say with respect to it (Kress, 1985:28).

Atlases and census data are discursive structures, which include sets of rule bound statements that constrain what gives them meaning. These are also objects or institutions through which the state agents get to know and project itself whence Canadians and Canada become subjects. Critically examining discourse therefore also includes considerations of power: the power to create, enact, direct and control what gets done, by whom, and how. Power has both positive and negative connotations. Government officials use power to control the categories of data the government will collect and map, to determine how it will act upon that evidence, and develop methodologies to maintain objectivity and accountability. According to Foucault, the author of the text(s) also "performs a certain role with regard to narrative discourse, assuring a classificatory function" (Foucault, 2006:284). An author creates a grouping that defines a relationship between texts and differentiates them from others (Foucault, 2006). Foucault provides the following characteristic traits of an author's function (Foucault, 2006):

1) it is linked to the juridical and institutional system that encompasses, determines, and articulates the universe of discourse;

2) it does not affect all discourse in the same way in all cultures;

3) it is not just spontaneous attribution, but it is a series of specific and complex operations; and 
4) it is not just about the individual, it can give rise to several selves, to several subjects - positions that can be occupied by different classes of individuals.

For example, a national atlas published by a government authority and signed by the head of government is different from an Oxford School Atlas or a Google map mash-up created by an open data advocate. The first is for evidence based decision-making, the second to educate school children, both are considered authoritative but are used for difference purposes, while a mash-up may be accurate, it may not hold the same authorial weight as a map created by an institutional author. Similarly, demographic data with a StatCan provenance are very different from those coming from the Fraser Institute or a citizen scientist. A national atlas and a census have authority; they are 'authoritative resources' considered part of the discursive field of science, considered to be representing an 'objective' view of the world. Furthermore, they are trusted because the authors and the underlying science are trusted.

The form of expression also determines how power and authority are expressed. For instance, certain genres of expression are accepted at different times and in different contexts. An Act is a genre of document that only appears once there is a government; an Act expresses a discourse, which has its own possibilities and limitations specifically associated with that genre. However, once the Act exists, the genre "immediately endows the discourse that it presents with a meaning beyond that expressed by the linguistic features of the text. It has a modal effect" (Kress, 1985:28). 
Although maps are different from acts, they nonetheless express a discourse and have modal effects, as Harley revealed, especially when they:

entered the law, were attached to ordinances, acquired an aureole of science, and helped created an ethic and virtue of ever more precise definition. Tracings on maps excluded as much as they enclosed. They fixed territorial relativities according to the lottery of birth, the accidents of discovery, or, increasingly, the mechanism of the world market (Harley, 1988:285).

The census also exerts this type of far-reaching power. The Statistics Act stipulates that the census must be conducted; therefore an infrastructure is built and supported in order to do so while data are put to work to count and characterize those who were born in the territory, or who are considered to 'officially' be part of the territory.

A national atlas and the results of the census are genres and forms, which are quite influential but in very different ways, as will be examined in this study. Through their study, the essence of pragmatic institutional programs and technological implementations are depicted and eventually actualized (Garland 1997). Also, the power/knowledge of government data and infrastructures, and their impact on Canadians, can also be examined in discourse as they:

delimit potentialities through the control of space-time-action and thereby produce certain types of subjects, actors and places. Power-knowledge is thus a form of power that is at the same time both delimiting-controlling and enabling: that is, it is a form of productive power (Pickles, 2004:111).

The perceived authority of geographic representations can also provide the reasoning or power/knowledge, for "certain groups to lay claim to particular territories and the spaces of others, and indeed why they may actually feel 
entitled to do so, owes much to the authority vested in their imaginative stories, descriptions and organizing views" (Massey, Allen \& Sarre, 1999:44). The oft used expression that the map precedes the territory comes to mind here, as do the exploration maps of early French and English colonialists in the Atlas of Canada. The power/knowledge relations enacted and invoked by an atlas are quite different from those of a census, but no less influential. Their power relations differ, and as discussed, the power/knowledge of an infrastructure lies in its momentum, invisibility, path dependencies and how it explicitly determines the actions of its users, contributors and maintainers.

Examining discourse also includes the pinpointing of discourse communities through the identification of groups or organizations that share common characteristics, such as goals that can be tacit or explicit (e.g., public officials constructing the CGDI); values and beliefs (e.g., accuracy and objectivity of the data); and communication methods (e.g., maps, tabulated numbers, portals). Each of these have a genre, their own language, terminology, vocabulary and specific expertise (e.g., statistics, geomatics) (Paltridge, 2006). Individuals and organizations can be members of different discourse communities. For example, a geomatician may develop open source technologies for a series of clients in the domain of agriculture, and may adhere to CGDI standards and specifications when doing so, but the products she/he produces might simply be the mediator between two discourse communities. 
There are also discursive communities within discursive communities. For example, the Federal Government of Canada is a government discursive community, which includes the discursive communities of NRCan and StatCan, but within these two agencies there are other sub-communities (e.g., specialists, scientists, cartographers or methodologists). Membership may be in loose knit or tight knit networks, and membership may be formal or informal. Social competence in discursive communities determines how language is used in social and institutional interactions in a particular context, and this is constrained by the setting of the communicative interaction (Paltridge, 2006:7). If the interaction is a government report, the language will be constrained by what is expected by that department, what the communications personnel have deemed appropriate based on ministerial responsibility, and how that content fits into their particular program and mandate. This reflects the fact that discourse is considered to be "constitutive of social relations in that all knowledge, all talk, [and] all argument, takes place within a discursive context through which experience comes to have, not only meaning for its participants, but shared and communicable meaning within social relations" (Purvis \& Hunt, 1993:492). For example, in Chapter 5, acts, regulations, programs, statistical methodologies, standards and dictionaries circumscribe census categories. However, as will be examined in this study, categories deemed appropriate in one era became politically incorrect in another, and the historical and cultural context of a particular discourse on disability or race, for example, circumscribes what is acceptable in government census reports at different times. 
The social construction of a reality approach to reading texts also leads the reader to interpret what is said or represented as a form of social and cultural practice. Power is also socially constructed. Individuals and organizations that wield power may behave in a way that assumes that that asymmetry is a natural state because "discourses are also plays of power which mobilize rules, codes and procedures to assert a particular understanding through which the construction of knowledge [is found] within these rules, codes and procedures" (Dalby, 1993:3). For example, "the social-political domination of the earth by Europe was inscribed in the geographic sciences and translated into a discursive authority over the earth. The discursive authority of geography, in turn, justified and consolidated Europe's social-political authority" (Tang, 2009:16). Such representations have normalizing effects:

whether it be taken-for-granted stock of knowledge at the everyday level or the exercise of a geopolitical imagination distributed through scholarly texts and periodicals, narratives and histories, film or various forms of statesponsored literature, the power of these forms of knowledge lies not only in their creation, but also in their ability to represent what is without provoking disbelief (Massey, Allen \& Sarre, 1999:44).

Language is also a mechanism in the process of social construction because language is a social practice; saying is also doing (Fowler, 1985). The language of regulation enforces a particular kind of authority over a practice, and it is the basis upon which people "base claims to exercise power, and also the statuses and roles which seem to require subservience" (Fowler, 1985:62). Furthermore, a map or tabular data derived from a government institution enforce a particular authority, which presupposes a social and geographic reality which shapes (i.e. geographical imaginations) and limits what can be done with those same data. 
Maps, in particular, also normalize certain kinds of knowledge. For example, Harley discussed how cartographic workshops standardize images of the world and how:

nature is reduced to a graphic formula...The power of the map maker was not generally exercised over individuals but over the knowledge of the world made available to people in general...It is a local knowledge which at the same time is universal. It usually passes unnoticed. The map is the silent arbiter of power (Harley, in Dodge 2011:288).

For example, counting who are bilingual and mapping bilingual districts presupposes that the Government of Canada considers the location of language politics important. The Canadian Geospatial Data Infrastructure Architecture Overview discussed earlier, is part of the discursive community of geo-IT, and this document instructs those who develop technologies related to the CGDI will code accordingly. Discourses are the arrangements:

of organizations of ideological materials in discursive form, and if these discourses exist in an already established repertoire of discourses in a social group, the individual speaker will not in fact be creating a discourse but will simply reproduce it (Kress, 1985:30).

The Atlas of Canada, further examined in Chapter 4, was overseen by chief editors and advisory committees, and while the editions reflect the inclinations of these actors, the Atlas also reproduced the discourse of government, and more specifically, the department that produced it and the scientific communities that produced its maps. 
Critically analyzing discourse also reveals how a particular text is created and maintained, and how this enacts power, define roles of institutions, and exert control. Examining discourse also helps reveal modes of exercising power, which depend on certain types of thinking (rationalities), specific ways of acting (technologies), and ways of governing (Garland, 1997). Critically analyzing discourse assists with problematizing practices by subjecting them to genealogical analysis, which is a way of tracing the lineage of a way of doing things (Garland, 1997). The history of atlases and census data, and their related infrastructures, are also examined in the chapters that follow. Ian Hacking's Framework was applied to the study of the Atlas of Canada and the Census of Canada and is discussed in Chapter 3.

Edward Said's analysis of the discourse of Orientalism, for example, demonstrated that western imperialism was not a plot or a centralized power structure to hold down the Oriental world, but was rather:

a distribution of geopolitical awareness into aesthetic, scholarly, economic, sociological, historical, and philosophical texts; it is an elaboration not only of a basic geographical distinction... but also of a whole series of 'interests' which, by such means as scholarly discovery, philological reconstruction, psychological analysis, landscape and sociological description, it not only creates but maintains; it is, rather than expresses, a certain will, or intention to understand, in some cases to control, manipulate, even to incorporate, what is manifestly different...it is above all a discourse that is by no means in direct, corresponding relationship with political power in the raw, but rather is produced and exists in a uneven exchange with various kinds of power, shaped to a degree by the exchange with power political, ...power intellectual, ...power cultural, ...power moral (1978:12).

He described the construction of an imagined geography and how it was written, performed, enacted, diffused and normalized. Said drew attention to 
Orientalism's creation as not being the result of power exerted by one agent, but as a result of power diffused across time and space.

Furthermore, it is suggested in this study, that data are considered essential for governing, be they viewed as scientific artifacts, part of socio-technological regimes, information ecology keystones, biopower, or the raison d'être of geospatial data infrastructures. Therefore, atlases and census data, and the institutions/agencies that produce them, are infrastructures in their own right. These institutions, their data and infrastructures, dissolve into the substrate of our societies and become part of what we do daily. As such, they are taken for granted, considered banal, and form part of contemporary socio-technical and scientific discourse. They are the texts that represent and inform imaginings.

The Atlas of Canada and the Census of Canada are considered to be objects that construct geographical imaginations, and Ian Hacking's framework of 'making up people' is the methodological approach used critically to examine their power/knowledge. Categories are the focal point of his framework. However, an examination of categories, based on Hacking's framework, necessitates an examination of the infrastructures that underpin them and the observation of how their discourses were deployed and legitimated. Not all aspects of their infrastructures will be examined, as that is beyond the scope of this research. However, it will be demonstrated that infrastructures envisioned as large sociopolitical-technological systems are part of the construction of categories which in turn shape and are shaped by geographical imaginations. Categories are part of maps and the census, whether "for cartography as much as other forms of 
knowledge, 'All social action flows through boundaries determined by classification schemes"' (Darnton in Harley, 2011:288). Hacking's framework, as applied to the analysis of atlases and census data as discourse is similar to "what Foucault offers [a]s a framework for undertaking concrete historical studies of the conditions and circumstances that made possible the emergence of some new set of institutional practices" (Purvis \& Hunt, 1993:490). The methodological approach used to examine the data and infrastructures of the Atlas of Canada and the Census of Canada, and how these construct geographical imaginations, are described and applied in Chapters 4 and 5 . Also, as will be seen, the social construction reading of the Atlas and the census, their data and infrastructures, as carried out in this study questions both how social reality is formulated and how concepts legitimate and reproduce power. The following chapters will foreground how government conceptualizes the territory and the governed, how atlases and census data help perform that vision, and how these, by making up people and places, construct geographical imaginations.

\subsection{Geographical Imaginations}

In the preceding sections, it was argued that data and infrastructure are sociotechnological and scientific constructivist knowledge producing texts and practices, which are shaped by and shape geographical imaginations. It was also argued that the geographical imaginations that shape data and infrastructures in the case of the Atlas and the census are socially constructed, gouvernemental and manifestations of biopower. 
This section will discuss geographical imaginations with a particular focus on data as representations of space ${ }^{27}$, and infrastructure as a spatial practice ${ }^{28}$. These representations are pragmatically put to work on a daily basis in government and non-governmental decision-making processes that affect social and material reality. The section will begin by illustrating the power of geographical imaginations with an iconic example (see Figure 3) that exemplifies a continuum of imaginative responses (i.e., spatial practices and biopolitics) to contemporary environmental issues (Osborne, 1988:162).

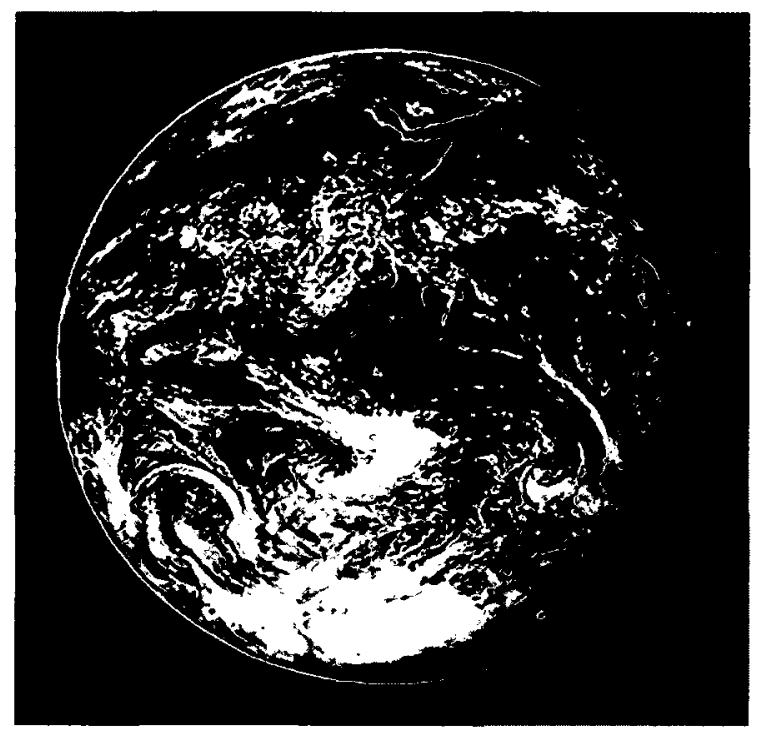

Figure 3. The 1972 Blue Marble Image of the Earth seen from Apollo 17 (Wikipedia, 2005)

${ }^{27}$ A concept by Henry Lefebvre in The Production of Space, representations of space are conceptions of space as seen in maps, the practice of survey engineering, or census data or as Gregory explains representations of space are "constellations of power, knowledge and spatiality - in which the dominant social order is materially inscribed" (1994:403).

${ }^{28}$ Spatial practices also "refer to the time-space routines and the spatial structures - the sites and circuits - through which social life is produced and reproduced" (Gregory, 1994:403). 
The 1968 NASA Apollo 8 Earthrise image AS8-14-2383, and the 1972 composite Blue Marble image taken by the Apollo 17 space crew, inspired new worldviews after their release. In 1966, as folklore has it, Stewart Brand, founder of the Whole Earth Catalog, initiated a public campaign to get NASA to release the then rumoured satellite images of the planet. He even had buttons made with the following line printed on them: "Why Haven't We Seen a Photograph of the Whole Earth Yet?"

Stewart Brand understood that this image was going to change people's perception of the world radically, and he presciently knew that it would become a powerful symbol around which ideals of global citizenship would form and evolve. With the release of these images, earth flags, Earth Day, thinking globally but acting locally, One World One Voice, and many other collectivist activities, movements and actions focused on the notion that 'we are all in this together', living on a floating borderless planet.

Today, access to satellite images of the earth and its surfaces has increased, and their resolution continues to improve. It is now possible to download myriad earth image data from the NASA Gateway ${ }^{29}$, and any number of satellite and radar images from the Canada Centre for Remote Sensing (CCRS) geospatial data portals ${ }^{\circ}$. Many maps are also derived from satellite imagery, such as land cover and land use composites, including maps found in the Atlas of Canada, and

29 NASA Gateway: http://eol.jsc.nasa.gov/

${ }^{30}$ Canada Centre for Remote Sensing Portal http://geoapps.nrcan.gc.ca/applications 
many fields have normalized the use of satellite imagery in their scientific practices (e.g., forestry, agriculture, ecology, geology, oceanography, glaciology, meteorology). The public can also use Google Earth and navigate its satellite image mosaic ${ }^{31}$ and they can use Google's infrastructure to create their own maps $^{32}$ as Google has enabled people, albeit people with a pretty sophisticated knowledge and skill set, to make and disseminate their own online maps by uploading their personal data and mixing them with Google's. Furthermore, organizations such as Amnesty International have been able to negotiate the acquisition of satellite images from private data suppliers such as Digital Globe, and partner with organizations such as the American Association for the Advancement of Science (AAAS), to foreground and employ the tools of science to document human rights issues happening in near real time (Lauriault, 2006, 2007). Satellite images have captured public imaginations and have become a popular form of media.

Government and others have used satellite images as evidence to inform myriad decisions, and the "digital proliferation of images and visual data has opened up entirely new ways for political entities to envision and be envisioned" (MacDonald, Hughes and Dodds, 2010:3).

${ }^{31}$ Google Earth, launched in 2005, satellite images are provided by Digital Globe, which has its own private satellite imaging systems.

${ }^{32}$ Google Earth Outreach "gives non-profits and public benefit organizations like yours the knowledge and resources you need to reach their minds and their hearts: See how other organizations have benefited from Google Earth Outreach, then learn how to create maps and virtual visits to your projects that get users engaged and passionate about your work" (2011). 
In a famous PBS interview between Joseph Campbell and Bill Moyers, published as The Power of Myth, there was a caption under a full page image of the earth seen from space that said: "when you see the earth from the moon, you don't see any divisions there of nations or states. This might be the symbol of a new mythology to come. That is the country that we are going to be celebrating. And those are the people that we are one with" (Flowers, 1988:14). Also, in relation to this photo, Campbell said:

They [myths] come from realizations of some kind that have to have their expression in symbolic form. And the only myth that is going to be worth thinking about in the immediate future is one that is talking about the planet, not the city, not these people, but the planet and everyone on it. That's my main thought for what the future myth is going to be. And what it will have to deal with will be exactly what all myths have dealt with - the maturation of the individual, from dependency through adulthood, through maturity, and then to the exit; and then how to relate to this society and how to relate this society to the world of nature and the cosmos. That's what the myths have talked about, and what this one's got to talk about. But the society that it's got to talk about is the society of the planet. And until that gets going, you don't have anything (Flowers, 1988:13).

For Campbell, these earth images were cosmographically significant and held the power to change worldviews and, in turn, affect human behaviour. Denis E. Cosgrove, in his book Apollo's Eye: A Cartographic Genealogy of the Earth in the Western Imagination, situates the Earthrise and Blue Marble images within:

deep geographical imaginations to practices of globalization that have helped define the West through continuous reworkings of an expanding archive of global images, narratives and myths [and that] attention to geographical and historical context, however, cannot ignore long genealogies of meanings and practices whereby cultures rework identity through memory, learning and imitation (2001:3-4).

These NASA images were game changing but they did not appear out of a vacuum, as there was a buildup in our collective memory that made us receptive 
to them. They were part of a long line of images, models and descriptions of the earth, the world and the globe that went from organic notions to social and spatial approaches and the spatiality of geometry, and these have been shaping identities and actions for centuries (Cosgrove, 2001). Cosgrove traces 'globe' imaginaries through a variety of discursive formations: imperial and poetic, classical, Christian, oceanic, visionary, emblematic, enlightened, modern and virtual. The images were also part of a global moment, simultaneously idolized and loathed (Anderson, 1991). The moon landing and the space race, in Cosgrove's view, taught us less about the moon and more about ourselves, and like Campbell, he does not think that we saw those images as scientific objects, but instead, we saw and reacted to their "cosmographic and elemental qualities" (Cosgrove, 2001:261). These virtual images were the end result of a genealogy of deep geographical imaginations, steeped in the Apollonian western worldview (2001:2); they are scientific products and part of the social-technopolitical regime of space exploration.

Campbell's society of the planet has not quite yet materialized. There remains a belief that continents are naturally determined (Lewis \& Wiggen, 1997), or determined by people who contribute to the production of knowledge that manufactures spaces such as the Orient or dark Africa (Said, 1978). Humans live according to the ideals of their nations (Anderson, 1991), societies continue to be categorized and divided according to socially constructed ethnicities (Anderson, 
1991, Lauriault, 2006b) 33, and maps are drawn to depict territorial borders which are assumed to be natural, impermeable and permanent. These representations of space (i.e., data, maps, globes) are social constructions that depict and 'make real' the geographical imaginings of continents, regions, nations, territory and identity. Concurrently, Earth Summits and sustainable development were shaped by and shaped geographical imaginations of 'whole earth' attitudes manifest in global social and environmental movements. These earth images have impact, but remain situated in a world with multiple and competing geographical imaginations, or within "different systems of meaning or discourses [that] compete for influence in society" (Sharpa \& Richardson, 2001:196). NASA earth images are also data, found in portals, the background of Google mash-ups or national atlas maps, and are part of very well resourced and technopolitical regimes, or the end product of GDIs. These data, portals and maps are part of space, military, geographical, science, and library information ecologies. These data and infrastructures fuel our imagination, paradoxically inspiring the creation of new myths. Furthermore, data as representations of space and the spatial practices of infrastructure guide decisions, which manifest in real programs and projects that affect day-to-day reality.

33 Outside looking in! Identity Science \& the Politics of Identity, 2006b, Blog Post about the Freedmen's quest for aboriginal identity claims as they aimed to prove historical and genetic membership in the Five Civilized Tribes of Oklahoma (the Cherokee, Chickasaw, Choctaw, Creek, and Seminole). Their objective was to use genetic testing to reclassify themselves as black tribesmen, wrongly classified by early census takers who could not conceive of a black person as also being an Indian. The tribes were trying to expel the Freedmen from their reservations as they were not 'aboriginal'. Benedict Anderson also discussed how colonial census takers in Asia kept changing the ethnicities of those accounted for in Census, Map and Museum. 
In their 2007 paper, The Infrastructure of Experience and the Experience of Infrastructure, Paul Dourish and Genevieve Bell explained that how we experience space is intertwined with:

multiple infrastructures - infrastructures of naming, of movement, of interaction, etc. - and these infrastructures emerge from and are sustained by the embodied practices of the people who populate and inhabit the spaces in question. Spaces are not neutral, and their complex interpretive structure will frame the encounter with pervasive computing; while, by the same token, the opportunities afforded by new technologies allows for a reinterpretation and re-encounter with the meaning of space for its inhabitants. Fundamentally, the experience of space is coextensive with the cultural practice of everyday life (2007:424).

These earth images, combined with the dream of space exploration were also used to help sustain and grow NASA's research and development (R \& D) funding.

Yola Georgiadou and Vincent Homburg examined the discursive practices employed by GDI advocates and discovered that dreams of a centralized, standardized and seamless web of geospatial data emerging from GDIs were their key selling points, and suggested that GDIs are:

hymns to progress, and as utopian visions or promises unfulfilled or even unfulfillable. Myths are composed by so-called bricoleurs: experts, politicians, bureaucrats and consultants, who, in language, attempt to fabricate rules that serve as a shared frame of reference that enables individuals and organizations to deal with contradictions that can never be fully resolved, eventually enabling the bricoleur to inflict changes in the way of thinking and doing (2008:33).

Al Gore's promotion of the Digital Earth and the Global Information Infrastructure were part of this form of mythmaking, as was the information highway metaphor. In the case of GDIs, standards, licenses, framework data and 
technological choices are some of the methods used by bricoleurs to collect, manage and disseminate geospatial data. Myths are created and used to help people to make sense of the intangible, be it concepts of an afterlife or the complexity of large socio-technopolitical systems. Myths are persuasive and can be used to resolve discursive struggles, particularly since they are more tangible than hard evidence in some instances. In this case, myths were used to mobilize resources to construct GDIs which are spatial practices which produce spatial representations that model 'classified things' to govern.

GDIs were often characterized as libraries, with data as books. Books were located by using the catalog (i.e. portal), which was driven by a catalog system (i.e. standardized metadata), and could be checked out by the user from the librarian over the counter (i.e. the Internet) or accessed via an inter-library loan (i.e. distributed database with third party use licenses and partnership agreements). P. Y. Georgiadou and V. Homburg found that GDIs were also framed as information marketplaces (i.e. digital commons), rationalized as important for emergency preparedness, and viewed, in the early days, as a potential seamless web of accessible data. The metaphor was grounded in something that non-specialists and politicians could understand in order to be able to attract funding and change institutional practices. GDI myths remained primarily in government related circles since GDIs are entities almost exclusively known to specialized communities of practice within the field of geomatics. GDI myths are instrumentally deployed to encourage the construction of GDIs in 
pragmatic terms and GDIs, in turn, provide the means (i.e. data and services) to envision a kind social and geographical reality.

Geographical imaginations are social constructions, as Edward Said, in his critique of Orientalism, aptly demonstrated:

men make their own history, that what they can know is what they have made, and extend it to geography: as both geographical and cultural entities - to say nothing of historical entities - such locales, regions, geographical sectors as 'Orient' and 'Occident' are man made (1978:5).

The Orient, or Ottawa's Chinatown in particular, have a history and a body of thought, imagery and vocabularies that are represented as fact and reality in maps and statistical reports, or even in a database of shops selling 'Peking Duck'. A national atlas provides a 'portrait of Canada' and a census 'takes stock' of the people; together, they provide a kind of snapshot, a set of preselected images of reality, that are representations of subjects considered important by decisionmakers; and their decisions affect the subjects they create - the governed.

Benedict Anderson, in Imagined Communities, demonstrated the instrumentality of three colonial institutions in shaping the way in which "the colonial state imagined its dominion - the nature of the human beings it ruled, the geography of its domain, and the legitimacy of its ancestry" (1991:163) and these were the census, map and the museum. He refers to studies about the mentalité of British, Dutch and Spanish census makers in Malaya, Indonesia and the Philippines. Specifically, he examines how their map, data and categories became more visibly and exclusively racial while religious categories disappeared. He also noted that wherever the Spanish went, the categories of hidalgo or 
esclavo always appeared. Such a race based approach to categories, clashed with the indigenous classification systems that grouped people by social rank. Locals could not figure themselves out in the classes imposed upon them by the colonialists. The incentives to count were to keep track of those who could pay taxes and be conscripted into the military and eventually to manage, regulate, restrict, count, standardize and create new institutions while subordinating local ones. Enumeration provided:

a demographic topography [which] put down deep social and institutional roots as the colonial state multiplied its size and functions. Guided by its imagined map it organized the new educational, juridical, public health, police, and immigration bureaucracies it was building on the principle of ethno-racial hierarchies which were, however, always understood in terms of parallel series. The flow of subject populations through the mesh of differential schools, courts, clinics, police stations and immigration offices created 'traffic-habits' which in time gave real social life to the state's earlier fantasies (Anderson, 1991:169).

Anderson also came to understand the 'power of maps' (Wood \& Fels, 1992) through the work of Thongchai Winichakul, who examined a series of pre-1851 maps of Siam and considered the mindset of those who drew and interpreted them. The Cosmograph was a series of supraterritorial heavens and subtraterrial hells, particularly useful for spiritual journeys but not necessarily great for wayfinding. Included with these maps were diagrammatic guides for military campaigns and maps for coastal shipping. These maps, however, had no borders, and they were drawn with oblique perspectives and not a bird's eye view. Thai leaders only began to think of continuous boundary lines in the 1870 s primarily because of encroaching colonialists. Early maps allowed viewers to imagine themselves in the cosmos and, in a functionalist way, to envision some part of the 
physical geography. The colonial map series, however, became a kind of 'political-biographical narrative' of the realm. This narrative was eventually adopted as truth or reality, and it was adapted by the new emerging nation-state or colonial state 'legatees'. The colonial vision in these maps eventually became legitimate stories of Siam and its bordered regions, and the "instantiation of state power [would] rest crucially on the creation and reproduction of imaginative geographies and their associated 'trajectories of affiliation"' (Radcliffe, 1999:233).

The census and the map provided an understanding of colonial state mentalité, about its domain but not necessarily 'the' domain. Anderson's analysis of these studies and maps demonstrated how maps and census shaped the grammar that made possible these colonial states. His work also demonstrated how these 'concretizations', which still narrate colonial spaces and places today, reflect, even after the colonial powers have left, their "peculiar imagining of history and power" (1991:185). These objects, along with those found in museums or photo archives, also came to represent imaginings of ancestors. Data and infrastructure leave traces, and those who have the data and the means to use the infrastructure, including rendering and disseminating maps and charts, maintain control over the framing of what 'is' and what can be imagined. As seen here, "early modern maps were used not just to represent space but also to negotiate the identity, the legitimacy and the agency of individuals, groups and ventures" (Edwards, 2005-6:127). Further, mapping "became a framework for thinking, imagining and projecting the desired realm; it became the language in which Siam was to be discussed" (Winichakul, 2011:410). 
It is also important to remember that colonialists were also explorers, and as John K. Wright (1947) poetically described in Terrae Incognitae: The Place of the Imagination in Geography, it was they who answered the calls of the sirens who sang:

of different things to different folk. Some they tempt with material rewards: gold, furs, ivory, petroleum, land to settle and exploit. Some they allure with the prospect of scientific discovery. Others they call to adventure or escape. Geographers they invite more especially to map the configuration of their domain and the distribution of the various phenomena that it contains, and set the perplexing riddle of putting together the parts to form a coherent conception of the whole. But upon all alike who hear their call they lay a poetic spell (1947).

The dreams of discovery and riches were in the explorer's maps and descriptions. The categories of early editions of the Atlas of Canada $(1905,1912)$ and the Canadian census ( 1871 to 1931 ) also represent French and British colonial imaginings, which were transformed to nation building imaginaries.

Institutions provided the 'data' upon which geographical imaginations could be constructed, while:

geography performed the function of an epistemic apparatus of collecting, transmitting, and processing spatial data in the service of the state; at the same time, as a theoretical discourse, geography provided the nation with an imaginary identity by interpreting national culture and history as the result of people's engagement with the singular conditions, structures, and processes of their terrestrial habitat (Tang, 2009:18).

Chenxi Tang in The Geographic Imagination of Modernity, traces "the rise of geography as a particular mode of describing and imagining culture and society" (Tang, 2009:241), and argues that a shift occurred in the late $18^{\text {th }}$ century and early $19^{\text {th }}$ century where the concept of "space in social and cultural thought" 
emerged. He examined the rise of geography, or geographical imagination, which coincided with the rise of political thought in terms of the idea of nation and territorial sovereignty and modernity "which transfigure the territorial state of the seventeenth and eighteenth centuries into modern nation-states" (Tang, 2009:242). The territory during that period, Tang observed, was considered to be the physical space upon which political power was imposed, transferable and exploited; in the nation-state discourse, territory was "quintessentially symbolic space, embodying the spiritual mission of the national and impregnated with its culture and history" (Tang, 2009:245). As the territory became a kind of holy ground, the geographic sciences - the spatialization of the human world - gave language to the spatial order of the European continent, the nation state and their projections in the colonies. Geographical imaginations take shape, and the "primary function of cartography in its capacity as a technique of orientation was to help citizens imagine the state as a unified territory" (Tang, 2009:139). Further, "given the close association of geography with state power...the geographical imagination exerted a palpable influence on political thinking" as this was also the period when geopolitical imaginations also emerged along with the creation of nation states (Tang, 2009:246). For John Agnew, the four underlying concepts of geopolitical imaginations are: "the world visualized as a whole; the definition of geographic areas as advanced or primitive; the notion of the territorial state as the highest form of political organization; and the pursuit of primacy by competing states" (Agnew in Tang, 2009:308 \#22). This is Winichakul's geo-body (1994), "the mapping of the nation-state onto (and over) the cultures of difference and identity that preceded the geopolitics of the 
national imagination" (Pickles, 2004:116). The inscription devices (i.e., infrastructures behind Atlas and census) of geopolitical imaginations shape what Gertjan Dijkink (1996) called the foreign policy belief-system, which is an "allencompassing set of lenses through which [decision-makers] perceive their environment" (Dijkink, 1996:14).

Cartography and geography provided the necessary representations for 'imagined communities' to form, providing individuals with the means to see collectively who they were, with who they belonged, and where they belonged. Furthermore:

descriptive geography served as the 'handmaiden to power' by providing factual knowledge of a state's own territory, as well as of the territories of competitors. Modern geography as it emerged around 1800 served power in a rather different way - by providing discursive tools for revealing its source or ground. It enabled the nation-state to construct its territory as a space from which its sovereign power emanates, and on which this power is then exercised (Tang, 2009:245-246).

Imagined geographical representations, as seen in the data, maps and museum objects of Siam, Malaya, Indonesia and the Philippines, are durable, do not mimic landscapes or the 'reality' that made them, and are immutable mobiles 34 that:

draw their robustness from their ability to make it difficult to see or make sense of things in ways other than that represented. There is an apparent obviousness about the way in which, for example, a distant landscape, or the peoples of a close territory, or a particular culinary culture are represented which makes it difficult to contest (Massey, Allen \& Sarre, 1999:44).

34 For Bruno Latour, inscriptions are the diagrams, graphs, maps, globes which model scientific data collected from inscription devices which do not physically change in shape or form in time or in space, they are immutable, however they are mobile as they can be re-used, re-purposed and re-interpreted in new contexts and places, they persist and stabilize ideas (1987). 
Bernard Debarbieux considers imagination to be the condition of being able to decipher sensory perception, which is required to discern patterns from objective reality; imagination becomes an essential element of knowledge creation. Geographical imaginations as represented in maps and data, according to Debarbieux, are models of the world, and they:

\begin{abstract}
are a way to interrogate reality and to confront it to other possibilities, by proposing a model of reality in how it functions and what is signifies, and once it is put to service, it is a way to act on the real to create fiction. In these situations, the disassociation between what is real and what is imagined is illusionary and the devaluation of the second under the pretext of the first, does not make much sense (1992:906).
\end{abstract}

For Debarbieux, geographical imagination is necessary and is found everywhere "in how we live in the world that surrounds us, in artistic creations, within mythical and religious thought, in scientific activities where it is part of reasoning. It conditions our practices in space" (Debarbieux, 1992:894). These imaginations are no more nor less objective than a scientific rendering of genetic structures, or the inscriptions from Latour's laboratories, as "there is nothing epistemologically special about the nature of scientific knowledge: it is merely one in a whole series of knowledge cultures (including, for instance, the knowledge systems pertaining to 'primitive tribes'” (Pinch \& Bijker, 1987:19). These observations, maps, graphs and tabular data are "scopic regimes constituted through grids of power, desire and knowledge, and their visual structures and practices enter intimately into the production of imaginative geographies" (Gregory, 2003:224). For Debarbieux, the process of creating imaginary places is called modeling, the geographer's and cartographer's bread and butter. This functional process of imagining, predicting and interpolating 
facilitates moving from data about real things, derived from experience to abstract representations of those data (Debarbieux, 1992). Geographical imagination is a way to make the unknown known, a way to satisfy a curiosity (Wright, 1947).

Like Debarbieux, John K. Wright wanted to return subjectivity to its rightful place in the scientific process, and he identified three imaginative processes of importance to geographic inquiry: promotional, intuitive, and aesthetic imagining. Promotional imagining is the persuasive aspects of ideas. Practicing geography with a social justice objective, for example, would be a form of persuasive imagination; the work William Bunge's Atlases 35 and his urban expeditions, and the work of David Harvey, Social Justice in the City, come to mind in this regard. This persuasive imagination relies on realistic conceptions to get the point across, but they are framed in a moral and social geography. Intuitive imagining is also intent on securing realistic conceptions. Such imagining is, however, a subjective process because it makes use of "one's personal impressions of selected facts instead of impersonally considering and weighing all pertinent evidence", and this has been part of the imagined realm of philosophers, prophets, statesmen, artists, and scientists (Wright, 1947). Aesthetic imagining is that of cartographers and modelers who carefully select and represent a set of facts. This imagining includes both subjective and intuitive imagination, and is an imaginative process to counter or complement "strictly

35 Fitzgerald; geography of the revolution (1971), Nuclear War Atlas (1988). 
objective--factual, realistic, but uninspired, and, like some of the geography of today, soon forgotten" geographical descriptions. Wright was interested in inspiring the study of geographic knowledge, or as he called it geosophy or what we might call human geography today. In short, all expressions of geographical imagination, be they maps, literature, urban form or monuments in a capital city, have one thing in common they: "create worlds where real elements are arranged and introduced in an interpretable system whereby individuals or collectivities on one side and the earth on the other are harmoniously arranged in a coherent fashion" (Debarbieux, 1992:902).

Models, while imagined, include real events, and just like earthquakes are real "and their occurrence is independent of consciousness; but it is their construction in discourse that determines whether they are 'movements of tectonic plates' or manifestations of 'the wrath of the gods'" (Purvis \& Hunt, 1993:492). Models or imaginings are part of the search for coherence. These imaginings or models interrupt reality in order to better understand it, and, in turn, they model and become the producer of spatial reality (Debarbieux, 1992). This is what is meant by the oft-repeated statement that data and infrastructure shape and are shaped by geographical imaginations.

Geography is experienced. It is also socially and physically imagined and continually reproduced in technological practices. A city, province or nation cannot be imagined in its totality, and data and maps, via infrastructures, provide the means to see beyond what we immediately know, think we know and cannot see, even these will always remain partial and fixed in the creator's field of vision. 
These data, maps and infrastructures function as a kind of collective narrative. This narrative tells the story, produces history, sets boundaries, defines culture, hierarchically situates dwellers, and conjures and creates categories that set the course for future actions that affect spaces and the day-to-day lives of people. These representations are not only depictions of the world but they are part of it, both generative and political (Phillips, 2009:543). Data, maps and infrastructures shape and are shaped by these. The modern nation, for example, "is a reformulation of the collective imagination, the crucial determinant in this process is defining who is part of the collective that is doing the (re)imagining" (Levine, 2007:123).

Joseph Campbell, stated that the image of the Blue Marble was cosmographically significant and Denis Cosgrove explained that it became so because the image and the infrastructure used to create it, are the result of a long global lineage images and artifacts which have become part of deep western geographical imaginations, which Derek Gregory might call a form embodied geographical imagination. Edward Said, David Livingstone, Derek Gregory and Denis Cosgrove also consider geographical imaginations to be a combination of authoritative historical bodies of thought, imagery, and vocabularies which are seemingly factual characterizations of spaces, and these 'facts' come to create imagined spaces (e.g., Orient). Paul Dourish and Genevieve Bell, conceptualize infrastructures as the human built world and normalized practices that inform how spaces are experienced and then imagined. On the other hand Benedict Anderson considers the practice of mapping and census taking as techniques 
used by the state to imagine its dominion, irrespective of how these clashed with the realities of the colonized. Furthermore, like Hacking's 'looping effect', and as observed by Thongchai Winichakul, these representations of reality, became political-biographical narratives and preceded the territory. Immutable mobiles, as Bruno Latour calls them (i.e., maps and data), became legitimate stories around which people self-identified or resisted. Chenxi Tang suggested that data, infrastructure and spatial sciences are at the service of state actors to help them form an imaginary identity of the state. Furthermore, he stated that geographical sciences give a language to a particular spatial ordering of things which allows people to imagine the state as a whole. These representations of space, according to Doreen Massey, John Allen, and Philip Sare, construct a reality which helps make sense of things, spatially arranged things done so in such a way that it becomes difficult to imagine them in any other way. Maps and data are the geographers tools according to John $\mathrm{K}$. Wright, and these help put together parts to create a conceptual whole, or as Bernard Debarbieux explained, geographical imaginations are ways to help us reason as imagination is a way for scientists to model reality, and that model gets put to work in the world to inform spatial practices. Geographical imaginations are socially constructed world views that become normalized with the help data, maps and infrastructure, and the next chapter will discuss the Hacking framework which will be applied to study the carefully assembled sets of classifications found in Atlas of Canada maps and those derived from census questions. 


\section{Chapter Three: Methodology and Data Collection}

\subsection{Introduction}

This chapter describes the adoption of Ian Hacking's analytical framework in the methodology applied to analyze the Atlas of Canada and the Canadian census to assess their role in constructing Canadian geographical imaginations. Hacking's 'looping effect' and 'making up people' framework, as described in Section 3.2, has been successfully applied to reveal the genealogy of classifications in the human sciences but it has not yet been applied to the study of geographic and cartographic classes. The framework was therefore modified in order to study 'making up spaces' and this is discussed in Section 3.3. Sections 3.4 and 3.5 describe the Atlas of Canada and Canadian census data used in this study.

\subsection{The Looping Effect and Making Up People: The Hacking Framework}

Ian Hacking is a distinguished academic who is recognized for his contributions to the study of the history and philosophy of mathematics. He currently holds the Chair of Philosophy and History of Scientific Concepts at the Collège de France. This study focuses on his work on the dynamic 'looping effect' of 
categories of people and the concept of 'making up people', based on how sciences can make up people that in a certain sense did not exist before. He has developed a framework to structure the examination of the social construction of categories, a theory that seeks to explore the historical context and social framing of seemingly 'natural' occurrences, which are thought instead to have been constructed through human actions and interactions. In Hacking's words "'making up people', refer[s] to the ways in which a new scientific classification may bring into being a new kind of person, conceived of and experienced as a way to be a person...the 'looping effect', refer[s] to the way in which a classification may interact with the people classified" (Hacking, 2006).

The historical context of how knowledge producing state agencies such as Statistics Canada (StatCan) and Natural Resources Canada (NRCan) apply scientific methods systematically to count, classify, categorize, and map people and territory is investigated using Hacking's framework. Hacking argues that once things are categorized actions are taken which 'make up people'. Once people are categorized or classed, they may interact with that class and eventually change its parameters. His framework has been modified to study the 'making up of spaces' as a process by which geographical imaginations are created. Canadian geographical imaginations are thought to be socially constructed by atlas and census knowledge, and in turn, geographical imaginations influence the construction of the atlas and the census. 
As discussed in Chapter 2, geographical imaginations are part of the body of knowledge and world view of geographers, colonialists, explorers and others involved in describing and representing human interaction with physical and social spaces. Maps and data are geographical representations, also known as objects or models, created to discern patterns from objective reality but which are actually derived from and reflect the geographical world view of their creators at a particular time and place. These objects or models, it was also argued, are immutable mobiles that further inform other models. They may be applied literally as in the background map upon which another is traced, or as a category repeated in subsequent census questionnaires. Or they may be applied more abstractly wherein the model becomes the portrait of a place not yet visited. As discussed in Chapter 2, models can also make spaces and precede the existence of a nation or a territory (e.g., Siam). For Hacking, classifications may bring into being new kinds of people, and these same classifications come into play and interact with those classified. His interests rest with how classifications interact with people, model them and also transform them, and by changing them, they in turn change the classifications. In this study, the analysis of classifications is focused on how they create spaces.

Hacking's categories are those used in the human sciences on a range of classes of people such as autists, multiple disorder personalities and the poverty line. In particular, Hacking explores the tenuous relationships between the measuring process and the thing being measured: (1) a category or classification and the category and classification as objects; (2) how a category or classification came 
into being; (3) how a category or classification becomes a convention; (4) which category or classification requires being accurately measured; and (5) how the objects thus measured are put to work. It is a form of labeling theory, but not one solely focused on the social response to deviance or the patterns associated with deviance as it is applied in the study of criminology. Hacking follows the category but not necessarily the classified, although the sociological interactionist perspective applied to the study of labeled people is related to the 'looping effect' of categories. He studies their perceptions of themselves once labeled and how others act towards the labeled as exemplified in his genealogical examination of the history of the poverty line.

According to Hacking, the concept of the poverty line emerged with England's 1601 poor laws which were then re-articulated in Victorian England by Charles Booth in his 'objective' quantifiable methodology to classify the poor in maps and in surveys. In 1887 , Booth conducted extensive field work to determine what constituted a line of poverty. He conducted door-to-door surveys, developed classification systems, and mapped and quantified his findings, which eventually led him to create the criteria to determine who was and was not above the line. Booth's poor were an invisible class analogous to today's working poor, and he argued that they should be eligible for social assistance if they were below a line of poverty. He found that a family of four earning more than 21 shillings per week was over the poverty line in terms of their ability to pay a school tax. Booth apparently never revealed how the 18-21 shillings was derived as the line's marker (Hacking, 2000:20). School board assessors institutionalized his 
parameters and assessed eligibility for educational tax breaks or school subsidies. The board also did not release the criteria used in order to avoid the possibility of people cheating the system.

Booth's concept of the poverty line migrated to the colonies and the United States. In 1889 , a family of four earning less than $\$ 5$ a week was considered below the poverty line, and as it turned out, this was equivalent to Booth's 21 shillings. Booth was a well-respected member of prestigious statistical societies, which gave his form of moral statistics validity within small and elite international circles. Canada's Low Income Cut Off (LICO) ${ }^{6}$, a standard measure of poverty produced by StatCan using census data, is a descendant of Charles Booth's $19^{\text {th }}$ century line of poverty. The poverty line has become the de facto 'objective' baseline to measure and administer the poor around the world today, although the algorithm has since changed and countries vary in how they measure it.

In the $19^{\text {th }}$ century, early statisticians used statistics as a way "to bypass conservative and particularist interests like church and nobility" (Porter, 1986:23). This reflected the mid- $19^{\text {th }}$ century trend where science was being used by a new generation of decision-makers in both the public and private sectors to undermine traditional arguments and justifications of an older and religious generation (Porter, 1986; Livingstone, 2010; Dupaquier, 1985 and Desrosières,

36 "LICOs are intended to convey the income level at which a family may be in straitened circumstances because it has to spend a greater portion of its income on the basics (food, clothing and shelter) than does the average family of similar size" (StatCan, 2011). 
1998). This changing of the guard led to new forms of nationalism and capitalism, and secular approaches to governance. Booth, the wealthy businessman and philanthropist, was of this new generation. He combined his status and influence with his scientific social mapping and statistical analysis to change the way certain classes of people were labeled and understood. Booth created a new kind of people by distinguishing those above and below the line of poverty. Through such endeavours as his London Cholera mapping, Booth also created new kinds of spaces:

[These maps] did not merely mirror the socio-spatial patterns of workingclass neighbourhoods, the structure of urban poverty and the morphology of modernizing landscapes but produced them and spatialized social categories in which new ways of thinking and representing people and places came into being, categories that in turn have since shaped urban social research and policy (Pickles, 2004:145).

Booth's categories and maps spatialized the developing field of public health, and population became a spatialized object to be observed by administrators (Pickles, 2004).

In terms of 'making up people', Hacking was unable to reveal how the people thus categorized envisioned themselves and whether or not they began to conceive of themselves as a new kind of person, something which he was more able to demonstrate in his work on autism and multiple personality disorder. Measuring, categorizing and administering the poor remain highly contentious, with multiple competing measures being debated among social policy experts, advocates and government administrators, as exemplified in measures such as the LICO, the Market Basket Measure, and social exclusion and income 
inequality measures. These measures and how they are applied by administrators directly affect people, whether in determining the outcomes for their children or in accessing housing and public services. Although Hacking's work with the poverty line did not reveal the self-perception of this new category of people, his framework did demonstrate how the poor were re-imagined by administrators, how a new class of people was created, and how the concept and discourse of poverty changed from the notion of vagabondage and pauperism to one of people and families or households requiring state assistance. He made visible the invisible and working poor.

The application of Hacking's framework in this study is not intended to yield direct answers to explain how people have become, or how they perceive themselves to be, but it does provide the means to investigate how institutions apply categories and statistical results, and structure these into policy. The method also assists with positioning atlas maps and census data in a social context, as opposed to the 'desocialized' scientific artifacts they are most often considered to be (Harley, 1988:303). This framework provides the means to map how census questions and categories and the Atlas of Canada act in the world.

Facts and classes are dynamically changing social constructs irrespective of their 'fixity' once they are authoritatively published. Statistical and map making institutions create methods to classify people and spaces, whereby often and over time, these same people and spaces get re-classified into something new. Such re-classification changes how people and spaces are seen and how people see 
themselves, which leads to new results and outcomes resulting in new actions. People, spaces and classes are continuously co-reconfigured.

As discussed in Chapter 2, knowledge producing state agencies, such as StatCan and NRCan, use scientific practices to create products which influence how things get done or administered. In so doing, they 'make up people', they produce spaces, and they construct geographical imaginations. Hacking is especially interested in the ways in which science creates new classifications and knowledge, as "people do not simply come sorted"; historically, some kinds of people would not have existed as a 'kind of people' until they have been so classified, organized and taxed", especially a people just colonized or conquered (Hacking, 2007:288). The same can apply to spaces.

Hacking's framework has five interactive elements of the 'looping effect' (see Figure 4 page 92 below):

\section{a) Classification:}

A classification is a general principle where things regarded as having shared characteristics are grouped together, and within the classification there are classes that force groupings. This can be applied to people or spaces. For example, Aboriginal people in Canada were often linguistically categorized and this assigned classification system is what was mapped 37 . Alternatively,

${ }^{37}$ Atlas of Canada Sheet 29 1st edition, Plate 32 2nd edition, Sheet 52 rrd edition, Pages 119-120 4th edition, Sheet 15.1, 15.3, 15.4 and $15.55^{\text {th }}$ edition, and many of the Native Peoples and Aboriginal Peoples maps in the 6th edition. 
explorers ${ }^{8}$ who came to Canada classified the people and spaces they encountered, and are themselves classified in the Atlas of Canada according to their sponsors, by the areas that they explored and mapped, and by the country which paid for their expeditions. Aboriginal people, formerly referred to as Indians, are the 'kinds of peoples' that colonialists and explorers excluded when drawing survey lines on Indian homelands. These same Indians, that do not appear as landowners on any Atlas of Canada exploration maps, but do appear on Historical Indian Treaties maps 39 that depict territories that were given, traded or taken away. The classification of aboriginal peoples and the mappings of the classes were done by colonialists and explorers, while the mappings of explorers were done by cartographers and explorers themselves.

\section{b) People:}

In the various classes, there are people which are the extensions of the classes just defined. These are real people that eventually start to self-identify according to the class. In the case of spaces, it is the real things mapped, and the way people envision and then act upon the things mapped. For example these can be an Indian Reserve or spaces defining clusters of people mapped by their Status Indian designation ${ }^{40}$.

${ }^{38}$ Atlas of Canada Sheet 32 , Sheet 33 2nd edition, sheets $1,2 \& 3$ 3rd edition, pages 71-90 4th edition, sheets 11.1, 11.2, and 15.1, 15. 5th edition, and the 20 maps in the history topic of the 6th edition.

39 Atlas of Canada 6th edition.

$4^{\circ}$ Atlas of Canada 5 th edition map sheet 15.2 and 6 th edition Aboriginal Identity which include mapped Census data by Census Division and Sub-Division for 1996, 2001 and 2006. 


\section{c) Institutions:}

Institutions such as the Canadian census and the Atlas of Canada, or government departments such as NRCan, StatCan or the Canadian Revenue Agency (CRA), place people where they belong, and tax them or dispense compensation accordingly. These institutions use the work of enumerators, accountants and cartographers, who "work within structured bureaucracies" as administrators, to "firm up the classifications" and manage the infrastructures to do so (Hacking, 2007:288).

\section{d) Knowledge:}

Knowledge "about the kinds of people [or places] in question, their characteristics, fierce or docile, artistic or warlike, skilled artisans or able hunters" or knowledge about linguistic groupings is an element known to experts (Hacking, 2007:289).

\section{e) Experts:}

Hacking describes experts as those "in the administration, local officers on the ground, [and] their regional allies" who exercise knowledge. "Some of the knowledge will consist of more traditional facts well known to the classified people themselves. Some will be imperial myths that over the years become characteristic facts" (Hacking, 2007:289). Classification can also form stereotypes where "classified people enhance and adjust" to what is true to them. Or the construction of stereotypical spaces such as the empty north, the oil rich west or the depleted fisheries of the Atlantic provinces. Hacking provides the example of Inuit soapstone carvings: "these combine traditional practices and 
shrewd marketing by art dealers. They are changing conceptions of who the peoples are, both for 'us' and for 'them'" (Hacking, 2007:289). Stereotypes, classifications, and map 'facts' persist, especially when congealed into authoritative artifacts such as an atlas or a census report.

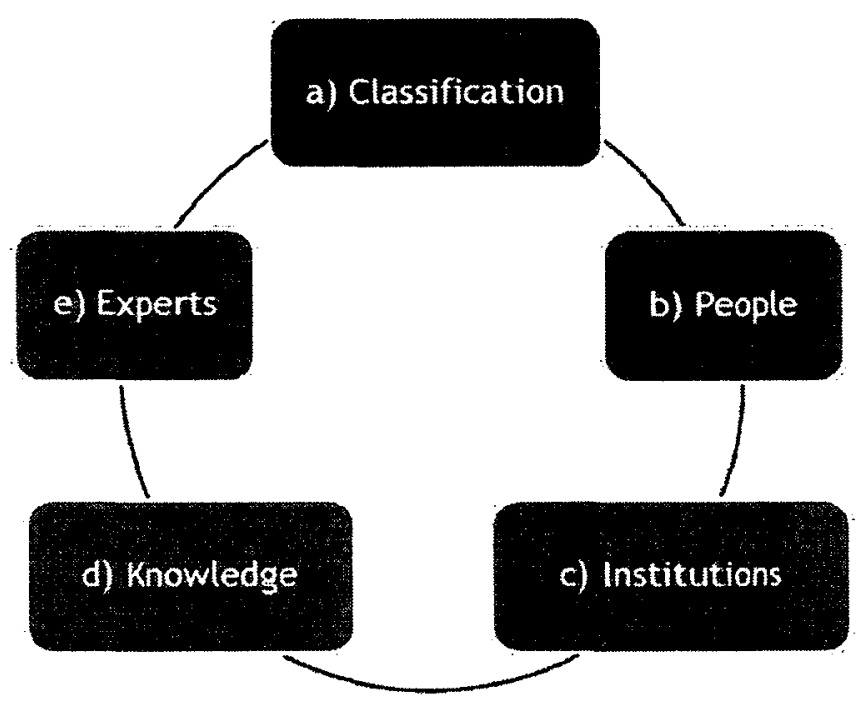

Figure 4. Hacking Five Interactive Elements of the Looping Effect People are classified for many reasons. Sometimes groupings are created to control people, as in the cases of 'Indians' and prostitutes, or they are used to help, such as in the classification of suicidal tendencies. At other times, they are created to organize and assist, such as in sensitive land classification. Other groupings are used to keep society safe and healthy; classifying the poor and the homeless for the purpose of administering supports, and creating classes to change behaviours, such as managing the amount of food consumed by obese people. Some classifications reify a kind of people and are created to enable others to emulate the people so classified, as is the case for geniuses. 
Geographical data classifications are also created for similar reasons.

Geographical groupings can inform agricultural decisions, as seen in the numerous agricultural maps in all the editions of the Atlas of Canada. Mapped hazards are used to manage where people choose to live, and climate maps may influence how people interact with the environment. These classifications will inform what can and cannot be done in certain areas. Maps can also be used to label and preserve a place of historical value, such as a UNESCO-Designated World Heritage Site (see 6th edition Atlas of Canada).

Hacking's kinds of people (e.g., Status Indians) and kinds of places (e.g., Indian Reserves) were created by classifications, and these people and places did not exist before the class was created as such. This is what Hacking calls 'making up people' and what I call 'making up spaces' by the construction of geographical imaginations. In addition, data and maps are immutable mobiles which represent classified people and spaces at a particular time -actions are often taken based on past fixed targets that may not exist when the decision is made and the actions are taken. Hacking's framework allows for the examination of social interaction with the classification, and therefore, for the study of the experts who classify, study and help people: "the institutions within which the experts and their subjects interact, and through which authorities control. There is the evolving body of knowledge about the people [and places] in question both expert knowledge and popular science" (Hacking, 2007:295). 
Hacking's nominalism is dynamic and was inspired by Michel Foucault's study of how names and things and names and people interact (Hacking, 2007). In terms of knowledge, Hacking means "presumptions that are taught, disseminated, refined, and applied within the context of the institution" (1986) or as discussed in Chapter 2, discursive practices. It is the examination of when classes become facts, such as the percentage of LICO people by census division. An example of a very subjective classification was the 'unsound mind' grouping of people, tabulated in the Canadian census until 1901 (see Figure 5). Families selfidentified their members of unsound mind, sometimes with the support of a doctor. Information regarding who was considered of unsound mind, and directions for their recording, were given to census enumerators who came to the door. The enumerator's definition on the heading of the sheet was generally

intended to include all those unfortunates who are plainly deprived of reason. As the enquiry on this head may be for many persons, very painful, the enumerator, if he is acquainted with the fact beforehand, must approach it with great delicacy (Dept. Agriculture, 1891:18).

District No. 198, Oumberlond, Schedule No. 1-Nominal Return of the Living.

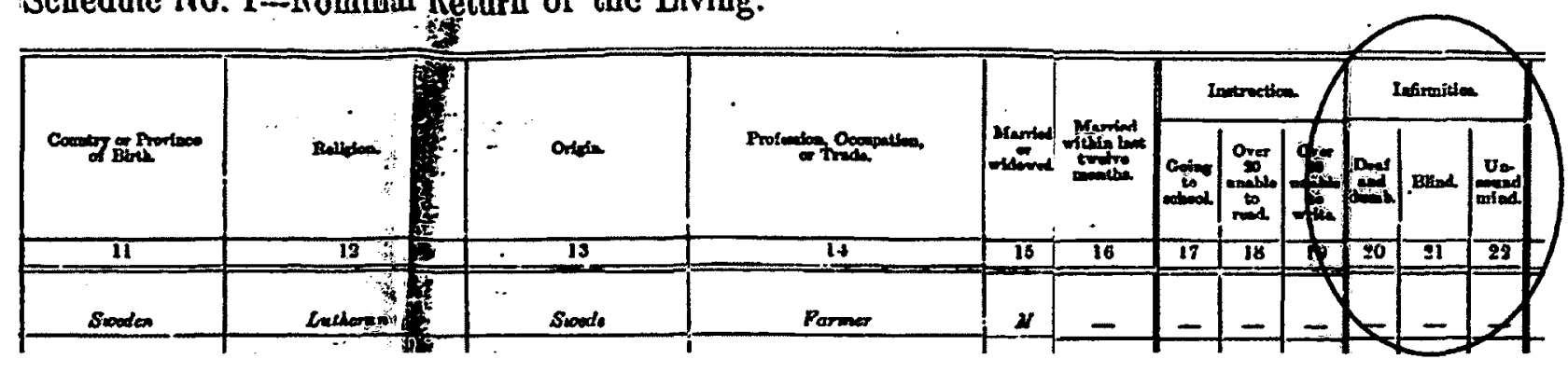

Figure 5. Infirmities Category of Unsound Mind, Schedule 1 Nominal Return of the Living of the 1871 Census, Nova Scotia (CCRI, 2012). 
Actions were taken as a result of these 'facts', irrespective of how useful or nefarious the classification and who the classifiers were. Insane and poor asylums, for example, were 'real' places often located on the outskirts of town, and were a direct result of the actions taken upon those classified as being of unsound mind or simply poor ${ }^{41}$ (see Figure 6). These data were the public health or moral statistics data, collected in earnest in the 1820-1840s, and they demonstrate the fascination with tabulating numbers. They were part of the 'avalanche of printed numbers', which tabulated "disease, madness, and the state of the threatening underworld, [and] les misérables, [and] created a morbid and fearful fascination for numbers upon which the bureaucracies fed" (Hacking, 1982:287). These moral statistics of 'deviancy' were found in the infamous British Blue Books, French Annual Reports and French Ministry of Justice minutes. This counting of deviance resulted in numbers on crime, insanity, prostitution, vagabondage, vagrancy and suicide - behaviours or states of being people feared and loathed most, or those with which the Ministries were concerned (Hacking, 1982). As with Britain and France, Canadian officials counted and mapped the deviances devised by their colonial officers.

Hacking studied the historical evolution of multiple disorder personalities (MDP) and while doing so, he observed that the treatment a patient received was contingent, among other things, upon whether or not the expert that was treating an MDP person actually believed in MDP. He also studied autism: how the

${ }^{41}$ Insane asylums appear on the planimetric maps of cities in the 1st, 2nd and 3 rd editions of the Atlas of Canada. References to mental health disappear altogether in the Atlas afterwards. 
diagnosis and characteristics of the definition evolved; how at one time there was a particular definition and those upon whom the label was assigned (autists) eventually developed a way of being autistic, of interacting with the world in an autistic way and were self-identifying themselves as such; how they became an autistic person and began to live in society in an autistic way; and how they experienced themselves as a kind of people and by doing so became agents of change and changed the meaning of their autism and autism itself. This process is what he calls the way "we make ourselves in our own scientific image of the kinds of people it is possible to be" (Hacking, 2007:305).

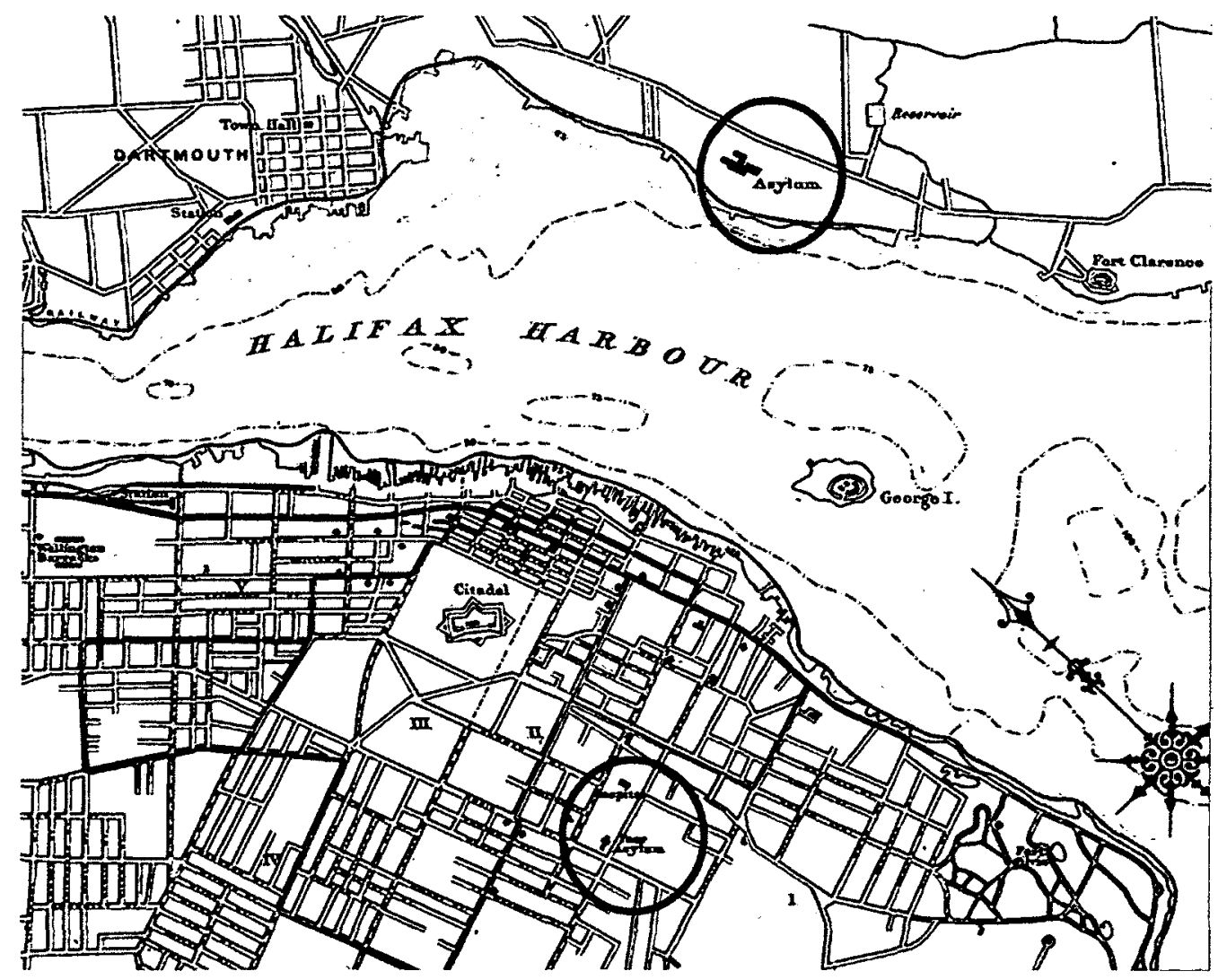

Figure 6. Detail of Halifax map extracted from Plate 39, 1st Edition, Atlas of Canada (1906) showing the location of the Insane and the Poor Asylums 
Hacking cautions that science is not alone in this process, as the kinds of people he speaks of are those that are studied, and that science is more than just its methods, as science is also associated with 'engines of discovery', which flow from classifying. 'Engines of discovery' consist of the following mechanisms: 1) counting; 2) quantifying; 3) creating norms; 4) correlation; 5) medicalization; 6) biologising; and 7) geneticising (see Figure 7).

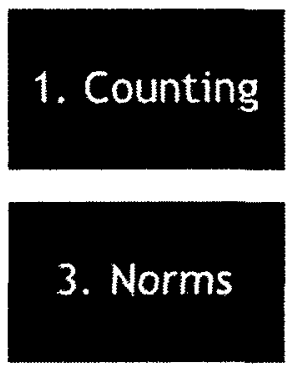

5. Clinical Medicine

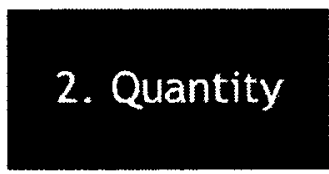

4. Correlation

6. Biology

w/neurology

7. Genetics

Figure 7. Seven Engines of Discovery (Hacking, 2007)

Along with his seven 'engines of discovery', Hacking adds three derived engines: 8) normalization, which he considers to be an engine to organize and control; 9) bureaucratization, which is the engine to administer; and 10) resistance or reclaiming identity, which is "resistance by the known to the knowers" (Hacking 2007:306) (see Figure 8). 


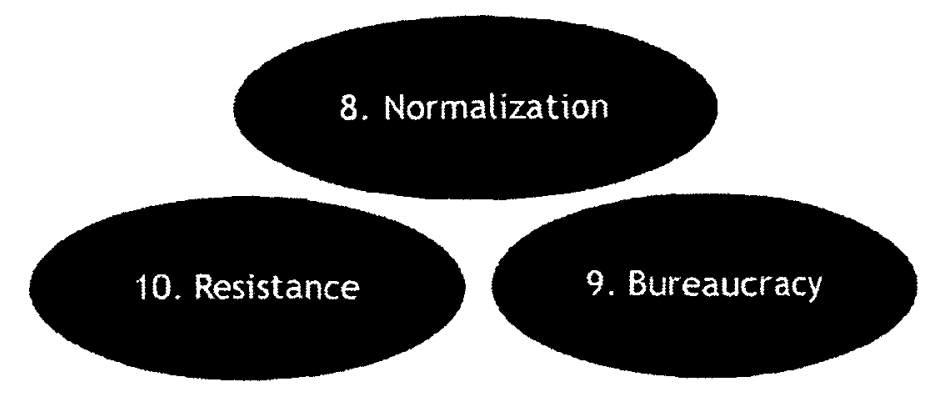

Figure 8. Three Derived Engines (Hacking, 2007)

Together, Hacking provides us with engines of scientific discovery described as follows:

\section{1) Counting:}

In the post-Napoleonic era, counting became part of the 'avalanche of printed numbers' (Hacking, 2007). Census taking grew in earnest in the colonies of France and Britain, particularly in Canada, which is lauded as having the first systematic census in the world: the 1665-1666 Census of New France conducted by Jean Talon. Natural resources, such as trees, were also counted according to particular classification schemes.

\section{2) Quantifying:}

Calculating the quantity can be evaluated with the use of bathroom scales, baselines, thresholds, or traits and characteristics. The Body Mass Index (BMI), for example, generated new kinds of people quantified within four BMI classifications: underweight, normal, overweight and obese. Other examples include the number of people considered bilingual; the areal extent of climatic 
regions as per the Thronthwaite Classification system used in the Atlas of Canada ${ }^{42}$, and, the mapping of clusters of trees into forested ecozones.

\section{3) Norms:}

Adolphe Quetelet's average man and Georges Canguilhem's study of "the normal and the pathological showed how medicine acquired the concept of normalcy not long after 1800" (Hacking, 2007:308). It is about discovering the norm within a classification. Foucault's "analyses of the discourses of medicine and psychiatry, for example, showed the importance of discourses in constructing and maintaining social norms, in turn shaping individual identities by delimiting and conditioning thoughts and actions" (Foucauldian Sharpa \& Richardson, 2001:197). Trees, in Canada were eventually classified into vegetation ecozones which became a normal way to map, characterize and understand forests.

\section{4) Correlation:}

Correlation is the statistical process developed by Francis Galton who made "deviation from the mean the core of his social philosophy" (Hacking, 2007). According to Hacking, the less we know about a category the more we search for correlations. For example, a BMI between 25 and 30 now defines what is overweight, and being overweight is thought to be bad as it correlates with numerous risk factors, which are themselves statistical entities (Hacking, 2007). Spatial autocorrelation, factorial analysis of satellite images image, interpolation are some of the methods used to map and assess spatial relationships. 


\section{5) Clinical Medicine:}

Many kinds of deviant people are relentlessly medicalized, and staying with Hacking's obesity example, anti-craving medicines and programs for the obese are forms of medicalization. Autism is another of his examples; it was once classified as a mental disorder, which meant that it could be addressed with specific behavioural therapies to normalize autistic people into mainstream society.

\section{6) Biology including neurology:}

Once biologized, a person is relieved of responsibility. Obesity is no longer a moral defect, and a 'retarded child' was once a liability and shameful for a family, while today an "autistic child is a human being somewhat different from most, but a person to understand, love and help" (Hacking, 2007:310). Biologizing certain types of classifications makes people thus classified normal, creating deviants out of those who treat them poorly.

\section{7) Genetics:}

Deviance, if inherited, as manifested in the gay gene or the autism gene, also absolves the classified of responsibility for their behaviour. Those genetically reclassified must be accepted as being a 'natural kind'. There was a time when people also thought that the criminal personality was genetic, a kind of inherited degeneracy.

\section{8) Normalization:}

Normalization is the process of making "unfavourable deviants as close to normal as possible" (Hacking, 2007:309). Whether making fat people thin, tempering 
the behaviour of autists, or decriminalizing prostitution, these actions normalize people. Hacking does not focus on treatment, as he believes that it is ideas that change people, because ideas precede treatment. Normalization also applies to spaces. Once a region has been deemed suitable for agriculture, or is classified as an ecozone, it becomes normalized as such in the minds of farmers, planners, foresters and any others who are making economic plans. In addition, once a neighbourhood in a city has been normalized or imagined as impoverished or crime ridden, real estate spatial practices begin to form. Once categories are normalized, they become conventional, standardized and bureaucratized. These "small conventions adopted early on are both inherited and ramify throughout the system" once they are normalized (Star \& Lampland, 2000:15).

\section{9) Bureaucracy:}

The system to manage, control or survey people, requires criteria in order to administer kinds of people. Programs for autistic children, for example, need to streamline who they are going to serve. Similarly, insurance companies penalize obese people, who are considered to be a bad risk, and use the BMI to assess that risk. Population health experts may map incidences of BMI in a city, and results may inform the development of targeted programs and services to reduce or maintain certain levels, or normalize obese children into thin children.

Bureaucracy has a way to standardize, "codify, embody, or prescribe ethics and values, often with great consequences for individuals [or spaces] (consider standardized testing in schools, for example)" (Star \& Lampland, 2000:5). Once the process is in place, it is quite difficult to change. 


\section{0) Resistance:}

Resistance is the action taken by people who have been classified, because the "kinds of people who are medicalized, normalized and administered, increasingly try to take back control from the experts and the institutions, sometimes by creating new experts, [and] new institutions" (Hacking, 2007:310). The most famous example is homosexuality, which is still considered to be deviant by some people in some parts of the world. People have attempted to medicalize (e.g., search for the gay gene, deprogramming of gay youth) and to normalize homosexuals (e.g., DMS reclassification as normal behaviour in 1973). Concurrently, gay pride has provided social and physical spaces where homosexuals control the characteristics of being gay or lesbian or transgendered; they have re-appropriated their classification system and, instead of being deviants, have become gay people who want to do normal things like get married, raise families and so on. Other examples include high functioning autists who are also starting to become experts on their own condition, and obese people who are beginning to lobby for respect (e.g., demanding larger seats on planes and representation in fashion through the use of plus size models). 


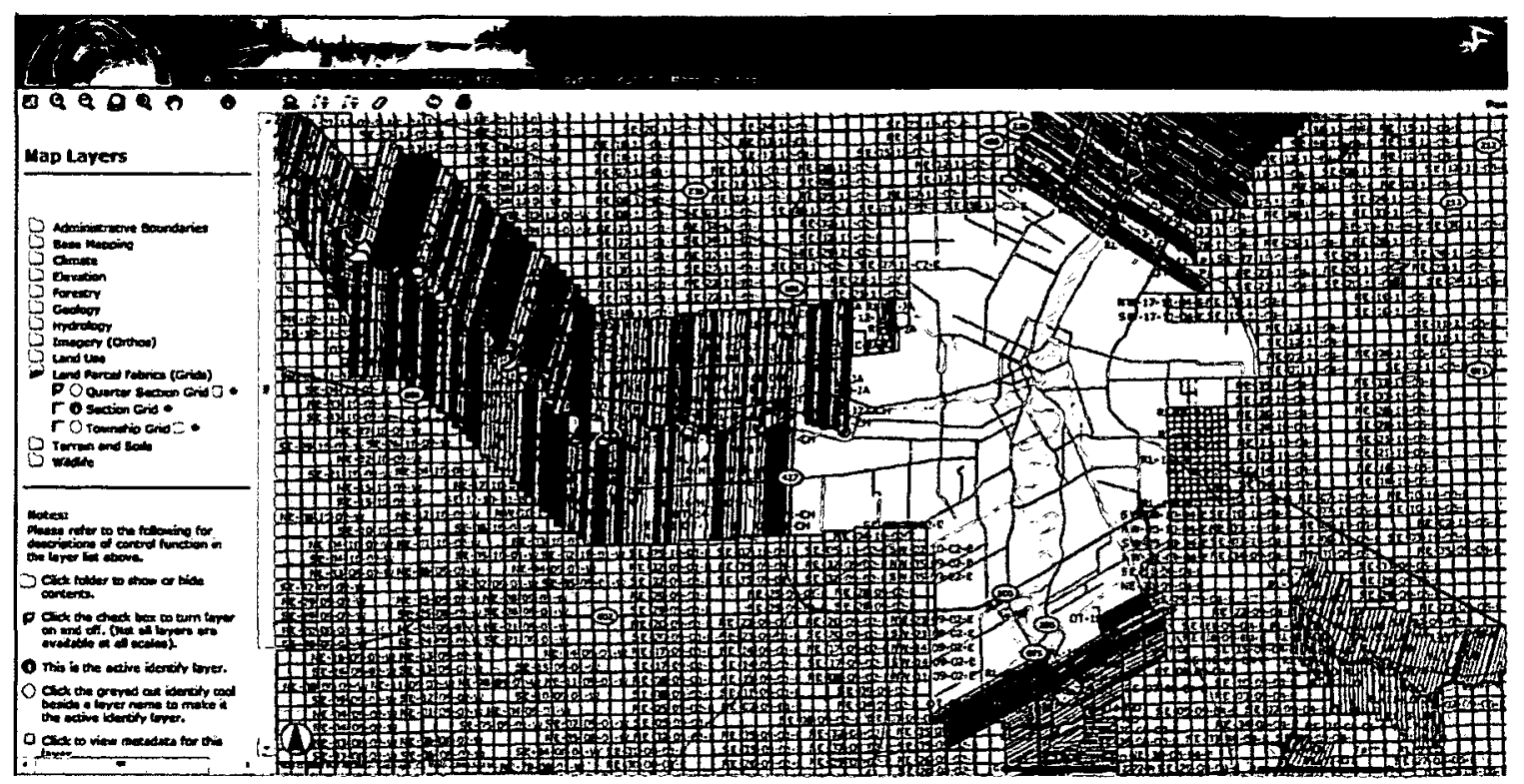

Figure 9. Elongated and Square Land Survey Grid Around Winnipeg Manitoba (Agri-Maps, 2011)

In terms of mapping, the Métis in Manitoba and Saskatchewan resisted the advancements of surveyors, and as an act of civil disobedience, Louis Riel, on October 11, 1869, stood on the Dominion Surveyor's chain as a way to resist the “imposition of a surveying and mapping system that threatened the Métis' very existence" (Morantz, 2002:80). The Métis organized and recognized themselves according to a different geometric system of an elongated grid, instead of square parcels (see Figure 9 above), that allowed more landholders to access the river's edge. This adopted grid provided more equitable access to irrigation and allowed for the closer proximity of farmsteads. They resisted because they "could not see their own nation on those maps" (Morantz, 2002:80). Early settlement areas along the Red River and Assiniboine were surveyed in 1813 by Peter Fidler, who received his instructions from Governor Miles Macdonnel, who modelled the survey based on the elongated lots of Québec (Historical and Scientific Society of Manitoba, 1970:183). Riel and the Métis resisted one colonialist's grid over 
another; they also did not resist the grid altogether nor the idea of property ownership, but instead self-identified according to one geometry and not the other. Resistance, in Hacking's sense, can be characterized as discursive struggles, namely "that meaning is never fully secured. The most immediate consequence being that different discourses can occur within the same discursive formation [and]...discourses are always subject to the play of alternatives and of struggle" (Purvis \& Hunt, 1993:492).

These engines affect Hacking's five interactive elements of the 'looping effect'. The engines of innovation, which include Hacking's engines of discovery and derived engines (see Figure 10), interact with these five elements that 'make up people', or produce spaces. Together, they are also part of the process of constructing geographical imaginations.

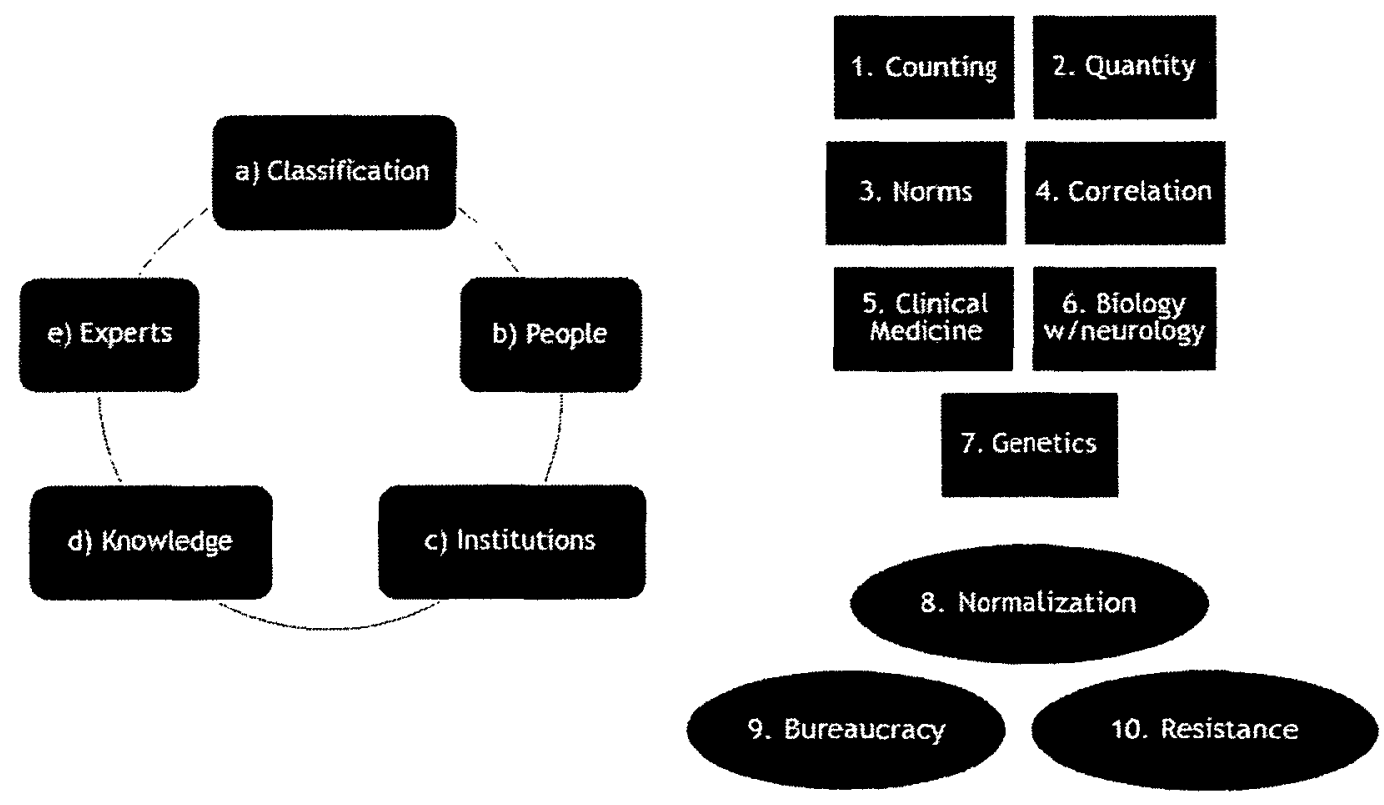

Figure 10. The Hacking Looping Effect and Making Up People Framework 


\subsection{Making up Spaces: Adapting Hacking's Framework}

The following explains how the 'looping effect' and 'making up people' framework was modified (see Figure 12, page 113) into the looping effect and making up spaces framework. Hacking's five interactive elements, just described (Figure 10), remain the same, although the focus shifts away from the human sciences and instead towards geography:

\section{a) Classification:}

In geography, classes can force territorial groupings, which in turn make up people or spaces; what gets marked on a map sometimes precedes the territory (Winichakul, 2011). For example, early survey maps parceled land into sizes suitable for farming, settlement and cities, which created places for people to settle according to a particular function before those cities or even Canada existed (Gentilcore \& Donkin, 1973). The World map circa 1914, the first map of the $2^{\text {nd }}$ edition of the Atlas of Canada, provides another useful example (see Figure 11). The World employs the Mercator projection, which prominently positions Canada as it beneficially distorts its size to make it look larger relative to the countries of the south, while concurrently enhancing the size of the British Empire, a relationship drawn in a thick red outline on the map as a technique of subliminal geometry to "magnify the political impact of an image" (Harley, 1988:290). The World is a very neatly divided geopolitical representation of twelve colonial territories, with the odd place not warranting a class (e.g., Austria, Mongolia, Persia), and where the continents are parceled amongst empire builders with little reference to the indigenous people who actually lived there 
(Harley, 1988). The physical sciences also have their classifications and these too leave traces. The elongated survey grid discussed earlier is one example, and minerals maps are another. Mineral maps show where a variety of resources are located, and the points on the map were once used to promote mineral extraction, key to fueling England's and France's industrial growth (Zaslow, 1975). Reading a little more closely, one can see rail lines, roads and ports near these mineral sites, and with a little imagination, one can see mine tailings, scarred land and contaminated water sites (e.g., Sudbury). Classifications have real, material, effects, irrespective of their constructedness.

\section{b) Spaces:}

Staying with The World map example, the people living in the coloured territories listed in the legend were quite literally forced into a new group called colonized, as their spaces became occupied and administered by outsiders who took and parceled land, extracted resources, exported slaves and/or imposed foreign languages and religions. The World map chauvinistically displayed to the people of the Dominion of Canada and the rest of the world where they fit, the extent of an empire's territorial powers, how the mapmakers saw the world, and how their administrations removed locals quite literally from view. This map depicts the geographical imaginations of colonialists who saw their empires as a unified whole. Today's world looks quite different, yet the reality of boundaries as drawn on this circa 1914 map, as discussed by Anderson (1991) and Winichakul (2011), left traces and individuals who today self-identify or resist the labels imposed upon them by their colonizers (e.g., Latinos, Indians or Esquimos). The British 
Empire is now the Commonwealth ( $3^{\text {rd }}$ edition sheet 110), with former British colonies now considered as its members. The overall extent of land surfaces did not change, however, their spatial arrangements did, and this in turn transformed spatial practices and national affiliations. As for the minerals maps, the dots created a new kind of people called gold, nickel or coal miners, and a new kinds of places called mining towns. The surveyors left their traces in the shape of an elongated survey grid (French) or squares (British).

\section{c) Institutions:}

The Geological Survey of Canada (GSC) was the primary institution behind the creation of the minerals maps in the Atlas of Canada; it eventually became an institution within NRCan, the same institution that created the Atlas and many of its maps. Explorers, scientists, surveyors and entrepreneurs put the locations of minerals on the maps and submitted these to the Dominion of Canada government of the day. In addition, the Department of the Interior, the Canadian National Railway (Osborne, 2003), and the Canadian census placed people in those places and marketed these as ideal places to which to immigrate.

Transportation networks and minerals showcased the Dominion's infrastructural breadth and wealth, while reinforcing the practical merits of a government sponsored geological survey (Zaslow, 1975). These institutions connected the dots on the map with numerous classifications (e.g., industry, transportation, resource extraction employment). In addition, state legislation, regulation, policies and programs require data and maps to monitor their implementation, evaluate their efficacy or to determine the allocation of resources. 


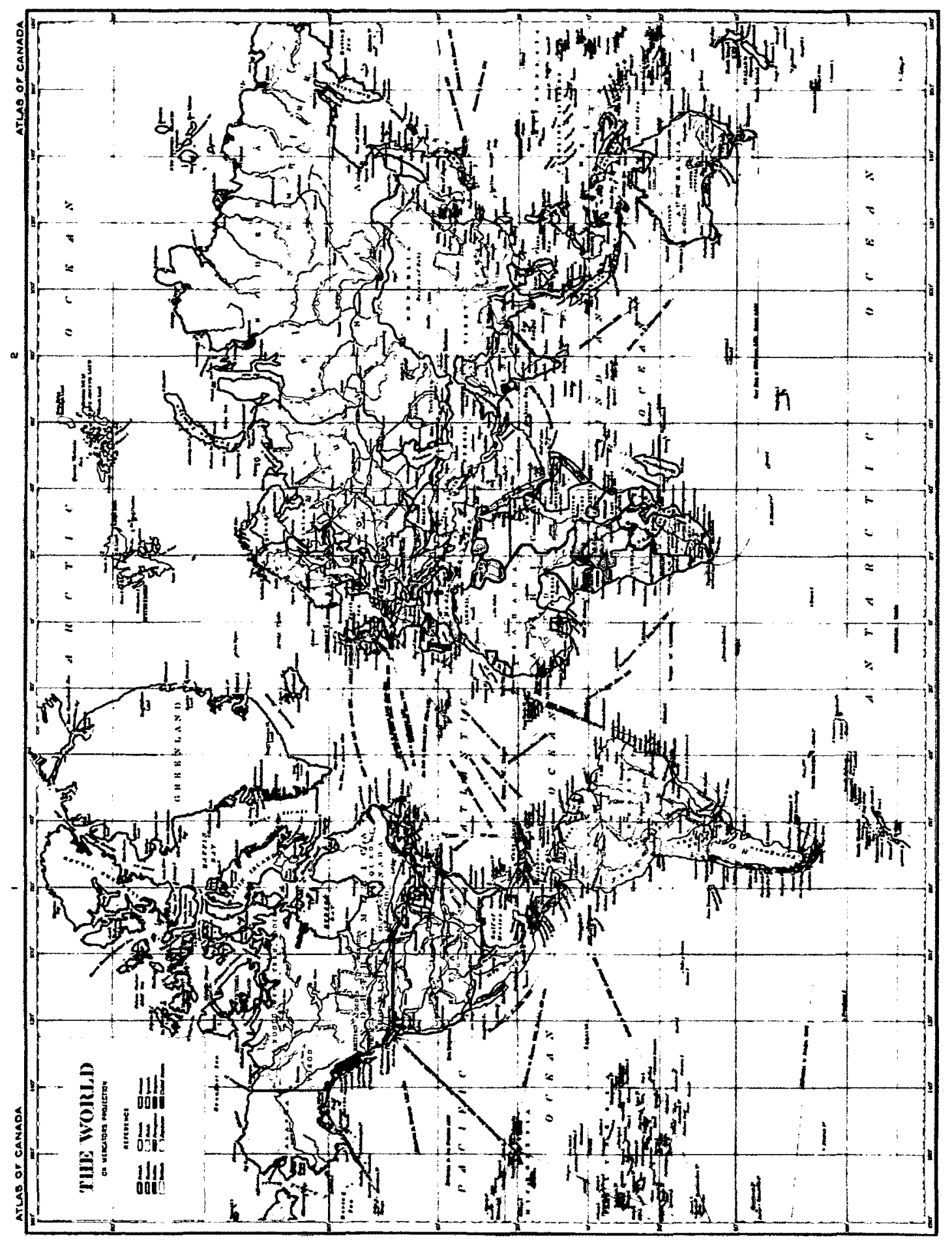

Figure 11. The World Map in the 2nd Edition of the Atlas of Canada Circa 1914 


\section{d) Knowledge:}

Maps represent the knowledge of those who collected the data, the cartographer's professional knowledge, and the institution that commissioned the map. Maps are knowledge representations, showing where kinds of people are located. They model regions, and by doing so, model what is possible in certain places. For example, the topography combined with meteorological knowledge, can determine areas good for farming, forestry, or fishing. The characteristics of people of different origins can also be represented in maps, and census commissioners, enumerators and administrators were instructed by way of manuals on how to classify the people they were to count. These characteristics once mapped, create clusters, islands, zones, or kinds of spaces, and a new type spatial knowledge that could be acted upon by experts.

\section{e) Experts:}

Knowledge is known by experts such as administrators, Hudson's Bay Traders, census enumerators, geographers, or surveyors, to name a few. The knowledge is known to experts, and sometimes by those who have been described, and it may be based on facts but often it is suspect. For example, Census Commissioners once bemoaned that it was:

deemed advisable to depart from the ordinary way of enumerating people, in regard of Indians; the objections to such a course were several, the primary one being the difficulties in regard to languages which was insurmountable; besides there is an excellent authority for stating that an attempt to enumerate the Indians in the regular manner would tend to excite them; that they would not understand the real object and would be sure to attribute it to a wrong and perhaps mischievous motive, so that the only way was deemed to call in the aid of the different agents, who have a record of all Indians receiving supplies and treaty payments from the Government (Dept. Agriculture.1886:xvi). 
As seen in this statement from the $1884-85$ census report of the North West Territories, some of the information provided by the expert is factual, some is conjecture, and some an outright fabrication. This knowledge, however, gets cemented into authoritative facts and propagated in discourse, which in turn becomes a practice of counting and a way of thinking about a kind of people or kinds of spaces (e.g., Indian reserves). This is exemplified by the stereotypical characterization of Aboriginal people as 'excitable Indians'. Authoritative documents and their experts, atlases or census reports reaffirm both the fact and the fiction. The class of Indian or Esquimo, now known as First Nations, Inuit, or Aboriginal people, are reclaiming and redefining the classes into which they were put. The characteristics that experts and their knowledge have constructed have been questioned, as have the acts committed as a result of that knowledge (e.g., residential schools or land treaties).

As for the engines of innovation used in this study, some modifications were been made. The engines of discovery, consisting of 1) counting, 2) quantifying, 3) creating norms and 4) correlation, are well known to geographers require no additional explanation, the focus will be on geography and social sciences instead of Hacking's examination of the human sciences. Hacking's three derived engines, 8) normalization, 9) bureaucratization and 10) resistance, also require no further explanation as these too are well known. The only modifications made are with respect to 5) medicalization, which becomes Taking Action, and 6) biologizing and 7) geneticizing, which are combined into one engine called scientification (see Figure 12). 


\section{5) Taking Action (instead of Clinical Medicine or medicalization):}

Hacking's medicalization examines the processes to shape 'deviant' kinds of people into 'normal' people. Institutions reaffirm the classification, wherein medicalization is characterized as a form of remediation or the creation of groups of people who take action upon those classified. Remediation, such as the process of restoring contaminated mining sites to a normal or natural 'state', is analogous to Hacking's medicalization, except the focus is on a physical space and spatial practices. However, not all spaces require this kind of action. Instead of remediation or medicalization, it is suggested here that economic, social or environmental actions may be taken once a space is classified in a certain way. For example, returning to The World map discussed earlier (see Figure 11, page 108), the empires featured and categorized on that map later became international organizations such as APEC, or the Commonwealth. These institutions reaffirmed and changed a classification, and by doing so these administrations acted upon issues in those places. For the mineral maps example, industrial associations may choose to develop mining areas or sites in a particular way or exploit resources based on the classification system and associated data. In both cases, actions are taken either to manage the new relationships between former colonies, or to exploit resources, or to remediate damaged areas. Once actions are taken, spatial arrangements change, which changes the spaces classified, in turn changing the class, which is part of the looping effect. 
Space and things cannot resist classification in the way Hacking's people do, but, classification does result in actions taken and new spatial practices, which change the kinds of spatial thing were classified. It is for this reason that taking action is considered to be on par with medicalization. In this case, however, it is about kinds of spaces and not people.

\section{6) Scientification (instead of Biology including neurology and Genetics):}

Once a classification has been scientifically and authoritatively accepted, adopted and normalized, how a class, a space or a kind of thing is understood changes. In Hacking's example he discussed the alleviation of individual responsibility if a class was biologized. Biological re-classification in such cases, as discussed earlier (e.g., autism, homosexuality, obesity), led to acceptance, changing practices, and the tempering of perceptions. Keeping remediation in mind, if a species has been scientifically classed as being in danger of extinction, hunters will change their behaviour toward hunting that species and Park officials will change how they manage that species' habitat (see Species at Risk Map, $6^{\text {th }}$ edition Atlas of Canada). It would not be possible to save that species on its inherent value alone. Alternatively, if risk of homelessness data demonstrate that the issue is political, economic and spatial, then individual responsibility for being homeless is reduced and collective state action is deemed acceptable. Blaming the poor or the mentally ill for being homeless, in theory, stops and spatial practices are altered with the construction of shelters or social housing. Scientification determines, to some extent, a new course of action. 


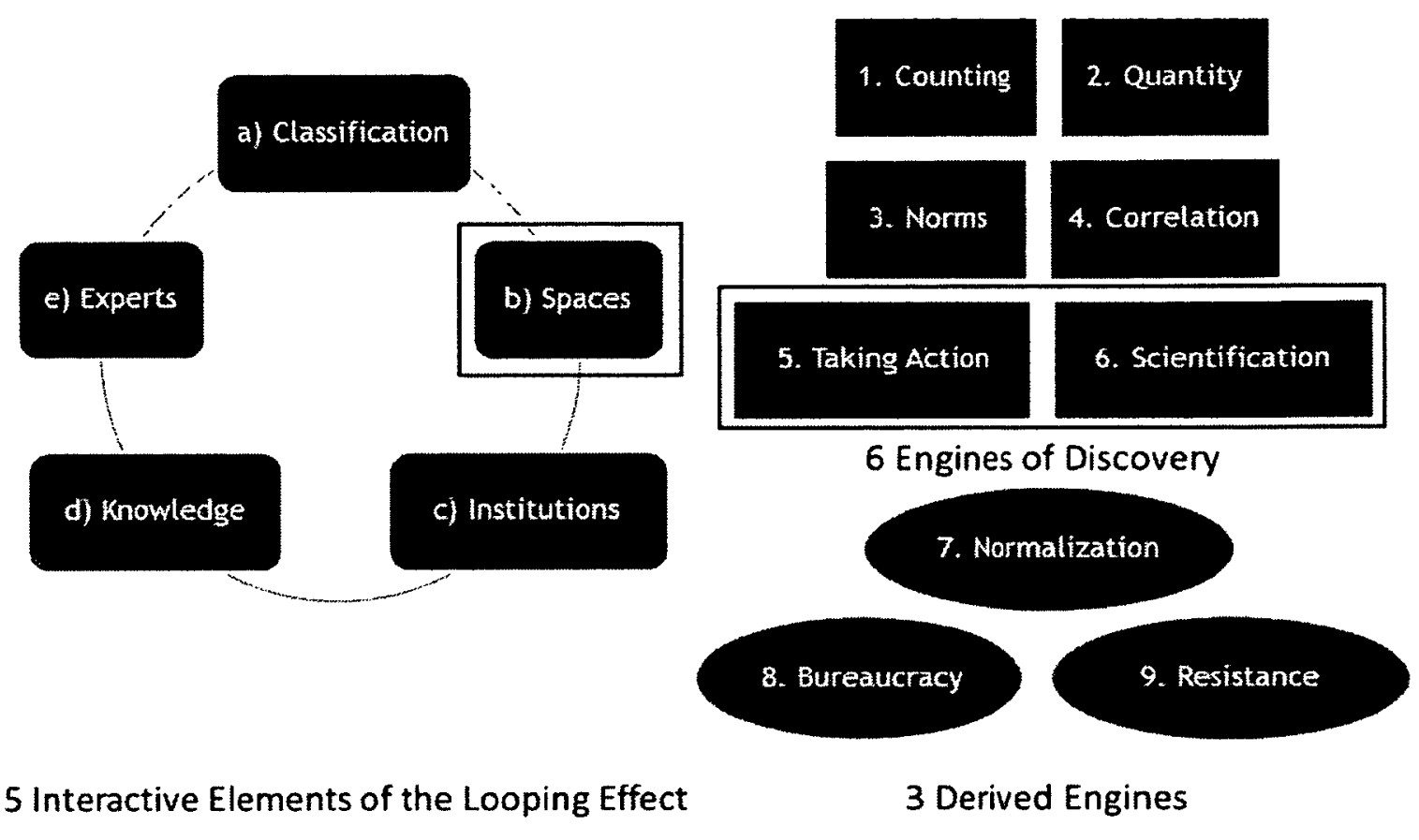

Figure 12. Modified Hacking Looping Effect - Making up Spaces

The framework and Hacking's looping effect as modified and discussed here, aswell as in the Introduction and in chapter 2, help reveal the genealogy or the social construction of classifications be they spatial or in the human sciences. Furthermore, the framework also unpacks biopower techniques and results which info biopolitical decisions and their gouvernementalité. In addition, by examining classes in this way, their underlying infrastructures are shown, and together with data, how these are involved with shaping social and geographical world views. Earlier, it was stated that the Atlas of Canada is a carefully and intentionally assembled set of government mapped classifications, while the census is a series of spatially referenced kinds of people derived from census questions. It was noted that their classifications were socially constructed and once mapped constructed kinds of spaces. These kinds of spaces, help form 
Canadian geographical imaginations. These ideas and the application of the framework will be re-assessed in the concluding chapter after first applying it to study the Atlas of Canada (Chapter 4) and the Census of Canada (Chapter 5).

\subsection{Atlas of Canada Data}

The six English editions of the Atlas of Canada, which are part of the MacOdrum Library Collection at Carleton University, were studied (Table 1). These versions were selected as these are the final bound versions distributed to the public. The information in the table below was extracted directly from the Atlases. It is interesting to note, that although the $6^{\text {th }}$ edition of the Atlas of Canada contains much information about data sources, models, and metadata, along with close to 1000 interactive maps, it contains little in the way of publication, transmission, preface, foreword, dedication, editorial or authorial information relative to the previous editions.

All hard copy editions of the atlases were available at the Carleton University MacOdrum Library. Each edition of the Atlas was published in many forms: individual sheets; folios; box sets; on CD-ROM; scanned maps archived in PDF form at the Atlas of Canada website; and interactive maps developed in a variety of software for different hardware. For this study the English bound copies of the $1^{\text {st }}, 2^{\text {nd }}, 3^{\text {rd }}$ and $4^{\text {th }}$ editions and the complete box set of the $5^{\text {th }}$ edition were examined, as these are considered their final form and their content of carefully selected maps were bound to be organized in pre-determined order. PDF copies of the maps of the hard copy editions of the Atlas are available on the Atlas of Canada website in the Archive section. The copies found in that section are 
incomplete, as the front matter material is missing, their verso notes are not included, and the order of the maps has radically changed. Further, the charts and tables of the $1^{\text {st }}$ and $2^{\text {nd }}$ editions are not included in the online versions. Reading the editions in their intended order, as will be seen, is important, as atlases are narrations and are carefully assembled stories, not just a series of maps to be treated as discrete information objects.

Form is also an expression, not only of the nature of the publishing technology of the time, but also of the intent of the editors and how they envisioned the atlases to be received, read and used. Only the current version of the $6^{\text {th }}$ edition of the Atlas was reviewed, because older versions were no longer available to the public, as these were developed with now obsolete software. Currently, earlier online versions are being kept on hard drives waiting to be archived. Unfortunately, the earlier online versions of the Atlas made available through the Library and Archives of Canada (LAC) Web Archive could not be reviewed. This archive was developed in such a way that only the layout of the map topic pages appear, but not the maps. The LAC only began producing this Government of Canada website in December 2005, with archival snapshots being taken on a semi-annual basis, which precluded the capture of the earlier versions of the online Atlas of Canada (LAC, 2007). 
Table 1. Atlas of Canada Editions Analyzed in this Study (Compiled by the author)

\begin{tabular}{|c|c|c|c|c|c|c|}
\hline & $\begin{array}{c}1^{\text {st }} \\
\text { Edition } \\
1906\end{array}$ & $\begin{array}{c}2^{\text {nd }} \\
\text { Edition } \\
\text { Revised } \\
\text { and } \\
\text { Enlarged } \\
1915 \\
\end{array}$ & $\begin{array}{c}\mathbf{3}^{\text {rd }} \\
\mathbf{1 9 5 7}\end{array}$ & $\begin{array}{c}4^{\text {th }} \text { Revised } \\
\text { Edition } \\
1974\end{array}$ & $\begin{array}{c}5^{\text {th }} \\
\text { Edition } \\
1978-1993\end{array}$ & $\begin{array}{c}6^{\text {th }} \\
\text { Edition } \\
1999- \\
\text { present }\end{array}$ \\
\hline Title & $\begin{array}{l}\text { Atlas of } \\
\text { Canada }\end{array}$ & $\begin{array}{l}\text { Atlas of } \\
\text { Canada }\end{array}$ & $\begin{array}{l}\text { Atlas of } \\
\text { Canada }\end{array}$ & $\begin{array}{l}\text { National } \\
\text { Atlas of } \\
\text { Canada }\end{array}$ & $\begin{array}{l}\text { National } \\
\text { Atlas of } \\
\text { Canada }\end{array}$ & $\begin{array}{l}\text { National } \\
\text { Atlas of } \\
\text { Canada } \\
\text { and Atlas } \\
\text { of Canada }\end{array}$ \\
\hline $\begin{array}{c}\text { Chief } \\
\text { Geographer }\end{array}$ & $\begin{array}{l}\text { James } \\
\text { White }\end{array}$ & $\begin{array}{c}\text { J. E. } \\
\text { Chalifour }\end{array}$ & & & & \\
\hline $\begin{array}{c}\text { Editor in } \\
\text { Chief }\end{array}$ & & & $\begin{array}{l}\text { N. L. } \\
\text { Nicholson }\end{array}$ & $\begin{array}{l}\text { Gerald } \\
\text { Fremlin }\end{array}$ & G. Falconer & \\
\hline Publisher & $\begin{array}{l}\text { Dept. of } \\
\text { The } \\
\text { Interior }\end{array}$ & $\begin{array}{l}\text { Dept. of } \\
\text { The } \\
\text { Interior }\end{array}$ & $\begin{array}{c}\text { MTS, Geo. } \\
\text { Branch, } \\
\text { Ottawa, } \\
\text { Canada }\end{array}$ & $\begin{array}{c}\text { Macmillan } \\
\text { Company of } \\
\text { Canada Ltd, } \\
\text { Toronto, } \\
\text { with EMR } \\
\text { Info. Canada, } \\
\text { Ottawa } \\
\end{array}$ & EMR & NRCan \\
\hline Minister & $\begin{array}{l}\text { Frank } \\
\text { Oliver }\end{array}$ & $\begin{array}{l}\text { W.J. } \\
\text { Roche }\end{array}$ & $\begin{array}{c}\text { Paul } \\
\text { Comtois }\end{array}$ & $\begin{array}{c}\text { Donald S. } \\
\text { Macdonald }\end{array}$ & & \\
\hline $\begin{array}{c}\text { Deputy } \\
\text { Minister }\end{array}$ & $\begin{array}{c}\text { W. W. } \\
\text { Cory, Esq. } \\
\text { D.M. }\end{array}$ & $\begin{array}{l}\text { W. W. } \\
\text { Cory, Esq. } \\
\text { D.M. }\end{array}$ & & & & \\
\hline $\begin{array}{c}\text { Trans- } \\
\text { mission }\end{array}$ & $\begin{array}{c}\text { June, } 30 \\
1906\end{array}$ & $\begin{array}{c}\text { January, } \\
1915 \\
\end{array}$ & & & & \\
\hline Foreword & & & $\begin{array}{c}\text { Paul } \\
\text { Comtois }\end{array}$ & $\begin{array}{c}\text { Donald S. } \\
\text { Macdonald }\end{array}$ & & \\
\hline Dedication & & & & $\begin{array}{c}\text { Pierre Elliot } \\
\text { Trudeau } \\
\text { Prime } \\
\text { Minister } \\
\end{array}$ & $\begin{array}{l}\text { Brian } \\
\text { Mulroney } \\
\text { Prime } \\
\text { Minister } \\
\end{array}$ & \\
\hline Preface & & & $\begin{array}{c}\text { N. L. } \\
\text { Nicholson }\end{array}$ & $\begin{array}{c}\text { Gerald } \\
\text { Fremlin } \\
\end{array}$ & G. Falconer & \\
\hline Language & $\begin{array}{l}\text { English } \\
\text { Only }\end{array}$ & $\begin{array}{l}\text { English } \\
\text { Only }\end{array}$ & $\begin{array}{c}\text { English } \\
\text { (French } \\
\text { version not } \\
\text { examined) }\end{array}$ & $\begin{array}{l}\text { English } \\
\text { (French } \\
\text { version not } \\
\text { examined) }\end{array}$ & $\begin{array}{c}\text { English } \\
\text { (French } \\
\text { version not } \\
\text { examined) }\end{array}$ & $\begin{array}{c}\text { English } \\
\text { (French } \\
\text { version } \\
\text { not } \\
\text { examined) }\end{array}$ \\
\hline
\end{tabular}


A database containing the following information was created for each hard copy edition of the Atlas of Canada:

- Content of each page (e.g. Foreword, TOC, map, table, etc.)

- Title and subtitle of each page or map sheet

- Page or sheet number

- Description of the map with associated notes and descriptions as written in the Atlas

- Data or map sources*

- Size of the document or sheet

Their sources are provided only when captured. If the list of sources was particularly long, the names of organizations involved and the types of sources are provided (e.g., databases, journal articles, other maps, models).

In the case of the $5^{\text {th }}$ edition:

- The date the sheet was published

- Sheet size

- Title of unpublished maps

For the $6^{\text {th }}$ edition the following was captured:

- Topic

- Sub-topic

- Map theme

- Map title

- URLs for $+/-75$ maps

- The date the map was last edited for $+/-75$ maps

- The date range of the data or the model used to create the map for $+/-75$ maps

There are close to 1000 or more maps in the $6^{\text {th }}$ edition, therefore not all of the source information was collected.

The information collected provided the necessary data to build comparison tables. Data were collected from: table of contents; notes in the atlases; text on 
the verso of map sheets; items and text in the legend; map abstracts; and metadata. Data were also collected from the maps themselves and from variables listed in tables, charts and legends. Unfortunately, the $2^{\text {nd }}$ edition of the Atlas did not contain notes, and the $1^{\text {st }}, 2^{\text {nd }}$ and $3^{\text {rd }}$ editions contained few actual data sources or accompanying text. These information gaps or silences have much to say about how maps and atlas were considered, the state as author versus public officials, cartographers or scientists as authors, and the evolution of scientific citation on the maps and the effects of form on citation practices. The $6^{\text {th }}$ edition, for example, does not list map authors, compilers, researchers or editors because "people felt uncomfortable having their names publicly listed on the Internet" (Williams, 2011). These details will be discussed in the following chapter.

Each atlas was read from front to back in sequential order many times. Also, for one reading, all editions were lined up on top of a map cabinet and read one page at a time, both concurrently and in sequence. This approach provided the means to compare the order of the content between editions. It also provided the means: to observe how themes changed over time; to examine the effects of size, format, page layout, and interactivity on reading; and to observe how the mapping of similar themes evolved or differed between editions.

Certain themes were selected for a closer reading. Given that most maps contained very little in terms of background information regarding data sources and models, additional research beyond the Atlas was required. This is discussed in greater detail in Chapter 4. 


\subsection{Census of Canada Data}

The census of population questions between 1871 and 2011 were captured in one large data base. Numerous censuses were taken prior to this time frame; however the 1871 census was the $1^{\text {st }}$ post Confederation census of the Dominion of Canada. Curtis considered the 1871 census to be the first to have been scientifically conducted (Curtis, 2002). The following table lists the population censuses examined in this study.

Table 2. List of Censuses 1871-2011 (Compiled by the author)

\begin{tabular}{|c|c|c|c|c|}
\hline Year & Census Method & Census Type & Forms & Geographic Extent \\
\hline $1870-71$ & Enumeration & Decennial & $\begin{array}{l}\text { Schedule no. } 1 \text { - Nominal } \\
\text { Return of the Living }\end{array}$ & $\begin{array}{l}\text { Dominion of Canada } \\
\text { (NS, NB, QC and ON) }\end{array}$ \\
\hline 1880-81 & Enumeration & Decennial & $\begin{array}{l}\text { Schedule no. } 1 \text { - Nominal } \\
\text { Return of the Living }\end{array}$ & $\begin{array}{l}\text { Dominion of Canada } \\
\text { (NS, NB, QC, ON, BC, } \\
\mathrm{MB} \text { and PEI) }\end{array}$ \\
\hline 1884-85 & Enumeration & $\begin{array}{c}\text { Special Regional } \\
\text { Census }\end{array}$ & $\begin{array}{l}\text { Schedule } 1-\text { Nominal } \\
\text { Return of the Living }\end{array}$ & North-West Territories \\
\hline $1885-6$ & Enumeration & Quinquennial & $\begin{array}{l}\text { Schedule No.1 - Nominal } \\
\text { Return of the People }\end{array}$ & $\begin{array}{l}\text { Special Census of } \\
\text { Manitoba }\end{array}$ \\
\hline 1891 & Enumeration & Decennial & $\begin{array}{l}\text { Schedule No. } 1 \text { - Nominal } \\
\text { Return of the Living }\end{array}$ & Dominion of Canada \\
\hline 1896 & Enumeration & Quinquennial & Unfound & Manitoba \\
\hline 1901 & Enumeration & Decennial & $\begin{array}{l}\text { Schedule No. } 1 \text { - } \\
\text { Population }\end{array}$ & Dominion of Canada \\
\hline 1906 & Enumeration & Quinquennial & $\begin{array}{l}\text { Schedule no. 1 - Population } \\
\text { and Livestock }\end{array}$ & $\begin{array}{l}\text { Northwest Provinces } \\
\text { (MB, SK and AB) }\end{array}$ \\
\hline 1911 & Enumeration & Decennial & $\begin{array}{l}\text { Schedule No. } 1 \text { - } \\
\text { Enumeration of the } \\
\text { Population }\end{array}$ & $\begin{array}{l}\text { Dominion of Canada } \\
\text { (NS, NB, QC, ON, BC, } \\
\text { MB and PEI, YK, } \\
\text { NWT) }\end{array}$ \\
\hline 1916 & Enumeration & Quinquennial & $\begin{array}{l}\text { Schedule No. 1- } \\
\text { Enumeration of the } \\
\text { Population }\end{array}$ & $\begin{array}{l}\text { Prairie Provinces (MB, } \\
\text { SK, AB) }\end{array}$ \\
\hline 1921 & Enumeration & Decennial & $\begin{array}{l}\text { Schedule No. } 1- \\
\text { Population }\end{array}$ & Dominion of Canada \\
\hline 1926 & Enumeration & Quinquennial & $\begin{array}{l}\text { Schedule No. } 1 \text { - } \\
\text { Population }\end{array}$ & $\begin{array}{l}\text { Prairie Provinces (MB, } \\
\text { SK, AB) }\end{array}$ \\
\hline 1931 & Enumeration & Decennial & $\begin{array}{l}\text { Schedule No. } 1 \text { - } \\
\text { Population }\end{array}$ & Dominion of Canada \\
\hline 1936 & Enumeration & Quinquennial & Form 1 - Population & $\begin{array}{l}\text { Prairie Provinces (MB, } \\
\text { SK, AB) }\end{array}$ \\
\hline 1941 & Enumeration & Decennial & $\begin{array}{l}\text { Form No. } 1 \text { - Population } \\
\text { Form No. } 4 \text { - Census of } \\
\text { Housing } 1 / 10 \text { Households } \\
\text { Enumerated }\end{array}$ & Dominion of Canada \\
\hline 1946 & Enumeration & Quinquennial & Form No. 1. Population & $\begin{array}{l}\text { Prairie Provinces (MB, } \\
\text { SK, AB) }\end{array}$ \\
\hline
\end{tabular}




\begin{tabular}{|c|c|c|c|c|}
\hline Year & Census Method & Census Type & Forms & Geographic Extent \\
\hline 1951 & Enumeration & Decennial & $\begin{array}{l}\text { Form No. } 2 \text { - Population } \\
\text { Form No. } 4 \text { - Census of } \\
\text { Housing }\end{array}$ & Dominion of Canada \\
\hline 1956 & Enumeration & Quinquennial & Form No. 2 - Population & $\begin{array}{l}\text { All provinces - } \\
\text { Territories? }\end{array}$ \\
\hline 1961 & Enumeration & Decennial & $\begin{array}{l}\text { Form } 2 \mathrm{~A}-\text { Population and } \\
\text { Housing } \\
\text { Form } 2 \mathrm{~B} \text { - Housing }\end{array}$ & Dominion of Canada \\
\hline 1966 & Enumeration & Quinquennial & Form 2-Population & Dominion of Canada \\
\hline 1971 & $\begin{array}{l}\text { Self-enumeration - } \\
\text { Mailout }\end{array}$ & Decennial & $\begin{array}{l}\text { Form } 2 A-\text { Short Form } \\
\text { Population and Housing } \\
\text { Form } 2 B \text { - Long Form } \\
\text { Population and Housing }\end{array}$ & Dominion of Canada \\
\hline 1976 & $\begin{array}{c}\begin{array}{c}\text { Self-enumeration - } \\
\text { Mailout }\end{array} \\
\end{array}$ & Quinquennial & Forms $2 A$ \& $2 B$ & Canada \\
\hline 1981 & $\begin{array}{l}\text { Self-enumeration - } \\
\text { Mailout }\end{array}$ & Decennial & Forms $2 A \& 2 B$ & Canada \\
\hline 1986 & $\begin{array}{l}\text { Self-enumeration - } \\
\text { Mailout }\end{array}$ & Quinquennial & Forms $2 A \& 2 B$ & Canada \\
\hline 1991 & $\begin{array}{c}\text { Self-enumeration - } \\
\text { Mailout }\end{array}$ & Decennial & Forms $2 A \& 2 B$ & Canada \\
\hline 1996 & $\begin{array}{c}\text { Self-enumeration - } \\
\text { Mailout }\end{array}$ & Quinquennial & Forms 2A \& 2B & Canada \\
\hline 2001 & $\begin{array}{c}\text { Self-enumeration - } \\
\text { Mailout }\end{array}$ & Decennial & Forms $2 A \& 2 B$ & Canada \\
\hline 2006 & $\begin{array}{l}\text { Self-enumeration - } \\
\text { Mailout \& Internet }\end{array}$ & Quinquennial & Forms 2A \& 2B & Canada \\
\hline 2011 & $\begin{array}{l}\text { Self-enumeration - } \\
\text { Mailout \& Internet }\end{array}$ & Decennial & Census (Short Form) & Canada \\
\hline
\end{tabular}

*Appendix A provides Sources for Census Questionnaires

As seen in Table 2, data from censuses between 1871 and 1966 were collected by enumerators who went door to door, met with respondents, asked the questions in person, and filled out the schedules and forms on the respondent's behalf.

Schedules covered themes such as population; agriculture and industry (see Appendix L, which lists all the schedules for each census year). Schedules were long sheets with variables listed along the top and a series of rows within which enumerators wrote the data they collected (a section of the 1871 schedule was shown earlier in Figure 5 on page 94). Enumerators were given instructions on how to ask the questions and how to fill in the forms. This was done between 1871 and 1946. Between 1951-1966, the form had changed to computer cards 
with scratch-in options. Starting in 1971, the census questionnaire, with instructions, was mailed out to households and the practice of having enumerators go door-to-door ceased. This was in practice until 2001. In 2006 mail out surveys and the first online survey was taken. Until this point, the census included, in some cases, hundreds of questions. After 1951, the practice of a short and long form was instituted for the decennial censuses and for all the censuses after 1971. In 2011, the size of the census was significantly reduced, as the long-form census was cancelled, and respondents are now encouraged to fill out the short-form census on the Internet. Initially, only decennial censuses, on 01 or 11 years, were to be taken, while quinquennial censuses were taken regionally and were shorter until 1956. A shorter quinquennial census was taken for all of Canada in 1966, and by 1971 long- and short-forms censuses were taken. The long-form was to be taken by a $20 \%$ sample of the population, or 1 out of every 5 households.

Collecting census schedules and questionnaires was not an easy task. There is no central repository in Canada that maintains a complete collection of all schedules, questionnaires and forms. StatCan has some forms scanned and some paper copies in two filing cabinets on two different floors. LAC maintains a list of questions for some of the schedules between 1851 and 1916, focusing primarily on questions of interest to genealogists, and these are available on the Internet. Early Canadiana Online has some of the schedules dating before 1920 on their website, while the Canadian Century Research Infrastructure (CCRI) project only has the decennial censuses of population between 1871 and 1951. The University 
of Toronto also maintains scanned copies of the indexes of the questions on their website. Many of the forms and/or lists of questions can be found in census reports, administrative reports, instructions to enumerators and commissioners, procedure manuals, and on the StatCan website. Once the forms were collected, census of population questions were typed into a spreadsheet to form a database of the questions. These are studied in Chapter 5 . 


\section{Chapter Four: The Atlas of Canada and Canadian Geographical Imaginations}

\subsection{Introduction}

This chapter will apply Hacking's framework as discussed in Chapter 3 , to analyze the Atlas of Canada and assess if it 'makes up spaces' and if it influences Canadian geographical imaginations. Section 4.2 defines national atlases and Section 4.3 examines the six editions of the national Atlas of Canada. The chapter ends with Section 4.4, which examines four specific Atlas map topics in detail: relief, forest biogeography, communications infrastructure and territorial evolution.

\subsection{National Atlases}

A national atlas is a distinct cartographic type of assembled sets of authoritative social, economic, environmental, natural and social data that are rendered into 'objective' maps. These maps are accompanied by charts, tables, text and sources of information and are bound into a volume; an arranged set of sheets, either in a box set, portfolio or binder, is available in a machine-readable form or disseminated on the Internet or portable memory devices. 
A national atlas is also multi-thematic but represents a single country. It is created to convey information for a variety of audiences. A national atlas serves to educate a country's people about themselves and their place in the world, to inform decision-makers, to showcase specialized, geographical, cartographic and scientific knowledge, and create an inventory of a nation's natural and human resources and their geographic relationships. An atlas is a collaborative, multisectoral and multi-departmental endeavour of scientists, administrators, academics, cartographers, geographers, technicians and subject matter specialists, directed by an editor, government department and/or a committee. Atlases take time to compile, are very expensive to produce and are prestigious artifacts. They impart the geographical knowledge of a country at a particular time. The process of creating atlases also improves national cartographic and geographic knowledge. Atlases demonstrate the extent of a country's geographic knowledge of itself and act as a scientific repository of that knowledge, a reference tool, an educational instrument, all which serve to 'present or interpret the characteristics and aspirations of a society to itself (Symons, 1979). Each national atlas functions as a cultural ambassador and promotes nationalism, internationalism and cosmopolitanism to its readers. It helps form an understanding of the territorial extent of a country, the shape of which becomes logoized43. A national atlas is also a graphic representation of a nation's collective experience, pride and unity around which an identity can be created.

43 The nation become a logo as it is seen in repeated images, where as soon as the shape and form is seen, the nation they belong too is immediately imagined (Anderson, 1991). 
Atlases contribute to cultural development by becoming part of political culture and providing a nation's people with the information it needs to play an effective role in national processes. Finally, they are time stamped cultural artifacts that merit being studied and valued as they are the result of a large administrative endeavor and a national worldview. Atlases legitimate certain geographical points of view of the nation and do not express less desirable views; they are geographic narratives and stories that reflect the era in which they were created, echo antecedent content and form, and reproduce the ideals of their patrons, in most cases, those of the map makers, the committees that oversee them, extant and accepted scientific knowledge, and to some extent, the governments who sponsor them. The content evolves, in part, because authors or chief editors change, as well as because knowledge producing practices of science evolve, technologies change practices, and the actual objects of study (e.g., population, forests, relief, communication, territory) within a single nation dynamically change along with how those objects are envisioned.

In spite of their ubiquity, national atlases are not extensively written about in academic literature, and when they are discussed, it is normally a review or in a report. In addition, they are normally thought of as 'objective' reference documents and not as cultural and historical artifacts that have merit in their own right. The Geographical Imagination in America 1880-1950, by Susan Schulten, is one of the few academic exceptions. It is a political, historical and cultural study of commercial atlases and maps in the US. Schulten observed that: 
until recently, cartographic historians had rarely treated atlases as deliberately conceived and composed texts, and there is a long tradition among collectors of dismembering atlases for the purpose of trading individual maps, a practice that treats the fact of the atlas as incidental (Schulten, 2001:6).

J. B. Harley also bemoaned the destruction of these artifacts throughout his career as there are few complete sets of historical atlases. Map historian James R. Ackerman, also had difficulties assembling a complete collection of historical German school atlases for his research on The Structuring of Political Territory in Early Printed Atlases (1995) as schools discarded and replaced old 'outdated copies' with new and updated versions. Historical school atlases depict how nations were described and show how authors wanted nations to be imagined by school children. These atlases were used to institutionalize a particular worldview very early on, and Ackerman's study described what German soldiers under Hitler read in their youth and discusses how those images informed a certain understanding of the fatherland. The Archive Section of the $6^{\text {th }}$ edition of the Atlas of Canada, for example, disassembles earlier editions into an incomplete series of scanned maps re-arranged into a new order for the web and subsequently disregarding the order of the story. At the turn of the $20^{\text {th }}$ century, the Dominion of Canada also published the Concise School and Western atlases, and hundreds of thousands of these were disseminated by immigration agents to schools and settlements in Canada as well as internationally. These mostly forgotten atlases were instrumentally published and disseminated to educate settlers, promote immigration and invite investment. 
Atlases are more than a neutral arrangement of facts. Harley in his study of English county and regional atlases argued that:

the unarticulated aspects of power in the atlas, that is to say on the hidden agenda of social power which operates on the reader as an unconscious force and through the symbolic meaning of the image as much as through the literal facts of geography (Harley, 2001:129).

Harley did not investigate how atlases got used in the halls of power, but he did study how "atlas maps worked to structure social attitudes and to support a preexisting geography of power relations" (Harley, 2001:128). Harley, along with Susan Schulten and James R. Ackerman, argued that atlases socially construct reality by reflecting and disseminating existing social and knowledge frameworks, and by legitimating and reinforcing geographical and social imaginings.

Marc Monmonier, in The Rise of the National Atlas (1994), suggested that the 1579 Christopher Saxton Atlas of England and Wales, commissioned by the Crown with editions published until 1770 , could be the first national atlas. Monmonier, after reading Harley's study of the Saxton Atlas, wrote that "in addition to giving the monarch information useful in administering her kingdom, the atlas gave identity to counties and localities, and illustrated how they belonged to the English state" (1994:2).

According to Soviet cartographer K. A. Salichtchev, editor of the International Geographical Union (IGU) report Atlas nationaux; histoire, analyse, voies de 
perfectionnement et d'unification (1960)44, posited that the 1899 Atlas of Finland, was the first 'real' national atlas as it demonstrated the "organizational ties and co-operation between the different geographical specializations" and it "set the standard for the national atlas as a cartographic status symbol" (1972:56). The report also suggested that Field Marshal de Vauban, a $17^{\text {th }}$ century French military engineer and economist, wanted an atlas to "trace...in the space of an hour the condition of a large kingdom...and to ascertain...its size, wealth and strength, the right and wrongs of its subjects, and what could be done to augment the first and remedy the latter" (Salichtchev, 1972:1). The Saxton and the de Vauban atlases are early examples of atlas use in spatial decision-making, and Salichtchev and Monmonier agree that national atlases are largely $\mathbf{2} 20^{\text {th }}$ century phenomenon.

What constitutes a national atlas is contingent upon the definition that one uses. For Monmonier, the "recognition of the national atlas as a national symbol requires abandonment of restrictive official definitions based on content but ignoring intent" (1994:3). The second official national atlas in the world, if the Salichtchev IGU 'official restrictive' or 'scientific' definition is suspended, is the $1^{\text {st }}$ edition of the Atlas of Canada published in 1906. Salichtchev did not believe that the $1^{\text {st }}$ and $2^{\text {nd }}$ editions qualified as atlases because these were not scientific or comprehensive enough, and Canada only started publishing 'real' national atlases with the $3^{\text {rd }}$ edition (1957). For Salichtchev, 'truly scientific' national atlases

44 This report was later translated by G. Fremlin and L. Sebert and published in Cartographica in 1972. 
started to be produced in the 19th century as a result of: the application of correlation in the study of geography; understandings of spatial relationships and natural laws; and the capacity to accumulate, synthesize and systematize large amounts of data. Atlases emerged as a form of extensions of topographical surveys due to advancements in the natural sciences and in particular earth sciences, climatology, oceanography, phytogeography, etc., and as a result of extensive statistical development after the industrial revolution in Britain and the French Revolution in France (Salichtchev, 1972). Also, atlas production significantly increased after WWI for the following reasons: new nations were being created; national self-sufficiency required countries to conduct research on resources and economic possibilities; colonial exploitation was intensified; and the general desire for more detailed information was on the rise. The need for geographical information cannot be understated; the world was reconfigured with the dismantling of previous empires, which gave rise to the creation of numerous nations that needed maps and data in order to govern.

National atlases are expensive undertakings, often beyond the reach of private publishers, and they became the purview of "scientific societies and organizations [that] felt that the preparation of atlases was a task of great scientific value, prestige and national importance. This view of the role of atlases facilitated the collection of public funds and made it possible to obtain state support" (Salichtchev, 1972:2). Atlases therefore have selling points and patrons, and patrons, in turn, have views expressed in these atlases. 
The $20^{\text {th }}$ century was a prolific period in terms of publishing national atlases. Monmonier (1994) counted45 12 pre-WWII national atlases, 40 by the late 1950s, and over 83 by the early 1980 s. He also attributed the rise of the national atlas to the fact that many new countries were formed after the war. In addition, Monmonier examined the frequency of atlas reviews in geographic and cartographic journals and documented 60 critical reviews between 1920 and 1940, followed by relative silence during the war period of relative silence and an increase in the 1950 at around the same time that cartography was becoming a distinct technical-scientific profession. Others have also developed methods to count, compare and review atlas content and form for a variety of specific needs (Nicholson, 1952; Kent \& Tobias, 1990; Stephenson \& Galneder, 1969, Dean, 1970, Hocking, 1991; Hocking \& Keller, 1993).

Monmonier found it difficult to create a definitive list of atlases and produce a clear set of timelines with atlases taking years to produce, and in some cases, as seen in the $4^{\text {th }}, 5^{\text {th }}$ and $6^{\text {th }}$ editions of the Atlas of Canada, it is hard to tell precisely when an atlas begins since the date range of the material often pre-dates the publication date and they are continuously added to when they are published online. The definition of national atlas is also fluid since some national atlases do not cover internationally recognized boundaries (e.g., Atlas National du Québec). To avoid this problem, N. L. Nicholson referred to them as Single Country Atlases (1952). If national atlases are evaluated according to current geographic

45 He studied national atlases lists and bibliographies: 1957 American Geographical Society; the 1960 Polish Academy of Sciences list and the 1980 Library of Congress list all of which were loosely compiled according to the Salichtchev criteria. 
knowledge and technology standards, older national atlases might be assumed to be too rudimentary, and this was the fate of the $1^{\text {st }}$ and $2^{\text {nd }}$ editions of the Atlas of Canada, as assessed by Salichtchev. An atlas however, as discussed, is more than the sum of its data; atlases are important historical records as they capture predominating knowledge.

Atlas form is also not fixed. A national atlas can be a series of map sheets, folio sets, box sets, bound volumes or an online presence, and there are questions as to whether or not an atlas is an atlas if it comes in the form of a database, as was apparently almost the case in the US in the 1980 s when "a digital cartographic information system almost became the country's 'de facto' national atlas - a role it presumably could have filled without censure as long as it was not called a national atlas" (Monmonier, 1994:12). D. R. Fraser Taylor, founder of the concept of cybercartography and producer of one of the world's first online atlases, had stated, during the advent of computer-assisted cartography, that atlases "should [not] be a random collection of maps but a carefully selected series" even if they are generated from digital data from many sources (1979:70) as atlases embody both theory and practice, while also narrating a story (2006).

Benoit Brouillette, the first Québecois to receive a doctorate degree in Geography, and also the first Québecois and Canadian Francophone to be appointed to the International Geographical Union (IGU) National Committee for Canada, was the research lead investigating the possibility of publishing a comprehensive atlas for Canada in 1943. His systematic study, entitled Atlas of Canada Project: A Preliminary Survey (1945), was conducted in anticipation of the $3^{\text {rd }}$ edition of 
the Atlas of Canada. The study was co-sponsored by the Canadian Social Science Research Council and the Carnegie Corporation of New York. He interviewed Canadian, British, French and US experts on their respective atlases and mapping offices. He also assessed who in Canada could potentially be enlisted into the production of atlas content, and conducted a thorough survey of the types of maps produced in Canada at the time.

Based on his analysis, there were two types of atlases: dictionary and geographic. The dictionary atlas is used to find places, and "such an atlas can be drawn by trained draftsmen, who need not have a great amount of geographical knowledge...that kind of atlas is essentially informative" (Brouillette, 1945:7) and is analogous to a gazetteer ${ }^{46}$. For Brouillette, the object of a geographic atlas was:

to inform its readers on the physiography of a country in such a way that he will differentiate it at first glance and will understand the climate according to its factors and the main types of weather, winds, etc.; the system of running waters; the various aspects of the vegetation cover of the country; the pattern of settlement, population density, etc.; the exploitation of resources: agriculture and all other industries, commerce, finance, etc. That kind of atlas is explicative. In short, the Geographic Atlas is made of scientific maps, drawn by specialists in their respective fields of interest and research (Brouillette, 1945:7).

In his report, Brouillette concluded:

The modern Atlas of a country is a scientific one. Its purpose is educational. Each map is the result of a great deal of research work done by specialists. Professional geographers and cartographers unite their crafts to give a true picture of a carefully selected number of represented phenomena (Brouillette, 1945:77).

\footnotetext{
${ }^{46} \mathrm{~A}$ gazetter is "a list of geographical place or feature names in alphabetical order, usually accompanied by geographic or grid coordinates and basic information about the feature, such as population or classification." (NRCan, Glossary, 2009).
} 
As will be seen in the Section 4.3, Brouillette's report was very influential. The most often cited 1960 Salichtchev report was lauded as the first and only systematic study of atlases; however Brouillette's report, published 15 years earlier, was the first while N. L. Nicholson's $195^{2}$ study of single country atlases was the second. Salichtchev (1972) defined national atlases as:

the basic multi-subject geographic atlases of single countries containing a summary representation of contemporary scientific knowledge of the country in the fields of physical, economic and political geography. To convey as much information as possible in a minimum amount of space, to present it in a visually intelligible (Introduction).

He considered atlas production to be "one of the essential tasks of modern geographers" (1972: Introduction) and believed that "national atlases, an inventory and expression of the achievements in contemporary geography, [were] the most important contributions that [could] be made by geography to the development of national culture" (Salichtchev, 1972:26).

Scientific societies were important to the formation of national atlases. The IGU Commission on National Atlases, for example, was created in Rio de Jainero in 1956 to help produce and improve national atlases, and to advance standardization to enable comparability. The Commission aimed to expand "geographical understanding, as well as to make it possible for national atlases to be used as documentary material for maps of the world" (Salichtchev, 1972: Introduction). Salichtchev's study was a part of this process and he recognized that creating an atlas was also important since: 
atlases also accelerate the development of geography itself and contribute considerably to the improvement of maps and geographic atlases. The maps reveal the areas where knowledge is lacking and encourage the elimination of such gaps...Information from various geographic disciplines is brought together, compared and validated through comparison in these atlases. Existing cartographic methods are improved and new methods are developed (Salichtchev, 1972:26-27).

This Salichtchev definition of a national atlas is as follows:

a) it covers a single country, or nation;

b) it provides a variety of thematic maps based on scientific data and covering the physical, economic, demographic, and cultural - historical geography of the country; and

c) it receives the enthusiastic support of the nation's scientific organizations and government agencies.

Salichtchev reviewed 22 national atlases from Europe, Africa, Asia, Australia, the US, Israel and Canada, Canada's $3^{\text {rd }}$ edition specifically (Salichtchev, 1972:4). As discussed, he did not consider the $1^{\text {st }}$ and $2^{\text {nd }}$ editions of the Atlas of Canada to be 'real' national atlases and he took issue with the exclusion of maps on finances, albeit, in both those editions, numerous charts on that topic were provided. The $1^{\text {st }}$ and $2^{\text {nd }}$ editions were intended to cover all aspects of Canadian geography, but at the time, very few physical maps were included since national surveys of soils and surface formations were almost completely lacking and, as a large fledgling country, it was relatively unexplored and unmapped at the turn of the $20^{\text {th }}$ century (Nicholson, 1952).

Two decades later, during the Pan-American Institute of Geography and History Seminar held in Ottawa: The Purpose and Use of National and Regional Atlases (1979), chaired by Richard Groot, Director of Geographical Services of the Department of Energy, Mines and Resources (EMR), national atlases were 
redefined. In his address Some thoughts on the Nature and Value of National

and Regional Atlases, Thomas H. B. Symons considered atlases to be two things:

[1] [a] system of objective information whose compilation is justified by its direct contribution to utilitarian decision-making as, for example, in national and local planning...[2] the atlas is seen as refining and extending the reader's perception of the nation, in which case the atlas contributes to national self-awareness and cultural development (1979:4).

Further, Symons recognized atlases as dense knowledge projects, which should be employed in culture and politics:

it is self-evident that governments at every level - whether national, regional, or local - must make the fullest and wisest possible use of the knowledge cartographers can place at their disposal...map culture should be part of political culture, and cartographic information and insights should be at the foundation of public policy (1979:4).

Symons also greatly valued the knowledge they contained and their work at constructing geographical imaginations:

whether as a scientific repository, a research framework, a reference tool, an aid to planning and decision-making and educational instrument, or a cultural interpreter, will serve to advance knowledge about the community under study. In so doing, the atlas will better enable the population of that community to know themselves and to help themselves. Good maps can often provide an immediate and graphic interpretation of our experience, helping us to understand who we are and why. Slice by slice, theme by theme, the pages of an atlas can enhance our knowledge and understanding of the society to which we belong. In this way, well-prepared national and regional atlases can help each of our societies to deal constructively with the opportunities and complexity of its modern inheritance (Symons, 1979:6).

His address resembles Joseph Campbell's thoughts about the NASA

Earthrise and Blue Marble images. Symons was also very concerned with

quality, objectivity, propaganda and overzealous patriotism, which could

be rendered into an atlas as 'objective facts': 
that is, the capacity of such atlases to present or interpret the characteristics and aspirations of a society to itself and others. This may well be, as some argue, the most important role for a national atlas. But it is also the most difficult and sensitive function that such an atlas has to perform. Those who recognize the enormous value of national atlases must also recognize the danger that they may be misused to promote a case of a cause or an ideology, or simply to boost a national community in a way which is not in line with the facts. This can occur only too easily, and perhaps particularly in these times when almost all such atlases are government funded. It is not difficult to confuse national purposes with the purpose of a national atlas, and to press the latter to accommodate the former...there is a fine line between an honest judgment and a patriotic preference. The only possible approach is on which consciously places the integrity of the atlas before all other considerations and consistently resists the temptations and pressures to confuse scholarship and patriotism (Symons, 1979:6).

As discussed in Chapter 2, objectivity and maps are mostly considered a given by most map readers, and this is no different for atlas readers as seen with Salichtchev's definition presupposes objectivity. Ackerman's study of pre- and post-war German school atlases revealed differing and time contingent representations of national patriotic thinking while Schulten's study of US popular atlases also challenged the assumption of objectivity in atlases:

this abundance of 'facts' and locations on the map and within the atlas suggest a veneer of encyclopedic objectivity, yet the volume of information should not obscure the presence of motive of rhetorical form. Though frequently idiosyncratic in their selection and presentation of information, atlases were deliberately constructed texts that contained particular kinds of maps, graphs, tables, pictures and narrative, all of which purported to explain, and contain, the world and its peoples (2001:28).

Each atlas is a visually complex constructed story built with data and maps. According to Symons, "maps are indeed a form of language and atlases are a kind of essay in communication" (1979:7). Atlases tell stories and serve specific instrumental purposes as stated by Francisco Vasquez Maure of the Instituto 
Geografico y Catastral of Madrid, who also presented a paper at the Purpose and

Use Seminar:

the purpose of a national atlas is, primarily, to provide information on the various aspects of a country's geography to those who must directly or indirectly make decisions on how to solve the problems facing that country. The public at which a national atlas is aimed, then, consists of legislators and other government officials, economists, sociologists, technicians, geographers in general, and of course the country's citizens, who will be able to play a more effective role in national processes if they understand their country well (1979:31).

National atlases were to be used for evidence based decision-making, whereas Groot, under whose authority the $5^{\text {th }}$ edition of the Atlas of Canada was created and who oversaw the transition to computerized mapping at NRCan (formerly EMR), thought that:

the function of a national atlas program is not, for example, to meet directly the needs of the public for a family atlas of Canada, but to assure ready access to an unbiased, well-balanced synthesis in map form of the geography of the country as a whole that will permit publishing houses to meet specific market demand (1979:43).

Groot introduced the idea of an atlas as a National Atlas Information

System (NAIS) where:

the outputs will provide a readily-available synopsis of spatial information at national and regional levels primarily for use in the administration and management of government. A source data index will allow rapid reference to the original data for more detailed information required in subsequent decision-making processes (Groot, 1979:45).

Groot views a national atlas as being there to support government decisionmaking; it is to serve the needs of officials and not citizens. Alternatively, Ferdinand Jan Ormeling Sr. viewed the function of an atlas as: 
a cultural ambassador. By presenting concepts about the nature of a country, its population, economy, culture and its achievements, by refining the user's perception of the national, the national atlas fosters a love of one's country and a feeling of national pride...Abroad, the national atlas shows the extent of geographical research of the country, the state of economic evolution, the level of culture and general development; it creates interest and serves to promote international understanding (Ormeling Sr., 1979:15).

Atlases, Ormeling Sr. thought, had most often followed the guidelines of the Satichtchev report too closely, which made them traditionalist and conservative in their content. Changing social times, he suggested, required less positive and more troubling aspects of a society be portrayed in maps. He believed such social aspects as criminality, homelessness, prostitution and unemployment should be mapped (Ormeling, Sr., 1979). The national atlases rarely discuss these issues, and as such, he felt that they gave "an incomplete, distorted, almost hypocritical image of present-day society...New trends in society ask for maps grouped in geographical problem categories such as environmental conditions, work and recreational aspects of the community" (Ormeling, Sr., 1979:20). William Bunge's work was considered quite radical in that he tried to inform urban planning from the perspective of children in poor neighbourhoods and used alternative indicators such as rat bites as a marker of more troubling social issues.

As will be seen later in this chapter, some maps in the $5^{\text {th }}$ edition of the atlas were not published because of their controversial nature. Issues such as climate change, public health and quality of life, begin appearing as themes in the $6^{\text {th }}$ edition, although controversial issues such as homelessness, nuclear power or industrial pollution are not discussed in that edition. With the example of 
forests, which are discussed as resources to be sustained and managed, the issues of clear cutting and protests by environmentalists remain absent from the discourse.

According to the Anglo-American Cataloguing Committee for Cartographic

Materials, librarians define atlases as:

systematically arranged collection of maps or charts intended to be shelved like a volume, either flat or vertically...Atlases share the characteristics of maps and books, having the content of maps and often the format of books. Like maps, most geographical atlases consist of graphical representations of the earth's surface; some include aerial photographs, photomaps, and remote-sensing imagery...An atlas in book form is distinguished from other books by its emphasis on maps: any textual material is secondary or complementary and serves mainly to support and explain the cartographic content. An atlas is distinguished from other collections of maps primarily by the publisher's or compiler's apparent intent that the work is to be used like a book and shelved in the form as issued (Stibbe et al., 1982:185).

Clearly the focus is on form and content which is of utmost importance to cataloguers.

In Matthew Edney's work, Cartography without Progress: Reinterpreting the Nature and Historical Development of Mapmaking, atlases are defined as:

a symbol of both its maker's professional status and the social worth of its owner (because of the greater financial capital involved in atlas production) and it is also a metaphor for the encyclopaedic sum of geographic knowledge (Edney, 2011:75).

While for Monmonier as stated in the article, Rise of the National Atlas, he defines its role as:

national atlas may be viewed as the inevitable systematic publication of institutionally collected geographic knowledge. But the national atlas also plays a second, and perhaps more important, role as a symbol of nationhood, national unity, or national pride (1994:2). 
Knowledge, pride and nationalism inspired the production of atlases between 1920-1930, and "the idea seems to have caught on worldwide among geographers and governments, and the national atlas emerged as a goal of nations seeking cartographic status among their peers" (Monmonier, 1994:8), which points to "the subtle yet real relationships of science to nationalism and culture" (Schulten, 2001:44).

Aileen Buckley (2003), cartographic specialist and atlas author, describes an atlas for what it is not: it is not a collection of datasets; it is not just a collection of maps; and it is not a gazetteer. She proceeds to define an atlas as:

a collection of carefully selected maps with a related theme (as in a road atlas) or a set of themes that relates to some selected region (as in a state or world atlas). Atlases are like other books - they tell a story. Atlases tell stories through themes that are illustrated with maps and associated graphics (such as charts, graphs and images), and the themes are sometimes explained in associated text (copy and tables)...Single maps also tell stories, but unlike an atlas, they have a limited amount of space to tell their story. Thus they are like an abstract or a short story. Atlases, on the other hand, are like a novel. They can lead you through the story from beginning to end, they can engage you and you can become familiar with the characters (e.g., themes or locations or regions), and they can have a plot (such as historical development of a region) (Buckley, 2003:149-150).

Buckley also discussed form. Paper atlases have restrictive printing and binding formats. However, as artifacts, they contain high quality graphics that readers can look at for extended periods of time. CD-ROM and DVD atlases include large amounts of information, are interactive and enable the user to navigate their content via a variety of tools, interfaces and media using such elements as animation, engaging visual displays and sound. Online atlases, on the other hand, provide similar functionality but also offer hyperlinks to content on the 
web, "thereby increasing the reader's scope of access to information" beyond the atlas (Buckley, 2003:151). Online or web atlases are also portals into large databases, as they are also often compilations of geomatics datasets that can be downloaded and re-used in other contexts. These "technological capabilities have thus transformed web atlases into services rather than products" since they provide access to data and not just their display (Buckley, 2003:151). Also, depending on how the atlas is designed and structured, the "map reader is also the map maker, and the map is generated for purposes defined by the specific needs or desires of the reader - each map (and as a result, atlas) is unique, ephemeral, and individualized" (Buckley, 2003:154). In addition, many online atlases include real and near real time data that are continuously updated via sensors. This continual refreshing of content requires that there be a good framework data and standardized systems to do so. Irrespective of form, Buckley concludes that:

atlases will continue to hold a unique position on reference shelves as authoritative sources for unified geographic information about a region or interest...A good map can convey ideas better than a bad map, and fluency in cartography will be reflected in the ease and elegance with which the geographic story is told. Atlases are still the best 'storybooks' for telling our geographic stories (2003:158).

Buckley and Denis Wood in his paper, Pleasure in the Idea/The Atlas as a Narrative Form (1987) and many others have made reference to atlases as narrations. The Atlas of Canada will be discussed in the next section. 


\subsection{The Atlas of Canada}

The Atlas of Canada is the Government of Canada's official national atlas. Six editions have been published and "each volume represents an evolution of information, format and media" (Williams, O'Brien and Kramer, 2003:8). The $1^{\text {st }}$ edition was published in 1906 and the $6^{\text {th }}$ edition was officially launched in 1999. A timeline indicating when the editions were published and the departments who were responsible for their production follows (see Figure 13). All the editions, except for the $6^{\text {th }}$ edition, were published as hard copy atlases while the 6 th was published on the Internet.

To assess the kinds of geographical imaginations that were constructed with these atlases, it is useful to understand the following: who the authors were along with their intentions; who read them; why content differed from one edition to the other; and what influenced those decisions. The record is incomplete. However, what we do know is that government is always the producer, and that Chief Geographers, Editors in Chief and departments left their marks such that no two editions are the same in terms of content and form, albeit the $1^{\text {st }}$ and $2^{\text {nd }}$ are very similar. All editions are artifacts of carefully assembled maps, texts, charts and tables representing the geographic knowledge, concerns and ideals of their time. Figure 14 is a photograph of all six editions while Table 3 provides data about form, print run and costs. Details of authors and titles were provided earlier in Table 1 on page 116. 


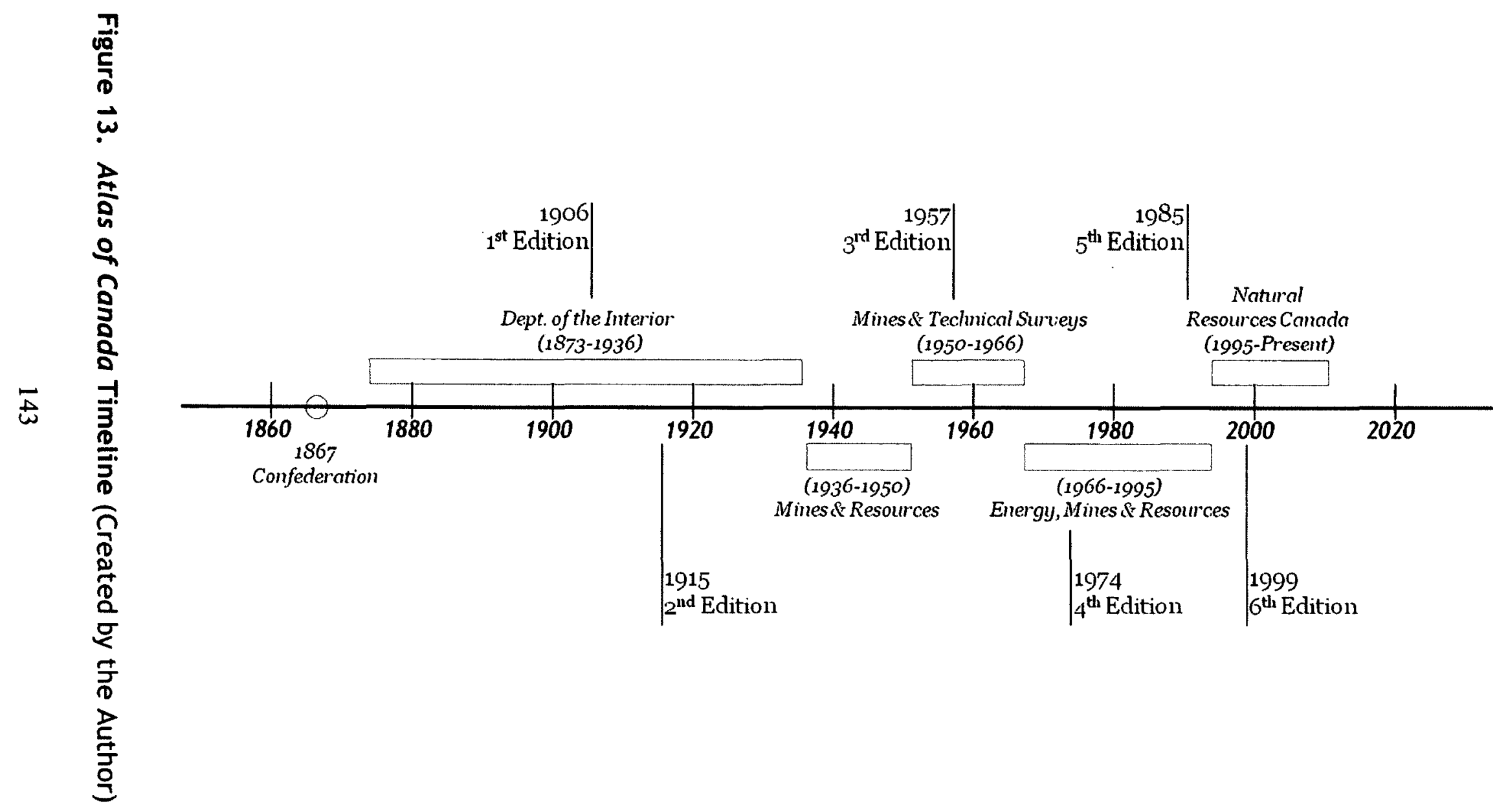




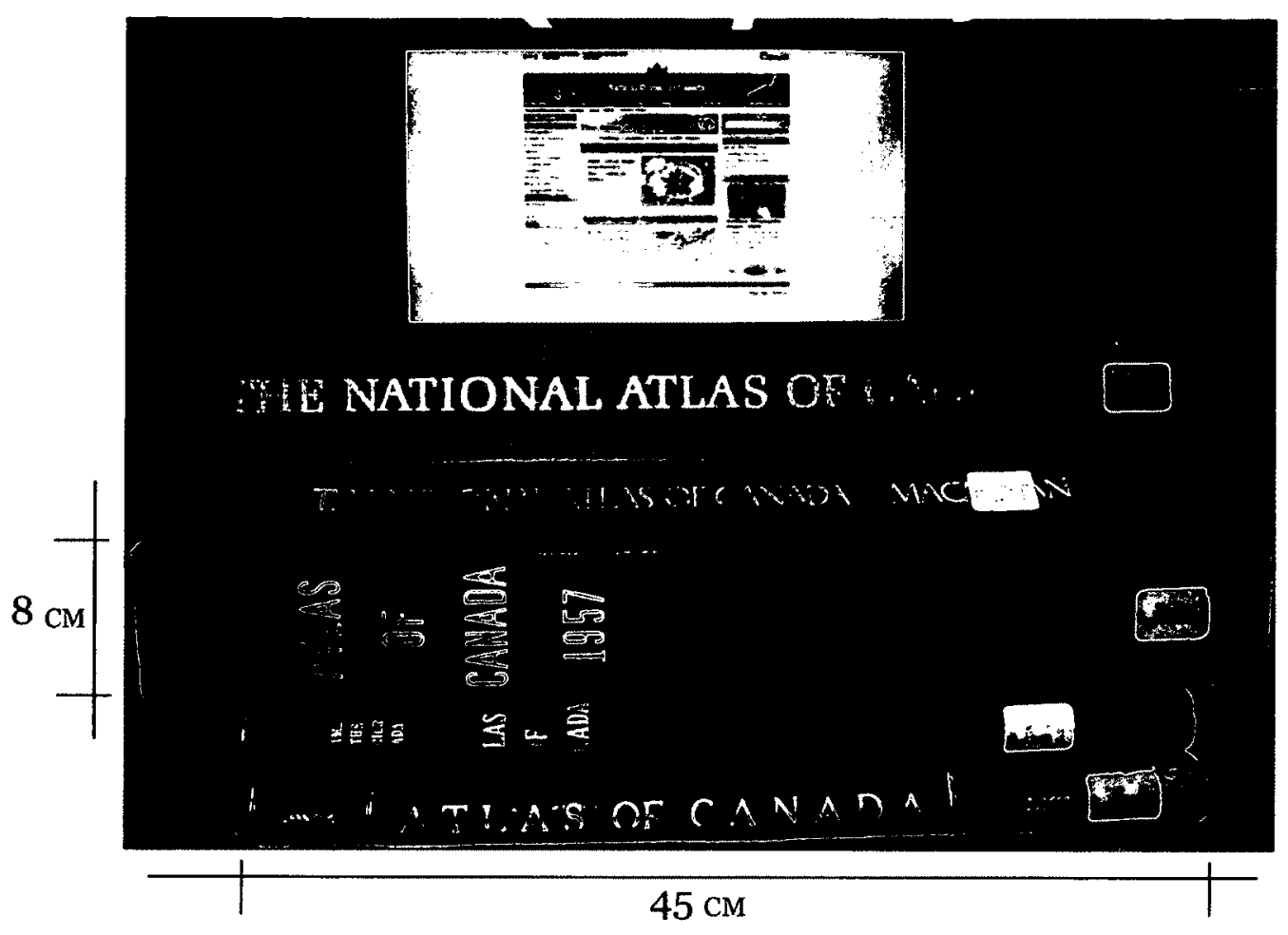

Figure 14. Photo of Atlases of Canada 
Table 3. Atlas of Canada Print, Cost, Size and Form (Compiled by the Author)

\begin{tabular}{|c|c|c|c|c|}
\hline Edition & $\begin{array}{c}\text { Number of } \\
\text { copies }\end{array}$ & Cost & Size & Form \\
\hline $\begin{array}{c}1^{\text {st }} \\
\text { Edition } \\
1906\end{array}$ & $\begin{array}{c}6000 \\
\text { Copies }^{* * *}\end{array}$ & $\begin{array}{l}\text { \$3.0o Half } \\
\text { leather } \\
\text { \$5.0o Full } \\
\text { Morocco }^{* * *}\end{array}$ & $\begin{array}{c}33.5 \mathrm{~cm} \mathrm{X} 45 \mathrm{~cm} \\
\times 3.5 \mathrm{~cm}\end{array}$ & $\begin{array}{l}\text { Hard cover bound } \\
\text { volume. Out of print } \\
\text { after } 2 \text { years }\end{array}$ \\
\hline $\begin{array}{l}2^{\text {nd }} \\
\text { Edition } \\
1915\end{array}$ & Unknown & $\begin{array}{l}\$ 3.00^{* * * * *} \\
(\$ 59.36 \\
2012)\end{array}$ & $\begin{array}{c}33.5 \mathrm{~cm} \mathrm{X} 45 \mathrm{~cm} \\
X_{3.5} \mathrm{~cm}\end{array}$ & $\begin{array}{l}\text { Hard cover bound } \\
\text { volume available and in } \\
\text { print up and until at } \\
\text { least } 1927\end{array}$ \\
\hline $\begin{array}{l}3^{\text {rd }} \\
\text { Edition } \\
1957\end{array}$ & $\begin{array}{l}7000 \text { English } \\
\text { Copies, } 5000 \\
\text { French } \\
\text { Copies, sold } \\
\text { out in } 2 \text { years* }\end{array}$ & $\begin{array}{c}\$ 25-32 \$ \\
\text { and sheets } \\
\$ 0.50^{*} \\
(\$ 206.68- \\
\$ 264.55 \\
\$ 4.13,2012)\end{array}$ & $\begin{array}{c}42 \mathrm{~cm} \mathrm{X} 53.5 \mathrm{~cm} \\
\text { X } 8 \mathrm{~cm}\end{array}$ & $\begin{array}{l}\text { Binder of loose leaf map } \\
\text { sheets with a three } \\
\text { holed punched linen } \\
\text { strips pasted into the } \\
\text { central fold. Also box } \\
\text { set and sheets. Also box } \\
\text { set and sheets* } \\
\end{array}$ \\
\hline $\begin{array}{l}4^{\text {th }} \\
\text { Revised } \\
\text { Edition } \\
1974\end{array}$ & $\begin{array}{c}12,800 \\
\text { English copies } \\
\text { and } 2,400 \\
\text { French copies } \\
\text { nearly sold out } \\
\text { by } 1983^{*}\end{array}$ & $\begin{array}{c}\$ 56 \text { retail }^{*} \\
(\$ 263.68 \\
2012)\end{array}$ & $\begin{array}{c}27.5 \mathrm{~cm} \mathrm{X} 38 \mathrm{~cm} \\
X_{3} \mathrm{~cm}\end{array}$ & $\begin{array}{l}\text { Hard cover bound } \\
\text { volume, Revised edition } \\
1974 \text {. Also sheets in } \\
\text { folio from } 1968 \text { onward, } \\
\text { a box set in } 1974^{*} \text {. }\end{array}$ \\
\hline $\begin{array}{l}5^{\text {th }} \\
\text { Edition } \\
1978- \\
1993\end{array}$ & $\begin{array}{l}1220 \text { English } \\
\text { and } 353 \\
\text { French Sets } \\
\text { sold by } 1994^{*} \text {. } \\
\text { 30 500 sheets } \\
\text { sere sold.* }\end{array}$ & $\begin{array}{c}\$ 185 \text { per } \\
\text { box set, } \\
\text { sheets } \\
9.75^{* *} \\
(\$ 291.13 \& \\
\$ 15.34,2012)\end{array}$ & $\begin{array}{c}\text { Box }-44 \mathrm{~cm} \mathrm{X} \\
48.5 \mathrm{~cm} X 7.5 \\
\mathrm{~cm} \text {. Sheets } \\
\text { between: } 92 \mathrm{~cm} \mathrm{X} \\
80 \mathrm{~cm} \text {, largest is } \\
148 \mathrm{~cm} \mathrm{X} 136.5 \\
\mathrm{~cm} .\end{array}$ & $\begin{array}{c}\text { Box of loose folded } \\
\text { maps. Colour } \\
\text { transparencies, sheets, } \\
\text { microfiche \& } \\
\text { computerized products. } \\
\text { Map packs of special } \\
\text { issues also sold.* }\end{array}$ \\
\hline $\begin{array}{l}6^{\text {th }} \\
\text { Edition } \\
\text { 1999- } \\
\text { present }\end{array}$ & $\begin{array}{l}\text { Number of } \\
\text { visits per year } \\
\text { between } \\
2000-2008- \\
46,521,741^{* * * *}\end{array}$ & $\begin{array}{l}\text { No cost to } \\
\text { the user }\end{array}$ & $\begin{array}{c}\text { Home }-21.5 \mathrm{~cm} \\
\text { X } 18 \mathrm{~cm}, \\
\text { Standard map } \\
\text { window }-12 \mathrm{~cm} \\
\text { X } 11 \mathrm{~cm}, \mathrm{M}-15 \\
\mathrm{~cm} \mathrm{X} 13 \mathrm{CM}, \mathrm{L}- \\
21 \mathrm{~cm} \mathrm{X} 19 \mathrm{~cm}, \\
\text { XL }-31.5 \mathrm{~cm} \mathrm{X} \\
36 \mathrm{~cm}\end{array}$ & $\begin{array}{l}\text { CD Rom Prototype with } \\
\text { viewing software that } \\
\text { had to be purchased, } \\
\text { Schoolnet \& Internet } \\
\text { Atlas }\end{array}$ \\
\hline
\end{tabular}

CPI Bank of Canada Inflation Calculator between 1914-2012 for 2012 Prices

* Falconer, Wonders and Taylor, 1999.

** National Atlas of Canada Products and Services Documents, 1998.

*** Department of the Interior Canada, 1909

**** Kramer, 2009.

***** Nicholson \& Sebert, 1981 


\subsubsection{The Making of the Atlas of Canada}

This section will discuss how each edition of the Atlas of Canada was produced. The information was compiled from annual reports, letters, award statements, personal communication, internal documents, papers, books and the Atlas. Hacking's framework, and his definitions of institutions, knowledge, experts, scientification, normalization and bureaucratization in particular, guided the collection and analysis of information.

The Atlas contains approximately 1,300 maps and thousands more variables making sorting a necessity. Brouillette (1945), Salichtchev $(1960,1972)$ and Chapman (1990) had their own methods to analyze atlas content, as did many others (Nicholson, 1952; Kent \& Tobias, 1990; Stephenson \& Galneder, 1969, Dean, 1970, Hocking, 1991, Hocking \& Keller, 1993). Some claimed scientific objectivity for their atlas themes while J. D. Chapman acknowledged that the realms for the $5^{\text {th }}$ edition were a subjective way to organize the world and to coordinate the work of putting together an atlas. For the purpose of this analysis, every effort was taken to not force content into the classifications of others, and instead, allowed the content of this Atlas to 'sort itself out'. The objective here is to understand the geographical imaginations constructed by the Atlas; and the groupings created here were developed to instrumentally enable comparison and facilitate analysis. 


\subsubsection{Grouping Atlas Content}

The table of contents (TOCs) for each edition of the Atlas of Canada can be located in the tables found in Appendices B to G. These tables include the author's content groupings, the title of each map sheet or page, and brief notes. Appendix $\mathrm{H}$ combines the content of all of the editions arranged by the author's groupings. Content groupings are defined in Appendix I. The development of these groupings was an iterative process, which involved the following steps:

a) Reading each edition of the Atlas starting from the $1^{\text {st }}$ to the $6^{\text {th }}$;

b) Reading the atlases together, side-by-side, atop of a map filing cabinet, and comparing content in the order that it appeared. This provided awareness of how the narratives were structured relative to each other.

c) Transcribing each edition's table of contents (TOC) and annotating maps.

d) Starting from the $1^{\text {st }}$ edition onward, subjective nominal groupings of like objects were created. No two maps are in the same group and groups are mutually exclusive.

The figure that follows (see Figure 15) provides an overview of the groupings, the content per edition, the number of pages dedicated to the grouping, and the proportion that grouping occupies are tabulated in a table (see Table 4). Figure 15 and Table 4 provide the reader with a snapshot of differences and similarities in order to see how concepts have evolved overtime; some concepts have persisted, disappeared, emerged and changed in prominence as in the proportion each edition allots to each topic. Content details will be discussed as each edition is examined. 


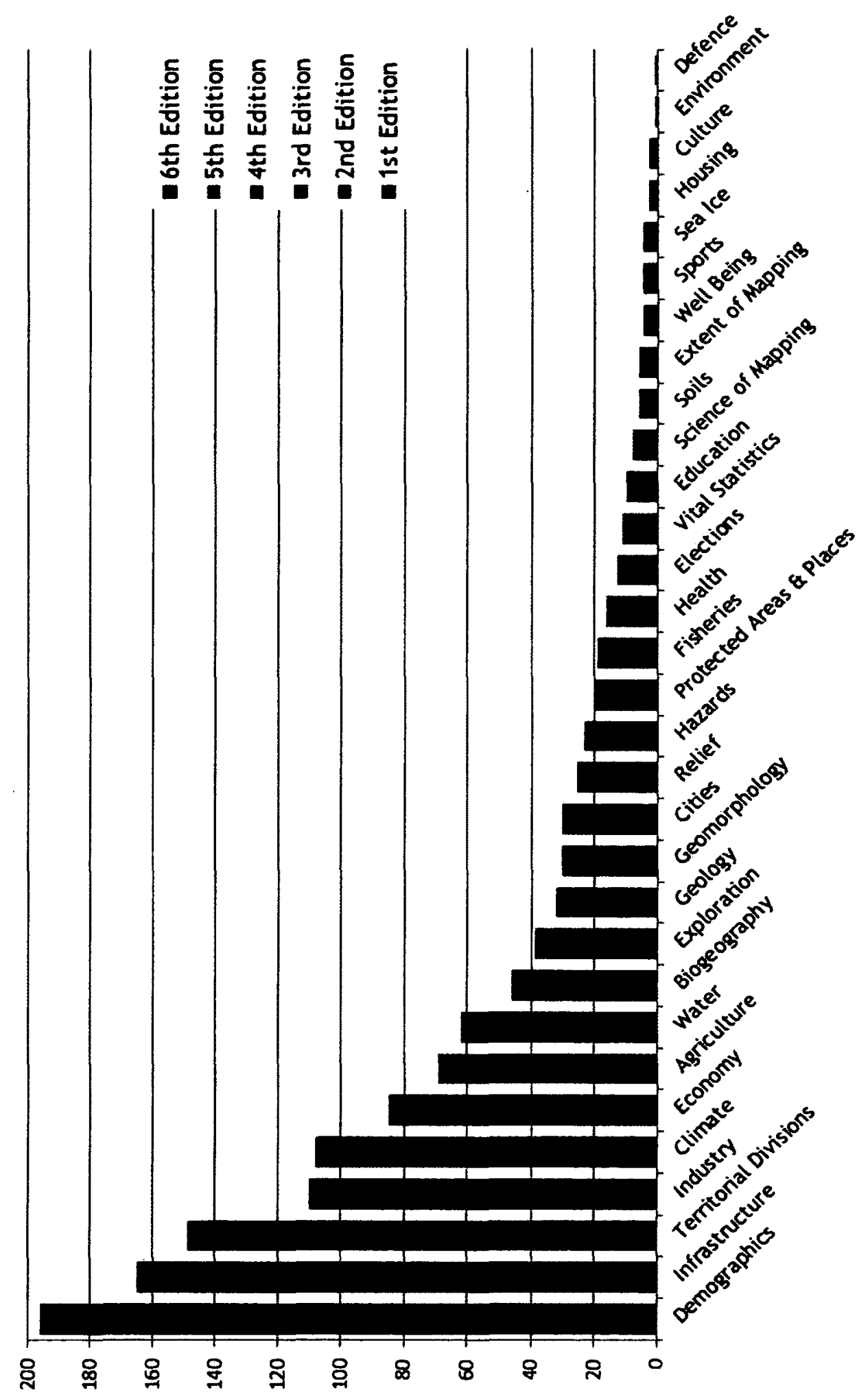

Figure 15. Atlas of Canada Content Comparison (Created by the Author) 
Table 4. Atlas of Canada Content Groupings (Compiled by the Author)

\begin{tabular}{|c|c|c|c|c|c|c|c|c|c|c|c|c|c|c|}
\hline \multirow{2}{*}{$\frac{\text { Groupings }}{\text { Demographics }}$} & \multicolumn{2}{|c|}{$1^{\text {st }}$ Edition } & \multicolumn{2}{|c|}{$2^{\text {nd }}$ Edition } & \multicolumn{2}{|c|}{$3^{\text {rd }}$ Edition } & \multicolumn{2}{|c|}{$4^{\text {th }}$ Edition } & \multicolumn{2}{|c|}{$5^{\text {th }}$ Edition } & \multicolumn{2}{|c|}{$6^{\text {th }}$ Edition } & \multicolumn{2}{|c|}{ Total \% } \\
\hline & 29 & $21.4 \%$ & 29 & $21.0 \%$ & 32 & $14.5 \%$ & 38 & $14.9 \%$ & 11 & $11.8 \%$ & 56 & $12.0 \%$ & 194 & $14.9 \%$ \\
\hline Infrastructure & 33 & $24.8 \%$ & 28 & $20.6 \%$ & 22 & $10.0 \%$ & 32 & $12.7 \%$ & 11 & $11.8 \%$ & 40 & $8.6 \%$ & 166 & $12.8 \%$ \\
\hline Territorial Divisions & 6 & $4.5 \%$ & 8 & $5.9 \%$ & 14 & $6.4 \%$ & 9 & $3.6 \%$ & 8 & $8.6 \%$ & 106 & $22.7 \%$ & 151 & $11.6 \%$ \\
\hline Industry & 5 & $3.8 \%$ & 5 & $3.7 \%$ & 26 & $11.8 \%$ & 29 & $11.5 \%$ & 10 & $10.8 \%$ & 35 & $7.5 \%$ & 110 & $8.5 \%$ \\
\hline Climate & 6 & $4.5 \%$ & 6 & $4.4 \%$ & 28 & $12.7 \%$ & 25 & $9.9 \%$ & 15 & $16.1 \%$ & 28 & $6.0 \%$ & 108 & $8.3 \%$ \\
\hline Economy & 15 & $11.3 \%$ & 15 & $11.0 \%$ & 4 & $1.8 \%$ & 27 & $10.7 \%$ & 3 & $3.2 \%$ & 20 & $4.3 \%$ & 84 & $6.5 \%$ \\
\hline Agriculture & 8 & $6.0 \%$ & 8 & $5.9 \%$ & 15 & $6.8 \%$ & 24 & $9.5 \%$ & 4 & $4.3 \%$ & 10 & $2.1 \%$ & 69 & $5.3 \%$ \\
\hline Water & 4 & $3.0 \%$ & 4 & $2.9 \%$ & 4 & $1.8 \%$ & 19 & $7.5 \%$ & 3 & $3.2 \%$ & 28 & $6.0 \%$ & 62 & $4.8 \%$ \\
\hline Biogeography & 4 & $3.0 \%$ & 4 & $2.9 \%$ & 12 & $5.5 \%$ & 3 & $1.2 \%$ & 6 & $6.5 \%$ & 16 & $3.4 \%$ & 45 & $3.5 \%$ \\
\hline Exploration & 2 & $1.5 \%$ & 2 & $1.5 \%$ & 6 & $2.7 \%$ & 8 & $3.2 \%$ & 2 & $2.2 \%$ & 19 & $4.1 \%$ & 39 & $3.0 \%$ \\
\hline Geology & 8 & $6.0 \%$ & 8 & $5.9 \%$ & 4 & $1.8 \%$ & 6 & $2.4 \%$ & 1 & $1.1 \%$ & 5 & $1.1 \%$ & 32 & $2.5 \%$ \\
\hline Geomorphology & & & & & 6 & $2.7 \%$ & 10 & $4.0 \%$ & 2 & $2.2 \%$ & 12 & $2.6 \%$ & 30 & $2.3 \%$ \\
\hline Cities & 6 & $4.5 \%$ & 12 & $8.8 \%$ & 8 & $3.6 \%$ & & & 1 & $1.1 \%$ & 2 & $0.4 \%$ & 29 & $2.2 \%$ \\
\hline Relief & 4 & $3.0 \%$ & 4 & $2.9 \%$ & 8 & $3.6 \%$ & 4 & $1.6 \%$ & 1 & $1.1 \%$ & 4 & $0.9 \%$ & 25 & $1.9 \%$ \\
\hline Hazards & & & 3 & & & & & $2 a$ & $y$ & . & 22 & $4.7 \%$ & 22 & $1.7 \%$ \\
\hline Protected Spaces & & & $\therefore$ & & 2 & $0.9 \%$ & 3 & 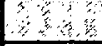 & $2:$ & 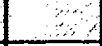 & 18 & $3.9 \%$ & 20 & $1.5 \%$ \\
\hline Fisheries & 1 & $0.8 \%$ & 1 & $0.7 \%$ & 7 & $3.2 \%$ & 8 & $3.2 \%$ & 2 & $2.2 \%$ & $x$ & 6 & 19 & $1.5 \%$ \\
\hline Health & & & 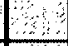 & 3 & 2 & $0.9 \%$ & $\infty$ & by & \% & 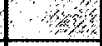 & 14 & $3.0 \%$ & 16 & $1.2 \%$ \\
\hline Elections & & & 3 & 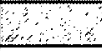 & 0 & $0.0 \%$ & 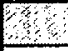 & ary & 9 & $9.7 \%$ & 4 & $0.9 \%$ & 13 & $1.0 \%$ \\
\hline Vital Sta & 2 & $1.5 \%$ & 2 & $1.5 \%$ & 2 & $0.9 \%$ & 0.5 & $0.2 \%$ & 1 & $1.1 \%$ & 4 & $0.9 \%$ & 12 & $0.9 \%$ \\
\hline Education & 1 & $0.4 \%$ & 1 & $0.4 \%$ & 2 & $0.9 \%$ & 4 & $1.6 \%$ & 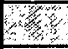 & , & 3 & $0.6 \%$ & 10 & $0.8 \%$ \\
\hline Science of Mapping & 3 & (2) & W & Whan & 8 & $3.6 \%$ & 3 & 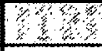 & wa & 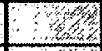 & S & Wysknghy & 8 & $0.6 \%$ \\
\hline Soils & m? & \% & 3 & Wh & 2 & $0.9 \%$ & 4 & $1.6 \%$ & W & 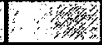 & W & 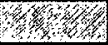 & 6 & $0.5 \%$ \\
\hline Extent of Mapping & 6 & 3 & 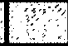 & mक & 4 & $1.8 \%$ & 2 & $0.8 \%$ & Fis & , & 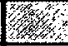 & Why & 6 & $0.5 \%$ \\
\hline Well Being & bi & 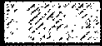 & $y$ & 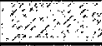 & L & $2 x$ & fres & 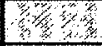 & W & 15 & 5 & $1.1 \%$ & 5 & $0.4 \%$ \\
\hline Sports & & 8, & \% & 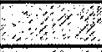 & 2,1 & , & w & SW & Wh & 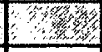 & 5 & $1.1 \%$ & 5 & $0.4 \%$ \\
\hline Sea Ice & 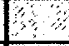 & W & 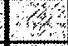 & 4 & 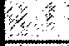 & & 2 & 28 & 1 & $1.1 \%$ & 4 & $0.9 \%$ & 5 & $0.4 \%$ \\
\hline Housing & & & 4 & & E & $\%$ & W & $3 \%$ & 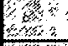 & m & 3 & $0.6 \%$ & 3 & $0.2 \%$ \\
\hline Culture & 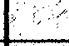 & 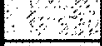 & $\therefore$ & , & 2 & $0.9 \%$ & & $x+y$ & \% & $\left(y_{0}, y_{2}\right.$ & 1 & $0.2 \%$ & 3 & $0.2 \%$ \\
\hline Environment & & & $y$ & & & & 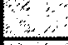 & 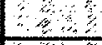 & 1 & $1.1 \%$ & 2 & $0.4 \%$ & 3 & $0.2 \%$ \\
\hline Defence & & 1 & 2 & & 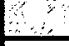 & & 2 & 3 & 1 & $1.1 \%$ & $\ldots$ & wat & 1 & $0.1 \%$ \\
\hline Total & 133 & & 136 & & 220 & & 252 & & 93 & & 466 & & 1300 & \\
\hline
\end{tabular}

Note: 1300 is a low count since some maps of the same title but different years were counted as one map for the $6^{\text {th }}$ edition, and in some cases, one map includes numerous data layers.

\subsection{3 $1^{\text {st }}$ Edition}

James White was the Chief Geographer tasked with the production of the $1^{\text {st }}$

edition of the Atlas of Canada. He was the Chief Draughtsman of the Geological

Survey (Zaslow, 1975:204) prior to becoming the Geographer of the Department

of the Interior between 1899 and 1909. The Department was founded in 1873 
and responsibility for immigration was assigned to it in 1891, "as it was felt that the work of administering the vacant lands of the country was so closely connected with their settlement that it would be in the public interest that the two duties should be entrusted to one department" (The Interior, 1905:ix). White occupied two posts simultaneously when he was both the Geographer and an Immigration Agent responsible for attracting settlers from the United States starting in 1897 (The Interior, 1910:129). White was considered to be "an enterprising topographic engineer who had risen through the ranks of the Geological Survey and the Department of the Interior, and had expanded the Office of the Geographer from just himself in 1899 to include a staff of 20 cartographers in 1909" (Monmonier, 1994:7). He was a boundaries expert and also involved with cartographic standardization as well as numerous mapping endeavours.

There are few writings about the $1^{\text {st }}$ and $2^{\text {nd }}$ editions of the Atlas of Canada and most of the following descriptions, unless otherwise stated, are derived from the Department's Annual Reports between 1899 and 1918, published in the Sessional Papers of the Dominion of Canada. The $1^{\text {st }}$ edition was originally planned as an economic atlas of Canada that was to show "in a general way the enormous, though largely undeveloped mineral, agricultural and forest resources of the country and ...the great possibilities of development" (Nicholson \& Sebert, 1981:165). 
The following earlier atlases may have influenced the $1^{\text {st }}$ edition of the Atlas of Canada: the Concise School Atlas of the Dominion of Canada and the Atlas of Western Canada, which are frequently mentioned in White's departmental reports. The Concise School Atlas of the Dominion of Canada, published by the Interior in 1900, included 15 maps and 33 pages of information about Canada's historical and physical features, including its provinces, territories and districts (Phillips, 1971:688, entry 1243). Under the direction of Sir Clifford Sifton, the Minister of the Interior at the time, the Atlas of Western Canada was issued in three editions: 1900, 1902 and 1903 (Phillips, 1971:688, entry 1244, 1245 and 1246). These two atlases were distributed to millions in Canada, the US, the United Kingdom and other diplomatic missions between 1899 and 1918 and potentially earlier. The Dominion government also produced an earlier physical atlas of Canada in 1880 that included 10 maps and 37 pages. Although the private sector also produced atlases47, White and his successor, Joseph Epiphane Chalifour, discussed none of these.

White's tenure at the Geographical Branch of the Department was during a period of active immigrant recruitment to settle the west. Immigration agents used earlier Department of the Interior atlases as a promotional tool and gave

47 Rand McNally in 1904 and 1905, a pocket Atlas and gazetteer of the Dominion in 1890 , a new standard atlas of the Dominion of Canada in 1875 that included rail, topographical, geological, postal and timber-land maps by Walker \& Milnes, an 1875 Selwyn Atlas of the Dominion that included maps of cities (Phillips, 1971:684-689). In addition a number of provincial atlases were created in the between the mid-18th and early 19th centuries (Phillips, 1971:690-692). N. L. Nicholson (1961) also makes reference to earlier atlases such as the Electoral Atlas of the Dominion of Canada printed in 1894 and earlier commercially published atlases with the first being the New Standard Atlas of the Dominion of Canada which appeared in 1875 . 
them away in the hundreds of thousands. These agents disseminated atlases, pamphlets and maps at county fairs and exhibitions, and they were marketed in newspapers, agricultural journals and at lectures.

Schools across the country were requesting copies of the Atlas of Westerm Canada and these were made readily available in order to "give the children of the Canadian schools all the advantages possible towards securing an education of their own country" (1901:163). Many of these atlases found their way into schools in the US, including US agricultural colleges, and in many other US institutions. Accordingly, White and his agents encouraged school children and teachers to write to the Department to request them and the most requested items were: the 'Canadian Atlas'; 'Western Canada'; 'Settlers' Experiences'; 'Delegates Reports'; and 'The Hard Wheat Belt' (1901:163). The Western Atlas of Canada was later translated into French, German, Scandinavian, Polish and other languages since at the time it was:

a most popular work, and demands have come for it from teachers and scholars in every state of the Union, in Great Britain and Ireland, and it has a large circulation in Canada, the scholars looking upon it as a most valuable text-book (1904:125).

White advocated for the creation of these atlases as he considered them to be:

one of the best mediums that has been placed in the hands of the agents, and it is always in great demand. Besides this the Concise School Atlas has been of considerable value and much interest, it being possible to get it circulated in several schools, and I would recommend that an additional number of these be published, those having paper covers being as satisfactory as the linen (1902). 
White and his agents also reported a growing demand for a wall map of Canada to be sent to schools and colleges, as well as for literature about Canada and its resources.

The first mentions of the Economic Atlas of Canada appear in the 1903 Interior Report with the list of content:

1. map of Canada that will show principal minerals, forests, agricultural and dairy resources;

2. geological map of Canada;

3. hypsometric maps of Canada;

4. maps showing telephone and telegraph lines and canals;

5. maps showing isotherms for each month of the year;

6. isobars for the seasons and for the year; and

7. limits of trees and shrubs.

This Atlas was to also include diagrams showing population, density of population, increase of population, percentage in various census years of urban and rural population, industries, and manufactured exports. He explained the importance of the contents of the Atlas as follows:

the value of these economic maps is obvious, but a few of the principal uses may be cited. The large economic map will indicate in a general way the enormous, though largely undeveloped mineral, agricultural and forest resources of the country and will also show the great possibilities for development. The isothermal maps indicate in a general way the limits of cultivation, for instance, the isotherm of $60^{\circ}$ for July, marks approximately the northern limits of practicable agriculture. On examining the map we find that it passes through Lake Mistassini in Quebec, north of York Factory in Ontario, through Great Slave Lake, and the southern portion of Great Bear Lake in the North-West Territories and north of Dawson in Yukon. Vegetables of all kinds and of excellent quality have been grown near Dawson in what was formerly supposed to be a country of eternal frost (1903:139-140).

Canada's successful campaign to recruit experienced US agricultural settlers (see Figure 16) was being countered by negative propaganda about Canada's climate, 
leading to using climatic maps and defining the details of just how far north one could farm. The notes about climate found in the $1^{\text {st }}$ edition of the Atlas are quite detailed. Minister Sifton equated agricultural wealth with national pride while concurrently taking a slight jab at the US by writing that "it seems remarkable that this great agricultural wealth should have remained dormant and ignored for so many years, when millions of land seekers from the old world were overcrowding themselves in the neighbouring republic to the south of us" (1904:ix). There was also a desire to prove that Canada had climatic prowess:

not only was Canada not an attractive field for settlement, but it has required the most persistent and vigorous propaganda to dispel the erroneous ideas and deep-rooted prejudices which existed, even amongst the educated and better classes, as to the climatic conditions of Canada and the possibilities of its resources (1904:ix-x).

White enlisted newspapermen to write in their dailies about Canada. He also ensured that his agents not only advertised (see Figure 16) but also travelled in the winter months of the school term to disseminate literature and maps and to hold town hall meetings (1905).

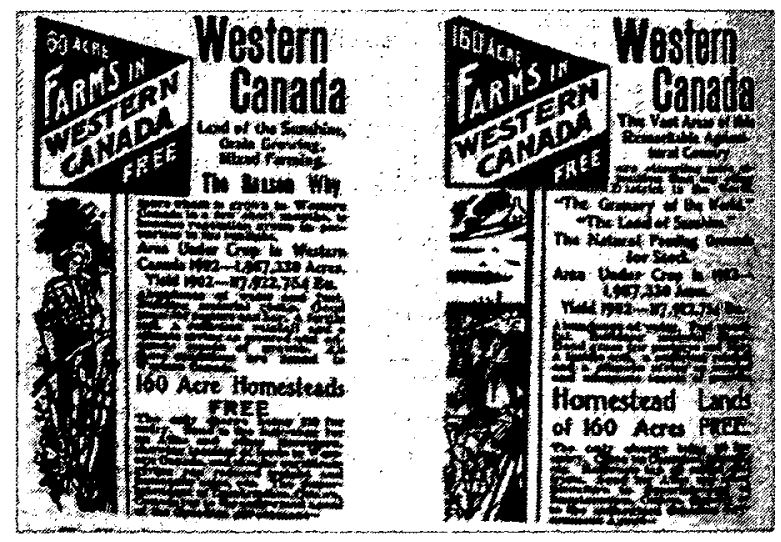

Figure 16. Department of the Interior Ads in US journals, Bulletins and Newspapers (1904:124) 
White wanted to include a hydrological map in the Atlas but data were lacking, and instead, he included in the Economic Resource Maps such water details as "the heights of many of the falls in the principal rivers, and altitudes of railway stations and higher mountain peaks" (1903:140) (see Drainage basins and Railways maps in the $1^{\text {st }}$ and $2^{\text {nd }}$ editions). He was very concerned about the lack of coal-bearing rock in Ontario and Quebec, and therefore, wanted to reinforce the importance of hydropower potential by indicating elevations and featuring Canada's large areas of water reservoirs:

whose capacity can usually be much increased, if necessary, by damming their outlets...In addition to the manufacture of wood-pulp, operation of electric railways and machinery of all kinds and production of electric light, water-power is of great value for the manufacture of calcium carbide, aluminium, \&c., for hydraulic mining, operating hoists and locomotives in mines, \&c. (1903:140).

He related such Atlas features as forests, mills and water power when he spoke of the great spruce forests north of Ontario and Quebec which could supply North American paper mills, highlighting how "this timber must be converted into pulp near the place of origin, and can only be so converted by water power" (1903:140). He later considered these data to be of such great importance for the Dominion that he dedicated much effort over many years to the collection of altitude data, which were consolidated into the Dictionary of Altitudes of the Dominion of Canada (1916).

In 1904, the Economic Atlas of Canada's became the Atlas of Canada (McKay, 1986:58) although there is no record explaining this change, it is, however, speculated that White may have been influenced by a presentation made at the 
$19048^{\text {th }}$ International Geographical Congress where the Atlas of Finland was introduced (Nicholson \& Sebert, 1981:165).

The $1^{\text {st }}$ edition was bound in 1906 , with a print run of 6000 of which 2000 were released as a preliminary edition. The Atlas was out of print by the end of 1906 (1910:129). White considered his atlas to be:

[a] unique publication as regards Canada, and no other country, except Finland, has issued a similar work, though the Census Atlas of the United States gives similar - though more detailed - graphic representations of the information obtained by the Census Bureau (1907).

The timing of publication was also fortuitous as Alberta and Saskatchewan had just joined Confederation in 1905 . The release of the Atlas was accompanied by:

an extensive distribution made to the higher educational institutions, public libraries, banks, newspaper \&c., in Canada. In Great Britain, 760 copies have been sent to the most important public libraries, clubs, newspapers, government offices, scientific societies, \&c. The distribution in Great Britain was made under the instructions of His Excellency Earl Grey who, in the circular letter of notification sent with each atlas, stated that he did 'not know of any work of equal merit published in any other country'. I need not say His Excellency's kindly interest in, and appreciatory remarks on my work are highly appreciated by me (1909:100).

White was a highly respected and dedicated public servant and, along with his many accomplishments, he was an advocate for the creation of the Office of the Geographer as he wanted to centralize the map making activities of the Dominion to avoid the duplication of effort in the creation of maps and to ensure that there be a repository of reports and surveys upon which new maps could be made. The Geological Survey, a much older institution of survey engineers, adamantly resisted White's proposition as it wanted to maintain the control it had over the surveying domain (Zaslow, 1975:210). 
White, by virtue of being Geographer and Immigration Agent, understood the importance of mapping for economic, exploration, resource extraction and manufacturing reasons. He was also well aware of the marketing and educational power of maps and used them in the promotion of the Dominion as a place to settle, build and invest. As discussed, he instrumentally used the School and Western Atlases for immigration and marketing purposes.

White's $1^{\text {st }}$ edition of the Atlas of Canada influenced decisions, consolidated existing geographic knowledge, and provided schools and other academic institutions with an excellent educational resource. Considered a prestigious artifact, the Atlas was distributed to decision-makers and scientists in the halls of power and academia in the UK and internationally. His Atlas, however, was not as widely distributed to the general public as the more popular Concise School Atlas of the Dominion of Canada and the Atlas of Western Canada. The $1^{\text {st }}$ edition was created for an elite class of readers and users while the School and Western Atlases were the atlases for the people. Further, the popular atlases were free while the $1^{\text {st }}$ edition cost $\$ 3$ or $\$ 5$, which would have been a little more than 2 to $31 / 2$ day's pay respectively for a production worker or a little more than 1 to $11 / 2$ day's pay for a supervisor and office employee in $1905^{48}$. The Atlas of Canada would have been a very large expenditure for either of these people.

$4^{48} \mathrm{~A}$ production worker in 1905 earned on average $\$ 375$ per year, his daily pay would have been approximately $\$ 1.44$. A supervisor or office worker's average annual earnings were $\$ 846$ with an estimated daily pay of $\$ 3.25$, data from Statistics Canada, 1983, Historical Statistics of Canada, data Series E41-48. Annual earnings in manufacturing industries, production and other workers, by sex, Canada, 1905, 1910 and 1917 to 1975. 
Readers were probably the decision-makers of their day, and settlers had their own free popular atlases. The School Atlases were very influential at recruiting and educating settlers and it is difficult to assess the influence of the $1^{\text {st }}$ edition. However, the data they generated were most likely used by immigration agents in their presentations abroad and the maps would have been used to demonstrate Canada's infrastructure and potential for manufacturing and resource extraction in Europe, the US and particularly in London. The maps were also most likely repurposed in reports such as the Canada Year Book. It was also an English only atlas, excluding francophone readers, if the price issue had not already made the atlas inaccessible. The free popular atlases, on the other hand, were published in many languages. The $1^{\text {st }}$ edition reflected the class and the colonial affiliations of those who created it. Atlas content also reflected the economic preoccupations of the Dominion. During that period, building the nation's infrastructure to ship goods, transport people from coast to coast by rail, and develop a modernized communication system, was considered paramount to ensure continental and transcontinental linkages (see table 5 below).

Table 5. Value of Export of most important national products (1913), (Adams, 1915:10)

\begin{tabular}{|c|c|c|}
\hline $\begin{array}{c}\text { National Product } \\
\mathbf{1 9 1 3}\end{array}$ & $\begin{array}{c}\text { Output in } \\
\text { Dollars }\end{array}$ & Export in Dollars \\
\hline Agriculture & 673771500 & 194930254 \\
\hline Forests & 182300 000 & 43255060 \\
\hline Mines & 144031047 & 57442546 \\
\hline Fisheries & 33389461 & 16336721 \\
\hline Furs & & 5415118 \\
\hline
\end{tabular}


Agriculture, industry and manufacturing related to natural resources were also critically important to the economy (see Appendix B and $\mathrm{H}$ and Table 5 above). White explicitly mentioned energy and forests, as well as agriculture, and factored climate as an important consideration. The $1^{\text {st }}$ edition does not include maps of agriculture but eight pages of statistical data in graph form in the Diagrams Section and there are 3 full sheets of climate maps demonstrating growing seasons. The $1^{\text {st }}$ edition is also an atlas of the Department of the Interior, which had the responsibility to settle the country, attract investors and determine the best places for them settle and set up operations. The Department was also responsible for mines, timber, ordinance, lands, school lands, land surveying, parks, forestry, hydrography and power, which are reflected in the Atlas.

The $1^{\text {st }}$ edition of the Atlas of Canada was also many years in the making. At minimum 5 years and potentially longer was devoted and production would have enlisted expertise from the Interior and other departments and branches such as Agriculture, Industry and Trade, Statistics, and Fisheries to name a few. It represented in maps, charts, tables and some text, the geographic knowledge of Canada at the turn of the $20^{\text {th }}$ century and economics was the organizing framework for its content.

\subsection{4 $2^{\text {nd }}$ Edition}

Very little is known about Joseph Epiphane Chalifour, the Chief Geographer of the $2^{\text {nd }}$ edition, except that he was Chief Draftsman of the Dominion under James White (1905-06, 1907, 1908, and 1909 reports), was Assistant Chief Geographer in 1910, Chief Draftsman under Chief Geographer R. E. Young (1911, 1912 
Reports) and later became White's successor as Chief Geographer in 1911 (1913). Chalifour was White's right hand man, covering for him while he travelled and responsible for drafting numerous maps (1904:139). One of his famous publications was the 8 sheet map of Canada for which 5000 copies of the $1^{\text {st }}$ edition and 2000 of the $2^{\text {nd }}$ were published and released in 1903,1905 and 1908 (McKay, 1986). He collaborated with White on the release of the 'revised and enlarged edition' of the Atlas, but in reality, it was barely enlarged although data were updated. No information was found about the production of the $2^{\text {nd }}$ edition. The Chief Geographer reports begin to disappear after White, and the few that do appear are very small indeed. There are none by Chalifour and the $2^{\text {nd }}$ edition of the Atlas is not mentioned in any of the Department of the Interior's Annual Reports. There are also no references in the annual reports published by the Department of Public Printing and Stationary for that period.

Chalifour and White did however share the French Roquette Gold Medal of the Société de Géographie de France for their work on the $1^{\text {st }}$ and $2^{\text {nd }}$ editions, awarded on April $20^{\text {th }}, 1917$. The award recognized Chalifour's French provenance and the nature of their work:

En récompensant une œuvre signée, à tour de rôle, par un descendant des deux nations qui ont fait du Canada, dans l'histoire, ce qu'il est aujourd'hui, la Société de Géographie est heureuse d'envoyer son salut cordial à ce noble pays, plus que jamais cher à tous les Français...

La deuxième édition, œuvre de M. J. E. Chalifour, et où les statistiques ont été rajeunies d'après le recensement de 1911, ne renferme pas moins de 124 planches : relief du sol, géologie, gîtes minéraux, forêts, cours d'eau, températures, pluies, - tous les facteurs, en un mot, qui contribuent à donner au vaste domaine de la «Puissance » sa physionomie propre, $y$ font l'objet d'autant les cartes, d'une exécution très soignée. La géographie humaine est également représentées, dans la collection, par plusieurs séries de cartes, figurant la densité et l'origine des habitants, le tracé des lignes 
télégraphiques et des chemins de fer, les canaux et l'emplacement des phares, l'extension des races indigènes, les variations des frontières nationales ou provinciales, etc. Cet ensemble fait le plus grand honneur à ceux qui en ont rassemblé les éléments (de Margerie, 1918).

Although the Department may not have recorded his contributions, White acknowledged Chalifour during his tenure, making regular references to him in his reports. Chalifour was recognized outside the Department and he received accolades from a most prestigious academic institution. The $2^{\text {nd }}$ edition is nearly identical to the first, but there are some small changes.

The $2^{\text {nd }}$ edition, like the first (see Appendix C) begins with tables of population statistics, including a table of the population of Cities, Towns and Villages and the area of land and water by electoral district (1911), and statistics about population and material industries $1868-1911$. The content of the $2^{\text {nd }}$ edition is nearly identical to the first, but with updated statistical data; there is one new map, The World (See Figure 11 on page 108), and the maps of cities have been updated with Edmonton, Regina and Victoria added as they grew in population and prominence. The notes that were part of at the $1^{\text {st }}$ edition are not included in the $2^{\text {nd }}$ edition, nor are the telephone maps.

The order of the maps also changes in the $2^{\text {nd }}$ edition where geology is followed by biogeography and water, which makes more relational sense as drainage, relief, geology and vegetation are related. This is followed by demographics and infrastructure, which is also a logical relationship between physical geography, people and the human built world. Maps about Aboriginal people, kept distinct from demographics, follow after a long series of infrastructure maps but precede 
exploration and boundary agreements. Explorers were primarily responsible for gathering First Nations linguistic data while mapping territories that once belonged to First Nations, yet oddly enough, the First Nations map appears before border agreements and the latter make no reference to First Nations, nor do any of the exploration maps. No explanation as to why the order changed is provided. After territorial divisions comes climate and then cities. Another logical place for climate could have been with physical geography. The map sections for both editions end with cities.

The Diagram Section for both editions is the same although data are updated for the $2^{\text {nd }}$ edition. These included Economy such as trade and commerce, Industry such as manufacturers, Demographics, Agriculture such as crops, farm and productive land, followed by Vital Statistics, Economy such as finance and banking, Fisheries, Infrastructure, Education and Immigration. The Diagrams Section resembles the content of an accountant's ledger and was probably compiled from taxation receipts, the census and public works. The editions that followed were not as detailed about expenditures on infrastructure and farming as these two editions were.

The first two editions have the least number of maps and are the least diverse in terms of content relative to the other atlases. The $1^{\text {st }}$ edition, in particular, did not include a world map, although hints of international connections are apparent in the border agreement and infrastructure maps, especially the telegraph (see Figure 17) and transportation maps. 


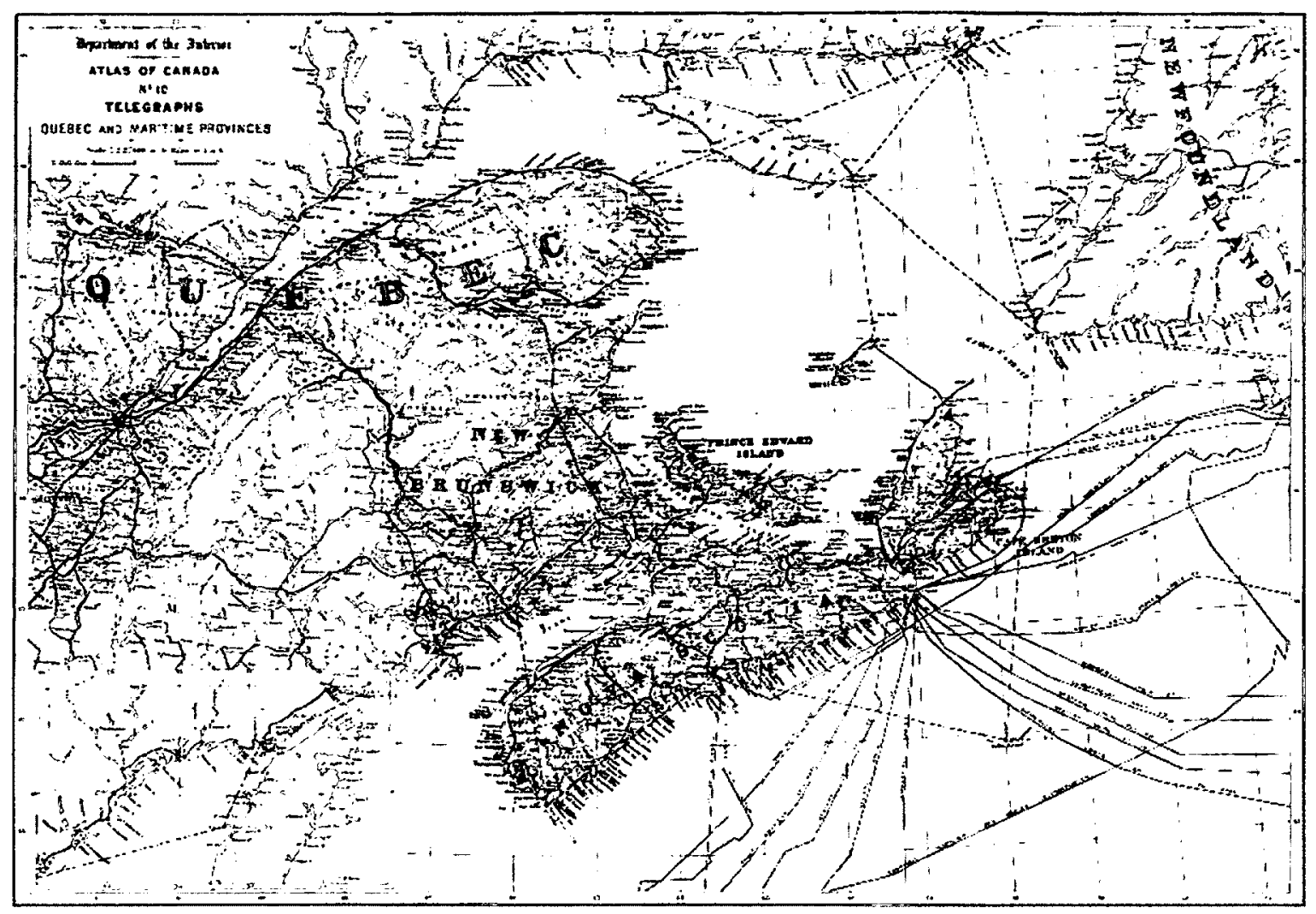

Figure 17. Telegraphs - Quebec and Maritime Provinces, $1^{\text {st }}$ Edition Atlas of Canada

The content of the $1^{\text {st }}$ and $2^{\text {nd }}$ editions reflected the priorities of the Department of the Interior and the overarching theme of economic development, with colonialism and nation building as their underlying theme. As seen in the TOCs of the $1^{\text {st }}$ and $2^{\text {nd }}$ editions (see Appendices B and C), related things are generally found together, although there are some outliers such as the Aborigines maps. Other maps could have been placed differently, for instance, cities could have logically been grouped with territorial divisions, as could have boundaries. Also, climate could have been closer to physical geography and Limits of the Forests maps, which is related to temperature, precipitation and sunshine. The Drainage Basins map seems to have found its logical place in the $2^{\text {nd }}$ edition, although its 
placement with Explorers in the $1^{\text {st }}$ edition demonstrated the relationship between Canadian mapping, trade and exploration which was conducted along coast lines and the river system before the infrastructure was built. Drainage Basins could also have been grouped with infrastructure since rivers are an energy source, and as discussed, White had the known heights of rivers placed on railway maps, in the $2^{\text {nd }}$ edition. It is difficult to assess if the placement of things had a particular meaning for the authors, and what instigated the changing of the order between editions. Perhaps it was the result of changing priorities, debates between data providers or comments from readers. The record is silent on these points.

The $2^{\text {nd }}$ edition, like the $1^{\text {st }}$, would have been considered as formal text that belonged in the homes of learned men, embassies, government offices and scientific associations. The books have official coloured seals on their title pages and include transmission pages to demonstrate that an officer of the state officially handed over the completed volume to the highest ranked public official of the Department. This formal transmission practice has since disappeared.

There were no data available on print runs for the $2^{\text {nd }}$ edition, however, the cost would have probably made it inaccessible to most of the population, as was the case with the $1^{\text {st }}$, and the popular atlases were still widely disseminated at the time, making them more desirable and accessible to most people (see list of other atlases published in Appendix $J$ ). As with the $1^{\text {st }}$, the $2^{\text {nd }}$ edition was also an English only Atlas. 


\subsection{5 $3^{\text {rd }}$ Edition}

The Depression, followed by the focus on WWII, delayed the production of a follow up atlas between 1914 and 1957. Discussions about a 3rd edition began in the mid-1930s by G.L.P. Grant-Suttie, who was chair of the National Committee for Geography of the IGU. It was proposed at a 1936 IGU meeting that countries produce national atlases (Nicholson, 1959) and as discussed, in 1943 the Canadian Social Science and Research Council appointed Benoît Brouillette to study the possibility of creating a new scientific atlas. Based on the findings in his report, published in 1945, the Geographical Branch was added to the Department of Mines and Technical Surveys (MTS) and one of its key responsibilities being to produce a new atlas (Nicholson \& Sebert, 1981:166).

In Grant-Suttie's 1947 address to the Toronto Commercial Intelligence Committee of the Canadian Manufacturers Association entitled, New Atlas of Canada, he spoke of the importance of Geography and its contribution to the war effort, and highlighted the fact that cartographic knowledge was greatly advanced by both wars. In addition, he discussed the role of the IGU National Committee members which share scientific knowledge gathered abroad to Canadians, their institutions and government. He lamented the lowly status of Canada in the geographical scientific community where geographers "have generally been humiliated by the deficiencies of Canadian achievements. In fact Canada has often been held up to the scientific world as one of the least progressive countries in the particular science of Geography" (Grant-Suttie, 1947). This was because Canada lacked an updated atlas of the country that could be "judged by modern 
standards and fit to take its place with the works of nations with which Canada usually thinks of aligning itself, such as the United Kingdom, France and the United States" (Grant-Suttie, 1947:94-95). Brouillette was also a member of the IGU National Committee for Geography and large sections of his 1945 Preliminary Survey are found in Grant-Suttie's article complete with his proposed table of contents. Grant-Suttie also expressed the difficulty of mapping in a country with divisions of power and a lack of a central mapping authority, and envied the excellent central authority of the Dominion Bureau of Statistics (DBS).

Grant-Suttie boasted that many of the key officers involved with mapping Canada were part of his National Committee for Geography, and in his capacity as Chair, he had created a sub-committee "charged with matters of the new Atlas" (GrantSuttie, 1947:97). The sub-committee was comprised of the Surveyor General, Dominion Statistician, Chief Topographical Engineer and an officer of the Bureau of Engineers of National Defence Headquarters as "these gentlemen combine within their offices the chief technical workers in the special field of the production of an Atlas" (1947:97). The proposed atlas publication, he reminded the Canadian Manufacturers Association (CMA), would be an asset not only among the institutions and people of Canada but also among industrial and commercial corporations in Canada and abroad. He told the members of the CMA Strategic Intelligence Committee that his Atlas Committee was willing to move ahead and carry out the work but still required the permission to do so from their respective Ministers. His presentation may have been to solicit input 
and support from CMA members, not only to sell the atlas to a captive audience but to encourage lobbying efforts as these men would have had close ties to Ministers.

Grant-Suttie was either naive or was being strategic to pragmatic businessmen when he stated that producing an atlas was not a matter of money, as "the amount is quite small. Largely it can be done as part of the normal functions of the various departments and branches without any additional expense until it comes to actual printing" and suggested that sales could actually generate a profit (1947:97). Norman Nicholson, who would follow Grant-Suttie as Chair of the Atlas Committee, later commented upon looking back on the work to produce the $3^{\text {rd }}$ edition that it appeared:

that those responsible for allocating the work to the Branch had no idea of all that was involved. There never seemed to be quite enough staff, or the Branch did not have the staff with the right skills or the staff at the right time, or else the staff required was not available (this was particularly true of draughtsmen) (Nicholson, 1957:64).

Cabinet approved the production of the $3^{\text {rd }}$ edition of the Atlas of Canada in 1948 (Falconer, Wonders \& Taylor, 1999). In 1949, Norman L. Nicholson chaired the Atlas Committee after Grant-Suttie's untimely death; he was also the Editor in Chief and the Assistant Director of the Geographical Branch, MTS. By 1961, he was a Senior Geography Professor at the University of Western Ontario, one of the key founders of the Canadian Geographer and a staunch supporter of the Royal Canadian Geographical Society, and like his predecessor White, a recognized boundaries expert (Pleva, 1985). The Department's Geographical Branch conducted the research, design and compilation of the Atlas while 
another departmental branch, the Surveys and Mapping Branch, drew base maps and other drafting and map production work. According to George Falconer et. al (1999), 150 geographers from the federal government, universities and other sectors were involved as well as 25 cartographers and drafting staff.

Nicholson was also the Secretary of the Atlas Committee. Five meetings were held and they conducted a comparative analytical study of single country atlases, which "informed the size of the maps to be included in the Atlas, and their scales and projections" (MTS, 1951a:107). The comparative study of 21 single country atlases developed the following definition of what the 'national' atlas could be:

a collection of maps to depict the physical properties of the land and water areas occupied and administered by the people of the country concerned, together with the adaptation and utilization of those physical resources through human occupancy. It is essentially concerned with the distribution of these items and with their relationship to each other; hence, it is essentially a geographical survey, and is perhaps the best means of portraying the geography of a country...It presents the country's land, peoples, and activities in a form that makes it possible to compare the distributional patterns of various factors and thus to see how human occupancy is related to the land. Such an atlas clarifies the scientific study of the influence of the physical environment on man and man's adjustment to his environment (Nicholson, 1952:34).

Nicholson's Atlas Committee definition went beyond Salichtchev's and Brouillette's by including ideas about human interaction with the environment. An atlas is a scientific study that depicts that interaction and an atlas can, in turn, influence human behaviour, a statement in keeping with Hacking's looping effect. Nicholson's Atlas Committee included civil servants from Agriculture, Northern Affairs and National Resources, Fisheries, Transport, Mines and Technical Surveys, Dominion Bureau of Statistics (DBS), Canadian Meteorological Service 
and the Public Archives (Nicholson, 1961:46). Nicholson's committee members were more thematically based while Grant-Suttie's members had reflected his focus on defence and engineering. The first issue the committee addressed was to decide on the purpose of the atlas, and they agreed that it:

should show the nature, extent and use of physical resources of Canada, and their effect on the economy and society of the country. At the same time, it was recognized that such an atlas would also be a historical record of the stage of development reached by Canada by 1951. Furthermore, if the Atlas of Canada was to be a national atlas in the best sense of the term, it was considered that it should present to the Canadian people and the world at large, a selection of authoritative maps of high accuracy and reliability, as well as high cartographic quality and artistry, which, when viewed in sequence should characterize and give meaning to the internal development of Canada and, to some extent, her international relations (emphasis added, Nicholson, 1961:46).

The thematic integrity of the atlas was ensured by the Atlas Committee's composition as it brought together "cartographic experience, the wealth of information available in the federal departments concerned essentially with physical geography, and the data stored in the departments concerned with statistical, economic and social affairs" (Nicholson \& Sebert, 1981:166). The scientific approach was defined as "a complex, comprehensive reference atlas presented in accordance with up-to-date geographical principles and based on adequate research" (Nicholson \& Sebert, 1981:166). Overall, the objective was an atlas that would be technically and scientifically well rendered and that would record the progress and physical resources of the country in keeping with the mandate of the Department.

The atlas was to have a topical national scale geographic approach, with some regional maps, as it was assumed that provinces would create their own atlases. 
A decision was also made to publish an English and a French version, as a bilingual version was considered unfeasible; previous editions had been published exclusively in English. The $3^{\text {rd }}$ edition was broadening its scope to become a resource for Canada's two 'colonial' linguistic groups, a scientific reference tool, and a nation-building instrument. Sub-committees reflecting the interests of inter-departmental committee members were created to direct and produce their respective sections. An editorial subcommittee was also created and by October of 1954, committee work was completed. The Atlas Committee adopted the Lambert Conformal Conic Projection with two standard parallels 49 and 77 degrees north for the whole of Canada to keep distortion of area and shape to a minimum; this became a convention for subsequent editions. Scales in multiples of 1: 1000 ooo were selected to facilitate comparisons. Base maps of the country were to be at a scale of $1: 10000$ ooo for full page maps, 1:20 000 ooo where there are four maps to a page and 1:50 000 o0o for a block of 20 maps and 1:5 000 ooo to cover Canada in three parts: Eastern, Western and Northern. Scale also determined sheet size, in this case to include Elsmere Island on a sheet 18.5 inches in height and a 1: 12 o0o ooo was required.

According to the Department of Mines and Technical Survey's (MTS) Annual Reports (between 1951-57): research was conducted to compare national atlases in 1951; proposals for the general format of the national atlas were created; data from provincial and federal departments were received; mock sheets showing in outline the regions and sections of Canada that could be used to include a study of new methods of presenting such data in atlas form were drawn; and 30 
draught sheets for depicting information on transportation, fisheries, and certain aspects of industrial geography were created (94-95). By 1952, details of the basic layout for 109 plates were determined, including 435 maps, and investigations were made as to the "methods of mapping demographic, economic and social statistics" (1952:102). In 1953, the Geographical Branch considered the new Atlas of Canada to be the most important ongoing project, with "each department contributing its share of the basic data, which [were] then prepared for representation in the Atlas" (1953:92). It was expected that all data would reach the Geographical Branch from the other departments by 1955 and that the Atlas would be published in 1956-1957.

The Geographical Branch's responsibility was primarily production, which included data acquisition either from existing sources or fieldwork. Various departments provided data differently; some provided raw data while others provided maps nearly ready for printing. Producing the French version was problematic, as naming conventions in French Canada had to be determined. Not all place names could be directly translated into French as many places use common English names and each of these had to be confirmed. Also, French expressions were an issue, as French Canadian scientific expressions were not necessarily the same as in France. The production of the bilingual $3^{\text {rd }}$ edition influenced the formation of French Canadian geographic knowledge by giving it a French geographical vocabulary. 
The ordering of the Atlas's content was also decided by committee, as seen in the lengthy quote from Nicholson's Geographical Bulletin paper, Some Elements in the Development of the National Atlas of Canada (1961). The quote from the Geographical Bulletin is included here at length since it is one of the few examples where it is explicitly stated, by the author of an atlas, that an atlas is a narrative and that it is intentionally structured to tell a particular kind of story. It also best summarizes the content of the Atlas (Appendix D):

The sheets of both the English and French editions of the atlas were arranged in such a way that, if they are read from beginning to end, as with a text book, they give a coherent story in maps of Canada's geography in all its aspects - historical, physical, human, economic, social and political. The first three sheets deal with the origins of the country; one shows the routes taken by principal explorers, and the other two show portions of the original maps that resulted from exploration (51)...From the old maps, the atlas proceeds to modern mapping with examples of present-day topographical sheets and aeronautical and hydrographic charts. This leads to maps of the physical aspects of Canada's Geography - relief, geology, magnetism, tides and an extensive section of fourteen sheets on various aspects of climate. This is followed by maps of drainage basins, profiles of major rivers, soil and forestry maps and an interesting set of six sheets, each of which contains a number of small maps showing the ranges of representative insects, plants, trees, mammals, birds and inland fish...The next section of the atlas is concerned with human resources and shows such things as distribution of population, origins of the people, principal religions, and birth, marriage and death rates. The third part of the atlas shows some of the ways in which the people have used the physical resources - what is generally referred to as economic geography. There are maps of fisheries, sawmills, pulp and paper mills, various aspects of agriculture, such as the distribution of farm animals and crops, mining, hydro- and thermoelectric power and manufacturing. This section ends with maps of transportation and communication which have developed as a result of resource use. They deal with canals, railways, airlines, shipping and radio and television networks...The last twenty maps in the atlas are concerned with the way in which institutions and towns, cities and rural municipalities have become distributed as a result of these activities. There are maps of hospitals, universities, libraries, art galleries and museums; all populated places, including large scale maps of eight larger cities, showing their growth and present land used; and maps of census divisions, and electoral districts. The last two sheets show the way in which Canada evolved politically from a series of colonies to a three-ocean state, and its overseas partners in the Commonwealth, the United Nations Organization, the Colombo Plan and the North Atlantic Treaty Organization (51-52). 
When viewed in sequence, the maps in the atlas were to characterize and give meaning to the internal development of Canada and, to some extent, the country's international relations, and to show Canada's historical, physical, human, economic, social and political geography in sequence (Nicholson \& Sebert, 1981:167). It was possible to show more statistical information in maps in the $3^{\text {rd }}$ edition as compared to the $1^{\text {st }}$ and $2^{\text {nd }}$ and that was attributed to the fact that there was more knowledge about the precise location of features. Additionally, surveyors, physical geographers, air photo interpreters and economic geographers had access to better tools, were able to fly and take air photos, and were more knowledgeable and capable to do fieldwork. These technical experts were also very well-funded to undertake their work. Those who did this mapping work were no longer voyageurs, explorers and colonizers; they were scientists and engineers recording development and progress. They were also actors engaged in socially shaping that progress with their new knowledge, processes and technologies.

The format of the $3^{\text {rd }}$ edition was a large binder with removable sheets. It was intentionally designed as a living document where revised sheets could replace out of date maps and new maps could be added (Nicholson, 1961). This was the best the non-Internet era could offer and it demonstrated the desire for timely information. It also underscored that the Atlas was conceived as an ongoing national information project and not a one off publication. Elsewhere, Nicholson discussed some of the unintended consequences of producing a national atlas: 
knowing that a national atlas was being produced encouraged many of the provinces to produce atlases. The best example of this is British Columbia although Ontario has also published one, and Quebec and Manitoba are preparing atlases. Some of the geographers now engaged on the production of provincial atlases had periods of seasonal employment with the Branch and cut their teeth on the Atlas of Canada (Nicholson, 1957:65).

Producing an atlas mobilizes and develops a certain kind of expertise that can be put to work in other areas and the task of producing an atlas is also related to the spread of geographic and cartographic knowledge. The Atlas of Canada was published by MTS in December of 1958, and in 1959 for the French version, and it was the main accomplishment of the Geographical Branch with the French $3^{\text {rd }}$ edition featured with a large photograph on the covers of 81 Government of Canada Annual Reports (MTS, 1958, 1959). It was a proud achievement indeed.

Each Atlas edition is unique, and the $3^{\text {rd }}$ edition, for example, includes a series of flora and fauna range maps. Wild animals and plants in other editions, if featured, are represented as commercial potential (e.g., furs, forestry), otherwise only domesticated animals and agricultural and forest vegetation are included. These range sheets include 20 maps that feature one or many species, like the Mammals map below. Range maps are also representations of habitats, a relatively new concept at the time, and judging by their location in the order of things in the atlas 49 , there is an allusion to ecosystems, which as will be seen in Section.4.2 Forest, ecological approaches to land management were emerging as a science and a practice at this time.

49 Located after climate, water and soils and before Parks and Faunal Reserves and population. 
These maps were compiled from a number of different departments: the National Museum of Canada, renowned for its biodiversity research; the Department of Northern Affairs and National Resources for the Forests; Parks and Faunal Reserves; the Canadian Wildlife Service; and the Department of Fisheries. A tremendous amount of inter-departmental cooperation and coordination took place to create the $3^{\text {rd }}$ edition Atlas. The $3^{\text {rd }}$ edition is also unique because it includes maps that explicitly depict map- making capabilities. These maps and tables showcase what government can create to conduct its business, for example, the Comparison of Scales, Aeronautical Charts, Hydrographic Charts, Soil Survey Maps, and the 40 Forest Inventory Maps (see Figure 18). These maps not only educate readers about the science of mapping, but they also market and showcase government knowledge. 

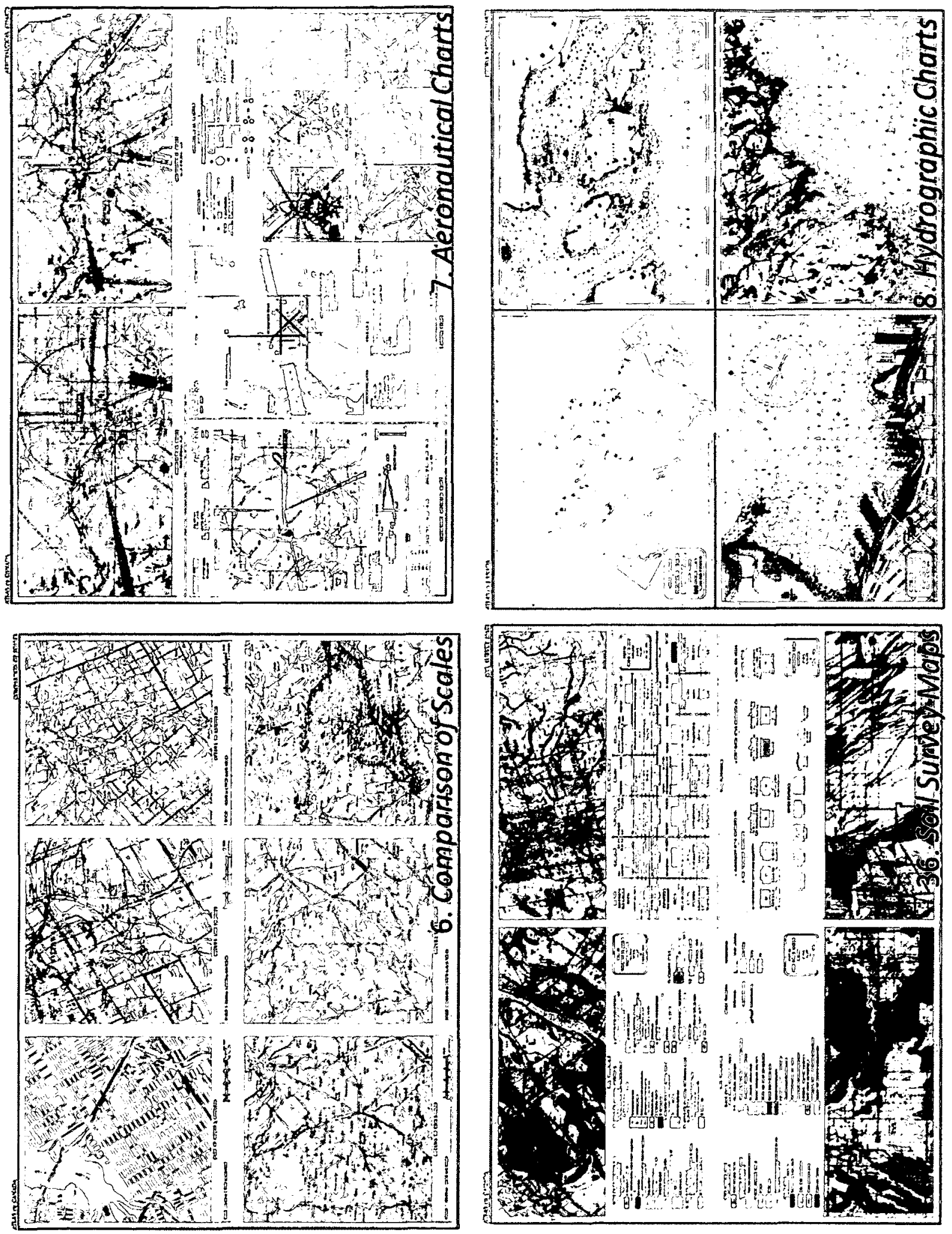

Figure 18. Maps about Mapping, $3^{\text {rd }}$ Edition, Atlas of Canada 
Map sheet No. 4, The Extent of Mapping Surveys - 1955 (see Figure 19), includes four maps showing extent of mapping by type of mapping such as: Legal Surveys; Air Photographic Surveys; Geodetic Surveys Triangulation; Geodetic Surveys Precise Astronomical Fixation; and Exploratory Fixation. This map sheet includes notes that define how this type of mapping is done, the kind of instrumentation used and the kind of precision possible. This sheet is followed by sheet No. 5, Extent of Topographical Mapping - 1955, that addresses progress to date and hints about the need for ongoing funds to keep up the good work. These maps are about showcasing capabilities, technologies, specialized knowledge and progress. These maps appear at the very beginning of the $3^{\text {rd }}$ edition, right after sheets No. 1: Routes of Explorers, No. 2: Mapping the Coast 1492-1874, and No. 3: Mapping The Interior - 1630-1870. According to this $3^{\text {rd }}$ edition, Canada's history begins with surveying and mapping, and the logical arrangement these of maps in the Atlas is a testament to that scientific and engineering legacy. 


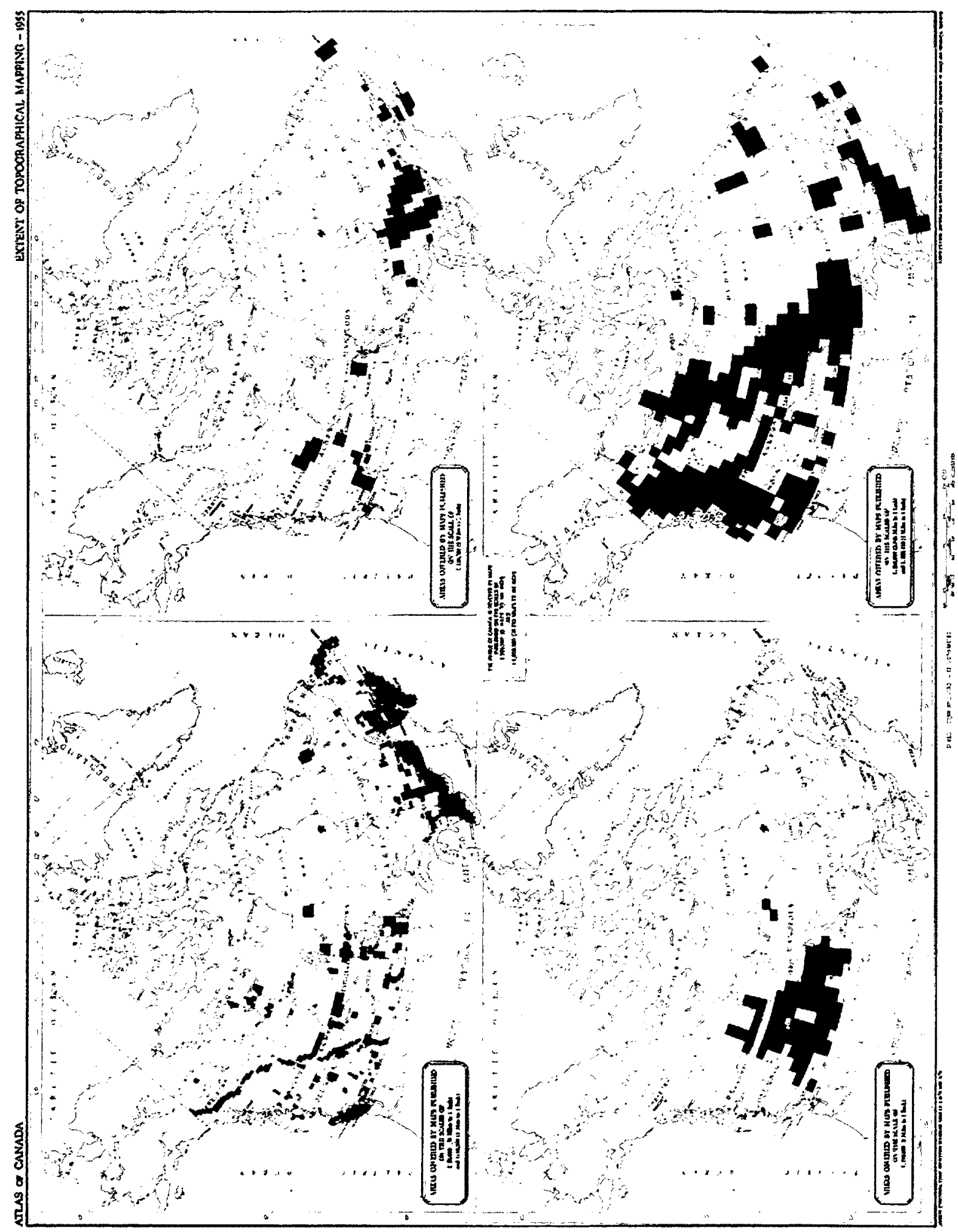

Figure 19. Extent of Topographical Mapping, $3^{\text {rd }}$ Edition, Atlas of Canada 
Some $3^{\text {rd }}$ edition maps not only depict the geographical feature being mapped but also the technological infrastructure related to the creation of that map. For example, sheet No.32, Weather Stations and Forecast Regions, includes the locations of public weather offices, synoptic weather reporting stations, climatological stations, as well as the jurisdictions public weather forecast equipment covers. The data on these maps provide a scientific indicator of measuring points from which weather data are extrapolated; they also serve as a data reliability indicator since the density of measuring stations determines the precision of weather predictions. In addition, the scarcity of weather stations in the north is an indicator of population density and transportation networks and priorities, as most of the weather stations are on coastlines. Weather stations also appear on the climate maps of the $4^{\text {th }}, 5^{\text {th }}$ but not the $6^{\text {th }}$ editions, and when they do appear, they are part of the feature being mapped and are not maps on their own. Sheet No. 33, Drainage Basin and River Flow, also includes the infrastructure of gauging stations.

In 1959, a promotional film was produced in both English and in French about the Atlas of Canada by the National Film Board (NFB) of Canada entitled, Portrait of Canada. The film is composed of many stereotypical images of the 1950 with 'voice of god' documentary style narration. It depicts men as scientists in various scenarios: measuring instruments in their field kakis; taking air photos from planes and helicopters in their flight gear; smoking while receiving the atlas in their business suits; carrying briefcases; driving to the department; analyzing data; and waiting anxiously at the printing press. Women, 
on the other hand, are shown dipping air photos into solution, typing in data, and passing drafts to cartographers. The film opens with explorers in canoes and a brief narrative of the history of Canada's mapping forefathers. MTS is introduced as images of the Chateau Laurier flash in the background, followed by a scene with a dark suited official holding the Atlas of Canada, which he carries over to a long wooden table in a wood paneled office where three men dressed in business suits await and then begin flipping through the Atlas.

The following is an extract of the film's script that illustrates the mechanics of putting together an atlas, using mapmaking as a metaphor. The narration reflects the grandness of the undertaking and underscores the underlying message of the government doing great and important scientific work:

(images - woman soaking air photos in developer's fluid and many air photos are laid beside each other)

Many miles and many pictures later Canada's portrait has now taken shape. The physical map is nearly complete but for the geographers this is still only the beginning, the blank outlines into which many details need to be filled to make the Atlas.

(image - men looking at a map, dark car driving north on Booth toward the Department)

Their first job was to collect information from business offices and scientific institutions and governments across Canada.

(image - man walking into the Department's entrance briefcase in hand)

What types of rock in the mountains? What region has most sun most snow? Where are the forests, farms, factories? The answers are all there, if you know where and how to look?

(image - woman typing information onto punch cards, punch cards lined up in the sorter, sheets of paper with numbers passing through a printer, woman digging through files and woman handing over sheets to men in suits standing in front of a display "Canada's Central Counting House")

But before the facts and figures can be entered in the Atlas they must be sifted and sorted, calculated and classified, and finally translated into the special symbol language of the map maker ready to be written on the blank page. 
(image - man smoking and typing in data and drawing at a map drawing table)

(image - The outline of the map brightens and a hand drawn image fades and a white image of a coastline appears)

Within each of the 500 maps the story of Canada unfolds across 3000 miles of geography from sea to sea. The habitat of wildlife, the structure of rock and soil regions, the results of years of scientific study in the field and in the laboratory are recorded in the Atlas reflecting the labours of naturalist, prospector, and soil scientist.

(image - mountains, habitat, soil regions, men taking agricultural samples, men looking at samples in a lab)

(image - printing press, men in suits smoking and watching)

Canada's latest portrait is the sum of knowledge that is accumulated since the first explorer; presented in a new way. Some of the men who were in at the inception are waiting like anxious parents for the birth of their book (image - man lighting another smoke with the end of the previous one and pulling out a map)

The last page rolls off completing ten years of intensive work, the geographers have written the story of their country in maps and captured between covers a new portrait of Canada.

(image - Flipping through the atlas ending at the cover)

The $3^{\text {rd }}$ edition was 21 years in the making; it took 10 years to discuss, lobby, conduct research and get Cabinet approval, followed by 11 or more years for Nicholson to produce it. This was the culmination of the work of the IGU, GrantSuttie, Brouillette, and Salichtchev to some extent, and traces of Brouillette's 1945 table of contents are seen in the published $3^{\text {rd }}$ edition of the Atlas of Canada. The Atlas was created by committee and was produced through a collaborative multi-department and multi-sectoral effort that was well researched, academically informed and well crafted. It was also informed and inspired by the IGU, an international organization whose distinguished membership would have contributed to the prestige of the project. Membership in the IGU required attendance at international events, where men of science met and made influential decisions. The travel required to attend was relatively rare 
and expensive in the 305,40 and 50 s. All the main players in the creation of the $3^{\text {rd }}$ edition wanted an authoritative, accurate, reliable and scientific atlas to showcase Canada to itself, to the international geographic scientific community, and to its allies throughout the world. It was to demonstrate proudly Canada's advanced geographical scientific knowledge and to be a prestigious national survey of the country - a record of progress and development.

It was highly praised by the Government of Canada, which commissioned the NFB to make the documentary about its production. It was also a post-WWII product where the business of data gathering, surveying and mapping, as featured in the film, reflected the prosperity of the time. "[T]he Surveys and Mapping Building, opened at 615 Booth Street, Ottawa, in 1960 to house this activity, and was at the time the largest single government building in the country. It was the centre of the largest single integrated mapping program in the hemisphere" (Taylor, 1994:10).

The purpose of the Atlas had evolved from recruiting settlers, encouraging immigration and promoting investment, to showcasing the advanced state of the Canadian economy; it achieved this by focusing on resources, infrastructure and agriculture, and how people use those assets and interact with the land. It was also about praising the government's mapping endeavours, its forward thinking and its success (i.e. the extent the country had been mapped). It was also a nation building exercise, where the nation was showcased in both English and French. Publishing a bilingual edition was instrumental to producing French Canadian geographic knowledge. 
The form is quite large ( $42 \mathrm{~cm} \mathrm{X} 53.5 \mathrm{~cm} \mathrm{X} 8 \mathrm{~cm})$ and difficult to handle, and it is also very heavy, weighing around $9 \mathrm{~kg}$. The Atlas does not fit on any typical household bookshelf and requires a kitchen table to open and read, and is wholly unsuitable for armchair reading. As discussed, the size of the Atlas was based on the desire to render all of Canada at 1:10 000 ooo scale when applying the Lambert Conformal Conic Projection (Preface, $3^{\text {rd }}$, edition). The colours used are not contrasting and are in the pastel ranges, with crisp black lines to differentiate features and light grey for most contours (Fremlin, 1963). There are brief explanatory notes on the verso of most of the maps in this edition but these did aid with map interpretation.

The Atlas contains 113 loose-leaf map sheets (226 pages) with a three hole punched linen strip pasted into the central fold of each map sheet. It is specifically designed for the "removal of individual sheets for special study and to allow for the replacement or addition of the 110 sheets it contains" (Preface, $3^{\text {rd }}$ edition). However, new sheets were never added to the Atlas. Missing maps is one of the disadvantages of using removable sheets, as was the case with the Carleton University Map Library's copy of the Atlas. Missing pages can be attributed to collectors and sellers cutting them out of atlases in order to sell individual sheets (Schulten, 2001) and in other cases maps were stolen, as I discovered when reading a $4^{\text {th }}$ edition copy of the Atlas borrowed from the Ottawa Public Library. 
The Atlas cost $\$ 32$ at the time of publication, which was $2 \frac{1 / 2}{2}$ days' pay for a production worker and about 2 days' pay for his or her boss, or \$265 in 2012 dollars, making it hardly accessible. In total, 12,000 copies were published, 7,000 English copies in 1958 and 5,000 French copies in 1959, and by 1962, all of the English copies were sold out. The Atlas was out of print by 1964 .

It is uncertain where the atlases were disseminated and it is presumed they were sent to universities, other government departments, potentially some high schools with well-equipped libraries, public libraries, and members of the public. It is expected that some of the officials who worked on it may have also brought a copy home. It is, however, hard to imagine the average person bringing this behemoth of a volume home, let alone being able to afford a copy.

\subsection{6 $4^{\text {th }}$ Edition}

Gerald Fremlin became the Editor in Chief of the $4^{\text {th }}$ edition of the Atlas of Canada, after Nicholson left for his post at the University of Western Ontario in 1961. He is a geographer, cartographer and an author. His writing focuses on how maps mediate worldviews (i.e. 'seeing'), with specific attention to the elements of cartographic communication that reveal meaning and enhance comprehension. The two works that best exemplify his approach are his Cartographica Monograghs, which was later published in a book entitled Maps as Mediated Seeing (1999 and 2005), and his short conference paper, entitled Colour and Design in the British Columbia and Manitoba Atlases and the Atlas of Canada (1963), which is associated with the comparative analysis of provincial atlases done with Nicholson in 1963 for presentation at the IGU. 
Prior to embarking on the recorded facts of the production of the $4^{\text {th }}$ edition, this section will begin with what Fremlin had to say about the Atlas he edited5o. Unlike the $3^{\text {rd }}$ edition, a committee did not create the $4^{\text {th }}$ edition, and instead, it was conceptualized and directed by Fremlin and co-produced with geographers, a cartographic designer, a layout planner, compilers, draftsmen and a secretary, with his direct oversight. Fremlin credited his team on the Acknowledgements page of the $4^{\text {th }}$ edition.

US geographer, Richard Hartshorne, known for his influential work, The Nature of Geography: A Critical Survey of Current Thought in the Light of the Past (1939), guided Fremlin's approach. In particular, the methodology of geography and the idea that landscape should analytically determine content were key. Fremlin eloquently explains his geographical imagination as follows:

the elementary experience of reality is landscape, the real world is this perceptual world, the experience of what you construe as reality, there is another reality, one analyzed into geology and history, the one that impinges on you from earliest times, is landscape, surface, it is this impression of being on a big object upon which other objects are scattered, when science is added, then it is analyzed into the way it is, and understanding why that is so (Fremlin, 2011).

When asked why the Atlas began first with land, and not the people who inhabit the land, he stated that:

the basics of landscape are that it is the hard ground surface of the earth, shape, not variation, it just shows shape, it gives you the picture of it, and then we build onto that... landscape determines who we are (Fremlin, 2011).

$5^{\circ}$ Gerald Fremlin kindly discussed his ideas and thinking about the $4^{\text {th }}$ edition with the author over the telephone in 2011. 
For Fremlin, landscape is the platform which determines action: the possibility to farm; the ability to travel coast to coast or cross mountain ranges; and the opportunity to access water for power. Each action, in turn, can determine other actions such as access to hydropower permitting wood milling. Like his predecessor White, he recognized the importance of relief but he viewed it from a different perspective. In response to my question about what inspired him to create the Atlas, Mr. Fremlin said:

The purpose is to explain the perceived landscape, these themes will cumulatively explain the landscape, one that is dynamically changing, enabling new realizations, the atlas should be progressive with ideas and new data, crucial to this is the topographic presentation of the country, the idea of showing the landscape and topography, map design does not express the topography very well, topographic maps are cartographic stereotypes - they evolved for practical purposes, they were the results of engineering and military, no one can ever tell you the subject of a topographic map, drainage is blue as a stereotype, it does not work well, it is a crucial thing to show the relief, if you can see it, you can understand the landscape, topography is an idea. We do not have a good picture of the landscape, not as good as it could be, the method of geography in my interpretation, is to present the landscape and then analyse, the profiles show a picture of what is not apparent (Fremlin, 2011).

This way of thinking is infused in the $4^{\text {th }}$ edition of the Atlas of Canada.

Fremlin's early analytical work on using colour and design to communicate cartographically also influenced this edition. The first map featured in the $4^{\text {th }}$ edition is a brightly coloured relief map (see Relief map, pages 1-2, $4^{\text {th }}$ edition). The second map is even more striking and unique (see Figure 20). This map of Relief Profiles has parallels transect the country east to west over land and water with topography drawn directly on those transects. It is a clever way to characterize the land and convey 'topography as an idea' in the absence of a three dimensional image. The $3^{\text {rd }}$ edition attempts this in a graph (see Figure 21) but it 
does not quite communicate the ideas of the shape of the land like the map in the $4^{\text {th }}$ edition. The $1^{\text {st }}$ edition opens with a political map of Canada, the $2^{\text {nd }}$ edition with a world map (see Figure 11 page 108), showing Canada's place in the world, and the $3^{\text {rd }}$ edition with explorers, mapping, the extent of mapping and types of maps in keeping with the development and scientific intent of its makers. In further contrast, the $4^{\text {th }}$ edition opens with Relief. The first three maps of the $4^{\text {th }}$ edition, Relief, Relief Profiles and Lakes, Rivers and Glaciers, are designed in such a way that landscape speaks for itself while in the $3^{\text {rd }}$ edition, the model is scientific (see Figure 21). Both are models, but how relief was imagined led to different representations. 


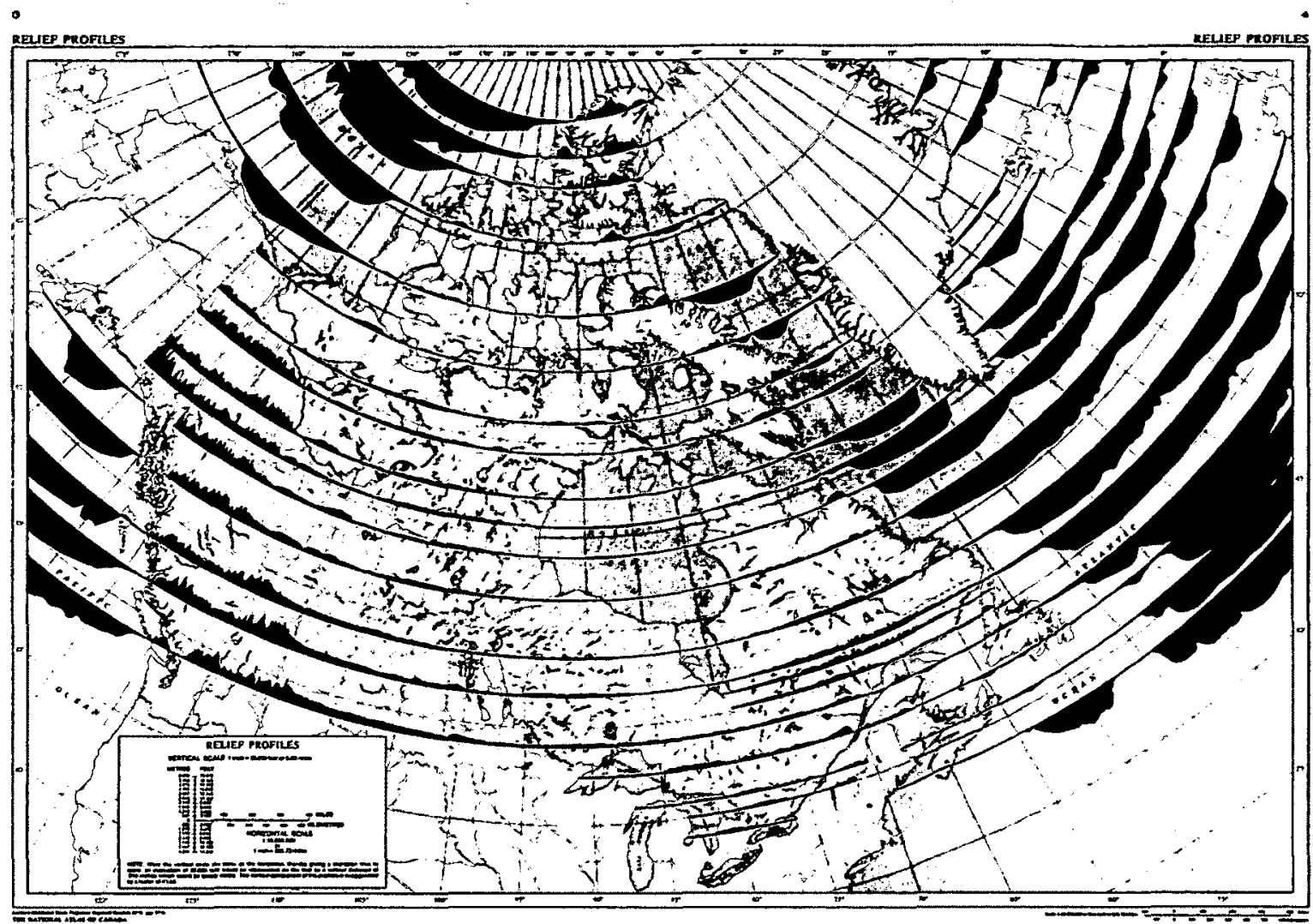

Figure 20. Relief Profile $4^{\text {th }}$ Edition, Atlas of Canada

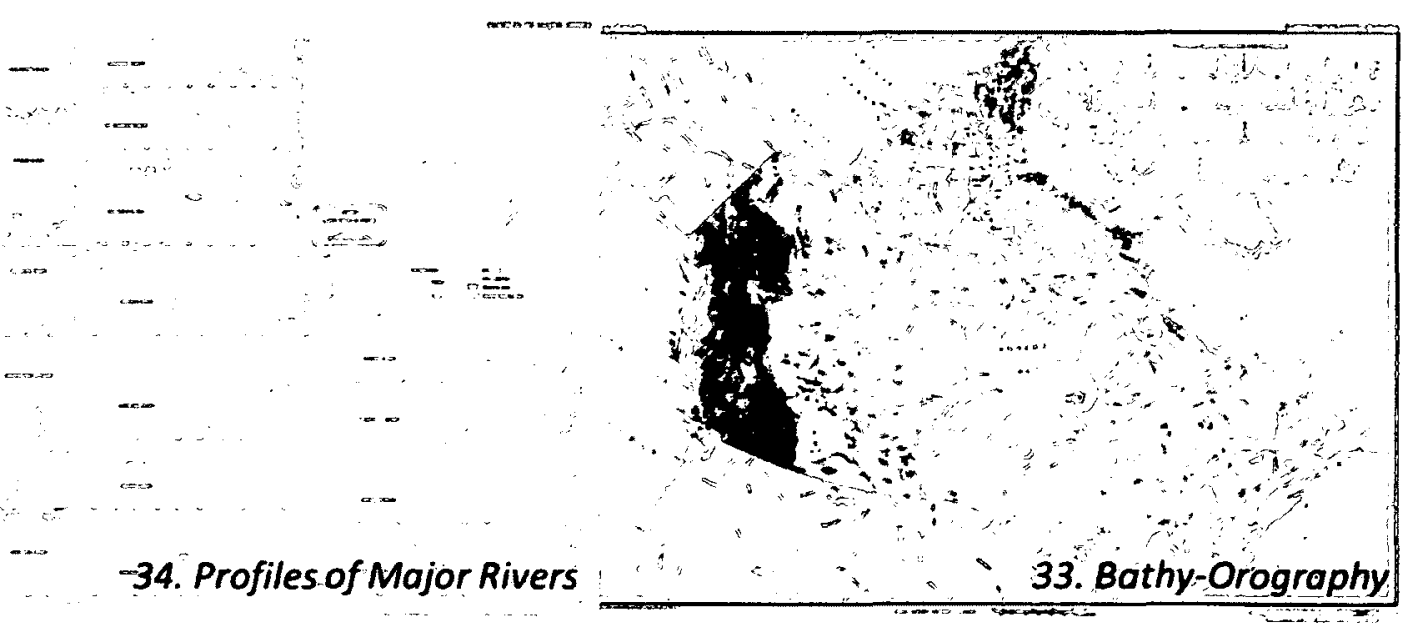

Figure 21. Relief Profiles, 3rd Edition Atlas of Canada 
Fremlin veered away from envisioning the concept of nation metaphorically and viewed the Atlas as a descriptive exercise. As Mr. Fremlin explained:

data describes nation, how I cook the data will create a picture. To objectively use the data and merely provide a lot of information upon which one can base the idea, few are doing that, some find geology more important and so on, there is no propaganda idea of nation, it is about description.

The thinking of the nation is disappearing, as consultants predominate the public service. This started in the 7os. There was more an economic incentive to the production of work.

The $4^{\text {th }}$ edition is very much in keeping with Hartshorne's ideas of a geography that chronicles what is there; it does not theorize but finds the best way to express what is observed. Hartshorne's influence can be seen in the unique way data are densely and carefully rendered in the Atlas. Finally, when I asked Mr. Fremlin how he went about planning the atlas, he explained that:

you decide what you want to do, then you develop a table of contents, base your ideas on previous atlases, what to show, I was more guided by the methodology of geography, the idea of the landscape analytically and that determined the content, you need a fair bit of information, what is available, how to use the statistics, the primary thing is to have a fair bit of education.

Fremlin clearly spent much time reflecting, directing and researching, and he must have encouraged his production staff to think geographically rather than just cartographically about the maps they were making and integrating into the Atlas. The resulting maps are quite unique, and show inventive ways to render a large amount of information on small sheets, relative to the other editions. Fremlin also brought with him a tremendous amount of experience as a cartographer and a researcher. 
Planning for the $4^{\text {th }}$ edition started shortly after the publication of the $3^{\text {rd }}$, and initially it was to be in four folios, in a specially designed titled box. In 1961, the Geographical Branch proposed that the $4^{\text {th }}$ edition be a desk atlas for students in high school as the primary target market and it was set to be released for Canada's Centennial in 1967 (Falconer, Wonders \& Taylor, 1999). In 1962, discussions on how to revise the Atlas of Canada were well underway and according to the 1964 MTS Annual Report, the planning of a smaller atlas was completed and "its production was formally adopted by the federal government as a departmental centennial project. Detailed planning and the accumulation of data were completed for many of the individual plates" (MTS, 1964) and base maps were under construction while topical maps were in the early stages of production. By 1965 , base maps were prepared and about $1 / 3$ of the atlas maps were compiled (MTS, 1965).

The $4^{\text {th }}$ edition was created during a time of cost cutting. The Geographical Branch was dissolved in 1966 and the work completed to date was transferred to the new Surveys and Mapping Branch (SMB) of the new Department of Energy, Mines and Resources (EMR) (Falconer, Wonders and Taylor, 1999). Gone were the post-WWII boom days of 1950's mapping. Work was salvaged and adapted to a defacto desk atlas format. In 1967, the production of the Atlas occupied the Division of Regional Geography; it was to be and more portable (EMR, 1967). Pages were to be 14.5 inches by 20 inches to accommodate the 1: 15000 ooo scale for a 2 page spread and 1: 75000 ooo for a three page spread. The projection of the maps followed the conventions set by the $3^{\text {rd }}$ edition. 
The centennial deadline was missed. By 1968 , many sheets had been produced but the first folio was not issued until 1970 and the second in 1972. Also, in 1972, a Cabinet committee agreed that the Atlas Programme should be continued for each census year and that the Treasury Board should establish adequate funding to permit a viable $5^{\text {th }}$ edition while ensuring the completion of the current edition. On May 11, 1972, cabinet confirmed the committee's recommendations ( $O$ 'Brien, 2006). The Department underwent further changes in priorities and this is reflected in its the annual report of 1970-71 as it was no longer structured according to Branch Reports which had been convention, but according to issues such as Resource Inventory and Potential, Economic and Social Aspects and Technology and Environmental Concerns including regulation, statutory responsibilities, research agreements and administration. The Atlas is not mentioned again until 1973.

The $4^{\text {th }}$ edition was finally published in 1974 in a loose-leaf format consisting of 266 pages, in both English and French, and with 334 multi-coloured maps and 400 graphs with text. Fremlin resigned from the Department shortly after.

A contract was also signed in 1974 with a private publisher to produce the bound edition in the fall of 1974 (EMR, 1974:19). This government and private sector release set a publishing precedent. A total of 16,000 copies were printed, 13,000 English and 3,000 French. Information Canada purchased 5,000 while EMR retained 1,000 copies. The rest of the copies were retained by the Macmillan Company and sold at $\$ 56$ each, the equivalent of $\$ 263.68$ per copy in 2012 (Nicholson \& Sebert, 1981:169 and EMR, 1975:17), which is still a little more than 
$11 / 2$ day's pay for a production worker and a little bit more than a day's pay for a supervisor or office employee. It was sold out by 1983. In 1976, the Gold Medal of the Royal Canadian Geographical Society was awarded to the Atlas of Canada for its outstanding contribution to geography. That same year, work began on the $5^{\text {th }}$ edition (EMR, 1976:19).

This $4^{\text {th }}$ edition, like its predecessors, was created with a particular view of geography, in this case with a landscape, relief and a chorological Hartshornian theory guiding its development. This edition also included data sources, explanations about the scientific models that were cartographically rendered, and references to the key publications that informed each map. I asked Mr. Fremlin about this since it was such a striking difference from the previous editions and his quick response was:

just because it's good scholarship, the earlier atlases say here is the data and they are thrown at you, anonymity in the civil service, I insisted on putting the names because there were people who did good work, they dropped that practice in the gazetteer, that was internal politics, no credit on topographic maps or aeronautical maps either.

I received excellent cooperation, I wrote letters asking for data and only one person did not cooperate and that was national parks, he would not give the parks data as he did not want to share the data. Even the private sector shared data, there were good relations with private sector, railways airlines traffic, private companies supplying data as requested.

It is uncertain if the private sector would be as accommodating today with information and data now that it is a commodity. Fremlin's citation practice was used in the $5^{\text {th }}$ edition and it is referenced in the Guideline for Authors National Atlas of Canada, $5^{\text {th }}$ Edition (Chapman, 1990). The $1^{\text {st }}, 2^{\text {nd }}$ and $3^{\text {rd }}$ editions are silent about the production team, although the $3^{\text {rd }}$ edition did acknowledge 
departments as compilers or as information contributors on all maps, either in the notes on the verso of the sheet or on the map. Unlike the $4^{\text {th }}$ edition, no individuals are mentioned unless they are the author of a paper that is referenced.

The $4^{\text {th }}$ edition also breaks ranks with its predecessors by providing explanatory text for some of its larger thematic areas. The $1^{\text {st }}$ and $2^{\text {nd }}$ edition include tables, maps and charts without explanatory notes, data sources or map authors. The $3^{\text {rd }}$ edition includes some explanatory notes about the map, how it was made and its content on the verso of most plates and, in some instances, a data source is provided on the map itself. The $4^{\text {th }}$ edition includes notes within some of the legends; pages are dedicated exclusively to text and tables about a subject such as Agriculture (p.135), index of Explorers (p.71-72) and 12 pages at the end of the Atlas dedicated to sources. The sources consist of published material, datasets, unpublished material, manuscripts, other maps and atlases, "miscellaneous current thematic maps, covering an agencies service area", unpublished lists of data, questionnaire answers, and personal communications. The sources also include the agencies most frequently cited. The $3^{\text {rd }}$ edition does this for a few maps, the $1^{\text {st }}$ edition provides notes at the beginning but this is purely descriptive of content and no information about the features on the map or the theme, the $5^{\text {th }}$ does this on most maps while the $6^{\text {th }}$ is the most extensive in this practice, including abstracts and links to related information. 
The $4^{\text {th }}$ edition is $84 \%$ maps, and the remaining $16 \%$ of pages are dedicated to either full pages of text, tables or charts. Refer to the following for complete content comparison: TOC and Appendix E; Table 4 Atlas of Canada Content Groupings on page 149; Figure 15 on page 148; and Appendix $\mathrm{H}$. The former editions also contain varied content, with the $1^{\text {st }}$ and $2^{\text {nd }}$ having the least number of maps, $42 \%$ and $47 \%$ respectively with a significant amount of the content being charts, $31 \%$ and $33 \%$ respectively. The $3^{\text {rd }}$ edition is the most diverse and both the $3^{\text {rd }}$ and $5^{\text {th }}$ editions also include charts, text and sources but these are directly on their maps and are not fully dedicated pages while the $4^{\text {th }}$ edition has complete pages of text to support thematic content and in some cases foregoes the use of maps altogether to represent some data such as trade.

The $4^{\text {th }}$ edition had a larger print run, but was still quite expensive. Its format was the most accessible of them all, fitting into a backpack or on a schoolroom desk, and packed quite a bit more information for its size and price. The $4^{\text {th }}$ edition maps contained more variables and information on smaller pages than did the $5^{\text {th }}$ on its large sheets or the $6^{\text {th }}$ edition, which benefits from data layering and interactivity. The $4^{\text {th }}$ edition Atlas also aimed to make the information it contained as accessible as possible to most audiences.

The $4^{\text {th }}$ edition Atlas received positive reviews overall, but the biggest complaint it received was with respect to the use of outdated 1961 census data, a direct consequence of cost cutting. Earlier maps based on 1961 census data could not be updated given cost constraints. The To Know Ourselves 1975 Report of the 
Commission on Canadian Studies by Thomas H. B. Symons, gave the atlas much praise:

The 254 pages of maps, graphs, tables and notes of the new National Atlas of Canada demonstrate superbly the vital contribution the study of geography can make to our perception and understanding of this country. Beyond this, they make clear the role that can be played by geographical studies in providing objective information essential for making plans and decisions in many areas of public policy at the level of both national and local affairs. As the editor in-chief, Mr. Gerald Fremlin, has noted in his thoughtful preface, a national atlas, in addition to its value for decisionmaking and for scientific purposes, can advance the cultural development of a country by refining and extending the reader's perception of the nation and thus contributing to national self-awareness and self-knowledge. For these reasons, the Commission hopes that the Canadian Government will now adopt a policy of providing the financial means to make possible the production of a new edition of the National Atlas every 10 years at middecade (57).

Symons later played a significant role in the creation of the $5^{\text {th }}$ edition.

The $4^{\text {th }}$ edition is also the first to have a Dedication from a Prime Minister, and in 1974 that was Pierre Elliot Trudeau. The $1^{\text {st }}$ and $2^{\text {nd }}$ editions were formally transmitted to the Minister of the Department; and the $3^{\text {rd }}$ and $4^{\text {th }}$ include a Foreword by the Minister. The $5^{\text {th }}$ edition includes a Dedication from then Prime Minister, Brian Mulroney, but nothing from the Minister. The $3^{\text {rd }}, 4^{\text {th }}$ and $5^{\text {th }}$ editions include a preface from their chief editors. The $6^{\text {th }}$ edition is mute on all of these aspects, making it the least officially endorsed atlas of them all. Trudeau's dedication however appears oblivious to Fremlin's intentions for the Atlas. They must not have met or spoken together, as surely Trudeau would have appreciated the underlying philosophy and might not have started off with the following statement: "The National Atlas of Canada provides a window on the pageant of Canada's progress" ( $4^{\text {th }}$ edition, Dedication). The dedication process 
was more a formality than a heartfelt endorsement one must assume. For the readers, however, they are reading a book officially endorsed by their leader, making it a most authoritative national government document.

\subsection{7 $5^{\text {th }}$ Edition}

Once the bulk of the work was completed on the $4^{\text {th }}$ edition, work on the $5^{\text {th }}$ began in 1971. The $5^{\text {th }}$ edition was also produced at the Department of Energy, Mines and Resources (EMR), and during its 22-year production cycle, the government downsized, reorganized several times, cut budgets and reduced staff, and introduced the transition toward computerized mapping. Within this context, this section will discuss the advisory committees that gave the Atlas direction, the formal support the Atlas received from the government, the influence of government re-organization, and how the $5^{\text {th }}$ edition was envisioned and reenvisioned. This will be followed by describing how it was actually produced and will end with overview of content as was done with previous editions.

Four advisory committees oversaw the Atlas development and production process. Lt Col L.J. O'Brien became the Chair of the National Atlas of Canada Advisory Committee after he established the first committee in 1971. The Director of Surveys and Mapping Branch established the second committee in 1974 in cooperation with the Geography Division, and Dr. J. Lewis Robinson of the University of British Columbia was appointed as Chair. He assembled a group of Canadian geographers to discuss the "functions, contents and format of a proposed $5^{\text {th }}$ edition of the National Atlas of Canada" (National Advisory Committee, 1975:1). The third committee, the National Advisory on the National 
Atlas of Canada Committee (NANAC), was created in 1986 and chaired by Thomas. H. B. Symons. NANAC included atlas content evaluators, the National Atlas Information System (NAIS) team, cartography staff, and 10 specialists in sub-fields of geography. By 1988, George Falconer, the Editor in Chief of the $5^{\text {th }}$ edition, left the public service. A new chief editor was not appointed, although Dianne M. Chapman was given responsibility for overseeing scientific editing and Dr. Iain C. Taylor was appointed Chief Geographer and head of research in 1991 (Falconer, Wonders \& Taylor, 1999). Chapman produced an excellent set of guidelines, Guideline for Authors National Atlas of Canada, $5^{\text {th }}$ Edition (1990). These guidelines provided much insight into the production of the $5^{\text {th }}$ edition, which ended in 1993.

The Atlas of Canada received formal government support through a 1972 Cabinet decision, which confirmed that it would financially support the creation of the $5^{\text {th }}$ edition and recommended updates every 10 years (Falconer, Wonders \& Taylor, 1999). By 1981, the Cabinet Committee on Science, Culture and Information, decided on a continuing Atlas publication program, after departmental reorganization, even in the absence of a legal requirement to do so (O'Brien, 2006). The 1984-1987 Surveys and Mapping Branch mandate was confirmed by Cabinet and it included the production of an up to date edition of the Atlas every midcensus (O'Brien, 2006). Fortunately, after more reorganization, Cabinet once again confirmed the 1984 mandate for the Surveys, Mapping and Remote Sensing Sector, formerly the Surveys and Mapping Branch, which included the production of the $5^{\text {th }}$ edition of the Atlas (O'Brien, 2006). The $5^{\text {th }}$ edition had 
many advocates as seen in the re-affirmation of its mandate and it is speculated, that because the Atlas changed hands in terms of production, its advocates wanted to ensure ongoing support during these transitions.

Production of the $5^{\text {th }}$ edition began during a period of austerity and by 1976 ; the project was re-examined and experienced a reduction in resources. The Atlas was to have been completed by Christmas of 1979; however, this deadline was not met, as the proposed joint venture between a private sector publisher and the Department did not materialize (Falconer, Wonders \& Taylor, 1999). The Department had once again been re-organized in 1989 and those who worked on the Atlas became key members of the new National Geographical Mapping Division. The project had to once again be re-conceptualized, and it was decided that its form would be a series of large sheets to resemble the Geographical Map Series. Later that same year, a directive to complete the Atlas by 1993 led to a priority setting meeting to determine the final content. Concurrently it was envisioned that "priority-setting for the content of the future digital information system will be largely issue-oriented, and will involve advice from an expanded network of specialists in subfields of geography" (Chapman, 1990:1). The Department was again re-organized and the Atlas group was split in two: Falconer remained as the Editor in Chief, a post he occupied after Fremlin's departure; and Groot, who was the Director of Geographical Services, headed the new Geographical Services division. The new Geographical Services division was to serve other Federal Department mapping needs (EMR, 1984). By 1987, the Surveys and Mapping Branch was split into five specialized centres: the Canada 
Centre for Surveying, the Canada Centre for Mapping, the Canada Centre for Remote Sensing, the Geographic Information Systems Division, and the Cartographic Information and Distribution Centre (Hamilton and Sebert, 1996). The Atlas fell under the responsibility of the Canada Centre for Mapping in 1988.

The Atlas was re-envisioned numerous times. The O'Brien Committee envisioned the $5^{\text {th }}$ edition as a 3 -volume set of 480 maps, thematically structured into socioeconomic, physical and historical sections, with general reference maps and a gazetteer. Between 1972 and 1974, much research on content was done and "a comprehensive series of base maps was also designed" (Falconer, Wonders \& Taylor, 1999:274). The Robinson Committee followed and wanted the $5^{\text {th }}$ edition to be different from previous editions, suggesting that it include "themes which are meaningful to the Canadian public" (National Advisory Committee, 1975:1). The Robinson Committee was certain that 'a safe' and non-controversial atlas could be produced by following previous formats, but that was considered an inadequate approach since new ideas and advanced cartographic techniques could better showcase Canada's leadership in atlas design (National Advisory Committee, 1975:1). The Robinson Committee eventually approved the creation of "a popular, compact national atlas of some forty thematic maps, which would incorporate dynamic synthesizing themes" (Falconer, Wonders \& Taylor, 1999:275) such as geographical changes and spatial movements. It was also to be user-friendly and broadly marketed to schools and libraries (EMR, 1987). Henry Castner, a member of Robinson's Committee, proposed different ways to reconceptualize the Atlas in his Canadian Geographer 1976 paper Concepts before 
Content? - A Question in Atlas Design with Special Reference to the National Atlas of Canada. He saw an opportunity to:

overcome what we might call the intellectual complexity of an atlas: how its subject matter is arranged and how one moves about within it in order to retrieve related concepts...Also, what if the approach were to choose topics because of their relevance to the question, not because of some cartographic or academic tradition. For example, one might ask such simple questions as: (1) How did Canada get to be the way it is? (2) What is it like to work or live there? (3) What is it like to visit there? or (4) What is Canada's place in the world? (1976:227).

Unfortunately, his ideas did not find their way into the $5^{\text {th }}$ edition. The Robinson Committee discussed the general lack of quantitative data about atlas users, inferring that users were primarily schools and libraries, and believed that the use of an atlas was primarily for reference purposes but could also "illustrate concepts of geography with specific Canadian examples" (National Advisory Committee, 1975:2). The Robinson Committee also decided that an atlas had three main functions: to serve as a reference tool; to present an image of the country as a whole to Canadians; and to promote an image of the country outside Canada since "in some foreign countries it may be the main source of factual, distributional information about Canada. The data on its maps become copied into the maps and books published in other countries and thus the Atlas has educational functions abroad" (National Advisory Committee, 1975:2). The Committee also added that a national atlas:

is an item of prestige and achievement. It shows the state of geographical knowledge in, and of, the country at a specific time, and also the state of the art of cartographic representation. The Atlas is a showpiece which reflects the financial and personnel resources of the country (National Advisory Committee, 1975:2). 
This Committee called the $3^{\text {rd }}$ and $4^{\text {th }}$ editions, "inventory atlas volumes" $(1975: 2)$ and members wanted to avoid that for the $5^{\text {th }}$ edition. They recommended that there be an increased focus on themes of concern and relevance to the Canadian public. The initial recommendations were for a "man and his environment in Canada" (1975:3) overarching theme, starting with the population and then showing aspects of the physical environment. Some members wanted to have an introductory section illustrating the character of the country, while other members wanted to focus on areal and thematic associations, with interpretation, correlation and multiple themes on one map. Other recommendations were for the inclusion of urban maps and maps that show change and movement. The Committee also advocated for a bound volume as opposed to loose leaf.

The Robinson Committee also recommended that a strict compilation and production schedule be followed, only current data be employed, fewer pages, and the practice of updating every 10 years. Further, the Committee approved the idea of contracting out the creation of maps, research and the compilation of data, and encouraged cooperation with other government departments. The $5^{\text {th }}$ edition, however, generally did not follow the Robinson Committee recommendations but the Geography Division did contract out and solicit proposals for content creation and produced a set of Guidelines for Authors both in-house and for contractors (Chapman, 1990). Also, the initial 1972 Cabinet Submissions ideas were radically changed by 1978 and it was decided that the $5^{\text {th }}$ edition be created with the use of new information technology. 
In the late 1970's, the Atlas was re-conceived as the National Atlas Information System (NAIS) and mapping with computer technology became a new framework to guide data acquisition and compilation. The shift toward a "new program based on new concepts, ideas and formats, using digital technology to treat data and produce thematic maps that could be delivered at user's request or be assembled in folio or book form" was approved and the Geographical Services Directorate was given a deadline of 1983 for this to be achieved (EMR quoted in Falcon, Wonders \& Taylor, 1999:276). The ideas, however, were ahead of their time and beyond existing technological capabilities, which resulted in another missed deadline.

By 1986, the NANAC was in place and it recommended that work on the $5^{\text {th }}$ edition enlist the participation of the academic community, that NAIS continue, that additional funding resources be dedicated towards it, and that a costrecovery initiative be considered in the form of a joint venture publication project and that the "challenge of marketing computerized information be addressed" (NANAC, 1988:2). NANAC also wanted NAIS to be more broadly promoted to all government departments, to encourage its use. NANAC provided an excellent definition of what it was to be:

For more than eighty years, Canada has been among the world leaders in providing geographical information on a national scale in the form of atlases, maps, graphics, and associated products. With the $5^{\text {th }}$ edition of the National Atlas of Canada as its centrepiece, the assemblage of geographic information and related products is now collectively termed the National Atlas Information System (NAIS).

The increasing volume, diversity and volatility of data relevant to planning and administration at the regional, national and international level places a burden on those who must grasp and assimilate complex geographic information as a basis for decision making and strategic planning. This 
geographical approach is of particular value in facilitating an integrated view of the world in which socio-economic, environmental, historical and physical factors are correlated and considered in terms of their interaction (1988:4).

NAIS was to include both paper and electronic data products, which users could manipulate, and its aim was to respond to immediate needs in a timely fashion with the most up-to-date information. In addition, unlike Groot, Symons wanted NAIS to be developed for educational purposes to foster a basic understanding of Canada, and accordingly, it was to "serve as an inspirational document, portraying and symbolizing as nothing else can, Canada's particular characteristics and achievements...and encourages respect, appreciation and understanding of our identity and future" (NANAC, 1988:4). NAIS was conceived as a system to coordinate, assimilate and integrate data and knowledge about Canada's geography from many sources.

The actual $5^{\text {th }}$ edition seemed to have neglected its public function altogether in terms of atlas form and content. It focused primarily on serving decision-makers and government as exemplified in this description of the atlas in the Guidelines for the $5^{\text {th }}$ edition:

the National Atlas of Canada is a means of providing a reliable summary of national-scope geographical information on an organized basis for use at senior decision-making levels in business and industry. It serves equally well as a scientific and scholarly repository of carefully researched geographical information for use in education and academic research (Chapman, 1990:iv).

This definition resembled Groot's earlier (1979) understanding of an atlas as discussed in Section 4.2. It was also conceived as being part of a NAIS with paper 
maps being one of many manifestations and with content available in computerized form. The paper form was however the final result.

In 1979, Groot presented a paper entitled Canada's National Atlas Program in the Computer Era. It was a radical way to re-think an atlas in the context of the early days of GIS and the Canada Land Inventory (CLI). The guiding principle for the design of the atlas was a database and Canada was seen as data. The philosophical groundings of Fremlin's Canada as landscape disappeared, there was no longer Nicholson's cohesive portrait of Canada, nor the White and Chalifour idea of an economic atlas of Canada to market Canada and build a nation. There were also no traces of the Robinson Committee's recommendations to illustrate concepts of geography with specific Canadian examples of issues important to Canadians. The $5^{\text {th }}$ edition became a technologically driven atlas without a cohesive story. Groot's quote below best exemplifies this:

The outputs will provide a readily-available synopsis of spatial information at the national and regional levels primarily for use in the administration and management of government. A source data index will allow rapid reference to the original data for more detailed information required in subsequent decision-making processes (1979:45).

And unlike the $4^{\text {th }}$ edition, the recommendation of the Robinson Committee, and NANAC, the target user was no longer the public, and Groot's atlas was to be made by the government for the government. The $1^{\text {st }}$ and $2^{\text {nd }}$ editions were also made for the government, but it was used instrumentally and disseminated outside of government with a specific purpose. The $3^{\text {rd }}$ edition was also a government atlas, but it had a national purpose and was not intended for on the 
ground decision-making, rather it was to showcase the government's ability to map the country's achievements and Canadian development. Like the $3^{\text {rd }}$ edition, a loose sheet format was chosen because maps could be added and data could be updated. This format had the same disadvantages as the $3^{\text {rd }}$ edition, namely, that it was difficult to store and sheets were easily lost.

A special selection of 46 Atlas of Canada maps was finally produced between 1978 and 1985 , and it was assembled and launched as the $5^{\text {th }}$ edition, entitled the National Atlas of Canada, by the Surveys and Mapping Branch as an attractive box set in January of 1986. The Atlas was also featured at Expo 1986 in a Canada in Motion map pack and a Vidiwal with a Telidon component, entitled Geographical Facts from the National Atlas of Canada (EMR, 1986:8). This was a display of 108 video monitors that included Atlas transportation and communication maps "specially adapted to use the Electronic Atlas System" (EMR, 1986:20). Also in 1986, the Royal Geographical Society advertised the Atlas in the Geographic Magazine, other journals were sent copies to review, a mass mailing of pamphlets was undertaken, and the council of Ministers of Education were briefed on the importance of the Atlas to educational institutions (NANAC, 1988). EMR reports stated that an electronic Atlas was also being created with the use of a MARK II computer and that cartographers and geographic staff was receiving training in automated mapping and analysis while specifications were being completed on the acquisition of automated mapping products to supplement the electronic atlas (EMR, 1988:16). 
The $5^{\text {th }}$ edition was structured into 44 realms which are classifications considered to be:

human constructs, devised to aid human comprehension by bringing order to reality, and as such, the realm structure has served its purpose well in providing a means of organizing geographical information for thematic mapping purposes (Chapman, 1990:1).

Guidelines were created for sub-contractors and in-house content creators.

These provided evaluators with the information they needed to assess

submissions up and until 1986 and they were as follows:

- Does it fit into the realms?

- Does it fill a cartographic or content gap?

- Is there the presence of partnerships?

- Was there existing investment in this topic by the contractor or the department?

- Does it address national concerns and are there associated government documents or is this a concern identified by the Advisory Committee?

There was also a subjective cost benefit rating to measure the cost of research versus merit of the final research contribution. The rating model was later modified to include: Does it meet 'departmental requirements' and was it 'relevant to departmental priorities'?

Once subjects were identified as priority for mapping, research was divided into phases such as: a feasibility study, research proposal, and research completion plan. A set of control systems with forms, procedures and files were put in place to document and manage progress. The Guidelines for the $5^{\text {th }}$ edition also included manuscript guidelines for authors, which focused on the application of sound statistical procedures and cartography principles of converting data into 
form that could be easily mapped in a readily comparable form. "This comparability of information [would be] facilitated by the standardization of base maps and scales, and [would] be further enhanced by data management in a digital information system" (Chapman, 1990:13).

Other author guidelines include instructions about legends, scale, tables, and inset maps. Data were disaggregated at the provincial level, if not a finer level where possible, but always "the national pattern [had to] be evident" (1990:13). The work, Elements of Cartography, by Arthur H. Robinson and that of George F. Jenks and Michael R. C. Coulson, Class Intervals for Statistical Maps, as found in the International Yearbook of Cartography III, were cited by the author guidelines as key reference sources for content authors. Text was to be scientific writing and more specifically, the Guideline describes this directive as follows: "[T]he presentation should be clear, concise, logical, accurate, and unambiguous. The content should be understandable to a non-specialist user, yet should be sufficiently sophisticated for use by specialists" (Chapman, 1990:16).

Regarding sources, the 1973 Fremlin memo to all geographers was adapted to provide definitions for map authors, specialist advisors and compilers. Further, toponymy was to conform to the Canadian Permanent Committee on Geographical Names (CPCGN) and verified by a toponymy specialist. Overall, the Atlas met these criteria. 
All content was to be based on the metric system and a set of scales was provided; forty Standard National Atlas Base Maps at a scale of 1:7500 ooo were created from which content authors could pick while base sheet layout schemes were provided. The Guidelines for the $5^{\text {th }}$ edition also include a set of Cartographic Standards created by Ken Lightfoot for the Cartography Section of NAIS. These were created to ensure that the series of maps share similar characteristics in format and style, resulting in the Atlas appearing as an integrated map set. While the standards were generally followed, the order of the content and the appearance of the maps did not tell a cohesive story, nor did the maps look like they are part of a cohesive set.

It is astonishing that a $5^{\text {th }}$ edition of the Atlas actually got published. Between 1974, when discussions began, and until the final box set of maps was printed, the production environment of the Atlas underwent the following challenges: severe budgetary cut backs; four major reorganizations; changes in organizational leadership, including being led by four distinct advisory committees (Col. Obrien 1971, Robinson 1974, NANAC 1986); and failure to meet pre-scheduled deadlines (Xmas 1979, NAIS 1983). Budget cuts also led to the end of production by 1993 , leaving some of the original 44 information realms devoid of maps. Changes in organizational leadership included the loss of the Editor in Chief in 1988; between 1988-1993, two officials acted as editors to continue the work. A further challenge included the transition to computerization, which led to the reconceptualization of the Atlas as a National Atlas Information System. Finally, content for the first time, was created by sub-contractors, and in order to create a 
sense of cohesion, they had to embrace the 1: 7500 ooo scaled outline of the full country and pick and choose from a set of 40 base maps, even if content could have been better represented in different scales.

The Atlas was conceptualized and produced as if it were digital product but instead was published as a set of loose sheets. Throughout the long production process, there was no underlying philosophical, geographical or ideological framework articulated to guide the creation of the $5^{\text {th }}$ edition. It was supposed to be an information product that:

aims at being more responsive to the reality of change and evolution, not only in the geography of Canada, but also in the rapidly expanding fields of information technology. In keeping with this aim, the fifth edition is planned as a continuing serial publication of separate but related maps, collectively dealing with all aspects of Canada (Preface, $5^{\text {th }}$ Edition, 1985).

It was created on paper, but it wanted to be its future self, "a dynamic and continuing means of responding to geographical information needs at national scales as these needs arise, rather than at long intervals as was the case with previous editions". The technology at that time could not deliver on the ideal. It was to be a database "with the aim of satisfying those users who have the means to create their own computerized displays using combinations of geographical information from the National Atlas database" (Preface, $5^{\text {th }}$ Edition, 1985). The technology was just not quite yet evolved enough for the Atlas to be a NAIS.

A look at the $5^{\text {th }}$ edition's two table of contents (see Appendix F), one printed for the first release and the second one in 1993 for the final release, which illustrate that in terms of how content was organized, it did not meet a story telling 
objective. The $5^{\text {th }}$ edition does include new concepts, such as environment, but it is not very 'risky' in its presentation. For example the Environment realm \#10 includes only one map, 10.1 Canada - The Potential of Soils and Bedrock to Reduce the Acidity of Atmospheric Deposition, which is a long winded and politically neutral way to say areas that can cope with the effects of acid rain. The title fails to acknowledge that acid rain was a political cleavage issue between the US and Canada and very much in the headlines in the 1980s. Also, many of the realms in the atlas represent issues associated with environmental ramifications, including but not limited to: Mining, Energy, Agriculture, and Manufacturing. Realm \#9 Ecology includes 4 maps: Distribution of Wetlands, Wetland Regions, Land Cover Associations, and Terrestrial Ecoregions. With this series, we begin to see relational geography where land is classified based on the "individual areas delineated on the earth's surface (i.e., ecozones, ecoprovinces, ecoregions, ecodistricts, etc.) gain their identity through spatial differences in a combination of landscape" (Environment Canada, 1996:1). When maps are classified in this way, they form part of the process of creating imaginations supporting an ecosystems approach to sustainable land management (see Section 4.4.2 for further details). The Terrestrial Ecoregions map, for example, is considered to be:

[the] first national approximation" (Environment Canada, 1996:1) of ecozones, ecoprovinces and ecoregions which are "the three first levels of a hierarchical classification developed by the Canada Committee on Ecological Land Classification. The Classification provides a natural rather than jurisdictional basis for ecosystem analysis and synthesis" (Legend notes, Map 9.4 Terrestrial Ecoregions). 
Another interesting example is the Ethnography realm \#15, which includes 6 maps of First Nations. The title suggests that such subjects as visible minorities, ethnicity, immigration and potentially language or religion are addressed, which they are not, nor are these ethnographic subjects addressed elsewhere in the $5^{\text {th }}$ edition. Language and Religion are their own realms but no maps were issued for either. Ethnography is only about First Nations and one of the maps is of Indian Treaties (15.6), depicting a prominent large purple swath of Post Confederation Treaties that covers most of the country (see Figure 22), which is not really what ethnography is about. This map does, however, represent a version of what was thought of as the territory once occupied by First Nations and the process by which it was 'legally' given up, even though it is not transparently framed in that way. This map also illustrates the human cost of the construction of the transCanada railway and subsequent settlement, issues in full force during White and Chalifour's tenure with the Department of the Interior, without addressing terms of their expropriating effects. White and Chalifour produced their editions during a time where railways were glorified as proof of progress and opportunities, and settlement by immigrants was crucial for nation building. With the $5^{\text {th }}$ edition, the purple swath represents aboriginal land titles that were cleared in exchange for reserves and the provision of benefits such as annuities, gratuities, education, schools, hunting and fishing rights, etc. The disproportionate distribution of these benefits remains in dispute today (e.g., Attawapiskat). Prior to this map, First Nations appeared in the atlas primarily as linguistic groups (see Appendix $\mathrm{H}$ for content comparison). 


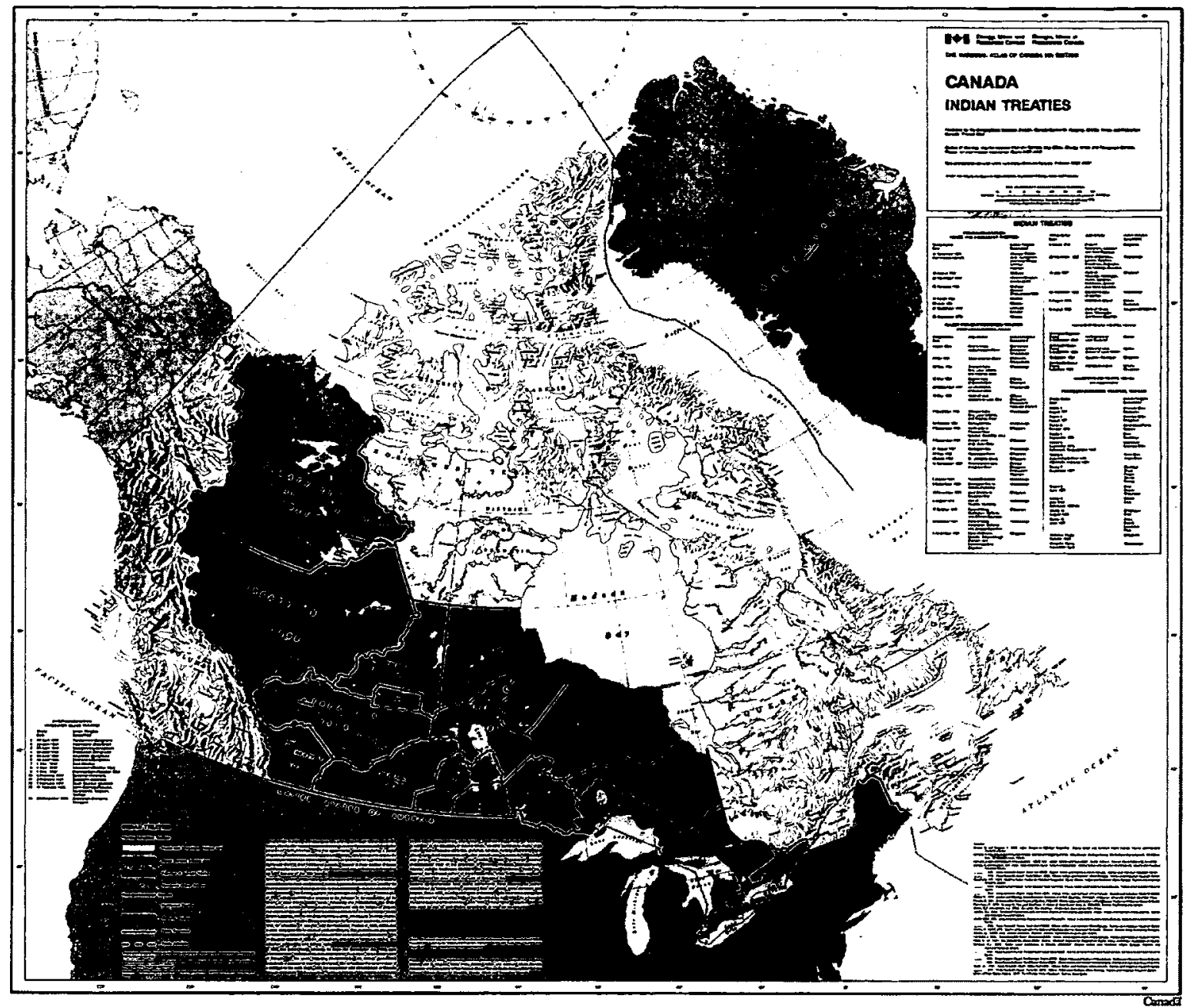

Figure 22. Indian Treaties Map, $5^{\text {th }}$ Edition Atlas of Canada

The $5^{\text {th }}$ edition is a very large and heavy box of sheets, which requires a very large dining room table, or preferably a dedicated reading table, to allow the reader to spread out the sheets, especially if one does not wish to refold the maps at each reading. With the largest map measuring $31.5 \mathrm{~cm} \mathrm{X} 36 \mathrm{~cm}$, the large sizes and number of sheets of this box set makes it impossible to read this atlas as if it were a story. The atlas was also incredibly expensive, at $\$ 185$ per box set or $\$ 9.75$ per sheet. Sales were lackluster with only 1,220 English and 353 French Sets sold by $1994^{*}$ along with 30,500 sheets (Falconer, Wonders \& Taylor, 1999). This should 
have been foreseen with a Gallup poll to 700 Canadians and focus group sessions indicating that the format and the cost would dissuade non-specialist users from acquiring the Atlas (Falconer \& Lloyd, 1984).

The box set contained 93 sheets organized into 44 realms listed in the original 1985 table of contents. By 1993 , the table of contents had notes beside 13 realms ${ }^{51}$ stating that: "No maps will be issued". The reasoning behind the deletions was: to complete this publication by 1993 [which] meant that it would be impossible to produce maps for some subject realms". However, there is at least one instance where politics, and not time, was the constraint. Dr. David Bennett of Carleton University, subcontracted by Dr. John Clarke to author the Health and Welfare map, stated on his CV that his map was suppressed for political reasons. Bennett further explained that it was removed from publication by a multi-departmental committee, which was struck to address its controversial content. Benoît Bouchard, then Minister of the Department of National Health and Welfare Canada under the Mulroney Government, might have been behind the decision since his riding fared poorly on the health and welfare index (Taylor, 2011 and Bennett, 2011). According to Bennett (2011):

the specific trigger may well have been that Bouchard's own riding showed up as "bad", but I think what really bothered the conservatives was that electorally they needed Quebec and on my map pretty much all of Quebec came out poorly. It was this broader "sensitivity" that made my map such an irritant.

${ }^{51}$ Empty realms: 6. Pedology; 8. Zoogeography; 12 . Settlement; 16 . Languages; 19. Health and Welfare; 20. Justice and Law; 22. Religion; 23. Education; 30. Construction; 33. Finance; 34. Commerce and Tourism; 35. Leisure; and 40. Regions of Canada. 
Other maps may not have been published for similar political reasons. For example, it seems quite unfathomable that there are no maps depicting Canada's multiculturalism and language since these are rather straightforward population demographic maps while some realms may have been excluded because extensive new research was required to produce them.

The $5^{\text {th }}$ edition includes notes and text on most pages, detailed legends, and map creators are extensively sourced on each and every map including: authors, compilers, editors, researchers, research assistants, cartographers and people who provided scientific advice. Also, almost all of the maps include a list of sources much like the $4^{\text {th }}$ edition. The $6^{\text {th }}$ edition returns to the practice of an anonymous map production team but extensively sources, models, papers, as well as data gleaned or reused from previous editions.

The benefit of large sheets is more information and greater detail. This was, however, not the case for most maps in the $5^{\text {th }}$ edition. An image featuring forest industry maps from each edition of the Atlas (see Figure 23), illustrates the differences in attributes related to forests. The image illustrates that the $4^{\text {th }}$ edition provides quite a bit of information, but at the expense of a complete national picture, while the $1^{\text {st }}$ edition contains a substantive amount of text and the $3^{\text {rd }}$ edition, which is the $2^{\text {nd }}$ largest, has little text. The $5^{\text {th }}$ edition editors were steadfast on keeping the standard 1: 7500 ooo scaled map of Canada wherever possible which meant that a significant amount of sheet space consisted of the Atlantic Ocean and the North Pole. It was also not the best scale for the demographic maps since most of the country is sparsely populated; focusing on 
areas in the north would have been more informative (Harding, 1987). The $6^{\text {th }}$ edition is small but contains about the same amount of information as the $5^{\text {th, if }}$ not more, given all associated windows linked to it.

The $5^{\text {th }}$ edition is probably the least accessible atlas of all editions. It was priced high, difficult to use and impossible to read. As stated by Groot earlier in Section 4.3 , the $5^{\text {th }}$ edition was not conceived for the public and was designed specifically to meet the needs of government officials and administrators. For Groot, a thematic atlas will have $1: 7.5 \mathrm{M}$ and 1:2M scaled maps:

of geographical phenomena on single sheets with a limited number of phenomena depicted on each sheet. These are called data base sheets because the collection of these maps will form the components of a graphic data base of the geography of Canada as a whole. We believe these maps will serve primarily government administration, scientific research, education and, to a lesser extent, the public (Groot, 1979:44). 


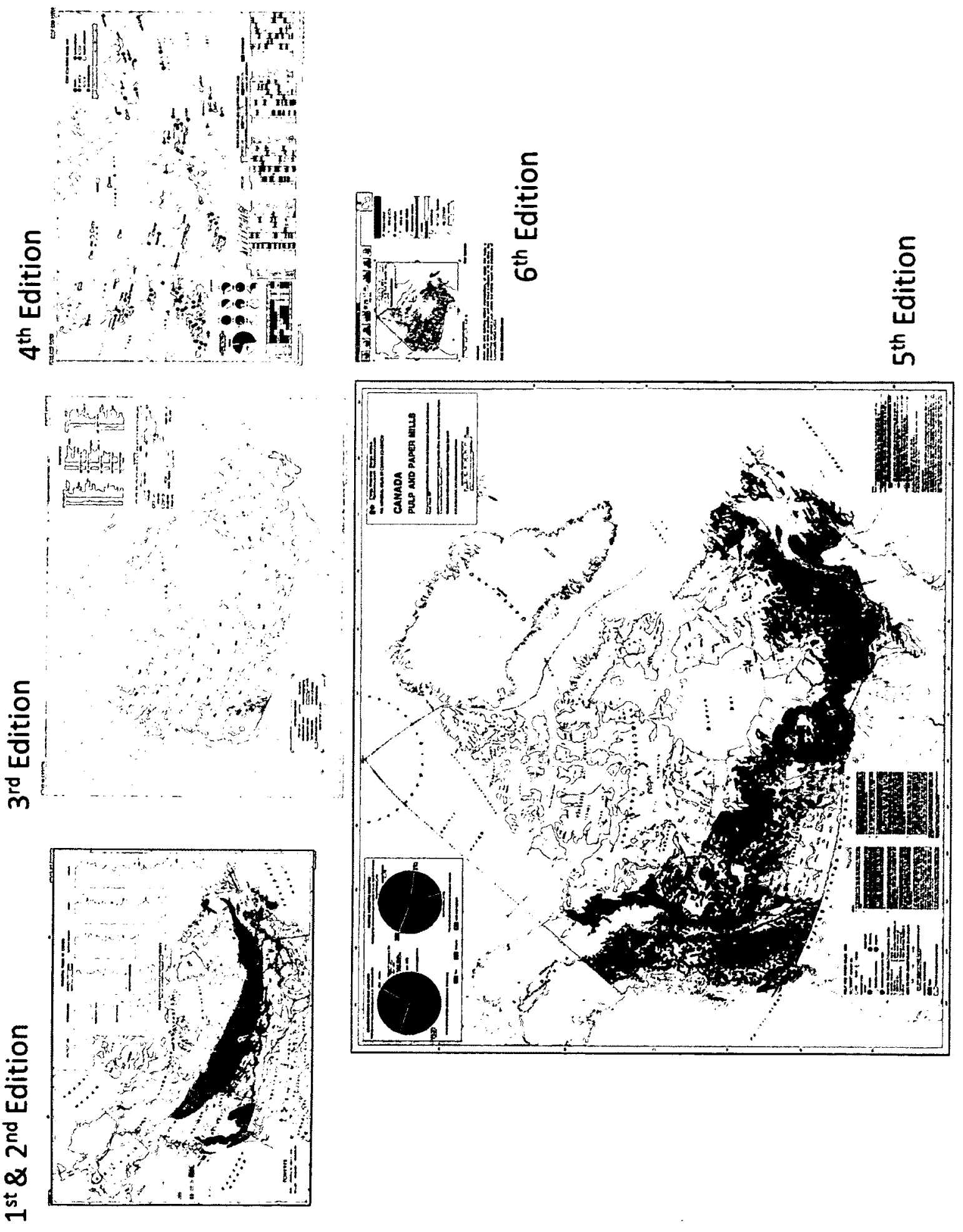

Figure 23. Forest Industry Maps, Atlas of Canada (Approximate scale) 
Map librarians disliked the $5^{\text {th }}$ edition "because the sheets were loose leaf and disappeared from their collections" (Williams, O'Brien \& Kramer, 2003:9). Despite efforts made to market this edition:

it did not sell well as users' needs were not being met. As a result of the low sales and the high cost of printing, the decision was made to end the paper editions of the Atlas and move towards digital solutions (Williams, O'Brien and Kramer, 2003:9).

The atlas did, however, include some innovative new thematic maps as previously discussed. However, it does not tell a story.

The first map is Canada - Seismicity, found under the realm of Geophysics, leading the reader to start their atlas experience with cracks and space of physical instability. The choice of subject matter is made worse by the ungainly use of yellow, orange and red circles. In all probability, Fremlin would not have approved of how the land is featured in this map. Nicholson, who focused on depicting Canada's development and progress, would probably have been confused by this choice of first map. The second map, Canada - Permafrost, also seems equally inappropriate and I can imagine White, who was focused on marketing the country's potential, disapproving of this choice since it would have frightened potential settlers. Although interesting and informative, this map is clearly for a specialist audience. The third map, Relief, would have made Fremlin proud. However, it is unfortunate that it was not followed up by relief profiles. The next realm is Climatology, the largest of the realms with 15 maps. The Atlas is unusual in that there are no soil maps, or maps of geological features, physiography, or land use. It could be characterized as an economic atlas, as 
many realms are about primary resource extraction, agriculture, manufacturing, employment, income, human resources, and energy and transportation infrastructure, arguably, however, most of the editions are.

Perhaps it is unfair to look for a story, as this atlas was intended to be a source of information, part of a National Atlas Information System, and perhaps the environment example provided earlier, typifies its intent. The politics or narrative is found behind scientific description, and it is up to the reader to come to this atlas with a significant amount of background knowledge to figure out the story. Or perhaps it is about allowing the reader to discover his or her own story of Canada, and to unravel the politics and policies found everywhere but nowhere in particular. It is the most scientific of all of the atlases and by far the least accessible to the public, however, the scientist and the evidence oriented policy maker will find plenty of geographic knowledge to carry out their work and reshape places with the knowledge represented in this atlas. For this audience, the Atlas with its many scientific sheets succeeds.

The $5^{\text {th }}$ edition was not solely produced by government since data were collected, compiled and mapped under contract by new experts, external to government. . The atlas was no longer about the promotion of Canadian self-awareness and instead became an inventory to facilitate government planning and resource management. Unforeseen by its creators, this unpopular $5^{\text {th }}$ edition eventually became the inventory atlas it was not supposed to become. It was however the beginning of a NAIS. 


\subsection{8 $6^{\text {th }}$ Edition}

The computerization of mapmaking came early in Canada and this included experimentation, creation of prototypes, and collaboration between the private sector and the Government of Canada. The Canada Geographic Information System (CGIS) is an early example as it was created in the 1960 s as one of the world's first computerized mapping systems and it was subsequently used to develop the Canada Land Inventory (CLI) in 1963. Groot introduced the idea of a computerized NAIS in the mid-1970s and some of the later $5^{\text {th }}$ edition maps were created using computer technology. As early as 1978, initial steps towards building NAIS were discussed by the Atlas Editorial Committee and inspired the standardized approach of using base maps in the $5^{\text {th }}$ edition, as well as its loose sheet format (ICA, 1990).

The creation of standardized fundamental geographical reference data sets, modeling thematic attributes and creating a database set the course for the transition to NAIS. There were also early discussions about developing a digital catalog of maps, atlases and geographic information (ICA, 1990). By 1995, NAIS was considered a component of the Knowledge Infrastructure in NRCan annual reports and was one of "the pioneer information technology initiatives discussed at the 1995 G7 Summit in Halifax" (NRCan, 1996a:7). In addition, the NRCan Information Service Team won the 1995 Gold medal in the Technology in Government Award Category 'Investing strategically' at the Summit (NRCan, 1996b:7). 
The first computer atlas prototype was built in 1981 at a time when there were plans to disseminate some of the $5^{\text {th }}$ edition maps on diskettes and on tape (ICA, 1990). This early atlas prototype featured dynamic animated mapping, underwent usability testing, and had a 1989 release date. In addition, three digital information-mapping packages were created in the 1980s: Canada in Motion, Canada's Wetlands and Canada Then and Now (ICA, 1990). A complementary public-private partnership project, $34^{\text {th }}$ Parliament of Canada on Hyper Card, was developed for the Macintosh computer which included constituency maps, statistical data, and information about members of Parliament (ICA, 1990).

The 1994 experiment National Atlas on the Net, was one of the earliest online interactive map artifacts. This experiment led to the prototype, Electronic National Atlas of Canada, developed jointly between EMR and a private company called INTERA TYDAC. The prototype required the purchase of a CDROM and, once installed, additional software also had to be purchased to view the maps. The cost, its complicated nature and the uneven access to computers at the time, made this an unpopular tool (Williams, O'Brien \& Kramer, 2003).

The technological shift from paper to digital media however, did shift the focus of the Atlas toward public education. This may have been influenced by the recognition that the public mattered, or it may have been a strategic move to demonstrate how easy it was to make maps online and to tap into a new market. The only source of insight into how the $6^{\text {th }}$ edition was being conceived is a hard copy of the National Atlas of Canada User's Guide (EMR, 1993). According to 
the User Guide, the Atlas was to be desktop mapping software and a national data base. The prototype included SPANS MAP desktop mapping software, a national database of 40 layers of geographic information with attributes, and a User's Guide. The User's Guide was divided into two sections, Layers and Case Studies. The User's Guide was a great example of early GIS use for education. The first section provides an excellent explanation of what map layers are, base maps, projection grids, census divisions, etc.

The 'Tour of the Attribute Layers' section explained populated places, resource dependence communities and other themes complete with hints to guide the user to focus on aspects of those layers, relationships to other layers, classifications, features, etc. The section concluded by showing users how to combine layers, including Q\&As on pattern recognition related to the maps, and instructions on how to read the maps and to export them. The section also included an extensive table that described a layer, its fields, what it depicts, issues related to a topic featured, the perspective of scientists on issues such as climate change.

Case Studies, such as the Wildlife at Risk, the Retail Market Analysis in an Urban Area, and the Atlantic Canada Cod Fishery, included learning modules about the study, details about models to discuss the topic, data collection map layers, and explanations of what they mean and indicate. They also include scenarios to interact with the data, view them, query them, and guides users to look for causes, conditions, issues, etc. Finally, users also got to create their own maps. The Case Studies section ends with a list of sources for more information, and items to think about. This innovative Atlas provided geography lessons using 
data and maps, and discussed issues of importance to Canadians. It did what the $5^{\text {th }}$ edition committees envisioned. This concept led to the development of geography content for the Industry Canada's SchoolNet 52 project, created as part of the early Information Highway initiatives. SchoolNet included hundreds of data layers and lesson plans (see Figure 24). A Teachers Advisory Group with representation from all across Canada provided direct feedback to the content authors of the SchoolNet National Atlas that resulted in such features as a quiz, resources for teachers, and increased textual information (Williams, O'Brien \& Kramer, 2003). In 1996, the SchoolNet National Atlas site won the Canadian Internet Award for Best Academic or Educational Site (NRCan, 1997a:64).

The $6^{\text {th }}$ edition officially launched online in 1999 (see Figure 25). This edition underwent many revisions and technological change. By 2000, the Atlas became a product of the newly established Canadian Geospatial Data Infrastructure (CGDI) - GeoConnections Program (Harker, 2006). Only the current version of the $6^{\text {th }}$ edition is examined here. Earlier versions are inaccessible as they are not compatible with current browser technology or the service contracts with initial software developers have expired. However, older versions of the $6^{\text {th }}$ edition are currently stored in hard drives at NRCan with the hope that they may one day be archived and made accessible. The current edition may soon become inaccessible with its kernel potentially expiring in 2012.

${ }^{2}$ Schoolnet was an Industry Canada project taken offline in 2007. I was unable to find the geography related material created by Natural Resources Canada on the Library and Archives Canada Government of Canada Web Archive (http://www.collectionscanada.gc.ca/webarchives/index-e.html). 
The first release of the $6^{\text {th }}$ edition included up to four user interfaces and an illconceived architecture. Users found searching complicated and causing confusion. In 2000, the Atlas of Canada program adopted a user centred approach to design and development (i.e. UCD) to gain insight improving the next release; focussing primarily on a needs assessment, user satisfaction and usability research (Kramer, 2009). Previously, users were only considered for user requirements studies (i.e. surveys to retailers, Gallup poll to 700 Canadians, and focus groups) conducted to inform the marketers of the $5^{\text {th }}$ edition (Falconer \& Lloyd, 1984). Usability studies were also carried out for the early 1981 prototype but this process was more analogous to beta testing (ICA, 1990).

The UCD work for the $6^{\text {th }}$ edition was the first comprehensive and systematic analysis of business needs, user requirements and usability, which made the atlas more outward looking. The UCD process included usability tests, online surveys, focus groups, and in-depth interviews. It was assessed that most users were professionals (40\%), followed by educational sector (32\%) with $19 \%$ being students and 13\% being teachers (Williams, O'Brien \& Kramer, 2003:11). The research indicated that there were few repeat visitors, but those first time visitors spent a significant amount of time on the site and teachers were using it for lesson plans and to update print materials. The site was again redesigned and retested, new architecture with consistent user interfaces was created, basic tools added, and content was reorganized into sections with simple descriptive labels. The Atlas redesign was a success and the UCD approach demonstrated to government that the public counts. 


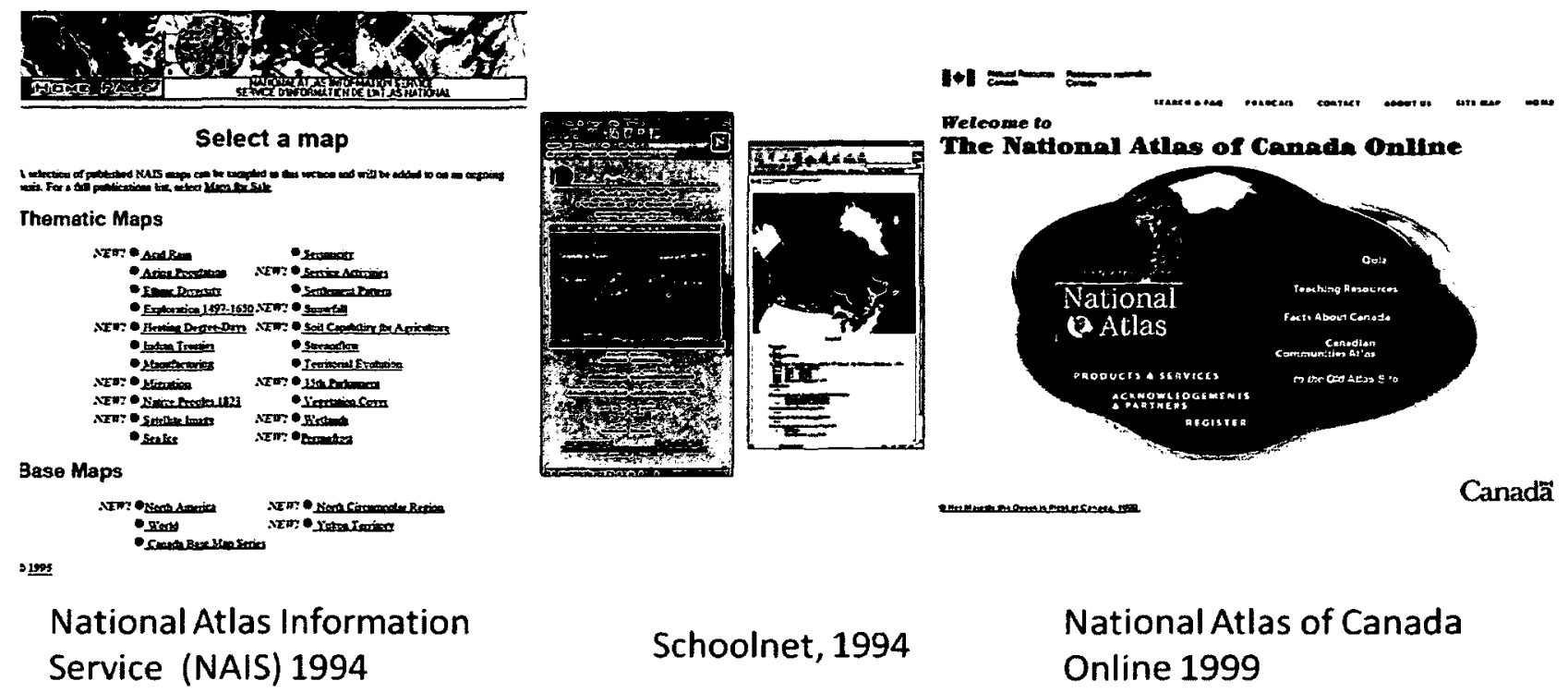

Figure 24. Former Iterations of Online National Atlas of Canada

The $6^{\text {th }}$ edition was re-presented in 2002 as "a portal to information about Canada" (O’Neil \& Frappier, 2002:slide No 7). It was also considered a communication tool that included: a set of services, a collection of authoritative information, and the means to bring a geographical dimension to issues of interest to Government and Canadians (O’Neil \& Frappier, 2002:slide No 9). Atlas themes were designed in such a way as to communicate Canadian national policy on environment, health and other departmental strategic directions such as understanding resource dependent communities. The $6^{\text {th }}$ edition achieved the 1975 Robinson Committee early goals: provided consistent views of issues, was structured for easy updating, was built to be scalable, and kept information timely and relevant through partnerships. The Atlas was recognized as a stable and established brand, published since 1906, and it was considered to be a nonthreatening and trusted object managed by experts (O’Neil \& Frappier, 2002). 
The 2000 re-designed web site with new content, maps and map creation capabilities cost \$2.65 million and served over 300 ooo visitors per month (NRCan, 2003:8). Oddly, it is barely mentioned in NRCan annual reports between 1995 and 2011. In 1998, the Government of Canada authorized an ongoing program for an Internet based National Atlas, and it became part of the 1999 GeoConnections program. It ceremoniously celebrated its $100^{\text {th }}$ anniversary in 2006 with the release of new maps.

As demonstrated earlier, atlases are systematically created and require a tremendous amount of coordination and standardization. The $20066^{\text {th }}$ Edition Editorial Manual provides insight into the conception and production process, including: terminology, site parameters, content development, content reference documents, editorial functions, formatting, bibliographies, and mapping hierarchy.

An editorial committee reviewed content proposals, feasibility studies, storyboards, and ongoing projects. The approval of a project lead to the creation of content in the process, which included images, text, maps, graphs, audio, video or other multimedia including metadata. Once loaded into the system, a project was peer reviewed with peers being recommended by the content creator. A number of content creation steps were involved and a final review occurred at the pre-publication stage with one final check once published. 
Data disclosure was sometimes an issue. For example, StatCan licence agreements restricted the dissemination of its raw data. As such, suggestions were provided to content creators on representation while system protections were implemented to control data viewing. $\mathrm{M}^{3} \mathrm{Cat} 53$ was the software used to generate metadata for the Atlas and basic instructions were provided on how to use the tool. Instructions were provided on drafting text, sources and the conventions for authors, data sources, bibliographies, etc. The Atlas also included an inventory of base data such as shapefiles, as well as a list of framework data and projection types provided.

The $6^{\text {th }}$ edition was completely published and remains available online. Readers land on a home page that includes a navigation bar under the heading of Explore Our Maps, which opens a table of contents with a list of 10 topics. A drop down menu of items on the navigation bar leads the reader to a thematic content page that describes the theme with hyperlinks in some text, followed by a list hyperlinked topic items. Clicking again leads the reader to a topic, which they can read more about or open a map. The map option provides the reader with a very small map in a window occupying about $1 / 3$ of the screen space, an abstract, some viewing tools, a legend, links sources, and some map themes to click on (see Figure 25).

53 M3Cat is a Multistandard, Multilingual, Metadata Cataloguing Tool for the creation of geospatial metadata developed under the CGDI GeoInnovations program by Intelec Geomatics (Intelec) and its partners, SoftMap Technologies, CrossDraw, and the Centre for Research in Geomatics (CRG) of Laval University. 
Each map page provides the user with a set of typical online map tools: Zoom in, View full map, Window Sizing, Get Info that allows for pointing on the map and generating a window of information related to the location, Print, and Help. The legend is interactive and different types of information or layers can be selected for viewing. The user is also provided with a link to map sources and can expand the abstract or can read that same text from a small window directly from the map. The map in the viewing window can be moved using direction arrows in the bounding box. Users can return to the topic area either by back clicking or following the path provided under the NRCan banner. The interface is not always smooth to use and the window size is quite small.

The $6^{\text {th }}$ edition is the most mobile of all the atlases as it can be read just about anywhere there is an Internet connected computer or hand held device. The $6^{\text {th }}$ edition is also free.

For past 20 years there has been much discussion on the following topics: computerization and cartography, cybercartography, GIS, web mapping, and cartographic visualization. That literature is not considered in detail here, as while it is true that the Atlas has changed media, it did not radically transform the content of the $6^{\text {th }}$ edition; irrespective of form, texts in the end constrain readers and readers take liberties with text of form and media (Darnton, 2006:21). What did change was how it was read, interacted with, created, maintained, and thought of, by atlas creators. Arguably, this is true for all the editions as form, technology and production environments changed with each edition, as did how atlas authors conceived their editions. The $1^{\text {st }}$ and $2^{\text {nd }}$ editions 
may be the exception. It can also be argued that changes in each edition were the result of advances in knowledge, science, technology, departmental and also chief editor priorities.

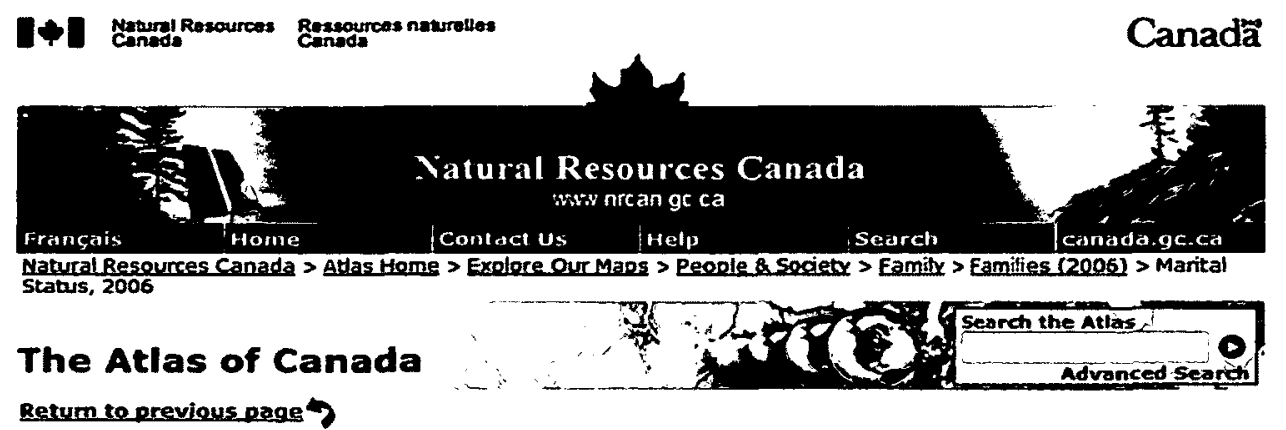

Retum to previous page $\%$
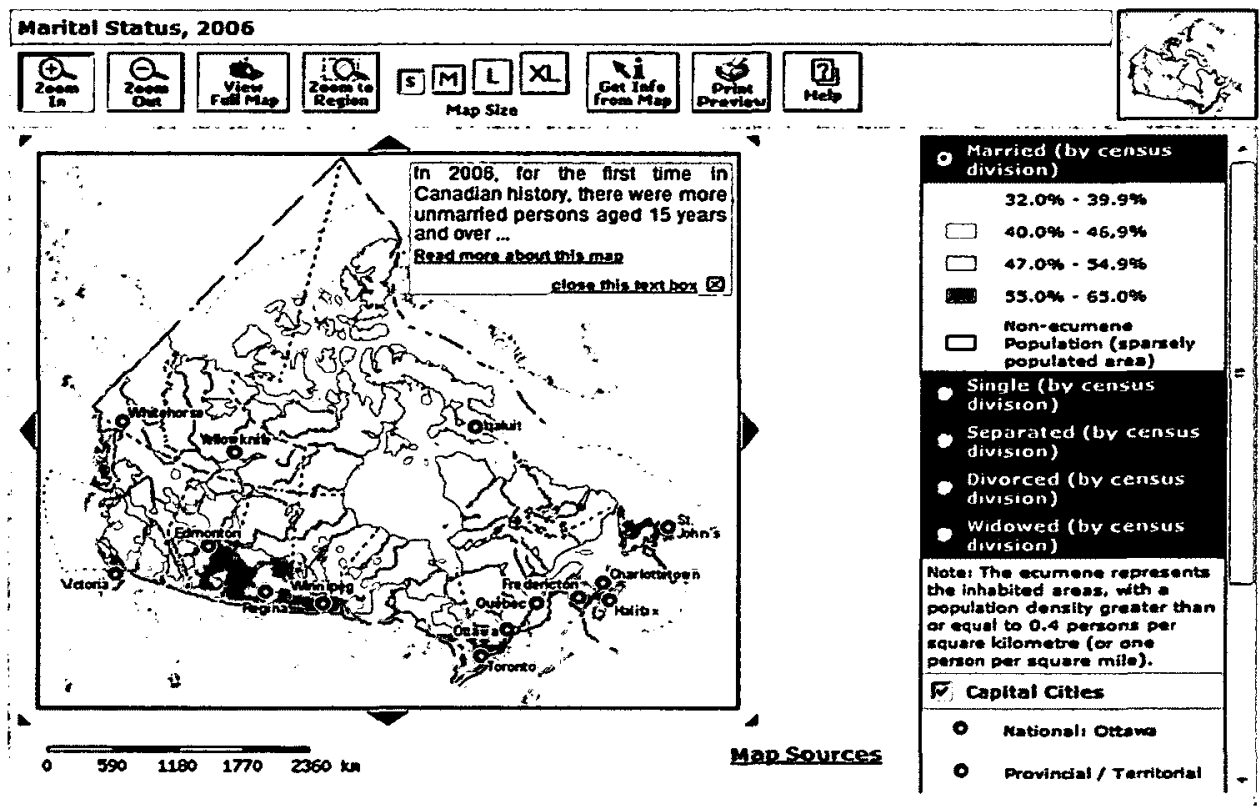

\section{Abstract}

In 2006, for the first time in Canadian history, there were more unmaried persons aged 15 years and over than legally married people. Just over one-half of Canada's population aged 15 years and over (51.5\%) was unmarried; that is, they had never been legally married (34.9\%), or they were divorced $(8.0 \%)$, widowed $(6.2 \%)$ or separated $(3.0 \%)$. Legally married people formed slighty less than half (47.9\%) of the poputation. Twenty years eartier, $61.4 \%$ of the population aged 15 years and over was legaty married while 30.6\% owed and separated persons have remained retatively stable over the past two decades, increases have occurred largety among the divorced and, even more so, among the single (never legally married) population.

Read more ebout this map

Date Modified: 2009-09-03 Ine of Page $\quad$ Importent Notices

Figure 25. Atlas of Canada Map Page, $6^{\text {th }}$ Edition 
The transformation to digital form was also not radical, as discussed in this chapter. That evolution was a slow and iterative process that started in the early days of the $5^{\text {th }}$ edition, which was probably the most affected as it was created during the technological transition. It took close to 30 years to get to today's $6^{\text {th }}$ edition while the $5^{\text {th }}$ edition was two decades in the making. The $4^{\text {th }}$ edition also underwent multiple forms before the revised edition was published while the $3^{\text {rd }}$ edition was in production for 20 years. The latter was published in a binder of loose sheets since it was hoped that sheets could be added. The $1^{\text {st }}$ and $2^{\text {nd }}$ editions were the most definitive in terms of form, size and style, and that is partially a reflection of the effort required to create new plates at that time.

Some may argue that a database focused way of thinking about the atlas has changed what an atlas is. But all editions of the Atlas of Canada have been driven by data. One only has to recall White's efforts at collecting altitudes data. However, media does not solely determine how an atlas tells its story, as was seen in the case of the $5^{\text {th }}$ edition; it is the process of intentionally selecting data, maps, and texts that are carefully compiled, assembled and structured within ordered topics and sub-topics that does.

The $6^{\text {th }}$ edition relies on a bound, well-designed and structured navigation system that leads the reader to topics and information within the Atlas. A bound book is the same, and like a hypertext, there is no promise that a book will be read from front to back. The $6^{\text {th }}$ edition is not randomly organized as it was systematically created and tested with the help of its target users. The $5^{\text {th }}$ edition could have benefited from such a process since it is difficult to read, void of a clear narrative 
and disliked by the average user. The $6^{\text {th }}$ edition moved from the static presentation of information and data management found in a book to a wellstructured internet based form with the now classic artifacts of a navigation bar and site map to replace the table of contents, pathways instead of page numbers, links instead of underlined or capitalized text pointing to related maps or concepts, and a URL instead of place on a shelf. The $6^{\text {th }}$ edition benefits from having more interactivity, more space for text, images and charts and more links to external information sources. However, it is quite basic by today's web standards. The $6^{\text {th }}$ edition also uses interchangeable framework data and refers to $5^{\text {th }}$ edition maps and data. It is an information rich edition, albeit the maps are small and not as aesthetically pleasing as earlier paper versions. Screen hardware at the time it was produced restricted the choice for the map window size when the $6^{\text {th }}$ editions were created, rendering it impossible to see the full extent of the country in the space provided. Plus it is not easy to have so many maps open at the same time. As already mentioned, the tools to interact with the Atlas are somewhat dated, users have become much savvier, and expectations have changed. The transition to digital media is ongoing. Archiving and preservation remain a challenge, as earlier digital versions are inaccessible and the long-term fate of this $6^{\text {th }}$ edition remains unknown.

The hard copy editions of the Atlas of Canada evolved from anonymous public officials, cartographers, compilers and researchers, to a system of full acknowledgements on each sheet, as well as extensive data sourcing and model referencing. Unfortunately, the $6^{\text {th }}$ edition reverted back to map author 
anonymity, but kept the rigorous practice of referencing sources. With the $6^{\text {th }}$ edition, there is no longer a chief editor, and content is decided upon within the Data Dissemination Division of the Mapping Information Branch in the Earth Science Sector which was formerly the GeoAccess Division of the Canada Centre for Remote Sensing (CCRS), and as mentioned, it was also part of the GeoConnections program with an Atlas advisory committee. The content of the $6^{\text {th }}$ edition was influenced by NRCan priorities, performance based management, issue driven approaches, and content creation for policymakers (i.e. decision makers). Earlier editions were officially transmitted and recognized by responsible Ministers and sometimes Prime Ministers, and bore official seals. The $6^{\text {th }}$ edition, by contrast, seems to be the least recognized by its highest ranking public officials and the least authoritative by its lack of symbols irrespective of its .gc.ca url and the Government of Canada logo on the site. Online atlases are not as revered as their hard copy counterparts despite how widely read they are or the fact that they are just as authoritative as their hard copy counterparts.

Beyond the type of content and the production environment, the main difference between the $6^{\text {th }}$ edition and the others is the amount of content the malleability and reuse of that content, the scalability, and the prominence of the user. In terms of content, there are over one thousand maps in the $6^{\text {th }}$ edition (see TOC in Appendix G), as well as thousands more variables and infinitely more information. Along with more maps and information, the $6^{\text {th }}$ edition is more diverse in terms of subject matters covered (see Figures 15 on page 148 and Table 
4 on page 149 above as well as the Content Comparison Table in Appendix H). Most notably, health, wellbeing, sports, protected areas and places, hazards, and housing are entirely new or expanded groupings. Further, new concepts and issues such as climate change, ecology, navigational ice conditions, service industries, and resource dependent communities are introduced. Overall, there is the same number of maps, if not more, in all of the other groupings with water, geormorphology and territorial divisions having greatly expanded. This is offset by a reduction in the prominence of infrastructure maps, especially communication and transportation, agriculture, and cities; the fisheries map disappears and energy, roads and automobiles are new sub-topics. How subjects are approached also changed as interactivity and hyperlinking permits a more relational geography.

\subsection{Making Maps and Making Up Spaces and Places}

Hacking's framework, as discussed in Chapter 3 , is a methodology to investigate how categories and classifications make up people, and in this case, make up places and spaces. The following examines four map topics, particularly their classification systems, using this methodology. Geography, at its most basic, is the study of human interaction with the environment, which includes among other things, classifying human activities and physical features in order to model and understand them. As Bernard Debarbieux (1992) defined it, modeling is a way to imagine geography in order to understand it. Cartography is the art and science of modeling classifications into maps while nominal classification is the qualitative assignment of similarity and difference of things, which can be 
activities, objects, features or ideas. Organizing atlas content into themes or content groupings is a type of nominal classification. In physical geography, classification is part of the scientific practice of modeling processes, and each field and sub-field has its own system and these evolve as do field classification systems. The Atlas, for example, includes: geological provinces and ecological regions; the Soil Classification System of Canada; the Thornthwaite Climate Classification System; Climate Change Modeling; Quality of Life Indicators; social determinants of health such as poverty; land treaties classified by their eras; the routes of explorers organized by the names of their patrons; and the territorial evolution of Canada, delineated by agreements, boundary disputes and acts of parliament. These represent but a few of the hundreds of classification systems used in the Atlas of Canada.

Each map illustrates a classification system, derived from the norms of each map author's science and discipline. The classified data are rendered into provinces and territories, isolines, regions, ecozones, census geographies or electoral districts to name a few. Each classification system creates new spaces and places to: mine; protect, control, develop; farm; understand spaces based on their evapotranspiration, temperature and precipitation; predict the places that may change due to climate; and create land classes and regions using pattern recognition satellite image algorithms. Mapped classes are further divided into scales to either rank or further differentiate the variables so mapped. Cartographers spend a great deal of their time following conventions and 
developing symbols and methods to render classifications into maps. At its most basic, classification is:

a process in which objects are placed in groups having similar or identical or similar features. The individuality and detail of each element is lost. Information is conveyed through identification of the boundaries of the group. Classification reduces the complexity of the map image, helps to organize the mapped information, and thus enhances communication (Dent, 1990:16).

Because it is not possible to review all the classes in the Atlas, a selection of maps and topics was selected for illustrative purposes: relief, forest biogeography, communications infrastructure, and territorial evolution. The grouping of relief was selected because it is a fundamental map found in most general atlases. In the Atlas of Canada, it is found within the first 5 pages of all of the hard copy editions and the $4^{\text {th }}$ edition begins with relief. Relief also represents the Canadian landscape. Biogeography includes vegetation, flora and fauna. The grouping of forest was selected as its mapping has greatly evolved over time. Forest appears in all of the editions with its importance to the Canadian economy and society, and it also represents a feature from the 'natural' world. Communications was selected from the grouping of infrastructure because it appears in all but the $6^{\text {th }}$ edition and it represents a human built feature important to the Canadian economy and culture. Territorial evolution was selected from the grouping of territorial divisions since it explains how the shape and extent of Canada officially came to be. Although demographics is the largest of all the groupings in the Atlas (see Figure 15 on page 148 and Table 4 on page 149), this grouping will not be discussed in great detail in this Chapter since demographics is a topic covered in the next Chapter dealing with the Canadian census. Many other groupings are 
also not discussed in detail due partially to their not appearing in all the editions or not being one of the largest groupings. These four topics, however, adequately illustrate how spaces are made up and how geographical imaginations shape space.

\subsubsection{Relief}

Relief is the shape and form of the surface of the earth below and above sea level. It is generally represented on maps with isolines and hypsometric colour tinting. Elevation is measured in feet and fathoms for the $1^{\text {st }}$ and $2^{\text {nd }}$ editions, feet only for the $3^{\text {rd }}$ edition, and metres for the $4^{\text {th }}, 5^{\text {th }}$ and $6^{\text {th }}$ editions. Land and bathymetric contours for oceans generally reference mean sea level, while lake bathymetry references mean lake levels. Accuracy is dependent upon the quality of measuring systems, the skill of land or ocean surveyors, the geodetic framework, the nature of the model and algorithm used, the concentration of points measured, as well as how these elements were interpolated and then generalized into contour lines. Contour intervals represent elevation while the contour represents the geometric form of the land surface such as angles, direction of slope and steepness. The legend is normally a bar of colours marking the range of depths and heights above and below sea level. It is featured as two full sheets in the $1^{\text {st }}$ and $2^{\text {nd }}$ editions, representing a west and east sheet. It is a series of four sheets in the $3^{\text {rd }}$ edition, depicting Canada as a whole, east, west, and north of $65^{\circ}$. In the $4^{\text {th }}$ edition, it is featured as four full pages; the first map being the standard relief map and the Relief Profile map discussed earlier (see Figure 20, page 188). There is only one sheet in the $5^{\text {th }}$ edition and one map for the $6^{\text {th }}$. 
Relief is an object of study in geomorphology and topographic maps are not the same as relief maps since topographic maps provide more detailed information about surface features that include relief, terrain, vegetation, soils, rivers and human made landscape features. Relief is strictly represented with contour lines, a technique developed in the late $18^{\text {th }}$ century by French cartographers that came into general practice by the beginning of the $19^{\text {th }}$ century, along with advances in topographic mapping (ImHof, 1982).

Relief maps in the Atlas (see Figure 26) are found with physical geography such as geology, geomorphology, physiography, regional geography or biogeography. In the $6^{\text {th }}$ edition, Relief is categorized within the topic of environment and the sub-topic of land; it is a framework data layer for other maps (e.g., the ecology series). The text accompanying the relief map in the $6^{\text {th }}$ edition describes regional landscapes and provides definitions for Atlantic Provinces, the Appalachians, St. Lawrence and Great Lakes lowlands, the Canadian Shield, the Prairies, the mountain ranges and high plateaus of the Canadian Cordillera, and Northern Canada. Regions are also a spatial classification system, based on "socially constructed generalizations about the world" that become embedded in our imaginations as facts about spaces (Gregory et. al, 2009:630). In the $5^{\text {th }}$ edition, Canada - Relief (sheet 3.1) is the only map classified within the realm of geomorphology. In the $3^{\text {rd }}$ edition, with its emphasis on science, relief maps are called Bathy-Orography (sheets 9-12; also see Figure 21 on page 188). In the $4^{\text {th }}$ edition, it is simply called Relief (pages 1-2) while in the $1^{\text {st }}$ and $2^{\text {nd }}$ editions, it is called Physical Map of the Dominion of Canada (sheets $2 \& 3$, pages 5-8). 
Relief is a fundamental map in most atlases because it is related to climate, water drainage, vegetation, and animal habitat. It also indicates where and what type of agriculture and other activities can be practiced. Relief is correlated with geology and geomorphology and, to some extent, determines the nature of surface material. Relief is also correlated with and determines the places where people can live, for example, a transportation barrier is a form of natural protection from intruders, and as Fremlin rightly stated, it is the platform upon which human actions occur. 

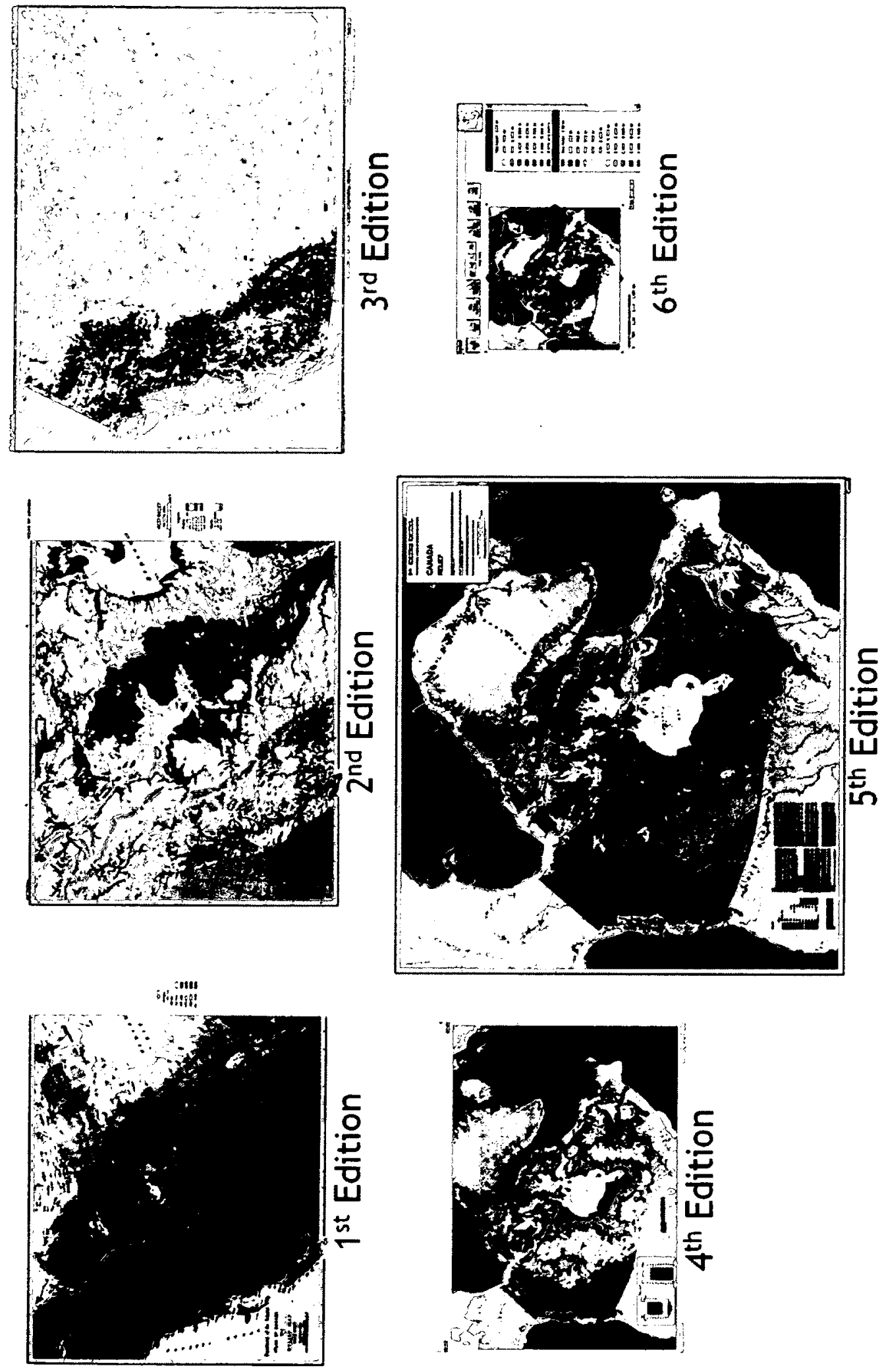

Figure 26. Atlas of Canada Relief Maps 
Relief maps require the expert knowledge of land, tidal and ocean surveyors, as well as geodetic experts and astronomers among others. While there were no notes accompanying the relief maps of the $1^{\text {st }}$ and $2^{\text {nd }}$ editions, we do know that White was insistent that altitude be known. He collected relief data over the duration of his career, which culminated into the creation of his Altitudes in the Dominion of Canada, first published in 1901 and then again in 1916, along with his Dictionary of Altitudes, first published in 1915. The data he used span from the 1880 s until 1915 . As previously discussed, White was determined to attract investment and wanted to ensure that geographical elements did not impede interest. For example, he knew Canada was not rich enough in coal for power generation so knowing the elevation of rivers was critical in order to demonstrate the potential for hydropower. He also recognized the obstacles for building the trans-continental rail line, promised to British Columbia if it entered Confederation.

White's 1901 Relief Map of Canada and the United States enlisted compilers with regional expertise about British Columbia, Central Basin, Ontario, Eastern Provinces, Labrador Peninsula, Alaska and Polar Regions (White, 1901). The data for that map were compiled from various sources, including what were, at that time, the "latest surveys and observations" (1901 Relief map legend notes). One such example, as noted on the legend, was: Data from the United States from the Map published by the U.S. Geological Survey. Other sources of data included the Canadian Deep Waterways Commission, responsible for measuring depths of waterways, which had already determined mean lake levels at that time. White 
also refers to a Geological Survey Bulletin, published in 1884 by J. W. Spencer, which lists the elevations of the Dominion. He compiled information from various sources54. The plane references he used were mean sea level, the base of rails opposite station buildings, and the centre of siding and bridges (White 1901:iii-iv). In the second edition of his Dictionary, he provides four pages of the principal authorities that provided altitudes data55. It is inferred that White used his altitude data to create the relief maps found in the $1^{\text {st }}$ and $2^{\text {nd }}$ editions. No information was provided regarding bathymetric depth source data but it is likely that the Hydrographic Service, which was created in 1883 , collected them by using leadlines and triangulation. The Service was also involved in tidal and current metering, starting from 1893 , along with precise water level gauging. Bathymetric mapping in Canada was indispensable to explorers. It informed the navigation of Canadian seas and coastlines; Samuel de Champlain's earliest surveys (1612) were of the relief of the Atlantic coast and many explorers followed suit (e.g., James Cook, William Edward Parry, Henry Bayfield) (Nicholson \& Sebert, 1981). The British North American (BNA) Act assigned hydrographic charting to the federal government and all hydrographic mapping was consolidated into one department by 1904 (Nicholson \& Sebert, 1981). Relief

\footnotetext{
${ }_{54}$ The Department of Railways and Canals, railway companies, GSC maps, the British Admiralty, US Coast and Geodetic Survey, US and Canadian Deep Waterways Commissions, reports of irrigation surveys, and the International Boundary Commission of Canada.

55 These included: individual surveyors, maps and charts, Boundary Commissions, power companies, city engineers, US Coast and Geodetic Survey, Committee of Conservation, Dept. of Lands, Forests and Mines Ontario, Geodetic Survey of Canada, irrigation surveys, Public Works, Railway and Canal Department, the Surveyor General, the Chief Astronomer, Levelling supervisors, engineers and Tidal Surveys. It also included Canadian Benchmarks on Great Lakes, Harbour Master Guages and Sea Level Datum, Mean Sea Level Determinations by Tidal and Current Survey.
} 
mapping of the Rockies was also critically important; between 1888-1892, maps were drawn using a system called photo-topography, a process used in Canada for 75 years (Nicholson \& Sebert, 1981).

The $3^{\text {rd }}$ edition referenced the Canadian Hydrographic Service as the provider of bathymetric data, the Topographical Survey for orographic data, and the Geographical Branch, Department of Mines and Technical Surveys (MTS), for information about names of principal features. The Geodetic Survey, launched in 1909 , was using advanced aerial photography reconnaissance by 1930 , which allowed for more extensive and precise mapping. Large areas of Canada had not been mapped topographically by the 1940 s but this changed at the end of the war. By 1957 , all of Canada had been photographed and a large portion of the country had been mapped topographically (Larsgaard, 1984). The Extent of Topographical Surveys map of the $3^{\text {rd }}$ edition is a testament to the mapping progress achieved by that time (see Figure 19; page 178). Relief mapping for the $3^{\text {rd }}$ edition reflected the boom days of mapping in Canada, which was marked by a period of significant investment and post war technological advancements.

The $4^{\text {th }}$ edition relief maps were compiled from the EMR Surveys and Mapping Branch Map Series MCR 5 1:2 000 ooo, the EMR National Topographic Systems Maps, and the 1: 1000 ooo EMR World Aeronautical Chart. Bathymetric data were compiled from the Department of the Environment Marine Sciences Directorate data, the 800 A revised and 896 series of the Hydrographic Services, the International Hydrographic Bureau General Bathymetric Charts of the Ocean, and the US Department of Commerce Coast and Geodetic Survey Hydrographic 
Chart 5052. In the early 1970 s, the process of digitizing maps had begun for the 1:50 ooo topographic maps, and terrain data, from this point on, was to be stored in digital form; the idea to develop digital terrain maps directly from plotting instruments began by 1976 (Larsgaard, 1984). Field specialists collected elevation data for their own specialist maps which were a primary source of information for the $4^{\text {th }}$ edition maps. The maps in this edition are a number of steps removed from original data and are part of the cartographic practice of generalizing small-scale maps into larger scaled maps. The $4^{\text {th }}$ edition maps did not require meeting high precision and accuracy standards since they were not created for navigation purposed.

The $5^{\text {th }}$ edition relief map was compiled from a number of ocean and inland water maps that came from many national and international institutions ${ }^{56}$. This was also the case with the $6^{\text {th }}$ edition 57 .

Today, surveying and hydrographic mapping in Canada is governed by numerous organizations, associations, and legislation such as the following:

${ }^{56}$ The EMR Geoscience Centre, Fisheries and Oceans, Canadian Hydrographic Service, and Survey and Mapping Branch; Canada Department of the Environment; UNESCO International Hydrographic Organization and Intergovernmental Oceanographic Commission; US Department of the Interior, US Naval Oceanographic Office and US Defence Mapping Agency. Hydrographic and Topographic Centre, US Army Corps of Engineers, US National Oceanic and Atmospheric Administration and USGS. Scientific advice for ocean areas was provided by Geoscience Mapping, Canadian Hydrographic Service, Fisheries and Oceans as well as other great lakes experts from the US.

57 Bathymetry data were derived from The GEBCO Digital Atlas (1997), published by the British Oceanographic Data Centre on behalf of the Intergovernmental Oceanographic Commission (IOC) of UNESCO and the International Hydrographic Organization (IHO) and relief elevation data were derived from the 1986 Canada-Relief, $5^{\text {th }}$ edition of the Atlas. 
- Canada Lands Surveyors Act

- Canada Lands Surveys Act

- Department of Natural Resources Act

- Resources and Technical Surveys Act

- Charts and Nautical Publications Regulations 1995

- Cartographic Standards and Speciation's, Centre for Topographic Information

Relief maps, although simple looking, require a collaborative effort from experts in the topographic, hydrographic, oceanographic, surveying and geographic fields. Mapping relief has a long history in Canada and has played an important role in its development. Figures 26 (page 238), 21 and 22 (pages 188) illustrate the increase in precise knowledge over time and evolution of Canadian relief while also demonstrating the standardized way of representing relief in maps.

\subsubsection{Forest Biogeography}

Biogeography is the study of the geographic distribution of plants and animals. The grouping includes maps that portray the distribution or range of plants or animals based on scientific taxonomies, habitat or ecology. However, if a map discussed forests in the context of forestry, it was grouped in industry. Similarly, fur bearing animals and wild game were classified as industry, and if fur was discussed in the context of a farm, it was grouped within agriculture. The same applies for animal husbandry.

A forest is a grouping of tree vegetation and forests in the Atlas of Canada, that are classed into regions according to their density, soil and atmospheric moisture regimes. They are also classed by type of forest or vegetation alliance, botanical names, forest ecological regions and sections, and ecozones; finally, they are 
mechanically classified into leaf types (see Figure 27). Forest appears in each edition for example: forests such as Range of Commercial Forests ( $3^{\text {rd }} \& 4^{\text {th }}$ ), pulp and paper and sawmills ( $3^{\text {rd }}$ to the $6^{\text {th }}$ ), and Forest-Reliant Communities $\left(6^{\text {th }}\right)$. These latter maps were grouped into forestry, which is a sub-group of industry. The $6^{\text {th }}$ includes forest fires, found under Hazard and Climate Change.

In the $1^{\text {st }}$ and $2^{\text {nd }}$ editions there are only two biogeographical maps: Forest (sheet 8, pages 17-18) and Limits of Forest Trees (sheet 9, pages 19-20). In the $1^{\text {st }}$ edition, these are grouped with physical geography, after minerals and before infrastructure. In the $2^{\text {nd }}$ edition, they are also positioned after minerals but before drainage basins, unlike the previous edition. The Forest map of the $1^{\text {st }}$ edition is classified into Southern Forests, Southern Forests Largely Cleared, Northern Forests Densely Wooded, Northern Forests not Densely Wooded, Cordilleran, Mixed Prairie and Woodland, Prairie, National Parks, and Timber Reserves, as well as Outliers of Wooded Country. The $2^{\text {nd }}$ edition is very similar however the Cordilleran Forests are further sub-classified into Coast, Dry Belt, Wet Belt and Interior Mountain Forests, and the national parks and timber reserves disappear. The classification system categorizes forest by the region where it is found (e.g., north, south, prairie, Cordillera), the density of the forest, and moisture regimes within the Cordillera region, and type of forest or vegetation alliance (e.g., mixed prairie and woodland), which was part of the vegetation classification system of the period. Both editions include an extensive list of Principal Trees of Canada with common, genera and species names that are in accordance with the "rules adopted at Botanical Congress, Vienna 1905". 


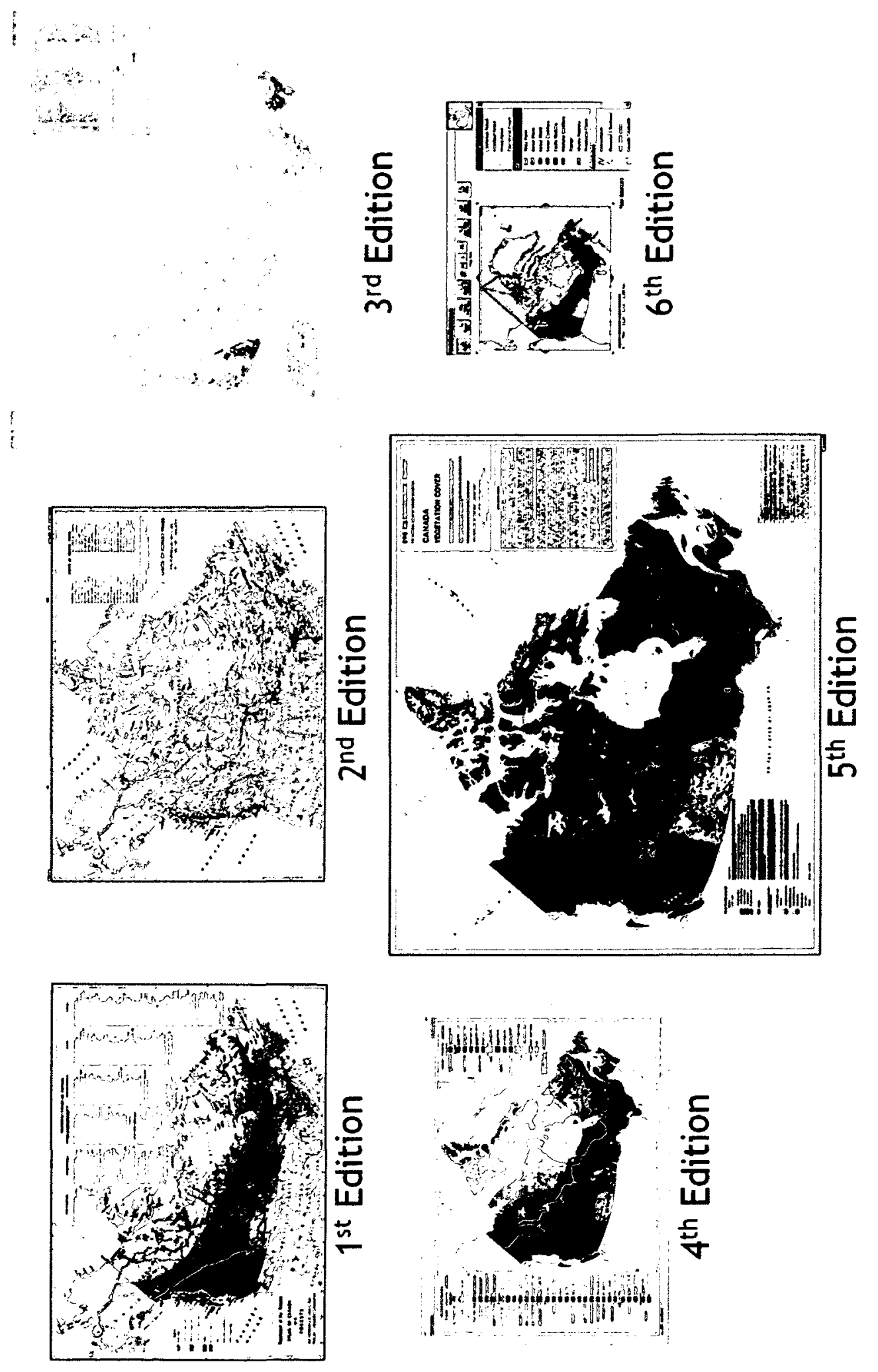

Figure 27. Maps in the Atlas of Canada that Feature Forest 
Although the $3^{\text {rd }}$ edition includes a number of forest maps (see TOC in Appendix D), the Forest Regions map (sheet 39) is the one examined here. It is grouped in the vegetation and animal section of biogeography, just after soils and before Parks \& Reserves and demographics. The legend classifies the Boreal Forest Region into sub-regions of Predominantly Forest, Aspen Grove and Forest, and Barren; the next forest regions are Subalpine, Montane, Coast, Columbia, Deciduous, Great Lakes - St. Lawrence, Acadian Forest, and Non-Forested areas. According to the Canadian Forest Service:

[the] forest region classification does not incorporate all of the environmental variables, but relies mainly on the nature of the vegetation or forest composition to classify the regions. A forest region is a geographic zone with a vegetation cover that is fairly uniform in terms of dominant species and stand types (CFS, 2011).

A forest was at this time understood as:

[a] major geographic belt or zone, characterized vegetationally by broad uniformity both in physiognomy and in the composition of the dominant tree species. It corresponds to the concrete forest 'formation' as generally understood, but without the classic ecological implications (Rowe, 1959:8).

The map also includes a list of Forest Sections for each region. A forest section is "a subdivision of the Region, conceived as a geographic area possessing an individuality which is expressed relative to other Sections in a distinctive patterning of vegetation and of physiography" (Rowe, 1959:8). The map includes shaded and coloured regions with sections depicted by their section letter and number. The map also includes bar charts showing the number of square miles for each forest region for Canada and by provinces and territories. This map applies an early forest ecological classification system of eight regions 
geographically represented as coloured areas with sub-regions called sections represented by its unique identifier, which are carefully described in Stanley Rowe's Forest Regions of Canada (1959).

Forest maps in the $4^{\text {th }}$ edition are all related to industry; however the Vegetation map includes forests (pages 45-46). Forest regions are further subdivided by their leaf types, such as needle leaf and broadleaf trees, and by species, which are labeled by their common names. The $4^{\text {th }}$ edition applies the same ecological classification system used in the $3^{\text {rd }}$, however, there are less regions represented due to scale and the broadness of the map's topic.

The $5^{\text {th }}$ edition only includes forestry maps. Like the $4^{\text {th }}$ edition, this edition's Vegetation Cover (sheet 7.1) map includes Forest Land of Continuous Forests, which includes Coniferous, Broadleaf, Mixed and Transitional forests. It is within the realm of Phytogeography, just after the physical geographical grouping of water and before the biogeographical sub-group of ecology. The land cover type called forest includes areas where $50 \%$ of the area is forest, and within that category, there is continuous forest, which represents $76 \%$ of the forest canopy that is coniferous. Transitional forest includes a mixture of land cover where tree cover is discernible as forest but occupies less than $50 \%$ of the land cover. This map "is a first approximation of vegetation cover categories of Canada that can be interpreted from satellite imagery" (Sheet 7.1. $5^{\text {th }}$ edition text). 
The $6^{\text {th }}$ edition includes a number of maps about forests, including: two forest protection maps; a number of biogeographical maps such as vegetation; wetland and forest maps; plant hardiness zones; and territorial ecozones. The map examined here is the Forested Ecozones under Environment/Forests. Forested Ecozones was selected because it applies an evolved version of the ecological classification system seen in the $3^{\text {rd }}, 4^{\text {th }}$ and $5^{\text {th }}$ editions. The map includes forested areas that are as follows: Coniferous, Broadleaf Forest, Mixed Forest and Transitional Forest. The data set used for these was the $5^{\text {th }}$ edition satellite image of Vegetation Cover. The map also includes 9 forest ecozones: Taiga Plains, Boreal Plains, Boreal Shield, Boreal Cordillera, Pacific Maritime, Montane Cordillera, Prairies, Atlantic Maritime and Mixedwood Plains.

[Ecozones] define the ecological mosaic of Canada on a sub-continental scale. They represent an area of the earth's surface representative of large and very generalized ecological units characterized by interactive and adjusting abiotic and biotic factors (Ecological Stratification Working Group (ESWG), 1996).

Two classification systems are applied to the study of ecozones: a remote sensing system and the National Ecological Framework for Canada (Marshall, Schut \& Ballard, 1999). Forests are the object of study of vegetation experts, botanists, forest specialists, foresters and conservationists to name a few. They were first managed by the Federal Government, since 1873, and later managed by federal, provincial and territorial governments. Forests are also a concern of the federally led Canadian Forestry Association, founded in 1900 to manage, study and inventory forests, and the Commission on Conservation, which oversaw their protection since 1909. Forests were at one time the responsibility of the now 
defunct Department of the Interior, and over time, responsibility for forests shifted to a number of departments: Fisheries, Northern Affairs, Agriculture and Environment. Today, forests are the responsibility of Natural Resources Canada, Canadian Forest Services and Parks, and their provincial and territorial counterparts, as well as a number of associations and research centres.

There are no notes to accompany the Forests maps of the $1^{\text {st }}$ and $2^{\text {nd }}$ edition. However, there was, at that time, much ongoing activity within the Department of the Interior. The Department was responsible for monitoring forest fires, planting trees, managing nurseries, inspecting for diseases, counting timber revenues, and surveying lands that were covered by forests or were deforested. There was concern about unmanaged forests and unabated forest clearing; a 1903 departmental report spoke of the deplorable past habits of old-world countries that resulted in the destruction of timber along waterways and the subsequent problems associated with desertification. Early reports also discussed the planning of forest reserves, which were forests set aside on crown lands in the territories and along railways, and on provincial lands for the purposes of ensuring a "permanent supply of timber, of maintaining conditions favourable to a continuous water supply and of protecting animals, fish and birds within the reserve boundaries" (DBS, 1915:222). These areas were equipped with forest rangers fire prevention services and management policies where "measures [were] taken, especially by the education and training of forestry experts, to bring the forest areas of Canada gradually under more scientific and remunerative management" (DBS, 1915:222). 
White left his post as Chief Geographer in 1909.to become the Director of the Commission on Conservation, where forests were one of its main concerns. The $1^{\text {st }}$ edition's Forest map, for example, appeared in a 1915 paper given to the Royal Society by a member of the Commission on Conservation, which discussed the deterioration forests and the scarcity of fine woods from some species in many parts of Canada. As early as the turn of the $20^{\text {th }}$ century, there was recognition that forests were not inexhaustible, were being depleted and required protection and management (Adams, 1915).

The Principal Trees of Canada Table of the $1^{\text {st }}$ edition Forest maps makes reference to the International Botanical Congress (IBC) and the International Rules of Botanical Nomenclature, adopted by the International Botanical Conference of Vienna 1905. The rules developed by the IBC informed the International Code of Nomenclature for algae, fungi and plants, with the first having been published as Species Plantarum by Carl Linnaeus in 1753. The Limits of the Forests maps illustrate how far north a particular tree species can be found with a series of lines and labels each line with both the familiar and the scientific name of the species. The Department of the Interior Report also makes reference to mapping timber limits and reserves (1903). No information was found regarding the classification system, however, an undated map entitled Map Showing General Physiographic Divisions of the Dominion of Canada regions in the 1915 Report of the Commission of Conservation by Frank D. Adams suggests that perhaps the general regions on the 1906 map are the physiographic regions Adams referred to and mapped in his report. Physiographic regions are often 
created by classifying the differences in the underlying rock structures and in the patterns of occurrence of land surfaces and Canada have been stereotypically described physiographically for quite some time (Putnam \& Putnam, 1970).

The $1^{\text {st }}$ edition includes National Parks and Timber Reserves, reflecting Canada's progressive position in being one of the world's first countries to develop a national park system as early as $\mathbf{1 8 8 5}$. The Forestry Commissioner, J. H. Morgan, stated in 1886 that the status of forests had shown "the pressing necessity which exists for their more careful preservation and extension by planting, as a sure and valuable source of National Wealth". Data for these Atlas maps came from the Department of the Interior's Forestry Branch as Superintendents were coordinating the work of their surveyors to inventory forests, as well as they came from the Department of Agriculture, which collected forest statistics between 1893-94 and published these as part of the Minister's Report (DBS, 1896). The multiple roles played by forests beyond the provision of timber were well known early on. For example, the Agriculture Statistician in his 1895 report stated:

the influence of forests on climate, on agricultural operations, on river fisheries, on water communications, on the health of the people and on the general traded and industry of a country is so far reaching that an examination of the value of our forests branches out in many directions, all of immense importance" and further "the mechanical effects of forests makes itself felt chiefly in regard to the distribution of the rain water, the preservation of soil on sloping ground, the binding and moving of sand, and the prevention of avalanches (DBS, 1896:135).

While not explicitly stated on the map, the classification system applied in the $3^{\text {rd }}$ edition of the Atlas resembles those developed by John Stanley Rowe. Rowe was 
a botanist and ecologist who worked with the Department of Forestry from 1948 to 1967 and who wrote the Forest Regions of Canada, first published in 1959 and later revised in 1972. His classification system updated the work of W. E. D. Halliday, author of $A$ Forest Classification for Canada that was published in 1937. Halliday, in turn, modified the work found in two sources: the 1929 book, Plant Ecology, by J. E. Weaver and F.E. Clement and the 1912 book, Forest and Land Classification of Canada, by B. E. Fernow (Halliday, 1937:5). Fernow, who was the Chief of the United States Division of Forestry in Washington D.C, and then Dean and Director of the New York State College of Forestry at Cornell, was well known in Canada. He had presented at the Canadian Forestry Association in $1902^{58}$ and published with White and C.D. Howe. The eight regions and sections on the $3^{\text {rd }}$ edition maps are the same as those listed in Rowe's 1959 publication. The classification takes into consideration physiographic, soil and climatic conditions which influence the character of the forest.

By 1921, forest mapping had become more prevalent, mostly due to advances in air photo surveys. Shortly after WWI, air photos were used to create a forest inventory series showing different wood types and such measuring of crown cover had become the norm (Nicholson \& Sebert, 1981). Forests were generally the responsibility of provinces and this was made explicit with the transfer of these responsibilities in the 1930 os as per the BNA Act. The federal government as a result of the Forestry Act now provides assistance to the 10 provinces and three 
territories for sustainable management of forest resources. This assistance is focused on forest protection from fire, insects and disease detection and management, recreational facilities, woodlot improvement projects, reforestation, publicity, and education, as well as subsidies to the forest industry for woodland management and research (DBS, 1956a). Part of the implementation of agreements between provinces and territories (P\&T) was conducting a forest inventory which was carried out by the P\&Ts and entailed the following: interpretation of ground control surveys; aerial photography and interpretation; field sampling; and preparation of forest maps and inventory reports which for the first four years of an eight year project resulted in a federal transfer of $\$ 3,630,223$ (DBS, 1956a:466), which is equivalent to $\$ 30011501$ in 2012 dollars CDN. The federal government was also involved in research into forest inventory methods and this included the construction of scientific research technology for aerial photography. The data derived from these forest inventories most likely informed the Forest Regions map in the $3^{\text {rd }}$ edition.

Responsibility for forests was with the Department of Northern Affairs and National Resources when the $4^{\text {th }}$ edition was produced. Rowe's forest regions are seen in the $4^{\text {th }}$ edition and his 1959 publication is specifically referenced as a source along with provincial atlases and forestry maps. Forestry was under the administration of the Department of Forestry and Rural Development, which was responsible, among many other things, with conducting forest surveys to inform their management and protection. The federal government was responsible for 
the territories, federal lands such as national parks, Indian reserves, military areas and forest experiment stations and relations with provinces (DBS, 1968).

The $5^{\text {th }}$ edition map was created with satellite imagery and ground observations. The new technology at the time was limited to a $1 \mathrm{~km}$ resolution, and only a limited number of categories could be identified. Vegetation was classified based on reflectance values and the classification techniques used were a combination of supervised, automated, 'maximum likelihood' and manual. In addition, classification training was based on the use of Landsat imagery, Atlas maps, the Canada Land Inventory and Canada's Forest Inventory Data, provincial sources and local knowledge. The images were also filtered and assembled digitally using the Scietex cartographic output system. (The map is currently available as a digital dataset.) Satellite imagery classification in 1993 could distinguish needle and broadleaf types and has since become more sophisticated as technology, techniques and resolution have improved. The classification system was developed based on the technological capabilities of a satellite sensor, which limited distinguishing the forest by the reflectance signatures of the canopy, its density and leaf type. The system was also based on using image analysis software and applying algorithms to understand the signatures, which included programming the software to recognize patterns found in other maps and ground truthing.

The $6^{\text {th }}$ edition maps also included a modified and enhanced version of Rowe's earlier forest regions. Rowe's work influenced the Canada Committee on Ecological Land Classification (CCELC), which developed Canada's ecological 
framework. The Land Directorate of Environment Canada met with key federal departments and agencies, provincial representatives and specialists from universities in 1976 and founded the CCELC, a national forum with the objective to "delineate, classify, and describe ecologically distinct areas of the earth's surface at different levels of generalization using various abiotic and biotic factors at each of the levels". With the formation of the CCELC, ecological representation became a new way to understand the biophysical world (EC 1979a). Between 1976 and the mid-1980s, a hierarchical classification evolved with seven levels of generalization and these are from the broadest to the smallest: ecozones, ecoprovinces, ecoregions, ecodistricts, ecosections, ecosites and ecoelements (ESWG, 1996).

Canada's 15 ecozones were prepared for the State of the Environment Report for Canada published in 1986. The predecessor of the CCELC were the subcommittee on Bio-Physical Land Classification and a sub-committee of the National Committee on Forest Land, which discussed survey techniques and were dissolved in 1972 (EC, 1979a). The first proximation of a vegetation classification system, at least the $1^{\text {st }}$ three levels of the hierarchy, was developed in 1987 and it was interconnected with the international community by working with the International Association for Landscape Ecology (IALE) (Rubec, Wiken, Thie \& Ironside, 1988). In 1991, the Ecological Stratification Working Group undertook a collaborative project with federal agencies and provincial and territorial governments, to revise and update previous work and establish a common ecological framework for Canada (Marshall, Schut \& Ballard, 1999). A 
holistic approach was required as a way to move away from particularistic elements and this necessitated the development of a national ecological framework:

to provide a consistent, national spatial context within which ecosystems at various levels of generalization can be described, monitored, and reported on. The use of such a framework of standard ecological units provides for common communication and reporting between different jurisdictions and disciplines (Marshall, Schut \& Ballard, 1999).

The standardization of the classification allowed for the creation of databases to be used by many other stakeholder classifications, and it was hoped that it would become as important as the Canadian System of Soil Classification. The ecological land classification system was incorporated into the Environmental Impact Assessment Review Process, established by Cabinet decision on Feb. 15 1977. The purpose of an Environmental Impact Assessment (EIA) based review process is to ensure that the effects of federal projects, programs and activities are assessed early in their planning. The types of projects subject to assessment can include hydroelectric developments, and these guidelines are to be applied to assist project planners, managers and specialists to gather and analyze environmental data using integrated and cost effective methods (EC, 1979b). Specifically, the ecological land classification approach was used to inform many development projects59.

59 Hydro projects, Integrated Land Resource Survey Ecological Land Classification in Québec, impact assessment, tourism and recreation projects, to evaluate agroclimatic capability, resource management in national parks, evaluate and assess wildlife habitats, ski lift and highway construction projects; urban development assessment; mine and mill site assessment, oil pipeline 
The ecological land classification system was normalized into fieldwork training packages (see Figure 28) and used by officials, scientists and field researchers at all levels of government to facilitate the work of classification using remote sensing systems and reconnaissance surveys (EC, 1990). The Canadian Vegetation Classification System (1990) included: the full classification system; diagrams to distinguish plant communities; a sheet that contained the full classification system that can be used as criteria for field surveys; and a Relevé Registry Form to capture surveyed field data. This helped standardize data gathering. The Vegetation Classification System report was designed specifically for vegetation scientists and resource managers "to participate in the continued development of this national system" (EC, 1990:7).The following lists some institutions involved with and agreements related to forests and their oversight:

- Canadian Forestry Association Conventions

- Forestry Act

- Canada National Parks Act

- The 1992, \& 1998 Forest Accord6o

- National Forest Strategies

- Canadian Council of Forest Ministers which produces the Canada Forest Inventory database

routing; Indian Reserve Studies; private sector forestry; regional planning to name a few (EC, 1979b).

60 Its 25 signatory organizations (the National Forest Strategy Coalition) are a broadly based coalition of federal, provincial and territorial governments, labour, industry, aboriginal peoples, environmental groups, academics and private woodlot owner organizations and Provinces, as signatories to the Accord, have developed their own forest accords and strategies with a great deal of public involvement, and some provinces have codes of practice for forest operations. Industrial signatories have also been working on plans for sustainable forest management. 
Conceptions of forest as an object changed in the Atlas of Canada. Beginning with inventory like vegetation maps of the $1^{\text {st }}$ and $2^{\text {nd }}$ editions, to the representation of ecological regions and technologically mediated classes in the $5^{\text {th }}$ and $6^{\text {th }}$ editions, and finally into an ecological framework of ecozones. This entailed the work of government officials and scientists from many fields in trans-disciplinary settings, the continuous refinement and building upon of earlier scientific knowledge, and the application of new technologies and models to create regions and, in turn, new kinds of spaces. 


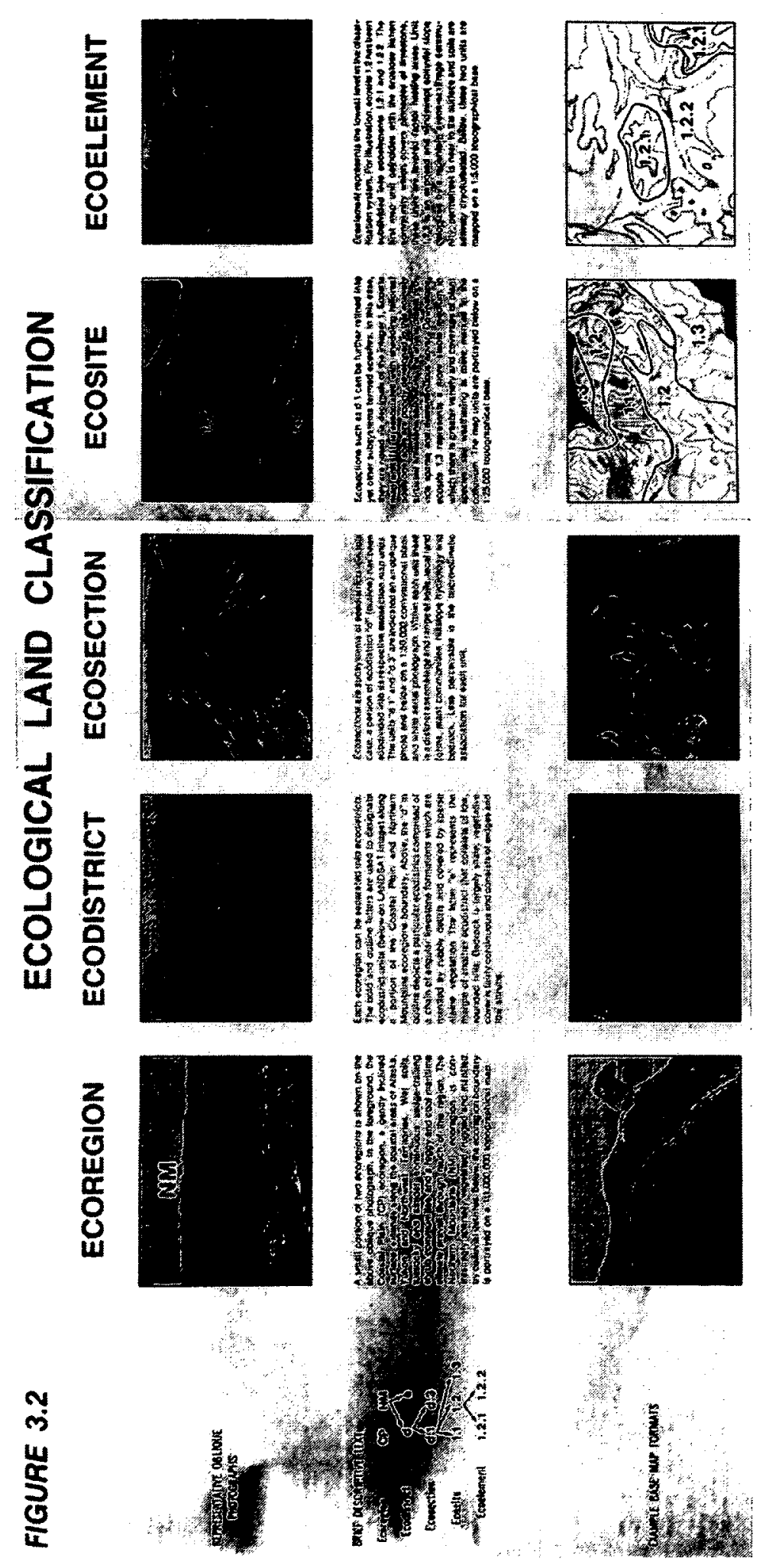

Figure 28. Classifying, Mapping and Normalizing Ecological Land Classification (EC, 1981) 


\subsubsection{Communication Infrastructure}

Infrastructure as a grouping refers to large, human built, socio-technological systems upon which the Canadian society and economy rely on to move people and goods, to communicate from coast to coast to coast, and to energize our homes and industries. Infrastructure as found in the Atlas of Canada is described by its material manifestation and less by its social and economic impact even though infrastructure related maps are located within the economy sections of many of the editions, $\left(3^{\text {rd }}, 4^{\text {th }}, 5^{\text {th }} \& 6^{\text {th }}\right)$. In a few instances, infrastructure is also a subgroup of climate where the map depicts the location of weather stations and forecast regions or as a sub-group of agriculture where the primary attribute on the map is grain elevators or irrigations systems. As discussed in Chapter 2, infrastructure is substrate, something that recedes into the background and is rarely seen or discussed unless it fails. This concept is further explored here in relation to specific Atlas maps, which demonstrate infrastructure technology but do not communicate how important these are in shaping Canadian identity, society, the economy and the nation.

The communication infrastructure enables people to communicate with each other, through broadcasting and machine-to-machine communication. It is classified according to the physical components of the communication networks represented (e.g., telegraph, telephone, wireless, radio and television) and it is characterized as a hub and spoke network in all of the editions (see Figure 29). 

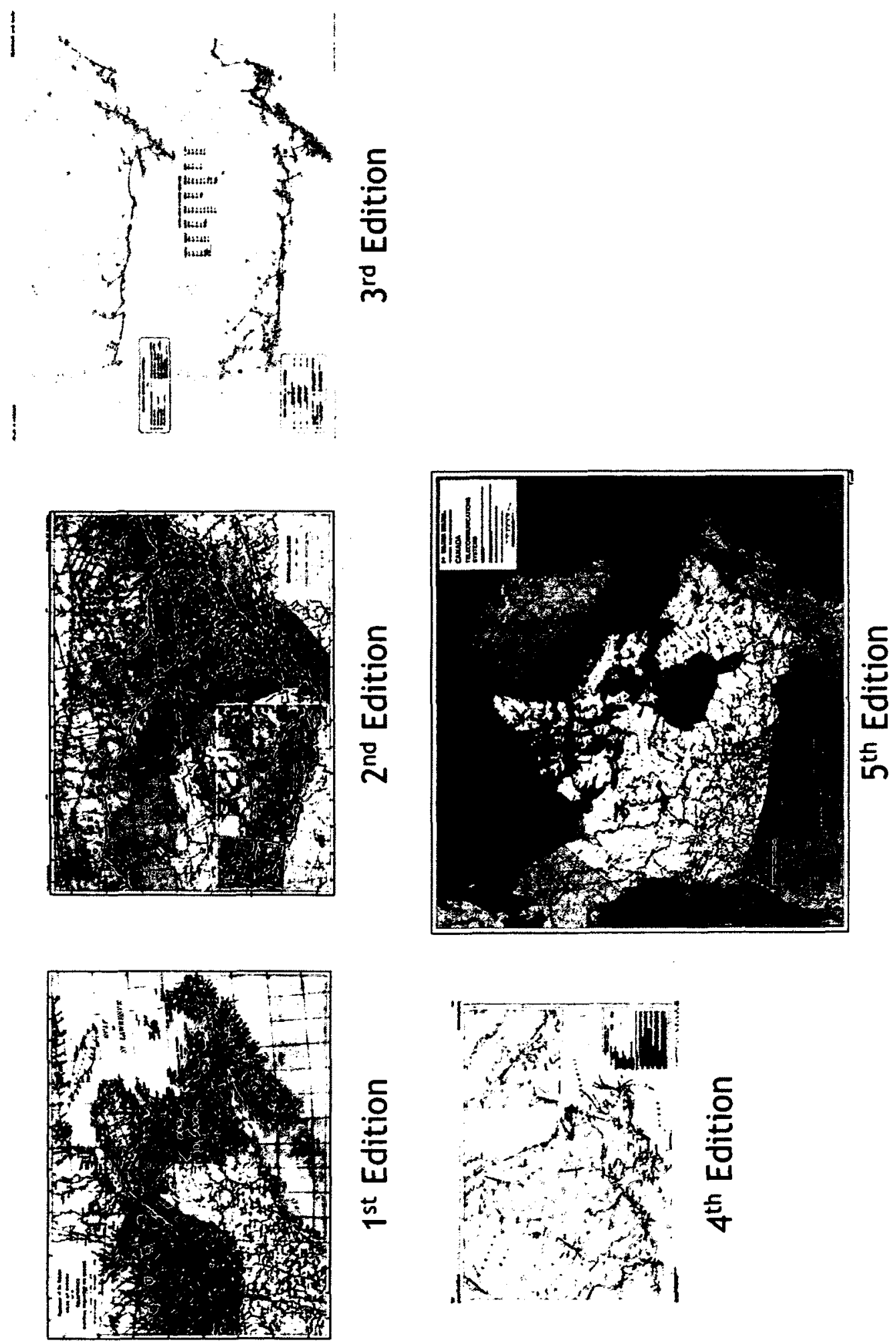

Figure 29. Selection of Communication Infrastructure Maps 
The infrastructure grouping is located after biogeography and just before climate for the $1^{\text {st }}$ edition and after demographics and just before Aborigines of Canada in the $2^{\text {nd }}$ edition. Infrastructure is the largest grouping in the $1^{\text {st }}$ edition and is tied with demographics in the $2^{\text {nd }}$ edition.

The communication infrastructure in the $1^{\text {st }}$ edition includes five telephone maps on 4 pages or 2 sheets and these are: Maritime Provinces and Quebec; Ontario and Quebec; and maps of Manitoba, Saskatchewan, Alberta, British Columbia and Yukon (sheets 14, pages $15 \& 16$ ). The maps depict telephone lines and the hubs where they interconnect. Telephone is not a map topic in the $2^{\text {nd }}$ edition. The $1^{\text {st }}$ and $2^{\text {nd }}$ editions include eight pages each of telegraph maps of Quebec and Maritime Provinces; Ontario and Quebec; Manitoba, Saskatchewan and Alberta; and British Columbia, Yukon, Alberta (sheets 10-13, pages 31-38). The maps depict national telegraph lines and stations. By 1902, Marconi had introduced wireless broadcast and wireless stations were depicted on the maps. The maps for both editions also include international submarine cables and the names of their owners, while the $2^{\text {nd }}$ edition includes a table listing the names of wireless stations and their range in miles.

Although not definitive, these communication infrastructure maps indicate the telegraph lines owned and operated by the Dominion, the railway and telegraph chartered companies, which included in 1914 10,312 miles in lines and 288 knots of submarine cables with 771 offices in 1914 (DBS, 1915:513). The data were most likely from the Ministry of Public Works, which published the location of lines and connecting point data in its annual reports, the Department of Railways and 
Canals, which published telegraph and telephone statistics, and the Department of Naval Service, which published data regarding wireless telegraphy, coast stations and radiotelegraph (DBS, 1915). The Canada Year Book 1915 was probably another source since it listed Chartered Companies with their miles of lines, miles of wire, number of messages and number of offices, along with Coast Stations name, situation and the range each wireless station.

The $3^{\text {rd }}$ edition includes a Television and Radio sheet that includes two maps: Television Stations and Networks and Radio Stations and Networks (sheet 91). Infrastructure is located after economy, specifically manufacturing and before health, education and culture. The Television Stations and Networks map distinguishes the Canadian Broadcasting Corporation (CBC), Private Affiliates, Private Stations (not in operation), Satellite Stations and Satellite Stations (not in operation). The stations classified as 'not in operation' were under construction and affiliates referred to local broadcasters that carried some of the programming of parent stations such as the CBC. The map includes lines depicting Connected English and Connected French television stations. Some stations were under construction and others were serviced by Kinerecordings ${ }^{61}$. The Radio Stations and Networks map includes basic and supplementary lines and stations for the Trans-Canada, Dominion and French networks. It also includes CBC owned and operated stations, non-network stations, pick-up and re-broadcast stations from $\mathrm{CBC}$ stations, $\mathrm{CBC}$ relay transmitters and stations located in selected urban areas.

\footnotetext{
${ }^{61}$ Kinerecordings which is system of recording television sound and image on photographic film used to rebroadcast live programs and Stations temporarily served by off-air pickup.
} 
The $4^{\text {th }}$ edition allots four maps or six pages to communication infrastructure and includes two Communications maps (pages 227-230) for Canada east and west. The maps depict communication systems "available to the public on a commercial basis. Private systems such as those by hydroelectric and pipeline companies and police forces for their own use have been omitted" (Map Text, $4^{\text {th }}$ edition, pp. $228 \& 230$ ). These maps include: microwave routes for message and television; message only and television only; tropospheric scatterwave; radio telephone link base and remote stations; landline and submarine cable. Points on the map represent microwave towers and tropospheric dish antennae.

The Radio map is one full page of Canada with the North cut off by a table listing the names, call signs ${ }^{62}$ and locations of AM or FM broadcasting stations. The map includes as points: the location of AM and FM broadcasting stations in French, English and bilingual; AM and FM English rebroadcasting stations; and shortwave stations. A shaded area depicts the area of usual daytime coverage by AM broadcasting station or low power relay transmitter. The Television Broadcasting map includes: TV broadcasting in English, French and bilingual; rebroadcasting stations that are English and French; and area enclosed by Grade 'B' service contour, a service that can be received by a simple outdoor antenna and where "the limit of television coverage as delineated on the map, is the line along which the signal strength is 0.22 millivolt per metre for channels 2 to 6 ,

${ }^{62}$ Call signs are the unique designation for a transmitting station and are often the name of the station transmitting and these are normally three or four letter designation of radio stations, three letter call signs are only allowed for the CBC. Call sign prefixes are regulated by national telecom institutions and prefixes are assigned by the International Telecommunications Union (ITU). The first radio broadcast was in 1922 by a private company. 
and 0.63 millivolt per metre for channels 7-13" (Legend notes). The map also includes a large table listing television stations by name, call sign and location.

The $5^{\text {th }}$ edition includes a Telecommunications Systems map within the realm of Communications (sheet 32.1), which is located within the grouping economy. The map was published in 1984 and is the last of the communications maps in the Atlas. (The $6^{\text {th }}$ edition does not include communications as a topic although it includes other infrastructure maps.) The Telecommunications Systems map includes: microwave radio systems over 890 megahertz and microwave routes both digital and analog; optical fibre system breakout points and digital cable; landlines of digital cable; telecommunications satellite systems by transmit/receive stations; submarine cables by terminal connection point and cable; and radio-telephone systems with VHF terminal and tropospheric scatter systems by transmit/receive stations and the linkages between them.

The communication infrastructure maps have one thing in common, they barely communicate the significance of the technologies that are mapped and by not doing so, they leave non-specialist readers informed only about the density of networks with very little information to help them understand the nature of the infrastructure and the components of the network. The user is absent, and indicators such as usage density or the number of devices per 100 people might have been more useful as these illustrate how important this infrastructure is to the economy and society. The communication infrastructure data is part of the expert knowledge of regulators, physicists, engineers, broadcasters, policy makers and a host of builders and carriers primarily in the private sector. 
The telegraph and telephone maps of the $1^{\text {st }}$ and $2^{\text {nd }}$ editions resemble Stephen Morse's 'nerve system' with red lines and dots crisscrossing the land to create "one neighbourhood of the whole country" (Morse, quoted in Babe: 1990:36). The telegraph, the daily press and the railways were integrated from the very beginning and are regarded as having propelled Canadian industrialization. The telegraph advanced the construction of early railroads by connecting engineers, delivering progress reports, and enabling the order of supplies (Babe, 1990). News and carriers were only desegregated in 1910. Telegraph lines followed rail lines, the latter providing the right of way for lines and poles and access to ticket offices to house telegraph stations (Burnet, 1996). The telegraph maps of the $1^{\text {st }}$ and $2^{\text {nd }}$ editions illustrate lines and points not described in a legend. As such, it is presumed that they are depicting telegraph stations that would have been located in train stations, department stores (i.e. Simpsons and Eatons), railway owned hotels, post offices and dedicated telegram offices. An 1875 New Railway and Postal Map of the Dominion of Canada of the Ottawa and Gatineau areas clearly indicated that postal offices and train stations served double duty as telegraph offices. The 1875 map also included the distance by road or rail between telegraph offices and outlying post offices.

The first wireless stations were also co-located within the lighthouse infrastructure since wireless stations were either trans-Atlantic radiotelegraph links or marine radio stations. In the 1840 , some telegraph stations and messaging concentrated around the shipping season to report the movement of ships along the St-Lawrence River to farmers (Burnet, 1996). The telegraph lines 
were mostly privately owned although the crown subsidized their construction (Sessional papers, and Burnet, 1996). It is presumed that the location of exchanges and operators are the points connecting the telephone lines. Bell, independents and some municipalities operated telephone lines. By 1905, Bell had 82,351 subscribers and 526 exchanges (Rens, 2001:84). Although the telephone was considered a public utility at that time, it was not considered a 'nationalized' public institution operated by government (Rens, 2001).

The $\mathrm{CBC}$ compiled the information for the $3^{\text {rd }}$ edition's television and radio network and stations maps. The 1936 Broadcasting Act provided for a national broadcaster and the CBC was created. This Act was preceded by the 1933 Act to create the Canadian Radio Broadcasting Commission, now known as the Canadian Radio-Television Commission (CRTC), to regulate broadcasting in Canada. By the 1940s, relay transmitters made it possible to broadcast in remote communities. CBC Television only began operations in 1952 . By 1953 , a private sector television broadcasting network of stations was formed and microwave links made it possible to carry some live US network programs while programming was only in black and white (CRTC, 2008). In 1952, there were 146,000 televisions in Canada and by 1955 there were more than $1,400,000$ (DBS, 1956a). By that point, $66 \%$ of Canadians had access to television (CRTC, 2008).

At the time of the $3^{\text {rd }}$ edition's production, broadcasting was the responsibility of the Telecommunications Division of the Department of Transport, which received advice on licensing from the $\mathrm{CBC}$ (DBS, 1955a). This map was published 
just one year before the Broadcasting Act was revised to separate out regulating authority from the $\mathrm{CBC}$ and just before the first national television broadcast was possible. By 1958, the communication superstructure in Canada was the longest network in the world. It would mark the decline of the railway's influence and connection to communications as independent telephone and telegraph services companies began to take over (Rens, 2001).

The $4^{\text {th }}$ edition communication infrastructure maps focused primarily on wireless communication technologies and provided landlines only when other means of transmission were not available. Some submarine cables are also on the map in coastal areas. Canada was the second highest among the world's users of microwave communications systems when this edition was compiled, mostly due to its vastness and large, underserved remote areas in the north. It was built to interconnect English and French $\mathrm{CBC}$ from coast to coast and to transmit colour television signals (DBS, 1968). Technological advancement also ushered in an era of greater competition from easily accessed US broadcasts. Both $\mathrm{CBC}$ and CTV, the largest Canadian private networks at that time, leased private microwave facilities for the relay of their programming.

The points on the $4^{\text {th }}$ edition map indicate fixed base and remote stations, with fixed base stations acting as hubs connected with remote stations. The related connections form star like patterns seen in northern areas and primarily used in the North for radiotelephone links. Other point symbols connecting lines are the locations of microwave towers that require a line of sight for transmission or tropospheric dish antennae. The map also includes tropospheric scatterware, 
which is a method to transmit messages over very long distances by beaming signals into the atmosphere, which then get reflected back as they bounce off the troposphere to large dish receiving antennae. This technology was primarily used in areas where line of sight technologies could not serve. As such, it is located in the north and far north as indicated on the map.

The $4^{\text {th }}$ edition map was created with 1968 data provided by the DBS Canada Year Book. According to the DBS Yearbook, $99 \%$ of Canadians received radio service and $96 \%$ television service (1968:878). Satellite broadcasting technology was not yet in operation when this map was created, although the Department of Transport ${ }^{63}$ was investigating two proposals for the creation of a Canadian domestic satellite system to deliver broadcasting in the North. There was also recognition that machine-to-machine communication associated with increased computerization would soon surpass human-to-human communication (DBS, 1968). The automatic switching system known as Broadband Exchange Service came online in 1967 , which enabled the creation of four main stations in Montreal, Toronto, Winnipeg and Vancouver, and allowed for non-mechanical transfer of voice and data (DBS, 1968). By the mid-1960s, CN Telecommunications had built the first computer controlled transmission system in Canada, followed shortly by Bell.

63 The Department of Transport had the responsibility for communications in Canada, which was administered by the Government Telecommunications Policy and Administration Bureau and the Telecommunication and Electronics Branch (DBS, 1968). 
The communications maps were compiled from maps supplied by many federal, provincial and territorial governments and private sector telephone and telegraph companies. The Radio and Television maps were specifically informed by the following: DBS Canada Year Book; the CRTC for the list of broadcasting stations by province; the Department of Communications, Telecommunications Regulation Branch for manuscript maps; and CBC broadcasting stations list as well as the locations of power relay transmitters.

The $4^{\text {th }}$ edition does not reflect the Accelerated Coverage Plan, which started to be implemented in the 1970 s with the objective of providing national radio and television to all communities with a population of 500 people or greater (Hallman, 1977). The plan was a project of the CBC, the CRTC and the Department of Communications, and the $\mathrm{CBC}$ was responsible for building the infrastructure. The plan for the 1970 s "envisaged broadcasting as an instrument in nation building, a unique form of communication for Canada since it can operate everywhere in English and in French" (Hallman, 1977:26). Broadcasting was considered to be more than just an infrastructure since it had the "vitally important task in identifying and strengthening cultural identities and community loyalties" (Hallman, 1977:26). There was tremendous concern that cable television was going to undermine the plan by increasing access to US broadcasts.

The $5^{\text {th }}$ edition map represents wireless, optical fibre, digital landlines and submarine cables distinguished by analog and digital routes or cables. (The shift from analog to universal digital signal for television is just taking place now.) The 
optical fibre system representation includes point data indicating the breakout points where cables connect to other types of telecommunications systems. The satellite system is also a new addition given that Telesat launched the first domestic commercial satellites in 1972, including strategically placed ground stations across the country (StatCan, 1978-79). It delivered television services across the country as well as telephone services in the North. The satellite system is represented on the map by fixed transmit/receive stations, which are located primarily in the North on the coastlines of islands with the most northern being Eureka on Ellesmere Island. Microwave network routes are also on this map and, as with the $4^{\text {th }}$ edition, these are used for broadcasting television and radio signals. These networks consist of microwave stations, which are spaced approximately 50km apart, and relay and amplify radio signals (StatCan, 1985). The three transnational microwave networks were still the backbone of communications in Canada in 1984.

The $5^{\text {th }}$ edition map was prepared in cooperation with the Department of Communications and Telecom Canada. Map sources are the $4^{\text {th }}$ edition of the Atlas of Canada, Canadian Telecommunications Carriers Association Microwave Catalogue, and a number of provincial and private sector telephone and satellite telecommunications companies.

Responsibility for regulation of the communication infrastructure today rests with the CRTC and Industry Canada, which together "[facilitate] access to the radio frequency spectrum by issuing authorities for its use, securing Canada's access to it through international negotiations and by ensuring its continued 
health, in Canada, through the preparation and enforcement of standards"

(Industry Canada, 2011). A few other institutions involved with and agreements related to communication infrastructure and their oversight:

- Board of Railway Commissioners

- Radiotelegraph Act 1905

- Canadian Broadcasting Act 1932

- 1936 Canadian Radio Broadcasting Commission

- Canadian Broadcasting Corporation (CBC)

- Telegraph act of 1952

- Radiotelegraph Act 1905

- 1972 Canadian Telecommunications Carriers Association (CTCA) became in 1985 the Frequency Coordination System Association (FCSA)

- Radio Advisory Board of Canada

- Technical Advisory Committee on Broadcasting since 1966 at Industry Canada

- Broadcasting database

- Industry Canada Spectrum Management and Telecom

- Broadcasting Act

- Telecommunications Act

- Licensing regime

- CRTC

- ITU

The above list is by no means exhaustive, and is specific to the maps viewed.

The communication network maps of the Atlas show the physical infrastructure of terminals, exchanges, stations, and transmission media but not network ownership, the names of carriers and the significance of the network to Canadians. It was represented in such a way that it seems that the cartographers did not understand what they were mapping. It also seems as if regulators, engineers and scientists took for granted that people would understand what was being mapped just by showing the technology, although, it is also possible that 
this same group of experts were technocrats who understood the necessity of building this infrastructure but could not explain the underlying reasons for building it.

The $1^{\text {st }}$ and $2^{\text {nd }}$ editions, along with the maps, included charts in the second part of their atlases that provided data about miles of cable, messages sent, and described in great detail aspects of all the other infrastructure and industries it mapped. Infrastructure is one of the most important features in the $1^{\text {st }}$ and $2^{\text {nd }}$ editions of the Atlas and is prominently showcased, but its underlying importance is forgotten. As discussed in Chapter 2, infrastructure amnesia sets in by the $3^{\text {rd }}$ edition, as this technology becomes normalized. Stephen Graham and Simon Marvin also discuss this phenomenon in their 2001 work, Splintering Infrastructure, whereby infrastructure no longer consists of large, state funded, nation building projects; infrastructure become a splintered system of many economic players, regulated by the state but no longer centrally managed, and it becomes difficult to piece it back together. It is predicted that as an infrastructure ages and requires replacement, such as the problems with the transportation infrastructure have shown, more problems become obvious and people take notice. Such was the case with the 1998 Ice Storm, where infrastructure weakness merited attention. These maps do however demonstrate the important coast to coast microwave network that was developed in 1958 while the $3^{\text {rd }}$ and $4^{\text {th }}$ edition also include some broadcasting organizations by name although, the focus is primarily on the $\mathrm{CBC}$ given its prominence at the time. With these maps, readers see the pattern of Canadian communication 
connectedness, and the continued pattern of core and periphery dynamics, which was not determined by technology, although connectedness was determined by technological possibilities, capabilities and policies.

\subsubsection{Territorial Evolution}

Territorial division as a grouping includes administrative divisions such as electoral districts, census geographies and economic regions, which are spaces created to organize the population for political, statistical and economic administration. This grouping also includes the typical 'political' map of provinces and territories in all editions except the $4^{\text {th }}$, national scale maps of municipalities in the $3^{\text {rd }}$ and $5^{\text {th }}$ editions, and maps of Indian reserves. World maps only appear in the $2^{\text {nd }}$ and $6^{\text {th }}$ editions of the Atlas. The $5^{\text {th }}$ edition includes a Circumpolar map. The $6^{\text {th }}$ edition includes maps of Adjacent Regions, and the $3^{\text {rd }}$ edition depicts international relationships in maps of the United Nations, North Atlantic Treaty Organization, Commonwealth and the Colombo Plan membership. There are also reference maps in this grouping such as Time Zones, Latitude and Longitude of Canada and Coastline and Boundaries of Canada. The planimetric land use and growth city maps of the $1^{\text {st }}, 2^{\text {nd }}$ and $3^{\text {rd }}$ editions are not included in the grouping of Territorial Divisions because they do not represent cities in administrative or political terms and they are not distinctly national scale maps. The Urban Network and Metropolitan Influenced Zones (MIZ) maps while national in scale were also grouped with cities because they pertain to the urban and economic geographic study of cities. 
Territorial evolution demonstrates in maps the changing spatial organization of the state and its territory, its changing shape and extent, specifically how the territory of pre-confederation Canada, the Dominion of Canada and Canada was demarcated and divided. This includes international borders, internal districts, provinces and territories drawn according to treaties and colonial boundary agreements. A territory is understood to be "a contiguous space that is used, organized and managed by a social group, individual person or institution to restrict and control access to people and places" (Gregory et. al, 2009:746).

Territorial evolution includes maps (see Figure 30) that are most often classified as historical maps in most atlases and are found in various editions of the Atlas of Canada as follows: International and Interprovincial Boundaries ( $\left.1^{\text {st }} \& 2^{\text {nd }}\right)$; Mapping the Coasts and the Interior ( $\left.3^{\text {rd }}\right) ;$ Territorial Evolution ( $\left.4^{\text {th }} \& 6^{\text {th }}\right), N e w$ France circa $1740\left(6^{\text {th }}\right)$, British North America circa 1823 (6 $\left.6^{\text {th }}\right)$, Indian Treaties $\left(5^{\text {th }} \& 6^{\text {th }}\right)$ and Canada-Territorial Evolution $\left(5^{\text {th }}\right)$. In the $6^{\text {th }}$ edition, the History topic includes 28 maps and a series on exploration. In the $1^{\text {st }}$ and $2^{\text {nd }}$ editions, the Boundaries maps are arranged between Origins of the People and the Routes of Explorers. The $3^{\text {rd }}$ edition starts with the Routes of Explorers, and the science of mapping group. The evolution maps in the $3^{\text {rd }}$ are more about 'mapping' the territory and not about 'the territory'. In the $4^{\text {th }}$ edition, the Territorial Evolution of Canada maps are grouped between exploration, fur trade posts, topographic map coverage and settlement, located within the realm of Political Geography.

As seen throughout this study, proximity in the order of things implies a relationship in the Atlas. Settlement, for example, is a key factor that influenced 
territorial evolution; however, it was grouped with demographics because it is also a way of depicting population distribution. Exploration is also clearly related to territorial evolution and mapping (Nicholson, 1954) and it was given its own grouping because it also relates to development. In addition, Historical Indian Treaties (see Figure 22; page 212) is a map within the History topic of the $6^{\text {th }}$ edition, while in the $5^{\text {th }}$ edition, it is grouped under the realm of Ethnographic, before the realms of Political Geography and Population, and followed by Migration. The Indian Lands and Languages of the $4^{\text {th }}$ edition could have been grouped here, but it was instead grouped under the sub-group of First Nations in demographics, as the map was more about linguistic groups and less about territorial divisions, despite including the location of reserves and Indian settlements. Regarding ordering, maps depicting First Nations are treated as separate from Canadian people in Canada, and only in the $1^{\text {st }}$ and $4^{\text {th }}$ editions are Aboriginals or Indians and Eskimos grouped with demographic maps. The term Eskimo went out of favour in Canada sometime in the 1970 s and Inuit, a term formally recognized in the Constitution, and First Nations has been in use since the 1980s. First Nations is also the most diverse sub-grouping in the Atlas and in the order of things, First Nations people keep changing places (see Appendix H). 


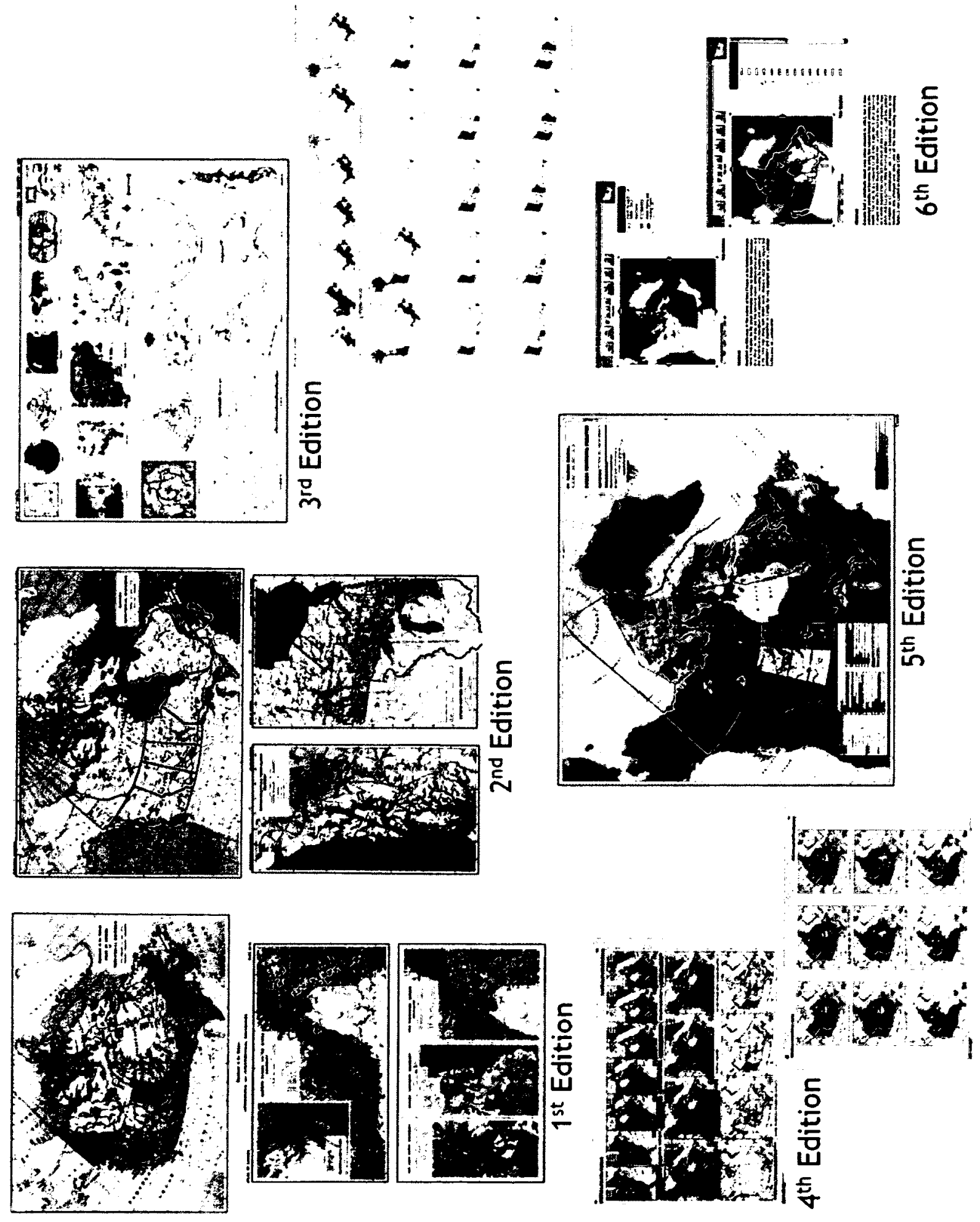

Figure 30. Selection of Maps Representing Territorial Evolution 
The $1^{\text {st }}$ and $2^{\text {nd }}$ editions include two sheets (4 pages) and seven maps representing boundaries that include: International and Interprovincial Boundaries - Bay of Fundy; Eastern Canada - United States; San Juan; Canada-Labrador; New Brunswick-Quebec; British Columbia and Yukon-Alaska; and OntarioManitoba. These maps include boundaries claimed and contended by Great Britain and the US, boundaries fixed, or awarded or recommended by Commissioners or Arbitrators, boundaries awarded by conventions and fixed by treaties, boundaries "According to the Award of the King of the Netherlands", and offered compromises, approximate boundary claims, portions of boundaries awarded by Acts of King George the IV or confirmed by Imperial Act of Parliament. The Ontario-Manitoba Boundary map alone includes nine separate contentions, claims or delineations by Imperial Acts and Acts of the Dominion. On some of the maps, the areal extent of a dispute is noted in square miles. The notes on the maps about boundaries are quite extensive in the $1^{\text {st }}$ edition. The British Columbia and Yukon-Alaska Boundary map of the $2^{\text {nd }}$ edition is notable as the text on the map of Canada faces toward the interior of the country while the text on the Alaska side faces the Pacific Ocean.

For the $3^{\text {rd }}$ edition, territorial evolution is expressed in two sheets. As the first sheet, Mapping the Coasts, 1492-1874, depicts 21 reduced, redrawn and hand coloured maps of original historical and archival maps. The sheet shows "by means of a series of historical maps, how the knowledge of the extent and shape of Canada grew from earliest times to the period around confederation" ( $3{ }^{\text {rd }} \mathrm{ed}$. Sheet 2 verso notes). The maps in order of appearance are shown in Table 6. 
Table 6. Mapping the Coasts, $3^{\text {rd }}$ Edition list of maps

\begin{tabular}{|c|c|c|c|}
\hline $\begin{array}{l}\text { Emergence of } \\
\text { the concept of a } \\
\text { new America }\end{array}$ & $\begin{array}{l}\text { Depicting how } \\
\text { the north east } \\
\text { took shape }\end{array}$ & $\begin{array}{l}\text { Showing how the } \\
\text { Arctic coasts were } \\
\text { gradually revealed }\end{array}$ & $\begin{array}{l}\text { Development of } \\
\text { Knowledge of } \\
\text { the west coast }\end{array}$ \\
\hline Stephanius 1590 & La Cosa 1500 & Mercator 1595 & De Laet 1630 \\
\hline Behaim 1492 & Caneiro 1502-04 & Foxe 1635 & Anonymous 1574 \\
\hline Ruysch 1508 & Descelier 1550 & Franklin 1823 & Cook 1784 \\
\hline $\begin{array}{c}\text { Waldseemüller } \\
1507\end{array}$ & Ribero 1529 & $\begin{array}{c}\text { British Admiralty } \\
1835 \\
\end{array}$ & Arrowsmith 1822 \\
\hline Agnese 1540 & Velasco 1610 & $\begin{array}{c}\text { British Admiralty } \\
1874\end{array}$ & \\
\hline $\begin{array}{c}\text { Ptolemy, } 1548 \\
\text { Edition }\end{array}$ & & & \\
\hline Zaltieri 1566 & & & \\
\hline
\end{tabular}

The second sheet is Mapping the Interior, 1630-1870 and was designed to depict, by way of nine redrawn and reduced maps (see Table 7), how pre-Confederation, Canada was mapped from coast to coast. The extent of the territory ceased to be unknown, at least in maps, by Confederation, and as seen in the first maps of the $1^{\text {st }}$ edition. The map of Canada in the $2^{\text {nd }}$ edition illustrates the territorial divisions of the country as they were in 1912.

Table 7. Mapping the Interior, list of maps $3^{\text {rd }}$ Edition

\begin{tabular}{|c|c|c|}
\hline Eastern Interior & Western Interior & $\begin{array}{c}\text { Knowledge about the } \\
\text { Cordillera and the } \\
\text { Pacific Coast }\end{array}$ \\
\hline Champlain 1632 & $\begin{array}{c}\text { Delisle 1750 and Buache } \\
1754 \text { Combined }\end{array}$ & $\begin{array}{c}\text { Arrowsmith } 1857 \text { and } \\
\text { Russel } 1868 \text { Combined }\end{array}$ \\
\hline Dollier and Galiné 1680 & Pond 1787 & Delabat 1710 \\
\hline Franquelin 1699 & Thompson 1814 & Duberger \\
\hline
\end{tabular}


The $4^{\text {th }}$ edition includes two sheets ( 4 pages) of 24 maps depicting the significant changes that occurred between 1667 and 1949 in the Territorial Evolution of Canada. It is the first edition that first depicts the influence of France and the French upon the shape of Canada's territory, while the $6^{\text {th }}$ edition includes a map of New France. References to French explorers are made in the $3^{\text {rd }}$ edition, but they are not depicted as arbiters of territory and boundaries, although maps and exploration are very closely related to territorial claims during the colonial era of the $17^{\text {th }}$ to the $20^{\text {th }}$ century. Interestingly, maps accounting for French language speakers only appear as a topic in the $4^{\text {th }}$ and $6^{\text {th }}$ editions. The $1^{\text {st }}$ and $2^{\text {nd }}$ editions also make no reference to any French entities with regards to boundary resolutions beyond the names of some French explorers.

The maps in the $4^{\text {th }}$ edition include English, French, Spanish, Danish, American and Russian settlements, claims and disputed areas. For example, Alaska is identified as Russian territory and Greenland as Danish territory. The first seven maps on pages $83-84$ of the $4^{\text {th }}$ edition delineate colonial territories in eastern Canada and the US, from 1667 to 1809 . The French disappear from the map as a result of the 1763 Treaty of Paris, making eastern North America a wholly British Colony except for St-Pierre de Miquelon Island, which remains with France to this day. Maps depict the west coast, indicating that by 1825 , most territory in British Columbia was jointly occupied by the British and the United States. (This resembles the territory of the proposed bioregional political entity and/or independent nation of Cascadia, which includes Oregon and Washington.) The 1846 Oregon Treaty resulted in British Columbia having its current international 
boundary. Another map captures the formal union of Upper and Lower Canada, the Province of Canada by 1849 . By 1866 , British Columbia becomes its own province, and in 1867 New Brunswick and Nova Scotia unite with the Province of Canada to become the Dominion of Canada, with the former province of Canada divided into Quebec and Ontario. That same year, the US proclaims the purchase of Alaska from Russia. In 1870, the North-West Territories, which included Rupert's Land and the North-Western Territory, are acquired by Canada from the Hudson's Bay Company and part of Manitoba is formed. The following year, British Columbia joins the Dominion followed by Prince Edward Island in 1876. Other notable events mapped include: changes in the boundaries of Ontario and Quebec in 1876; the transfer of British Rights to the Arctic Islands to Canada; growth of Manitoba by 1882; and the creation of new districts in the west (i.e. Alberta, Athabasca, Saskatchewan and Assiniboia). By 1889, the OntarioManitoba dispute is settled (see $1^{\text {st }}$ and $2^{\text {nd }}$ editions) and Ontario is enlarged. By 1912, the boundaries of Ontario and Manitoba reflect current ones while Quebec is extended north. In 1927, the national boundaries are extended northward as per international law and the Quebec-Labrador border is settled. In 1949, after a plebiscite, Newfoundland enters Confederation as the $10^{\text {th }}$ and final province.

The $5^{\text {th }}$ edition maps include territorial evolution between 1867-1981 showing present day International, Provincial or Territorial, District, Unsurveyed and the Dividing Line - Canada and Greenland boundaries. The historical boundaries of Canada, many of which were not surveyed, are also international and provincial and territorial, and include the Northwest Territories Districts and Rupert's 
Land. This map includes a chronology of boundary changes, which are depicted and labeled on the map sheet but are hard to distinguish.

Between the $1^{\text {st }}$ and the $4^{\text {th }}$ edition, covering the years $1906-1974$, there is no mention of treaties, agreements, secession, disputes or acts pertaining to First Nations people, and the maps are silent about the position of First Nations and their role in terms of the territorial evolution of Canada. The first time that Aboriginal people were included on a map, in terms of influencing the shape of Canada's 'official' territory, is the 1991 Indian Treaties map of Canada in the $5^{\text {th }}$ edition mentioned earlier (see Figure 22 page 212). Even in this case, the map is grouped in the realm of Ethnography as opposed to the realm of Political Geography, and it could have been placed with Exploration. The map includes the pre- and post-Confederation Treaties and Boundary lines as listed in Table 8.

Table 8. List of Types Indian Treaties, $5^{\text {th }}$ Edition sheet 15.6

\begin{tabular}{|c|c|}
\hline Pre-Confederation Treaties & Post-Confederation Treaties \\
\hline Friendship Treaties Area & 14 Numbered Treaties \\
\hline Upper Canada Treaties Area & William's Treaties \\
\hline Province of Canada Treaties & Treaty Boundaries \\
\hline Vancouver Island Treaties & Treaty Adhesion boundaries \\
\hline
\end{tabular}

The treaties are also listed in another table that includes the "Indian Peoples Concerned", the year, and the areas ceded for all but the Friendship and PostConfederation Treaties. There is also a list of pre-Confederation, Province of Canada Treaties between 1850-1862 and a footnote to the legend stating: "Treaty boundary lines are approximate". This is important because maps turn things 
into facts that can later be used in legal disputes. This footnote ensures that people do not presume that the boundaries on this map are legally binding. This map when examined along with the Territorial Evolution of Canada maps of the $4^{\text {th }}$ edition, provides much insight into the relationship between treaties and changes in the internal boundaries of 'official' Canada, determined by British colonialists and many of the 'Indian People Concerned' that were listed 64 . The $6^{\text {th }}$ edition Indian Treaties map is essentially the same, with a few additional references. However, it is arranged differently for the web and includes modified text. The map also references a number of different framework base layers.

The Territorial Evolution series of the $6^{\text {th }}$ edition includes 21 maps, many of which are the same as those of the $4^{\text {th }}$ edition; however, the $6^{\text {th }}$ only starts in 1867. The newest map additions in the $6^{\text {th }}$ edition are the 1999 map that introduces the new territory of Nunavut and a historical map showing boundary changes between 1867-1999. The text accompanying each of these maps is quite extensive and provides much context, which could not be provided in the $4^{\text {th }}$ due to space limitations. Nunavut, as a topic in the $6^{\text {th }}$ edition, is a mini atlas of its own within the topic of People and Society.

The $6^{\text {th }}$ edition also includes a map of New France, which shows "the extent of New France at its territorial height circa 1740 prior to its great territorial losses to British North America. It includes territorial claims, administrative divisions,

${ }^{64}$ Abenaki, Maliseet, Micmac, Six Nations Chippewa, Mississauga, Potawatomi, Wyandot, Saugeen, Ojibwa, Swampy Cree, Saulteaux, Plain Cree, Wood Cree, Blacfoot, Blood, Peigan, Sarcee, Stoney, Beaver, Slave, Dogrib, Loucheux, and Hare 
and the distribution of population and settlement (including fur trading posts)" (6 $6^{\text {th }}$ ed. map abstract). Finally, a map of British North America circa 1823, which "shows the emergence of British influence prior to Confederation" ( $6^{\text {th }}$ ed. map abstract) is added to the $6^{\text {th }}$ edition. This latter map is almost the same as the 1825 map in the $4^{\text {th }}$ edition. Appendix $\mathrm{K}$ includes the list of boundary changes discussed in the Atlas of Canada.

Relief is the platform upon which human actions occur, and territorial divisions bind those actions spatially and determine who is responsible for taking that action in a political and administrative sense. Boundaries are imagined as firm and never changing, yet that is far from true, especially after examining the territorial evolution of Canada. Boundaries are "a geographical marker of territory and a geographical maker of regulative authority in social relations" and "international boundary lines actively operate to create and consolidate the global norms of national-state territoriality and the national identities forged under the aegis of state sovereignty" (Gregory et. al, 2009:55). Boundary demarcation is a matter of surveying, documenting and the "establishment of a true and unalterable boundary according to law, so that no possible dispute in regard to its position can arise in the future" (Nicholson, 1954:93). Boundary demarcation, according to Norman L. Nicholson involves the following steps:

- Determining the boundary from delimitations documents and surveys

- Marking the boundary on the ground by selecting sites for the placement and erection of markers and monuments (e.g., stones, signs, beacons, pillars) and vistas for wooded areas which involves the clearing of forests,

- Plotting the location of markers on large scale maps

- Describing from marker to marker the area and also the markers

- Reporting to governments concerned 
Territorial boundaries, to serve their purpose, need to be maintained and a 1925 special treaty between the US and Canada created the International Boundary Commission. Between provinces, the matter is less pressing and issues normally result in a re-survey. International boundaries are made between the sovereign powers concerned in treaties, and if provincial boundaries are part of international boundary discussions, provinces have a say in those boundary changes. The federal government has the right to create new provinces but cannot change provincial boundary lines once they have been created without consent from the provinces concerned (e.g., Newfoundland). Boundaries are ratified by Acts describing the boundary or any of its changes at both the federal and provincial government levels. Territorial boundaries are fixed by an act of parliament.

According to Nicholson (1954), regionalism was a factor in the determination of inter-provincial boundaries even though boundaries do not necessarily reflect scientifically determined regional lines, and the $49^{\text {th }}$ parallel line between the US and Canada border would not be considered a border that was demarcated for regional reasons. Irrespective, boundaries have had the effect of creating regions as seen in the Maritimes or Atlantic Provinces, the Prairies and the North, and these developed as a way to manage resources (Putnam \& Putnam, 1970; Nicholson, 1954), although, that thinking changed with the creation of ecological zones which cross political boundaries. Prior to Confederation, boundaries between provinces were demarcated to reflect the administration of areas based on trends of the population, such as patterns of industry, historical groupings of 
the population, the town influence zones, etc. (Nicholson, 1954). After Confederation, a sort of quantitative standard applied to secure similar areal extent or population numbers and to limit the number of provinces to be created. In Canada, provincial boundaries cut across sparsely populated regions thus distributing responsibilities for rural and remote areas to all, and also providing greater autonomy to each given a variety of diverse regions thus a variety of resources to manage.

In the $3^{\text {rd }}$ edition, territorial evolution maps between 1492-1874 illuminate how the concept of America emerged in maps, and how the contours of Canadian coastlines began to be known, and re-known via maps, by patrons, navigators, and explorers. The idea of America and its coastlines, or its natural borders, are copied and re-rendered by cartographers in Europe, and the maps of explorers who refined and enhanced them. The Mapping the Interior, 1630-1870 maps begin to elucidate how colonialists knew the territory; there was Champlain's New France, the 'Pais' and 'Terres' of the 'Esquimaux' and the 'Nations Des Sioux' to name a few known territories. First Nations also had their maps as seen in the Cartes tracées par le sauvage Ochagach on the Delisle 1750 and Bauche 1754 Map. First Nations are also seen in place names such as Miramachi, Algonquin, Ottawa, Keewatin, Saskatchewan, Quebec, Nunavut and Manitoba. The maps illustrate how the knowledge of the interior grew. Canada becomes known by explorers, missionaries and map compilers (e.g. Jean Baptist Louis Franquelin), and fur traders and their companies also gradually began to know the interior and they developed more precise knowledge of the areas where they traded, while 
cartographers were creating local large scale topographic maps of settled areas. Just as these experts gained and mapped their territorial knowledge, they also indicated the locations of First Nations on their maps. The First Nations also knew their own territory, but did not map it in the 'colonial' way as seen on the map of Delisle and Buache just mentioned.

The Arrowsmith 1857 and Russel 1868 Combined map is the first in this series to show territorial divisions of Canada at Confederation. The maps of the $4^{\text {th }}, 5^{\text {th }}$ and $6^{\text {th }}$ editions show the evolution of what is today known as Canada between 1667 and 1999. The territories mapped are those of colonies, land owned by the Hudson's Bay Company, the shapes of the provinces, the territorial extent at Confederation, the addition of provinces and territories into the Dominion, and the changing shape of districts, and then districts into provinces and territories, and the changes of provincial borders. The $1^{\text {st }}$ and $2^{\text {nd }}$ editions provide greater detail into claimed, contended, recommended and awarded boundaries, including information on compromises. The Territorial Divisions of Canada maps of the $1^{\text {st }}$ and $2^{\text {nd }}$ editions reflect the latest boundaries at the time; the 1905 maps shows the inclusion of Alberta and Saskatchewan and the 1912 map indicates boundary changes for Manitoba.

The treaty maps of the $5^{\text {th }}$ and $6^{\text {th }}$ editions depict the extent of negotiated territory between First Nations and Europeans, and then later with colonial administrations, such as the 1763 Royal Proclamation that established a process to acquire crown lands and clear Indian titles. This process included the negotiation of a large number of land-cession agreements, which allotted land to 
Empire Loyalists and military Indian allies such as the Iroquois. This entailed lump sums and annuities while after 1850 , the Robinson and the Douglas Treaties included provisions for reserves and allowances for hunting and fishing on 'unoccupied' crown land. The 1867 BNA gave jurisdiction over "'Indians and Lands reserved for the Indians' to the Government of Canada" (Map notes, Map sheet $15.6,5^{\text {th }}$ edition). The clearing of First Nations' title continued after Confederation to facilitate the construction of the railroad and for settlement. Titles were surrendered by First Nations and they received tracks of land for reserves in return, as well annuities, gratuities, schools, hunting and fishing rights, gifts of agricultural implements and cattle, cash payments for ammunition and other material goods. After 1982, land claim agreements replace or follow the treaty system and are more complex. Sub-Section 35(1) and its 1984 amendments of the Constitution govern land claim agreements.

The $4^{\text {th }}$ edition references the $3^{\text {rd }}$ edition maps as a data source, as well as the following: a 1965 paper by Ivan Head entitled, Canadian Claims to Territorial Sovereignty in the Arctic Regions; Nicholson's 1954 memoir, The Boundaries of Canada, Its provinces and Territories; Marcel Trudel's 1961 book, Atlas Historique du Canada français; and the Atlas of United States History by Thorndyke. The $5^{\text {th }}$ edition references many historians and statute documents, as well as Nicholson's 1979 work, The Boundaries of Canadian Confederation, and the Geomatics Canada 1995 Territorial evolution of Canada [CD-ROM]. Dr. Nicholson, who was the editor of the $3^{\text {rd }}$ edition and then a professor at the University of Western Ontario, was contracted to oversee the research for the $5^{\text {th }}$ 
edition's Territorial Evolution map. He references numerous historical documents and statutes, including a 1913 document by James White entitled, Boundary Disputes and Treaties, and one of his own books, The Boundaries of Canadian Confederation (also referenced in the $4^{\text {th }}$ edition).

The 1987 First Ministers Conference on Aboriginal Constitutional Reform informed the Indian Treaties map of the $5^{\text {th }}$ edition; it also reflects research conducted by the Treaties and Historical Research Centre and Treaty Policy Branch and the Comprehensive Claims Branch of the Department of Indian Affairs and Northern Development (DIAND). The map also lists as sources DIAND Treaties Research reports and academic research on specific treaties, including provincial treaties, treaties with Canada and the Union of Nova Scotia Indians 1987 Mi'kmaq Treaty Handbook. There are no maps in the Atlas informed by First Nations organizations, and the maps are made by and reference government or university research institutions. Interestingly, a 1995 report entitled The Feasibility of Representing Traditional Indigenous Knowledge in Cartographic, Pictoral and Textual Forms, produced by the Assembly of First Nations and supported by the National Aboriginal Forestry Association, was submitted to the National Atlas Information Service; it discussed methods to incorporate indigenous knowledge in maps, the ambivalence First Nations have toward maps, and the growing interest "in mapping which may signify an emerging tendency in the evolution of traditional knowledge". The recommendations of this report did not appear in the $6^{\text {th }}$ edition of the Atlas. 
Territorial evolution is documented in agreements, treaties, government Acts and the Constitution. The resulting boundaries were shepherded by land surveyors who demarcated them, they were debated by lawyers, settlers, lords and other interested parties such as the Hudson's Bay corporation, they are adhered to by elected officials domestically, and they are recognized by the international community under the territorial state regime. International boundaries are established between sovereign powers and established by treaties. The CanadaUS border, for instance, was negotiated between 1782-1925, during which time 17 treaties, conventions and protocols were signed, two arbitrations were called for, and several appearances before international commissions were required to dispute the particularities of treaties (Nicholson, 1954). Since international borders often coincide with provincial and territorial borders, this involves the federal and international governments requiring the formulation of different acts to recognize those demarcations. The responsibility for mapping the international borders of Canada now rests with the Surveyor General at NRCan, which follows the International Boundary Commission Act. Monitoring and managing borders, including the control of people and goods, is the responsibility of the Canadian Border Service and the Canada/US International Boundary Commission, whose Commissioner is appointed by Order-in-Council and reports to the Minister for Foreign Affairs. The United Nations Convention on the Law of the Sea (UNCLOS) governs maritime borders, and is decided by UN recognized member states. These boundaries are adjudicated by considering customary international law, which is derived from custom as well as general principles of law and treaties. 
Geographical boundaries such as those created by natural physiographic or climatic regions have influenced the economy and society. However, "human boundaries are often more important than physical ones in changing the landscape. Indeed, very frequently they supersede the physical ones" (Nicholson, 1954). Cultural regions such as those between Quebec and Ontario were demarcated by a river in some places, yet the land use pattern differs and is very much that of two different survey systems (see Figure 9 Page 103 Survey Grid of Winnipeg) that were culturally specific as previously discussed (Watson in Nicholson, 1954:viii). Political boundaries also shape cultural, legal and political systems, which have material effects on the landscape and have profound effects on development. Over time, "boundaries probably make, rather than are made, by geography" (Watson in Nicholson, 1954:viii).

As a federation, Canada is an aggregation of internal governing units which have real effects upon what children will learn in school, how health care will be delivered, where forest management is critical, and even what kind of beer people drink, to name but a few of the powers allocated to provinces and territories. Canadian boundaries and territorial extent are not fixed, although, these have become very difficult to change, especially its international and provincial boundaries. They are the result of compromise between political, legal and economic forces and were always negotiated, and it was during negotiations that the physical geography of the landscape, relief, rivers, coastlines and settlement were some of the many considerations. 
According to Nicholson, early boundaries in Canada were created from what people imagined the geography to be and not what it actually was, and it was for this reason, that parallels and meridians were used as references in lieu of a physiography and population analysis. This meant that natural boundaries were often disregarded. The $49^{\text {th }}$ parallel and the $141^{\text {st }}$ meridian of the Canada-US border are examples of this, and once drawn, "the political use of the space bounded by it leads to an orientation of route-ways, a choice of site settlements, policies of resource development, programs of colonization, and so forth, and profoundly affect the human geography of the area" (Watson in Nicholson, 1954:IX). Most of Canada's boundaries underwent evolutionary stages: loose delimitation, transitional stage of precise delimination, and the final stage or the stage of demarcation (Nicholson, 1954). Loose delimitation consisted of the preEuropean contact, European exploration and discovery, the setting of latitudinal and longitudinal limits, and claims of sovereignty. The transitional state or precise delimitation consisted of exploitation and settlement where boundaries were requested by settlers or colonial administrators, and political decisions on the allocation of territory and then delimited in a state document. The final state of demarcation includes demarcations in documents and other agreements that were often physical features later supplanted by survey and monuments delimited by surveyors, and finally administration and maintenance.

Boundary disputes remain, especially in the North. The spaces occupied by First Nations people have nearly been erased, although land treaties and titles are still being negotiated. Territory is part of the official discursive regimes of the nation 
state as documented in its most sacred documents such as a constitution, acts, regulation and treaties that are enacted by state institutions which oversees and maintains them. And because of these, they are also an object of the science of surveying, geodesy and mapping, as there are legal-geographical aspects related to their exact demarcation. Nicholson would also add:

impulses that led to boundary delimitation were not always the same as those that led to demarcation. This was, in some cases, due to the long interval of time between the two processes, during which changes in human values and scientific knowledge occurred (Nicholson, 1954:120).

Further, after 1932 the allocation of resource management to the provinces made boundary delimitation a priority.

\subsection{Summary}

This chapter applied the modified Hacking framework to assess if the Atlas of Canada helps shape geographical imaginations. The chapter began (Section 4.2) by examining the academic literature about national atlases which defined them as carefully and intentionally assembled sets of thematic maps about a single country normally produced by government or well resources scientific associations and their form normalized in the $20^{\text {th }}$ century. They are a repository of national scientific and expert knowledge which aims to advance an understanding and a particular story in maps about the country under study. They provide a set of factual spatial representations which help a nation's people know and imagine themselves geographically while also providing a cohesive national portrait of the subjects their authors or patrons consider important. 
National atlases normalize world views that are generally conservative, noncontroversial, depict the country as a cohesive whole and in a positive light.

Section 4.3 examined the six editions of the Atlas of Canada (See Figure 31). The following Hacking elements and engines guided the analysis: institutions, knowledge, experts, scientification, normalization and bureaucratization. The Atlas timeline of Figure 13 (page 143) depicted publication dates and the different government departments which oversaw their production. To assess Atlas thematic content, maps were organized into 31 groupings ${ }^{65}$ as shown in Figure 15 and Table 4 (pages $148 \&$ 149). Each edition is unique, however thirteen subjects were found in all of the Atlases ${ }^{66}$ with the top three being demographics, infrastructure and territorial division. Overall the Atlas has an economic and resource based orientation reflecting departmental priorities. Each edition was examined in detail and in each case descriptions of editors, committees, or advisory groups was provided along with how they envisioned the Atlas to be and what influenced their views (i.e., $\mathbf{1}^{\text {st }}$ and $2^{\text {nd }}$ immigration and economic development, nation building, $3^{\text {rd }}$ science and progress, $4^{\text {th }}$ landscape and regional description, $5^{\text {th }}$ a national information system for decision makers, $6^{\text {th }}$ computerization and education). Editors were almost always high ranking and well educated government officials mostly within NRCan and its earlier permutations who mobilized infrastructure and assembled teams of experts (i.e.,

65 Appendices $B$ to $G$ list the content of each atlas along with how they were grouped, appendix $H$ compares the content, and appendix I explains the groupings.

66 These topics were in descending order, demographics, infrastructure, territorial division, industry, climate, economy, agriculture, water, biogeography, exploration, geology, relief and vital statistics. 
cartographers, scientists, geographers, survey engineers, and etc.) to transform mostly government data and historical records into maps. Maps were authored by subject matter experts who modeled their specialized knowledge into spatial representations according to normalized practices, techniques and applying the technologies of their time. Atlas maps are official and authoritative factual representations of the nationally important subject they produced and represented. An overview of the bureaucracies that oversaw their production (i.e., divisions, branches and etc.) was also provided along with some of the bureaucratic issues which affected both content and production (i.e., budgets, cuts, departmental re-organization and the adoption of new technologies).

Section 4.4 examined four Atlas groupings: relief, forest, communication infrastructure and territorial evolution. Their analysis was guided by all of Hacking's framework elements and engines, with a particular focus on classification, spaces, counting, quantity, norms, correlation, taking action, scientification, and resistance. This provided for a closer examination of the classifications used in the atlas, the looping effect as well as how kinds of spaces are produced, constructed, represented, imagined and how these resulted in new spatial practices which changed those spaces. All were part of national mapping and data collection programs which were governed by legislation, regulation, policy and international scientific and engineering professional and industrial associations.

An examination of relief maps (Section 4.4.1) revealed how its mapping normalized into a distinct cartographic form (i.e., isolines and hypsometric 
tinting) ( $4^{\text {th }}$ edition Figures $20 \& 21$ page 188). The actual shape and form of the Canadian landscape at the scales mapped in the Atlas did not radically change yet its spatialization did. This is the result of techniques, technologies, field work and expert knowledge which enabled the modeling of a more accurate depiction of relief overtime. A change in relief spaces modifies how the landscape is imagined and as a foundational framework dataset this influences other kinds of spaces which are modeled on relief (e.g., climate, hydropower, agriculture, etc.). this affects spatial practices, which in turn modifies relief and other spaces as per the looping effect. In this case, technological evolution producing new knowledge created new kinds of spaces.

Canadian forests in the Atlas start by being classified into regions based on the location of trees, density, moisture regimes and internationally accepted botanical vegetation classification systems (Section 4.4.2) The same trees are later classed into regions based on an evolving and continuously refined ecological system. It first appeared in the $3^{\text {rd }}$ edition, was referenced as a model in the $4^{\text {th }}$, and later was refined by government supported national and international ecological scientists in committees, associations, and working groups. These same experts conducted and oversaw an extensive inventory of Canada's trees and created forest ecological regions based air photos and satellite imagery combined with carefully conducted field work with results appearing in the $5^{\text {th }}$ edition and that dataset was reused in the $6^{\text {th }}$ edition. Although, clusters of trees did get cut and forests were replanted with new species, which actually changed the spatialization of forests in real terms, but again, at the scale mapped 
this would not have been greatly apparent, what did however radically change the spatial understanding of kinds of forests spaces and resulting spatial practices was the model upon which their classification system is based. The looping effect in this case was the new geographically imagined scientific orientation of forests as complex interrelated ecological systems.

The depiction of the communication infrastructure in the Atlas is normalized as a network configuration of technology. In all cases core- periphery and northsouth spatializations of the network persisted closely following populated spaces. Network components changed in each edition, for example, the telegraph as a system actually disappeared. Furthermore the type of network subjects mapped also differed (i.e., telephone, telegraph, broadcasting, and telecommunications) and these were the newly built and planned infrastructural innovations and investments of their time. The kinds of spaces made up are spatial networks which influenced where people, organizations and institutions chose to locate, therefore reinforcing and maintaining the business model of delivering services based on population density. In this case the looping effect is based on relational aspects of physical geography, population density and socio-technopolitical regimes which were involved in the affirmation of the shape of the network and the changes in its components.

The representation of territorial evolution in the Atlas is always related to officially recognized and geopolitically authorized international and national administrative boundaries of 'Canada' before and after confederation. These maps depict changing territorial extent but always within the internationally 
recognized boundaries of the shape of Canada when the map was published in the Atlas making it seem as if the final shape was intentional. How that was done and what was mapped changed (i.e., areal extent versus many lines on one map, a series of small maps) although aboriginal people never appear as arbiters of territory and the French only appear on some. While the Mapping the Coasts (page \#) map of the $3^{\text {rd }}$ edition depicts how knowledge of the territory was gained, it does not show how territory was not claimed, affirmed and negotiated. The looping effect here is related to the discursive struggles over the claiming of space within the international legal geopolitical regime, and within property acquisition, colonialism, nationalism, development and regionalism, which bound political and administrative actions spatially which radically change the real landscape. Once affirmed these boundaries became hard to change, and because Canada's shape and form is constantly repeated, it becomes branded making it difficult to imagine Canada differently.

It was demonstrated that the Atlas includes a set of carefully selected biopolitical mapped subjects of importance to the government. Furthermore, the maps depict real physical things (i.e., trees, relief) and human made things (i.e., networks, boundaries) classified and modeled to make up thematically based Canadian kinds of authoritative spaces. The maps produced imagined spaces which led to spatial practices that in turn changed the spaces as per Hacking's looping effect, his regime of resistance includes the notion technologically and scientifically mediated spatial discursive struggles and relational. 
As discussed, each edition includes is a series of carefully selected and arranged maps that narrate a particular story of Canada in maps. Also, each represents the power/knowledge of national mapping interests, which are part of ongoing programs and evolving infrastructures. This is partially influenced by the government department where the Atlas is produced, but it also reflects Canadian spatial preoccupations. The Atlas produces and represents geographical imaginations, which influence decision-making. The next chapter examines the Census of Canada.

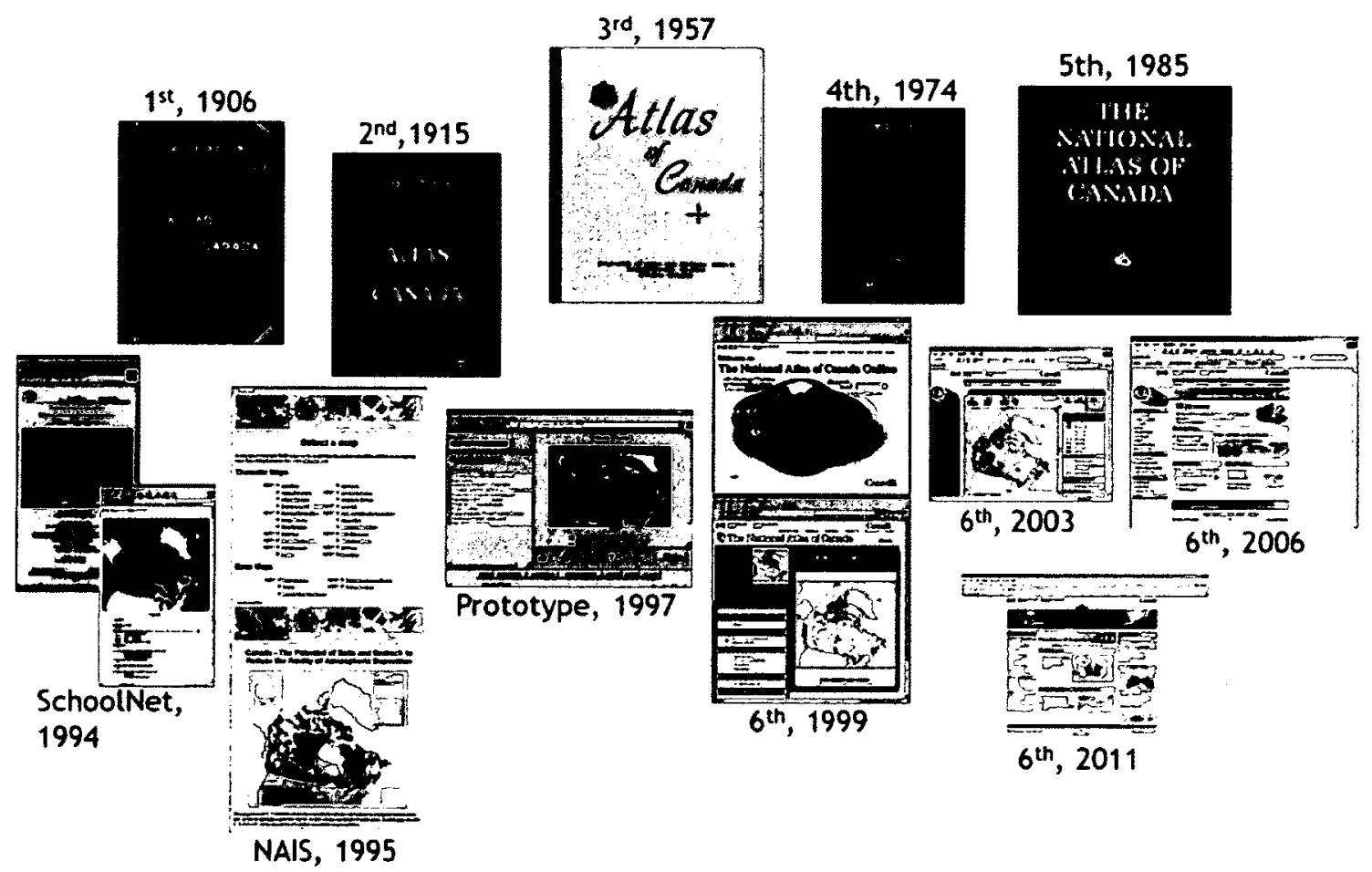

Figure 31. Evolution of the Atlas of Canada (1905-2012) 


\section{Chapter Five: \\ The Census of Canada, Making up Spaces and Canadian Geographical Imaginations}

\subsection{Introduction}

This chapter, like Chapter 4, will feature the application of Hacking's framework, as described in Chapter 3, to analyze the Census of Canada and assess if it 'makes up spaces' and influences Canadian geographical imaginations. Section 5.2 describes what a census is and provides some historical context on how it evolved. Section 5.3 describes the census of Canada between 1871 and 2011 with a particular focus on census legislation, questions and categories. Also, as was the case in Chapter 4, two themes were selected for closer examination and those are citizenship in Section 5.3.4 and official languages in Section 5.3.5. This Chapter will conclude with Section 5.4 by discussing how the modified Hacking's framework was applied to the analysis of collected census question data and illustrate the 'kinds of people and spaces' the census makes up.

Many historians, sociologists and philosophers of science have critically studied statistical thought and censuses (Alonso \& Starr, 1987; Curtis, 2001; Desrosières, 1998; Dupaquier \& Dupaquier, 1985; Hacking, 1982; Pearson, 1978; Porter, 1986 
\& 1995; Szreter, Sholkamy \& Dharmalingam, 2004; Walker, 1929; and Westergaard, 1968). It is not the intention here to include a full retrospective of the history of statistics and statistical thought, however, some of the main events, individuals and institutions most closely related to census taking will briefly be discussed as these influenced the Census of Canada. Key actors such as Adolphe Quetelet from Belgium and statistical associations will be examined as they were instrumental at shaping bureaucratic statistics and censuses. However, the intricacies of their full body of work will not be examined. The objective of this Chapter is to apply Hacking's framework to the examination of Canadian census categories and classifications, which played a role in constructing Canada's geographical imaginations. Many inventors of the statistical methods commonly used today such as Karl Pearson, Siméon-Denis Poisson, Carl Friedrich Gauss, Edmond Halley, and others will also not be discussed, nor will statistics in other fields such as biology, astronomy, or even geography. Fields related to population statistics such as population health, demography and vital statistics will be mentioned when they intersect with the shape and form of census taking, classes and categories, otherwise their rich and interesting histories are also not be examined.

\subsection{Census}

The United Nations (UN) Principles and Recommendations for Population and Housing Censuses (2007) guidebook begins by stating that taking a census: 
[is] among the most complex and massive peacetime exercises a nation undertakes. It requires mapping the entire country, mobilizing and training an army of enumerators, conducting a massive public campaign, canvassing all households, collecting individual information, compiling vast amounts of completed questionnaires, and analyzing and disseminating the data (UN, 2007:1).

It is one of the few times that government, beyond taxation, reaches out to every home and individual in a nation, making it a collective simultaneous civic moment. The role of a census "is to collect, process and disseminate such small area detailed statistics on population, its composition, characteristics, spatial distribution and organization (families and households). Censuses are conducted periodically in the majority of the countries in the world" (UN, 2007:5). In more detail:

a) A census has a role in public administration. The results of a census are used as a critical reference to ensure equity in distribution of wealth, government services and representation. It provides the facts to develop a public consensus of a nation's priorities.

b) A census is also the benchmarking system of a national statistical system. It is the sampling frame upon which other national surveys are based.

c) It generates statistics for small geographic areas, which are the building blocks of data which can be aggregated into any number of other geographies.

d) Census data are used as benchmarks for research and analysis.

In Chapter 4, it was shown that national atlases are loosely defined government objects. Censuses, however, are a very different kind of gouvernementalité and are carefully defined objects, with explicit methodologies, adhering to international principles and national legal frameworks often tied with representative government. They also create subjects to govern. Censuses are 
standardized state activities, carried out by professional statisticians who are part of official government. For the public to trust a nation's census, the census needs to be objective and impartial to political influence. Census results are only as good as the methods used to enumerate the population, necessitating disclosure to the public about how the count is done, how its privacy will be maintained and the how the census will not be used for taxation nor conscription. It is government science and a form of biopower. According to the UN Principles and Recommendations, a population census is "the total process of collecting, compiling, evaluating, analysing and publishing or otherwise disseminating demographic, economic and social data pertaining, at a specified time, to all persons in a country or in a well delimited part of a country" (2007: 7). Its essential features are "individual enumeration, universality within a defined territory, simultaneity and defined periodicity" (2007:8).

In the year 2000, 190 countries conducted a traditional census and they either collected data from a mail-out or an online questionnaire or possibly relied on the help of enumerators. A short-form census was used by many; it has fewer questions, normally it is disseminated to the entire universe of the population, rather than a long-form census, which includes a larger number of questions disseminated to a subset of the population by way of a systematic sampling methodology.

The traditional census "is particularly suitable for countries having a federal structure and having the requirement of producing population numbers by various social and economic characteristics simultaneously for all geographical 
levels to meet the needs of planning and the allocation of funds" (UN, 2007:18). The Canadian census was a traditional census until 2010 when the government discontinued the long-form and transformed it into a national household survey.

There are other census methods, such as register-based approaches. The precondition for these, however, is to have a central population register of linked government records and a unique identifier for each individual that is tied to all records. This is, however, not possible in all countries as there are privacy laws that preclude this type of record linking. There are also rolling censuses, which include a series of smaller sample surveys eventually covering the whole nation over a period of time. The drawback of this process is the repeat sampling of the same individual, and the lack of a snapshot of the population at any given time, making temporal comparisons difficult. There is also the traditional enumeration system that is mixed with yearly updates of characteristics. In this method, a short-form census is universally taken and each year a sample of the population is surveyed with a longer-form or a form seeking data on particular population characteristics. Canada has adopted something like this latter system, although there is no systematic plan for the sampling of population characteristics in the National Household Survey (NHS) created when the long form census was cancelled. Like the rolling census, it is complicated to conduct, expensive and requires ongoing and extensive planning.

Large, trusted, formalized, standardized, 'a-political' and 'objective' institutions such as a census do not emerge overnight. The process of counting and categorizing is historically constructed. For an institution like a census to 
become a stable form, it requires many years of refinement, collaboration and consensus building among government, scientific and professional associations, experts such as statisticians both bureaucratic and scientific, administrators, the population to name a few of the main actors. While most censuses are considered objective that does not mean they are politically neutral, despite many having measures in places to ensure political parties do not influence them. As discussed in chapter 2, censuses are large state infrastructures, which are sociotechnopolitical systems that have receded into the background of our imaginations as they go about doing their business to structure the affairs of the nation's people and territory. That does not make it nefarious or insidious, but it is a powerful institution and it should be critically examined periodically to assess its currency, question its assumptions and examine what it creates.

Paul Starr has examined the sociological history of official statistical agencies in his co-authored book, The Politics of Numbers, with the late urban demographer and policy analyst, William Alonso. Starr defines the purpose of a statistical system:

[it is] for the production, distribution, and use of numerical information. A statistical system may be said to have two kinds of structures - social and cognitive. Its social organization consists of the social and economic relations of individual respondents, state agencies, private firms, professions, international organizations and others involved in producing flows of data from original sources to points of analysis, distribution and use. Cognitive organization refers to the structuring of the information itself, including the boundaries of inquiry, presupposition about social reality, systems of classification, methods of measurement, and official rules for interpreting and presenting data (Starr, 1987:8). 
Both the social and cognitive structures of the census are examined in this chapter. Operational aspects will not be elaborated any further than what was already mentioned in relation to the $\mathrm{UN}$ guidelines 67 . It is worth mentioning that Canada does detail how it conducts its national census more than adequately. However, reports from the early 1980 s onward were less comprehensive on reporting administrative matters.

For Bruce Curtis, Canadian census historian and sociologist, infrastructural work includes:

all the arrangements necessary to translate the imaginings of state officials about social relations into practical observations and measures of the population (2001:32).

Censuses also embody the theory and practice of statistics and demography, and are situated in the power knowledge structures of state politics and administration that control or direct individuals toward collective goals. Like standardized systems of weights, measures, time and currency, they help control and coordinate social interests and can be characterized as a form of national intelligence gathering (Starr, 1987). Statistics and demographics for some historians:

Ne cherche pas à saisir le réel, elle est, nos soviétologues l'ont bien montré, partie d'un rite incantatoire, elle a moins la fonction d'informer que la fin de justifier et flagorner (Chaunu in Preface of Dupaquier, 1985 :10).

${ }^{67}$ The UNStats website includes data and documentation regarding the censuses of their member countries http://unstats.un.org/unsd/default.htm as does the UN Population Fund http://www.unfpa.org/public/home/sitemap/pid/6734. 
As a form of political arithmetic ${ }^{68}$, statistics, censuses and their systems of categorization create consensus on 'real' human issues and reflect the "presuppositions and theories about the nature of society" while echoing its past (Alonso \& Starr, 1987:1). Census taking can also be characterized as the 'eyes of politics' focusing and extending the administrative gaze (Gian Domenico Romagnosi in Curtis 2001:7). Censuses, like atlases, are objects of history, sources for historians and part of the history of sources and facts (Dupaquier, 1985). Further, the census also "provides a unique opportunity to investigate census making as an experimental science and to draw the links among knowledge forms, state power, and social imaginaries" (Curtis, 2001:5).

Harald Ludwig Westergaard, a renowned Danish statistician and historian of statistics, suggested that the practice of counting and tabulating evolved in part from the desire of rulers to describe their realms or states (1968). Science historian Theodore Porter shares a similar view:

the wealth and strength of the state depended strongly on the number and the character of its subjects. Accordingly the sovereign was frequently enjoined to take measures to protect the lives or health of his subjects...[Also], it was the standpoint of the sovereign that was almost always assumed, and the members of society typically appeared as objects that could and should be manipulated at will (Porter, 1986:19).

Westergaard considered Aristotle to be the first statistician as he used facts to describe the state of Greece. Nonetheless, the $16^{\text {th }}$ century Italian and French philosophers, theologians and astronomers are considered the forefathers of

68 William Petty is recognized as the founder of the term political arithmetic sometime between 1671 and 1676 . While he coined the term the practice of doing political arithmetic had been ongoing for some time. 
today's understanding of census taking and statistics. According to the scientific statistician Karl Pearson69, the origin of the word statistics came from Giovanni Botero's (1540-1617) text Dell ragione di Stato, published in 1587, which discussed affairs of the state and its constitution. The word stato was formed from the word statista, which signified a statesman or a state.

Earlier examples of statistical compilations or table statistics were also found in the middle ages. One of the most famous examples was the English 1086 Domesday Book. Other examples from England and France include kings counting English church lands, French tax registers counting tax payers, and Bills of Mortality counting the dead in England (Walker, 1929). Helen M. Walker (1891-1983), one of the pioneer women in statistics, compiled a list of early censuses and she records the first to be the 1605 record of population of Port Royal Canada and the Jean Talon census of New France taken in 1666 which is considered to be the "first census of modern times to be taken by name" (1929:34).

Censuses, statistical compilations and statistics are closely interrelated; censuses are, however, often referred to as a bureaucratic form of political statistics as opposed to scientific statistics. Censuses do not focus on the purely applied mathematical aspects of statistics and are influenced by government actors as opposed to academic theoreticians. The tension between applied and theoretical statisticians remains and re-emerges from time to time. For example, early

\footnotetext{
${ }^{69}$ Karl Pearson's lectures between 1921-1933 were amalgamated in a book edited by his son E. S. Pearson in 1978, Early History of Statistics.
} 
attempts to found a Canadian Statistical Society were turned down by the

Dominion Bureau of Statistics (DBS) in the 1960 os because the proposal was too "heavily preoccupied with theoretical rather than applied aspects of statistics" while the National Research Council was concerned that the proposal overly focused on teaching and not research (Bellhouse \& Genest, 1999:81). Censuses as well as registries were needed by scientific statisticians to applied their methods to the analysis of populations to test inferences and hypotheses.

The $16^{\text {th }}$ century statisticians referred to by Westergaard and others were statists; primarily described the political economy of regions. Censuses were understood as instrumental objects that rulers could use as seen in Les Six livres de la République, published by French jurist and philosopher Jean Bodin (1529-1596), who explained their utility in Book IV entitled The Census and the Censorship:

Rightly understood the word census means simply an assessment of each individual's belongings. If we are going to discuss the revenue, we must first enquire into the census, for of all the magistrates in a commonwealth, none are more indispensable than those responsible for it. If the necessity of their function is evident, even more so is its utility, both in establishing the number and quality of persons, and the amount and character of each individual's possessions, but also as a means of disciplining and reprimanding the subject...The first advantage to be derived from taking a census relates to the ordering of persons. If one knows the number, age, and status of all one's subjects, one can judge how many can be called upon for military service and how many must be left at home, how many can be despatched abroad to found colonies and how many employed in forced labour upon public works such as fortifications. One can also estimate the supply of food necessary for the needs of the inhabitants of each town, especially useful when one has to provision a town against a siege. None of these things can be done well if one has no idea of the number and distribution of the population (Bodin, 1576 translated by M. J. Tooley, 1955).

Bodin's idea of a census was very much like that of an accountant taking an inventory of a realm's assets. He recognized that such knowledge could be 
harnessed for additional purposes; people counted could be controlled or censored, or put to work and their assets could be depended on to add wealth to the realm. People were well aware that censuses were used for purposes not necessarily in their best interests and many refused to participate, some in England even revolted against them being taken (Porter, 1986, 1995, and Desrosières, 1998). This was also the case in Canada during the taking of the preConfederation censuses (Board of Registration and Statistics, 1853), and a similar sentiment persists today among some Canadians and may have influenced the recent changes in census taking. In addition to privacy concerns vis-à-vis state authority, making it against the law to refuse to respond to the census also rankles some Canadians. Census respondents in Canada have been obliged to respond fully to the census or risk a fine or imprisonment.

Colonialists, very much in keeping with Bodin's ideas, organized censuses in Newfoundland, Acadia, the Antilles and New France among others. In 1666, New France Intendant Jean Talon was specifically requested to know the role of each inhabitant in the colony, to inform the king of strengths in the region and to estimate the kind of resistances that would be available to him in the event of an attack (Dupaquier \& Dupaquier, 1985). Early census categories and processes may have been informed by Sébastien Le Prestre de Vauban, Marshal of France and a military engineer and fortification specialist, who developed methodologies to count people wherever he was posted. This is the same Vauban mentioned in Chapter 4, who wanted an atlas at his disposal. Late in life, the French royal government vilified him for his work on the plight of peasants and their unfair 
taxation, an argument for reform strengthened by the use of statistics 70 (Westergaard, 1968).

The term statistics, according to Pearson, proliferated after Parisian bibliophile Gabriel Naudé (1600-1653) used it in the title of his book Political Discussions About Statistical Contrivances. It was used extensively in Germany by statists and physiocrats, but primarily in the context of political economy writings and regional descriptions. Westergaard considered the Germans to be the authors of the definitive statist texts, which included methods to govern and teach future public administrators. German mathematician and philosopher Gottfried Leibniz (1646-1716), for example, had developed a kind of demographic catalog of fundamental census questions in 1680 (Dupaquier \& Dupaquier, 1985:131).

The $17^{\text {th }}$ century is also the period where the idea of political arithmetic emerges in the work of English Captain John Graunt (1620-1674) who published Natural and Political Observations on the London Bills of Mortality, the first treatise on vital statistics. Graunt is attributed with systematizing political arithmetic. His methodical process consisted of: (a) developing a system to critically evaluate data sources; (b) developing processes to analyze collected data compiled into tables; and (c) applying and testing methods with case studies. Graunt is also recognized with having developed the scientific instruments of demographic age profiles and mortality rates, which have remained quite stable (Dupaquier \& Dupaquier, 1985 and Westergaard, 1968). His friend and protégé Sir William

7o Projet d'une dixme royale was published in 1707 without royal permission and was burned (Westergaard, 1968:38). 
Petty (1623-1687) coined the term Political Arithmetick in an essay written sometime between 1671 and 1676 . Petty was interested in the study of political anatomy; he wanted to understand the political body of a place and dissect it as a medical student would a specimen. His was the study of the extent and value of lands, population, construction, economy, manufacturing and fisheries (Dupaquier \& Dupaquier, 1985 and Westergaard, 1968). Petty's list reads like the table of contents of the $1^{\text {st }}$ and $2^{\text {nd }}$ editions of the Atlas of Canada, and is similar to the contents of the Canada Year Books referenced in Chapter 4 or the list of the 1871 census schedules in Canada (see Appendix L). His work is exemplary of numbers, facts and data about people and their characteristics being put to work.

The statistical thinking of the $18^{\text {th }}$ century was also greatly influenced by German statists, such as Gottfried Achenwall (1719-1772) who used the term statistik in his texts. His work was in the German tradition of political economy and regional description, was not statistics as a practice as it is thought of today. The work of Johann Peter Süssmilch (1749-1827) The Divine order in the circumstances of the human sex, birth, death and reproduction, published in 1741, is a notable example. Süssmilch, a former army chaplain, pursued the study of human welfare and actions required to improve it, and his research was guided by his desire to see people prosper and grow according to god's will. His statistics informed actions such as the support for medical care and the reduction in taxes. Süssmilch also advocated for the growth of the government apparatus to collect numbers and also to act upon them (Porter, 1986). By 1749, the first official national census was conducted in Sweden (Dupaquier \& Dupaquier, 1985 and 
Westergaard, 1968). In general, $18^{\text {th }}$ century population data were primarily acquired from tax lists, household inventories and vital statistics, reflecting the registry based statistical census approach still in practice in Sweden today. Population statistical sampling was developed by the early $19^{\text {th }}$ century by Pierre Simon, marquis de Laplace (1749-1827), a mathematician and astronomer, who used the method to estimate population growth in France. (Population sampling became the census taking approach used in Canada, starting in 1941).

The term statistics, by the $18^{\text {th }}$ century, according to Pearson and Porter (1986), had become naturalized into the English language replacing Petty's political arithmetic. Scotsman Sir John Sinclair (1745-1835) first used it in his Statistical Account of Scotland, published between 1791 and 1792:

an inquiry for the purpose of ascertaining the political strengths of a country or questions respecting matters of state, whereas, the idea, I annex to the term is an inquiry into the state of a country, for the purpose of ascertaining the quantum of happiness enjoyed by its inhabitants, and the means of its future improvement (Sinclair 1798 in Pearson 1978:8-9).

While the new term was commonly used, it was not until 1855 , according to Michel and Jacques Dupaquier, statistical historians and sociologists, that statistics is formally defined by health demographer Jacques Bertillon (18511922) as: "the study of enumerating things, people and facts71" (Dupaquier \& Dupaquier, 1985:22).

${ }^{11}$ English translation of "l'étude du dénombrement des choses, des personnes et des faits" (Dupaquier, $1985: 22$ ). 
Census and statistics are not the same, but they are interrelated. Censuses inform statistical analysis and statistical analysis requires data collected from a scientific count. Counting was "the empirical arm of the political economy" of the Victorians and its principal task was to "chart the course of economic and social evolution" (Porter, 1986:27). The $19^{\text {th }}$ century (i.e. Victorian Age) is considered the period where tables of data appear in earnest, when scientifically counting observations becomes normalized and emphasized, and when improved methods and practices of probability are applied to the investigation of population.

Statistics and demographics are the tools of the human and social sciences as well as political economists, starting with the $15^{\text {th }}$ century double entry bookkeeping used by bankers and insurers or the $16^{\text {th }}$ century church birth and death registries (Poovey, 1998; Porter, 1986 and Dupaquier \& Dupaquier, 1985). Statistics as a science took shape in the 18th century in societies and congresses when they became institutionalized practices. Statistics were also being formalized into summaries and systems of encoding, summing, calculating and rendering into charts and graphs, and statistical data became a common reference (Desrosières, 1998).

In the $19^{\text {th }}$ century with its centralized governance, science and state meet (Dupaquier, 1985 and Desrosières, 1998) and bureaus or offices of statistics became common starting in the 1830 (Westergaard, 1968). This was part of the process of wanting to know the nation in order to govern it. The latter half of the $19^{\text {th }}$ century is characterized by statistical enthusiasm, when statistics garnered public interest and many statistical journals were published (Westergaard, 1968). 
Furthermore, institutions backed results and statistical societies gave statistical results credibility, permitting state actors to take action based on objective numbers (Porter, 1995).

Census, moral statistics or political arithmetic is the purview of government bureaucrats and took form when the census became a formal institution of national governments in the 19th century, although as discussed, European cities had been counting their populations as early as the $15^{\text {th }}$ and $16^{\text {th }}$ centuries. It was a merging of the science of statistics and applied statistics, or administrative statistics, which needed to take into consideration more than just the numbers, but also the politics of those numbers, which were used to link "knowledge and action, and toward description and prescription" (Desrosières, 1998:9). Censuses are also the outcome of large state monarchies, political thinking, biopolitics and perfecting administrative techniques. According to the Dupaquiers (1985), censuses flourished along with rationalism, individualism and the ideas of the average man. Taking a census was considered to be a rational approach to decision-making and it was scientifically conducted with logical operations, nomenclatures, questionnaires, sampling methods, verification and extrapolation.

In the $19^{\text {th }}$ century, the representation of society as being the sum of individuals (i.e. population) and the political philosophy of liberalism were factors along with Quetelet's concept of the 'average man', where biological and moral issues converge into a kind of social physics and statistical laws. Statistics were deterministic as normally distributed factors as deviance from the norm was 
undesirable (Porter, 1986 and Westergaard, 1968). For Quetelet, statistical science could advance knowledge, promote sound governance and improve social ills (i.e., moral statistics) ${ }^{72}$. One of his greatest fans was Florence Nightingale who believed that administrators could should be guided by statistical knowledge (Walker, 1929). By the late $19^{\text {th }}$ century, the period coined by Hacking as 'the erosion of determinism' (Hacking, 1990), the idea of agency and free will was to be left to philosophers and statisticians descended from their podium to accept that collecting observations and controlling results provided a rational base line of data upon which others could make decisions within the broader context of society and history (Westergaard, 1968). However, as will be seen in relation to questions on official languages in Canada, statistics can shape political decisions.

Censuses were formalized as offices or bureaus of statistics within government departments, which eventually consolidated into centralized statistical agencies with high-ranking public officers coordinating the collection of data for ministries. Statistics became an official empirical, quantitative and institutionalized social science. With the use of censuses, the stabilization of statistical practices and their bureaucratization, and the desire for efficiency, came the realization that populations were not just recipients of public policy, but a changing, dynamic, autonomous entity that needed to be understood by the state before action could be taken; furthermore, the state was beginning to realize that it was constrained by statistics (Porter, 1986).

${ }^{72}$ Moral statistics are centred on crime, illiteracy, suicide, illegitimacy, abortion, divorce, prostitution, and pauperism. 
The institutionalization of statistics first took place in societies or institutes whose members were savants, doctors, engineers, astronomers, actuaries, mathematicians, advocates for public health and statisticians (Dupaquier, 1985). The institutes, such as the Société de statistiques de Paris, primarily focused on the science of statistics and eventually became advocates for national statistical agencies. They also ensured that statisticians got recognized as scientists even if many of them were also bureaucrats. The French established their first statistical bureau as part of their Department of the Interior in 1800 (Dupaquier, 1985). The Bureau de Statistiques in the Department of the Interior, on the other hand, not only used the census to count the population but also included questions to help it evaluate the performance of political representatives, hoping that these statistics would promote national unity by creating an informed citizenry through the dissemination of results (Porter, 1995:35). Unfortunately, those ideals were not met and the Bureau was eventually closed by Napoleon in 1811; as the Bureau failed to deliver the information Napoleon needed to inform conscription, requisition and taxation decisions (Porter, 1995).

Debates around the ideals and instrumental needs of data continue. For example, should statistical agencies simply produce statistics or should they also focus on the creation of information products and reports to explain the results observed. This ongoing debate was recently underscored with the Treasury Board of Canada Secretariat's decision to publish its Open Data Pilot portal without providing context to the data it was disseminating. 
Statistics were considered to be an instrument of social progress and a primary cure for all social and physical ills. In the United Kingdom (UK), a bureau of statistics was housed in the Board of Trade in 1832 and statistics became a government civil responsibility, under the Registrar General, shortly thereafter, in 1837. Despite the impressive official title of Statistical Superintendent of the Register General, no centralized statistical agency emerged with each ministry undertaking its own statistical work. Nevertheless, esteemed epidemiologist William Farr (1807-1883), the father of medical statistics and hygiene, was an early Statistical Superintendent (Westergaard, 1968). Two notable UK institutes of the period were the Statistical Society of London, founded in 1834 , and the Manchester Statistical Society, founded in 1833. Some of the prestigious members and founders were Charles Babbage, Thomas Malthus, Adolphe Quetelet and Charles Booth. They eventually became the Royal Statistical Society in 1887. The Royal Statistical Society focused on moral statistics as well as scientific statistics, and data were compiled at the service of philanthropists. Statistics was an empirical science grounded in the idea of an 'apolitical' science, guided by the principle of ameliorating the quality of life of the working classes. However, statistics were also a tool in the service of the elite. Statistics were used to create popular schools, to alleviate the social ills of the poor, and often scholarly journals dedicated many pages to the discussion of the condition of the poor in general (Westergaard, 1968 and Dupaquier, 1985). One of the societies maintained: 
the value of statistical information can no longer be doubted. It stimulates benevolence, and gives aim and effect to the energies of the philanthropist; it furnishes the legislator with materials on which to form remedial measures for social happiness (Cornwall Polytechnic Society 183 ? in Westergaard, 1968:141-142).

This concern for the welfare of the poor was at the forefront of the 1860 Congress in London and it passed a resolution urging statesmen, political economists, philanthropists and administrators to study the condition of the poor, their wants, and resources in order to measure their well-being (Westergaard, 1968). This manifestation of an 'apolitical science' was reliant on letting the numbers (i.e. statistics) speak for themselves and the push not to let opinions enter into the analysis (Porter, 1995:78).

The American Statistical Society (ASA) was founded in 1839. Its members, including British, French and Canadian statisticians73, participated in international Congresses, and it too was involved in moral and political statistics. Canadian statisticians participated in the ASA very early on; eight ASA presidents 74 were Canadians including R. H. Coats in 1939 and Herbert Marshal in 1954. A Canadian Chapter of the ASA was founded in Montreal in 1955 and thrived until the late formation of the Canadian Statistical Society in 1977 (Bellhouse \& Genest, 1999). According to Dupaquier (1985), these societies started as scientific societies but eventually they became policy-making venues

73 The ASA member directories for 1839-1872 and 1913 list British and French statisticians such as Farr, Bertillon and included E. S. McPhail from Canada Census Office, H. H. Godfrey Canada Census Office and Dr. Archibald Blue, Chief Office of the Census and Statistics Office as members. 74 The ASA Website includes a History of ASA Presidents, the 1938 33rd, 1954 49th, 197267 th, 198378 th, 1994 89th, 2004 99th, 2010 105th and the 2013 108th were and will be Canadian presidents. 
for bureaucrats, as governments began to insert their authority in the realm of statistics. With this transformation, came a synergy between these institutes and governments. For example, the Statistical Society of London developed a committee to help prepare the 1841 census for the UK government. The ASA was also engaged in supporting the US Census. The International Statistical Congresses (1853-1876), first convened by Quetelet and inspired by Charles Babbage, were a gathering place for government ministers to discuss weights and measures, tariffs, monetary standards, public health and census making.

The first Congress called for the formulation of national, centralized statistical commissions. The theme of later Congresses was the standardization of methods, particularly with respect to the registration of populations. Early resolutions consisted of conducting a nominal census of the population, instituting decennial censuses conducted by enumerators, and appointing special agents to ensure the quality of the collected and tabulated data. A list of the early categories of data to be collected were: name, age, location of birth, language spoken, religion, vital statistics, profession and economic condition, children at school, types of housing, infirmities such as blindness, hearing impaired, insane and the creation of a population register (Congress Resolutions of 1853 in Dupaquier, 1985:305). These categories are essentially the same components as Quetelet's censuses, which were a combination of vital, moral, cultural and economic statistics, and nearly identical to those asked in early Canadian censuses. England and Belgium were the first to inaugurate household based censuses in 1841 and 1846 respectively. They also made responding to the census obligatory. The 
Congresses also established the categories for the taking of vital statistics, the development of cause of death nomenclatures and the collection of immigration statistics. Immigration and migration grew from few data collected at ports to an important methodology as a result of outmigration to the colonies. Unlike Quetelet's categories, their focus was not necessarily on assessing well-being:

on remarquera en passage à quel point les phénomènes sociaux préoccupent alors les statisticiens : on ne parle pas du phénomène démographique que représente la 'migration' en soi, mais de l'influence qu'elle exerce sur la fortune publique de la mère patrie, de l'espoir d'accroitre son bien-être en s'établissant dans un autre pays (Dupaquier \& Dupaquier, $1985: 308)$.

Quetelet ultimately wanted to create standardized international population statistics and current UN principles are a living testament to that. The Congress collapsed in 1879 due to competing national interests but was reinvigorated by the International Congress on Demographics in Paris in 1878 and the 1885 International Statistical Institute founded in London. The former discussed vital statistics, immigration, health and cartography, and the latter focused on national statistics and censuses. The 1885 objectives of the International Statistical Institute (ISI) were to support: the progress of administrative and scientific statistics; the standardization of data collection and tabulation methodologies for international comparability; the publication of journals to establish a rapport between the world's statisticians; and the promotion of public education toward the creation of the knowledge of statistics (1885 in Dupaquier, 1985:317). Statistics were being disciplined and this marked a time of great collaboration between and within nations and Canada remained a constant member of the Institute and hosted the $34^{\text {th }}$ Session in Ottawa. 
The latter half of the $19^{\text {th }}$ century was characterized as a period of standardization and application, as well as the operationalization of methods. Also, it was a period in the growth of municipal statistical offices, inspired by early epidemiologists and public health offices. By that time, western countries had established national statistical agencies, bureaus and offices and successful censuses had been conducted. The foundations for mathematical statistics are believed to date back to a period between 1890 and 1930, while a statistical viewpoint had been established as a style of reasoning in the social sciences for governing, and population thinking was normalized (Porter, 1986).

The British Colonial Conferences were another venue for the discussion of standardization, with the first being held in 1887 . It focused on collaboration between the colonies on matters pertaining to defence, trade and telegraph communication. Conferences that followed addressed the normalization of definitions on naturalization (1902), the uniformity of colonial trade statistics (1907), trademarks and patents to name a few (UK National Archives, 2011). The Colonial Conferences were a testament to the normalization of thinking about population and precursor to many thematic conferences, and the creation of the Commonwealth Statistical Conference or Imperial Statistical Conference in 1920 was one of them. R. H. Coats was a founding member, as well as a member of the Empire's Census Committee, and attended the first meeting in London in 1920, and hosted the second meeting in Ottawa in 1935. This institute's purpose was to standardize data gathering and classification systems among Commonwealth Nations. This first meeting discussed standardization of census classifications 
and the inclusion of the following classifications: divorce; fertility; uniform classification for industry and occupations; data about 'aliens'; and population characteristics presented by age. Other topics discussed include the need to improve data pertaining to infirmities and to provide more specificities regarding migration between the nations of the Empire and others (Glenny, 1920).

Canada had become an important intergovernmental and international player in the statistical community and became an international advisor (Worton, 1998). After WWII, the UN Statistical Commission was established in 1947 and was chaired by Canadian statistician Herbert Marshall for the first three sessions between 1947 and 1948. This body's mandate was to set "statistical standards, the development of concepts and methods and their implementation at the national and international level" (UN Statistical Commission, 2011). Canada also contributed to the UN Population Commission starting in 1947 and continues to be an active contributor and member to many of the 45 Sessions, including the 1954 Eighth Session chaired by Marshall. Canada was also one of the founding members of the International Labour Organizations (ILO), established by the League of Nations in 1919 and now a specialized UN agency, and hosted the office in Montreal during the WWII. In its infancy, the ILO was engaged in numerous labour statistical standardization activities, particularly with respect to employment and unemployment. The ILO was instrumental in the development of the International Standard Classification of Occupations (ISCO), adopted in 1957. Canadian statistician N. L. McKellar, who was a DBS director and also engaged in the UN Commissions, made a significant contribution to the ISCO 
(Worton, 1998). Canada was also a founding member of the Organization for European Economic Co-operation (OECD) since 1961, and the OECD, like the UN Statistical Commission, the ILO, International Statistical Institute and the Commonwealth Statistical Conferences, is concerned with the standardization of classifications and inter-member comparable statistics. Canada was OECD Secretary between 1996 and 2006.

Census taking is biopolitics in action (Hacking, 1982) and the "census became the hallmark of the enlightenment, but always for what at first sight seemed good practical purposes" (Hacking, 1982:289). Historically, statistics were viewed as the "all-important side of political economy" and an "empirical form of social knowledge" (Porter, 2004:169). Taking a census became a cultural process of historical significance as it was part of the "drive to achieve objectivity through the cultivation of technical methods"(Porter, 2004:166) and statistical reasoning contributed to "the rise of social science as disciplined science" (Porter, 2004:166). Counting people is a form of rational-technical discourse to dispel 'democratic distrust' and with an "ethic that reins in experts even as it assigns important decisions to them" (Porter, 2004:166). A population census:

configures social relations by tying human beings to virtual spaces within the physical space of political territories. The execution of a census of population typically depends on the capacity of state agencies to define territorial boundaries, to subdivide them in convenient ways, and to attach political subjects to such subdivisions (Curtis, 2001:26). 
This configuration of social relations was evident in the territorial division and demographic maps in the Atlas of Canada, and as will be seen in the construction of bilingualism in Canada. Thinking with 'objective' numbers and acting upon them has become the norm and a census structures:

the ways people imagine their social existence, how they fit together with others, how things go on between them and their fellows, the expectations that are normally met, and the deeper normative notions and images that underlie these expectations [it is what] makes possible common practices and a widely shared sense of legitimacy (Taylor, 2004:22).

Censuses and statistics have been used for evidence-based decision-making for quite some time. Bodin's $16^{\text {th }}$ century description is one early example, and by the mid-19 $9^{\text {th }}$ century, evidence-based decision-making is normalized as exemplified in 1860 Statistical Society of Paris resolution stating that "statistics is nothing else than knowledge of the science of facts" and these "ought to provide the basis upon which society is governed" (in Porter, 1995:80). The UN definitions introduced at the beginning of this section and its accompanying guidelines give an aura of impartiality with its absence of ideological thinking, however, as seen here, the modern sanitized form of census taking has a religious, health, political, economic and moral lineage and it is one of the most political of institutions a national government has at its disposal. 


\subsection{The Canadian Census}

This section provides a brief history of the Census of Canada, which is followed by an examination of census questions and their associated categories between 1871 and 2011. This section concludes with the study of two census classifications, citizenship and official languages, with the use of Hacking's framework as the guide to collecting, organizing and analyzing content.

\subsubsection{Study Parameters}

Many censuses were conducted prior to 1871 . However, for the purpose of this analysis, the first official national census 75 after Confederation was chosen as the starting point. The first post-Confederation census, as will be seen and as just discussed, was influenced by the experience gained from earlier censuses at home and abroad. Other influences include international actors in Great Britain, France and the United States; and knowledge produced and legitimized at international statistical societies and transnational organizations. These influences guided how the Canadian census was conducted, the nature of the questions asked and the classification systems adopted.

Only census questions and associated categories are examined here as opposed to the outcomes of the census since it is these that 'make up spaces' (Hacking, 1986, $1991,2001,2005,2006,2007)$. It is understood that actions are taken based on census outcomes, but before there are outcomes, there were plans for collecting

\footnotetext{
75 An Act Respecting the First Census, 33. Victoria, C. 21, 1870 section 1, The First Census of Canada, to be taken in the year 1871 , hereinafter termed "the Census", shall be so taken as to ascertain and show, with the utmost accuracy possible...all statistical information which can conveniently be obtained and stated in tabular form..."
} 
certain types of data about certain types of people in certain kinds of ways and it is these choices that are examined. Census questions are seemingly natural choices and categories and:

through an array of state rituals and social practices, people consciously or unconsciously conform to the categories set up in official statistics. Censustakers and statisticians, however, have little control over the life of the categories and classifications that they establish. 'Counting' as Ian Hacking observes - 'generates its own subdivisions and rearrangements' (Patriarca, 1996:11).

Booth's poverty line discussed in Chapter 3 was an example of this as were the classifications systems discussed in Chapter 4.

It was not possible to examine all census questions across 21 national censuses and eight regional censuses. The scope of this examination is therefore limited to citizenship and official language questions. The schedules, forms and questionnaires from which data were collected and analyzed are listed in Chapter 3 (see Table 2; page 119). Appendix L includes a list of the complete set of schedules for each census and Appendix A provides schedules and questionnaire sources. The focus is the population census and not vital statistics, which were part of earlier Canadian censuses (See Appendix L).

As was demonstrated with the examination of the Atlas of Canada, the framework upon which census questions and categories are studied is based on Hacking's concept of the 'looping effect' to assess how a category interacts with the people classified, and how that constructs geographical imaginations. His framework includes: 1) classification; 2) people classified; 3) experts who classify; 4) institutions within which the experts and their subjects interact, and through 
which authorities control; and 5) knowledge about the people in question (Hacking, 2006: 295). Hacking's engines of innovation are also part of the framework, as discussed in Chapter 3 and demonstrated in Chapter 4, and these are: counting, quantifying, correlation, norms, taking action, scientification, normalization, bureaucracy and resistance.

The configuring of social relations, social shaping or imagination making will become quite apparent with census classifications (e.g., citizen and bilingual people) as these become seemingly 'natural' classifications where in reality, they are part of the human way of sorting things:

nos classifications des gens interagissent avec les gens que nous classons. Les classifications des gens sont « interactives ». Il n'en va pas de même pour les classements des choses : ils n'interagissent pas avec les choses, ils sont « indifférents ». C'est l'aspect le plus important de l'idée qu'une classification est « naturelle » (Hacking, 2001-2002).

In Chapter 4, the analysis of the classifications of relief, forest biogeography, communication infrastructure and territorial evolution relied on resources external to the Atlas since the description of the classifications used were not provided within the object itself. The census, however, is a very different type of object, bounded by a scientific methodology that systematically dictates how data are to be collected, compiled, analyzed, abstracted and published. This process is carried out within the confines of its legislative mandate and as per the mandate of its producing agency (i.e. StatCan), which is: 
To provide statistical information and analysis about Canada's economic and social structure to:

- develop and evaluate public policies and programs.

- improve public and private decision-making for the benefit of all Canadians.

To promote sound statistical standards and practices by:

- using common concepts and classifications to provide better quality data.

- working with the provinces and territories to achieve greater efficiency in data collection and less duplication.

- reducing the burden on respondents through greater use of data sharing agreements (sources used include annual tax records, monthly employee payroll records and customs records).

- improving statistical methods and systems through joint research studies and projects (StatCan, 2011a).

To ensure logical consistency among millions of census respondents, questions are carefully defined and StatCan publishes its departmental standard definition, including the international standards which it adheres to (StatCan, 2011a). Between 1871 and 1966, census data were collected at the respondent's door by enumerators who swore an oath to secrecy, to conduct their work with integrity and to collect accurate data. A census commissioner trained enumerators and census officers trained those commissioners. Commissioners and enumerators were hired on a short-term basis to carry out the data collection duties of the census. Commissioners drew enumeration area boundaries, managed schedules and directed enumerators on how to collect data, and then submitted completed schedules to their officers, who in turn, coordinated their distribution to tabulators and so on within the census processing process. Census commissioner and enumerator manuals and instruction booklets were created specifically for training purposes but served as the key reference tool used in the field by enumerators. These manuals contained information about the census, schedules, descriptions of what was to be collected for each question, the oaths, relevant 
sections of the Statistics Act in force and sometimes entire classification systems, and in other cases, sections of other relevant Acts, such as the Naturalization Act of 1914 , and references to relevant treaties. In addition, these manuals also provided lists of languages, countries, international boundary changes and occupations along with fees, wages and dispensation processes.

Census taking was and remains a very labour intensive activity. In 1891, for example, there were 4,366 enumerators and 241 commissioners, and by 1961 , there were 30,000 enumerators and 1,300 commissioners and each was instructed to collect data in the same way. Census taking, as previously discussed, is one of the few acts of civic simultaneity, and for over one hundred years, thousands of people were systematically instructed, and in many cases, memorized the information provided in these training manuals which contained information about Canadian history and geography, world affairs and geography, society, culture, language, health, history and labour, and legislation. These same people also knew a great deal about the private affairs of members of their communities. It was a cadre who knew the nation, the rules that governed collecting data, and their important role in that process.

Between 1971 and 2001, the census became a mail-out and mail-back system, and in 2006, it was also conducted over the Internet. Some door-to-door enumeration still took place in rural and remote communities, including First Nations reserves. Respondents were provided with instruction booklets for the questions and were given contact information should there be a need for more information. Questions were printed with examples to guide respondents; 
questions were carefully crafted and less open ended to avoid misinterpretation. In addition, census manuals and census dictionaries were created to inform census data analysts on coding procedures while methodological manuals explained how data were tabulated, errors captured, etc. Census taking was, and remains, very well structured. Nonetheless, there were enumerator errors, biases, erroneous tabulations, undercounts, and respondents' misinterpretation of questions, and these are well documented in methodological reports. The analysis of citizenship and official languages will rely heavily on Census of Canada manuals, reports and dictionaries.

\subsubsection{Census and Legislation}

The Census of Canada is one this country's most powerful official institutions. It is a necessary component of our representative electoral system as it determines the size of electoral boundaries, the number of seats in parliament, the thickness of spending envelopes, the destination for those envelopes, and the allocation of those funds. It is also one of the few national civic moments where the government comes to everyone's door.

The Canadian census was enshrined in the British North America (BNA) Act of 1867 , which stated that a census was to be taken in 1871 and the count was to determine the number of seats in parliament for the new representative democratic political system ${ }^{76}$ The census counted the people, directed how they

\footnotetext{
${ }^{76}$ Section 51 of the British North America Act of 1867 , and the Consolidated Constitution Act of
} 1867-1982. 
were to be administered and told Canadians who they were on census day. The census maps social and geographic change and, to some extent, determines the future people, programs and nature of Canadian society. It is state-based and evidence-based decision-making in action. The 1871 census was described in instruction manuals as follows:

a census is taken for the purpose of ascertaining, as exactly as possible, the population and resources of a country, and thereby furnishing a sufficiently correct idea of its strength and capability...the results it exhibits, like those of any other statistical enquiries, are directly connected with the science of government; which pre-supposes a general knowledge of the wants and capabilities, the defects and advantages, numerically presented, of the population and the country (Dept. Agriculture, 1871:9).

Figure 32 below provides a census timeline and Table 9 includes institutional arrangements and details about the census. David A. Worton's book, Dominion Bureau of Statistics, discussed the work of drafting and lobbying for the adoption of the different Statistics Acts and Orders in Council by the chief statistician. His work will not be repeated here extensively, but where warranted, some will be referenced. 


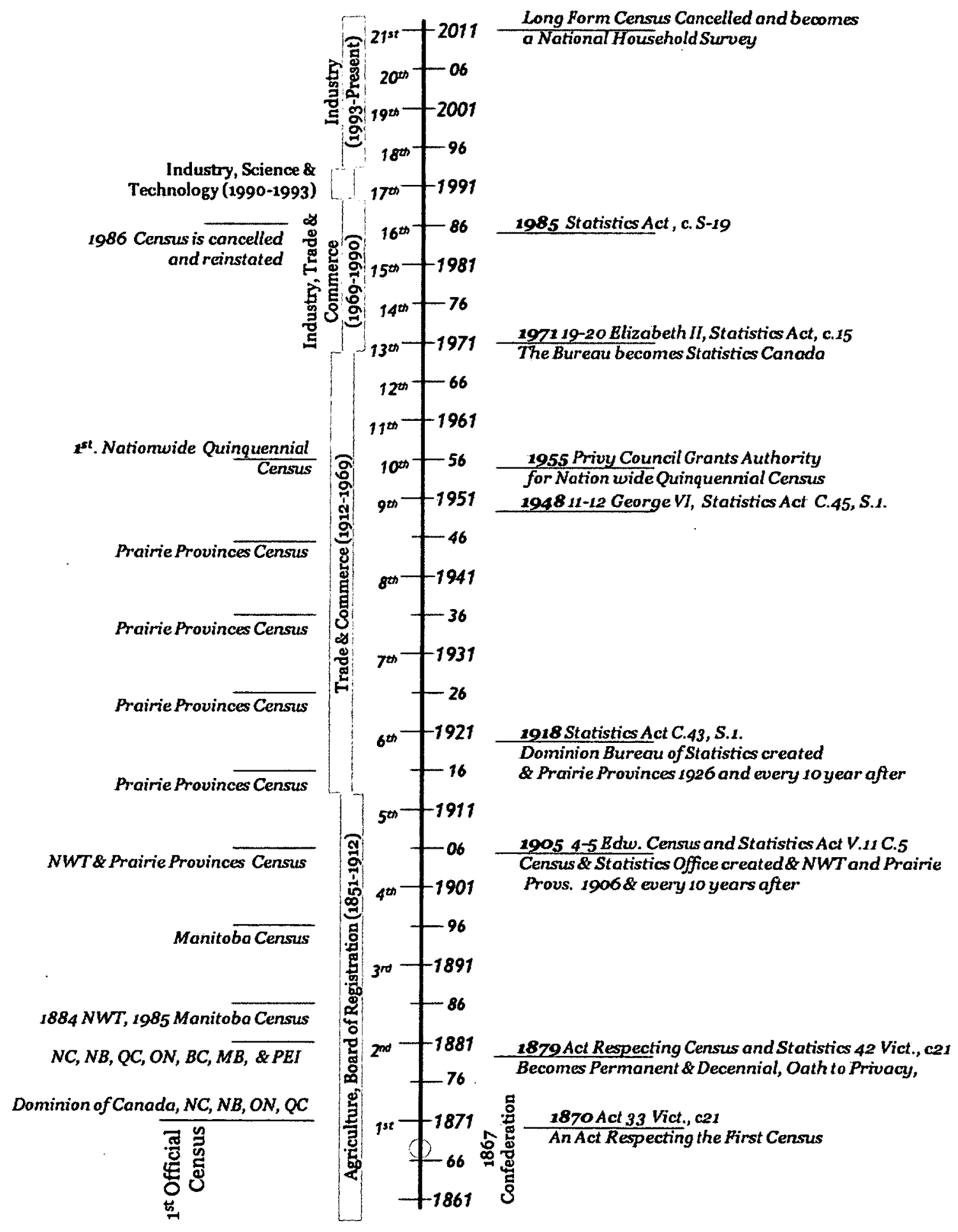

Figure 32. Census of Canada Timeline (Created by the Author) 
Table 9. Census of Canada and Institutional Information (Compiled by the Author)

\begin{tabular}{|c|c|c|c|c|c|c|c|c|}
\hline Year & $\begin{array}{c}\text { Census } \\
\text { Type }\end{array}$ & Process & $\begin{array}{c}\text { Geographic } \\
\text { Extent }\end{array}$ & Forms* & Officer & Title & Office & Ministry \\
\hline $\begin{array}{c}1870- \\
71\end{array}$ & $1^{\text {st }}$ Decennial & \multirow{9}{*}{ Enumeration } & $\begin{array}{c}\text { Dominion of } \\
\text { Canada } \\
(\mathrm{NC}, \mathrm{NB}, \mathrm{QC} \& \\
\mathrm{ON}) \\
\end{array}$ & $\begin{array}{l}9 \text { Schedules } \\
\text { \& } 260 \\
\text { questions }\end{array}$ & & & \multirow{8}{*}{$\begin{array}{l}\text { Board of } \\
\text { Regis- } \\
\text { tration }\end{array}$} & \multirow{9}{*}{ Agriculture } \\
\hline $\begin{array}{c}1880 \\
-81\end{array}$ & $2^{\text {nd }}$ Decennial & & $\begin{array}{c}\text { Dominion of } \\
\text { Canada } \\
\text { (NC, NB, } \\
\text { QC,ON, BC, } \\
\text { MB \& PEI) } \\
\end{array}$ & $\begin{array}{c}9 \text { Schedules } \\
\& 561 \\
\text { questions }\end{array}$ & J. C. Taché & $\begin{array}{l}\text { Mepuly } \\
\text { Minister }\end{array}$ & & \\
\hline $\begin{array}{c}1884^{-} \\
85 \\
\end{array}$ & $\begin{array}{l}\text { Special } \\
\text { Regional }\end{array}$ & & $\begin{array}{l}\text { North-West } \\
\text { Territories }\end{array}$ & 5 Schedules & $\begin{array}{l}\text { J. G. G. } \\
\text { Layton, }\end{array}$ & $\begin{array}{c}\text { Statistical } \\
\text { Officer }\end{array}$ & & \\
\hline $\begin{array}{c}1885^{-} \\
86\end{array}$ & $\begin{array}{c}\text { Regional } \\
\text { Quinquennial }\end{array}$ & & $\begin{array}{l}\text { Special Census } \\
\text { of Manitoba }\end{array}$ & 6 Schedules & $\begin{array}{l}\text { E. H. Str. } \\
\text { Denis }\end{array}$ & $\begin{array}{c}\text { Acting } \\
\text { Statistical } \\
\text { Director } \\
\end{array}$ & & \\
\hline 1891 & $3^{\text {rd }}$ Decennial & & $\begin{array}{c}\text { Dominion of } \\
\text { Canada }\end{array}$ & 9 Schedules & George & & & \\
\hline 1896 & $\begin{array}{c}\text { Regional } \\
\text { Quinquennial }\end{array}$ & & Manitoba & $\begin{array}{l}\text { Head count } \\
\text { only }\end{array}$ & Johnson & Statistician? & & \\
\hline 1901 & $4^{\text {th }}$ Decennial & & $\begin{array}{l}\text { Dominion of } \\
\text { Canada }\end{array}$ & $\begin{array}{c}13 \text { Schedules } \\
549 \\
\text { questions }\end{array}$ & \multirow{3}{*}{$\begin{array}{l}\text { Archibald } \\
\text { Blue }\end{array}$} & $\begin{array}{l}\text { Special } \\
\text { Census } \\
\text { Commis- } \\
\text { sioner } \\
\end{array}$ & & \\
\hline 1906 & $\begin{array}{c}\text { Regional } \\
\text { Quinquennial }\end{array}$ & & $\begin{array}{c}\text { Northwest } \\
\text { Provinces } \\
(\mathrm{MB}, \mathrm{SK}, \mathrm{AB})\end{array}$ & 2 Schedules & & $\begin{array}{l}\text { Chief } \\
\text { Officer }\end{array}$ & & \\
\hline 1911 & $5^{\text {th }}$ Decennial & & $\begin{array}{l}\text { Dominion of } \\
\text { Canada }\end{array}$ & $\begin{array}{c}13 \text { Schedules } \\
\& 522 \\
\text { Questions }\end{array}$ & & $\begin{array}{l}\text { Chief } \\
\text { Officer }\end{array}$ & $\begin{array}{l}\text { Census } \\
\text { and } \\
\text { Statistics } \\
\text { Office } \\
\end{array}$ & \\
\hline
\end{tabular}




\begin{tabular}{|c|c|c|c|c|c|c|c|c|}
\hline Year & $\begin{array}{c}\text { Census } \\
\text { Type }\end{array}$ & Process & $\begin{array}{c}\text { Geographic } \\
\text { Extent }\end{array}$ & Forms* & Officer & Title & Office & Ministry \\
\hline 1916 & $\begin{array}{c}\text { Regional } \\
\text { Quinquennial }\end{array}$ & & $\begin{array}{c}\text { Prairie } \\
\text { Provinces } \\
(\mathrm{MB}, \mathrm{SK}, \mathrm{AB})\end{array}$ & 3 Schedules & \multirow{5}{*}{ R. H. Coats } & $\begin{array}{c}\text { Dominion } \\
\text { Statistician } \\
\& \\
\text { Controller } \\
\text { of Census } \\
\end{array}$ & & \multirow{10}{*}{$\begin{array}{l}\text { Trade and } \\
\text { Commerce }\end{array}$} \\
\hline 1921 & $6^{\text {th }}$ Decennial & & $\begin{array}{c}\text { Dominion of } \\
\text { Canada }\end{array}$ & $\begin{array}{c}5 \text { Schedules } \\
\& 565 \\
\text { questions } \\
\end{array}$ & & \multirow{9}{*}{$\begin{array}{c}\text { Dominion } \\
\text { Statistician }\end{array}$} & \multirow{9}{*}{$\begin{array}{l}\text { Dominion } \\
\text { Bureau of } \\
\text { Statistics }\end{array}$} & \\
\hline 1926 & $\begin{array}{c}\text { Regional } \\
\text { Quinquennial }\end{array}$ & & $\begin{array}{c}\text { Prairie } \\
\text { Provinces } \\
(\mathrm{MB}, \mathrm{SK}, \mathrm{AB})\end{array}$ & 3 Schedules & & & & \\
\hline 1931 & $7^{\text {th }}$ Decennial & & $\begin{array}{l}\text { Dominion of } \\
\text { Canada }\end{array}$ & $\begin{array}{c}3 \text { Schedules } \\
\text { \& Census } 2 \\
\text { Schedules } \\
\text { NWTs }\end{array}$ & & & & \\
\hline 1936 & $\begin{array}{c}\text { Regional } \\
\text { Quinquennial }\end{array}$ & & $\begin{array}{c}\text { Prairie } \\
\text { Provinces } \\
(\mathrm{MB}, \mathrm{SK}, \mathrm{AB})\end{array}$ & 2 Forms & & & & \\
\hline 1941 & $8^{\text {th }}$ Decennial & & $\begin{array}{c}\text { Dominion of } \\
\text { Canada }\end{array}$ & $\begin{array}{c}3 \text { Forms \& } \\
\text { 10\% Housing } \\
\text { Sample } \\
\end{array}$ & \multirow{3}{*}{$\begin{array}{l}\text { Herbert } \\
\text { Marshall }\end{array}$} & & & \\
\hline 1946 & $\begin{array}{c}\text { Regional } \\
\text { Quinquennial }\end{array}$ & & $\begin{array}{c}\text { Prairie } \\
\text { Provinces } \\
(\mathrm{MB}, \mathrm{SK}, \mathrm{AB})\end{array}$ & 2 Forms & & & & \\
\hline 1951 & $9^{\text {th }}$ Decennial & & \multirow{3}{*}{$\begin{array}{l}\text { Dominion of } \\
\text { Canada }\end{array}$} & $\begin{array}{c}8 \text { Forms \& } \\
20 \% \text { Housing } \\
\text { Sample }\end{array}$ & & & & \\
\hline 1956 & $\begin{array}{c}\text { 10th } \\
\text { Quinquennial }\end{array}$ & $\begin{array}{c}\text { Short } \\
\text { Enumeration }\end{array}$ & & 2 Forms & \multirow{2}{*}{$\begin{array}{l}\text { Walter, E. } \\
\text { Duffett }\end{array}$} & & & \\
\hline 1961 & $\begin{array}{c}\mathbf{1 1}^{\text {th }} \\
\text { Decennial }\end{array}$ & Enumeration & & 4 Forms & & & & \\
\hline
\end{tabular}




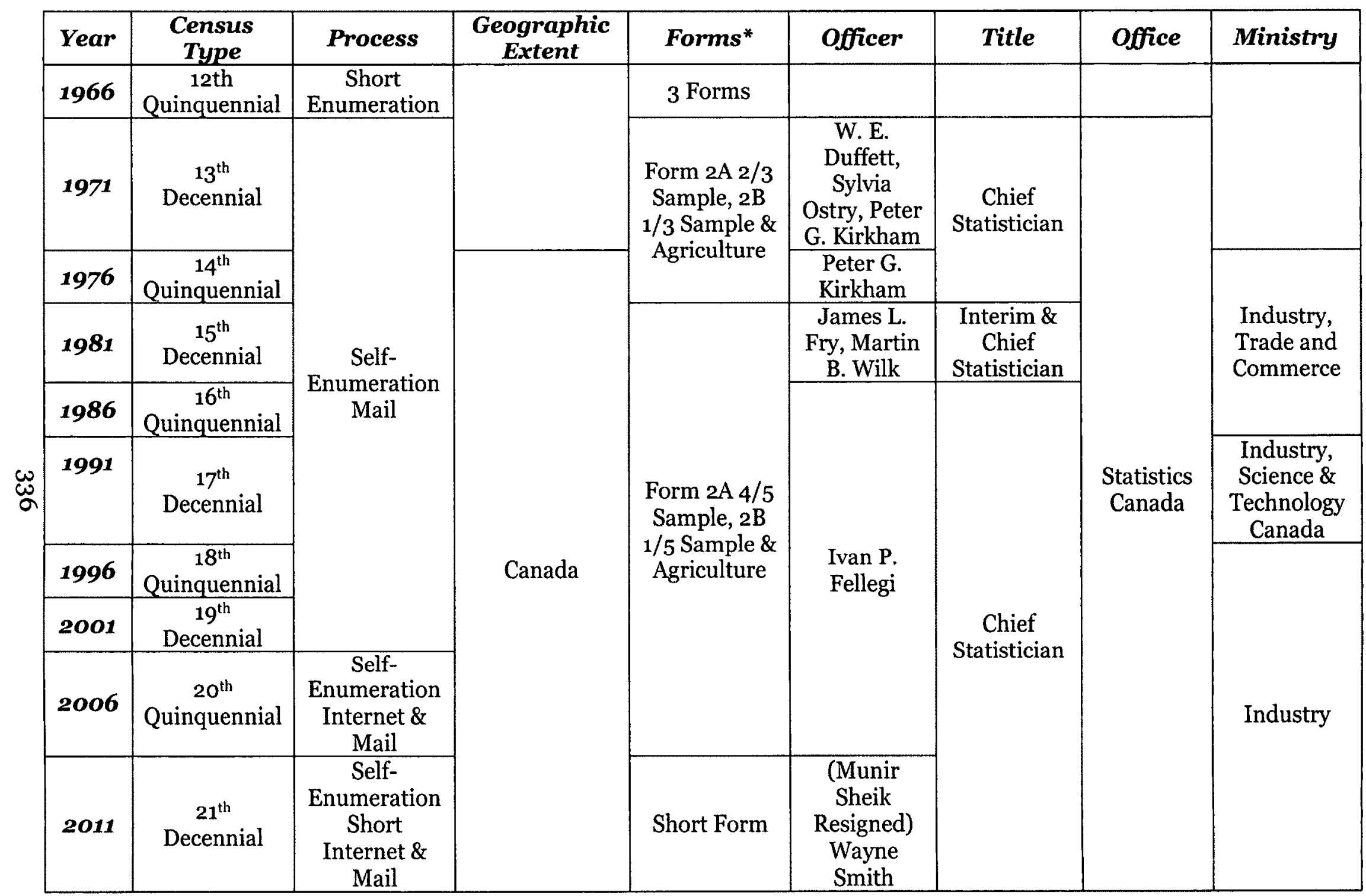


The census of population and agriculture dates as far back as 1666 and as earlier stated, conducted in New France by Jean Talon (1625-1694) according to the de jure77 method. This census is often referred to as the first official census by name in the world (Godfrey, 1918, Walker, 1929), although as already discussed, many counts were taken elsewhere in the world prior to this one. Talon's schedule included questions about families, sex, conjugal condition, age, professions and trades, and the results led him to insist that France send more women to the colony of New France. The same results also informed his economic diversification strategy toward developing a home-based type of industry (StatCan, 2008a). Numerous censuses have intermittently taken place between 1665 and Confederation. Religious orders and linguistically separate groups representing French and British colonial powers conducted these. French and English colonial governments counted the population of Lower and Upper Canada, which became the united Province of Canada, as well as a few smaller territories in Assiniboine and Red River Districts, New Brunswick and Nova Scotia.

The legal framework is used as a guide to structure the evolution of the Canadian census. Many changes have taken place throughout the history of census taking in Canada and it is not the intention here to describe what has already been well documented by David A. Worton and Bruce Curtis. Legislation is, however, the

$\pi$ A census conducted according to the de jure method counts people by their legal residence and not by where they are on census day. 
highest government authority legitimizing the taking of measures. The following are some reasons:

provide legitimacy for administrative actions, in large part because they provide standards against which people judge themselves. Grades in school, scores on standardized examinations, and the bottom line on an accounting sheet cannot work effectively unless their validity, or at least reasonableness, is accepted by the people whose accomplishments or worth they purport to measure. When it is, the measures succeed by giving direction to the very activities that are being measured. In this way individuals are made governable; they display what Foucault called governmentality. Numbers create and can be compared with norms, which are among the gentlest and yet most pervasive forms of power in modern democracies (Porter, 1995:45).

Legislation not only guides, but also validates census taking in Canada. The funding of the census will not be discussed. Suffice it to say that there is a budget set aside for conducting a census which covers a census cycle that is approximately seven to eight years in duration and includes inception, planning, consultations, execution, tabulation, reporting and dissemination.

Censuses are a requirement of representative government and Charles Poulett Thomson (1799-1841), the first Governor of the united Province of Canada and a member of the London Statistical Society, was appointed in 1839 to develop a system of representative democracy in the new colony. A census was not mentioned in the 1839 Bill to unite the provinces ${ }^{78}$ although a population count by electoral districts was. In 1840 , the Act of Union instituted elections by representation requiring an official count and, in 1841, a Census Act was passed (Worton, 1998), and shortly thereafter a census was instituted in 1842 . In 1847 , a

78 1839, Upper and Lower Canada a bill for re-uniting the provinces of Upper Canada and Lower Canada. 
Board of Registration and Statistics was created and chaired by the Inspector General of the colonial government and this marked one of the first attempts to formalize census taking. The board was later transferred to the Department of Agriculture in 1857. Rawson W. Rawson (1812-1899), the former secretary of the London Statistical Society and later its president, became responsible for implementing nominal census taking using Quetelet's practices in England. In 1842 , as the Civil Secretary to the Governor-General of Canada, Rawson brought enumeration schedules to Canada East, and by 1851 , the British Colonial Office distributed the Queteletian census method, discussed earlier, to all colonial governors (Curtis, 2001:21-22). Royal assent was given to legislation for a decennial census in Canada in 1851, and a census statute in 1859. In 1861, a decennial census was taken.

The impetus for conducting a scientific census in Canada, however, was also to quell English and French Canada, or Upper and Lower Canada, as tensions over the allocation of seats in the House of Commons were high. The application of a census would hopefully make representation in the House objective Canada's census taking coincided with the institutionalizing of periodic censuses in most advanced states in Europe and with the understanding that "without numbers, legislation is considered ill-informed or haphazard" (Porter, 1986:37).

The 1851-52 and 1861 censuses were considered to be unreliable counts, and as Joseph Charles Taché (1820-1894), then Deputy Minister of Agriculture responsible for the 1871 census, unabashedly stated: they were "fallacious statements, and not to be relied upon in any essential point" that included 
"absurdities of the most ridiculous character" and most of the 'absurdities' were related to poor collection and tabulation (Godfrey, 1918:191-182). Taché had bold plans to develop "a monument at which the enlightened part of the population would certainly look with complaisance and other countries with a great deal of interest" (Taché, 1865 in Godfrey, 1918:183) and he wanted a body of statistics to guide the development of the Province of Canada (Worton, 1998). Taché was also a politician who wanted to ensure that French-speaking Québec had the right number of seats allocated (Curtis, 2001).

By 1871, taking the census had become a normalized administrative function; infrastructures were in place and census taking was easier for a number of reasons including: the population was more educated; numeracy was increasing; and more people understood the notion of the benefits of science (Curtis, 2001:213). Shortly after the 1867 British North America Act (BNA) was passed by Parliament, Taché was appointed as Deputy Minister of Agriculture79. The BNA made census and statistics official matters of national importance (see Figure 32 page 333 and Table 9 page 334). Clause 51 of the BNA (30 Vic.c.III), for example, enshrined representation by population for the House of Commons in keeping with the results of the census. The first allocation of seats in 1867 was based on the 1861 census. The Taché census was endorsed by an 1870 Act by the Dominion Parliament and this Census Act ${ }^{80}$ included census questions and

\footnotetext{
79 In the 1867 BNA Act, the taking of a Decennial Census was sub-section 8 of Part II Union and sub-section 51 under the House of Commons regarding how it was to be used to divide seats in the House of Commons, the Senate and the extent of electoral districts.

${ }^{80} 1870,33$ Vict. The Census Act, c.21 Section 1.
} 
categories $^{81}$; appointment of officers; creation of census geographical districts and sub-districts to "correspond as nearly as possible with the Municipal or other recognized divisions" and electoral districts; scheduling of census; duties of the Minister of Agriculture, Governor in Council, Commissioners and Enumerators; forms; penalties and fines for non-respondents; and responsibilities for making tables and reporting results. The categories covered moral, social, economic and territorial statistics collected with nine schedules and 211 questions. Collecting these data was quite a daunting process considering that the census was conducted by enumerators in the spring. The design and instructions to enumerators and commissioners:

by no means eliminated interpretive and conceptual difficulties; but taken together, they underline the scientific character of the 1871 census. The 1871 effort involved the application of carefully considered, well-articulated, and thorough observational protocols by an efficiently equipped body of observers, to a set of reasonably well-defined objects and relations. Taché and his team had done the infrastructural work necessary to extend their conclusions about past census making into the field (Curtis, 2001:273).

The census became a state-related science and remained the responsibility of the Department of Agriculture until 1912. The placement of the census with the Department of Agriculture was no accident; early demographers and political arithmeticians were also physiocrats who believed the economy of a state was

${ }^{81}$ All statistical information which can conveniently be obtained and stated in tabular form, touching - their population and the classification thereof, as regards age, sex, social condition, religion, education, race, occupation, and otherwise, - the occupied land therein, and the condition thereof, as town, village, country, cultivated, uncultivated, and therein, - the produce, state and resources of the agricultural, fishing, lumbering, mining, mechanical, manufacturing, trading and other industries thereof - the municipal, educational, charitable and other institutions thereof - and whatever other matters may be specified in the forms and instructions to be issued, as hereinafter provided (1870, 33 Vict. The Census Act, c.21 Section 1). 
directly related to its agriculture and its land development. Antoine-Laurent de Lavoisier (1743-1794), the father of modern chemistry for example, developed food consumption statistics and proposed that statistical departments be created to study agriculture and population (Westergaard, 1968). In the $17^{\text {th }}$ century and in earnest in the $18^{\text {th }}$ century, several European countries enumerated livestock and humans, and conducted population counts at the same time; they conducted agricultural counts of the number of labourers, their wages, mean weight of produce, etc. England, in particular, standardized this practice in 1870 . To this day, the Canadian population census and the census of agriculture continue to be conducted at the same time. Also worth noting, the 2011 census of agriculture remained mandatory and a long-form.

In 1879, the decennial Census was made permanent in the new Census and Statistics Act, which was created in preparation for the 1881 census $^{82}$. All persons employed in the execution of the Act had to take an oath of office:

before entering on his duties, shall take and subscribe an oath binding him to the faithful and exact discharge of such duties, in such form, before such person, and returned and recorded in such a manner, as by Order in Council shall be prescribed $(1878,42$ Victoria c. 21 , Section 12$)$.

It governed the $2^{\text {nd }}, 3^{\text {rd }}$ and $4^{\text {th }}$ censuses and it stated that the Department was to collect beyond the census, moral statistics such as those pertaining to crime, vital statistics and others related to agriculture and the economy as required.

82 An Act Respecting Census and Statistics, Victoria, 1979, C. 21, "Whereas it is expedient to establish and permanently to organize the taking of the census and the collection and publication of statistics" (Preamble). 
By the turn of the century, new government Trade and Commerce and Labour Departments were created and reflected the growth of Canadian industrialization, which demanded more statistics. In 1905, the Minister of Agriculture created the Census and Statistics Office and one of its mandates was to conduct a quinquennial census of the prairie provinces (Worton, 1998:88). The Census and Statistics Office later became a branch of the Department of Agriculture $^{83}$, the position of the Chief Officer of Statistics was created and the $3^{\text {rd }}$ regional quinquennial census was instituted. The first regional quinquennial censuses were conducted in $1884-85^{84}$ and also 1896 , which included only the province of Manitoba and it was solely a head count. The mid-decade 1906 regional census was to include the three Northwest Provinces of Manitoba, Saskatchewan and Alberta, the latter two of which had just recently joined the dominion in 1905. The 1905 Act Respecting the Census and Statistics and its revision in 1906, added the taking of an oath to secrecy along with the oath of office as stated in the 1878 Act. Also, some categories changed and new ones were added into the $1906^{85}$ Act, which included more details on infrastructure, race (i.e. changes to colour identification), nationality as a new concept, wage

\footnotetext{
${ }^{83}$ An Act Respecting the Census and Statistics, 4-5 Edward VII, c. 5: "There shall be a permanent office under the Minister of Agriculture, to be called the Census and Statistics Office, and the Governor in Council may appoint thereto a chief officer, a secretary, and such other officers..." Part I. Organization, Section 3. This Act was revised in 1906 as 4-5 Edward VII, c. 5 s.1. 84 An Act to provide for the taking of a Census in the Province of Manitoba, the North-West Territories and the District of Keewatin, 1885, 48-49 Victoria c.3.

851906 as 4-5 Edward VII, c. 5 s.1.
} 
earnings and penal data ${ }^{86}$. The 1906 Act Respecting the Census and Statistics also included, in Part IV Criminal Statistics, nine sections dedicated to the collection of these data. New provisions to the 1906 Act were added in 1911 by Order in Council87. The date the census was to be taken changed to June; the census of Indians living on reserves or otherwise was instituted, including the possibility of enlisting the Royal Northwest Mounted Police or other agents to enumerate the Aboriginal population; and a census of infirmities was added as was the adoption of the Bertillon International nomenclature for the tracking of mortality (GC, 1911). Graunt and Farr, among many others, were involved in the creation of early mortality nomenclatures. However, it was Jacques Bertillon's International Statistical Institute (ISI) committee that presented the Classification of Causes of Death in Chicago in 1893, which was adopted as the standard (WHO, 2004). It was adopted internationally and, shortly thereafter, it became the International Classification of Diseases (ICD), which is periodically updated by the World Health Organization (WHO). Bertillon's classification was

86

a) ...colour,...nationality,...number of persons deceased,

b) the houses for habitation, stores, warehouses, factories and other buildings therein, and their classification was occupied or vacant, under construction or otherwise;

c) the occupied land therein, and its value, and the condition thereof as improved for cultivation, in fallow, in forest, unbroken prairie, marsh or waste land and otherwise;

d) the products of factories, farms, fisheries, forests, and all mines therein, and other industries, with the values of all the said products and of the plant and real estate employed in the said industries, within the census year;

e) the wage-earnings of the people thereof within the census year;

f) the municipal, educational, charitable, penal and other institutions thereof;...( 1906, 4-5 Edward VII, c. 5 s.1) Section 14.

87 Government of Canada, 1911, Orders in Council of the Imperial Government together with Treaties Negotiated between His Majesty the King and Foreign Powers, Ottawa: Charles Henry Parmelee, Law Printer to the King's Most Excellent Majesty. 
referenced and adopted in the 1901 Census of Canada and enumerators and commissioners were instructed to use its categories for Schedule No.3 Death:

Bertillon nomenclature in use in the Province of Ontario and Quebec and the Republic of Mexico is to be used, and was endorsed in Canada on January 1,1901 for 10 years by the delegates of 10 countries to the International Commissions in Paris during the year 1900 to deals "as uniformity of statistics is essential in making comparative studies of mortality" (Department of Agriculture, 1901:4).

The Bertillon Nomenclature was also, at times, included in the instruction manuals as an appendix along with the revised Act (Department of Agriculture, 1911a).

In 1912, the administration of the Canadian census moved to the Department of Trade and Commerce. Concurrently, there were discussions of centralizing the function of government statistics into one central agency that would cooperate with other departments to do the Dominion of Canada's statistical work. This coincided with the British Government Dominion Royal Commission suggestion that comparability among imperial statistics and the dominions was necessary, and to standardize this practice, one of the recommendations was the creation of an Empire statistical office to facilitate this work. In Canada, the Department of Trade and Commerce grew in prominence as a result of rapid industrialization and the increase and importance of international trade. The transfer of the census to this department was due in part to the over-extension of the Department of Agriculture's mandate to collect industry related statistics, the dispersed collection of these statistics across various government departments, and the ongoing push for centralization of this function in order to reduce the 
duplication of data collection efforts (Worton, 1998). R. H. Coats was appointed as Dominion Statistician in 1915 and he developed a plan to implement the Imperial Commission's recommendations. He began inter-departmental and provincial negotiations for collaboration but encountered much resistance, which led him to draft the Statistics Act of 1918. The new Act established the Dominion Bureau of Statistics (DBS) (Worton, 1998:91). Coats, however, failed to achieve departmental status for the new Bureau, which he believed "was essential for the public perception that it was not subservient to political and special interest influences" (Worton, 1998:92). Coats wanted to take the census out of politics. Had he succeeded, it might have been harder to cancel the long-form census in 2010. The DBS was created with this Act and its role was specific:

To collect, abstract, compile and publish statistical information relative to the commercial, industrial, social, economic and general activities and condition of the people;

To collaborate with all other departments of the Government in the compilation and publication of statistical records of administration according to the regulations;

To take the census of the Dominion as hereinafter provided (The Statistics Act of 1918, c. 43, s.1).

Cross-departmental collaboration was mandated, and the nature of the data to be collected was articulated from inception. The Bureau was responsible for the collection of all data except for data related to non-agricultural land because that was the responsibility of the Department of the Interior. However, the Bureau did collect Interior data during the census period. In addition, the Act created the role of the Dominion Statistician, and instituted the Oath to Office and secrecy provisions (Section 15 is solely dedicated to matters of secrecy), and outlined how the Bureau was to be administered. There were also sections of the 
Act that describe the relationship and arrangements to be made with provinces. The Act also addressed the regional quinquennial censuses and new categories were added, including: conjugal condition; relation to the head of the household; and professions. Many of the new classifications added to this Act, and those mentioned in previous Acts, were already included in census schedules. The fact that they were explicitly mentioned in these Acts demonstrates their importance.

The 1918 Act also instructed the Bureau to take a periodic Census of Industry that included mining, fisheries, forestry and manufacturing, not unlike the items on Petty's political anatomy list. These industry focused censuses were specific schedules in earlier national censuses, but this Act stated that these could be taken at time intervals chosen by the Ministry of Trade and Commerce, which meant that these were no longer necessarily part of the national census and were more like general surveys. Further, annual statistical reports pertaining to trade and commerce, transportation, and crime were also included. The collection, abstraction and tabulation of annual statistics related to population, births, deaths and marriages, immigration and emigration, agriculture, education, and finances, were made explicit. The Bureau was a centralized agency, responsible for collecting statistics from many departments and it was expected to report these on a regular basis. This change to a centralized institution demonstrates how political judgment guided the creation of categories, when to measure them, the representation of results and how "these choices become embedded in the statistical systems of the modern state and the information they routinely produce" (Alonso \& Starr, 1987:3). 
In 1948 , the Act $^{88}$ was updated once again and, in this case, the Minister was given the right to collect statistics by "means of the statistical method known as 'sampling'" in Section 8. (2), a method instituted to reduce costs. Sampling had been used for the first time in the 1941 census where one in every ten households was asked to answer a series of questions on the description of their dwellings. It proved to be a successful experiment and in 1951, the sample size was increased to one in five households in order to improve geographic detail. Later in 1971, the sampling method was applied for the long-form census and a short-form was universally administered, a practice normalized up and until the 2011 census.

In the 1948 Act, the annual reporting of statistics from public utilities and carriers was instituted under general statistics ${ }^{89}$. The updated Act also included the regional prairie province census and it was to be taken as the same time as the population and agriculture census.

The Act was once again updated in $1951^{90}$ and service industries and construction were added as categories, and additional questions related to power generation and household consumption were included. Physically, the schedule had changed to a card format allowing for computer tabulation. In 1955, the Privy Council abolished the regional quinquennial census and instead created a shorter, national scale quinquennial census in 1956 (to be taken every ten years).

88 11-12 George VI., c.45.

89 Epidemiology and morbidity; employment, unemployment, payrolls and man-hours; horticulture, dairying and cold storage; factories, mines and productive industries generally; wholesale and retail trade; hospitals, mental institutions, tuberculosis institutions; and prices and cost of living.

90 Statistics Act 1948, c. 45, s1. 
The taking of a nationwide quinquennial census was inspired by "the extremely large increases and shifts in population shown by intercensal estimates since 1951 and by the rapid changes occurring in the agriculture economy of the country" (DBS, 1958a).

The 1970 Revised Statutes of the Statistics Act ${ }^{91}$ was a consolidation. In 1971, Statistics Canada (StatCan) was created with a mandate "to promote the avoidance of duplication in the information collected by departments of government" among other responsibilities (19-20 Elizabeth II Statistics Act 1971, c.15 Section 3. (d)). The former position of Dominion Statistician had evolved and formally became Chief Statistician through this Act. New sections pertaining to the hiring of temporary and contractual employees were added, as was a clause about informing respondents regarding access to records in other ministries and the joint collection of information between ministries. Some new general statistical categories were also added including: communication; electric power; gas and water utilities; insurance; public administration; and community services. This was also the first year where the census was conducted by a mailout self-enumeration, a method instituted to reduce response errors and the overwhelming number of enumerator errors. This change was informed by the rigorous research of methodologists (Worton, 1998). A new section was added to permit the exchange of data from the Minister of National Revenue; today, this appears as the tick box on the form granting StatCan the right to acquire income

91 Chapter s-16 An Act respecting the Dominion Bureau of Statistics, Statistics Act R. S., C. 257, s. 1. 
tax revenue data on the respondent's behalf. Also, census categories were no longer listed in the Act and it stated "[the] Governor in Council shall by order prescribe the questions to be asked in any census taken by StatCan under section 18 [population] or 19 [agriculture]" (19-20 Elizabeth II Statistics Act 1971, c.15 Section 20). This Act marked the end of enumerators coming to most people's doors; the government no longer was seen directly by citizens on census day and the process of administering the census became faceless and more distant.

The 1971 self-enumeration process was, however, very well publicized. Enumerators picked up forms in rural areas while people in remote areas were still enumerated by officials at their door. The year 1971 was also the $100^{\text {th }}$ anniversary of the Canadian census and the mail-out census was accompanied with 'Count yourself In' campaign literature. The campaign also featured a televised short film entitled 'On a clear day you can count for ever'. Other campaign features included a commemorative stamp and an outreach initiative targeting students in schools, where they were encouraged to conduct their own mock surveys (Worton, 1998). This Government communication strategy was put in place to ensure that Canadians filled in and sent back their census questionnaires.

The repatriation of the Constitution in 1982 necessitated the consolidation of the Statistics Act92, which has subsequently been revised up to 2005. It is generally the same as the Statistics Act of 1971, although new statistical categories were

921985, c. S-19. 
added such as health, welfare and law enforcement. Other changes were related to the archiving of census data and the acceptable time period for their public release.

These changes in the Act made the questions and the content less explicit and opened the way for Government to arbitrarily change census content as was seen with the 2011 Census of Canada. The census was reduced to a short-form of seven questions while the long-form became a voluntary survey that was not conducted by way of a systematic sampling methodology, something earlier methodologists went to great pains to study. The Governor in Council was legally entitled to make this change as according to the Statistics Act Section 21 it was the final authority regarding census questions. The Federation of Francophone and Acadian Communities of Canada, however, submitted a court challenge suggesting that the lack of French Language questions contravened the Official Languages Act. The Harper Government conceded, before the court decision was made, and chose to reinstate three language questions from the voluntary survey into the short-form. However, the Harper Government did not respond to the pressure of groups, universities, scientists, statisticians, cities, associations, provincial ministries and private citizens to reinstate the long-form census in its entirety93. The census was taken, the volunteer survey was administered and

93 The Datalibre.ca blog, co-authored by Tracey P. Lauriault and Hugh McGuire, documented 487 organizations who organized petitions, facebook pages, toolkits, approved city council motion or wrote letters to their MPs expressing their disagreement with the cancellation of the long form. The blog includes references to newspaper articles and editorial cartoons from the major Canadian dailies, papers written by academics, conference presentations, statements by the Statistical Council of Canada, former chief statisticians, references to articles and statements by Dr. Munir Sheikh who resigned from his post as chief statistician because of this change. 
census data are currently being tabulated and released. There is, however, a pending Federal Court challenge entitled the Equal Right to be Counted, deposed by twelve community-based organizations representing ethno cultural visible minority groups who requested:

the right to be counted in the census on the basis of their race, ethnic origin, Aboriginal ancestry and disability, just as other Canadians are counted according to their marital status, age and sex [and they argue that] the exclusion of these groups constitutes prima facie discrimination and perpetuates the stereotype that certain minority groups are less worthy of being seen as part of Canada's national portrait than others. The Applicants submit that this violates section 15(1) of the Canadian Charter of Rights and Freedom (Champ and Associates, 2011).

The 2011 Census of Canada may have been conducted in accordance with the Statistics Act, but now that individuals have come to describe themselves and be counted according to those descriptions, it may be proven by the courts that this census has contravened the Canadian Charter of Rights and Freedoms. The Charter protects the rights of minority groups, and as a result, government programs and services were created to ensure conformance to the Charter. To evaluate the performance and targets of those government activities, census data are required; the inability to measure this performance is what is at stake. There is also the fear that Canadians might be portrayed as whiter, abler and wealthier in the popular imagination if protected Charter groups are eliminated from the census count. This change may potentially transform how Canada is known, portrayed and imagined. 
The change to the 2011 census also put official statisticians in a difficult position. They cannot speak publicly against a Government of Canada decision on census methodology because of their employee status but by not doing so; they contravene the International Statistical Institute's (ISI) Declaration on Professional Ethics which stipulates:

Statisticians should pursue objectivity without fear or favor, only selecting and using methods designed to produce the most accurate results. They should present all findings openly, completely, and in a transparent manner regardless of the outcomes. Statisticians should be particularly sensitive to the need to present findings when they challenge a preferred outcome. The statistician should guard against predictable misinterpretation or misuse. If such misinterpretation or misuse occurs, steps should be taken to inform potential users. Findings should be communicated for the benefit of the widest possible community, yet attempt to ensure no harm to any population group (ISI, 2010:6).

As discussed, the Canadian population census was a traditional census comprised of a short-form and long-form questionnaires. The current Canadian system most closely resembles traditional enumeration mixed with yearly updates. However, there is currently no official position on the periodicity of the national household survey and the topics to be covered in these updates, nor is there a systematic system of sampling the entire country about these population characteristics.

The legal framework for the Canadian census is enshrined in the Consolidation of Constitution Acts between 1867 and 1982 and the Statistics Act. The changes in statistics acts from 1870 until 2005 reflect changes in the administration of the function of counting, new methodologies, information technology, the centralization of the agency that required greater collaboration with other 
departments, federal-provincial responsibilities in terms of the collection of vital and other statistics, and the nature of political arithmetic in general that required new categories and classifications.

In addition to explicit legislation dictating the collection of statistics by StatCan, there are also 31 acts and 72 regulations, which refer to the census according to the Department of Justice and Law Key Word search94. This does not mean that StatCan must collect those data, but those data do provide key information related to these acts. For example, citizenship is a determinant of rights to different subsets of the Canadian population, and under the Charter, citizens are guaranteed minority language education rights. The Charter does not require StatCan to collect and make available data on citizenship and mother tongue in support of this clause; however, such data could be admissible before the courts as pertinent to the issue of determining whether the number of children of citizens possessing minority language education rights warrant the provision of minority language education out of public funds. In 1986, when the Mulroney Government tried to cancel the quinquennial census altogether, and the business community objected. Questions were however revised and assessed by StatCan, and the maintenance of these census questions was considered vital to ensure that language rights are applied in a fair and informed manner and that groups are not denied access due to a lack of reliable information (StatCan, 1986:30).

94 Basic Key Word search of the terms Census with restricted to Acts, and then again with a restriction for regulation November 32011 from http://laws-lois.justice.gc.ca. 
An examination of Canadian legislation finds a number of departmental statutes referring explicitly to the use of population data from the census or census-based population estimates in the administration of one or more sections of their corresponding legislation (see Appendix L). These statutes or legislation also refer explicitly to the use of census-defined geographic areas for the purposes of the implementation (often thresholds for eligibility) of one or more provisions of statutes associated with each department; some refer to the use of census data derived from the 2B (long-form) questionnaire while others that do not refer explicitly to the use of census data, but for which census data (both short- and long-form) are used extensively in the design, implementation and evaluation of policies and programs under their respective legislation. Table 10 that follows lists major federal legislative census requirements as of 2010.

\section{Table 10. Major Federal Legislative Census Requirements (Email Correspondence Statistics Canada, 2010)}

\begin{tabular}{|l|l|}
\hline Department & Legislation \\
\hline \multirow{2}{*}{$\begin{array}{l}\text { Canada Mortgage and Housing } \\
\text { Corporation }\end{array}$} & Canada Mortgage and Housing Corporation Act \\
\cline { 2 - 2 } Canada Revenue Agency & Intional Housing Act \\
\hline \multirow{2}{*}{$\begin{array}{l}\text { Citizenship and Immigration } \\
\text { Canada }\end{array}$} & Canadian Multiculturalism Act \\
\cline { 2 - 2 } & Citizenship Act \\
\cline { 2 - 2 } Department of Justice & Immigration Act \\
\hline \multirow{2}{*}{ Elections Canada } & Canadian Human Rights Act \\
\hline \multirow{3}{*}{ Finance Canada } & Canada Elections Act \\
\cline { 2 - 2 } & Electoral Boundaries Readjustment Act \\
\hline & $\begin{array}{l}\text { Funding for Diagnostic and Medical Equipment } \\
\text { Act }\end{array}$ \\
\cline { 2 - 2 } & $\begin{array}{l}\text { Canada-Nova Scotia Offshore Petroleum } \\
\text { Resources Accord Implementation Act }\end{array}$ \\
\hline
\end{tabular}




\begin{tabular}{|c|c|}
\hline Department & Legislation \\
\hline & $\begin{array}{l}\text { Nova Scotia and Newfoundland and Labrador } \\
\text { Additional Fiscal Equalization Offset Payments } \\
\text { Act (2005) }\end{array}$ \\
\hline & Budget Implementation Act 2007 \\
\hline & Budget Implementation Act 2009 \\
\hline & Federal-provincial Fiscal Arrangements Act \\
\hline & Bank Act \\
\hline & $\begin{array}{l}\text { Canada-Newfoundland Atlantic Accord } \\
\text { Implementation Act }\end{array}$ \\
\hline \multirow{2}{*}{ Health Canada } & Canada Health Act \\
\hline & Food and Drug Act \\
\hline \multirow{7}{*}{$\begin{array}{l}\text { Human Resources and Skills } \\
\text { Development Canada }\end{array}$} & Canada Pension Plan Act \\
\hline & Old Age Security Act \\
\hline & Canada Student Loans Act \\
\hline & Canada Student Financial Assistance Act \\
\hline & Employment Equity Act \\
\hline & Canada Pension Plan Investment Board Act \\
\hline & Employment Insurance Act \\
\hline $\begin{array}{l}\text { Indian and Northern Affairs } \\
\text { Canada }\end{array}$ & Indian Act \\
\hline \multirow[b]{2}{*}{ Industry Canada } & Consumer Packaging and Labelling Act \\
\hline & $\begin{array}{l}\text { Social Sciences and Humanities Research } \\
\text { Council Act }\end{array}$ \\
\hline \multirow{2}{*}{ Canadian Heritage } & Official Languages Act \\
\hline & Canada Council for the Arts Act \\
\hline $\begin{array}{l}\text { Public Works and Government } \\
\text { Services Canada }\end{array}$ & Payments in Lieu of Taxes Act \\
\hline \multirow{2}{*}{ Transport Canada } & Railway Relocation and Crossing Act \\
\hline & Canada Transportation Act \\
\hline Veterans Affairs & War Veterans Allowance Act \\
\hline
\end{tabular}

*Added to the table from StatCan, 2002

The 1991 Census Handbook (see Appendix A) lists many more that either implicitly or explicitly require census data. Census categories and their data are formally and intricately interconnected to the Canadian bureaucratic system and they shape what actions are undertaken, and they also stipulate where things get 
done in many areas (see Table 11 below and Appendix L). Census data are used to structure programs and these, along with census categories, shape how we know and imagine ourselves to be.

The institutionalization, bureaucratization and normalization of the census taking process, including certain categories of data, demonstrate that censuses:

do not simply report aspects of social relations existing in a pristine condition prior to the work of census making. Rather census making configures social relations in keeping with particular political and cultural objectives and interests in order that such relations may be known and governed. In its pursuit of relevant knowledge, census making cannot but specify and discipline investigators and information and their social relations (Curtis, 2001:32).

These statistics convey a specific image of society through the regulation of content (Patriarca, 1996:60). Furthermore, as statistician and historian Alain Desrosières observed in his work, The Politics of Large Numbers: A History of Statistical Reasoning, the themes of the surveys, the questions asked and the nomenclatures used by statistical bureaus, are influenced by the forms of public action predominant at a given time. The dynamic periods in the life of a statistical bureau correspond to the times when it manages to link investigations closely to current questions, "simultaneously producing the categories of action and the means to evaluate them" (Desrosières, 1998:248).

Census questions and how they are worded give evidence to what state officials considered worth counting while silences reveal what was not. How these questions were chosen, formulated and distributed changed overtime and revealed the social interaction between people, state and knowledge at that time. 
Statistical systems shape society subtly: "the questions asked (and not asked), categories employed, statistical methods used, and tabulations published ... change images, perceptions and aspirations" (Alonso \& Star, 1987:2). The census is taken and the count determines action, and it is those actions that officially shape our geographical imagination. The nature of the questions will be examined next.

\subsubsection{Census Questions}

The Census of Canada has included hundreds of questions, some being constant such as name, age, sex and marital status, while others changed from one census to another. Table 11 identifies 27 groupings and when they were applied between 1871 and 2011.

Whether questions are asked in some, many or in all censuses, they have changed as have the underlying understanding of the classifications. Even the most common and taken for granted questions vary in purpose and meaning. For example, it was not until 1981 that full date of birth was asked in the census; between 1966 and 1976 the month and year were asked, and prior to that, age or the year of birth were asked.

Other seemingly fixed, census questions, such as gender identification and marital status categories, can fail to recognize certain classes of people. Gender identification or 'sex' has always been either male or female even though intersex is a recognized biological class and people self-identify as transsexuals. Adhering to the normalized dimorphic classification means that people biologically classed 
otherwise are abnormal or invisible to the rest of society, even though they are biologically natural kinds of people and not 'made up kinds' of people. Between 1871 and 1891 , people were only asked to indicate whether they were married or widowed even though Acts of Parliament could dissolve marriages. Divorced and single were added as marital status categories in 1901, and legally separated in 1911. Enumerators were instructed to label people "separated only as to bed and board" as married in 1911 (Department of Agriculture, 1911b:27) and that same category of "persons who are legally separated as to bed and board" were considered to be divorced in 1921 (DBS, 1925:x). By 1981, opposite-sex partners could be classified as living in a common-law relationship, and this status was extended to same-sex partners in 2001. Although same-sex marriage was legalized in 2005, same-sex and opposite-sex couples were still classified as being in common-law relationships in the 2006 census and the same-sex married classification appeared in the 2011 census. As seen, different types of unions existed prior to the creation of census classes but they became official once they were counted or legalized.

Kinds of people become legitimized in census classes, and groups of people can then begin to use these authoritative numbers to collect benefits or lobby for equal recognition as a kind of person as "the census questionnaire is a sign of the times in that its content reflects the concerns of the period in which it was developed" (StatCan, 1997:13). Once classed and counted, if a 'kind of people' is eliminated from the census they may take the government to court if they believe that their 'equal right to be counted' has been violated. 
The date of birth, gender and marital status examples reveal a variety of issues related with the most banal looking, common and taken for granted classifications: age, sex and relationships. The census questions that will be examined here are also commonplace classes and these are citizenship and official languages. The citizenship class was chosen because it counts and defines the Canadian people officially recognized as being members of the sovereign territory of Canada. The classification of official languages was selected because it relates to the 'founding' peoples of Canada, the colonials, and their European languages, legally protected with the formation of Canada. Official languages also relate to culture; cultural identity is dependent on one's ability to understand and participate in broader Canadian society, which is officially conducted in French and English. 
Table 11. Census Question Categories Between 1871 and 2011 (Compiled by the author)

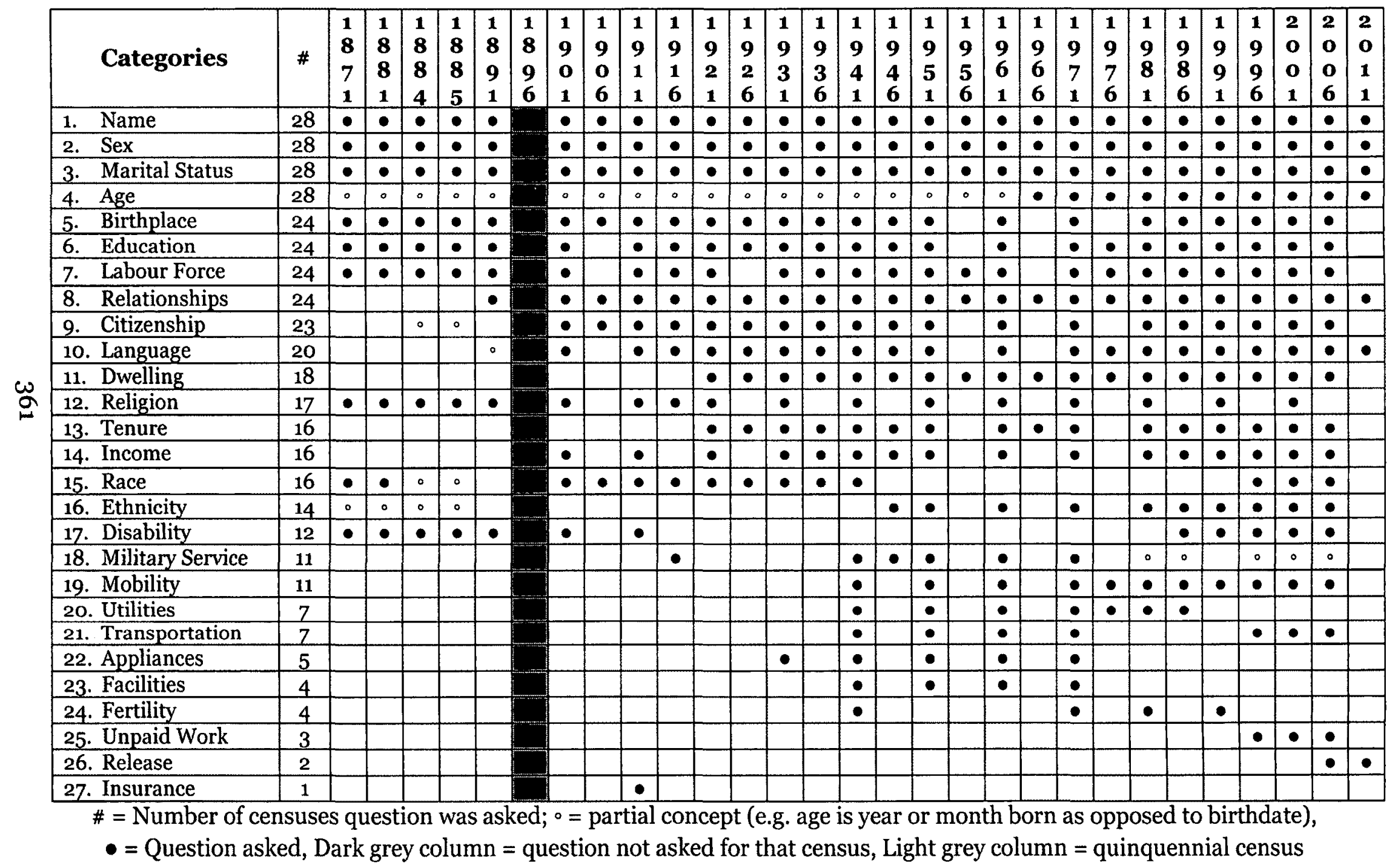




\subsubsection{Citizenship}

Citizenship questions are listed in Table 12 and these include questions that pertain to: nationality, naturalization, citizenship and landed immigrant status. The place of birth classifications in Table 13 are used to determine who may be citizens of other jurisdictions and to further qualify citizenship data, and they are often used as a filter for responses on immigration (StatCan, 1986a).

Citizenship and place of birth questions were asked in one way or another in most decennial censuses. Citizenship questions were not asked in $1871,1881,1891$ and 2011. These classes also appeared in most quinquennial censuses except for 1956,1966 and 1976, which were very short. The place of birth of a respondent's parents was also asked in many censuses $(1891,1921,1926,1931,1971,2001$ and 2006).

\section{5·3.4.1 Reasons for Collecting Citizenship Data}

The reasons for collecting citizenship data were not always documented in early census manuals and reports, however, during a re-evaluation of the questions in 1986 and in user consultations $(1971,1986 \mathrm{~b}, 1991,1996)$ a number of government departments and specialists provided the following uses:

- inform citizenship and immigration programs and policies;

- determine long-term adjustment, integration, assimilation and the rate of adaptation patterns in terms of their demographic, cultural, educational and occupational characteristics to the Canadian environment and socioeconomy;

- assess changes in settlement policies;

- assist in the determination of immigration levels, quotas and targets; 
- inform internal migration, assess in and out migration, net migration and the characteristics of that population and help determine to what extent immigrants have remained in Canada and the characteristics of those leaving the country;

- determine the time it takes to acquire Canadian Citizenship;

- ensure that minority language rights are adhered to as per the Charter;

- qualify place of landing data which are limited for labour forecasts and combined with mobility, these help assess if integration and labour objectives are being realized;

- assess the occupational structure of recent immigration in terms of the requirements of the Canadian labour market;

- inform in combination with cultural variables such as mother tongue and ethnic origin multicultural development programs and locating communities with certain nationalities;

- administer, target and locate post-entry services including citizenship classes and programs, language instruction; sponsored immigration and refugees programs; immigrant settlement and adaptation programs;

- measure of how world events and immigration policy change the composition and numbers of immigrant groups;

- assess voting eligibility;

- place of birth of parents data provide information on socio-economic conditions of second-generation Canadians.

StatCan user consultations were quite extensive, and input was solicited from provincial and territorial departments and agencies, municipalities and regional governments, federal departments and agencies, community groups and nonprofit organizations, academia, private industry, StatCan advisory committees and private citizens (StatCan, 2009). The earliest record of consultations discovered during the course of this research was a 1941 census report where the Bureau consulted with federal and provincial departments, universities and interests groups on the content of the census schedules (DBS, 1945). 
Citizenship and immigration census data are used for evaluating and monitoring federal legislation, policies and programs including (StatCan, 2009, 2010):

- Citizenship Act

- Immigration and Refugee Protection Act

- Language Instruction for Newcomers to Canada

- Immigration Act

- Multicultural Act

The following is the current StatCan departmental standard definition (1998) for the classification of immigration:

Immigration concerns the movement of nationals of any given country to another country for the purpose of settlement. It applies to a person who has been granted the right to permanently live in Canada by immigration authorities. It usually applies to persons born outside Canada but may also apply to a small number of persons born inside Canada to parents who are foreign nationals. Similarly, some small numbers of persons who are Canadian by birth have been born outside Canada to Canadian parents. Once a person has been accorded immigrant status it becomes a life-long attribute as long as the person lives in Canada. Therefore, immigrants are often further classified by period of immigration in order to distinguish between recent immigrants and earlier immigrants.

A landed immigrant is defined as "a person who has been granted the right to live in Canada by immigration authorities" and once a landed immigrant has applied for citizenship and it is granted, he or she becomes a citizen by naturalization. The non-permanent resident class includes migrant workers, foreign students, refugees, and diplomatic staff. 
Table 12. Citizenship and Immigration Classifications between 1871 and 2011 (Compiled by the author)

\begin{tabular}{|c|c|c|c|c|c|c|c|c|c|c|c|c|c|c|c|c|c|c|c|c|c|c|c|c|c|c|c|c|c|}
\hline Citizenship & $\begin{array}{l}1 \\
8 \\
7 \\
1\end{array}$ & $\begin{array}{l}1 \\
8 \\
8 \\
1\end{array}$ & $\begin{array}{l}1 \\
8 \\
8 \\
4\end{array}$ & $\begin{array}{l}1 \\
8 \\
8 \\
5\end{array}$ & $\begin{array}{l}1 \\
8 \\
9 \\
1\end{array}$ & $\begin{array}{l}1 \\
8 \\
9 \\
6\end{array}$ & \begin{tabular}{|l|}
1 \\
9 \\
$\mathbf{0}$ \\
$\mathbf{1}$
\end{tabular} & \begin{tabular}{|l|}
1 \\
9 \\
0 \\
6
\end{tabular} & $\begin{array}{l}1 \\
9 \\
1 \\
1\end{array}$ & \begin{tabular}{|l|}
1 \\
9 \\
1 \\
6
\end{tabular} \mid & $\begin{array}{l}1 \\
9 \\
2 \\
1\end{array}$ & $\begin{array}{l}1 \\
9 \\
2 \\
6\end{array}$ & $\begin{array}{l}1 \\
9 \\
3 \\
1\end{array}$ & $\begin{array}{l}1 \\
9 \\
3 \\
6\end{array}$ & \begin{tabular}{|l}
1 \\
9 \\
4 \\
1
\end{tabular} & \begin{tabular}{|l|}
1 \\
9 \\
4 \\
6
\end{tabular} & \begin{tabular}{|l|}
1 \\
9 \\
5 \\
1
\end{tabular} & \begin{tabular}{|l|}
1 \\
9 \\
5 \\
6
\end{tabular} & $\begin{array}{l}1 \\
9 \\
6 \\
1\end{array}$ & \begin{tabular}{|l|}
1 \\
9 \\
6 \\
6
\end{tabular} & $\begin{array}{l}1 \\
9 \\
7 \\
1\end{array}$ & $\begin{array}{l}1 \\
9 \\
7 \\
6\end{array}$ & \begin{tabular}{|l|}
1 \\
9 \\
8 \\
1
\end{tabular} & \begin{tabular}{|l|}
1 \\
9 \\
8 \\
6
\end{tabular} & $\begin{array}{l}1 \\
9 \\
9 \\
1\end{array}$ & $\begin{array}{l}1 \\
9 \\
9 \\
6\end{array}$ & $\begin{array}{l}2 \\
0 \\
0 \\
1\end{array}$ & $\mid \begin{array}{l}2 \\
0 \\
0 \\
6\end{array}$ & $\mid \begin{array}{l}2 \\
0 \\
1 \\
1\end{array}$ \\
\hline Nationality or Origin & & & $\circ$ & $\circ$ & & & & & & & & & & & & & & & & & & & & & & & & & \\
\hline Immigration Year & & & & & & & $\bullet$ & $\bullet$ & $\bullet$ & $\bullet$ & $\bullet$ & $\bullet$ & $\bullet$ & $\bullet$ & $\bullet$ & $\bullet$ & $\bullet$ & & $\bullet$ & & $\bullet$ & & $\bullet$ & $\bullet$ & & & & & \\
\hline $\begin{array}{l}\text { Naturalization Year } \\
\text { (1911 if formally an } \\
\text { alien) }\end{array}$ & & & & & & & $\bullet$ & & $\bullet$ & $\bullet$ & $\bullet$ & $\bullet$ & $\bullet$ & $\bullet$ & • & & & & & & & & & & & & & & \\
\hline Nationality & & & & & & & $\bullet$ & & $\bullet$ & $\bullet$ & & & & & & & & & & & & & & & & & & & \\
\hline $\begin{array}{l}\text { Nationality } \\
\text { (country owing } \\
\text { allegiance) }\end{array}$ & & & & & & & & & & & $\bullet$ & & $\bullet$ & $\bullet$ & & & & & & & & & & & & & & & \\
\hline $\begin{array}{l}\text { Nationality or } \\
\text { Citizenship (country } \\
\text { owing allegiance) }\end{array}$ & & & & & & & & & & & & $\bullet$ & & & $\bullet$ & $\bullet$ & & & & & & & & & & & & & \\
\hline $\begin{array}{l}\text { Citizenship } \\
\text { (Nationality) }\end{array}$ & & & & & & & & & & & & & & & & & $\bullet$ & & & & & & & & & & & & \\
\hline $\begin{array}{l}\text { Citizen of what } \\
\text { country }\end{array}$ & & & & & & & & & & & & & & & & & & & & & $\bullet$ & & $\bullet$ & $\bullet$ & • & • & $\bullet$ & $\bullet$ & \\
\hline $\begin{array}{l}\text { Canada by } \\
\text { Naturalization }\end{array}$ & & & & & & & & & & & & & & & & & & & & & & & $\bullet$ & $\bullet$ & $\bullet$ & $\bullet$ & $\bullet$ & & \\
\hline Landed Immigrant & & & & & & & & & & & & & & & & & & & & & & & & & $\bullet$ & $\bullet$ & $\bullet$ & $\bullet$ & \\
\hline
\end{tabular}

$\circ=$ Concept resembles the category (e.g. origin is a mixed concept analogous to ethnicity), $\bullet=$ Question asked, Dark grey column $=$ question not asked for that census, Light grey column = quinquennial census 
Table 13. Place of Birth Classifications between 1871 and 2011 (Compiled by the author)

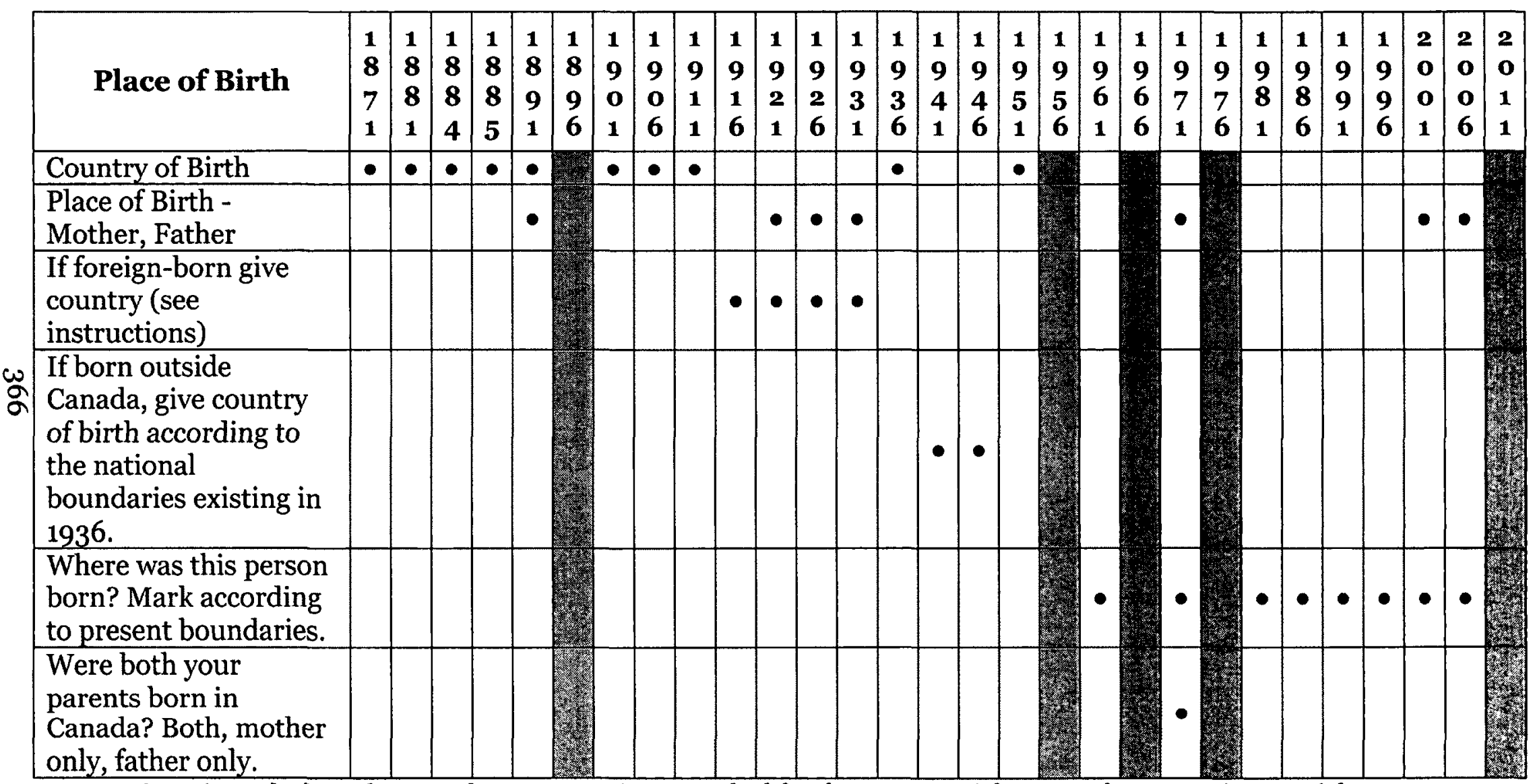

$\bullet=$ Question asked, Dark grey column = question not asked for that census, Light grey column = quinquennial census 


\subsubsection{Definitions and Historical Context for Citizenship Questions}

Citizenship implies official membership in a nation state and with it comes rights and duties to the state. Because Canada was a colony of the United Kingdom, Canadians were firstly British subjects and were subjected to the common law of England which stated:

Every person born within the Dominion of the Crown, no matter whether of British or foreign parents, and in the latter case whether the parents were settled or merely temporarily sojourning in the country, was considered British. Also all children or grandchildren of British Parents, though born in a Foreign State, were considered British subjects, owing their allegiance to and entitled to the protection of the Sovereign (DBS, 1951a:153).

The ideas of official citizenship in Canada began with the Immigration Act of 190695 which did not describe who citizens were, but did explain what an immigrant was and it stipulated who was unwelcome: the ill; insane; physically disabled; prostitutes or criminals. People were also examined and sometimes quarantined by a medical examiner (DBS, 1970a). Prior to Confederation, the Crown had reassured property owners with the Act of Legislation of Lower Canada, which confirmed that they were in fact British subjects ${ }^{96}$. At Confederation, persons born in the Dominion of Canada were automatically British subjects. Aliens and naturalization legislation was adopted by 1870 , which allowed certain classes of persons, non-British subjects or aliens, to be naturalized.

\footnotetext{
95 An act respecting immigration and immigrants Canada Ottawa: S.E. Dawson, 1906, 6 Edward VII. Chap. 19, http://www.canadiana.org/ECO/ItemRecord/9_07188.

${ }^{96} 1832$ Act of Legislation of Lower Canada (I William IV, c.53).
} 
The Immigration Act of $1910^{97}$ was more specific and defined a Canadian as "a person born in Canada who has not become an alien; a British subject who has Canadian domicile or a person naturalized under the laws of Canada who has not subsequently become an alien or lost Canadian domicile" and an alien as a person who was not a British subject. An immigrant was defined as a person "who enters Canada with the intention of acquiring Canadian domicile" and unwanted classes were identified as the 'physically defective', 'diseased', 'mentally defective' and criminals. Between 1886 and 1910, legislation included restrictions and protective measures to ensure traveler safety, including rules on the number of passengers in a vessel and how people were to be received at ports.

At the turn of the last century, policies restricted the entry of people considered to be undesirable. People of Asiatic races, for example, were deemed unsuitable and officials justified their classification as follows: "because of their low standard of living to underbid the white man in selling his labour, is fundamentally an economic rather than a racial problem" (DBS, 1931a:184). Such discrimination was noted as early as 1884 , when a head tax of $\$ 10$ was imposed on all Chinese people entering Canada; it was increased to $\$ 50$ in 1885 , doubled to $\$ 100$ in 1901 and raised to $\$ 500$ by 1904 . Chinese immigrants were legally restricted entry by the Chinese Immigration Act of 1923 and this severely reduced the numbers of those who immigrated to Canada. Japanese immigrants were also considered as a desirable group and agreements were made between

97 An act respecting immigration Canada Ottawa: C.H. Parmelee, 1910, 9-10 Edward VII. Chap. 27, http://www.canadiana.org/ECO/ItemRecord/9_o7184. 
Canada and Japan to limit the number of passports issued to Japanese people. East Indians, even though members of the British Empire were also restricted entry, although people living in Canada prior to the 1910 Act, could bring their wives and minor children and restrictions were altogether lifted in 1951 quotas although quotas were set (DBS, 1931a:186 and DBS, 1970a).

The Naturalization Act of $1914^{98}$ defined who were natural British born subjects and which aliens could be naturalized, such as people who lived in the Dominion or were in service to the Crown for no less than five years and people of good character who understood French and English to some extent and who intended to reside in the Dominion. This 1914 Act was patterned after the British Nationality and Status of Aliens Act of 1914 and people in Canada were given the same status held by British subjects in other parts of the Empire. At this point, the Federal Government's Naturalization Branch began to centralize the issuance of certificates (DBS, 1951a). It is interesting to note that the granting of naturalization or citizenship, according to the Act, was at "the absolute discretion of the Minister, and he may, with or without assigning any reason, give or withhold the certificate as he thinks most conducive to the public good, and no appeal shall lie from his decision" (Flournoy \& Hudson, 1929:77). By the time Canada became a signatory to the Treaty of Versailles, Canadian nationality was starting to congeal. Membership to the League of Nations meant that two

\footnotetext{
${ }^{88}$ Naturalization Act of 1914, An Act Respecting British Nationality, Naturalization and Aliens, 1914 c.44, s.35 as amended and published in 3 revised statutes 1927, c.138, p.2837 in Flournoy \& Hudson, 1929 as part of the statutes used by the League of Nations Meeting in 1930 for the drafting of conventions of Nationality, Responsibility of States for Damage done in their Territory to Person or Property of Foreigners and Territorial Waters.
} 
Canadian nationals were to have seats at the Conference; however, since Canada was part of the British Empire, it did not have Canadian nationals who were distinct from British subjects. Canadian nationality had to become an official Act of Parliament 99 , which further parameterized the boundaries of the class:

Any person born out of Canada, whose father was a Canadian national at the time of this person's birth, or with regard to persons born before the passing of this Act, any person whose father at the time of such birth possessed all the qualifications of a Canadian national, as defined in this Act.

Canadian nationals became a new subclass of British subjects. Canadians became members of an internationally recognized nation and Canadian nationality was officially constructed. This more independent status as a nation enhanced the powers of the Dominion; and this 1914 Act gave the government the power to renounce citizenship.

The citizenship of the wives of Canadian male citizens was a different matter altogether. Until 1932, the citizenship of wives was determined to be that of their husbands and changes to the Naturalization Act meant that women were their own persons with their own identities, and census enumerators no longer assumed their citizenship to be that of their husbands (DBS, 1936a). Prior to this Act, women were dependents and were classed along with "minors, lunatics and idiots as persons under disability" (DBS, 1951a:189). Incidentally, the list of

\footnotetext{
99 An Act to define Canadian Nationals and to provide for the Renunciation of Canadian Nationality", Chapter 21, Revised Statuses of Canada, 1927, p. 699-701 in Kennedy, W. P. M. (William Paul McClure), 1930, Constitutional documents of Canada: Statutes, treaties and documents of the Canadian Constitution, 1713-1929, Toronto: Oxford University Press access from Early Canadiana Online http://www.canadiana.org/ECO/ItemRecord/9_03428?id=ddocafof6f6d123c.
} 
undesirable Canadians in 1931 included anarchists, beggars and vagrants, people 15 years and older who were unable to read, people afflicted with tuberculosis or other loathsome diseases, epileptics and the industrial unfit (DBS, 1931b).

All these Acts defined the Canadian population by determining who was in and who was out of the Dominion of Canada, and who was a national member. Citizenship, however, only became a legal construct when the 1947 Canadian Citizenship Act came into force, which meant that from this point on native-born Canadians and newcomers who met the requirements were to be recognized as citizens of Canada. This was a first among the Commonwealth nations and former British colonies. The objective of the 1947 Act:

To give a clear and simple definition of Canadian citizenship and to provide an underlying community of status for all the people of Canada that will help to bind them together as Canadians (DBS, 1951a:155).

The legal parameters of Canadian citizenship and membership were firm from that point forward. Canadians were officially recognized as their own group and no longer as British subjects; women were enfranchised by this Act and no longer lost their citizenship if they married an alien and alien women who married a Canadian man had to apply for naturalization. Canadian government officials could independently determine who its citizens were going to be and all earlier acts were repealed. (Canadians however kept their status as British Subjects until the repatriation of the Constitution in 1982). The Department of Citizenship and Immigration was created in 1950 and it became possible to do "the scientific planning of education and training in respect to the value and the importance of 
citizenship in Canada" (DBS, 1951a:156). This department also collected data pertaining to citizenship certificates while the DBS collected data about the characteristics of the population who had become citizens. The Act has changed numerous times since it consolidation in 1985 and many adjustments have been made since; as did the kinds of people it created changed along with it.

Acts after 1947 became more inclusive and less discriminatory. Changes included support for family reunification and humanitarian entry of refugees.

Bureaucratic changes reflected demographic concerns and the promotion of Canadian national goals (StatCan, 1990a). Canada became a refuge for many: Polish war refugees; orphaned Jewish children; people who had fled from Czechoslovakia; and many others from Eastern Europe (DBS, 1970a).

As policies changed, so did the language around why immigration was sought in Canada. Prior to 1930, the thrust was settlement; after 1920, industrial workers were sought after, and by the 1960s, skilled labour was the key target. By 1971, immigration was sought for the following reason:

to expand the domestic market, reduce per capita costs on administration, stimulate economic activity by providing new skills, ideas and enthusiasm, and support a higher level of cultural independence and creativity. Canadian experience indicated that a substantial volume of immigration is highly desirable but new population cannot be added haphazardly (StatCan, 197a:219).

The numerous acts were specific, but the ability to determine the class of people deemed desirable to become citizens or to immigrate to Canada, as well as creating quotas, was a matter of government policy that could be stated in Orders 
in Council (DBS, 1957b:170). New selection policies and quotas were instituted into regulation in 1967 to assess applicants based on their education and training, occupational skills, knowledge of French and English, and employment opportunities in area of destination to name a few. Criteria for admission have also changed since this regulation has been put into force.

The collection of immigration statistics in Canada has been:

For the most part a by-product of legislation to control the solicitation and transportation of immigrants and their reception at ports of entry and to protect the resident population against communicable diseases and charitable burdens and the immigrants against physical and economic exploitation at the hands of transportation companies and the crimps and land jobbers who found them as easy marks (Urquhart \& Buckley, 1965:9)

The earlier acts most certainly reflected this sentiment, and these were the data collected at ports of arrival. Citizenship, nationality and naturalization classifications were used to parameterize the collected data starting in 1901 and the collection of landed immigrant data started in 1991. Prior to 1901, 'nationality and origin' was a class; it however most resembled the classification of race and ethnicity, which was never a solid concept in the census. Also, between 1871 and 1901, the place of birth of respondents and that of their parents was used as the indicator of citizenship (Department of Agriculture, 1892:114).

In 1901, a person classified as an immigrant was essentially a person born in a country other than the United Kingdom or Canada, and naturalization classified non-British subjects who applied to be a citizen of the Dominion (Department of Agriculture, 1901:14). Immigrants born in the United Kingdom and the British Commonwealth, being British subjects by birth, had no need to be naturalized or 
to obtain British citizenship in Canada until the enactment of the Citizenship Act of 1947. Nationality was a relatively new term, as was the term Canadian. For example: "the expression new nationality was in this sense introduced in the speech with which the Governor General opened the first Canadian Parliament it is proper to use Canadian...as descriptive of every person whose home is in the country and who has acquired rights of citizenship in it" (Department of Agriculture, 1901:14). A person in 1901 was categorized as a Canadian in the census if they met the following criteria: were born in Canada; lived in Canada and had become a Canadian citizen through naturalization, irrespective of their place of birth or race; and born in the United Kingdom or a British colony thereof who resided permanently in Canada. Non-Canadians were to be classified by the country of their birth, or the country to which they professed allegiance (LAC, 2008). A large wave of immigration to Canada occurred between 1901 and 1913 to settle the Northwest (DBS, 1930), and immigration agents such as White, discussed in Chapter 4, were responsible for the recruitment of settlers and homesteaders.

In 1911, the definition of naturalization in the census was narrowed to apply "to persons 21 years of age and over, who were born in a country outside the UK or any of its dependencies, and who had subsequently become naturalized. A person who had applied for citizenship papers but had not yet achieved full citizenship" was to be marked as such (Department of Agriculture, 1911b). Also, geopolitics had changed the boundaries of European countries between 1901 and 1911, and subsequently, people had to be reclassified. For example, if a person 
was born in Austria-Hungary, they now needed to report the province where they were born ${ }^{100}$; if born in Poland, Lithuania or Finland, their place of birth changed since Poland had ceased to be recognized as an independent country and people were categorized as German Poland, Austrian Poland, or Russian Poland. As for Finnish people, they were no longer from Russia but from Finland, and people born in Turkey were to be sub-classed as European or Asiatic Turkey (Department of Agriculture, 1911b:28).

Confusion related to where one belonged became apparent in the 1916 census results due to world affairs. The 1916 census was conducted in the midst of WWI and the War Measures Act was in effect, which changed the classes of people accepted into Canada while people's allegiances and countries also changed. For example:

many persons of German origin gave their birthplace as Russian, or Belgian or Austria-Hungary or Switzerland or France, nevertheless the ethnic relationship is the important dominant factor. Moreover, after the close of the present struggle, it is impossible that the country of origin of many European peoples resident in Canada may be known by a different name to that accepted at the last census (Dept. of Trade and Commerce, 1918:xxx).

It is interesting to note that ethnicity and race were mixed concepts at the turn of the past century and up until WWI, and questions pertaining to racial or tribal origin were asked but not ethnicity per se. Reclassification continued to occur in $1921^{101}$ and "the statistics of 1901 and 1911 [were] re-compiled to correspond with

${ }^{100}$ Austria, Tyrol, Bohemia, Moravia, Silesia, Galicia, Bukovinia, Dalmatia, Hungary, Transylvania, Croatia, Slavonia, etc. ${ }_{101}$ "If a person says he was born in Austria-Hungary, Germany, Russia, or Turkey, as they were before the war, enter the name of the Province (State or Region) in which born, as Alsace- 
the territorial re-arrangements consequent from the World War, 1914-1918".

Reference tables of territorial change were created and this enabled tabulators to create fairly accurate, comparative statistics of country of birth (DBS, 1925:xiv). As already mentioned, a number of countries gained and lost territory ${ }^{102}$ (DBS, 1931c:26).

Because of these territorial re-alignments, "strictly accurate comparisons with pre-war censuses as to the classification of foreign-born in Canada according to country of birth are not possible" (DBS, 1925:xvii) even though there are many instances in many of the Bureau's reports doing just that. The people and their classes got all mixed up yet the published data appear neat, tidy, accurate and authoritative even though things were not quite right.

After WWI, immigration was restricted with the objective of making work available to returning soldiers. Canadian land was no longer being given away to settlers and it was to be sold, and only those who could purchase it were allowed entry (DBS, 1931b). This change combined with the high cost of travel and the depreciation of European currency meant that fewer people were able to immigrate. Although, by 1923, a new passage agreement was instituted between

Lorraine, Bohemia, Bavaria, German or Russian Poland, Croatia, Galicia, Finland, Slovakland, etc. Or the name of the city or town in which born, as Berlin, Prague, Vienna, etc." (DBS, 1921:24). ${ }^{102}$ Austria lost territory to Czechoslovakia, Italy, Yugoslavia, Poland and Rumania. Hungary, lost territory to Austria, Czechoslovakia, Italy, Poland, Rumania, and Yugoslavia. Bulgaria, lost territory to Greece and Yugoslavia. Germany, lost territory to Belgium, Czechoslovakia, Danzig, Denmark, France, Lithuania and Poland. Russia lost territory to Estonia, Finland, Latvia, Lithuania, Poland and Turkey. Turkey lost territory to Greece, Italy, and from which the following areas became independent; Iraq (Mesopotamia); Palestine (including Transjordan); Syria (including the Lebanon); and various states and Kingdoms in Arabia (Asir, Hejaz and Yemen). 
Canada and Great Britain to pay for the $3^{\text {rd }}$ class travel to Canada for certain classes of British immigrants as a supply of cheap farm and housekeeping labour. Shortly thereafter, others were awarded loans to settle certain parts of Canada and this practice ended in 1930 due to the Depression. By that time, only practical farmers with capital to sustain themselves could immigrate to Canada (DBS, 1931b:192). This marked the period ending the solicitation of immigration to Canada for settlement.

Issues related to citizenship or naturalization and integration were beginning to emerge in the analysis of census data, although the difficulty to 'Canadianize' certain classes was already an issue. For example, a 1926 census report distinguished naturalization from "Canadianization":

it merely signifies the intention of the immigrant to make a more or less permanent home in Canada and the desire to share in determining the Country's political destiny. Whether the influence of the newly naturalized immigrant will be to the best interest of Canada and whether he will be able to use the franchise wisely, is determined by many forces of far greater importance than the mere act of swearing allegiance to the adopted country and receiving thereupon the full rights and responsibilities of citizenship. Indeed it is quite possible for naturalization, when carried out prematurely, to be an actual menace to Canada's democratic ideals as well as to her political and social institutions (DBS, 1929a:140).

Beyond the racist implementation of the head tax previously mentioned, and the sexist practice of disallowing wives their citizenship identities, there were earlier instances that aimed to reduce the immigration of 'negroes' from Bermuda to Nova Scotia. In 1815 , they were described as follows: "unfitted by nature to this climate, or to an association with the rest of His Majesty's Colonists" (DBS, 1958:168). In 1919, a list of excluded classes was drawn because of "climatic, 
industrial, social, educational, labour or other conditions or requirements of Canada or deemed undesirable because of their customs, habits, modes of life and methods of holding property and their inability to become readily assimilated" (DBS, 1958:168). Many of these regressive restrictions were lifted after the 1947 Citizenship Act came into force. However, issues pertaining to difference remain and issues and tensions continuously re-emerge in Canada, as seen in the 2008 Bouchard and Taylor Commission on Reasonable Accommodation in Quebec or the strongly worded editorials and articles in the Canadian dailies in relation to the Shafia women murder trials.

The integration, assimilation and Canadianization of immigrants was of great concern to "help the immigrants of so many linguistic and cultural backgrounds adjust to life in Canada has been a major undertaking requiring the joint efforts of the government and the people generally" (DBS, 1959:176). Interestingly, the 1947 Act stipulated who was and was not a citizen, but judges determined the form and extent of the examination of individuals, as there was no standardized exam and British subjects did not have to appear before a court for examination.

The concept of multiculturalism started to appear in late 1950s with the recognition that assimilation with ideas of total absorption into the dominant culture was not expected while integration "recognizes and respects the cultural contributions that may be made by people of diverse ethnic backgrounds who, nevertheless, are devoted to the welfare of the same country" (DBS, 1959:177). The focus of the government was to encourage and support non-governmental 
organizations to help with social and welfare programs for immigrants, including language education, paving the way for immigrant aid organizations.

In the 1926 census, a Canadian was a person "who has acquired rights of citizenship by birth, naturalization or otherwise. A person who was born in the United States, or France, or Germany or other foreign country, but whose home is Canada and who is a naturalized citizen, should be entered as 'Canadian'" (DBS, 1926:24-25) while the definition of naturalization in the census remained the same ${ }^{103}$. WWII brought with it more geopolitical realignment and the censuses of 1941 and 1946, place of birth classifications were to follow continental European borders as they were in 1936 (DBS, 1941:35). In addition, special classifications were allotted to a person who "has come to Canada from another country in 1939, 1940 or 1941 as a result of war conditions... It will, however, include all so-called 'refugees' or 'Evacuees' for the duration of the war" (DBS, 1945:38). Further, the 1941 manuals provided a list of all of the countries of the British Empire as a reference. In the 1941, 1946 and 1951 censuses, enumerators were specifically instructed to take special care when classifying people from Ireland, as "caution to mark Republic of Ireland or Northern Ireland, Ulster is insufficient as 6 of its 9 counties are in Northern Ireland and the remaining are the Republic (DBS, 1951b:44). Clear instructions respecting the classification of Irish born people remained a census feature, and if people were not sure whether

103 "the legal process by which a citizen of a foreign country becomes a citizen of Canada. A person born or naturalized in any part of the British Empire does not require naturalization in Canada provided he or she had not at any time taken the oath of allegiance to a foreign country" (DBS, 1931c:28). 
their town was considered in Northern Ireland or the Republic, they were to state the nearest city where they were born $(1971,1981,1986)$.

The Citizenship Act was in force at the taking of the 1951 census and enumerators counted British Commonwealth persons as Canadian citizens if they had completed five years residency in Canada prior to January 1, 1947, as they were no longer simply naturalized. Persons not born in a Commonwealth country were enumerated as citizens if they had completed five years of residency and obtained naturalization papers, and one year for women if married to a Canadian citizen (DBS, 1956a). A number of other criteria were added for those who served in the Canadian Forces and for children under the age of 21. This was the first census to show "the number of persons owing allegiance to Canada distinct from British subjects owing, allegiance to other Commonwealth countries" while noncitizens were classified according to the country to which they owed allegiance.

The definition of citizen remained essentially the same from this point onward and international geopolitics continue to influence the composition of the population which immigrates to Canada ${ }^{104}$. In 1961, people were asked if they were citizens of Canada, and if they were not or were uncertain, enumerators were instructed to inform them of the criteria, including asking respondents if they were British subjects who had immigrated to Canada prior to the January 1, 1947, and if not, when had they made an application to become a citizen. If the

\footnotetext{
104 Some that have had real numerical effect were the Suez Canal affair, the Hungarian Revolution of the 1950s, boat people coming from Vietnam as refugees as well as waves of refugees coming from the former Yugoslavia, Somalia and may others and that also meant changing the names of places where people came from (e.g., East Timorese people were no longer from Indonesia).
} 
respondent was a woman who was a Canadian citizen but lost her citizenship by marrying an alien prior to January 1,1947 , then she was a Canadian. If neither the husband nor the wife were Canadian citizens, they had to apply for citizenship. If a child was born outside of Canada after his father's death, he or she acquired the citizenship of his or her father, and the death of a husband did not affect the citizenship of a widow. There were other questions asked as part of a decision-making tree to assess the citizenship of respondents (DBS, 1965).

In 1962, a new immigration regulation was put in place and it specified who was eligible to apply for immigration to Canada, which included:

anyone, regardless of origin, citizenship, country of residence or religious belief, who is personally qualified by reason of education, training, skills or other special qualifications to become satisfactorily established in Canada....and attributes of the applicant for admission are related to the needs and interests of Canadian society in any of its diversities - economic, social or cultural (DBS, 1969a:205).

This marked the beginning of the principle of non-discrimination. It also instituted a closer examination of factors associated with adaptability, which marked a significant change from the earlier and more arbitrary processes, although there always were and remain exclusion lists.

In 1971, people could only enter the last citizenship acquired on census forms; people who had lost their citizenship were to be marked as stateless, while aliens were a class given to people who were not citizens of Canada or the United Kingdom, while immigrant was a classification applied to people born outside of Canada, and stateless people were refugees. After 1971, people were no longer asked their citizenship or their nationality, but instead they were asked their 
country of birth. Country of birth combined with citizenship questions was used to infer other forms of membership.

In the late 1960 s and in the 1970 s, waves of refugees were allowed into Canada and this policy continues but is dependent on world geopolitics and the Government's capacity to support refugees ${ }^{105}$. Refugee as a class of people was added to the 1976 Immigration Act as defined by the UN Convention on Refugees. This inclusion was considered to be part of the culture of Canadian humanitarianism. Until they became landed immigrants, refugees were counted as stateless (StatCan, 1990a). Refugee quotas were set in cooperation with provinces and territories, federal agencies and non-governmental organizations that help with settlement (StatCan, 1990a).

From 1981 onward, people were identified by their legal citizenship status and could indicate the number of citizenships they had with other countries.

Canadian citizens were asked to distinguish themselves as being citizens by birth or by naturalization, meaning they had been a landed immigrant for more than three years, and had applied and been awarded Canadian citizenship. The intent of these questions was to determine the final legal step taken to qualify for reclassification (StatCan, 1986a). There were also many classes of immigrants such as: family reunification immigrants; business immigrants; retired immigrants; refugees; and non-permanent residents (StatCan, 1984).

105 People from Tibet, Jews from Iraq, Asians from Uganda, Chileans, Vietnamese people, Greek Cypriots could apply to join their families after the Turkey-Cyprus wars, and there were policies on family reunification of Chinese Canadians (StatCan, 1990a). 
Starting in 1996, census respondents could also indicate the name of other countries where they held legal citizenship (2001 Census Dictionary). In 1986, 1991, 1996 and 2006, although not clear on the questionnaire, respondents were to report the year they received landed immigrant status by answering the question about the year they first immigrated to Canada (Census Dictionaries). Landed immigrant questions appear on the 1991 census form and they were added to begin counting the refugee claimant population, people with work permits, student visas and minister's permits. A landed immigrant was defined as a person who was not a Canadian citizen by birth but was granted the right to live in Canada permanently, and this allowed analysts to distinguish Canadian citizens by birth, permanent and temporary resident populations. Temporary residence is provided to migrant workers, foreign students and diplomats. This class needs to be factored into the analysis of census data, as this class of resident is not entitled to the same benefits as other residents.

The definitions of citizenship and nationality did stabilize from 1961 to 2006, and it can be said that with that stabilization came reliability. This analysis of the impact of these census classifications had on society, demonstrates that "the character of Canada's foreign-born population at any point in time is a reflection of immigration policy and its implementation during prior decades" (DBS, 1970a).

\subsubsection{Official Language}

The questions pertaining to official languages, as seen in Table 14, include: English and French, mother tongue, language use, knowledge of, and language 
used at work. Questions related to non-official or other languages were also asked and respondents had the opportunity to select or list the language categories they belonged to.

This section will focus primarily on official languages since these are the foundational languages due to the colonial history of Canada. Aboriginal languages were here first, but they are unfortunately not recognized as official, even though there are nine official Aboriginal languages in addition to French and English recognized in the North West Territories while Inuktitut and Inuinnaqtun are also considered official in Nunavut, along with French and English.

There are many language groups in Canada as a result of Canada's immigration history. However, the formation of language communities, even though supported in the Charter as part of Canada's multicultural heritage and minority language rights, is less explicit when compared to the official formation of bilingual kinds of people and places. The purpose here is to provide examples of census classifications and to examine if these have created kinds of people and places, and shaped Canadian geographical imaginations. As will be seen, official languages are most insightful in this regard.

Census schedules, forms and questionnaires are the primary datasets used to create Table 14, and where necessary, enumerator and commissioner instruction manuals as well as census reports qualified the classifications. Official language questions begin to appear in 1891 and were asked in every census since then with 
the exception of the Manitoba census of 1896 and in three short quinquennial censuses, namely, 1906, 1956 and 1966 . The earlier censuses of $1871,1881,1884-$ 85 and 1885-86 did not ask about language directly. However, questions about origin, place of birth, ethnicity and race were erroneously used to infer French and English language use. These classes also informed official bilingualism policy. The place of origin questions, in particular, identified people as being from French or English races, while questions on ethnicity counted some people as 'French-half breeds' Métis, or 'British half-breeds', a classification used to identify the language capabilities of mixed race Aboriginal people. No other people of mixed ethnicity or race were categorized in this way. 
Table 14. Language Classifications, 1871 and 2011 (Compiled by the author)

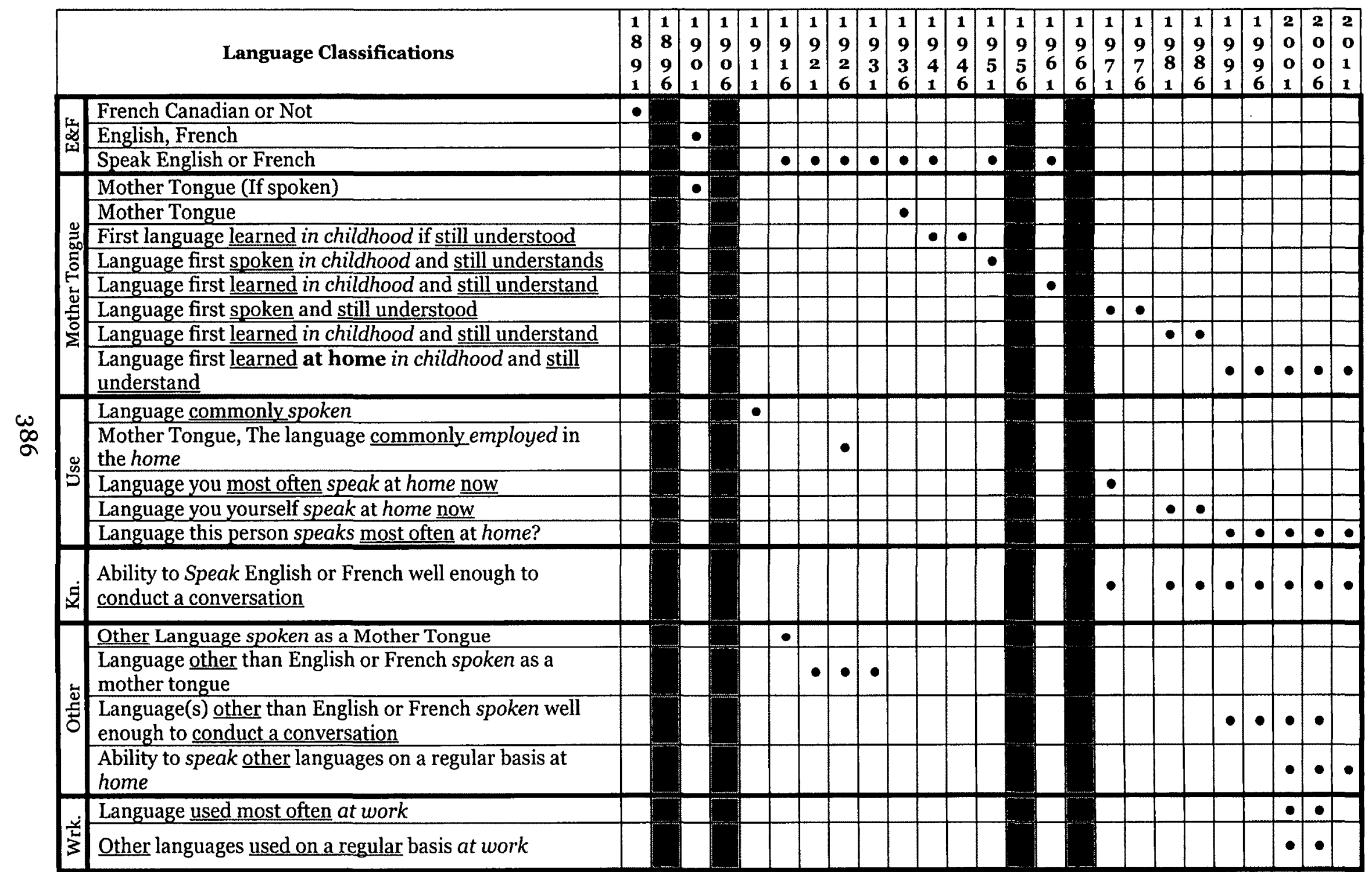

- = Question asked, Dark grey column = question not asked for that census, Light grey column = quinquennial census 
The limitations of relying on race and ethnicity in terms of language

determination were later recognized as being problematic since:

the extent to which each of the two principal races is responsible for the number speaking its own language is not revealed by the race's total population alone, some speak it as an acquired language. It is necessary to know, for instance, the number of English-speaking races in their capacity to acquire the official languages of Canada (DBS, 1936a:247).

The recognition of this limitation later led to asking questions about the official language spoken. Origin and ethnicity questions, however, were still in use well into the 1970 s to determine language shift and assimilation.

\subsubsection{Reasons for Collecting Language Data}

Nineteenth century Dominion of Canada officials understood that it was necessary to collect data about English and French people for historical and political reasons; these languages were described as "having been officially recognized by Great Britain shortly after the conquest of Canada in 1760, and having been confirmed at various times in the subsequent history of the Country" (Department of Agriculture, 1892a:106). The territorial evolution maps of the Atlas of Canada, discussed in Chapter 4, identify the territories of French and English colonialists, particularly the evolution maps found in the $3^{\text {rd }}, 4^{\text {th }}$ and $5^{\text {th }}$ editions, and it is evident that the geography of the concentration of English and French language groups has generally persisted. Confederation made both languages official and the 1867 BNA Act made it explicit that the Federal 
government was to serve the population in both English and in French ${ }^{106}$.

Counting people linguistically began with the 1891 census and enumerators were instructed simply to distinguish between French Canadians and all the others; as stated officially: "this subdivision is made because it is the great fact of Canada's population that it is bi-lingual, and accurate statements respecting this great fact are necessary for many practical purposes" (Department of Agriculture, 1891a:3 bulletin). Unfortunately, this early attempt was based on the ethnocentric assumption that all the 'others' spoke English.

Immigration and the subsequent assimilation of new comers were of considerable concern for decades. This concern seemed to have fueled the desire to collect language data:

English and French being official languages of the country a special record has been taken to show if the person speaks one or both of these, and also his mother tongue if spoken. In a country peopled with so many foreign elements as Canada, it is desirable to know if they are being absorbed and unified, as may appear by their requirement of one or other of the official languages. And as English is now in a very large degree the language of commerce throughout the world, it is also desirable to ascertain to what extent citizens of French origin are able to speak it in addition to their own (Dept. Agriculture, 1902:viii).

Other reports discuss how some 'races' were better than others at learning Canada's official languages. The Scandinavians, Dutch and Germans were considered desirable immigrants because of their exceptional ability to learn English quickly and their familiarity with similar democratic contexts. People from Eastern Europe were thought less successful in assimilating given their 
'Canadianization' in the Prairies, which was considered to be problematic. People from the Orient were considered even less able to assimilate "according to the general opinion of Canadians" (DBS, 1931b:175). Note that none of the DBS reports examined in this study have included any public perception surveys and there were no references provided to qualify this 'general opinion'. These assumptions were informed by the descriptive statistics of immigrants and their citizenship, origin, race, ethnicity and country of birth with their ability to speak English or French.

The rate of intermarriage between people of different races or ethnicities was also used as an indicator of assimilation. These studies indicated that Chinese and East Indians or 'Hindoos' did not intermarry with 'founding' Canadians or assimilated northern Europeans, and from these data, it was concluded that Asian 'stock' did not assimilate. For example, when discussing Japanese, Chinese and East Indian people in an evaluation of the results of the 1921 census, the report stated: "as in the case of assimilation by intermarriage with the basic stock in the country, so in the matter of learning the languages of the nation, these stocks are far behind the others" (DBS, 1929a:161). Causation, however, was not discussed in these early Bureau reports. The head tax and the fact that many Chinese men were already married when they came to Canada but were not allowed to bring their wives or children might have contributed to the low intermarriage rates. In addition, the restrictions, quotas and taxes might have been better used as indicators of how the easily assimilated, desirable 'races' manufactured the idea that it was undesirable to marry Asian or 'Oriental' people. 
Official language ability was also a criterion for people applying to immigrate to Canada, and the following statement, once again, exemplifies the thinking regarding language and assimilation:

where there is considerable immigration into a democratic society, the racial and linguistic composition of the immigrants is of great importance. Canadians generally prefer that settlers should be of readily assimilable type, already identified by race or language with one or other of the two great races now inhabiting this country and prepared for the assumption of the duties of democratic Canadian citizenship (DBS, 1931b:175).

Democratic participation in the context of immigration also meant assimilation, for example:

Canada is the meeting place of many peoples. Within her boundaries many tongues are spoken. The development and use of a common medium of communication has in the past, as the sociologist avers, conditioned the emergence of human societies. Unless individuals can be known to the other members of the group their feelings and thoughts, and unless they in turn are able to understand and appreciate the emotions and ideas of their fellows, a group consciousness is impossible. The 'animated moderation' which has gradually been replacing the rule of force is based on discussion which, in turn, is conditioned by the ability to converse. Common media of communication are as important in modern democracies as with primitive peoples (DBS, 1929a:160).

These same ideas appear in later reports: "a common medium of expression is necessary, however, if individuals are to understand the ideas, thoughts, and feelings of their fellows and a thorough knowledge of the predominant language is essential if persons of foreign origin are to become fully assimilated in the Canadian way of Life" (DBS, 1950:255); and "the language spoken by the people of a country has distinct bearing upon its problems of nationality and assimilation" (DBS, 1945b:36). Mother tongue, which will be explained in greater detail shortly, was also considered "the standard to measure the extent of 
integration of widely-differing ethnic groups in Canada, but also a means of distinguishing different cultural groups" (DBS, 1956a:196). Language questions continued to be asked and collected for the explicit purpose of assessing the ability of immigrants to integrate into Canadian society well into the early 1960 's. The Bureau thought "the primary step in the integration process [was] to learn the language. Without knowledge of the language spoken in a community, there can be no real communication with the people who live there and only an inadequate understanding of the laws and customs of the country" (DBS, 1959:176). As discussed earlier, the census was used to inform the demand for and the locating of immigration settlement programs, which included language training for new comers. As such, language was one of the classifications used to make that determination.

The language used in reference to official languages changed drastically in Bureau reports from the 1960 s onward; it went from collecting and analyzing official languages data to assess assimilation, integration and democratic participation to bilingualism. Assimilation was still an issue, but it became an issue related to minority language shift, pull of English, language loss and retention (particularly with respect to French language), language mobility, language continuity, and language indices of segregation and dissimilarity. Bilingualism policy was rooted in a very political reaction to the threat of separation of Québec from Canada, which coincided with the end of the Duplessis Regime and the emergence of the quiet revolution, which in turn, ushered in the Québec separatist movement under the leadership of René Levesque. This 
marked the period when language issues became ideological, tied to the identity politics of the Québecois people and Québec nationalism. The Bureau reports, of course, made almost no mention of these issues, as per its 'objective' and 'apolitical' approach to data gathering. The reports did, however, discuss the use of language data: to inform the Royal Commission on Bilingualism and Biculturalism; to meet the requirements of the Official Languages Act, which received royal assent in 1969; and to guide the work of the Bilingual District Advisory Board. An additional use for language data was to meet the constitutional requirements of Minority Language Rights as stated in the 1982 Charter of Rights and Freedom. The Bureau, which later became StatCan, may be 'apolitical' but the data it collects, the classes of people it creates and the questions it uses to count people are not, although they do seem that way when looking at a census form and a table of numbers.

The term demolinguistics ${ }^{107}$ first appeared in the Bureau reports in the 1960 s. The 1966 UN National Statistical Commission recommended that demolinguistic data related to the concepts of language use, knowledge of a language and mother tongue be collected internationally for the up and coming censuses of the 1970 . The language recommended questions were as follows:

107 Demolinguistics is a sub-discipline of demography and not linguistics; its focus, in the Canadian context, is the linguistic diversity of Canadians, the evolution of linguistic groups and the transmission of mother tongues across generations (StatCan, 1993 MT). 
(a) Mother tongue, defined as the language usually spoken in the individual's home in his early childhood;

(b) Usual language, defined as the language currently spoken, or most often spoken, by the individual in his present home;

(c) Ability to speak one or more designated languages (UN, 1970:21).

By 1991, Canada was one of the only countries that collected all of these in detail (StatCan, 1993a). Also, as mentioned, official language data were being collected to inform political events such as the passing of the Official Languages Act of 1969:

which sought to define Canada as officially bilingual. The declaration of multicultural policy in 1971 implied some degree of official support for the maintenance of languages other than English and French. Legislative developments in the province of Quebec since the election of the Parti Québecois in 1976 have fortified the link between language and ideology, thus heightening the salience of language issues for the continued survival of Canadian society as we know it (StatCan, 1980a:16).

The Act was the result of a recommendation made by the Royal Commission on Bilingualism and Biculturalism (i.e. B \& B Commission), which was chaired by A. Davidson Dunton and André Laurendeau. The B \& B Commission was created in 1963 by Lester B. Pearson to quell the tensions and avert the 'crisis' of Québec separation. It had an explicit mandate:

[to] inquire and report upon the existing state of bilingualism and biculturalism in Canada and to recommend what steps should be taken to develop the Canadian Confederation on the basis of an equal partnership between the two founding races, taking into account the contribution made by the other ethnic groups to the cultural enrichment of Canada and the measures that should be taken to safeguard that contribution (B \& B Commission, 1963 Terms of Reference, in the 1965 Preliminary Report). 
The Commission conducted numerous studies, held cross-Canada consultations with premiers, and hosted public hearings on the issues of bilingualism in Canada. The Preliminary Report (1965) revealed sentiments, assumptions and facts about French and English people, cultures and places. Chapter 5 of the Report, Political Aspects, included a section entitled Ideas of Democracy: a Number's Game, which discussed issues of majority and minority rules and noted that "those who developed the argument for majority rule tended to reduce considerably the actual proportion of citizens of French origin in Canada, which the 1961 census was 28.1 per cent according to language and 30.4 per cent for ethnic origin" (B \& B Commission, 1965:97). Canadian people had imagined Canada differently and the count realigned the popular imagination on this issue. When asked, people estimated the population at 10 or 12 percent of the population nearly the same proportion of people of ethnic minorities. Furthermore, the report noted that some had emphasized that the French population since Confederation had been decreasing and that French Canadians were solely confined to the province of Québec. Investigations using census data from Confederation to 1961 , demonstrated that the population assumption was not true. Origin data had demonstrated that the proportion of the population of French origin was "remarkably stable, 31 in 1871 and 30.4 in 1961, and this in spite of continuing immigration" (B \& B Commission, 1965:98).

The Commission examined bilingualism and biculturalism, and to do this, it became important to distinguish between the two languages, English and French, and the two cultures, an English one and French one, while not excluding 'other' 
groups. This meant distinguishing between language and culture, and it was decided that the census question on mother tongue was to be used to count French, English and 'other' language groups. It was also decided no longer to use ethnic origin data in language deliberations since those were considered better at informing culture and roots (Appendix IV, 1965:186 footnote). Appendix V of the Report includes 9 pages of 1961 StatCan data classifications organized by Census Metropolitan Areas (CMA) as follows:

- Mother tongue "the language first learned in childhood and still understood";

- Official language which refers to "the number of persons who reported they were able to speak either one or both the official languages of Canada"; and

- Ethnic group, which is "traced through the father. The question asked was 'To what ethnic or cultural group did you or your ancestor (on the male side) belong on coming to this continent?' The language spoken at that time by the person, or his paternal ancestors was used as an aid in the determination of the person's ethnic group. Special instructions were provided in cases where the language criterion was not applicable".

This marked the beginning of officially using mother tongue to count official language groups and to map where they were.

In the Commission's second report, referred to as Book I, published in 1967, a number of definitions clarified issues of concern, as identified in consultations and based on feedback from the Preliminary Report. For example, the term race is used in reference to the two 'founding races' of Canada, and it was stated that the term reflects how it was historically used in reference to a national group as opposed to one of biological significance, in a way similar to its French translation of peuple. Ethnicity, in Book I, was distinguished from its statistical 
definition. Ethnicity, in Book I, did not necessarily mean the culture or biology of one's 'forbearers' as it is asked on the census, but instead, it referred to a sense of belonging and the report stated that "from this point of view it seems that the important phenomenon is not ethnic origin itself, or even mother tongue, but the feeling of belonging to a group and the desire of this group to exist as such" (1967:xxiii). The Report stated that bilingualism only refers to official languages and refers to people who combine the knowledge of "their mother tongue with a more or less extensive and active knowledge of the second language" (1967:xxviii). In addition, Book I explained that bilingual people include those who can speak both languages interchangeably (i.e. people of French origin who acquired English as a second language, people of English origin who acquired French as a second language, and 'other' Canadians who acquired French and English as their second language). The Report also made clear that language was a necessary but not an insufficient condition for the preservation of a culture: "language is much more than a simple means of communication, and culture is much more than the persistence of a few psychological traits or expressions of folklore" (1967:xxxviii). The ideal of an equal partnership was greatly discussed along with many other political, economic and religious aspects of this ideal.

Book I of the B \& B Commission (1967) also dedicated an entire chapter to counting and mapping, entitled Composition of the Population: The Two Main Language Groups, and it is there where the limitations of census language questions were discussed. For example, the questions, 'do you speak English? French?', only counted those who spoke official languages; it did not distinguish 
between recent immigrants who may have difficulty expressing themselves in either and native speakers. Mother tongue, on the other hand, counts people by what they learned and may classify them for their entire lives this way, even though they may in fact understand the language but not speak it and communicate primarily in English, French or both. The Commission recommended keeping these questions and adding a new one that would track "the main language of each Canadian, and would enable us to tell which language he speaks most often at home and at work" (1967:18). In Book I commissioners also recognized that counting official languages using the mother tongue question underestimated the number of people who speak either French or English relative to the question on whether or not people speak French or English, but as explained, both have limitations and it was decided that the mother tongue question was more precise. There was also the recognition that "in all probability the reality - that is the number of people for whom English, French or another language is the working or main language - lies somewhere between" (1967:85).

The Report examined the statistics on ethnic origin between 1881 and 1961 . The same 'assimilation' data used in earlier Bureau reports were instead put to work to examine: language preference by ethnic group; assimilation of the French; geographical concentration of the French in Quebec and its neighbouring regions; language transfer into English; and population distribution by mother tongue as seen in the map that follows (see Figure 33). In addition, commissioners also identified official language minority concentrations across Canada as seen in Figure 34 . 


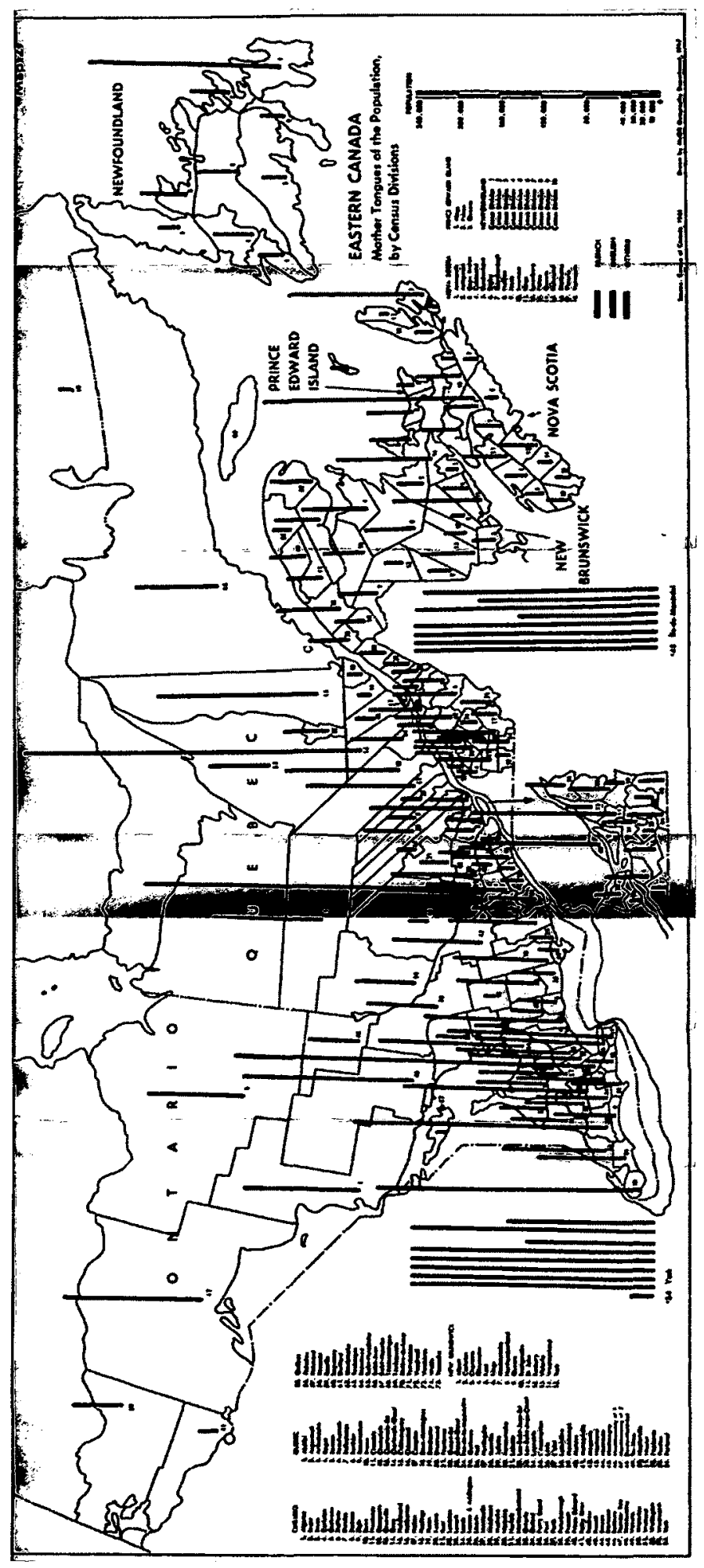

Figure 33. Mother Tongues of the Population Map, B \& B Commission, Book I 1967 


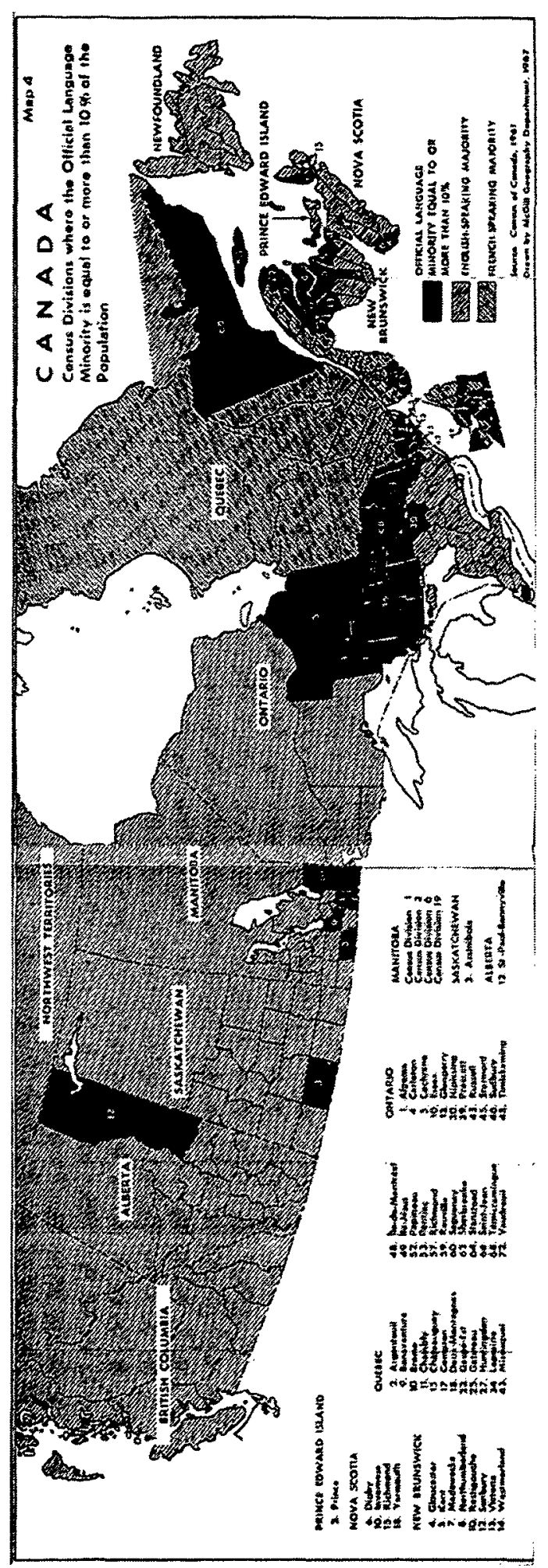

Figure 34. Official Language Minority is equal to or is more than $10 \%$ of the population by CD, B \& B Commission, Book I 1967 
Based on consultations, research, submissions, statistical analyses and mapping, Book I recommended ${ }^{108}$ the following:

- That English and French be formally declared the official languages of the Parliament of Canada, of the federal Courts, of the federal Government, and of the federal administration (1967:91).

- Any province whose official-language minority reaches or exceeds 10 per cent declare that it recognizes French and English as official languages and that it accepts the language regime that such conditions entails (1967:99).

- That bilingual districts be established throughout Canada and that negotiations between the federal government and the provincial government concerned define the exact limits of each bilingual district (1967:110).

- The establishment of a federal-provincial review council whose main duties would be: a) to recognize as bilingual districts or as parts of bilingual districts new areas where the official minority attains or surpasses 10 per cent, and $b$ ) to remove from official bilingual districts those areas where the numerical importance of the official-language minority has substantially decreased (1967:148).

- That the Governors in Council appoint a Commissioner of Official Languages charged with ensuring respect for the status of French and English in Canada (1967:141).

This was a space and statistically based policy, to create bilingual people and spaces. The commission defined bilingual districts as follows:

108 The recommendations listed here only include those relevant to this analysis, the full list is provided in the 1967 report pages 147-149. 
areas where the official-language minority is numerous enough to warrant the kind of linguistic reorientation we feel desirable. We will propose that they be defined essentially by regional clusters of the official-language minority. This geographic framework will thus be closely related to real language needs (1967:106).

The commissioners also supported the use of existing local boundaries "to reduce confusion and to provide a base for proposing responsibilities to existing local governments" (1967:106). This meant administrative boundaries such as school board catchment areas, cities, municipalities or counties. The Commission was also very clear that "the bilingual district is neither a new jurisdiction nor, technically speaking, a new administrative structure. Rather it is designed to bring about linguistic co-operation in the services of existing governments" (1967:106). The Commission chose to use the Census Division (CD) as the geographical unit to determine district boundaries. District creation was to be considered for those CDs where 10 per cent or more of the population was identified as an official language minority, based on the 1961 census results of mother tongue. Fifty-four CDs satisfied this criterion as seen in the map of Figure 34 above. The commissioners understood that while these CDs met the $10 \%$ criterion, these maps did not adequately explain the distribution of the population within that $\mathrm{CD}$. Furthermore, $54 \mathrm{CDs}$ would need to be examined in detail with local and provincial governments in order to understand distribution, and determine the population bases and boundaries of these districts. It was also recommended that Ottawa, as the Capital region, be bilingual irrespective of the uneven distribution of French mother tongue speakers within the city. The commissioners were in essence advocating for a place-based approach to federal, 
provincial and local service delivery as a way to promote bilingualism. The objective to create bilingual districts or regions was to develop "a network of bilingual areas across Canada, to provide services to Francophones in those regions and to give the actual image of the rural nature of Canadian society" (1967:128). Book I also included a draft Official Languages Act, which stipulated:

The provisions of subsection 2 shall apply to any additional province in which those persons whose mother tongue is English or French shall reach or exceed 10 per cent of the population of the province; and to any province which declares that English and French are official languages...

Whenever in any province the English or French speaking population of the appropriate administrative unit reaches a substantial proportion, this unit shall be constituted into a bilingual district... (1967:149, emphasis added).

On July 9th, 1969, the Official Languages Act, (17-19 Eliz II, c. 54) received royal assent, and English and French became official languages (Section 2) and bilingual districts were instituted (Sections 12-18). The Act describes districts as spaces where 13(2) (a) both official languages are spoken as a mother tongue by persons residing in that area; and (b) the number of persons who are in the linguistic minority in the area, in respect to an official language spoken as a mother tongue, is at least 10 per cent of the total number of persons residing in the areas. Also Section 14(1), states that a District Advisory Board be created at the end of each decennial census and the Dominion Statistician "shall prepare and send to the clerk of the Privy Council a return certified by him showing the population of each of the provinces and census districts in Canada, categorized according to the official languages spoken as a mother tongue by 
persons resident therein as ascertained by that census" (GC, 1969:c.54:11). Furthermore, the Act stipulates in Section 16 that the "Dominion Statistician and the director of the Surveys and Mapping Branch of the Department of Energy, Mines and Resources [(EMR)] shall make available their services and facilities of their respective offices, and render all such other assistance to a Bilingual Districts Advisory Board as may be necessary" and EMR, as seen in Section 18, will also help with the production of maps for each district in each province, and with individual maps for local government districts (1969:c.54:11).

The Act was extremely detailed and defined the following: the dataset to be used; the population concentration algorithm; the geographic unit; the new position and role of the Commissioner of Official Languages; the role of the Dominion Statistician; and the role of the Mapping Branch. The explicit directions found within the Act appeared to be a strategy to absolve politicians of the outcome of the process by clearly defining responsibilities and entrusting the objective scientific arms of the government to produce trusted numbers and maps. It seems that the authors of this Act wanted to avoid accusation of lack of objectivity and efficiency, reminiscent of criticism of the 1851-52 and 1861 censuses, which were considered to be unreliable counts. Earlier Statistics Acts were also quite explicit but not quite like this one.

On February 12, 1970, ten commissioners were appointed to the first Bilingual Districts Advisory Board. The Board was restricted to mapping 1961 mother tongue data and determining districts based on the $10 \%$ rule. The Board considered this to be problematic because there had been significant shifts in 
population since 1961. Some federal employees were concerned that their jobs were at risk if they could not speak the official minority language in certain areas. Others considered the $10 \%$ rule inequitable for larger Canadian cities such as Winnipeg, where the number of French speakers was higher than anywhere else in the province but not high enough to meet the $10 \%$ criterion for a $\mathrm{CD}$. To counter this latter criticism, the Board recommended that the $\mathrm{CBC}$, private radio and television broadcasters and the CRTC provide bilingual services to these districts nonetheless. The $10 \%$ rule needed to be re-examined to factor in population density. The communication infrastructure maps discussed in Chapter 4 , specifically the $3^{\text {rd }}$ edition of the Atlas, clearly demarcated where French and English services were provided. Figures 35 and 36 are examples of the kinds of maps produced to create bilingual districts in Southern Ontario and Ottawa and its Eastern CDs. 


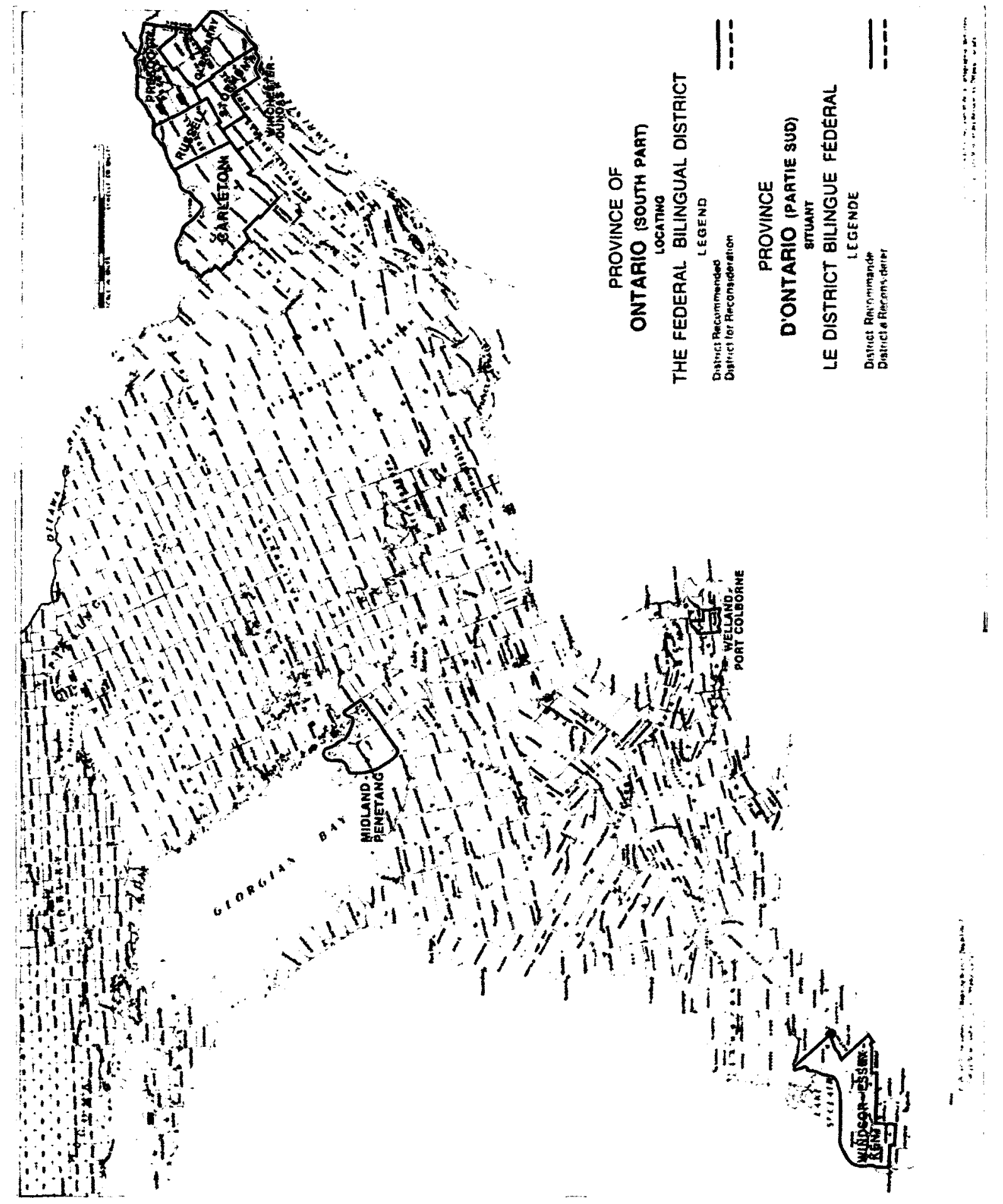

Figure 35. Ontario District Recommendation's Map, $1^{\text {st }}$ Bilingual Districts Advisory Board, 1971 


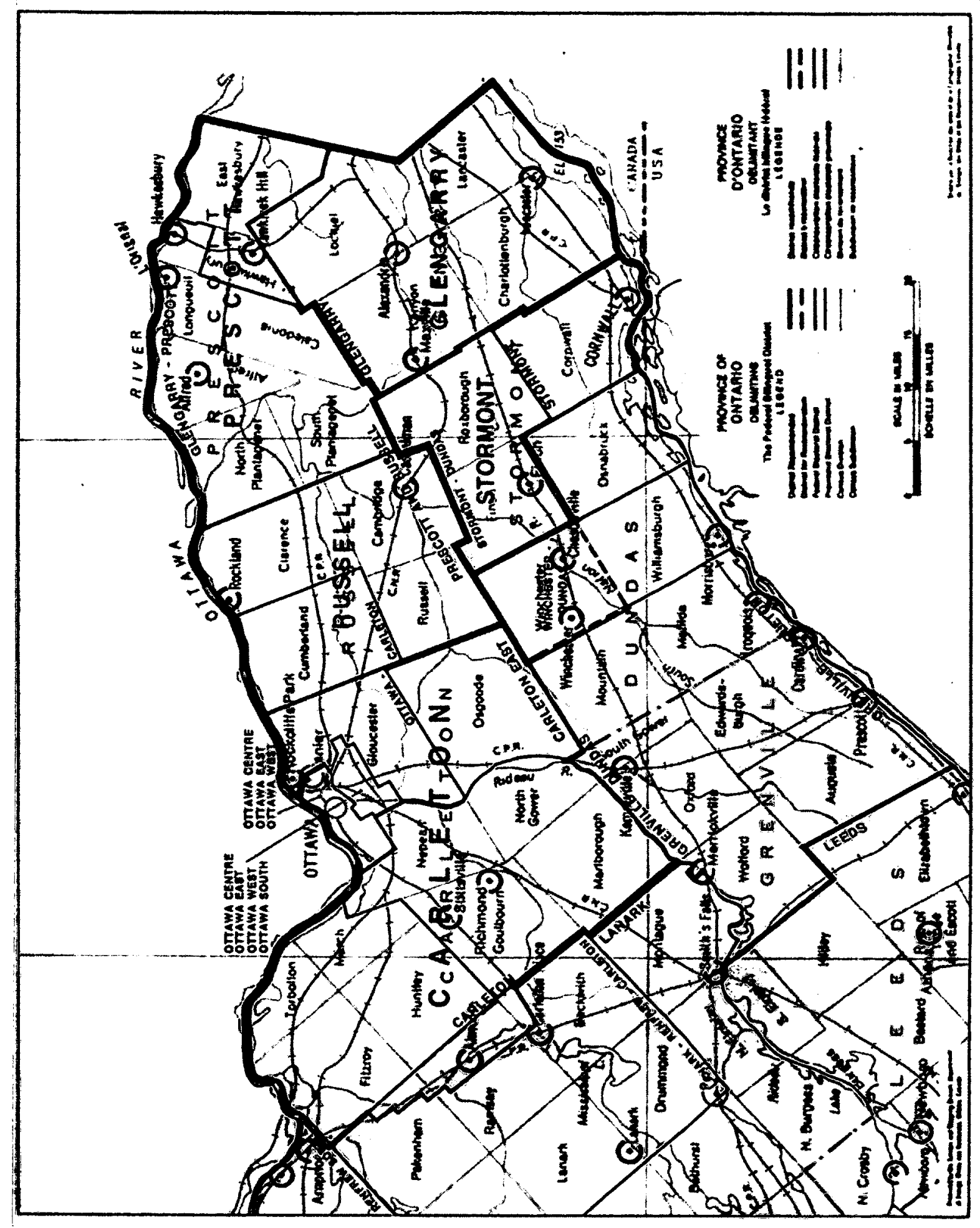

Figure 36. Ottawa Area Recommendations, $1^{\text {st }}$ Bilingual Districts Advisory Board, 1971 
The second Districts Advisory Board report (1975) included a complete list of the 1971 census bulletins it used. The Board also received data presented in cartographic form, which informed the determination of districts (Bilingual District Advisory Board 1975 Report). The 10\% criterion re-emerged as an issue of concern since no provincial capital city met the criterion despite having large numbers of residents with French as their mother tongue. Additionally, many small local areas that did meet the criterion were in reality small in density such as only 5 or 10 people. The second Board examined the idea of creating language communities, which made more sense for densely populated urban areas. This examination led to the recommendation of a new criterion, where 5,000 people who primarily spoke the official minority language was set as the benchmark instead of mother tongue and CMAs. Furthermore, Census Agglomeration Areas (CAs) were used instead of the Census Division (CD) in these situations.

Only two Boards were constituted, and the creation of districts based on population was never implemented. The government deemed the territorial determination for the delivery of services not to be a viable solution as it was too onerous a process to administer and instead focussed on making the public service and federal services bilingual. The Commission later focused on instituting the language of work, distributing services to the public, implementing equitable representation, and examined conventions based on the principle of significant demand. The Charter supplanted these exercises as it recognizes official bilingualism and minority language rights. The Official Languages Act was amended to reflect this change. 
The Charter and the Act do not specify the type of data to be used nor a geographic entity, although in the latter, the idea of community could be considered a geographic unit. Irrespective, census data, especially those collected from the mother tongue questions, have been used to fulfill the requirements of the Official Languages Act ${ }^{109}$ and Section 23 of the Canadian Charter of Rights and Freedom ${ }^{110}$. Section 23 refers to "the first language learned and still understood" in relation to minority language educational rights of official languages", which is the mother tongue question.

The B \& B Commission and the two District Advisory Boards changed how the geolinguistic landscape of Canada was imagined. Canadians began to see French minority language islands, zones and communities (Cartwright, 1976), bilingual regions (Board, $1967 \&$ 1971, Joy, 1967) and districts as being across Canada and not confined to Québec, bilingual belts in areas around Quebec and in Ontario (Cartwright, 1976 and Joy, 1967). Also, concepts of language distant decay, language shift, language intensity indices, and unilingual and bilingual areas, were new measures introduced in later official bilingualism reports. The 1971 census added new language questions, partially as a result of the Commission's work, and as a response to the UN recommendations. The unit of geographic analysis was also questioned, should it be CMA, CD, CA, other StatCan geographies or the use of the ecumene.

109 Official Languages Act, R.S.C., 1985, c. 31 (4th Supp.), Official Language Act 1969, http://epe.lac-bac.gc.ca/100/200/301/pco-bcp/commissions-ef/dunton1967-1970ef/dunton1967-70-eng.htm.

110 Canadian Charter of Rights and Freedoms PART I OF THE CONSTITUTION ACT, 1982 http://laws.justice.gc.ca/eng/charter/. 
Examining the reliability of assessing language with the current census questions remains an issue; Canadian Heritage, the department responsible for the Official Languages Act, has commissioned a series of reports on the evolution of Canada's linguistic situation for the 1991, 1996, 2001 and 2006 censuses. These reports are prepared in collaboration with StatCan and address the methods of collecting and assessing language data.

In 2010, the Harper Government cancelled the long-form census, choosing a voluntary survey in its stead. There was unprecedented protest to this move, especially from language minority, aboriginal and ethno-cultural visible minority groups, who each tabled separate court challenges. The Federation of Francophone and Acadian Communities (FFAC), for example, argued that this move contravened the Official Languages Act, which requires the government to proactively "enhance the vitality" of French and English minority communities. As discussed, the current Act became much less specific regarding data sets, methodologies and geographies, while it is uncertain if the term community is to be considered sociologically or geographically in the Charter. The Government, before hearing the outcome of the case, reinstated the language questions in the 2011 short-form census. It is speculated that this move was influenced by Canada's long history of contentious language issues; the governing party's standing in Québec, and the fear of a Charter challenge ruling against their decision to extinguish the mandatory long-form census. Irrespective, the Federal Court later rejected the FFAC submission precisely for the lack of specificity found in the amended Official Languages Act. While the original Act, there is no 
specific reference to the methodology to be used to collect language data, and as such, the court considered that the administrative method of the 2011 census did not violate the Act.

It is worth noting that in 1986 , the census was under threat of cancellation altogether under the Mulroney Government, and at that time, StatCan undertook a complete evaluation of all the census questions to see if some could be cut to reduce costs and to assess which ones had to be maintained for legislative reasons. The mother tongue question was ruled indispensable for the following reasons:

it is also anticipated that mother tongue data will be required in future litigation under the Canadian Charter of Rights and Freedoms minority language education rights clause to determine whether, in any given area, the number of children potentially admissible to minority language education warrants provision of that education out of public funds. The Charter of Rights and Freedoms also undertakes to support the multicultural character of the Canadian Population and therefore current mother tongue data will be necessary to determine the viability of cultural services to non-official minorities in given areas such as those envisioned in the culture retention programs of the Secretary of State (StatCan, 1986b).

Language data are also used for a number of other reasons, including:

- to analyze discriminatory employment and remuneration practices with respect to linguistic minorities,

- to ensure equitable representation of minority language groups within the public service,

- to measure the success of policies and programs designed to preserve the linguistic heritage of Canada's Aboriginal People (StatCan, 1986b),

- to study the evolution of linguistic minorities such as language transfer, language shift and language retention (StatCan, 1988 \& 1992), 
- to determine the need for language education and services in both official languages (StatCan, 1992), and

- to administer the Canadian Charter of Rights and Freedoms and the Official Languages Act (StatCan, 1997).

The 2009 Census Consultation report indicated that these questions were used for evaluating and monitoring federal legislation, policies and programs including:

- Canadian Charter of Rights and Freedoms

- Official Languages Act

- Official Languages Support Programs

An earlier 1996 Review of Census Questionnaire Content produced a list of major users, which included 16 major federal agencies and departments, provinces and territories, and over 30 city and non-governmental organizations. This report also listed the following legislative and program requirements beyond those already mentioned:

- Heritage Culture and Languages Program

- Immigrant Settlement and Adaptation Program

- L'Office de la langue française

- Office of the Commissioner of Official Languages

- Canadian Multiculturalism Act

\subsubsection{Definitions}

As seen in Table 14 on page 386 at the beginning of this section, there have historically been four main methods to collect official language data and within these four broad categories of speakers, users, knowers and mother tongue, there 
have been multiple ways to ask language questions, which affects comparability overtime. What follows is an examination of each of these four categories starting with the current departmental standard definition of mother tongue.

\subsubsection{Mother Tongue}

According to the 2009 departmental standard, mother tongue refers to:

the first language learned at home in childhood and still understood by the person at the time the data was collected. If the person no longer understands the first language learned, the mother tongue is the second language learned. For a person who learned two languages at the same time in early childhood, the mother tongue is the language this person spoke most often at home before starting school. The person has two mother tongues only if the two languages were used equally often and are still understood by the person. For a child who has not yet learned to speak, the mother tongue is the language spoken most often to this child at home. The child has two mother tongues only if both languages are spoken equally often so that the child learns both languages at the same time (StatCan, 2009).

Mother tongue data have consistently been collected since 1931 in all censuses although the question has varied. The 1916 to 1936 questions are narrower in scope compared to those beginning in 1941, which coincides with the start of historical trend analyses. Since 1941, it has varied between 'spoken' to 'learned', and has always included 'still understands', while starting in 1991 'in childhood' was replaced with 'at home'. Reports have stated that these questions remain comparable (StatCan, 1993a). As discussed, it was the question used to formulate the first Official Languages Act and to subsequently determine bilingual districts. Census consultations have reported that users would like to see the 'still understands' part removed as this would reduce the size of the count, while others wanted to remove it to bring it in alignment with the international UN 
standard 1996. It is important to note, however, that being able to understand a language does not mean that a person can speak it, but the ability to understand can connect a person to a group.

Mother tongue is considered to be the inherited language and not the acquired language, "one's native language, the language of his race, but not necessarily the language in which he thinks, or which he speaks most fluently, or uses chiefly in conversation" (1902) or "the name of the language of origin or race, if spoken" (Dept. Agriculture, 1912:38). Mother tongue may also:

be taken as indicative of ethnic groups. The principal exception to this rule is the case of persons reported as of English mother tongue. Under this head are included such widely different ethnic groups as English, Irish, Scotch and Welsh. While English as a mother tongue thus covers more than one racial groups of people, the opposite is true of Yiddish, which is reported as the mother tongue for only a part of the Hebrews, the other being reported as speaking Polish, Russian, German, English etc." (DBS, 1925:xviii).

The 1925 observation on English could apply to French since there are many French speaking European, Middle Eastern and African countries. Mother tongue was described in 1925 as the language transmitted by parents, the language of the homeland, and the language representing an ethnic group (DBS, 1925:xviii). In 1936, it was the language learned in childhood or the language spoken before coming to Canada. Also, "each immigrant brings with him the language of his homeland, his 'mother tongue', which for him and his family and his descendants may be a common medium of expression for quite a long period of time" (DBS, 1965a:9-1). 
Mother tongue is a question that categorizes people based on the language people first learned and may still understand, not necessarily a language used, but to some extent, there is knowledge of a language. This is the classification used to assess language transfer or shift and assimilation, and the size and location of linguistic groups. In addition, it is used as a reference to qualify ethnicity, place of birth and ethno-cultural visible minority classifications. Since 1991, analysts have been advised to consider removing the non-permanent residents from their calculations as these may affect the actual numbers in smaller geographies in a significant way and to address multiple responses with sensitivity.

\subsubsection{Knowledge of French or English}

Between 1891 and 1961, the census classified people as French Canadians or not, and those who could speak French or English. These two classes of people were not necessarily the same as those who listed either or both official languages as a mother tongue, although, the 1911 and 1926 questions on mother tongue more closely resembled the ability to speak or the knowledge of the official language concept. The question 'most often spoken at home' was first introduced in the 1971 census on the recommendation of the B \& B Commission and it was considered to be "vitally important in the assessment of the success of the federal government's official language policies and programs, as it shows the current language use of Canadians" (StatCan, 1986b:17). The 'at home' component was added to assess language behaviour in homes where more than one language is spoken, particularly where spouses have different mother tongues. In addition, the retention of mother tongue by people living in a minority situation was also of 
particular interest (StatCan, 2002a:7). The question 'well enough to conduct a conversation' was also added to the 1971 census to assess the level of knowledge and to complement language use responses.

The current departmental standard (2009) is as follows:

refers to the language the person speaks most often at home at the time of data collection. A person can report more than one language as "spoken most often at home" if the languages are spoken equally often.

For a person who lives alone, the language spoken most often at home is the language in which he or she feels most comfortable. For a child who has not yet learned to speak, this is the language spoken most often to the child at home. Where two languages are spoken to the child, the language spoken most often at home is the language spoken most often. If both languages are used equally often, then both languages are included here.

The 'language spoken at home' question categorizes people into a class of current 'language use' that the mother tongue question could not provide. It is considered "essential for the evaluation of federal and provincial government programs designed to promote official bilingualism in the public service and the general population" (StatCan, 1986b:19). The questions also help measure the extent to which the population does not speak either official language, assess the adaptability of immigrants, evaluate language training provisions, estimate the need for third language translation, and review programs directed at immigrants (StatCan, 1986b).

\subsubsection{Language Used At Work}

The 'language used at work' is the latest addition, asked on the 2001 and 2006 questionnaires to those 15 years of age and older and in the work force. It is not asked as part of the language questions reinserted into the 2011 census because it is considered a labour force question and not exclusively a language question. 
However, it provided insight into the vitality of official languages among official and non-official minority language groups, the use of language on the job, the breadth of linguistic integration, and the integration of allophones or immigrants into the labour force (StatCan, 2002a). The question provides insight into how official linguistic minorities use their language beyond the home and in the broader community, which was a concern expressed by the B \& B Commission and the Districts Advisory Boards in their assessment of language use in a community, district or region. The current Departmental Standard is (2009):

refers to the language the person uses most often at work. A person can report more than one language as "used most often at work" if the languages are used equally often...

Other language(s) used regularly at work refers to the languages, if any, that the person uses in their job on a regular basis, other than the language or languages he or she uses most often at work.

Regarding the question of age, it is important to note that this affects the comparability of questions and of course population size. In 1901 and 1911, language questions pertained to those who were 5 years of age and older, and in 1921 and 1931, they applied to those 10 years of age and older (DBS, 1936b:247). The nature of the questions, the age of the population surveyed and whether or not the questions were asked to the total population or a $20 \%$ sample, affect trend analysis and these parameters need to be taken into consideration when doing historical analysis. 


\subsection{Summary}

This chapter applied the Hacking framework to the study of the Census of Canada. The role, function and history of censuses which evolved into a powerful, authoritative, trusted, standardized and bureaucratic form of government science-gouvernementalité was discussed in Section 5.2. The Canadian census was part of the avalanche of numbers and statistical ways of thinking about population - biopower - in the $19^{\text {th }}$ century and has since become a well-established infrastructure. In Section 5.3 the development of the Canadian census was discussed with an emphasis on legislation and regulation ${ }^{111}$ making it a legally mandated political institution deeply embedded it into the government bureaucracy and democratic system (see the timeline in Figure 32 page 333 and institutional information in Table 9 page 334).

The Canadian census is a powerful Canadian institution with a long lineage and a well-established infrastructure. It was initially an institution of French and British colonialists having intendants and officers inventory the people, their characteristics, the territory and its bounty. As the nation was forming, it became the object of representative government. The census became more scientific as the science of statistics and census taking was being disciplined, normalized and bureaucratized in Europe. British and French members of European societies were appointed to take the count in the colonies. Europeans exported their practices to the fledgling nation and once these were adopted and adapted,

${ }^{111}$ Table 10 on page \# list major legislative requirements, and Appendix $\mathrm{M}$ lists federal legislation referring to the census. 
Canadians co-shaped the practice of scientific census and survey taking, as well as the field of statistics, by being engaged and often being leaders in those fields and societies. The Canadian census also became an official object of the Dominion, and later the Government of Canada, at which point it was governed by its own legislation. The Census of Canada is now embedded within government and informs legislation; it is guided by and informs Charter responsibilities. The census formed part of official government bureaucracy; over the years it was as a component of the Board of Registration, a branch of the Department of Agriculture, a portfolio under the Department of Trade and Commerce, and finally a stand-alone federal agency as Statistics Canada as part of the Industry portfolio. Programs and services as well as government transfer payments continue to be determined by the count.

Questions for each census were organized into 27 groupings listing the subjects the government was interested in surveying and managing (Table 11 page 361). Only four sets of questions were asked in all censuses: name, sex, age and marital status $^{112}$. These are fundamental to demographers, epidemiologists, labour and educations statisticians to name a few. Generally questions are concerned with characteristics of the population, labour, economy, movement and material indicators of wealth. As was the case with the Atlas, two sets of census questions (e.g., citizenship and official languages Sections 5.3.4 \& 5.3.5), were examined in detail to assess if these made up Canadian spaces as per the Hacking framework.

\footnotetext{
112 Appendix list the names of the schedules and questionnaires for each census, Appendix A provides the sources for these questionnaires.
} 
The census not only determines government representation but it also affects the social and material reality of people across Canada. As was seen in the two examples, of citizenship and official languages, the census not only counted the people, the census with legislation and policy created Canadian people and shaped the size and composition of the population while also mapping where citizens were from, where bilingual people were concentrated and thereby producing spaces and new spatial practices. The parameters of the census questions changed as the laws changed, and those laws changed because of the count. Throughout the history of the Canadian census, people resisted the way they were labeled, excluded or undercounted (e.g., women and identity, head tax, minority language groups), and this in turn, influenced changes made to the census.

The analysis of citizenship and place of birth questions (Table 12 and Table 13 pages $365 \& 366$ ) showed changing conceptions of what a Canadian citizen is, how geopolitics changed ideas of 'appartenance' and the attempt to connect populations to their right national kinds of spaces and to deal with people who officially belonged nowhere (i.e. refugees) or elsewhere (i.e. landed immigrants, temporary residents). Early classifications were modeled on the spatial practice of populating and settling the country in order to build the transportation infrastructure, farm, to provide labour for the resource extraction industries and claim territory ${ }^{113}$. Overtime the model shifted to an educated work force and a

${ }_{113}^{13}$ See $1^{\text {st }}$ and $2^{\text {nd }}$ editions of the Atlas of Canada in appendices B \& C for settlement patterns and later editions for origin and citizenship maps. 
reduction in race, origin and ethnicity based criteria although quotas based on their count and language criteria remained. Although the analysis did not discuss kinds of Canadian spaces, it provided an understanding of spatial belonging, geopolitics and changing territorial boundaries (see Sections 4.4 .4 and the 4.5 Summary) reaffirming Benedict Anderson's concept of imagined communities. It was demonstrated that national and state affiliations were fluid which put into question the reliability of defining a political space by its people and kinds of spaces based on the people who happen to find themselves within socially constructed spatial arrangements of nation states irrespective of 'official' recognition. As a result the Canadian population was not always what it was thought to be even though accurately measured. Geopolitical forces and related politics and international institutions made up spaces and people, census questions attempted to place people and then make regulation and policy based on those not so reliable 'placings' forming a Canadian population that was not quite what public officials thought it was. The geopolitics and imagined notions of with what and where one was affiliated was part of the looping effect of making up national spaces.

Official language questions were examined as seen in Table 14 (page 386). In that case, the making up of bilingual spaces was a very political, bureaucratic, legal and intentional process. Census questions were chosen and language populations were mapped to make up bilingual districts across Canada ${ }^{114}$. The 
data and the mapping of the questions resulted in the spatial practice of delivering place based bilingual services. People's pre-conceived notions of where the French 'speaking' population was concentrated had to be re-imagined as zones, clusters, regions and districts of minority French and English populations dispersed across Canada and in places where they were not thought to be. These questions produced new ways to measure language, the field of demolinguistics which became a normalized institutional discipline.

The count made categories official and different kinds of people once counted, self-identified around the classification and could then become an aggregate community who could advocate for rights, place based programs and services. Spatially bounded communities and clusters of people once identified, provided Canadians with the means to see beyond the spatial stereotypes they once thought were true and to re-imagine the Canada they knew. Today's Canadians would find it difficult to imagine a non-bilingual Canada or a homogeneous population.

The census also provided for the exertion of power at a distance, as once politicians and census advocates decided upon the subjects that mattered, the count and its spatial arrangements determined how many mattered and where it mattered in 'real' terms, providing officials with an objective means to govern and distribute resources. The census makes up people and spaces, resulting in the looping effect of producing spaces which change. Furthermore, the census and its questions is a socially constructed gouvernementale instrument which shapes and is shaped by geographical imaginations. 


\section{Chapter Six: \\ Conclusion}

The central argument of this dissertation is that Canadian reality is conditioned by government data and their related infrastructures. Specifically, Canadian geographical imaginations are strongly influenced by the Atlas of Canada and the Canadian census. Geographical imaginations are important as they affect social and material reality (chapter 2). To determine the validity of this assertion, Ian Hacking's modified 'making up people' framework, discussed in Chapter 3, was adapted and used to structure a critical examination of the discourse of Atlas (chapter 4) and Census (chapter 5) to assess how these 'make up Canadian spaces'. The premise is that the government manages territory and people biopower, the Atlas and the Census help perform that function by 'making up kinds of spaces' providing spatial subjects to govern, and by doing so construct geographical imaginations. Furthermore, these geographical imaginations influence the Atlas and the census. 


\subsection{The Atlas of Canada: Making up Spaces and Geographical Imaginations}

The Atlas of Canada is a socio-technopolitical and authoritative gouvernemental object that describes in maps, the geographical power/knowledge of scientists, engineers, cartographers and public officials at different points in time. The geographical and cartographic imaginations of the Atlas are therefore technocratic, scientific, bureaucratic and biopolitical. The first two editions were nation building atlases, the $3^{\text {rd }}$ edition was the Atlas of science and progress, the $4^{\text {th }}$ edition focused on landscape and chorology, the $5^{\text {th }}$ edition was the Atlas of technological transition, austerity and bureaucratic reorganization, and the $6^{\text {th }}$ edition continued with technological transition, specifically with its Internet presence and its issue and user orientation. Each edition was conservative in content, reinforcing status quo ideals of national subjects, which were depicted in a 'neutral', objective' and positive light (e.g., one map out of close to 2,000 discusses the environment critically in the $6^{\text {th }}$ edition industrial discharge map). The overarching theme was that of economic development of natural resources (see Appendices B to H, Figure 15 and Table 4 on pages 148-149). The editions were not produced with the general public in mind, except for the $6^{\text {th }}$ edition; the first five editions were expensive artifacts.

Maps represented the scientific models, cartographic techniques and the map making infrastructures of their era and Canadian national atlases eventually normalized into a kind of cartographic discursive form, but not in a formulaic way. Each edition concretized its gouvernementale and biopolitical version of the nation and provided sets of stable and recognizable representations of 
Canada (e.g., the Canadian territory filled the page and a constant projection was used). Many themes such as infrastructure, climate, agriculture and industry, were also constant, and these were always tied to natural resources at a national scale. Other aspects of Canadian life, by their near absence in the Atlas, made them seem unimportant, such as health, environment, education, social welfare, culture and sport, which only appeared in the $6^{\text {th }}$ edition. Although there were many demographic maps in the Atlas, they mostly focused on such topics as distribution, marital status, sex, population density and characteristics of First Nations, and to a lesser degree, language and cultural diversity although official languages and bilingualism appear in the $4^{\text {th }}$ and $6^{\text {th }}$ editions, while origins, citizenship and/or immigration appear in each. The Atlas of Canada was not a prescriptive object yet the datasets compiled and modeled into its maps were tied to explicit government programs, which built infrastructures that survey and normalized subjects to be governed (e.g., meteorological data, geological data).

The Atlas of Canada contains hundreds of classification systems and the following subset of four was selected for closer examination: relief; forest biogeography; communication infrastructure and territorial evolution. Each of these subjects was governed by regulation or legislation, and was part of the bureaucracy; maps conformed to the standards, practices, methodologies and models of each subject's science and it was shown, that classifications systems dynamically evolved as knowledge, techniques, technologies and policies changed. In addition, these were inscriptions that revealed in detail the state of knowledge on that topic at a particular point in time. 
Once these subjects were classified, normalized and concretized into inscriptions, they were reused in other contexts, which dynamically changed the terrain. For example, the scientifically 'made up spaces' of the ecological framework informed planning decisions (e.g., impact assessment, protected areas). Relief informed the ecological framework and, as a base dataset, it informed the placement and type of components of the communication infrastructure (e.g., line of sight). Territorial evolution was tied to relief through the exploitation of natural resources, the development of infrastructure and the original colonial territorial imagination that later became a nation building imperative focused on natural resources. Hacking's framework helped unravel the process by which classifications and the classified dynamically change, as well as the dynamic aspects of relational geography.

Beyond the institutional boundaries of government, the classification systems and the data used to render Atlas maps were also the products of scientists, specialists and professionals who held very specific knowledge and expertise about their subjects. These experts were members of national and international associations and participated in fora where they set standards and developed methodologies to classify, capture and model their data uniformly (e.g., Canada Forest Inventory database). This expert knowledge was endorsed by Atlas creators, and Atlas creators self-referenced their own maps in subsequent editions. Atlas editors were also map makers and specialists: James White was a forest conservationist and an international boundary and relief expert; Joseph Epiphane Chalifour was a cartographer; Norman L. Nicholson was an expert on 
regionalism and boundaries; Gerald Fremlin was a specialist geographer with a fondness for relief and regional description; and the advisors for the $5^{\text {th }}$ and $6^{\text {th }}$ editions were seasoned public officials from many fields. The maps and each edition of the Atlas reflect the individual interests of the specialists involved in their creation. Their imprint included a combination of the period, values and beliefs of each of these specialists and those of the governing bodies. This interplay of values had an impact on the content and style of the publications, and, therefore, on the imaginations they sought to create. The Atlas provided a public face to national mapping, and although the story in each edition was told from the perspective of its creators, it reflected governmental imaginations.

Maps are the products of data and individual datum are aggregated (e.g., trees into forests), interpolated (e.g., altitude into isolines), correlated into regions (e.g., ecological regions), and counted and located on maps as points and lines (e.g., stations and wires), and in each case there are standardized ways of doing this. Things are also mapped in standardized ways, using common reference systems, projections, scales, techniques and files. This type of standardization allows for the mapping of trends in a consistent fashion, facilitates the visual recognition of relationships between maps, and normalizes the framework within which objects will be placed consistently in each edition and across time. Computerization greatly facilitated this practice and standardization and data reuse were the inspiration for the National Atlas Information System (NAIS). Standards, once part of the infrastructure, have a momentum of their own and establish a particular spatial narrative style. This not only normalizes subjects, 
but it normalizes how spaces are depicted, and it becomes hard to imagine them in any other way (e.g., wildlife is mapped for its fur, forests seem continuous and absent of clearcuts). This also occurs thematically, for example, the insistence on mapping Canada's territory in its entirety in the $3^{\text {rd }}, 5^{\text {th }}$ and $6^{\text {th }}$ editions instead of focusing on spatial particularities, patterns and trends.

This thematic approach often results in reinforcing Canadian stereotypes such as an empty north, a resource based economy, and non-existent urban and cultural life. Specifically, the physical components of resources and infrastructure are depicted while their industries are less so, nor are interconnected manufacturing zones, industrial trade, resource reliant communities or the natural resource labour force, albeit there are the some maps do so in the $6^{\text {th }}$ edition. Most Canadians live in urban centres, yet cities are not discussed beyond planimetric views in the $1^{\text {st }}$ and $2^{\text {nd }}$ editions and interesting growth maps in the $3^{\text {rd }}$. The $6^{\text {th }}$ edition, for example, allows for zooming but there is no zooming into cities. The Atlas reflects the priorities of the Department that created it, which has a scientific federal level and natural resources management mandate. Further, the territory in its entirety must be shown because it is a federal institution, and cities due to divisions of power are the responsibility of the provinces. The atlas reinforces these standardized images of things and themes and it becomes difficult to imagine Canada differently.

The shape and form of the landscape is interrelated and at times correlated with numerous other geographical features; it determines to some extent human settlement, agriculture, transportation and many other human factors. For 
example, the ecological and remote sensing classification system to characterize forests created new zones or regions of action and fundamentally changed how natural resources were managed and understood. Ecological zones are affected by relief among many other geographical phenomena and features, and they transcend political boundaries. Their adoption by the federal government and provincial and territorial governments, and by international institutions, is a testament to the power exerted by scientists and conservationists with respect to the protection of the environment, sustainable development, resource management and normalizing the idea that environmental factors are interrelated. Furthermore, the adoption of ecological frameworks was revolutionary as it included humans as part of the dynamic climatic, vegetation, hydrographic and geophysical system, and by doing so, these frameworks changed how actions are taken and decisions are made. Territorial maps link actions to their jurisdictions, demarcate constitutional responsibility and determine international relations. As Nicholson (1954) correctly pointed out, human made boundaries are shaped by and shape geography and these have real material effects. Ecological frameworks may cross these jurisdictional boundaries, but actions based on ecological considerations are taken by the jurisdiction. Overall, the Atlas may not have addressed environmental issues directly, but the ecological way of thinking about the environment became part of the Canadian geographical imagination. 
A classification system, once scientifically accepted, adopted, normalized, and mapped, changes how a class, a space and people are understood, which in turn, may change the class, the space and the people. This is the dynamic aspect of Hacking's framework and his looping effect. As discussed while examining the $1^{\text {st }}$ edition, climate and elevation mapping was considered critically important because both affected development. For example, enticing settlers was a key motive for mapping, and it was important to point out just how far north agriculture was feasible. Knowledge of altitude provided information to builders who might want to invest in hydro projects, which would yield more development and also entice more settlers. The more detailed the relief, the more specificity that could be provided to agricultural and ecological zoning. Geographically rezoning a place changes its characteristics and its character as it may encourage new practices, while creating new ecological regions re-conceptualizes the strengths, sensitivities and potential of large spaces. How spaces are perceived changes how they are managed. By mapping the communication infrastructure network, false perceptions of universal Canadian connectivity are challenged. Connecting the North, relief and the distances between the Atlantic and the Pacific coasts posed technological challenges; technologies and networks were therefore built to overcome some of these challenges, which in turn, increased the need and desire for more connectivity, including the ability to deliver national messages. The communication infrastructure technology shaped the nature and extent of broadcasting in Canada. It allowed the $\mathrm{CBC}$ to distribute common programming in French and in English, changed the regulatory framework and shaped how Canadians could communicate. The CRTC, new technologies and 
how they are imagined is continuously changing, even though, most do not consider its physicality and its spatialization. The $6^{\text {th }}$ edition does not include communication infrastructure maps, which limits the ability of the public to see its unequal distribution. This exclusion allows for the disavowed assumption that communication reduces distance between core and periphery to thrive, and not seeing may have made communications related federal cutbacks easier for decision-makers.

The shape and form of the territory was logoized (Anderson, 1991) in the Atlas; it was a picture recognized locally and internally, and it became a natural way to order Canadian space (Black, 1997). The $5^{\text {th }}$ and $6^{\text {th }}$ editions especially emphasized the full extent of Canada, often at the expense of adequately depicting a national subject that may not be distributed everywhere (e.g., communication infrastructure). The standardized use of the Lambert Conformal Conic Projection with two standard parallels of 49 and 77 degrees north for the whole of Canada since the 1950s, was not only a method to ensure internal consistency in depicting Canada in maps, but it was also a technique to brand the shape and form of Canada to Canadians and to the international community. The shape and the form of things in Canada were solidified, and it would be hard for Canadian youth to imagine a Canada shaped differently, even if Nunavut did just not too long ago.

The analysis in Chapter 4, demonstrated that spaces depicted in the Atlas dynamically changed because of material and social changes, and more, because of how subjects were classified and mapped. With time, classifications were 
normalized. Spaces do not resist change or reclaim identities in the way that Hacking's people do. The engine of resistance it was argued, is not the best fit when it comes to physical spaces, is driven by scientific discursive struggles, technological change and relational geography. It was these that changed the classifications, the making up of new spaces and influenced spatial practices which in turn change the classes as per the looping effect. However, collecting data and modeling them into maps changes the way people see spaces, and this informs the spatial decisions they make. It was shown, that spaces in Canada and Canadian themes, as represented in the Atlas, were dynamically made up.

The production of each edition was a major undertaking, requiring significant financial, human and technological resources and the Department gave their directors and chief geographers a strong mandate with budgets to produce it. The Atlas of Canada received special Cabinet Committee support and Approval, and as such, the federal government authorized the development of the Atlas, as a high profile program. The Atlas is an authoritative artifact which was officially transmitted, includedofficial seals and Prime Minister and minister signatures for some editions and the $. g c . c a$ address for the $6^{\text {th }}$ edition. The Atlas was also discussed in departmental annual and performance reports, more so for the first four editions, and was presented at conferences, and committees. There were other commercial atlases (see appendix $\mathrm{J}$ ) that constructed the imaginations of students and the general public, but the Atlas of Canada, alternatively, was targeted to a highly sophisticated audience. The Atlas showcased scientific work and informed public officials, with the $6^{\text {th }}$ edition being the exception. 
The Atlas belongs "to circuits of communication that operate in consistent patterns, however complex they may be. By unearthing those circuits, historians can show that [atlases] do not merely recount history, they make it" (Darnton, 2006:22). The history made by the Atlas of Canada reflects the discursive communities of those who created it and mirrors the discursive fields of the specialist maps it contains. The Atlas also embodies geographical practices, which rest on the territorial and socio-spatial inventories in each edition's collection of maps.

The Atlas of Canada is an institution and an infrastructure representing national mapping interests. It has become a trusted and authoritative source of information about Canada's people, resources, economy, history and territory, which are portrayed in maps and bound within the normalized cartographic form of a national atlas. The Atlas also reflects the sentiments and the times and the society it imagines and represents, although it is primarily gouvernementale.

\subsection{The Census of Canada: Making up Spaces and Geographical Imaginations}

The biopower of Census of Canada changes the shape and form of the Canadian population and territory. As an object, it is much more closely constrained than the Atlas, even though statistical associations influenced the types of questions to be asked and in later censuses consultations were held. Legislation framed the institutionalization, bureaucratization and the normalization of the Canadian census and its questions. Government experts with specialized knowledge developed the Canadian census, much like the creation of the Atlas, it configures 
social relations aligned with political objectives. However, unlike the Atlas, the census is almost exclusively Dominion Bureau of Statistics (DBS) or Statistics Canada (StatCan) directed even though many other departments rely on its outputs.

Census statistics and categories conveyed a 'scientifically accurate' and 'objective' image of the Canadian population and carried forward prescriptive content (e.g., bilingualism, immigration quotas). Furthermore, as Alain Desrosières observed in his work of comparing statistical bureaus, and as seen in Canadian legislation, the questions asked and nomenclatures used, were influenced by the forms of public action predominant at a given time in Canada, and framed somewhat by scientific institutions locally and internationally, it produced classifications and the means to evaluate them.

The census is embedded more deeply in the governing process and is a much more explicitly and closely linked apparatus of the state when compared to the Atlas, although as discussed, national mapping data were very closely tied to state programs, while the Atlas was not directly so, but contained subjects important to the government. The census defines democratic representation, determines provincial and territorial dispensation fairly and objectively, and provides the statistics used to evaluate the performance of legislated programs. The biopower of the Canadian census is more overt than that of the Atlas; it is an inscription device with a momentum of its own, and with actions circumscribed by the legal infrastructure of the state and embedded into its bureaucratic system. The census is an infrastructure with an autonomous life of its own; it is indirectly 
shaped by society, as once a counting system is in place its results systematically and deterministically shape the population. People are not the silent recipients of policy, but once a particular counting practice is in motion, it becomes hard to change. Biopower manifests itself in the counting of individuals who are then managed as population groups, or subjects, and the numbers guide decisionmaking by applying a kind of mechanical objectivity (Porter, 1995). As Bruno Latour (1987) discussed, inscription devices allow for decisions to be made at a distance. The census may be accurate and objective, but it is also political since political decisions determine its budget, when it will be taken and the nature of the questions to be asked.

Twenty-seven broad census classifications were observed (see Table 11, page 361) and an examination of citizenship and official languages questions showed how questions were politically charged. It was evident that classifications were not fixed, but once counted; certain groups of people became legitimate concerns. Citizens, landed immigrants and temporary residents, as well as unilingual, bilingual and minority languages, constructed kinds of people who were recognized and to whom rights and privileges were allocated. Many of these classes of people were the target audiences for a variety of programs and services. These classifications normalized and persisted even though be imperfect. In the case of language, mother tongue was the classification used from 1971 onward even though it does not capture language ability or language use. To say that results stemming from this question accurately represent minority language speakers is misleading. 
Legislation limited official and political citizenship in Canada, policies further created restrictions and quotas, and the census classified and counted who citizens were, where they were born and did so with its own definitions, which did not stray from legislation but captured the effects of policy and geopolitical territorial changes. These categories informed and shaped the nature and the location of citizenship and defined immigration programs and services. By determining who was and was not a member, these decisions on immigration shaped the nature of the Canadian population. Tabulated census results convey accuracy and certainty; however, the reality behind the rows and columns of data was quite messy and uncertain. This became evident after having examined regulations, exclusion lists, head taxes, quotas and ever-changing policies and territories. The 'facts' should come with a series of caveats and footnotes.

The census eventually defined the immigrant population, and did so by age, date of immigration, location of parents' birth, adoption of official languages, degree of assimilation through intermarriage to name a few, and the data collected with such questions enabled the evaluation of the number and status of residents, the type and period of immigration, and the rate of assimilation. The census did not define the rights and responsibilities of being a citizen, and being counted did not mean that persons necessarily had democratic citizenship rights. For example, women were not allowed to vote federally until 1919 and Aboriginal people could not vote until the 1960s. Social citizenship or equality was unevenly distributed at different periods of time. Classifications frequently changed, as did geopolitical boundaries, which affected the nature of the population classified. 
Despite the apparent objectivity of census taking, inaccuracies occur even where data are methodologically and scientifically collected, tabulated and reported. Such is the case with 'place of birth' classifications, where population comparisons between 1871 and 2011 are erroneous, especially when taking into account changes to the geographical parameters of Canadian population over time, as demonstrated in the territorial evolution analysis in Chapter $4^{115}$. However, a comparative analysis could be made if boundary adjustments are taken into consideration. Also, census categories are accurate according to a model, yet in the real world; people's identities, allegiances and membership do not neatly align themselves according to the population classifications constructed in a census. But that does not preclude analysts from using these data and making decisions and assumptions about who was and was not a Canadian on the day of the count according to the definition, laws and policies of that day. The definitions did stabilize from 1961 to 2006, and it can be said that that marks the time when the number of Canadians and who they are, in terms of citizens and immigrants, becomes more reliable at least as far as the classification is concerned even though "the character of Canada's foreign-born population at any point in time is a reflection of immigration policy and its implementation during prior decades" (DBS, 1970a).

115 A DBS 1963 report of the population entitled History 1901-1961 used the numbers as they were but footnoted when boundaries changed. Statistical historians however do pay attention to these nuances and adjust their data accordingly as seen in the Historical Statistics of Canada (1965). Many users are however unaware of these issues. 
World geopolitics changed the names of the countries people held allegiances to, and in the territorial and historical evolution of Canada, it made certain residents British subjects, followed by Canadians of the British Empire, Canadians of the Dominion of Canada and members of the Commonwealth, and eventually Canadians. Nationality and resident status was further refined to include Canadians by birth, naturalized Canadian, landed immigrant, permanent resident and refugee. Upon examination of citizenship questions it was revealed in examining that it was hard to figure out which territory one belonged to as labels kept changing along with boundaries. Perhaps for those years, enumerators could have conducted the count with maps, and could have asked people to point where they were from, and extrapolate 'appartenance' from there.

The process of Canadianization was measured with data collected from citizenship and other census questions, which together created indicators of assimilation such as intermarriage, official language acquisition and period of time to be naturalized. These were considered to demonstrate that people were normalizing into homogenous notions of Canadian culture, which is predominantly white and English speaking. Results indicated which groups were not Canadianizing, which resulted in these groups becoming less desirable recruitment targets. Bureau reports, however, failed to explain why these groups kept to themselves rather than integrate. Immigration policy, as was shown in Chapter 5 , constructed the undesirability of certain groups and these measures simply affirmed that construct. This was especially so for women, as they were forced for a period of time to forego their Canadian identity if they married a 
non-Canadian, while foreign women gained Canadian citizenship if they married a Canadian man. An 'unnatural' increase in the number of female Canadians was noted once the policy was abolished. These measures missed other indicators of Canadianization such as voting, school enrollment of children, economic contributions, community engagement and the paying of taxes, which were all Canadian things these 'non-assimilated' groups did. When multiculturalism was not yet part of the Canadian geographical imagination, census reports, like the content of national atlases, were conservative and non-controversial in nature, and they emulated the rules determined by other institutions, and in this case, experts created indicators to affirm notions of otherness and maintain predominating geographical imaginations.

The language classifications did not change as radically as did the qualifications pertaining to the classification of citizenship, but how those data were used did. Data derived from questions on who could spoke English or French prior to the mid-1950s were used to assess assimilation, Canadianization and intermarriage, which were closely related to citizenship and immigration. By the end of the 1950s, language had become a political issue in Canada and ideas of bilingualism and biculturalism became important as a unification strategy; measuring who spoke French, English or both and where these people were, became important, especially when notions of protecting official language minority rights were legislated. 
After the 1960s, it became a legally prescribed political project to create bilingual spaces and people. Language became an issue related to minority rights, language shift, pull of English, language loss and retention related particularly to French, language mobility, language continuity, and language indices of segregation and of dissimilarity. Determining bilingualism was predominantly a reaction to the threat of Québec separation. The 1971 census represented a transition with respect to language classifications; more questions were added, and 'mother tongue' was the agreed upon method to distinguish and count French, English and bilingual kinds of people, and to designate spaces in Canada where services and programs were to be made available to the minority language group in their own language. The kinds of people mother tongue questions created, however, were not necessarily people who speak or use the language they learned in childhood or at home and still understand, but they were people who inherited a language. It was more a measure of culture and less a measure of preference and ability. The mother tongue questions helped create bilingual places, zones and belts as well as language islands or clusters across Canada, and the count revealed that French as an official language was not restricted solely to the province of Québec and the proportion was much higher than what people imagined it to be. Canadians had to re-imagine Canada with pockets of French people everywhere and the count adjusted people's underestimation of Canadian 'Frenchness'. 
The experts who classified citizens also advised politicians who drafted citizenship and immigration legislation and government officials who created policies in accordance to the legislation. Government officials were also responsible for checking papers at ports of entry to enforce the rules of who could and could not enter, and judges were awarded the authority to determine who did and did not qualify as citizens prior to the examination process. The Bureau and later StatCan officials counted people according to the qualifications as stated in legislation. Prior to citizenship being legislated, people were counted based on their country of birth and how they responded to questions of origin. The counting, quantifying and correlating of country of birth data with citizenship, language, place of origin and conjugal status, and how those data were used, affected legislation, policy and public perceptions, and these in turn, shaped who qualified to enter Canada and become a citizen. As was already demonstrated, the numbers may have been accurate, however, experts at the Bureau who were most knowledgeable of the numbers used them to support a particular notion of 'Canadianness'. In time, temporary residents and refugees were also counted and made visible and this included people who reside in Canada but have chosen to not become Canadian citizens, the landed immigrant. The classifications for refugee claimants, along with the questions to be asked on the citizenship test and the process to attain Canadian citizenship, were also heavily bureaucratized processes. These processes continue to be revisited as the numbers come in and as they are renegotiated; new policies change the classification, which in turn, changes the number of people counted. 
Language classifications were constructed in a different way. Language experts were statisticians at the Bureau, and later when language was politicized, they were replaced by demolinguists and academics; members of the B \& B Commission who were academics, public servants and provincial politicians, and the two Bilingual Districts Advisory Boards, became the new experts, a new authoritative community (Curtis, 2002). These institutions were specifically created to classify, identify, count, quantify and correlate data to locate French, English and bilingual kinds of people and language communities. Once those determinations were made, how and who to count and how and where to make official language spaces, was legislated. The Office of the Language Commissioner was a new institution created to report on the status of official languages and it relied explicitly on census classifications and their data to fulfill its role and to ensure that the Canadian Charter of Rights and Freedoms and the Official Languages Act were adhered to.

Language institutions, knowledge and experts had a clear impact on statistical reasoning about official languages in Canada, which led to the bilingual federal public service, French immersion programs and support for French language islands across Canada by ways of services and programs. This created a kind of spatial consciousness or geographical imagination that allowed French and bilingual people to recognize the role of space in their own linguistic biography; the idea of districts was to create a space within which they could continue to perform being that kind of person (Harvey, 2009). It is now normal to be bilingual in western Canada or French in Atlantic Canada to name a few 
examples. The numbers and where those numbers were clustered, scientifically informed actions that politicians could take; the numbers irrefutably pointed them toward those decisions because statistics countered assumptions and backed what were perceived as unpopular decisions.

Analysts still grapple with the inadequacy of language questions, and qualify the mother tongue questions with data collected from the other language questions including questions on citizenship and ethnicity in order to understand linguistic heritage, although, decision makers use the mother tongue question as the final arbiter on the determination of spending envelopes and to measure targets. The re-insertion of the language questions into the 2011 census demonstrates not just how legally and politically entrenched the counting of linguistic groups has become, but also how resilient these made up categories are, and how people have self-identified with the class. The Canadian census does not count things as they are; it makes up the things to be counted (Curtis, 2002).

The census as an institution has a long history, as discussed in Chapter 5. The Canadian census was influenced by and influenced international societies, associations and transnational organizations like the UN Statistical Division, which have created international principles and standardized statistical methodologies and questions. Census taking is a normalized practice internationally: it is a standard bureaucratic government function; it structures information, the boundaries of inquiry and presuppositions about social reality; and it classifies, measures and counts people accordingly. 
The Census of Canada is gouvernementalité and biopower in action and it makes up people and spaces, and by doing so, it constructs Canadian geographical imaginations. And like the Atlas of Canada, it does so dynamically, as the numbers go on to continuously reconfigure the size and shape of the classes of people counted, changing the made up spaces and therefore the nature of the subjects mapped.

\subsection{Socio-Technopolitics, Gouvernementalité and Biopower}

The Atlas of Canada and the Census of Canada are socio-technopolitical objects of the state since the government has strategically built and uses these data infrastructures to constitute, embody or enact politics to serve its expert authority (Hecht, 2001). In addition, atlas and census are part of the technopolitical regime of the state, as these are grounded in institutions that connect engineers, scientists and technological practices with technological artifacts, political programs, and as seen in Chapter 2, ideologies, which act together to develop technologies to pursue technopolitics. Infrastructures include a chain of practices, processes and technologies by which geographical information is gathered. Infrastructures are also involved in normalizing the collection of geographical facts and are engaged in the modeling and ordering of these facts to construct imagined geographies.

The practices of national map making and census taking enlist infrastructures or inscription devices, which are state apparatuses that act as the eyes of politics or a form of geosurveillance. Enumerators at the door and air photos taken by pilots in military planes in the north or satellites capturing vegetation imagery 
are examples of this kind of geosurveillance. The Atlas and census are scientific and technological systems "in a linked network of artifacts, knowledges, and institutions operating in a coordinated fashion toward a specified material goal" (Hecht, 2001:257). The goals are to sense, measure, map and count Canadian spaces and the population, in order to manage and govern them. These technologies are required as the "state's power to act is an immediate consequence of the limitations of its power to know" (Gordon, 1991:16) and map making and census taking are also forms of recognizance to inform rational decision. They are also positivist processes with progressive ideals, to democratize science and objectivize decision-making, even if technocratically undertaken (Pickles, 2004).

Although not discussed in great detail but alluded to in the case of the Atlas, technology was an ongoing pre-occupation for the Bureau and later StatCan, as the institution was an early adopter of tabulating and calculating technology to help it manage its millions of questionnaires. Prior to that, it enlisted and organized human computers to tabulate results, and like Energy, Mines and Resources (EMR) and Natural Resources Canada (NRCan), it was an early implementer of computerization. The design of forms and the codification of data collection as found in instruction manuals, dictionaries and methodological manuals associated with the census also formed part of the infrastructure of the count. The production of the $3^{\text {rd }}$ edition of the Atlas, in particular, boasted of the use of post-war technology, the ability of the department to use the tools of progress and enlist its men of science to map the development of the nation was 
evidenced in this edition's maps. Many of the $5^{\text {th }}$ edition maps explicitly referenced the technologies used to create them, while the $6^{\text {th }}$ was one of the first national atlases to be disseminated on the Internet. The Atlas in many respects, "also documents the history of more precise instrumentation and measurement; [and the] increasingly complex classifications of its knowledge" (Harvey, 1992:234). As discussed in Chapter 2, NAIS and the network of survey engineers who produced relief maps in the $1^{\text {st }}$ and $2^{\text {nd }}$ editions were part of the technopolitical regime of Canadian mapping.

Geospatial data and infrastructures not only script, narrate and render the story of Canada's people, places and their relations in space and time, they also provide the stage and cues for those stories to be performed and enacted. Canada's geographical imaginations, as constructed by the Atlas of Canada and the Canadian census with their data and infrastructures, are therefore also state formation activities. Mapping space and counting people are part of the administration of the territory and population, the geo-body which are the nexus between government, knowledge and power. These are biopolitical acts; the infrastructures of map making and census taking are biopower in action as they are the linked tools, techniques and technologies used to capture matters of national interest numerically. These are the technologies, systems and instruments of the state which bring life and its "mechanisms into the realm of explicit calculation and make knowledge-power an agent of the transformation of life" while "distribut[ing] the living in the domain of value and utility" (Foucault in Rabinow, 1984:265, 266). 
Biopower is enlisted in the creation and normalization of subjects, whether they are same sex couples, linguistic communities or ecological regions. Once these kinds of people and spaces are made socio-technopolitical, legal systems are built to ensure they persist and continue to be actionable objects (Curtis, 2002). The Atlas and the census, as discussed in Chapters 4 and 5, are concerned with the things the federal government is concerned with, and they are also its concern; each infrastructure is the ensemble of techniques it uses to govern and these are part of the art of government, or gouvernementalité (Foucault in Burchell, Gordon \& Miller 1991). Individuals are no longer governed but biopolitical subjects are, and once created, they reflect society and space, and in turn, are instrumental in producing them. Canadian geographical imaginations are gouvernementalité and biopolitical.

\subsection{Hacking's Framework and Geography}

Hacking's interests rest with how classifications interact with people, how they model them and also transform them, and by doing so, change them, and then how they in turn, dynamically change the classifications. Hacking's Looping Effect and Engines of Innovation Framework of making up people as modified to making up spaces, has been very useful at structuring the analysis of the discourse of the Atlas of Canada and Census of Canada, enabling an evaluation of how these influence geographical imaginations. Although he applies the framework to study the genealogy of classifications and how these make up people, it was demonstrated here that it can also be applied to the study of making up spaces, which are considered to the geographical imaginations. 
Furthermore, applying his framework to examine the history of classifications necessitates also investigating the social and technological relations of institutionalized expert knowledge that enlists the bureaucracy to count, quantify, correlate and normalize things into scientific classes, which then become subjects to govern and manage. As discussed in chapters 4 and 5 , the application of the framework helped reveal not only the discourse of a classification, but also how classifications dynamically change as a result of discursive struggles; once kinds of people and places are made into subjects, which are concretized into immutable but mobile inscriptions such as an atlas or a census, world views, technologies, science, techniques, instruments, institutions, laws and policies related to the subjects also change, in turn changing the parameters of that class. His dynamic looping effect also reinvigorates the argument of whether or not socially constructed facts are scientifically true. Bruno Latour and Michel Calon have been actively engaged for decades in separating science from the facts that science establishes, while the work of Thomas P. Hughes, Andrew Feenberg and others, as discussed in Chapter 2, have inserted 'social' into the construction of technologies, not just in how they perform, but in how they were built. For Latour, the revelation that facts are socially constructed does not invalidate them, but simply makes them what they are by attaching them to the process of what creates facts in the first place. 
As previously discussed, this process simply demonstrates the socialness of facts and un-black boxes the taken for granted assumptions of the objects that are measured. Hacking's framework also helps pinpoint what David Harvey (2009:12)calls acts of categorization, which he considered to be quite fundamental, because these transform the spatial arrangements of things Classifications, produced spaces that were acted upon in real terms and affected the day-to-day lives of kinds of peoples and how people acted on kinds of things in those spaces (e.g., bilingual zones, communication infrastructure maps, relief).

Determinism has been discredited because of its racist past that gave credence to eugenics. While geographical and environmental determinism are controversial concepts, which have been replaced with investigations of human interaction with the environment, local, partial or soft determinism is resurfacing. Jared Diamond's 1997 bestseller, Guns, Germs and Steel, is an example of the revisiting of this concept. Diamond examines how proximity to natural resources that can be exploited is positively or negatively associated with development. He demonstrates how the characterization of underdevelopment associated with a lack of industrial development is overly simplistic, and refutes the idea that the West is greater because of intellectual, moral or inherent genetic superiority.

Environment and geography do play a role in determining some things, but not the things early determinists claimed it did. Other social research points to the likelihood that someone born into poverty will remain poor, or that keeping an urban neighbourhood free of graffiti, broken windows and strewn waste will reduce crime. Neither assertion is true in all cases, nor are these assertions 
lacking in controversy and prone to debate; they are also not predictive in an absolute sense. Hacking's framework does, however, provide for a hermeneutic analysis of dynamically changing kinds of people, kinds of spaces and classification systems.

Looking at facts, categories and maps in this way, especially at how they perform in the world, reveals their determining effects. It can also be argued that these effects are well known, and this is precisely why statisticians, scientists, geographers and cartographers go through such pains to demonstrate the strengths of their models and the objectivity of results. Evidence leads to action, even if the concept of determinism causes discomfort to social scientists.

Evidence-based decision-making is premised on facts, and that is why a census or an atlas exists in the first place. Censuses, atlases and statistical and geographic surveys are part of a language of shaping reality, and as was examined, the "discursive production of categories give meaning to and shape people's lives" (Patriarca, 1996:11). Social determinants of health and measuring health inequality are classic examples of assessing who is more likely to have poor health outcomes, based on a number of demographic and geographic characteristics. Programs and services are designed, located and implemented accordingly, to prevent poor health outcomes and to save on health care costs. Social change is about determining possible outcomes and promoting one possibility over another. Classifications are constructed, but not arbitrarily so. The engine of resistance, is scientific discursive struggles or technological. 
While the geographical imaginations that have shaped and have been shaped by the Atlas of Canada and the Census of Canada thus far are gouvernementale and biopolitical, emerging open data initiatives, citizen science, indigenous knowledge, user-generated content and volunteered geographic information (VGI) are 'non' governmental approaches to mapping involved in affirming, challenging or creating new Canadian geographical imaginations and producing new 'kinds of spaces'.

\subsection{Contributions to Geography}

This multidisciplinary study makes a contribution to the disciplines and fields of cultural and human geography, the study of large technological systems, information studies, public policy and geomatics. This research adds to the literature of geographical imaginations by providing an empirical study of two 'politically neutral' and 'objective' state formation activities - national atlas and census. In addition, the framework used to guide and structure the analysis is typically used in the human sciences. It was modified and applied here to not only study the production of human subjects, but to also examine the social construction and production of spaces and the spatial practices resulting from new forms of geographical imaginations. This is an innovative approach to the study of geographical imaginations, and the use of this framework has much potential for geographers as it can readily be applied to study the genealogies of geographic categories often thought of as being 'natural' because they are derived from 'objective' scientific practices, and the consequences or the dynamic looping effect that classification has on making up spaces. 
This thesis adds to the study of technological systems and information studies because it draws out the socio-technopolitical aspects of geospatial data infrastructures, which have not yet been critically examined in those fields. For the field of geomatics, this study provides a way to critically think about the space producing and deterministic aspects of the infrastructures that produce the Atlas of Canada and the Census of Canada; it recommends that map builders begin to consider the geographically imagined socio-technopolitics they are embedding within these technologies, and to critically reflect upon the categories and themes being mapped.

\subsection{Conclusion}

Canadian reality is conditioned by government generated data and related infrastructures. The Atlas of Canada case study applied the modified Hacking framework and determined that spaces were indeed made up even if 'real' things were modeled, classified and mapped. Relief classifications were influenced by technological evolution. Forest classification changed as a result of new scientific models to envision clusters of trees as part of a dynamic ecological system. The communication infrastructure network patterns persisted even though technologies changed which was attuned to changes in socio-technopolitical regimes, population density and the will to connect the territory. The representation of territorial evolution was always related to officially recognized and geopolitical international and national administrative authorities. The shape and extent of the Canadian territory becomes branded and repeated in the Atlas making it hard for many people to imagine Canada in any other way. It was part 
of the discursive struggles of claiming space within geopolitical regimes, property acquisition, colonialism, nationalism, development and regionalism, binding political and administrative actions spatially. These subjects and the kinds of spaces that were made up are part of the process of modeling, classification and mapping. Made up spaces produce new kinds of spatial relations. Maps of these spatial relations were carefully assembled with many others into the Atlas providing readers and its makers with a cohesive way to imagine all of these things as part of a whole called Canada.

The Census of Canada study demonstrated the space producing qualities of census questions. The census is a more deterministic form of biopower because of its legislative status and the embeddedness of results within the bureaucracy while questions demarcate government preoccupations over time. The closer examination of citizenship revealed that authoritative notions of 'appartenance' do not quite line up with where people think they belong while geopolitical changes affected where public officials placed people resulting in an inaccurate understanding of the composition of the Canadian population and ill-informed policies and quotas. Official language questions, it was shown, are explicitly tied to the making up of bilingual spaces and of bilingual Canadians. Their mapping challenged assumptions about where certain kinds of Canadians were distributed, and by doing so created new geographical imaginations. These imaginations led to the support of place based spatial practices which firmed up new kinds of spaces around which French speaking and English speaking kinds of people could identify as spaces where they officially belonged. 
The Atlas and the Census are infrastructures, they influence and are influenced by geographical imaginations. Classifications were the starting point of this analysis, however, an examination of these led to examining their discursive formation and the infrastructures that underpin them. Infrastructures envisioned as large socio-political-technological systems were shown to be actors in the construction of categories. The analysis of the Atlas and Canadian census in this way, revealed how some new set of institutional practices emerge

These data and maps as representations or inscriptions are part of the growing archive of Canadian images, narratives and myths, which in turn, are part of the long genealogies of meanings and practices whereby Canadian culture reworks identity through memory, learning and imitation. These have been layered in our collective memory to shape what people have come to know and imagine the territory, space and people of Canada to be. They are not the only ones, but they are ones that do affect the day-to-day life of people and where they live. Also, these representations are steeped in scientific, cartographic, statistical and gouvernementale discourse, which are social constructions or staged productions mirroring 'natural' realities. They are human made and what we know about Canada is what we have made it to be. These representations are shaped by the world views of their authors and these go on to influence other geographical imaginations which have material effects and are part of and influence spatial practices. Furthermore, data as representations of space and the spatial practices of infrastructure guide decisions which manifest in real programs and projects. The Atlas and the Canadian census are representations of Canada and not 
Canada; they are part of a system of representations of carefully arranged facts within a specific cultural perspective that reflect the dominant value system of their society and through daily actions, support the dominance of this value system, which produce what we have come to know Canada to be.

Maps and data became what their authors (i.e., the government) desired Canada to be (e.g., territorial evolution, exploration and survey maps) and these performed the function of an epistemic apparatus of collecting, transmitting and processing spatial data in the service of the state. Concurrently, that same geography, as represented in the Atlas and the census, provides Canadians with a set of imagined spaces within which they can place themselves even if the spaces are not quite right (e.g., Indian reserves). To paraphrase the quotes at the beginning of Chapter 2, the Atlas of Canada is a mountain of facts collected by scientists and experts in the field and the lab, and the story which unfolds in its pages is the sum of Canadian expert knowledge that has accumulated since the first explorers, resulting in the deep geographical imaginations that have built up over centuries. The census as the periodical inventory of the people and their characteristics produces the Canadian population and creates a standard by which other facts relating to the country are measured, baselined and normalized in order to map the wellbeing of the state, be it physical, moral or economic. Through its data, the census captures the evolution of Canadian life and in turn produces that Canadian life. 


\section{References}

Ackerman, James R., 1995, The Structuring of Political Territory in Early Printed Atlases, Imago Mundi, Vol. 47, pp. 138-154.

Adams, Frank D., 1915, The National Domain in Canada and its Conservation Proper: Presidential Address before the Royal Society of Canada, 1914, Ottawa: Lowe-Martin Co., Limited.

Alexander, Gerard L., 1977, Guide to Atlas Supplement: World, Regional, National, Thematic, An International Listing of Atlases Published 1971 through 1975 with Comprehensive Indexes, Metuchen N. J.: The Scarecrow Press, Inc.

Allen, John, 2004, The Whereabouts of Power: Politics, Government and Space, Geographiska Annaler, 86 B, pp. 19-32.

Allen, Michael Thad and Gabrielle Hecht, 2001, Authority, Political Machines, and Technology's History. Introduction in Technologies of Power: Essays in Honour of Thomas Parke Hughes and Agatha Chipley Hughes. eds. by Hecht, Gabrielle and Michael Thad Allen. MIT Press, pp. 1-24.

Allen, Michael Thad and Gabrielle Hecht, eds. 2001, Technologies of Power: Essays in Honor of Thomas Parke Hughes and Agatha Chipley Hughes, MIT Press.

Alonso, William and Paul Starr, 1987, The Politics of Numbers, New York: Russell Sage Foundation.

American Statistical Association (ASA), 1872, Organization and Proceedings of the American Statistical Association 1839-1872, accessed January 15, 2011 from the Iowa State Digital Collection, http://cdm16001.contentdm.oclc.org/cdm/compoundobject/collection/p1503 1 coll $20 / \mathrm{id} / 1167 / \mathrm{rec} / 3$.

American Statistical Association (ASA), 1872, Record of the Board of Directors of the American Statistical Association 1839-1872, accessed January 15, 2011 from the Iowa State Digital Collection, http://cdm16001.contentdm.oclc.org/cdm/compoundobject/collection/p1503 1coll $20 / \mathrm{id} / 604 / \mathrm{rec} / 4$.

American Statistical Association (ASA), 1914, 75 th Anniversary Celebration of the Association in 1914 in Boston, in the 1914 ASA New Volume 14, pp. 1-5 Series 105, accessed March 21, 2012, http://asapresidentialpapers.info/documents/75th_Anniversary_1913.pdf as part of the ASA presidential Papers Collection http://asapresidentialpapers.info/4 subia.html.

American Statistical Association (ASA), 1940, Fellows and Regular Members Reviewed, Journal of the American Statistical Association, Vol. 35, No. 210, Part 2: Centenary Membership Directory, June, pp. 7-83 accessed January 17 from http://www.jstor.org/stable/2278762 . 
American Statistical Association (ASA), 2010, Presidential Papers, accessed January 15, 2011 from http://www.asapresidentialpapers.info/4 sub1a.html.

Anderson, Benedict, 1991, Imagined Communities, Revised Edition, New York: Verso.

Anson, R. W., 1973, Review of the $4^{\text {th }}$ Edition of the Atlas of Canada, The Geographical Journal, Vol. 139, No. 2, pp. 378-379.

ASCE, 2002, Me, Myself and Infrastructure: Private Lives and Public Works in America a commemorative exhibit celebrating 150 years of the American Society of Civil Engineers, Chicago, Illinois.

Author?, 1875?, New Railway and Postal Map of the Dominion of Canada, sheet no. 8. Toronto?: Miles \& Co.?Barnes, Trevor J. And James S. Duncan, eds. 1992, Writing Worlds: Discourse, Text and Metaphor in the Representation of Landscape, London: Routledge.

Babe, Robert E., 1990, Telecommunications in Canada: Technology, Industry and Government, Toronto: University of Toronto Press.

Barney, Darin, 2004, The Network Society, Cambridge: Polity Press.

Barney, Darin, 2007, One Nation Under Google: Citizens in the Technological Republic, The 2007 Hart House Lecture, Toronto: University of Toronto.

Bellhouse, David R. and Christian Genest, 1999, A History of the Statistical Society of Canada: The Formative Years, Statistical Science, Vol. 14, No. 1, 80125 accessed January 15 from http://www.ssc.ca/webfm_send/73.

Bennett, David, 2011, email communication, September 11, 2011.

Bijker, Wiebe E., Thomas P. Hughes and Trevor F. Pinch eds. 1987, Social Construction of Technological Systems: New Directions in the Sociology and History of Technology, MIT Press: Cambridge.

Bilingual Districts Advisory Board, 1971, Recommendations of the Bilingual Districts Advisory Board March 1971, Ottawa: Information Ottawa.

Bilingual Districts Advisory Board, 1975, Report of the Bilingual Districts Advisory Board, Ottawa: Information Ottawa.

Bilingualism and Biculturalism, Royal Commission on, 1965, A Preliminary Report, Ottawa: the Queen's Printer.

Bilingualism and Biculturalism, Royal Commission on, 1967, Volume I, Ottawa: The Queen's Printer.

"biopower" A Dictionary of Critical Theory, by Ian Buchanan. Oxford University Press 2010, Oxford Reference Online, Oxford University Press. Carleton University, accessed 29 May 2012 from http://www.oxfordreference.com/views/ENTRY.html?subview=Main\&entry= t306.e87. 
Board of Registration and Statistics, 1853, First Report of the Secretary of the Board of Registration and Statistics for 1851-52, Volume I, Quebec: John Lovell, Mountains Street.

Board of Registration and Statistics, 1857?, Abstract Census and Return of the Population, \&c. Of Newfoundland 1857, City?:E.D. Shea Printer.

Board of Registration and Statistics, 1861, Abstract of the Census of the Population and other Statistical Returns of Prince Edward Island, city?: John Ings, Queens Printer.

Board of Registration and Statistics, 1864, 1860-61 Census of Canada: Agricultural Produce, Mills, Manufactories, Houses, Schools, Public Buildings, Place of Worship, Quebec: S. B. Foote, Steam Press Printing Establishment.

Bodin, Jean, 1576, Les Six livres de la République, Abridged and translated by M. J. Tooley, Published 1955, Oxford: Basil Blackwell.

Bowker, Geoffrey C. and Susan Leigh Star, 1999, Sorting Things Out Classification and its Consequences, accessed March 21, 2002 from http://epl.scu.edu:16080/ gbowker/classification/.

British Colonial Office, 1839, Upper and Lower Canada a bill for re-uniting the provinces of Upper Canada and Lower Canada, and for the government of the united province, London, accessed January 182011 from the Early Canadian Online Resources http://www.canadiana.org/cgi$\mathrm{bin} / \mathrm{ECO} / \mathrm{mtq}$ ? doc $=901401$.

Brouillette, Benoît, 1945, Atlas of Canada Project: A Preliminary Survey, Ottawa: The Canadian Social Science Research Council, November. Funded by the Carnegie Corporation of New York.

Buckley, Aileen, 2003, Atlas Mapping in th2 21 $1^{\text {st }}$ Century, Cartography and Geographic Information Science, Vol. 30, No.2, pp. 149-158,

Bunge, William W. And R. Bordessa, 1975, The Canadian Alternative: Survival, Expedition and Urban Change, Geographical Monograph, Department of Geography, York University, Toronto.

Bunge, William, 1971, Fitzgerald; Geography of the Revolution, Cambridge, Mass., Schenkman.

Bunge, William, 1988, Nuclear War Atlas, Oxford, UK: Blackwell.

Burchell, Graham; Colin Gordon and Peter Miller, eds., 1991, The Foucault Effect: Studies in Governmentality with Two Lectures by and an Interview with Michel Foucault, Chicago: University of Chicago Press.

Bureau of Agriculture and Statistics, Census Dept. Board of Registration and Statistics, 1863 , 1860 Personal Census. Quebec: S. B. Foote, Steam Press Printing Establishment.

Burnet, Robert, 1996, The Canadian Railway Telegraph History, Etobiko: Telegraphy Key \& Sounder 
Callon, Michel, 1987 , Society in the Making: The Study of Technology as a Tool for Sociological Analysis in The Social Construction of Technological Systems : New Directions in the Sociology and History of Technology, eds. by Wiebe E. Bijker, Thomas P. Hughes, and Trevor J. Pinch. Cambridge, Massachusetts: MIT Press, pp. 83-106.

Canada Gazette, 2011, Questions for the 2011 Census, accessed November 7, 2011 from http://www.gazette.gc.ca/rp-pr/p1/2010/2010-08-21/html/orderdecret-eng.html.

Canadian Century Research Infrastructure (CCRI), 2011, Scanned Copies of Census Schedules and Questionnaires for 1871, 1881, 1891, 1901, 1911, 1921, 1931, 1941, 1951, accessed November 7, 2011 from http://www.canada.uottawa.ca/ccri/CCRI/1871.html, http://www.canada.uottawa.ca/ccri/CCRI/1881.html, http://www.canada.uottawa.ca/ccri/CCRI/1891.html, http://www.canada.uottawa.ca/ccri/CCRI/1901.html, http://www.canada.uottawa.ca/ccri/CCRI/1911.html, http://www.canada.uottawa.ca/ccri/CCRI/1921.html, http://www.canada.uottawa.ca/ccri/CCRI/1931.html, http://www.canada.uottawa.ca/ccri/CCRI/1941.html, http://www.canada.uottawa.ca/ccri/CCRI/1951.html.

Canadian Forest Service (CFS), 2011, Forest Types and Inventory, Natural Resources Canada, Updated 14 Dec. 2011 accessed Dec. 14, 2011 from http://cfs.nrcan.gc.ca/pages/125.

Canadian Radio-television and Telecommunications Commission, 2008, CRTC Origins, Accessed Dec. 16 from http://www.crtc.gc.ca/eng/backgrnd/brochures/b19903.htm.

Carlson, W. Bernard, 2001, The Telephone as Political Instrument: Gardiner Hubbard and the Formation of the Middle Class in America, 1875-188o, Chapter 2 in Technologies of Power: Essays in Honor of Thomas Parke Hughes and Agatha Chipley Hughes, eds. by Allen, Michael Thad and Gabrielle Hecht, pp. 25-57.

Cartwright, D. G., 1976, Language Zones in Canada: A Reference Supplement to the Report of the Second Bilingual District Advisory Board, Ottawa: Information Canada.

Castner, Henry, 1976, Concepts before Content? A Question in Atlas Design with Special Reference to the National Atlas of Canada, The Canadian Geographer, Volume 20, Issue 2, pp. 124-234.

Champ, Paul, and Anne Levesque, 2011, Applicant's Memorandum of Fact and Law (Vol. V of V) Memorandum of Fact and Law, Federal Court File Number Court File Number: T-1706-10, Ottawa.

Chapman, Diane, 1990, Guideline for Authors National Atlas of Canada, $5^{\text {th }}$ Edition, Ottawa: National Atlas Information Service, Geographical Division, September. [Document provided by Donna Williams, October 2011]. 
Coats, R. H., 1929, The Place of Statistics in National Administration - Function and Organization of Statistics - Scope and Method of the Dominion Bureau of Statistics, Royal Society of Canada, pp. 81-93.

Coats, R. H., 1932, Fifty Years of Statistical Progress, Ottawa: Dominion Bureau of Statistics, pp. 77-83, Royal Society of Canada.

CODATA, 2007, Working Group on Archiving Scientific Data, accessed 9 January 2007, http://www.nrf.ac.za/codata/.

Coleman, David and John McLaughlin, 1997, Defining Global Geospatial Data Infrastructure (GGDI): Components, Stakeholders and Interfaces, in Geomatica, Vol.52, No. 2, pp. 129-143.

Coleman, Mathew, 2009, Spaces of Insecurity: the Localization of Immigration Enforcement in the War on Terror, Institute of Political Economy Celebrating our Graduates Lecture Series, Ottawa, Carleton University, January 9.

Cosgrove, Denis and Stephen Daniels, eds., 1988, The Iconography of Landscape: Essays on the Symbolic Representation, Design and Use of Past Environments, New York: Cambridge University Press.

Cosgrove, Denis, 2001, Apollo's Eye: A Cartographic Genealogy of the Earth in the Western Imagination, Baltimore: Johns Hopkins University Press.

Cosgrove, Denis, 2005, Mapping/Cartography in Atkinson, David, Peter Jackson, David Sibley and Neil Washbourne, eds. 2005, Cultural Geography: A Critical Dictionary of Key Concepts, London: I. B. Taurus, pp. 27-34.

Crampton, Jeremy, W., 2011, Cartographic Rationality and the Politics of Geosurveillance and Security, Chapter 5.8 in Dodge, Martin; Rob Kitchin and Chris Perkins, Eds. The Map Reader: Theories of Mapping Practice and Cartographic Representation, West Sussex: Wiley \& Blackwell, pp. 440-447.

Crowley, David and Paul Heyer eds., 1991, Communication in History: Technology, Culture and Society, New York: Longman.

Curtis, Bruce, 2001, The Politics of Population: State Formation, Statistics, and the Census of Canada, 1840-1875, University of Toronto Press: Toronto.

Dalby, Simon, 1993, The 'Kiwi Disease': Geopolitical Discourse in Aotearoa/New Zealand and the South Pacific, Political Geography, Vol. 12, No. 5, September, 437-456.

Darnton, Robert, 2006, What is the History of Books? Chapter 2 in Finkelstein, David and Alistair McCleery, eds., The Book History Reader, $2^{\text {nd }}$ Edition, London and New York: Routledge, pp. 9-27.

Data, 2008, The Concise Oxford English Dictionary, Twelfth edition. Ed. Catherine Soanes and Angus Stevenson. Oxford University Press, Oxford Reference Online. Oxford University Press, accessed September 9, 2010, http://www.oed.com.proxy.library.carleton.ca/view/Entry/47434? redirectedF rom=data\#eid. 
Datalibre.ca, 2011, Census Watch page and blog posts on the Census, accessed March 21, 2012, http://datalibre.ca/census-watch/.

de Margerie, Emmanuel, 1918, Prix Alexandre de La Roquette, Médaille d'or, MM. James White et J. E. Chalifour, le 20 avril 1917 pour l'Atlas du Canada de James White et J.E. Chalifour, « La Géographie », tome XXXII, Scanned Page from the Rapporteur, Received by email from the Sociéte by Michel Dagnaud, Secrétaire Général, November 29, 2011.

Dean, W. G., 1970, The Structure of Regional Atlases: An Essay on Communications, The Canadian Cartographer, Vol. 7, No 1, June, pp. 48-60.

Debarbieux, Bernard, 1992, Imagination et imaginaire géographiques, \#49 Encyclopedie de géographie, Economica, pp. 893-906.

Dent, Borden, D., 1990, Cartography: Thematic Map Design, Melbourne: Wm. C. Brown Publishers.

Department Energy, Mines and Resources (EMR) \& Interal Tydac, 1993, User's Guide for The National Atlas of Canada Electronic Atlas, Ottawa. [Manual lent to Author by Donna Williams, NRCan.]

Department of Agriculture and Statistics, 1892, Report of the Census of 1891 : Volume I, Ottawa: S. E. Dawson, Printer to the Queen's Most Excellent Majesty, accessed from Early Canadiana Online Scanned from the original publication held by Library and Archives Canada.

Department of Agriculture, 1871, Manual Containing "The Census Act" and the Instructions to Officers Employed in the Taking of the First Census of Canada, Ottawa: Brown Chamberlin, Printer to the Queen's Most Excellent Majesty.

Department of Agriculture, 1873, 1870-71 Census of Canada: Volume I, Ottawa: I. B. Taylor, 29, 31, \& 33 Rideau Street, accessed from Early Canadiana Online Scanned from the original publication held by Library and Archives Canada.

Department of Agriculture, 1881, Manual Containing "The Census Act" and the Instructions to Officers Employed in the Taking of the Second Census of Canada (1881), Ottawa: Brown Chamberlin, Printer to the Queen's Most Excellent Majesty.

Department of Agriculture, 1882, 1880-1881 Census of Canada: Volume I, Ottawa: Maclean, Roger \& Cio. Wellington Street.

Department of Agriculture, 1885 , General Report of the Census of Canada, 188081, Volume IV, Ottawa: MacLean, Roger \& Co., Wellington Street.

Department of Agriculture, 1886, 1884-5 Census of the Three Provisional Districts of the North-West Territories, Ottawa: Maclean, Roger \& Co., Welling Street, accessed from Early Canadiana Online Scanned from the original publication held by Library and Archives Canada.

Department of Agriculture, 1886, Manual Containing "The Census Act" and the Instructions to Officers Employed in the Taking of the Census of Manitoba 
(1886), Ottawa: Brown Chamberlin, Printer to the Queen's Most Excellent Majesty.

Department of Agriculture, 1887, 1885-6 Census of Manitoba, Ottawa: Maclean, Rogers \& Co., Wellington Street.

Department of Agriculture, 1887, The Census of Manitoba 1885-6, Ottawa: Maclean, Roger \& Co. Wellington Street.

Department of Agriculture, 1891, 1891 Census of Canada: Bulletin No. 1. Printer? Geo. Johnson, Statistician.

Department of Agriculture, 1891, Manual Containing "The Census Act" and the Instructions to Officers Employed in the Taking of the Third Census of Canada (1891), Ottawa: Brown Chamberlin, Printer to the Queen's Most Excellent Majesty.

Department of Agriculture, 1891, The Statistical Year Book of Canada for 1891 by Sydney C. D. Roper Assistant Statistician, Ottawa: The Government Printing Bureau.

Department of Agriculture, 1892a, The Statistical Year Book of Canada for 1892, Ottawa: The Government Printing Bureau.

Department of Agriculture, 1893, 1890-91 Census of Canada, Volume I, Ottawa: S. E. Dawson, Printer to the Queen's Most Excellent Majesty.

Department of Agriculture, 1893, 189o-91 Census of Canada, Volume II, Ottawa: S. E. Dawson, Printer to the Queen's Most Excellent Majesty. 25c

Department of Agriculture, 1896, Canada Year Book for 1895, Ottawa: Government Printing Bureau.

Department of Agriculture, 1901, Fourth Census of Canada 1901, Instructions to Chief Officers, Commissioners and Enumerators, Ottawa: Government Printing Bureau.

Department of Agriculture, 1902, 1901 Fourth Census of Canada: Volume 1 Population, Ottawa: S.E. Dawson, Printer to the King's Most Excellent Majesty.

Department of Agriculture, 1907, 1906 Census Northwest Provinces Manitoba, Saskatchewan, Alberta, I Population of 1906 compared with 1901 and II Summary Statistics of Field Crops and Live Stock, Ottawa: S. E. Dawson, Printer to the King's Most Excellent Majesty.

Department of Agriculture, 1907, 1906 Census of the Population and Agriculture of the Northwest Provinces: Manitoba, Saskatchewan, Alberta, Ottawa: S. E. Dawson, Printer to the Kings Most Excellent Majesty.

Department of Agriculture, 1911a, Fifth Census of Canada 1911: Instructions to Officers, Commissioners and Enumerators, Ottawa: Government Printing Bureau. 
Department of Agriculture, 1911b, Fifth Census of Canada 1911: Instructions to Enumerators in the Northwest Territories and Yukon Territory, Ottawa: Government Printing Bureau.

Department of Agriculture, 1912, 1911, Fifth Census of Canada: Area and Population by Provinces Districts and Sub-districts. Ottawa: Printed by C.H. Parmelee, Printer to the Kings' Most Excellent Majesty.

Department of Agriculture, 1912, Fifth Census of Canada 1911, Special Report on Area and Population, Ottawa: Printed by C. H. Parmelee, Printer to the King's Most Excellent Majesty.

Department of Agriculture, Statistical Office, 1886, Census of the Three Provisional Districts of the North-West Territories, 1884-85, Ottawa: MacLean, Roger \& Co., Wellington Street.

Department of Agriculture, 1904, Canada Year Book for 1903, Ottawa: W. E. Dawson, Printer of the King's Most Excellent Majesty.

Department of the Interior Canada, 1900, Concise school atlas of the Dominion of Canada: historical and physical features of provinces, districts, and territories of the Dominion, Ottawa: Dept. of the Interior.

Department of the Interior Canada, 1901, Annual Report for the Year 1901 Department of the Interior, Sessional Papers No 25, December 17, Ottawa: S. E. Dawson Printer to the Queens Most Excellent Majesty.

Department of the Interior Canada, 1902, Annual Report for the Year 1900-1901 Department of the Interior, Sessional Papers No 25, submitted by Clifford Sifton, November 30, Ottawa: S. E. Dawson Printer to the Queens Most Excellent Majesty.

Department of the Interior Canada, 1903, Annual Report for the Year 1902, Department of the Interior, Sessional Papers No 25, To Clifford Sifton, November 15, Ottawa: S. E. Dawson Printer to the Queens Most Excellent Majesty.

Department of the Interior Canada, 1904, Annual Report for the Year 1902-1903, Department of the Interior, Sessional Papers No 25, submitted by, December 6, 1903, Ottawa: S. E. Dawson Printer to the Queens Most Excellent Majesty.

Department of the Interior Canada, 1905, Annual Report for the Year 1903-1904, Department of the Interior, Sessional Papers No 25, submitted by Clifford Sifton, November 10, 1904, Ottawa: S. E. Dawson Printer to the Queens Most Excellent Majesty.

Department of the Interior Canada, 1906, Annual Report for the Year 1904-1905, Department of the Interior, Sessional Papers No 25, submitted by Frank Oliver, December 14, 1905, Ottawa: S. E. Dawson Printer to the Queens Most Excellent Majesty.

Department of the Interior Canada, 1906, Atlas of Canada, $1^{\text {st }}$ Edition, Toronto: Toronto Lithographing Company, Ltd. 
Department of the Interior Canada, 1907, Annual Report for the Year 1905-1906, Department of the Interior, Sessional Papers No 25, submitted by Frank Oliver, October 29, 1906, Ottawa: S. E. Dawson Printer to the Queens Most Excellent Majesty.

Department of the Interior Canada, 1908, Annual Report for the Year 1906-1907, Department of the Interior, Sessional Papers No 25, submitted by Frank Oliver, August 10, 1907, Ottawa: S. E. Dawson Printer to the Queens Most Excellent Majesty.

Department of the Interior Canada, 1909, Annual Report for the Year 1908, Department of the Interior, Sessional Papers No 25, submitted by Frank Oliver, September 1, 1908, Ottawa: C. H. Parmelee, Printer to the King's Most Excellent Majesty.

Department of the Interior Canada, 1910, Annual Report for the Year 1909, Department of the Interior, Sessional Papers No 25, submitted by Frank Oliver, August 2, 1908, Ottawa: C. H. Parmelee, Printer to the King's Most Excellent Majesty.

Department of the Interior Canada, 1911, Annual Report for the Year 1910, Department of the Interior, Sessional Papers No 25, submitted by Frank Oliver, August 31, 1910, Ottawa: C. H. Parmelee, Printer to the King's Most Excellent Majesty.

Department of the Interior Canada, 1912, Annual Report for the Year 1911, Department of the Interior, Sessional Papers No 25, submitted by R. Rogers, August 31, 1911, Ottawa: C. H. Parmelee, Printer to the King's Most Excellent Majesty.

Department of the Interior Canada, 1913, Annual Report for the Year 1912, Department of the Interior, Sessional Papers No 25, submitted by R. Rogers, October 19, 1912, Ottawa: C. H. Parmelee, Printer to the King's Most Excellent Majesty.

Department of the Interior Canada, 1914, Annual Report for the Year 1913, Department of the Interior, Sessional Papers No 25, submitted by W. J. Roche, January 14, 1914, Ottawa: C. H. Parmelee, Printer to the King's Most Excellent Majesty.

Department of the Interior Canada, 1915, Atlas of Canada: Revised and Enlarged Edition, $2^{\text {nd }}$ Edition, Ottawa.

Department of Trade and Commerce, 1916, Census of Manitoba, Saskatchewan and Alberta 1916: Instructions to Commissioners and Enumerators, Ottawa: Government Printing Bureau.

Department of Trade and Commerce, 1918, Census of Prairie Provinces, Population and Agriculture, Manitoba, Saskatchewan and Alberta 1916: Instructions to Commissioners and Enumerators, Ottawa: J. De Labroquerie Taché, Printer to the Kings Most Excellent Majesty. 
Desrosières, Alain, 1998, The Politics of Large Numbers: A History of Statistical Reasoning, translated by Camille Naish, Cambridge: Harvard University Press.

Dijkink, Gertjan, 1996, National Identity \& Geopolitical Visions: Maps of Pride \& Pain, London: Routledge.

Dodge, Martin, ed., 2011, Classics in Cartography: Reflections on Influential Articles from Cartographica, West Sussex: Wiley-Blackwell.

Dodge, Martin; Rob Kitchin and Chris Perkins, eds., 2011, The Map Reader: Theories of Mapping Practice and Cartographic Representation, West Sussex: Wiley \& Blackwell.

Dominion Bureau of Statistics (DBS), 1915, Canada Year Book for 1914, Ottawa: J. De L. Taché, Printer to the King's Most Excellent Majesty.

Dominion Bureau of Statistics (DBS), 1921, Sixth Census of Canada 1921: Instructions to Commissioners and Enumerators, Ottawa: Government Printing Bureau.

Dominion Bureau of Statistics (DBS), 1924, 1921 Sixth Census of Canada, Volume 1-Population: Number, Sex and Distribution - Racial OriginsReligions, Ottawa: F.A. Acland, Printer to the King's Most Excellent Majesty.

Dominion Bureau of Statistics (DBS), 1925, Sixth Census of Canada 1921: Volume 2 - Population, Age, Conjugal Condition, Birthplace, Immigration, Citizenship, Language, Educational Status, School Attendance, Blindness and Deaf Mutism, Ottawa: F.A. Acland, Printer to the King's Most Excellent Majesty.

Dominion Bureau of Statistics (DBS), 1926, Census of Manitoba, Saskatchewan, and Alberta 1926: Instructions to Commissioners and Enumerators, Ottawa: Government Printing Bureau.

Dominion Bureau of Statistics (DBS), 1929, 1926 Report on the Census of the Prairie Provinces: Population and Agriculture, Manitoba, Saskatchewan and Alberta, Ottawa: F.A. Acland, Printer to the King's Most Excellent Majesty.

Dominion Bureau of Statistics (DBS), 1929a, Origin, Birthplace, Nationality and Language of the Canadian People (A Census Study bases on the Sixth Census of 1921 and Supplementary Data), Ottawa: F. A. Acland Printer to the King's Most Excellent Majesty.

Dominion Bureau of Statistics (DBS), 1930, Census of the Northwest Territories; certain Parts of the Yukon; Eastern Shore of Hudson Bay north of Great Whale River; and Southern Shore of Hudson Strait and Ugava Bay 1931: Instructions to Enumerators, Ottawa: F. A. Acland, Printer to the King's Most Excellent Majesty.

Dominion Bureau of Statistics (DBS), 1931b, The Canada Year Book 1931: The Official Statistical Annual of the Resources, History, Institutions, and Social 
and Economic Conditions of Canada, Ottawa: F. A. Acland, The King's most excellent printer.

Dominion Bureau of Statistics (DBS), 1931c, Seventh Census of Canada 1931: Instructions to Commissioners and Enumerators, Ottawa: F. A. Acland, Printer to the King's Most Excellent Majesty.

Dominion Bureau of Statistics (DBS), 1936, Census of Manitoba, Saskatchewan and Alberta, 1936: Instructions to Commissioners and Enumerators, Ottawa: J. O. Pateneaude, I.S.O. Printer to the King's Most Excellent Majesty.

Dominion Bureau of Statistics (DBS), 1936, The Canada Year Book 1936, Ottawa: J. O. Patenaude, King's Printer.

Dominion Bureau of Statistics (DBS), 1936a, 1931 Seventeenth Census of Canada, Volume 1, Population Summary, Ottawa: J. O. Pateneaude I.S.O. Printer to the Kings most Excellent Majesty.

Dominion Bureau of Statistics (DBS), 1938, 1936 Census of the Prairie Provinces, Volume I, Population and Agriculture, Ottawa: J.O. Patenaude, I.S.O, Printer to the King's most excellent Majesty.

Dominion Bureau of Statistics (DBS), 1939, The Canada Year Book 1939, Ottawa: J. O. Patenaude, King's Printer.

Dominion Bureau of Statistics (DBS), 1941, The Canada Year Book 1941: The Official Statistical Annual of the Resources, History, Institutions, and Social and Economic Conditions of Canada, Ottawa: Edmond Cloutier, The King's Printer.

Dominion Bureau of Statistics (DBS), 1942, Seventh Census of Canada 1931: Volume XIII Monographs: Unemployment, Dependency of Youth, Rural and Urban Composition of the Canadian Population, Racial Origin and Nativity of the Canadian People, Ottawa: Edmond Cloutier, Printer to the King's Most Excellent Majesty.

Dominion Bureau of Statistics (DBS), 1945, Eighth Census of Canada 1941: Instructions to Commissioners and Enumerators, Ottawa: Edmond Cloutier Printer to the King's Most Excellent Majesty.

Dominion Bureau of Statistics (DBS), 1945b, Eighth Census of Canada 1941: Administrative Report of the Dominion Statistician, Ottawa: Edmond Cloutier Printer to the King's Most Excellent Majesty.

Dominion Bureau of Statistics (DBS), 1946, Census of Manitoba, Saskatchewan and Alberta, 1946: Instructions to Commissioners and Enumerators, Ottawa: Edmond Cloutier Printer to the King's Most Excellent Majesty.

Dominion Bureau of Statistics (DBS), 1947, The Canada Year Book 1947, Ottawa: Edmond Cloutier, King's Printer and Controller of Stationery.

Dominion Bureau of Statistics (DBS), 1949, 1946 Census of the Prairie Provinces, Volume 1, Population, Ottawa: Published by the Authority of the Right Honourable C. D. Howe, Minster of Trade and Commerce. 
Dominion Bureau of Statistics (DBS), 1949, 1946 Census of the Prairie Provinces, Volume 1, Population, Ottawa: Published by the Authority of the Right Honourable C. D. Howe, Minster of Trade and Commerce.

Dominion Bureau of Statistics (DBS), 1950, 1941 Eighth Census of Canada: Volume 1, General Review and Summary Tables, Ottawa: Edmond Cloutier, The King's Most Excellent Majesty and Controller of Stationery.

Dominion Bureau of Statistics (DBS), 1951, Ninth Census of Canada 1951: Enumeration Manual, Ottawa: Dominion Bureau of Statistics.

Dominion Bureau of Statistics (DBS), 1951, Ninth Decennial Census of Canada, June 1951: Proofs of Mats and Cuts Available from the Press and Publicity Section, Ottawa: Dominion Bureau of Statistics, Sussex Street.

Dominion Bureau of Statistics (DBS), 1951a, The Canada Year Book 1951: The Official Statistical Annual of the Resources, History, Institutions, and Social and Economic Conditions of Canada, Ottawa: Edmond Cloutier, King's Printer and Controller of Stationery.

Dominion Bureau of Statistics (DBS), 1951b, Ninth Census of Canada, 1951, Ninth Census of Canada, 1951: Training Manual, Ottawa: Dominion Bureau of Statistics.

Dominion Bureau of Statistics (DBS), 1953, Ninth Census of Canada 1951, Volume 1, Population, General Characteristics, Ottawa: Queen's Printer.

Dominion Bureau of Statistics (DBS), 1953, Ninth Census of Canada, 1951, Volume 1, Population, General Characteristics, Ottawa: Queens Printer.

Dominion Bureau of Statistics (DBS), 1955, Ninth Census of Canada, 1951, Volume XI, Administrative Report, Ottawa: Queen's Printer.

Dominion Bureau of Statistics (DBS), 1955a, Canada Year Book for 1955, Ottawa: Edmond Cloutier, C.M.G., O.A., D.S.P., Queen's Printer and Controller of Stationery.

Dominion Bureau of Statistics (DBS), 1956, 1956 Census of Canada: Field Manual for Census Commissioners and Field Supervisors, Ottawa: Dominion Bureau of Statistics.

Dominion Bureau of Statistics (DBS), 1956, Canada Year Book for 1956, Ottawa: Edmond Cloutier, C.M.G., O.A., D.S.P., Queen's Printer and Controller of Stationery.

Dominion Bureau of Statistics (DBS), 1956, Ninth Census of Canada, 1951, Volume X, General Review, Ottawa: Edmond Cloutier, Queen's Printer.

Dominion Bureau of Statistics (DBS), 1956a, 1951 Census of Canada: Volume X General Review and Summary Tables, Ottawa: Dominion Bureau of Statistics.

Dominion Bureau of Statistics (DBS), 1956a, 1956 Census of Canada: Enumeration manual, Ottawa: Dominion Bureau of Statistics. 
Dominion Bureau of Statistics (DBS), 1956b, 1956 Census of Canada: Training manual for Instruction of Census Enumerators, Ottawa: Dominion Bureau of Statistics.

Dominion Bureau of Statistics (DBS), 1958, 1956 Census of Canada, Volume 1, Population: General Characteristics, Households and Families, Introduction and Appendices to Volume 1, Bulletin 19-2-1958, Ottawa: Edmond Cloutier, C. M. G. The Queens Printer and Controller of Stationery.

Dominion Bureau of Statistics (DBS), 1958a, 1956 Census of Canada, Analytical Report: Administrative Report of the 1956 Census, Ottawa: The Queens Printer and Controller of Stationery.

Dominion Bureau of Statistics (DBS), 1958b, The Canada Year Book 1957-58, Ottawa: Edmond Cloutier, King's Printer and Controller of Stationery.

Dominion Bureau of Statistics (DBS), 1959, Canada Year Book 1959, Ottawa: The Queen's Printer and Controller of Stationery.

Dominion Bureau of Statistics (DBS), 1961, 1961 Census of Canada: Enumeration Manual, Ottawa: Dominion Bureau of Statistics.

Dominion Bureau of Statistics (DBS), 1961, 1961 Census of Canada: Field manual, Ottawa: Dominion Bureau of Statistics.

Dominion Bureau of Statistics (DBS), 1963, Post-War Immigrant Families, Bulletin 2.1-8, Ottawa: Minister of Trade and Commerce.

Dominion Bureau of Statistics (DBS), 1965, Canada Year Book 1965, Ottawa: The Minister of Trade and Commerce.

Dominion Bureau of Statistics (DBS), 1965, Citizenship in Canada, Bulletin 7.1-8, Ottawa: Minister of Trade and Commerce.

Dominion Bureau of Statistics (DBS), 1965, Native and Foreign Born Population, Bulletin 7.1-7, Ottawa: Minister of Trade and Commerce.

Dominion Bureau of Statistics (DBS), 1965a, Mother Tongue and Official Languages, Bulletin 7.1-9, Ottawa: Minister of Trade and Commerce.

Dominion Bureau of Statistics (DBS), 1966, 1966 Census of Canada: Commissioner's Manual, Ottawa: Dominion Bureau of Statistics.

Dominion Bureau of Statistics (DBS), 1966, 1966 Census of Canada: Enumeration Manual, Ottawa: Dominion Bureau of Statistics,

Dominion Bureau of Statistics (DBS), 1966, Historical 1901-1961, Bulletin 1.1-10, Ottawa: Minister of Trade and Commerce.

Dominion Bureau of Statistics (DBS), 1966, Labour Force: Occupation and Industry Trends, Bulletin 18-3-1966, Ottawa: Minister of Trade and Commerce.

Dominion Bureau of Statistics (DBS), 1966, Origins of the Canadian Population, Bulletin 7.1-6, Ottawa: Minister of Trade and Commerce. 
Dominion Bureau of Statistics (DBS), 1968, Canada Year Book for 1968, Ottawa: Roger Duhamel, F.R.S.C., Queen's Printer and Controller of Stationery.

Dominion Bureau of Statistics (DBS), 1969, 1961 Census of Canada, General Review, Administrative Report of the 1961 Census, Bulletin 7.2-12, Ottawa: Published by the Authority of the Minister of Industry, Trade and Commerce.

Dominion Bureau of Statistics (DBS), 1969, 1966 Census of Canada, Introductory Report to Volume 1, Ottawa: Queen's Printer

Dominion Bureau of Statistics (DBS), 1970, 1966 Census of Canada, Administrative Report of the 1966 Census, Ottawa: Published by Authority of the Minster of Trade and Commerce.

Dominion Bureau of Statistics (DBS), 1970a, The Impact of Immigration on Canada's Population, Monograph Series of the 1961 Census by Warren E. Kalback, Ottawa: Ministry of Industry, Trade and Commerce.

Dominion Bureau of Statistics (DBS), 1971, 1971 Census, Procedures Manual: Canvasser Areas, Ottawa: Dominion Bureau of Statistics.

Dominion Bureau of Statistics (DBS), 1971, Commissioner's Manual: SelfEnumeration Areas, 1971 Census of Canada, Ottawa: Dominion Bureau of Statistics.

Douglas, Ian; Richard Huggett and Chris Perkins, eds., 2009, Companion Encyclopedia of Geography from Local to Global, Second Edition, Volume 2, London: Routledge.

Dourish, Paul and Genevieve Bell, 2007, The Infrastructure of Experience and the Experience of Infrastructure: Meaning and Structure in Everyday Encounters with Space, Environment and Planning B: Planning and Design, Volume 34, pp. 414-430.

Dreiker, Gregory K., Tiffany Soule Anderson, Lauren DeMille, Emily Duwel, Mary Mahon, Alex Marshall and Leili Towfignt, 2002, Me, Myself and the Infrastructure: Private Lives and Public Works in America, American Society of Civil Engineers (ASCE) and Chicken \& Egg Public Projects: US.

Dunton, A. Davidson; André Laurendeau and Jean-Louis Gagnon, 1970, Royal Commission on Bilingualism and Biculturalism, 1967-1970, Ottawa: Commission of Inquiry, accessed February 10, 2012 from http://epe.lacbac.gc.ca/100/200/301/pco-bcp/commissions-ef/dunton1967-1970ef/dunton1967-70-eng.htm.

Dupaquier, Michel and Jacques, 1985, Histoire de la démographie, Paris : Librairie Académique Perrin.

Ecojustice, 2009, Court victory forces Canada to report pollution data for mines, Media Release, April 24, 2009, accessed August 4, 2011 from http://www.ecojustice.ca/media-centre/press-releases/court-victory-forcescanada-to-report-pollution-data-for-mines. 
Ecological Stratification Working Group (ESWG), 1996, A National Ecological Framework for Canada, Environment Canada (EC), Ottawa, Minister of Supply and Services Canada, accessed Dec. 1, 2011 from http://sis.agr.gc.ca/cansis/publications/ecostrat/cad report.pdf.

Edney, Matthew H., 1997, Mapping an Empire: The Geographical Construction of British India, 1765-1843, Chicago: The University of Chicago Press.

Edney, Matthew H., 2011, Cartography without Progress: Reinterpreting the Nature and Historical Development of Mapmaking, Chapter 1.10 in Dodge, Martin; Rob Kitchin and Chris Perkins, eds. The Map Reader: Theories of Mapping Practice and Cartographic Representation, West Sussex: Wiley \& Blackwell, pp. 73-83.

Edwards, Jesse, 2005-6, Study, Marketplace and Labyrinth: Geometry as Rhetoric', in New Formations 57, Winter, 2005-6, pp. 126-44.

Edwards, Paul N., Steven J. Jackson, Geoffrey C. Bowker and Cory P. Knobel, 2007, Understanding Infrastructures: Dynamics, Tensions and Design, Report of a Workshop on History \& Theory of Infrastructure: Lessons for New Scientific Cyberinfrastructures, US National Science Foundation, accessed June 22, 2008 from http://www.si.umich.edu/cyberinfrastructure/UnderstandingInfrastructure FinalReport25jano7.pdf.

Egli LeGear, 1974, A List of Geographical Atlases in the Library of Congress, Washington: Government Printing Office.

Elden, Stuart, 2007, Governmentality, Calculation, Territory, in Environment and Planning D: Society and Space, Vol. 25, pp. 562-580.

Energy Mines and Resources (EMR), 1967, 1966-67 Annual Report, Geographical Branch Report, Ottawa, pp. 20-21.

Energy Mines and Resources (EMR), 1968, 1967-68 Annual Report, Surveys and Mapping Branch Report, Ottawa, pp. 3-9.

Energy Mines and Resources (EMR), 1969, 1968-69 Annual Report, Surveys and Mapping Branch Report, Ottawa, pp. 3-8.

Energy Mines and Resources (EMR), 1970, 1969-70 Annual Report, Surveys and Mapping Branch Report, Ottawa, pp. 9-15.

Energy Mines and Resources (EMR), 1971, 1970-71 Annual Report, Surveys and Mapping Branch Report, Ottawa, pp. 21-26.

Energy Mines and Resources (EMR), 1972, 1971-72 Annual Report, Resource Inventory and Potential, Ottawa, pp. 5-7.

Energy Mines and Resources (EMR), 1973, 1972-73 Annual Report, Resource Inventory and Potential, Ottawa, pp. 5-9.

Energy Mines and Resources (EMR), 1974, 1973-74 Annual Report, Survey and Mapping, Ottawa, pp. 17-20. 
Energy Mines and Resources (EMR), 1974, $4^{\text {th }}$ Revised Edition, The National Atlas of Canada, Toronto: Macmillan Company of Canada Limited.

Energy Mines and Resources (EMR), 1975, 1974-75 Annual Report, Survey and Mapping, Ottawa, pp. 16-23.

Energy Mines and Resources (EMR), 1976, 1975-76 Annual Report, Surveys and Mapping Branch, Ottawa, pp. 33-36.

Energy Mines and Resources (EMR), 1977, 1976-77 Annual Report, Surveys and Mapping Branch, Ottawa, pp. 33-36.

Energy Mines and Resources (EMR), 1978, 1977-78 Annual Report, Surveys and Mapping Branch, Ottawa, pp. 44-47.

Energy Mines and Resources (EMR), 1979, 1978-79 Annual Report, Surveys and Mapping Branch, Ottawa, pp. 38-42.

Energy Mines and Resources (EMR), 1980, 1979-80 Annual Report, Earth Sciences Services Program, Ottawa, pp. 43-47.

Energy Mines and Resources (EMR), 1984, 1982-83 Annual Report, Earth Sciences Services Program, Ottawa, pp. 14-15.

Energy Mines and Resources (EMR), 1985, 1984-85 Annual Report, Surveys and Mapping Branch, Ottawa, pp. 19-20.

Energy Mines and Resources (EMR), 1986, 1985-86 Annual Report, Surveys and Mapping Branch, Ottawa, pp. 30-32.

Energy Mines and Resources (EMR), 1987, 1986-87 Annual Report, Surveys and Mapping Branch, Ottawa, pp. 24-25.

Energy Mines and Resources (EMR), 1988, 1987-88 Annual Report, Canada Centre for Mapping, Ottawa.

Energy Mines and Resources (EMR), 1988, 1988-89 Annual Report Surveys, Mapping and Remote Sensing Sector, Ottawa.

Energy Mines and Resources (EMR), 1993, The National Atlas of Canada, $5^{\text {th }}$ Edition, Ottawa: Energy, Mines and Resources Canada.

Environment Canada (EC), 1978, Applications of Ecological (Biophysical) Land Classification in Canada, Proceedings of the $2^{\text {nd }}$ Committee Ecological (Biophysical) Land Classification April 4-7, Victoria, BC, Ecological Land Classification Series Number 7, Ottawa: Minister of Supply and Services Canada.

Environment Canada (EC), 1979a, Land and Wildlife Integration, Ecological Land Classification Series Number 11, Proceedings of a technical workshop to discuss the incorporation of wildlife information into ecological land surveys, Environmental Conservation Service Task Force, Ottawa: Minister of Supply and Services Canada.

Environment Canada (EC), 1979b, Report on the 1977 Vancouver Symposium in Environment Canada, Application (Biophysical) Land Classification in Canada, 
Ecological Land Classification Series Number 7, Proceedings of the Second Meeting Canada Committee on Ecological (Biophysical) Land Classification, 4-7 April 1978, Victoria, BC, Ottawa: Minister of Supply and Services Canada, pp. 51-56.

Environment Canada (EC), 1980, Land and Wildlife Integration, Proceedings of a Technical Workshop to discuss the Incorporation of Wildlife Information into Ecological Land Surveys, Saskatoon, 1979, Ecological Land Classification Series Number 25, Ottawa: Minister of Supply and Services Canada.

Environment Canada (EC), 1981, Ecological Land Survey Guidelines for Environmental Impact Analysis, Ecological Land Classification Series Number 13, Environmental Conservation Service Task Force, Ottawa: Minister of Supply and Services Canada.

Environment Canada (EC), 1990, The Canadian Vegetation Classification System, Ecological Land Classification Series Number 25, Ottawa: Minister of Supply and Services Canada.

Fact, 2008, The Concise Oxford English Dictionary, Twelfth edition. Ed. Catherine Soanes and Angus Stevenson. Oxford University Press, Oxford Reference Online. Oxford University Press, September 9, 2010, http://www.oed.com.proxy.library.carleton.ca/view/Entry/67478?rskey=RZlT Zw\&result $=1$ \&is Advanced $=$ false $\#$ eid.

Falconer, G. and P. J. Lloyd, 1984, Marketing the National Atlas of Canada, paper presented at the Symposium on the Marketing of Cartographic Information, May 14-17, at Queen's University in Kingston Ontario.

Falconer, George; Lillian J. Wonders, and Iain C. Taylor, 1999, Canadian Atlases, National, Provincial, Educational and Thematic, Chapter 10 in McGrath, Gerald and Louis M. Sebert, eds., 1999, Mapping a Northern Land: The Survey of Canada, 1947-1994, Montréal: McGill-Queen's University Press, pp. 270-304.

Feenberg, Andrew, 2008, Momentum: A Concept in Technology Studies, accessed June 22, 2008 from http://www.sfu.ca/\%7Eandrewf/momentum.htm.

Fernow, B. E., 1912, Forest Resources and Problems of Canada, Proc. Soc. American Foresters, 7:133-144.

Finkelstein, David and Alistair McCleery, eds., 2006, The Book History Reader, $2^{\text {nd }}$ Edition, London and New York: Routledge.

Flournoy, Richard W. and Manley O Hudson, 1929, A Collection of nationality laws of various countries, as contained in constitutions, statutes, and treaties, New York : Oxford University Press.

Flowers, Betty Sue, ed., 1988, Joseph Campbell: The Power of Myth with Bill Moyers, New York, Doubleday. 
Foucault, Michel (2007), Security, Territory, Population: lectures at the Collège de France, 1977-1978; ed. by Michel Senellart; and translated by Arnold I. Davidson;

Foucault, Michel, 1986, Of Other Spaces, Diacritics, 16:1, 1986: Spring, pp. 22-27.

Foucault, Michel, 1991, Governmentality, in Burchell, G., C. Gordon, P. Miller, Eds. The Foucault Effect: Studies in Governmentality, Chicago: University of Chicago Press, pp. 87-104.

Foucault, Michel, 2003, Society Must be Defended: Lectures at the College de France, 1975-76, Edited by Mauro Bertani and Alessandro Fontana, translated by David Macey, New York: Picador.

Foucault, Michel, 2006, What is an Author? Chapter 20 in in Finkelstein, David and Alistair McCleery, eds., The Book History Reader, $2^{\text {nd }}$ Edition, London and New York: Routledge, pp. 281-292.

Foucault, Michel, 2010, Biopower, in Paul Rabinow, Ed. The Foucault Reader, New York: Vintage Books. Pp. 257-273.

Foucault, Michel, 2010, Space, Knowledge and Power, in Paul Rabinow, Ed. The Foucault Reader, New York: Vintage Books. Pp. 239-257.

Fowler, Roger, 1985, Power, in Teun A. van Dijk, ed. Chapter 5, Volume 4, Handbook of Discourse Analysis, Academic Press, London, pp. 61-82.

Fremlin, Gerald and Arthur Robinson, 1999, Maps as Mediated Seeing, Cartographica, Monograph 1951.

Fremlin, Gerald, 1963, Color and Design in the British Columbia and Manitoba Atlases and the Atlas of Canada, The Geographical Bulletin, Ottawa: Department of Mines and Technical Surveys.

Fremlin, Gerald, 2005, Maps as Mediated Seeing: Fundamentals of Cartography, Victoria, B.C.: Trafford Pub.

Fremlin, Gerald, 2011, Telephone conversation about the $4^{\text {th }}$ edition of the Atlas of Canada, August.

Garland, David, 1997, 'Governmentality' and the Problem of Crime: Foucault, Criminality, Sociology, in Theoretical Criminology, Vol.1 (20), pp. 173-214.

Gentilcore, Louis and Kate Donkin, 1973, Land Surveys of Southern Ontario: An Introduction to the Field Notebooks of the Ontario Land Surveyors 1784-1859, Cartographica Monograph, Supplement No. 2 to the Canadian Geographer, Vol. 10, 1973, Toronto: York University.

GeoConnections, 2003, About GeoConnections, Government of Canada, downloaded April 12, 2003 http://www.geoconnections.org/english/about/index.html.

GeoConnections, 2005, The Canadian Geospatial Data Infrastructure Architecture Description, Version 2.0, accessed February 27 from 
http://www.geoconnections.org/publications/tvip/arch_E/CGDI_Architectur e_final_E.html.

GeoConnections, 2011, Key Facts, accessed March 8, 2011 from http://geoconnections.nrcan.gc.ca/6.

Georgiadou, P.Y. and V. Homburg, 2008, The argumentative structure of spatial data infrastructure initiatives in America and Africa, in Social dimensions of information and communication technology policy: proceedings of the 8th International conference on human choice and computers HCC8, IFIP TC 9, Pretoria, South Africa, September 25-26, 2008 / ed. by C. Avgerou, M.L. Smith and P. van den Besselaar. Boston: Springer, pp. 31-44.

Glenny, W. J., 1920, British Empire Statistical Conference, 1920. Report and resolutions adopted by the first conference of government officers engaged in dealing with statistics in the British Empire, held at the Board of Trade on 20th January-26th February 1920, accessed from the British House of Commons Parliamentary Papers January 25, 2012 http://parlipapers.chadwyck.com.proxy.library.carleton.ca/fullrec/fullrec.do?i $\mathrm{d}=1920-023548 \&$ DurUrl $=$ Yes.

Godfrey, Ernest H., 1918, History and Development of Statistics in Canada, Book II chapter 4 in Koren, John, Ed. ,The History of Statistics: Their Development and Progress in Many Countries in Memoirs to Commemorate the Seventy Fifth Anniversary of the American Statistical Association, New York: Macmillan Company, pp. 177-198.

Godfrey, Ernest H., 1929, Organization of the Official Statistics of the Dominion of Canada, XVI Session de L'Institut International de Statistiques, Roma, pp. 3-15.

Google Earth, 2011, Google Earth Outreach, accessed February 27, 2012 from http://earth.google.com/outreach/index.html.

Gordon, Colin, 1991, Governmental Rationality: An Introduction, Chapter 1, Burchell, Graham; Colin Gordon and Peter Miller, eds., in the Foucault Effect: Studies in Governmentality with Two Lectures by and an Interview with Michel Foucault, Chicago: University of Chicago Press, pp. 1-51.

Government of Canada (GC), 1867, British North America Act, 1867, 30-31 Vict., c. 3 (U.K.), accessed January 17, 2011 from http://www.justice.gc.ca/eng/pi/const/lawreg-loireg/p1t11.html.

Government of Canada (GC), 1911, Orders in Council, \&c, Department of Agriculture, in Orders in Council of the Imperial Government together with Treaties Negotiated between His Majesty the King and Foreign Powers, Ottawa: Charles Henry Parmelee, Law Printer to the King's Most Excellent Majesty, pp. ix-xiii.

Government of Canada (GC), 1927, An Act respecting the Dominion Bureau of Statistics, 1918, c. 43, s.1, in The Revised Statutes of Canada, Vol. IV, Ottawa: 
Frederick Albert Acland, Law Printer to the King's Most Excellent Majesty, pp. 3905-3916.

Government of Canada (GC), 1927, The Revised Statutes of Canada, Vol. IV, Ottawa: Frederick Albert Acland, Law Printer to the King's Most Excellent Majesty.

Government of Canada (GC), 1948, An Act respecting the Dominion Bureau of Statistics, Assented to $30^{\text {th }}$ June 1948, 11-12 George VI, c. 45, Prefix to Statutes, List of Proclamations from October 1947 to July 1949, Ottawa: Edmond Cloutier Printer to the King's Most Excellent Majesty Controller of Stationery, pp. 329-341.

Government of Canada (GC), 1948, Prefix to Statutes, List of Proclamations from October 1947 to July 1949, Ottawa: Edmond Cloutier Printer to the King's Most Excellent Majesty Controller of Stationery.

Government of Canada (GC), 1952, Chapter 257 An Act respecting the Dominion Bureau of Statistics, Statistics Act 1948, c. 45, s.1. in The Revised Statutes of Canada, Volume IV, Ottawa: Edmond Cloutier, Queen's Printer and Controller of Stationery, pp. 4985-4997.

Government of Canada (GC), 1952, The Revised Statutes of Canada, Volume IV, Ottawa: Edmond Cloutier, Queen's Printer and Controller of Stationery.

Government of Canada (GC), 1952-53, Acts Proclaimed in Force, Ottawa: Edmond Cloutier, Queens Printer and Controller of Stationery.

Government of Canada (GC), 1953, 1-2 Elizabeth II, An Act to amend the Statistics Act, Assented to $31^{\text {st }}$ March, 1953, in Acts Proclaimed in Force, Ottawa: Edmond Cloutier, Queens Printer and Controller of Stationery, pp. 6367.

Government of Canada (GC), 1969, Acts of the Parliament of Canada, First Session of the Twenty-Eighth Parliament, 17-18 Queen Elizabeth II, 1968-69, Bill c-12o Official Language Act, C.54, Ottawa: Queen's Printer for Canada

Government of Canada (GC), 1970, Chapter s-16 An Act respecting the Dominion Bureau of Statistics, Statistics Act R. S., C. 257, s. 1. in Revised Statutes of Canada, Proclaimed and Published under the authority of Chapter 48 of the Statutes of Canada, 1964-65, Volume VII, Ottawa: Queens Printer, pp. 71297143.

Government of Canada (GC), 1970, Revised Statutes of Canada, Proclaimed and Published under the authority of Chapter 48 of the Statutes of Canada, 196465, Volume VII, Ottawa: Queens Printer.

Government of Canada (GC), 1972, 19-2o Elizabeth II, An Act Respecting statistics of Canada, Assented to $11^{\text {th }}$ February, 1971 in Acts of Parliament of Canada, Third Session of the Twenty-Eighth Parliament, Passed in Session Held in the 19-20-21st Years of the Reign of Her Majesty Queen Elizabeth II, Ottawa, pp. 437-455. 
Government of Canada (GC), 1972, Acts of Parliament of Canada, Third Session of the Twenty-Eighth Parliament, Passed in Session Held in the 19-20-21 Years of the Reign of Her Majesty Queen Elizabeth II, Ottawa.

Government of Canada (GC); 1985, Charter S-19, An Act Respecting statistics of Canada, in Revised Statutes of Canada, Prepared under the authority of the Statute Revision Act, Volume VIII, Ottawa, Queens Printer.

Government of Canada (GC), 1985, Revised Statutes of Canada, Prepared under the authority of the Statute Revision Act, Volume VIII, Ottawa, Queens Printer.

Government of Manitoba (GC), 2011, View of Land Parcel Survey Grid around Winnipeg Manitoba, Agri-Map viewer, accessed November 4, 2011 from http://geoapp2.gov.mb.ca/website/MAFRI/html parcels3/asp.htm?Title=Arc IMS\%20Parcel\%20Information\%2oViewer.

Governmentality: A Dictionary of Sociology, John Scott and Gordon Marshall, Oxford University Press 2009, Oxford Reference Online, Oxford University Press accessed from Carleton University, 29 May 2012 from http://www.oxfordreference.com/views/ENTRY.html?subview=Main\&entry= t88.e951.

Graham, Stephen and Simon Marvin, 2001. Splintering Urbanism: Networked Infrastructures, Technologies and the Urban Condition, London: Routledge.

Graham, Stephen, 1998, The End of Geography or the Explosion of Place? Conceptualizing Space, Place and Information Technology, Progress in Human Geography, 22, pp. 165-185.

Gregory, Derek, 1994, Geographical Imaginations, Cambridge: MA: Blackwell.

Gregory, Derek, 2003, Emperors of the Gaze: Photographic Practices and Productions of Space in Egypt, 1839-1914, Chapter 8 in Schawartz, Joan M. and James R. Ryan, eds., Picturing Place: Photography and the Geographical Imagination, pp. 193-195.

Gregory, Derek, 2008, War, Culture and Imperialism, presented at the Counterpoint Conference in honour of Edward Said, Saturday November $\mathbf{1}^{\text {st }}$, Ottawa, Canada.

Gregory, Derek, Ron Johnston, Geraldine Pratt, Michael J. Watts and Sarah Whatmore, eds. 2009, The Dictionary of Human Geography, $5^{\text {th }}$ Edition, Malden: Wiley-Blackwell.

Gregory, Derek, Ron Johnston, Geraldine Pratt, Michael J. Watts and Sarah Whatmore, eds. 2009, Infrastructure, The Dictionary of Human Geography, $5^{\text {th }}$ Edition, Malden: Wiley-Blackwell, pp. 382-383.

Groot, Richard and John Douglas McLaughlin, 2000, Geospatial Data Infrastructures: Concepts, Case and Good Practice, Oxford, Oxford University Press. 
Groot, Richard, 1979, Canada's National Atlas Program in the Computer Era, Cartographica, Monograph, No. 23, pp. 40-52.

Hacking, Ian, 1982, Biopower and the Avalanche of Numbers, in Humanities in Society: Foucault and Critical Theory: The Uses of Discourse Analysis, Vol.5, Numbers 3\&4, pp. 279-295.

Hacking, Ian, 1986, Making Up People, in Reconstructing Individualism, ed., T. Heller et al, Stanford, Calif.: Stanford University Press, pp. 222-236.

Hacking, Ian, 1990, The Taming of Chance, Cambridge: Cambridge University Press.

Hacking, Ian, 1991, A Tradition of Natural Kinds, Philosophical Studies: An International Journal for Philosophy in the Analytic Tradition, Vol. 61, No. 1/2, The Twenty-Ninth Oberlin Colloquium in Philosophy, Feb., pp. 109-126.

Hacking, Ian, 1999, The Social Construction of What? Cambridge: Harvard University Press.

Hacking, Ian, 1999a, What about the Natural Sciences? Chapter 4 in The Social Construction of What? Cambridge: Harvard University Press, pp. 63-100.

Hacking, Ian, 2000, Façonner les gens Chapter 1 in The Age of Numbers: Statistical Systems and National Traditions edited by Jean-Pierre Beaud and Jean-Guy Prévot, Presse de L'université du Québec, pp. 17-37.

Hacking, Ian, 2001-2002, Façonner les gens (2001-2002), École de France Philosophie et histoire des concepts scientifiques (2001-2006), accessed May 10, 2011 from http://www.college-defrance.fr/media/historique/UPL46356_UPL35836_ihackingreso102.pdf.

Hacking, Ian, 2005, Why Race Still Matters, Daedelus, Vol. 134, No. 1, On Race, pp. 102-116.

Hacking, Ian, 2006, Making up people, London Review of Books, LRB Vol. 28 No. 16 dated 17 August 2006, accessed May 2010 from http://www.generation-online.org/c/fcbiopolitics2.htm.

Hacking, Ian, 2007, Kinds of People, Moving Targets, British Academy Lecture, Read at the Academy 11 April 2006, accessed September 13, 2011 from http://www.proc.britac.ac.uk/tfiles/151p285.pdf, pp. 285-318.

Hall, Stuart, 1993, Culture, Community, Nation, Cultural Studies, 7:3, pp. 349363, http://dx.doi.org/10.1080/09502389300490251

Halliday, William Edward Durant, 1937, Forest classification for Canada, Ottawa: Printer to the King.

Hallman, E. S. and H. Hindley, 1977, Broadcasting in Canada: Case Studies on Broadcasting Systems, London: Routledge.

Hamilton, A. C, and L. M. Sebert, 1996, Significant Dates in Canadian Surveying, Mapping and Charting, Ottawa: Geomatica Press. 
Hanson, Clare, 2008, Biopolitics, Biological Racism and Eugenics Chapter 5 in Morton, Stephen and Stephen Bygrave, eds. 2008, Foucault in an Age of Terror: Essays on Biopolitics and the Defence of Society, New York, Palgrave Macmillan, pp. 106-118.

Hanson, R. B., 1935, The Dominion Bureau of Statistics: Its Origin, Constitution and Organization, Ottawa: J. O. Patenaude, King's Printer.

Harding, Katry, 1987, The National Atlas of Canada, Fifth Edition: Format, Scale and Distribution, ACML Bulletin No. 65, pp. 13-14.

Harker, Paul, 2006, Editorial Manual for the Atlas of Canada, $6^{\text {th }}$ Edition, Revised to April 15, 2006, Atlas Framework Section, GeoAccess Division, Natural Resources Canada.

Harley, J. B., 1988, Maps, Knowledge and Power, Chapter 14 Daniels, Stephen and Denis Cosgrove, eds. 1988, The Iconography of Landscape: Essays on the Symbolic Representation, Design and Use of Past Environments, New York: Cambridge University Press, pp. 277-312.

Harley, J. B., 1989, Deconstructing the Map, in Cartographica, Vo. 26, No.2 Summer, pp. 1-20.

Harley, J. B., 1992, Deconstructing the Map, Chapter 13 in Barnes, Trevor J. And James S. Duncan, eds. Writing Worlds: Discourse, Text and Metaphor in the Representation of Landscape, pp. 231-247.

Harley, J. B., 2001, Power and Legitimation in the English Geographical Atlases of the Eighteenth Century, Chapter 4 in The New Nature of Maps: essays in the History of Cartography, Edited by Paul Laxton and J. H. Andrews, Baltimore: The John Hopkins University Press, pp. 109-148.

Harley, J. B., 2001, The New Nature of Maps: essays in the History of Cartography, eds. by Paul Laxton and J. H. Andrews, Baltimore: The John Hopkins University Press.

Harley, J. B., 2011, Deconstructing the Map, Chapter 16 in Dodge, Martin, ed., Classics in Cartography: Reflections on Influential Articles from Cartographica, West Sussex: Wiley-Blackwell, pp. 274-294.

Harvey, David, 2009, Social Justice and the City, London: The University of Georgia Press.

Hay, Ian, 2010, Qualitative research Methods in Human Geography, ed., Don Mills, Ont.: OUP Canada.

Hayes, Brian, 2005, Infrastructure: A Field Guide to the Industrial Landscape, W.W. Norton \& Company: New York.

Hecht, Gabrielle, 2001, Technology, Politics, and National Identity in France, Chapter 8 in Technologies of Power: Essays in Honor of Thomas Parke Hughes and Agatha Chipley Hughes, eds. by Allen, Michael Thad and Gabrielle Hecht, MIT Press, pp. 145-174. 
Hindness, Barry, 1997, Politics and Governmentality in Economy and Society 26 (2): 257-272.

Hocking, Diana and C. Peter Keller, 1993, Analysis of State and Provincial Atlas Reviews, The Professional Geographer, 45 (1) pp. 73-83.

Hocking, Diana, 1991, Thematic Content of Canadian Provincial Atlases, Cartographica, Volume 28, No2, Summer, pp. 38-50.

Homeless Individuals and Families Information System (HIFIS), accessed March 27, 2012, http://hifis.hrsdc.gc.ca/index-eng.shtml

Howe, C. D. 1952, The Dominion Bureau of Statistics: History, Function, Organization, Ottawa: Dominion Bureau of Statistics.

Hughes, Thomas P., 2004, Human-Built World: How to Think About Technology and Culture. Chicago, IL: University of Chicago Press.

Imhof, Eduard, 1982, Cartographic Relief Presentation, Berlin: Walter de Gruyter.

Industry Canada, 2011, Canadian, Radio-Television Telecommunications Commission (CRTC), accessed April 2, 2012 from http://www.ic.gc.ca/eic/site/smt-gst.nsf/eng/home.

International Cartographic Association (ICA), 1990, National Atlas of Canada Program: Contribution to the Technical Report of the ICA Commission on National Atlases, Proceedings of the ICA National Atlas Commission in Beijing.

International Statistical Institute (ISI), 2010, Declaration on Professional Ethics, Adopted by the ISI Council, 22 \& 23 July 2010, Reykjavik, Iceland, accessed November 2, 2011 from http://isiweb.org/about/declarationprofessionalethics-2010uk.

Johnston, R. J., Derek Gregory and David M. Smith, 1994, The Dictionary of Human Geography, 3rd Edition, Oxford: Blackwell Publishers.

Joy, Richard, 1967, Languages in Conflict, Ottawa: by the Author.

Joy, Richard, 1972, Languages in Conflict: The Canadian Experience, Toronto: McClelland and Stewart Limited

Joy, Richard, 1992, Canada's Official Languages: The Progress of Bilingualism, Toronto: University of Toronto Press.

Justice Canada, 1982, Canadian Charter of Rights and Freedoms PART I OF THE CONSTITUTION ACT, 1982, Accessed February 10, 2012 from http://laws.justice.gc.ca/eng/charter/.

Justice Canada, 1985, Official Languages Act, R.S.C., 1985, c. 31 (4th Supp.), An Act respecting the status and use of the official languages of Canada, accessed August 5, 2011 from http://laws-lois.justice.gc.ca/eng/acts/O-3.01/page1.html. 
Justice Canada, 2011, Consolidation of Constitution Acts, 1867 to 1982, Accessed January 18, 2011 from http://www.justice.gc.ca/eng/pi/const/lawregloireg/p1t11.html.

Justice Canada, 2011, Search of Statutes and Laws, conducted November 3, 2011, http://lawslois.justice.gc.ca/Search/Search.aspx?\&h1dd3n1d=E1\%3aR8GRKUP3SKAC$31 \&$ ddCont 3 ntTyp $3=$ Statutes\&h1dd 3 Pag 3 Num $=5 \&$ txtS3archA11 $=$ census\&h1t son1y=1.

Justice Canada, 2011, The British North America Act, 1867, Accessed January 18, 2011 from http://www.justice.gc.ca/eng/pi/const/lawreg-loireg/p1t11.html.

Kennedy, W. P. M. (William Paul McClure), 1930, Constitutional documents of Canada: Statutes, treaties and documents of the Canadian Constitution, 17131929, Toronto: Oxford University Press accessed from Early Canadiana Online http://www.canadiana.org/ECO/ItemRecord/9_o3428?id=ddocafof6f6d123c

Kent, Robert B., and Tobias, Thomas J., 1990, State Atlases: Funding Sources and Thematic Content, The Professional Geographer, 42(3), pp. 313-323.

Kim, Y.-C. and S. J. Ball-Rokeach, 2006, Civic Engagement From a Communication Infrastructure Perspective, Communication Theory, 16, pp. 173-197.

Kitchin, Rob, 1998, Cyberspace: The World in Wires, John Wiley \& Sons: Toronto.

Koren, John, Ed., 1918, The History of Statistics: Their Development and Progress in Many Countries in Memoirs to Commemorate the Seventy Fifth Anniversary of the American Statistical Association, New York: Macmillan Company.

Kramer, Eric, 2008, Interaction with Maps on the Internet - A User Centred Design Approach for The Atlas of Canada, The Cartographic Journal Vol. 45 No. 2, Use and Users Special Issue, pp. 98-107.

Kramer, Eric, 2009, Atlas of Canada Online Survey 6, Final Report Version 1.o, Ottawa: Natural Resources Canada.

Kress, Gunther, 1985, Ideological Structures in Discourse, in Teun A. van Dijk, ed. Chapter 3, Volume 4, Handbook of Discourse Analysis, Academic Press, London, pp. 27-42

Lachapelle, Réjean et Jean-François Lepage, 2010, Les langues au Canada : Recensement de 2006, Ottawa: Canadian Heritage and Statistics Canada.

Lampland, Martha and Susan Leigh Star, 2009, Reckoning with Standards, Chapter 1 in Standards and Their Stories: How Quantifying, Classifying, and Formalizing Practices Shape Everyday Life, Ithaca: Cornell University Press, pp. 3-24. 
Lampland, Martha and Susan Leigh Star, eds. 2009, Standards and Their Stories: How Quantifying, Classifying, and Formalizing Practices Shape Everyday Life, Ithaca: Cornell University Press.

Laroche, Hans-Olivier, 2010, Scanned Copies of Census Schedules and Questionnaires for 1871, 1881, 1901, 1906, 1911, 1916, 1956, $1961 A \& B, 1966$, $1971 A \& B, 1976 A \& B, 1981 A \& B, 1986 A \& B, 1996 A \& B, 2001 A \& B$, Ottawa: Statistics Canada Library.

Larsgaard, Mary Lynette, 1982, Topographic Mapping of the Americas, Australia, and New Zealand, Littleton: Libraries Unlimited.

Latour, Bruno, 1987, Science in Action: How to Follow Scientists and Engineers Through Society, Philadelphia: Open University Press.

Latour, Bruno, 1999, Pandora's hope: Essays on the Reality of Science Studies, Cambridge, Massachusetts: Harvard University Press.

Latour, Bruno, 2011, Drawing Things Together, Chapter 1.9 in Dodge, Martin; Rob Kitchin and Chris Perkins, eds. The Map Reader: Theories of Mapping Practice and Cartographic Representation, West Sussex: Wiley \& Blackwell, pp. 65-72.

Lauriault, T. P., B. Craig, P. L. Pulsifer, and D. R. F. Taylor, 2008, Today's Data are Part of Tomorrow's Research: Archival Issues in the Sciences. Archivaria \#64, 123-179.

Lauriault, Tracey P. and D. R. Fraser Taylor, 2007, Geospatial Data Infrastructure for the Sustainable Development of East Timor, GSDI-9 Research and Theory in Advancing Spatial Data Infrastructure Concepts, ESRI available here http://gsdidocs.org/gsdiconf/GSDI-

9/papers/TS58.4paper.pdf.

Lauriault, Tracey P., 2003, A Geospatial Data Infrastructure is an Infrastructure for Sustainable Development in East Timor, Supervisor: D. R. Fraser Taylor, Ottawa: Carleton University.

Lauriault, Tracey P., 2006, Bout' Time - Satellite Imagery for Human Rights, Blog Post on Serendipityoucity, accessed February 27, 2012 from http://serendipityoucity.blogsome.com/2006/05/31/bout-time-satelliteimagery-and-human-rights/

Lauriault, Tracey P., 2006b, Outside looking in! Identity Science \& the Politics of Identity, blog post on Serendipityoucity, http://serendipityoucity.blogsome.com/2006/04/13/outside-looking-inscience-vs-appearances/

Lauriault, Tracey P., 2007, Satellite Images - Eyes on Darfur, Accessed February 272012 from http://serendipityoucity.blogsome.com/2007/06/18/satelliteimages-eyes-on-darfur/

Lauriault, Tracey P., 2008, Discuss and Critically Assess Community Built Communication Infrastructures as Possible Solutions for Contested 
Territories: With Nagaland and its Environs as a Case Study, Unpublished Comprehensive Exam, Ottawa: Carleton University.

Lauriault, Tracey P., 2008, Radarsat 2 blog posts on Serendipityoucity, accessed August 2011 from http://serendipityoucity.blogsome.com/2008/04/07/radarsat-2-sagacontinues/ and http://serendipityoucity.blogsome.com/2008/03/20/doingcitizenship-radarsat-2/

Lefebvre, Henri, 1991, The Production of Space, Translated by Donald NicholsonSmith, Oxford: Blackwell Publishers.

Levine, Mark, 2007, Fateful Triangles: Modernity and its Antimonies in a Mediterranean Port City, Chapter 6 in Cinar, Alev and Thomas Bender, Eds, 2007, Urban Imaginaries: Locating the Modern City, Minneapolis, University of Minnesota Press.

Lewis, Martin W. and Kären E. Wigen, 1997, The Myth of Continents: A Critique of Metageography, Los Angeles: University of California Press.

Library and Archives Canada (LAC), 2007, LAC's Government of Canada Web Archive, accessed November 7, 2011 from http://www.collectionscanada.gc.ca/whats-new/013-315-e.html.

Library and Archives Canada (LAC), 2008, Schedule of Living Persons or Schedule of Population, updated 2008-11-18 and accessed February 2, 2012 http://www.collectionscanada.gc.ca/databases/census-1901/001013-131e.html

Library and Archives Canada (LAC), 2011, List of Population Census Question for 1871, 1881, 1891, 1901, 1906, 1911, 1916 accessed November 7, 2011 from http://www.collectionscanada.gc.ca/databases/1871-ontario/index-e.html, http://www.collectionscanada.gc.ca/genealogy/022-911.010.010-e.html\#b, http://www.collectionscanada.gc.ca/databases/census-1881/index-e.html, http://www.collectionscanada.gc.ca/genealogy/022-911.010.011-e.html\#a, http://www.collectionscanada.gc.ca/databases/census-1891/index-e.html, http://www.collectionscanada.gc.ca/genealogy/022-911.010.012-e.html\#a, http://www.collectionscanada.gc.ca/databases/census-1901/index-e.html, http://www.collectionscanada.gc.ca/genealogy/022-911.010.013-e.html\#a, http://www.collectionscanada.gc.ca/databases/census-1906/index-e.html, http://www.collectionscanada.gc.ca/databases/census-1911/index-e.html, http://www.collectionscanada.gc.ca/genealogy/022-911.010.015-e.html\#a, http://www.collectionscanada.gc.ca/genealogy/022-911.010.016-e.html\#a.

Livingstone, David N., 2010, Cultural Oolitics and the Racial Cartographics of Human Origins, Transactions of the Institute of British Geographers, Volume 35, Issue 2, April, pp. 204-221.

MacDonald, Fraser, Rachel Hughes and Klaus Dodds, 2010, Introduction: Envisioning Geopolitics, in MacDonald, Fraser, Rachel Hughes and Klaus Dodds, eds. Observant States: Geopolitics and Visual Culture, New York: I.B. Tauris, pp. 1-23. 
MacDonald, Fraser, Rachel Hughes and Klaus Dodds, eds. 2010, Observant States: Geopolitics and Visual Culture, New York: I.B. Tauris.

Marks, John, 2008, Michel Foucault: Biopolitics and Biology, Chapter 4 in Morton, Stephen and Stephen Bygrave, eds. 2008, Foucault in an Age of Terror: Essays on Biopolitics and the Defence of Society, New York, Palgrave Macmillan, pp. 88-104.

Marshall, I.B., P.H. Schut, and M. Ballard, 1999, A National Ecological Framework for Canada: Attribute Data, Agriculture and Agri-Food Canada, Research Branch, Centre for Land and Biological Resources Research, and Environment Canada, State of the Environment Directorate, Ecozone Analysis Branch, Ottawa/Hull. Accessed Dec. 14, 2011 from http://sis.agr.gc.ca/cansis/nsdb/ecostrat/1999report/intro.html.

Massey, Doreen; John Allen, and Philip Sare, 1999, Introduction: Part II Imaginative Geographies, in Massey, Doreen; John Allen, and Philip Sare, eds. Human Geography Today, Cambridge: Polity Press, pp. 41-43.

Massey, Doreen; John Allen, and Philip Sare, eds. 1999, Human Geography Today, Cambridge: Polity Press.

McGrath, Gerald and Louis M. Sebert, eds., 1999, Mapping a Northern Land: The Survey of Canada, 1947-1994, Montréal: McGill-Queen's University Press.

McKay, Daniel S., 1982, James White: Canada's Chief Geographer, 1899-1909, Cartographica, Vol. 19, No.1, pp.51-61.

Mines and Technical Surveys (MTS), 1951a, 1950 Annual Report, Geographical Branch Report by Director J. W. Watson, Ottawa: Edmond Cloutier, C.M.G., O.A. D.S.P. Kings Printer and Controller of Stationery, pp. 107-109.

Mines and Technical Surveys (MTS), 1951b, 1951 Annual Report, Geographical Branch Report by Director J. W. Watson, Ottawa: Edmond Cloutier, C.M.G., O.A. D.S.P. Kings Printer and Controller of Stationery, pp. 94-96.

Mines and Technical Surveys (MTS), 1952, 1951-52 Annual Report, Geographical Branch Report by Director J. W. Watson, Ottawa: Edmond Cloutier, C.M.G., O.A. D.S.P. Kings Printer and Controller of Stationery, pp. 101-103.

Mines and Technical Surveys (MTS), 1953, 1952-53 Annual Report, Geographical Branch Report by Director J. W. Watson, Ottawa, pp. 91-92.

Mines and Technical Surveys (MTS), 1954, 1953-54 Annual Report, Geographical Branch Report by Director J. W. Watson, Ottawa, pp. 97-98.

Mines and Technical Surveys (MTS), 1955, 1954-55 Annual Report, Geographical Branch Report by Acting Director N. L. Nicholson, Ottawa, pp. 107-110.

Mines and Technical Surveys (MTS), 1956, 1955-56 Annual Report, Geographical Branch Report by Acting Director N. L. Nicholson, Ottawa, pp. 101-105.

Mines and Technical Surveys (MTS), 1957, 1957 Annual Report, Geographical Branch Report, Ottawa, Queen's Printer, pp. 79-86. 
Mines and Technical Surveys (MTS), 1957, Atlas of Canada, $3^{\text {rd }}$ Edition, Ottawa: Geographical Branch.

Mines and Technical Surveys (MTS), 1958, 1958 Annual Report, Geographical Branch Report, Ottawa, pp. 76-83.

Mines and Technical Surveys (MTS), 1959, 1959 Annual Report, Geographical Branch Report, Ottawa, pp. 93-99.

Mines and Technical Surveys (MTS), 1960, 1960 Annual Report, Geographical Branch Report by N. L. Nicholson, Ottawa, pp. 57-60.

Mines and Technical Surveys (MTS), 1962, 1962 Annual Report, Geographical Branch Report by N. L. Nicholson, Ottawa, pp. 78-82.

Mines and Technical Surveys (MTS), 1964, 1964 Annual Report, Geographical Branch Report by J. D. Ives, Ottawa, pp. 51-54.

Mines and Technical Surveys (MTS), 1965, 1965 Annual Report, Geographical Branch Report by J. D. Ives, Ottawa, pp. 47-51.

Minister of Regional Economic Expansion, 1970, Toward Integrated Resource Management: Report of the Subcommittee on Multiple Use, National Committee on Forest Land, Ottawa: Queen's Printer for Canada.

Mitchell, William J., 2003, Wunderkammer to World Wide Web: Picturing Place in the Post Photographic Era, Chapter 12 in in Schawartz, Joan M. and James R. Ryan, eds., Picturing Place: Photography and the Geographical Imagination, pp. 283-304.

Monmonier, Mark. 1994, The Rise of the National Atlas, Cartographica, Spring 1994. Vol. 31, Iss. 1, pp. 1-15.

Morantz, Alan, 2002, Where is here? Canada's maps and the stories they tell. Toronto: Penguin Books.

Morgan, J. H., 1886, Forests of Canada, Ottawa: MacLean and Roger Co.

Morgan, J. H., 1886, Report on the Forests of Canada: in which is shewn the pressing necessity which exists for their more careful preservation and extension by planting, as a sure and valuable source of national wealth, with an appendix, Ottawa: Printed by McLean Roger \& Co., Wellington Street, accessed from the Internet Archive Dec. 15, 2011 from http://www.archive.org/details/reportonforestsooomorg.

Mosco, Vincent, 2004, The Digital Sublime: Myth, Power, and Cyberspace, MIT Press, Cambridge.

Moss, Michael R., 1988, Landscape Ecology and Management, Proceedings of the First Symposium of the Canadian Society for Landscape Ecology and Management of Guelph, May, 1987, Montreal: Polyscience Publications.

Nardi, Bonnie A. and Vicki L. O'Day, 1999, Information Ecologies: Using Technology with Heart, Cambridge Massachusetts: MIT Press. 
Nardi, Bonnie A. and Vicki L. O'Day, 1999a, Information Ecologies: Using Technology with Heart, Cambridge: MIT Press, accessed June 22, 2008 from http://www.firstmonday.org/issues/issue4 5/nardi chapter4.html.

NASA, 2008, The Gateway to Astronaut Photography of Earth, http://eol.jsc.nasa.gov/ (captured 17 November 2008).

National Advisory Committee for the National Atlas of Canada (NANAC), 1988, Report to the Minister of State (Forestry and Mines) by the National Advisory Committee for the National Atlas of Canada, Ottawa.

National Advisory Committee, 1975, Report of the National Advisory Committee on a National Atlas of Canada, Vancouver, May 1975. [Document provided by Donna Williams, Natural Resources Canada, October 2011].

National Film Board of Canada (NFB), 1959, All Canadian Atlas, Directed by Hector Lemieux and Produced by Tim Wilson, 10 minutes short film.

National Science Foundation, 2005, Report of the National Science Board: Long-Lived Digital Data Collections: Enabling Research and Education in the 21st Century, Arlington, accessed 23 August 2007, http://www.nsf.gov/pubs/2005/nsb0540/nsb0540 4.pdf.

Natural Resources Canada (NRCan), 1996a, Performance Report for the Period Ending March 31, 1996, Ottawa: Public Works and Government Services Canada.

Natural Resources Canada (NRCan), 1996b, Business Plan 1996-1999, Ottawa: Public Works and Government Services Canada.

Natural Resources Canada (NRCan), 1997a, Performance Report for the Period Ending March 31, 1997, Ottawa: Public Works and Government Services Canada.

Natural Resources Canada (NRCan), 1997b, Business Plan 1997-2000, Ottawa: Public Works and Government Services Canada.

Natural Resources Canada (NRCan), 1998, Performance Report for the Period Ending March 31, 1998, Ottawa: Public Works and Government Services Canada.

Natural Resources Canada (NRCan), 1999, Performance Report for the Period Ending March 31, 1999, Ottawa: Public Works and Government Services Canada.

Natural Resources Canada (NRCan), 2000, Performance Report for the Period Ending March 31, 20oo, Ottawa: Public Works and Government Services Canada.

Natural Resources Canada (NRCan), 2001, Performance Report for the Period Ending March 31, 2001, Ottawa: Public Works and Government Services Canada. 
Natural Resources Canada (NRCan), 2002, Performance Report for the Period Ending March 31, 2002, Ottawa: Public Works and Government Services Canada.

Natural Resources Canada (NRCan), 2003, Performance Report for the Period Ending March 31, 2003, Ottawa: Public Works and Government Services Canada.

Natural Resources Canada (NRCan), 2004, Performance Report for the Period Ending March 31, 2004, Ottawa: Public Works and Government Services Canada.

Natural Resources Canada (NRCan), 2005, Performance Report for the Period Ending March 31, 2005, Ottawa: Public Works and Government Services Canada.

Natural Resources Canada (NRCan), 2006, Performance Report for the Period Ending March 31, 2006, Ottawa: Public Works and Government Services Canada.

Natural Resources Canada (NRCan), 2007, Performance Report for the Period Ending March 31, 2007, Ottawa: Public Works and Government Services Canada.

Natural Resources Canada (NRCan), 2008, Performance Report for the Period Ending March 31, 2008, Ottawa: Public Works and Government Services Canada.

Natural Resources Canada (NRCan), 2009, Gazetteer, accessed September 19, 2011 and updated 12 August, 2009 from http://atlas.nrcan.gc.ca/site/english/learningresources/glossary/results.html? letter $=\mathrm{G}$.

Natural Resources Canada (NRCan), 2009, Performance Report for the Period Ending March 31, 2009, Ottawa: Public Works and Government Services Canada.

Natural Resources Canada (NRCan), 2010, Performance Report for the Period Ending March 31, 2010, Ottawa: Public Works and Government Services Canada.

Natural Resources Canada (NRCan), Earth Science Sector page, Accessed August 10, 2011 http://ess.nrcan.gc.ca/mapcar/index_e.php

Natural Resources Canada, 1999-Present, Atlas of Canada $6^{\text {th }}$ Edition, Ottawa: http://atlas.nrcan.gc.ca/site/english/index.html.

Nicholson, N. L. and L. M. Sebert, 1981, Atlases, Chapter 14 in The Maps of Canada: A Guide to Official Canadian Maps, Charts, Atlases and Gazetteers, Kent: W.M. Dawson \& Sons Ltd, pp. 164-178.

Nicholson, N. L., 1952, A Survey of Single Country Atlases, Geographical Bulletin, No. 2, pp. 19-35.

Nicholson, N. L., 1954, The boundaries of Canada, Ottawa. 
Nicholson, N. L., 1957, The Geographical Branch 1947-57, Volume 3, Issue 10, December 1957, pp. 61-68.

Nicholson, N. L., 1959, Canada and the International Geographical Union (IGU), The Canadian Geographer, Volume 4, Issue 14, pp. 37-41.

Nicholson, N. L., 1961, Some Elements in the Development of the National Atlas of Canada, Geographical Bulletin, No. 16, pp. 45-61.

Nicholson, N. L., 1965, A Feast of Maps, Canadian Geographer, Volume 9, Issue 2, June, pp. 97-100

Nicholson, N. L., 1970, Canada in Six Atlases, The Canadian Cartographer, Vol. 7, No 2, December, pp. 126-130

Nicholson, N.L. and L.M. Sebert, 1981, The Maps of Canada: A Guide to Official Canadian Maps, Charts, Atlases and Gazetteers, Folkestone, Kent: W. Dawson.

NRCan, Earth Science Sector, Mapping Page, Accessed August 10, 2011 from http://ess.nrcan.gc.ca/mapcar/index e.php.

O'Brien, Douglas, 2006, Some Notes, Milestones and Significant Dates, the Atlas of Canada, September, Version 1.2 [Document provided by Doug O'Brien].

O'Neil, Bob and Joanne Frappier, 2002, About Canada...The Atlas of Canada, Presentation to Donna Wood \& Donna Achimov, Communications Canada, January 11, 2002, Ottawa: GeoAccess Division, Canada Centre for Remote Sensing.

Office of Management and Budget (OMB), 2002, Guidelines for Ensuring and Maximizing the Quality, Objectivity, Utility, and Integrity of Information Disseminated by Federal Agencies; Notice; Republication, Federal Register, vol. 67 no. 36, Washington DC, Friday, February 22, accessed 17 January 2007, www.whitehouse.gov/omb/fedreg/reproducible2.pdf.

Ogborn, Miles, 2003, Knowledge is Power: Using Archival Research to Interpret State Formation, in Cultural Geography in Practice, Alison Blunt, Pyrs Gruffudd, Jon May, Miles Ogborn, and David Pinder (Eds), Edward Arnold, London, pp. 9-20.

Omerling Sr., F. J., 1979, The Purpose and Use of National Atlases, Cartographica, Monograph, No. 23, pp. 11-23.

Osborne, Brian S., 2003, Constructing the State, Managing the Corporation, Transforming the Individual: Photography, Immigration and the Canadian National Railway, 1925-30, Chapter 7 in Schawartz, Joan M. and James R. Ryan, eds., Picturing Place: Photography and the Geographical Imagination, pp. 162-193.

Osborne, Brian S., 1988, The Iconography of Nationhood in Canadian Art. Chapter 8, Daniels, Stephen and Denis Cosgrove, eds. 1988, The Iconography of Landscape: Essays on the Symbolic Representation, Design and Use of Past Environments, New York: Cambridge University Press, pp. 162-178. 
Ottmann, Liane, 1971, Direction des levés et de la cartographie, Compte rendus, Atlas national du Canada, $2 e$ édition, Ottawa, Ministères de l'énergie, de mines et des ressources, Revue de géographie de Montréal, Vol. XXV, pp. 419.

Paltridge, Brian, 2006, Discourse Analysis, Continuum, London.

Patriarca, Silvana, 1996, Numbers and Nationhood: Writing Statistics in Nineteenth-Century Italy, Cambridge: Cambridge University Press.

Peace-Moses, Richard, 2005, A Glossary of Archival and Records Terminology, accessed March 27, 2012, http://www.archivists.org/glossary/term_details.asp?DefinitionKey=105.

Pearce-Moses, Richard, 2007, A Glossary of Archival and Records Terminology Chicago, accessed 23 August 2007, http://www.archivists.org/glossary/.

Pearson, E.S., ed. 1978, The History of Statistics in the 17th and 18th Centuries Against the Changing Background of Intellectual, Scientific, and Religious Thought: lectures by Karl Pearson given at University College, London, during the academic sessions, 1921-1933. London: C. Griffin.

Penrose, Jan and Susan J. Smith, 2009, Performativity: Identity and its Geographical Significance, Chapter 63, in Douglas, Ian; Richard Huggett and Chris Perkins, eds., 2009, Companion Encyclopedia of Geography from Local to Global, Second Edition, Volume 2, pp. 1005-1016.

Perkins, Chris, 2009, The Geographical Imagination, Part V in Douglas, Ian; Richard Huggett and Chris Perkins, eds., 2009, Companion Encyclopedia of Geography from Local to Global, Second Edition, Volume 2, pp. 535-536.

Perkins, Chris, 2009a, Mappings, Chapter 35 in Douglas, Ian; Richard Huggett and Chris Perkins, eds., Companion Encyclopedia of Geography from Local to Global, Second Edition, Volume 2, pp. 553-571.

Phillips, P. L., 1971, A List of Geographical Atlases in the Library of Congress, Washington: Government Printing Office.

Phillips, Richard, 2009, Words, Chapter 34 in Douglas, Ian; Richard Huggett and Chris Perkins, eds., Companion Encyclopedia of Geography from Local to Global, Second Edition, Volume 2, pp. 537-553.

Pickles, John, 1992, Texts, Hermeneutics and Propaganda Maps, Chapter 12 in Barnes, Trevor J. And James S. Duncan, eds. Writing Worlds: Discourse, Text and Metaphor in the Representation of Landscape, pp. 193-230.

Pickles, John, 2004, A History of Space, Cartographic Reason, Mapping and the Geo-Coded World, London: Routledge.

Pimmins, J. P., 1979, Ecological Classification of Forest Land in Canada and Northwestern U.S.A.: Report on the 1977 Vancouver Symposium in Environment Canada, Application (Biophysical) Land Classification in Canada, Ecological Land Classification Series Number 7, Proceedings of the Second Meeting Canada Committee on Ecological (Biophysical) Land Classification, 
4-7 April 1978, Victoria BC, Ottawa: Minister of Supply and Services Canada, pp. 51-56.

Pinch, Trevor J. and Wiebe E. Bijker, 1987, The Social Construction of Facts and Artifacts: Or how the Sociology of Science and the Sociology of Technology might Benefit Each Other, in The social Construction of Technological Systems: New Directions in the Sociology and History of Technology, Eds by Wiebe E. Bijker, Thomas P. Hughes, and Trevor J. Pinch. Cambridge, Massachusetts: MIT Press, pp. 17-51.

Pleva, Edward G., 1985, Norman Nicholson 1920-1984, Canadian Geographer, Volume 29, Issue 2, June, Pages: 98-99.

Poovey, Mary, 1998, A History of the Modern Fact: Problems of Knowledge in the Sciences of Wealth and Society, University of Chicago Press: Chicago.

Porter, Theodore M., 1986, The Rise of Statistical Thinking, New Jersey: Princeton University Press.

Porter, Theodore M., 2004, The Culture of Quantification and the History of Public Reason, Journal of the History of Economic Thought, Volume 26, No. 2, June, pp. 165-177.

Porter, Theodore, 1995, Trust in Numbers: the Pursuit of Objectivity in Science and Public Life, Princeton, N.J.: Princeton University Press.

Powel, Alison, 2006, Ile Sans Fil as a Digital Formation, Final Report : Practiques Collaboratives, LABCMO, Ecoles des Medias, Université du Québec à Montréal, 20 Juillet.

Pulsifer, Peter L., Taylor, D. R. F. 2007, Spatial Data Infrastructure: Implications for Sovereignty in the Canadian Arctic, in the Canadian Polar Commission newsletter, Meridian, spring-summer, April 25, pp. 1-5.

Purvis, Trevor and Alan Hunt, 1993, Discourse, Ideology, Discourse, Ideology, Discourse, Ideology, The British Journal of Sociology, Vol. 44, No. 3 Sep., pp. 473-499.

Putnam, Donald F. and Robert G. Putnam, 1970, Canada: A Regional Analysis, Toronto: J. M. Dent and Sons.

Rabinow, Paul, ed., 2010, The Foucault Reader, New York: Vintage Books.

Radcliffe, Sarah, 1999, Popular and State Discourse of Power, in Massey, Doreen; John Allen, and Philip Sare, eds. Human Geography Today, Cambridge: Polity Press, pp. 219-242.

Raveneau, Jean, 1987, La cinquième édition de l'Atlas national du Canada, Cahiers de géographie du Québec, vol. 31, n 82, p. 51-68.

Rens, Jean-Guy, 2001, The Invisible Empire: A History of the Telecommunications Industry in Canada, 1846-1956, translated by Kathe Roth, Montreal \& Kingston: McGill-Queen's University Press. 
Rowe, John Stanley, 2011, The Canadian Encyclopedia, accessed Dec. 14, 2011 from http://www.thecanadianencyclopedia.com/index.cfm?PgNm=TCE\&Params $=$ A1ARTA0006964.

Rowe, R., Stanley, 1959, Forest Regions of Canada, Ottawa, Dept. of Northern Affairs and National Reserves, Forestry Branch, Queen's Printer and Controller of Stationery.

Rubec, C. D. A., E. B. Wiken, J. Thie and G. R. Ironside, 1988, Ecological Land Classification and Landscape Ecology in Canada: The Role of the C.C.E.L.C. and the Formation of the C.S.E.L.M., Section 6 in Moss, Michael R., Landscape Ecology and Management, Proceedings of the First Symposium of the Canadian Society for Landscape Ecology and Management of Guelph, May, 1987, Montreal: Polyscience Publications, pp. 51-57.

Said, Edward W., 1978, Orientalism, City: Vintage Books.

Said, Edward W., 1990, Narrative, Geography and Interpretation, Raymond Williams Memorial Lecture, delivered in London on 10 October 1989. New Left Review, 180, pp. 81-98.

Said, Edward, 1985, Orientalism Reconsidered, Chapter 2 in Europe and its Others, Volume One, Proceedings of the Essex Conference on the Sociology of Literature, July 1984 edited by Francis Barker, Peter Hulme, Margaret Ivernsen and Diana Loxley, Colchester: University of Essex, pp. 14-27.

Salichtchev, K. A. Eds., 1960, Atlas nationaux; histoire, analyse, voies de perfectionnement et d'unification. Rédige à la demande de la commission. Report of the International Géographia Union, Commission des atlas nationaux, Moscou, Edition de l'Académie des Sciences de l'U.R.R.S.

Salichtchev, K. A. eds., 1972, National Atlases, Their History, Analysis, and Ways to Improvement and Standardization, Translation of the Commission on National Atlases of the International Geographical Union, report in Cartographica, Monograph No4, translated by G. Fremlin and L. M. Sebert.

Schulten, Susan, 2001, The Geographical Imagination in America 1880-1950, Chicago: the University of Chicago Press.

Schwartz, Joan M. and James R. Ryan, 2003, eds., Picturing Place: Photography and the Geographical Imagination, London: I.B. Tauris.

Schwartz, Joan M. and James R. Ryan, 2003, Introduction: Photography and the Geographical Imagination, Chapter 1 in Schawartz, Joan M. and James R. Ryan, eds., Picturing Place: Photography and the Geographical Imagination, pp. 1-19.

Secretary of the Board of Statistics, 1862, 1861 Report of the Secretary of the Board of Statistics on the Census of Nova Scotia, Halifax: Printed by Order of the Government. 
Sharp, Liz and Tim Richardson, 2001, Reflections on Foucauldian Discourse Analysis in Planning and Environmental Policy Research, Journal of Environmental Policy \& Planning, 3: 193-209.

Sparke, Matthew, 2011, A Map that Roared and an Original Atlas: Canada, Cartography and the Narration of Nation, Chapter 5.7, in Dodge, Martin; Rob Kitchin and Chris Perkins, Eds. The Map Reader: Theories of Mapping Practice and Cartographic Representation, West Sussex: Wiley \& Blackwell, pp. 430-439.

Stamp, L. Dudley, 1960, Review of the $3^{\text {rd }}$ Edition of the Atlas of Canada, The Geographical Journal, Vol. 126, No. 2, pp. 241-242.

Stams, W., 1980?, National and Regional Atlases: a Bibliographic Survey (up to and including 1978) The Netherlands?: International Cartographic Association.

Star, Susan Leigh and Karen Ruhleder, 1996, Steps Toward an Ecology of Infrastructure: Design and Access for Large Information Spaces, Information Systems Research, Vol. 7, No. 1, March, pp. 111-134.

Starr, Paul, 1987, The Sociology of Official Statistics, in The Politics of Numbers, New York: Russel Stage Foundation, pp.7-58.

Starr, Susan Leigh, 1999, The Ethnography of Infrastructure, American Behavioral Scientist, 43, pp. 377-391.

Statistics Canada, 1971, Content of questionnaire for the 1971 Census of Canada, Ottawa: Statistics Canada

Statistics Canada, 1972, Dictionary of the 1971 Census Terms, Ottawa: Statistics Canada.

Statistics Canada, 1972a, The Canada Year Book, Ottawa: Ministry of Industry, Trade and Commerce.

Statistics Canada, 1974, 1971 Census of Canada, Population Geographical Distribution, Ottawa: Information Canada.

Statistics Canada, 1976, 1971 Census of Canada, General Review, Administrative Report of the 1971 Census, Ottawa: Printer?

Statistics Canada, 1976, 1971 Census of Canada, Population Volume 1 (Part: 3), Ottawa: Minster of Industry, Trade and Commerce.

Statistics Canada, 1976, Census Commissioner's Manual Self-Enumeration Areas, 1976 Census of Canada, Ottawa: Statistics Canada.

Statistics Canada, 1976, Procedures Manual Self-Enumeration Areas, 1976 Census of Canada, Ottawa: Statistics Canada.

Statistics Canada, 1976, Procedures Manual, Canvasser Areas, 1976 Census of Canada, Ottawa: Statistics Canada.

Statistics Canada, 1976, Telephone Assistance Service Manual, 1976 Census of Canada, Ottawa: Statistics Canada. 
Statistics Canada, 1978, Canada Year Book 1978-79, Ottawa, Minister of Supply and Services.

Statistics Canada, 1979, 1976 Census of Canada, Population: Geographic Distributions, Introduction to Volume 1, Ottawa: Minister of Supply and Services.

Statistics Canada, 1980, 1976 Administrative Reports Part 1, Ottawa: Minister of Supply and Services.

Statistics Canada, 1980, 1976 Administrative Reports Part 2, Ottawa: Minister of Supply and Services.

Statistics Canada, 1980, 1976 Administrative Reports Part 3, Ottawa: Minister of Supply and Services.

Statistics Canada, 1980, 1976 Administrative Reports Supplement, Ottawa: Minister of Supply and Services.

Statistics Canada, 1980a, Language Use in Canada, by John de Vries and Frank G. Vallée, Ottawa: Mister of Supply and Services.

Statistics Canada, 1981, Census Commissioner's Manual Self-Enumeration Areas, 1981 Census of Canada, Ottawa: Statistics Canada.

Statistics Canada, 1981, Language in Canada, Ottawa: Minister of Supply and Services Canada.

Statistics Canada, 1981, Procedures Manual, Canvasser Areas, 1981 Census of Canada, Ottawa: Statistics Canada.

Statistics Canada, 1981, Procedures Manual, Self-Enumeration, 1981 Census of Canada, Ottawa: Statistics Canada.

Statistics Canada, 1981, Telephone Assistance Service Manual, 1981 Census of Canada, Ottawa: Statistics Canada.

Statistics Canada, 1982, 1981 Census Dictionary, Ottawa: Minister of Supply and Services Canada.

Statistics Canada, 1983, 1981 Census Summary Guide: Total Population. Ottawa: Minister of Supply and Services Canada 1984.

Statistics Canada, 1983, 1981 Census Summary Population: Mother Tongue, Official Languages and Home Language, Ottawa: Minister of Supply and Services Canada.

Statistics Canada, 1983, Historical Statistics of Canada, data Series E41-48. Annual earnings in manufacturing industries, production and other workers, by sex, Canada, 1905, 1910 and 1917 to 1975.

Statistics Canada, 1984, 1981 Census Summary Guide: Sample Population. Ottawa: Minister of Supply and Services Canada 1984.

Statistics Canada, 1985, Canada Year Book 1985, Ottawa, Minister of Supply and Services. 
Statistics Canada, 1986, 1986, Questionnaire Content, 1996 Census of Population, Ottawa: Statistics Canada.

Statistics Canada, 1986, Content of the Questionnaire Census of 1986, Ottawa: Government of Canada

Statistics Canada, 1986, Procedures Manual, Self-Enumeration, 1986 Census of Canada, Ottawa: Statistics Canada.

Statistics Canada, 1986a, $A$ User's Guide to 1981 Census Data on Ethnic Origin, by Walton O. Boxhill, Ottawa: Minister of Supply and Services Canada.

Statistics Canada, 1986b, Briefing Manual on Statistics Canada, Ottawa: Statistics Canada.

Statistics Canada, 1987, 1986 Census Reference Dictionary, Ottawa: Ministry of Supply and Services Canada.

Statistics Canada, 1987, Strategic Overview October 1987, Ottawa: Statistics Canada October 1987.

Statistics Canada, 1988, 1986 Census Handbook, Ottawa: Minster of Supply and Services Canada.

Statistics Canada, 1989, 1986 Census Canada a Linguistic Profile, by Robert Bourbeau, Ottawa: Minster of supply and Services Canada.

Statistics Canada, 1989, General Review of the 1986 Census, Ottawa: Minister of Supply and Services Canada.

Statistics Canada, 1990, Ethnic Diversity in Canada, by Pamela White, Ottawa: Ministry of Regional and Industrial Expansion.

Statistics Canada, 1990, The Canada Year Book, Ottawa: Minister of Supply and Services.

Statistics Canada, 1990, User's Guide to the Quality of 1986 Census Data, Sampling and Weighting, Ottawa, Statistics Canada.

Statistics Canada, 1990, User's Guide to the Quality of 1986 Census Data, Ottawa: Minister of Industry.

Statistics Canada, 1990a, Immigrants in Canada: Selected Highlights, Ottawa: Ministry of Regional and Industrial Expansion.

Statistics Canada, 1991, 1991, Questionnaire Content, 1996 Census of Population, Ottawa: Statistics Canada.

Statistics Canada, 1991, Census Commissioner's Manual, Canvasser Areas, 1991 Census, Ottawa: Statistics Canada.

Statistics Canada, 1991, Census Commissioner's Manual, Mail Back Areas, 1991 Census, Ottawa: Statistics Canada.

Statistics Canada, 1991, Content of Questionnaire, Census of Canada 1991, Ottawa: Statistics Canada. 
Statistics Canada, 1991, Procedures Manual, Canvasser Areas, 1991 Census, Ottawa: Statistics Canada.

Statistics Canada, 1992, 1991 Census Handbook of the 1991 Census, Ottawa: Supply and Services Canada.

Statistics Canada, 1993, 1991 Census Dictionary, Ottawa: Minister of Industry, Science and Technology.

Statistics Canada, 1993a, 1991 Census Technical Reports: Mother Tongue, Reference Product Series, Ottawa: Minster of Industry, Science and Technology.

Statistics Canada, 1994, 1991 Census Technical Reports: Home Language and Knowledge of Languages, Reference Product Series, Ottawa: Minster of Industry, Science and Technology.

Statistics Canada, 1994, 1996 Census Consultation Report, \#2, Ottawa: Statistics Canada.

Statistics Canada, 1996, 1996 Census Collection Specifications, Ottawa: Statistics Canada.

Statistics Canada, 1996, 1996 Census Communications Evaluation Volume 2, Ottawa: Statistics Canada.

Statistics Canada, 1996, 1996 Census Questions and Answers, Ottawa: Statistics Canada.

Statistics Canada, 1996, 1996 Census Questions and Answers, Ottawa: Statistics Canada.

Statistics Canada, 1996, 1996, Questionnaire Content, 1996 Census of Population, Ottawa: Statistics Canada.

Statistics Canada, 1996, Questionnaire Content; 1996 Census of Population, Ottawa: Statistics Canada.

Statistics Canada, 1997, 1996 Census Handbook: Reference, Ottawa: Industry Canada.

Statistics Canada, 1998, Immigration, http://www.statcan.gc.ca/concepts/definitions/immigr-eng.htm.

Statistics Canada, 1999, 1996 Census Dictionary Final Edition Reference, Ottawa: Ministry of Industry.

Statistics Canada, 1999, 2001 Census Consultation Report, Ottawa: Ministry of Industry.

Statistics Canada, 1999, Sampling and Weighting: 1996 Technical Report, Ottawa: Minister of Industry.

Statistics Canada, 2001, @StatCan, Special Issue 2001, Ottawa: Statistics Canada. 
Statistics Canada, 2001, Census Representative's Edit and Email Follow-up Manual (Mail-Back Areas), Ottawa: Statistics Canada.

Statistics Canada, 2001, Major Users of Census Information, 2001 Census of Population. Ottawa: Government of Canada. Part of the Census Determination Project March 2001

Statistics Canada, 2001, Major uses of census information, Ottawa: Statistics Canada, 2001.

Statistics Canada, 2001, Statistics Canada: Yesterday, Today and Tomorrow. January 24.

Statistics Canada, 2002, 2001 Census Dictionary, Ottawa: Ministry of Industry.

Statistics Canada, 2002a, 2001 Census Handbook, Ottawa: Industry Canada.

Statistics Canada, 2004, 2006 Census Management Guide, Ottawa: Planning and Integration, December 2004 sent by email from Marie-Claire Lauzon, January 22, 2010v Marie-Claire.Lauzon@statican.gc.ca

Statistics Canada, 2005, 2006 Census Dissemination Consultation Report, Ottawa: Industry Canada.

Statistics Canada, 2006, Census Dictionary, accessed April 5, 2012 from http://www5.statcan.gc.ca/bsolc/olc-cel/olc-cel?catno=92-566-X\&lang=eng/

Statistics Canada, 2008, 2011 Census Content Consultation Report, Chapter 11 Unpaid work, accessed August 4, 2011 from http://www.statcan.gc.ca/pub/92-137-x/2008001/ch/5200715-eng.htm.

Statistics Canada, 2008a, Jean Talon: 1625-1694, accessed January 18 from http://www.statcan.gc.ca/pub/98-187-x/4064814-eng.htm.

Statistics Canada, 2009, 2011 Census Content Consultation Report, accessed February 2, 2012 http://www12.statcan.ca/censusrecensement/2011/consultation/ContentReport-RapportContenu/indexeng.cfm.

Statistics Canada, 2009, Language spoken most often at home of person, April 20, 2009, http://www.statcan.gc.ca/concepts/definitions/language-langueo2eng.htm.

Statistics Canada, 2009, Language used most often at work of person 15 years or over, April 20 2009, http://www.statcan.gc.ca/concepts/definitions/language-langueo7-eng.htm.

Statistics Canada, 2009, Mother Tongue, http://www.statcan.gc.ca/concepts/definitions/language-langueo1-eng.htm, April 20, 2009.

Statistics Canada, 2010, Copies of Original Schedules and Questionnaires from the Vertical Folder for the following Census Years: 1901, 1906, 1911, 1931, 1941, 1946, 1951, 1956, 1961, 1966, 1971, Ottawa: Statistics Canada. 
Statistics Canada, 2010, email correspondence from Anna Marangone (anna.marangone@statcan.gc.ca) in response to questions asked to Rosemary Bender and Peter Morrison, March 9, 2010.

Statistics Canada, 2010, Online Access to Census forms for 1996, 2001 and 2006, accessed November 7, 2011 from http://www12.statcan.ca/english/censuso1/info/question2.cfm, http://www12.statcan.ca/english/censuso1/Products/Reference/2001handbo ok/pdf/2B.pdf, http://www12.statcan.ca/censusrecensement/2006/ref/question-guide-eng.cfm.

Statistics Canada, 2010a, 2006 Census Dictionary, Ottawa: Ministry of Industry, accessed February 3, 2012 from http://www12.statcan.gc.ca/censusrecensement/2006/ref/dict/pdf/92-566-eng.pdf.

Statistics Canada, 2011, Low Income Cut-offs Main Product Page, accessed September 292011 from http://www.statcan.gc.ca/bsolc/olc-cel/olccel?catno $=13-551-X \& l a n g=$ eng.

Statistics Canada, 2011a, About Us page, accessed November 3, 2011 from http://www.statcan.gc.ca/about-apercu/about-apropos-eng.htm.

Stephenson, Richard, W. and Mary Galneder, 1969, Anglo-American State and Provincial Thematic Atlases/ A survey and Bibliography, The Canadian Cartographer, Vol. 6, No1, June, pp. 15-45.

Stibbe, Hugo L.P. Gen. Ed. And Vivien Carmell and Velma Parker, eds., 1982, Cartographic Materials: A Manual of Interpretation for AACR2, Prepared by the Anglo-American Cataloguing Committee for Cartographic Materials, Ottawa: Canadian Library Association.

Subcommittee on Bio-physical Land Classification, 1979, Guidelines for BioPhysical Land Classification, For Classification of Forest Lands and Associated Wildlands, Complied by D. S. Lacate Chairman, Ottawa: Minister of Fisheries $s$ and Forestry.

Suttie, G. L. P., 1947, The New Atlas of Canada, Industrial Canada, No 12, Volume XLVII, Toronto, April, Canadian Manufactures Association, pp. 94-97.

Symons, T. H. B., 1975, To Know Ourselves: The Report of the Commission on Canadian Studies, Vol. I \& II, Ottawa: Association of Universities and Colleges of Canada.

Symons, T.H.B., 1979, Some thoughts on the Nature and Value of National and Regional Atlases, Cartographica, Monograph, No. 23, pp. 1-10.

Szreter, Simon; Hania Sholkamy and A. Dharmalingam, eds. 2004 Categories and Contexts: Anthropological and Historical Studies in Critical Demography, Oxford: Oxford University Press, 2004.

Tang, Chenxi, 2009, The Geographic Imagination of Modernity: Geography, Literature and Philosophy in German Romanticism, Stanford: Stanford University Press. 
Taylor, Charles, 2004, Modern Social Imaginaries, London: Duke University Press.

Taylor, D. R. F. and Caquard, S., Guest eds., 2006, Special Issue: Cybercartography, Cartographica, 41(1), 100.

Taylor, D. R. Fraser, 1979, Development Atlases Using Computer Techniques, Cartographica, Monograph, No. 23, pp. 67-78.

Taylor, Iain C. 1994, Official Geography and the Creation of Canada, Cartographica, Winter 1994. Vol. 31, Iss. 4; pp. 1-15

Thomson, Don W., 1966, Men and Meridian, Volumes I, Ottawa: Department of Energy Mines and Resources.

Thomson, Don W., 1967, Men and Meridian, Volumes II, Ottawa: Department of Energy Mines and Resources.

Thomson, Don W., 1969; Men and Meridian, Volumes III, Ottawa: Department of Energy Mines and Resources.

Todd, Edmund, 2001, Engineering Politics, Technological Fundamentalism, and German Power Technology. Chapter 5 in Technologies of Power: Essays in Honor of Thomas Parke Hughes and Agatha Chipley Hughes. Edited by Allen, Michael Thad and Gabrielle Hecht, pp. 145-174.

Treas, Judith, 2009, Age in Standards and Standards for Age: Institutionalizing Chronological Age as Biographical Necessity, Chapter 2 in Standards and Their Stories: How Quantifying, Classifying, and Formalizing Practices Shape Everyday Life, Ithaca: Cornell University Press, pp. 65-88.

UK National Archives, 2011, Imperial and Commonwealth Conferences Collection Description, accessed January 252012 from http://yourarchives.nationalarchives.gov.uk/index.php?title=Imperial and C ommonwealth Conferences.

UN Statistical Commission, 2011, Home Page, accessed January 25, 2012 from http://unstats.un.org/unsd/statcom/commission.htm.

United Nations, 1970, Principles and Recommendations for the 1970 Population Censuses, Second Statistical Printing, Papers Series M. No. 44, accessed February 10, 2012 from http://unstats.un.org/unsd/demographic/standmeth/principles/Series M44v 2en.pdf.

United Nations, 2001, Handbook on Census Management for Population and Housing Censuses, Department of Economic and Social Affairs, Statistics Division, Series F, No.83/Rev. 1, accessed November 3, 2011 from http://unstats.un.org/unsd/censuskb20/KnowledgebaseArticle10066.aspx.

United Nations, 2006, Fundamental Principles of Official Statistics, Department of Economic and Social Affairs, accessed November 3, 2011 from http://unstats.un.org/unsd/methods/statorg/FP-English.htm. 
United Nations, 2007, Principles and Recommendations for Population and Housing Censuses Revision 2, Department of Economic and Social Affairs, Statistics Division, Statistical papers Series M No. 67/Rev.2, accessed November 2, 2011 from http://unstats.un.org/unsd/censuskb20/Attachment455.aspx.

United Nations, 2010, Handbook on Population and Housing Census Editing, Rev. 1, accessed April 6, 2012 from http://unstats.un.org/unsd/demographic/standmeth/handbooks/Series_F82 Rev1En.pdf,

University of Toronto, 2011, Data Liberation Initiative References table of Contents for the 1884-85, 1885-86, 1916 and 1926 Censuses of Population, accessed November 7, 2011 from http://prod.library.utoronto.ca:8090/datalib/reference/can census/1885/18 85.pdf, http://prod.librarv.utoronto.ca:8090/datalib/reference/can census/1886/18 86.pdf, http://prod.library.utoronto.ca:809o/datalib/reference/can_census/1916/191 6.pdf, http://prod.library.utoronto.ca:809o/datalib/reference/can census/1926/19 26.pdf.

UNStats website http://unstats.un.org/unsd/default.htm.

Urquhart, M. C, and K. A. H. Buckley eds., 1965, Historical Statistics of Canada, Toronto: The Macmillan Company of Canada LTD.

Valentine, Gill, 1999, Imagined Geographies: Geographical Knowledges of Self and Other in Everyday Life, Chapter 3 in Massey, Doreen; John Allen, and Philip Sare, eds. Human Geography Today, Cambridge: Polity Press, pp. 4347.

Van Dijk, T. A., 1985, Introduction: Discourse Analysis as a New Cross Discipline, in Teun A. van Dijk, ed. Chapter 1, Volume 1, Handbook of Discourse Analysis, Academic Press, London, pp. 1-8

Vasquez Maure, Francisco, 1979, National Atlases, Natural Resources and the Environment, Cartographica, Monograph, No. 23, pp. 24-34.

Waitt, Gordon, 2010, Doing Discourse Analysis, Chapter 11 in Qualitative research Methods in Human Geography, ed. Ian Hay, Don Mills, Ont.: OUP Canada, pp.217-240.

Walker, Helen M., 1929, Studies in the history of statistical method, Baltimore.

Waring, Marilyn. 1988. If Women Counted: A New Feminist Economics, San Francisco: Harper \& Row.

Watson, J. W., 1975, Review of the $4^{\text {th }}$ Edition of the Atlas of Canada, The Geographical Journal, Vol. 141, No. 3, pp. 500-501. 
Watts, Michael John, 1999, Collective Wish Images: Geographical Imaginaries and the Crisis of National Development, Chapter 5 in Massey, Doreen; John Allen, and Philip Sare, eds. Human Geography Today, Cambridge: Polity Press, pp. 85-109.

Westergaard, Harald, 1968, Contributions to the History of Statistics, New York: Agathon Press, Inc.

White, James, 1901, Altitudes in the Dominion of Canada with a Relief Map of North America, Department of the Interior, Ottawa: Printed by S. E. Dawson, Printer to the Kings most Excellent Majesty.

White, James, 1915, Altitudes in the Dominion of Canada, Department of the Interior, Ottawa: Mortimer Co. Ltd., Printers.

White, James, 1916, Dictionary of Altitudes in the Dominion of Canada with a Relief Map of North America, Department of the Interior, Ottawa: Mortimer Co. Ltd., Printers.

WHO, 2004, History of the development of the ICD, accessed January 18 from http://www.who.int/classifications/icd/en/HistoryOflCD.pdf as part of the WHO documentation of the ICD here http://www.who.int/classifications/icd/en/.

Wiken, E. B., Year? Ecological Framework of Canada Website, http://ecozones.ca/english/regionalization.html

Wikipedia, 2005, Image of the Blue Marble, accessed February 27 from http://en.wikipedia.org/wiki/File:The_Earth_seen_from_Apollo_17.jpg.

Williams, Donna, 2011, Personal Interview, October 18, 2011 at NRCan.

Williams, Donna; Douglas O'Brien and Eric Kramer, 2003, The Atlas of Canada Web Mapping: The User Counts, Cartographic Perspectives, No. 44, Winter 2003, pp. 8-28.

Williams, Peter, 2001, Beacon on the Rock: The Dramatic History of Lighthouses from Ancient Greece to the Present Day, New York: Baron's Education Series, Inc.

Winichakul, Thongchai, 2011, Mapping: A new Technology of Space; Geo-Body, from Siam Mapped: A History of the Geo-Body of Nation, Chapter 5.4 in Dodge, Martin; Kitchin, Rob and Chris Perkins, Eds. The Map Reader: Theories of Mapping Practice and Cartographic Representation, West Sussex: Wiley \& Blackwell, pp. 407-411.

Winner, Langdon, 1986, The Whale and the Reactor, Chicago: The University of Chicago Press. Wood, Denis and John Fels, 1992, The power of Maps, New York: Guilford Press.

Wood, Denis, 1987, Pleasure in the Idea/The Atlas as Narrative Form, Cartographica 24:1, pp. 24-46.

Worton, David A., 1998, Robert H. Coats, Architect of Canada's national statistical system, Chapter 5 in The Age of Numbers: Statistical Systems and 
National Traditions edited by Jean-Pierre Beaud and Jean-Guy Prévot, Presse de L'université du Québec, pp. 87-105.

Wright, John K. 1947, Terrae Incognitae: The Place of Imagination in Geography, Annals of the Association of American Geographers, 37: 1-15, accessed March 6 from http://www.colorado.edu/geography/giw/wright-

$\mathrm{jk} /$ 1947_ti/body.html.

Wright, John K., 1977, Map Makers are Human: Comments on the Subjective of Maps, Cartographica, Monograph No. 19, The Nature of Maps, pp. 8-26.

Zaslow, Morris, 1975, Reading the Rocks: the Story of the Geological Survey of Canada, 1842-1972, Toronto: Macmillan Company of Canada; Ottawa: Department of Energy, Mines and Resources; Ottawa: Information Canada. 
Appendices

See attached CD-ROM. 